\title{
The domestic impact and effectiveness of the process of state reporting under UN human rights treaties in the Netherlands, New Zealand and Finland: Paper- pushing or policy prompting?
}

Citation for published version (APA):

Krommendijk, J. (2014). The domestic impact and effectiveness of the process of state reporting under UN human rights treaties in the Netherlands, New Zealand and Finland: Paper-pushing or policy prompting? [Doctoral Thesis, Maastricht University]. Intersentia. https://doi.org/10.26481/dis.20140703jk

Document status and date:

Published: 01/01/2014

DOI:

10.26481/dis.20140703jk

Document Version:

Publisher's PDF, also known as Version of record

Please check the document version of this publication:

- A submitted manuscript is the version of the article upon submission and before peer-review. There can be important differences between the submitted version and the official published version of record. People interested in the research are advised to contact the author for the final version of the publication, or visit the DOI to the publisher's website.

- The final author version and the galley proof are versions of the publication after peer review.

- The final published version features the final layout of the paper including the volume, issue and page numbers.

Link to publication

\footnotetext{
General rights rights.

- You may freely distribute the URL identifying the publication in the public portal. please follow below link for the End User Agreement:

www.umlib.nl/taverne-license

Take down policy

If you believe that this document breaches copyright please contact us at:

repository@maastrichtuniversity.nl

providing details and we will investigate your claim.
}

Copyright and moral rights for the publications made accessible in the public portal are retained by the authors and/or other copyright owners and it is a condition of accessing publications that users recognise and abide by the legal requirements associated with these

- Users may download and print one copy of any publication from the public portal for the purpose of private study or research.

- You may not further distribute the material or use it for any profit-making activity or commercial gain

If the publication is distributed under the terms of Article $25 \mathrm{fa}$ of the Dutch Copyright Act, indicated by the "Taverne" license above,

Download date: 26 Apr. 2023 
The Domestic Impact and Effectiveness of the Process of State Reporting under UN Human Rights Treaties in the Netherlands, New Zealand and Finland Paper-pushing or policy prompting? 
School of Human Rights Research Series, Volume 63

The titles published in this series are listed at the end of this volume. 
The Domestic Impact and Effectiveness of the Process of State Reporting under UN Human Rights Treaties in the Netherlands, New Zealand and Finland Paper-pushing or policy prompting?

JASPER KROMMENDIJK

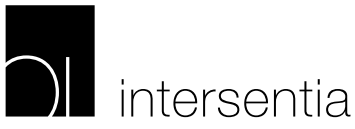

Cambridge - Antwerp - Portland 
Intersentia Publishing Ltd.

Sheraton House | Castle Park

Cambridge | CB3 0AX | United Kingdom

Tel.: +44 1223370170 | Email: mail@intersentia.co.uk

Jasper Krommendijk

The Domestic Impact and Effectiveness of the Process of State Reporting under UN Human Rights Treaties in the Netherlands, New Zealand and Finland. Paperpushing or policy prompting?

ISBN 978-1-78068-244-0

$\mathrm{D} / 2014 / 7849 / 90$

NUR 828

Cover images: Top left: demonstration against the Dutch political party SGP by women's rights activists (C) ANP/Phil Nijhuis - Top right: protest march in New Zealand against the Foreshore and Seabed Act (C) New Zealand Herald/Bret Phibbs - Below: campaign of Amnesty International against violence against women in Finland (C) Katja Tähja.

(C) 2014 Intersentia

www.intersentia.com | www.intersentia.co.uk

British Library Cataloguing in Publication Data. A catalogue record for this book is available from the British Library.

No part of this book may be reproduced in any form, by print, photoprint, microfilm or any other means, without written permission from the publisher. 
To Eva, Abel and Rosa 


\section{ACKNowledgments}

This book is the result of an intellectually stimulating exercise of conducting research in Maastricht, Wellington and Helsinki. In the past 4.5 years of my research, I had the pleasure to work with and have conversations with several people who helped shape my ideas. I would never have been able to finish my dissertation without the help and support of the people around me. It is only possible to particularly mention some of them here.

First and foremost, I would like to express my deepest gratitude to my supervisors prof. dr. Fons Coomans and prof. dr. Fred Grünfeld. Fons and Fred, I especially appreciate the enormous trust and freedom you both gave me in conducting the research. You both provided excellent guidance and personal interest throughout the entire process of writing my thesis. I admire the incredible amount of time you put into reading all my work carefully, even the most preliminary drafts. Fons, thank you for your prudent comments and suggestions which improved my work considerably. I also valued your personal interest and the fact that you popped into my office on a regular basis to discuss a wide variety of issues. Fred, I was not always able to comprehend your 'hieroglyphs', which gave me an excuse to drop by your office to have them deciphered. These meetings always resulted in nice conversations about politics, news, travelling or Abel. I also want to thank you for the chance you offered me to work on your last research project on the genocide in Darfur. Our intensive and stimulating cooperation resulted in an impressive book: Failure to prevent gross human rights violations in Darfur.

I would like to thank the members of my reading committee: prof. dr. Theo van Boven, prof. dr. Cees Flinterman, dr. Esther Versluis, prof. dr. Laurence Helfer and prof. dr. Martin Scheinin. Their comments and suggestions were helpful in finalising and improving this book. My appreciation also goes to Carol Ní Ghiollarnáth for her thorough English language review.

I want to express my gratitude to the people who made it possible and helped me to conduct my research in New Zealand and Finland. Petra Butler gave me the chance to be a visiting researcher at the Victoria University of Wellington in June and July 2012 and was extremely helpful - together with Peter Shuttleworth and Claudia Staal - in providing me with contacts and documents. Special thanks to Peter for filing a request under the Official Information Act to obtain several internal government documents which I could otherwise not have accessed. Tuomas Ojanen made it possible for me to visit the Erik Castrén Institute twice in November 2012 and April/May 2013. Miia Halme-Tuomisaari was very helpful in introducing me to Finnish officials working in the field of human rights. Special thanks also for Lauri 
Acknowledgments

Hannikainen with whom I had the pleasure to share an office and who made my first research stay in Helsinki such an enjoyable experience.

I would like to thank the following people for commenting upon earlier versions of the chapters in this book (see appendix with the list of interviewees for the function of some of them): Birsen Erdogan and Phyllis Livaha (Ch.1-3), Maria Lourijsen and John Morijn (Ch. 4 and Ch. 11), Machteld Inge van Dooren, Dirk Houtzager and Gerbrig Klos (Ch. 5), Ineke Boerefijn and Vincent Böhre (Ch. 6), Marlies Hesselman (Ch. 7), Leontine Bijleveld, Margreet de Boer and Marjolein van den Brink (Ch. 8), Jaap Doek, Majorie Kaandorp Carla van Os, Aysel Sabahoglu and Beate Stapers (Ch. 10). Wendy van der Tol (Ch. 11). Petra Butler, Bevan Marten, Janet McLean, Peter Shuttleworth (Ch. 12), Miia Halme-Tuomisaari, Lauri Hannikainen, Miko Lempinen, Tuomas Ojanen (Ch. 13), Martine Boersma, Claudia Engelmann, Eliza Malathouni and Jennifer Sellin (Ch. 14). For any errors or inadequacies that may remain in this work, of course, the responsibility is entirely my own.

Many thanks also to all my 175 interview respondents for taking the time to share their ideas with me in all openness.

I would like to thank all my colleagues of the Faculty of Law, particularly the department of International and European Law and the Maastricht Centre of Human Rights. The lunch lectures, conversations, and coffees stimulated my thinking and helped me to improve my dissertation. Over the years, I have had the honour to collaborate with many of you in the context of the Board of the Maastricht Centre as well as different projects and seminars. It is unfortunately impossible to thank you all individually. Special thanks to Chantal Kuypers for our nice cooperation and our regular chats. Cees Flinterman, I appreciate your interest in and comments on my research. I am grateful to Menno Kamminga for giving me the opportunity to join in teaching a course in human rights at the China EU Law School in Beijing twice. My thanks also go to the Science Committee for providing me with additional funding to visit Finland for the second time.

I am also glad about my involvement in and the opportunities offered by the School of Human Rights Research. My involvement in the Graduate Committee and Board of the School as a $\mathrm{PhD}$ representative and Chair of the $\mathrm{PhD}$ Council also gave me the possibility to engage with many interesting people. I am especially grateful for my dear friend René who urged me to establish a Working Group on International Relations and Human Rights within the School together with him. We have had two great years full of interesting meetings and debates! Fortunately we continued meeting after the Group itself ceased to exist. 
Warm thanks also go to all my friends in Maastricht who made my stay here such a joyous experience. I have dear memories of our joint Christmas dinners, the parties, game nights and hanging out in the park. It was especially a great pleasure to teach at UCM with Birsen and Phyllis and sit in UCM's courtyard in the summer while discussing everything from politics to music and movies. I also enjoyed drinking Belgian beers after work with Florin, Gustavo, Serban, Fernando and Agustin. My appreciation also goes to Martine for introducing me to the colour locale of Mestreech, pèlskes, Fabrizio and Vastelaovend. I appreciated the friendship and regular encounters and chats with my 'sparring partner' Jennifer. Thanks also for my dear neighbours-colleagues-friends; Eliza and Jeroen and Claudia and Torsten. I was also lucky to have such great office mates in Martine, Emma and Zamira who endured the sometimes loud volume of the music blasting through the computer's speakers. Thanks for all those with whom I had regular coffees, lunches or drinks, including Adela, Anamaria, Anke, Anna, Maartje, Roland, Siamak, Suzanne and Viorelia.

I also appreciate all the support from all those in 'Holland', particularly my WFC friends from high school (Elbert, Hanne, Has, Kim, Matthijs, Michael, Niek and Simon) and my close friends from Groningen (Bertram, Hendrik, Idwer, Meyndert and Syb). Gracias también a Laura por tu amistad y tu apoyo desde España. Most of you have directly contributed to my research by providing me with the opportunity of staying overnight for early morning flights abroad or for interviews or conferences in the Randstad. But above all, your friendship and our joint adventures - in the form of winter sport snowboarding holidays or trips to Morocco or New York - have given me the necessary and welcome distraction from my work.

Lastly, I would like to express my gratitude to my parents Mieke and Hans as well as my brother Michiel for always being there, no matter what. You have always actively encouraged me to make my own choices and to do what I like. I have always appreciated your lay questions which challenged me to explain my research and its (societal) value. Eva, Abel and Rosa, this book is dedicated to you. You are everything to me. This book would have never been as it is without the endless support and love you have given me.

Maastricht, April 2014 


\section{Contents}

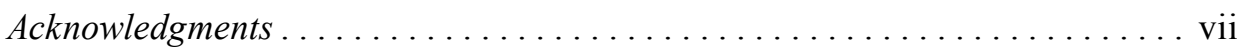

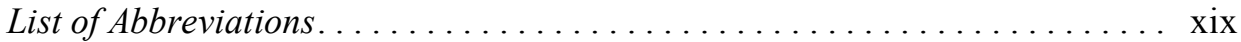

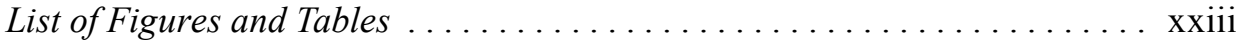

Chapter I

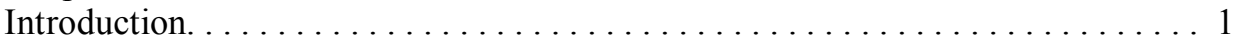

1. Brief overview of the process of state reporting and the legal status of

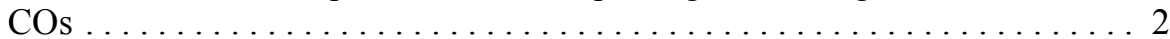

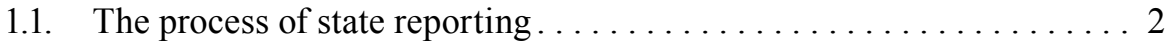

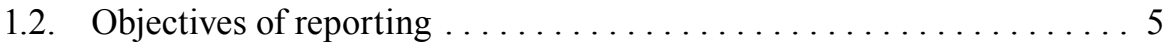

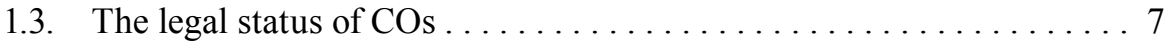

2. Overview of the deficiencies of the treaty body system . . . . . . . . . 9

2.1. The treaty body reform discussion . . . . . . . . . . . 10

2.2. The weaknesses in the treaty body system, the dialogue and the COs . . 11

2.3. Recent improvements ........................ 19

3. Overview of contemporary research on the effectiveness of COs . . . . . 20

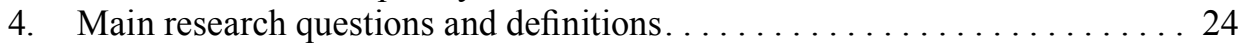

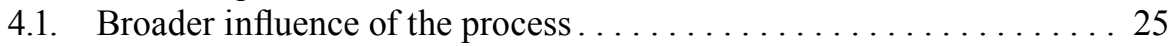

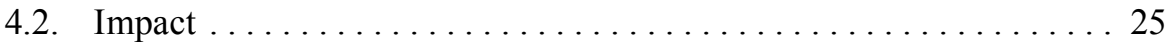

4.3. Effectiveness ........................ 26

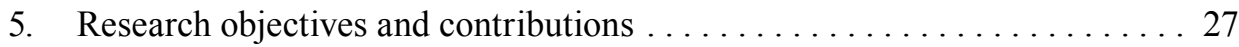

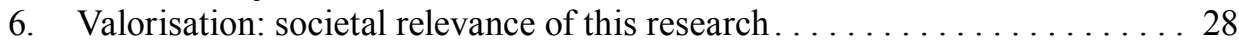

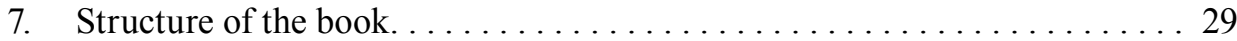

\section{Part A}

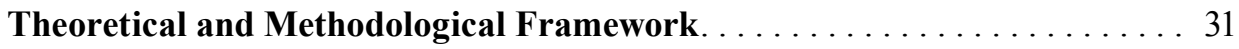

Chapter II

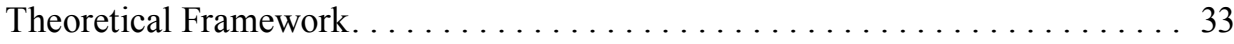

1. Logic of consequences: instrumentalist or rationalist models . . . . . . . 35

1.1. External or international incentives models . . . . . . . . . . . 35

1.2. Domestic politics, institutions and mobilisation . . . . . . . . . . 37

2. Logic of appropriateness: ideational norm-centred approaches . . . . . . . 41

2.1 The managerial model. . . . . . . . . . . . . . . . 42

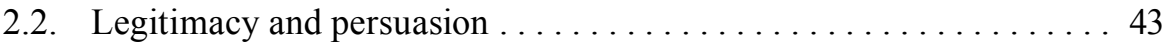

3. Combining the two logics: transnational human rights advocacy . . . . . . 44

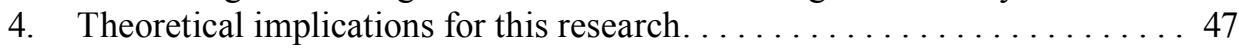


Contents

Chapter III

Methodological Framework . . . . . . . . . . . . . . . . . . . . . . . . . . . . 49

1. Country selection ............................... 49

1.1. Western liberal democracies as most likely cases. . . . . . . . . . . . 49

1.2. The Netherlands as the main case ................. 52

1.3. Two additional most similar countries: New Zealand and Finland ... 53

2. Methodology .................................. 56

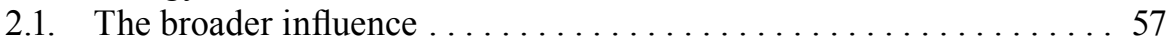

2.2. Domestic impact and domestic mobilisation ............. 58

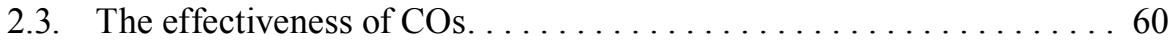

2.4. Limitations to the measuring of effectiveness $\ldots \ldots \ldots \ldots \ldots \ldots 63$

2.5. Explaining the (in)effectiveness of $\mathrm{COs} \ldots \ldots \ldots \ldots \ldots \ldots \ldots 6$

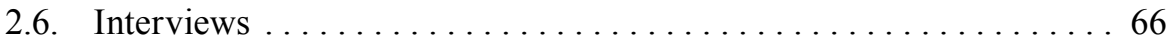

\section{Part B}

The Netherlands

Chapter IV

The Role and Place of Human Rights and State Reporting in the Netherlands. . 71

1. Background to the Dutch legal and political system $\ldots \ldots \ldots \ldots \ldots \ldots 71$

2. The role of human rights in the Dutch legal order ............. 73

2.1. Government.................................. 74

2.2. Parliament ............................... 76

2.3. National courts and legal practice.................. 77

2.4. The legal (human rights) culture . . . . . . . . . . . . . . . 79

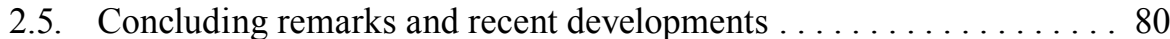

3. The broader influence of the reporting process $\ldots \ldots \ldots \ldots \ldots \ldots 82$

3.1. The organisation of the process of state reporting $\ldots \ldots \ldots \ldots . \ldots 3$

3.2. The attitude of government officials towards the process of state reporting ............................. 85

3.2.1. The value of reporting $\ldots \ldots \ldots \ldots \ldots \ldots \ldots \ldots 5$

3.2.2. The importance given to reporting in practice........ 87

4. The views of government officials about the quality of treaty bodies and the COs ................................. 90

4.1. The irrelevance of the dialogue . . . . . . . . . . . . . . . . 91

4.2. The superficiality of the dialogue ................. 93

4.3. The absence of a constructive dialogue ............... 95

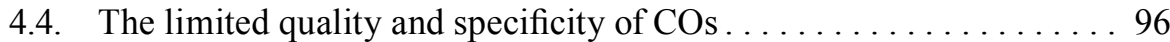

5. Conclusion..................................... 98 
1. Domestic impact and domestic mobilisation ................... 99

1.1. Governmental attention. . . . . . . . . . . . . . . . . . . . . . . 99

1.2. Parliamentary scrutiny $\ldots \ldots \ldots \ldots \ldots \ldots \ldots \ldots \ldots \ldots \ldots \ldots \ldots \ldots \ldots \ldots$

1.3. Courts and legal practice........................ 102

1.4. NGOs. . . . . . . . . . . . . . . . . . . . . . . . . . . . . . . 103

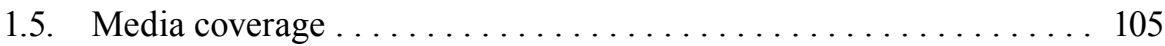

1.6. Conclusion ............................... 105

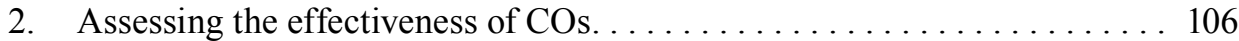

2.1. COs that have been rejected .................... 108

2.2. Standing policy measures in line with the COs $\ldots \ldots \ldots \ldots \ldots 110$

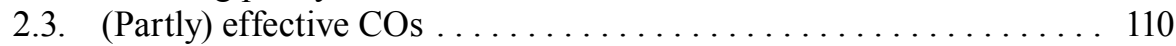

3. Treaty specific reasons for the (in)effectiveness of COs............. 114

3.1. Factors related to the domestic context . . . . . . . . . . . . . 114

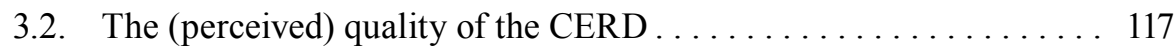

4. Conclusion................................... 121

Chapter VI

ICCPR ...................................... 123

1. Domestic impact and domestic mobilisation . . . . . . . . . . . . 124

1.1. Governmental attention. . . . . . . . . . . . . . . . . . 125

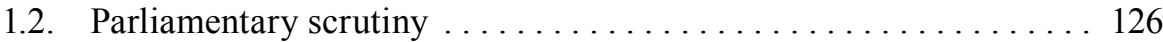

1.3. Courts and legal practice. . . . . . . . . . . . . . . . . . . . 127

1.4. NGOs. . . . . . . . . . . . . . . . . . . . . . . . . . . 128

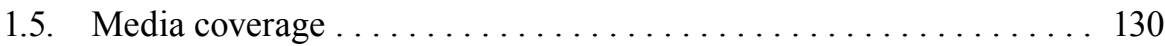

1.6. Conclusion .................................... 130

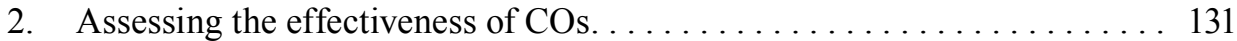

2.1. COs that have been rejected $\ldots \ldots \ldots \ldots \ldots \ldots \ldots \ldots \ldots \ldots \ldots \ldots$

2.2. Standing policy and legislative measures in line with the COs .... 133

2.3. (Partly) effective COs . . . . . . . . . . . . . . . . . . . . . . . 134

3. Treaty specific reasons for the (in)effectiveness of COs............ 136

3.1. Factors related to the domestic context . . . . . . . . . . 136

3.2. The (perceived) quality of the HRC $\ldots \ldots \ldots \ldots \ldots \ldots \ldots \ldots$

4. Conclusion....................................... 141

Chapter VII

ICESCR ........................................... 143

1. Domestic impact and domestic mobilisation ................ 143

1.1. Governmental attention. .......................... 143

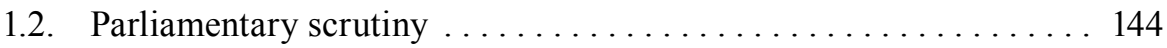


Contents

1.3. Courts and legal practice. . . . . . . . . . . . . . . . . . 146

1.4. NGOs. . . . . . . . . . . . . . . . . . . . . . . . . . . . . . . . . . . . . . 147

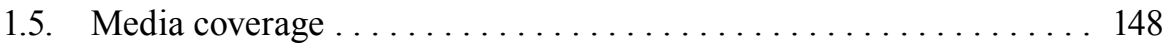

1.6. Conclusion . . . . . . . . . . . . . . . . . . . . . . . . . . . . . . 149

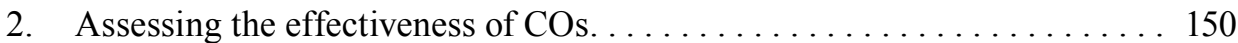

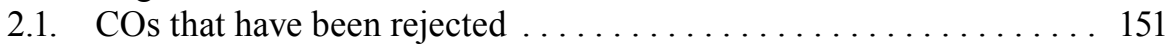

2.2. Standing policy and legislative measures in line with the COs . . . 153

3. Treaty specific reasons for the (in)effectiveness of COs. . . . . . . . . . 154

3.1. Factors related to the domestic context . . . . . . . . . . . . . . 154

3.2. The (perceived) quality of the CESCR . . . . . . . . . . . 158

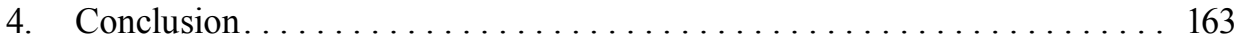

Chapter VIII

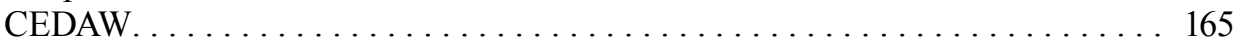

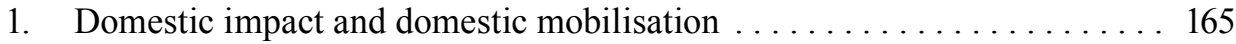

1.1. Governmental attention. . . . . . . . . . . . . . . . 167

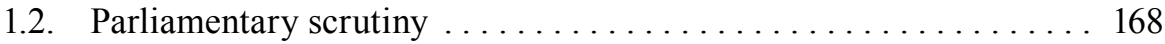

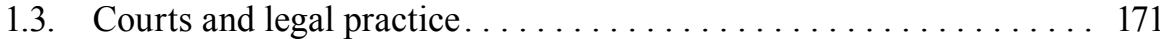

1.4. NGOs. . . . . . . . . . . . . . . . . . . . . . . . . . 172

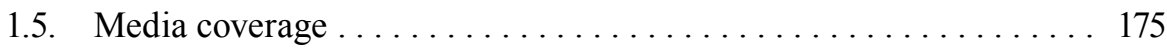

1.6. Conclusion. ........................... 176

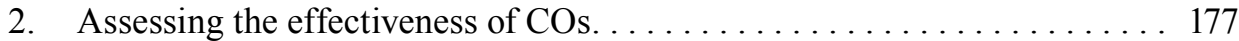

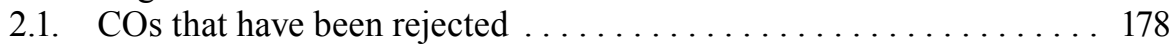

2.2. Standing policy and legislative measures in line with the COs . . . . 181

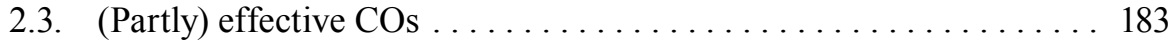

2.3.1. The SGP case . . . . . . . . . . . . . . . . . . . 184

2.3.2. Law on Names . . . . . . . . . . . . . . . . . . . 185

2.3.3. Reinstatement of maternity benefits for self-employed

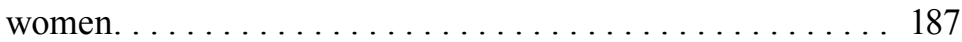

2.3.4. More attention to the gender aspects of domestic violence . . 188

2.3.5. Evaluation gender dimension asylum policy . . . . . . . . . 190

2.3.6. Uninterrupted long school day . . . . . . . . . . . . . . . . 191

2.3.7. Training and education for prostitutes leaving their profession .......................... 191

3. Treaty specific reasons for the (in)effectiveness of COs. . . . . . . . . . . 192

3.1. Factors related to the domestic context . . . . . . . . . . . . . . . 192

3.2. The (perceived) quality of the CEDAW Committee. . . . . . . . . . . 195

4. Conclusion. . . . . . . . . . . . . . . . . . . . . . . . . . . . . . . . . . . 198 
Chapter IX

CAT.............................................. 199

1. Domestic impact and domestic mobilisation ................. 200

1.1. Government informing parliament .................. 200

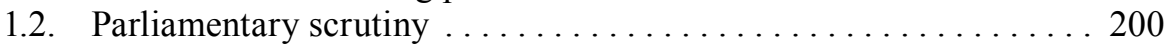

1.3. Courts and legal practice....................... 201

1.4. NGOs. . . . . . . . . . . . . . . . . . . . . . . . . . . . . . 201

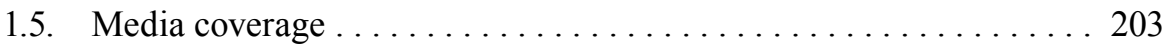

1.6. Conclusion ................................ 203

2. Assessing the effectiveness of COs.................... 203

2.1. Standing policy and legislative measures in line with the COs . . . 204

2.2. (Partly) effective COs ........................ 206

3. Treaty specific reasons for the (in)effectiveness of COs. . . . . . . . . 207

3.1. Factors related to the domestic context . . . . . . . . . . . . . 207

3.2. The (perceived) quality of the CAT Committee ........... 211

4. Conclusion.................................... 212

Chapter X

CRC....................................... 213

1. Domestic impact and domestic mobilisation . . . . . . . . . . . . 213

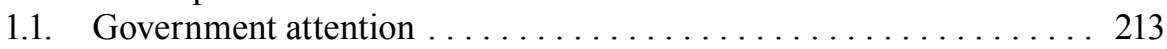

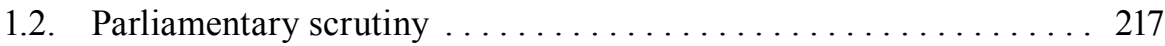

1.3. Courts and legal practice....................... 221

1.4. NGOs. ................................. 223

1.5. Media coverage ......................... 226

1.6. The broader influence of the reporting process under the CRC . . . 227

2. Assessing the effectiveness of COs. ...................... 230

2.1. COs that have been rejected $\ldots \ldots \ldots \ldots \ldots \ldots \ldots \ldots \ldots \ldots \ldots \ldots \ldots \ldots$

2.2. Standing policy and legislative measures in line with the COs . . . 232

2.3. (Partly) effective COs ........................ 233

2.3.1. The establishment of a Children's Ombudsman ......... 234

2.3.2. The separate housing of juvenile offenders .......... 235

2.3.3. Increased dissemination and raising awareness about the CRC ............................ 236

2.3.4. Improvements in the asylum procedure for children ...... 237

2.3.5. The prohibition of corporal punishment .......... 240

2.3.6. Improved interaction between NGOs and the government . . 241

2.3.7. Initiatives in the context of human rights education . . . . . 242

2.3.8. The abolition of life imprisonment for minors. . . . . . . . . 243

2.3.9. Renewed consultations about foster care . . . . . . . . . . 244

2.3.10. The promotion of breastfeeding ................ 245 
Contents

3. Treaty specific reasons for the (in)effectiveness of COs. . . . . . . . . . 245

3.1. Factors related to state level . . . . . . . . . . . . . . . . . . . . . . 245

3.2. The (perceived) quality of the CRC Committee . . . . . . . . . . . . 249

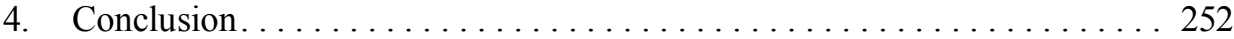

Chapter XI

Comparison of the findings for the Netherlands.................. 253

1. The broader influence of the reporting process $\ldots \ldots \ldots \ldots \ldots \ldots 253$

1.1. Reporting as an opportunity for reflection? . . . . . . . . . . 253

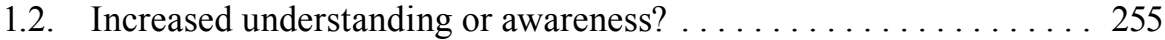

2. The domestic impact of the reporting process and the COs. . . . . . . 255

2.1. The impact of COs. . . . . . . . . . . . . . . . . . . 255

2.2. Recent developments which might strengthen the impact of the COs . 259

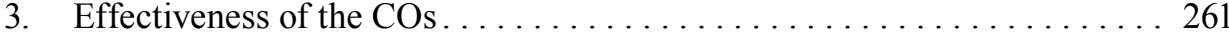

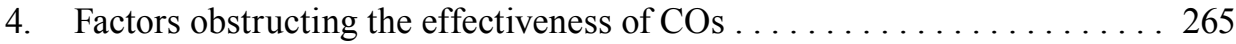

5. Factors contributing to the effectiveness of $\mathrm{COs} \ldots \ldots \ldots \ldots \ldots \ldots$

\section{Part C}

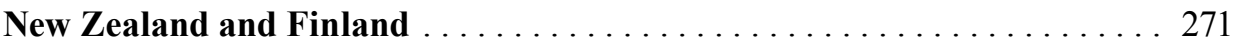

Chapter XII

New Zealand . . . . . . . . . . . . . . . . . . . . . . . . . . . 273

1. Background: the New Zealand legal and political system . . . . . . . . . . 274

2. The broader influence of the reporting process . . . . . . . . . . 276

2.1. The organisation of the process of state reporting . . . . . . . 276

2.2. The attitude of government officials towards the process of state

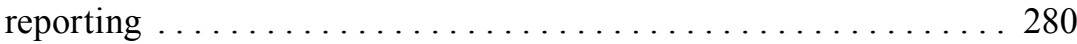

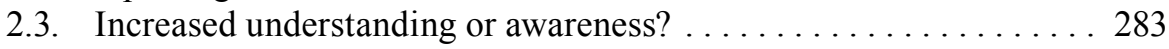

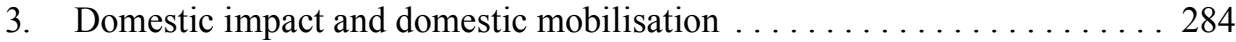

3.1. Governmental attention. . . . . . . . . . . . . . . . . . . . . 284

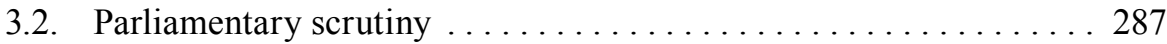

3.3. Courts and legal practice. . . . . . . . . . . . . . . . . . . 290

3.4. Human Rights Commission and Office of the Children's

Commissioner . . . . . . . . . . . . . . . . . . . . . 291

3.5. NGOs. . . . . . . . . . . . . . . . . . . . . . . . . . . . . . 293

3.6. Media coverage .......................... 295

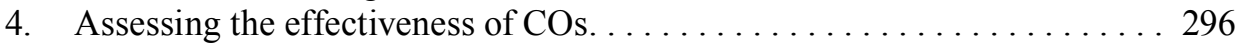

4.1. Prohibition of corporal punishment through the repeal of section 59 . 299

4.2. Avoiding age mixing in prison . . . . . . . . . . . . . 301

4.3. The repeal of the Foreshore and Seabed Act 2004 . . . . . . . . . . . 302

4.4. Education for unlawfully present children . . . . . . . . . . . 303

4.5. Withdrawal of the reservation to CEDAW: women in armed forces . 304 
4.6. The independence of the Police Conduct Authority . . . . . . . . . 306

4.7. The strengthening of the Children's Commissioner . . . . . . . . 306

4.8. The incorporation of the prohibition of non-refoulement . . . . . 307

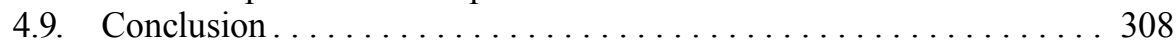

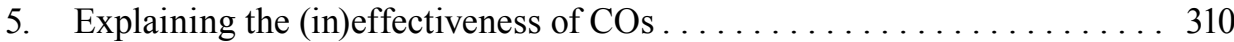

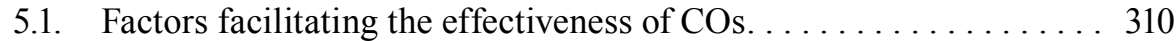

5.2. Factors obstructing the effectiveness of COs $\ldots \ldots \ldots \ldots \ldots \ldots 311$

6. Conclusion ................................. 316

Chapter XIII

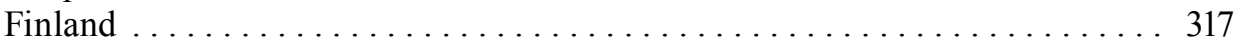

1. Background: the Finnish legal and political system ............. 317

2. The broader influence of the reporting process $\ldots \ldots \ldots \ldots \ldots \ldots \ldots . \ldots . \ldots 321$

2.1. The organisation of the process of state reporting . . . . . . . 321

2.2. Attitude of government officials towards the process of state

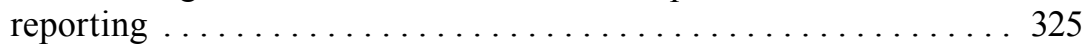

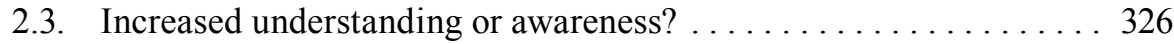

3. Domestic impact and domestic mobilisation . . . . . . . . . . . . . . 327

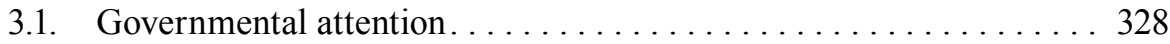

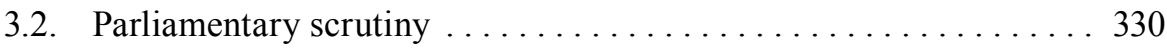

3.3. Courts and legal practice..................... 332

3.4. Ombudsmen and Human Rights Centre . . . . . . . . . . . . . . . . . 334

3.5. NGOs. . . . . . . . . . . . . . . . . . . . . . . . . 336

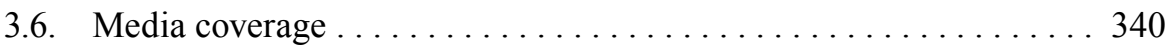

4. Assessing the effectiveness of COs. ................... 341

4.1. The establishment of an assistant Parliamentary Ombudsman and an Ombudsman for Children. . . . . . . . . . . . . . . . . . 345

4.2. Sami land rights and the ratification of ILO Convention $169 \ldots \ldots 346$

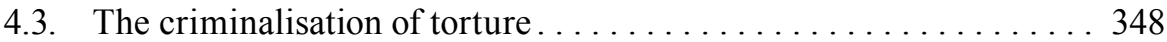

4.4. Violence against women in the $1990 \mathrm{~s} \ldots \ldots \ldots \ldots \ldots \ldots \ldots \ldots$

4.5. The establishment of the Ombudsman for Minorities ......... 351

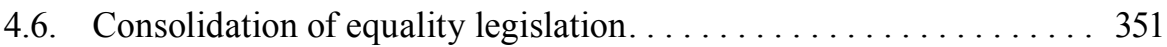

4.7. The reduction of the length of the alternative service for conscientious objectors . . . . . . . . . . . . . . . . . . . 352

4.8. The CRC in school curricula . . . . . . . . . . . . . . . . 354

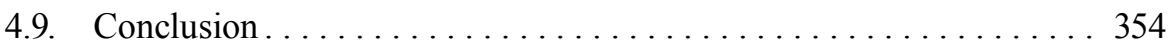

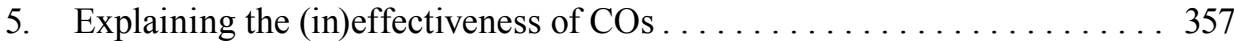

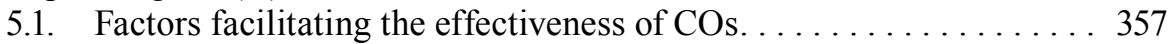

5.2. Factors obstructing the effectiveness of $\mathrm{COs} \ldots \ldots \ldots \ldots \ldots \ldots 361$

6. Conclusion..................................... 362 


\section{Part D}

Chapter XIV

Conclusion: Main Findings and Reflections........................ 367

1. The broader influence of the reporting process $\ldots \ldots \ldots \ldots \ldots \ldots . \ldots 368$

2. The domestic impact of the reporting process and the COs......... 369

3. Effectiveness of the COs ............................. 372

4. Factors contributing to the (in)effectiveness of $\mathrm{COs} \ldots \ldots \ldots \ldots \ldots 376$

4.1. Factors contributing to ineffectiveness of COs ............ 376

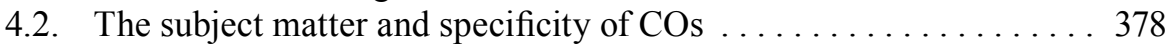

4.3. Domestic factors contributing to the effectiveness of COs. . . . . . 379

4.3.1. Domestic mobilisation ..................... 381

4.3.2. Structure: the organisation of the reporting process and follow-up to COs. . . . . . . . . . . . . . . . . . . . . . 383

4.3.3. Commitment: views and outlook of decision makers ..... 385

4.3.4. Cultural, political and legal factors . . . . . . . . . . . 387

5. Reflections and discussion . . . . . . . . . . . . . . . . . . . . 388

6. Policy recommendations ............................... 390

6.1. Suggestions for the treaty bodies: less is more . . . . . . . . . . 391

6.2. Suggestions for domestic stakeholders: COs as practical props . . . . 394

Nederlandse samenvatting [Summary in Dutch] .................. 395

Appendix 1. List of persons interviewed by the author ............. 405

Appendix 2.Databases and search terms used . . . . . . . . . . . . . 417

Appendix 3. Interview Checklist. . . . . . . . . . . . . . . . . . . 427

Bibliography.................................... 429

Index ..................................... 451 


\title{
List of Abbreviations
}

\author{
ABRvS \\ Afdeling Bestuursrechtspraak van de Raad van State \\ (Administrative Jurisdiction Division of the Council of State) \\ $\mathrm{ACVZ}$ \\ ACYA \\ CAT \\ CAT Committee \\ CDA \\ CEDAW \\ CEDAW Committee \\ CERD \\ CESCR \\ CFR \\ $\mathrm{CNV}$ \\ $\mathrm{CO}$ \\ $\mathrm{CoE}$ \\ $\mathrm{CRC}$ \\ CRC Committee \\ CRPD \\ CRvB \\ $\mathrm{CU}$ \\ DCI \\ D66 \\ EC \\ ECHR \\ ECJ \\ ECOSOC \\ ECPT \\ ECRI \\ ECSR \\ Adviescommissie voor Vreemdelingenzaken (Advisory \\ Committee on Migration Affairs) \\ Action for Children and Youth in Aotearoa Incorporated \\ (New Zealand children's rights NGO) \\ Convention Against Torture and other cruel, inhuman or \\ degrading treatment or punishment \\ Committee Against Torture \\ Christen Democratisch Appèl (Dutch centre-right Christian- \\ democratic party) \\ Convention on the Elimination of all forms of Discrimination \\ Against Women \\ Committee on the Elimination of Discrimination Against \\ Women \\ Committee on the Elimination of all forms of Racial \\ Discrimination \\ Committee on Economic Social and Cultural Rights \\ Charter of Fundamental Rights of the European Union \\ Christelijk Nationaal Vakverbond (National Federation of \\ Christian Trade Unions) \\ Concluding Observation \\ Council of Europe \\ Convention on the Rights of the Child \\ Committee on the Rights of the Child \\ Convention on the Rights of Persons with Disabilities \\ Centrale Raad van Beroep (Central Appeals Tribunal) \\ ChristenUnie (Dutch social Christian party) \\ Defence for Children International \\ Democraten '66 (Dutch centrist social-liberal party) \\ European Community \\ European Convention on Human Rights \\ European Court of Justice \\ UN Economic and Social Council \\ European Committee for the Prevention of Torture and \\ Inhuman or Degrading Treatment or Punishment \\ European Commission against Racism and Intolerance \\ European Committee of Social Rights
}




$\begin{array}{ll}\text { ECtHR } & \text { European Court of Human Rights } \\ \text { ESC } & \text { European Social Charter } \\ \text { EU } & \text { European Union } \\ \text { FCNM } & \text { Framework Convention for the Protection of National } \\ & \text { Minorities } \\ \text { FNV } & \text { Federatie Nederlandse Vakbeweging (trade unions } \\ & \text { confederation) } \\ \text { GA } & \text { United Nations General Assembly } \\ \text { GC } & \text { General Comment } \\ \text { GL } & \text { GroenLinks (Dutch green left party) } \\ \text { GR } & \text { General Recommendation } \\ \text { HRC } & \text { Human Rights Committee } \\ \text { IACHR } & \text { Inter-American Court of Human Rights } \\ \text { ICCPR } & \text { International Covenant on Civil and Political Rights } \\ \text { ICERD } & \text { Convention on the Elimination of all forms of Racial } \\ \text { ICESCR } & \text { Discrimination } \\ \text { ICJ } & \text { Rnternational Covenant on Economic, Social and Cultural } \\ \text { IL } & \text { International Court of Justice } \\ \text { ILA } & \text { International Law } \\ \text { ILO } & \text { International Law Association } \\ \text { IR } & \text { International Labour Organization } \\ \text { ISO } & \text { International Relations } \\ \text { JWS } & \text { Interstedelijk Studenten Overleg (Dutch National Student } \\ & \text { Association) } \\ \text { LBR } & \text { Johannes Wier Stichting (Dutch NGO for health } \\ \text { professionals) } & \text { Landelijk Bureau Racismebestrijding (Dutch National } \\ \text { LOI } & \text { Bureau against Racial Discrimination) } \\ \text { LOIPR } & \text { List Of Issues } \\ \text { MP } & \text { List Of Issues Prior to Reporting } \\ \text { NGO } & \text { Member of Parliament } \\ \text { NJCM } & \text { Non-governmental Organisation } \\ \text { NZBORA } & \text { Nederlands Juristen Comité voor de Mensenrechten (Dutch } \\ \text { OAS } & \text { section of the International Commission of Jurists) } \\ \text { OHCHR } & \text { New Zealand Bill Of Rights Act 1990 } \\ \text { OP } & \text { Organisation of American States } \\ \text { OPCAT } & \text { Office of the United Nations High Commissioner for Human } \\ & \text { Rights } \\ \text { Optional Protocol } \\ \text { Optional Protocol to the UN Convention Against Torture } \\ \end{array}$


PvdA

PVV

$\mathrm{Rb}$.

SGP

SIM

TEU

TFEU

UDHR

UN

UNHCR

UNICEF

UPR

VCLT

VVD

VVR

WHO
Partij van de Arbeid (Dutch centre-left social democratic labour party)

Party Voor de Vrijheid (Dutch right-wing party)

Rechtbank (Dutch district court)

Staatkundig Gereformeerde Partij (Dutch orthodox protestant party)

Studie- en Informatiecentum Mensenrechten

Treaty on European Union

Treaty on the Functioning of the European Union

Universal Declaration of Human Rights

United Nations

Office of the United Nations High Commissioner for Refugees

United Nations International Children's Emergency Fund

Universal Periodic Review

Vienna Convention on the Law of Treaties

Volkspartij voor Vrijheid en Democratie (Dutch centre-right liberal-conservative party)

Vereniging voor Vrouw en Recht (Netherlands association for women and law)

World Health Organisation 


\section{List of Figures and Tables}

\section{Figures}

Figure 2.1. A theoretical overview with its implication for this research..... 34

Figure 3.3. Two-stage methodology for the establishment of the effectiveness of COs .............................. 62

Figure 8.1. Parliamentary references to CEDAW and the COs of the CEDAW Committee in the Netherlands (1995-2011)......... 170

Figure 10.1. The impact of the CRC and the COs of the CRC Committee on the Dutch government $(1995-2011)$. . . . . . . . . . . . . . . 217

Figure 10.2. The impact of the CRC and the COs of the CRC Committee on the Dutch parliament (1995-2011) . . . . . . . . . . . . 220

Figure 10.3. The impact of the CRC on Dutch courts (1995-2011) . . . . . 222

Figure 10.4. The growing impact of the CRC in the Netherlands (1995-2011) . 229

\section{TABLeS}

Table 3.1. Modalities of impact and their indicators ............... 59

Table 3.2. Operationalising and measuring effectiveness............. 61

Table 5.1. Overview of (partly) effective COs of the CERD in the Netherlands ............................ 111

Table 8.1. Overview of ineffective COs of the CEDAW Committee in the Netherlands . . . . . . . . . . . . . . . . . . . . . . . 178

Table 8.2. Overview of (partly) effective COs of the CEDAW Committee in the Netherlands . . . . . . . . . . . . . . . . . . . . . 184

Table 10.1. References to the COs of the CRC Committee by the government and parliament in the Netherlands (1995-2011) . . . . . . . . 215

Table 10.2. Overview of (partly) effective COs of the CRC Committee in the Netherlands .......................... 233

Table 11.1. The domestic impact of the COs from 1995 to 2011 in the Netherlands .............................. 256

Table 11.2. Quantitative overview of the number of COs that have been effective in the Netherlands .................... 263

Table 11.3. Overview of (partly) effective COs in the Netherlands . . . . . . . 264

Table 12.1. Number of occasions during which MPs referred to various treaties, treaty bodies and COs in New Zealand (2000-2012) . . . 287

Table 12.2. Examples of COs that were (partly) effective or played a noticeable role in New Zealand. 
Table 12.3. Quantitative overview of the number of COs that have been effective in New Zealand ....................... 308

Table 12.4. Overview of (partly) effective COs in New Zealand .......... 309

Table 13.1. Examples of COs that were (partly) effective or played a noticeable role in Finland ........................... 342

Table 13.2. Quantitative overview of the number of COs that have been effective in Finland ............................... 354

Table 13.3. Overview of (partly) effective COs in Finland ............ 356

Table 14.1. The impact of COs in the Netherlands, New Zealand and Finland compared ......................... 370

Table 14.2. Quantitative overview of the number of COs that have been effective in the Netherlands, New Zealand and Finland. . . . . . . 374

Table 14.3. A comparison across countries of the factors affecting the effectiveness of COs . . . . . . . . . . . . . . . . . 380 


\section{Chapter I INTRODUCTION}

'The treaty bodies stand at the heart of the international human rights protection system as engines translating universal norms into social justice and individual well being.'

[UN Secretary-General Ban Ki-moon in June 2012] ${ }^{1}$

'The Geneva-based UN human rights mechanisms constitute some of the most powerless, underfunded, toothless, formulaic, and politically manipulated institutions of the UN.'

[Uvin in 2004] ${ }^{2}$

The process of state reporting is generally regarded as one of the best universal mechanisms to monitor the implementation of human rights treaty standards, at least on paper. Already in 1989, Alston held that the treaty body system is the 'cornerstone' of the UN human rights endeavours, with reporting lying 'at the very heart' of the system and of 'central importance'. ${ }^{3}$ Connors also stated that state reporting is 'the most widespread and established method of' and 'best available means of overseeing' the implementation of international human rights norms. ${ }^{4}$ Kälin argued that the procedure is the 'key mechanism' at the international level, also because it is mandatory, whereas the individual complaints procedure is optional. ${ }^{5} \mathrm{He}$ and others also noted that the process of reporting might be more effective in prompting a change of state behaviour than the latter, since it is better equipped to identify systemic and structural problems. ${ }^{6}$ As a result, the adoption of recommendations in the context of the process of state reporting is still 'the single most important activity' of the UN human rights treaty bodies. ${ }^{7}$ This chapter will leave aside whether these observations are (still) justified, especially in the light of the recent establishment of the Universal Periodic Review (UPR) in the UN Human Rights Council in 2008.

A different matter is whether the state reporting procedure is able to achieve its full potential in practice. The quotes above suggest that opinions differ a lot as to the actual impact of the treaty bodies. This domestic impact is the subject of this book. The focus is on the reporting process under the six main UN human rights

Ban Ki-moon in Pillay (2012), 7.

Uvin (2004), 140.

Alston (1989), para. 26 and 31.

In this context she quoted from Alston's final report that the treaty body system 'has the potential to be an important and effective means by which to promote respect for human rights' which 'has not in any way been superseded by other approaches or mechanisms'. Alston (1997a), para. 9. Connors (2000), 4 and 21.

Kälin (2012), 16.

Steiner (2000), 37. Kälin (2012), 40.

O'Flaherty (2006), 27. 
treaties; the International Convention on the Elimination of All forms of Racial Discrimination (ICERD), the International Covenant on Civil and Political Rights (ICCPR), the International Covenant on Economic, Social and Cultural Rights (ICESCR), the Convention on the Elimination of All Forms of Discrimination Against Women (CEDAW), the Convention against Torture and Other Cruel, Inhuman or Degrading Treatment or Punishment (CAT) and the Convention on the Rights of the Child (CRC). More specifically, this book investigates the impact and effectiveness of the recommendations issued by the six treaty bodies monitoring these treaties, the so-called Concluding Observations (COs), in the Netherlands, New Zealand and Finland.

Before presenting the main research questions and definitions used in this research (in section 4), this introductory chapter offers a brief overview of the workings of the process of state reporting and the legal status of the COs in the first section. The second section addresses the (deficient) functioning of the treaty body system on the basis of a literature review of the last two decades. The third section provides an overview of the research conducted so far on the impact and effectiveness of COs. The last part of this chapter outlines the research objectives (section 5), the societal relevance of this research (section 6) and the structure for the remainder of the book (section 7).

\section{BRIEF OVERVIEW OF THE PROCESS OF STATE REPORTING AND THE LEGAL STATUS OF COS}

\subsection{The process of state reporting ${ }^{8}$}

Before outlining the operation of the current process, a couple of words should be devoted to the historical background and the drafting of the process of state reporting. ${ }^{9}$ This process was the result of the complex and long negotiations which took place between 1947 and 1966 leading to the adoption of the ICCPR and ICESCR. The initial call for strong human rights supervision by Western states, including the establishment of an international court of human rights, met with strong opposition from the Soviet Union and other eastern states. These communist states argued that such a system would run counter to Article 2(7) UN Charter and violate their sovereignty over their own internal affairs. Given the geopolitical situation at that time, the emphasis was on information exchange and assistance based on a constructive and cooperative spirit, rather than the issuance of judgments

8 It is not the aim of this section to provide an exhaustive and detailed account of the reporting process and the differences between the various treaty bodies. For a recent report on the different working methods of the treaty bodies see UN Doc. HRI/ICM/2011/4 (2011). For an academic account thereof, see especially Boerefijn (1999), Vandenhole (2004), Tyagi (2011) and Kälin (2012).

9 For a good historical overview, see Boerefijn (1999), 13-24. 
by the treaty bodies. In its reporting guidelines of 1977, the Human Rights Committee (HRC), for example, held that its aim 'was to contribute to the development of friendly relations'. ${ }^{10}$ The international stalemate explains why reporting became the 'major control mechanism' and individual communication procedures were only made optional. ${ }^{11}$ The reliance on self-reporting was inspired by the already existing reporting system of the International Labour Organisation (ILO) as well as reporting arrangements set up by the UN Economic and Social Council (ECOSOC). ${ }^{12}$

All the major UN human rights treaties include an obligation for states to report to a committee which is entrusted with the monitoring of the implementation of the treaty obligations by the state parties. This committee or treaty body consists of independent experts who are 'persons of high moral character and recognised competence in the field of human rights' ${ }^{13}$ The treaties stipulate that states have to report at regular intervals, usually every four or five years, about the legislative, judicial, administrative, or other measures taken to implement and give effect to the treaty provisions. ${ }^{14}$ Treaty bodies have furthermore requested states to provide information on, among others, the constitutional and legal framework for the implementation of the rights, statistics about the factual situation and follow-up measures to the previous COs.

The system of reporting is based on a so-called 'constructive dialogue' between the treaty body and representatives of the state party. This dialogue is still seen as the core of the process of reporting. ${ }^{15}$ The idea of a 'constructive dialogue' stems from the approach of treaty body members from communist countries during the Cold War who held that it should contribute to cooperation and the strengthening of friendly relations between states. ${ }^{16}$ It is intended not to be contentious or adversarial. The idea is rather that treaty bodies support or assist the state parties in

10 UN Doc. A/32/44 annex IV, para. 7. Kälin (2012), 35.

11 MacDonald as quoted in Boerefijn (1999), 19.

12 Article 22 of the ILO Constitution from 1919 requires members of the ILO to "make an annual report to the International Labour Office on the measures which it has taken to give effect to the provisions to which it is a party'. Both Kälin and Leary noted that the reporting has been 'modelled on' the ILO system, even though Leary noted several differences. Leary (1992), 596. Kälin (2012), 17. ECOSOC Resolution 624 B (1956) asked states to submit a report describing developments and progress with respect to human rights initially every three years and from 1965 on an annual basis. The procedure was terminated in 1980. For more information, see Boerefijn (1999), 9-13.

13 Article 28(2) ICCPR.

14 Initial reports must be submitted within one or two years. See Article 40(1) ICCPR, Article 17(1) ICESCR, Article 18(1) CEDAW, Article 19(1) CAT, Article 44(1) CRC. For ICERD, there is an obligation to report every two years under Article 9(1) ICERD. In practice, treaty bodies have (sometimes) decided to forego the reporting deadlines in the treaty. UN Doc. HRI/ICM/2011/4 (2011), para. 27-34.

15 Kälin (2012), 24.

16 Kälin (2012), 35. 
their implementation of human rights. ${ }^{17}$ The input for the dialogue not only comes from the periodic report submitted by the state but also from alternative information presented by UN specialised agencies and especially NGOs and civil society actors. The latter are able to submit so-called alternative or parallel reports. Most of the treaty bodies have also given NGOs the opportunity to present their views orally during a special pre-sessional meeting prior to the dialogue with the government delegation and/or during an informal lunch with the treaty body expert members.

Most treaty bodies also adopt a List of Issues (LOI) shortly before the actual dialogue with a list of questions and requests for information on the basis of the analysis of the state report. The LOI is also used by the treaty bodies as an opportunity to receive updated information. This is because the time period between the submission of the periodic report and the consideration by the treaty body is usually a couple of years. Note that some treaty bodies, including the HRC and the Committee Against Torture (CAT Committee), have recently begun issuing a List of Issues Prior to Reporting (LOIPR). The responses to the LOIPR replace the periodic state report. ${ }^{18}$ The idea is that this LOIPR contributes to simplified, faster and more focused reporting which would diminish the burden for states. All six treaty bodies designate 'country rapporteurs' who are primarily responsible for the country under review and prepare drafts of the LOI and the COs. They are also the most active during the constructive dialogue. ${ }^{19}$ The examination of a state report ends with the adoption of COs by the treaty body. COs contain suggestions and recommendations for an improved implementation of the treaty standards by the state concerned. The present-day COs consist of three sections, the introduction, 'positive aspects' or 'follow-up measures and progress achieved by the state' and the 'main areas' or 'principal subjects of concern and recommendations'. The initial draft of the COs is prepared by the Secretariat sometimes together with the responsible country rapporteur(s). ${ }^{20}$ The rapporteurs work further on this draft and they seek comments and amendments from other members to prepare a final draft. The Committee on Economic, Social and Cultural Rights (CESCR), the Committee on the Elimination of Discrimination Against Women (CEDAW Committee) and the CAT Committee have a closed session immediately after the constructive dialogue during which members already give their preliminary views and suggestions to the country rapporteur that feed into the rapporteur's draft. ${ }^{21}$ The draft is discussed during a closed plenary meeting at the end of the dialogue or session, where the COs are eventually adopted by consensus. ${ }^{22}$ As will be discussed

Connors (2000), 6 .

O'Flaherty and Tsai (2011), 41.

CESCR, CERD, the CEDAW Committee appoint one rapporteur, while the CAT Committee and the CRC Committee appoint two rapporteurs. The HRC has a country task force consisting of one to three experts. UN Doc. HRI/MC/2009/4 (2009), para. 60-62. UN Doc. HRI/ICM/2011/4 (2011), para. 63-66.

O'Flaherty (2006), 32.

UN Doc. E/2011/22 - E/C.12/2010/3 (2011), para. 30-32. O'Flaherty (2006), 32.

UN Doc. HRI/MC/2009/4 (2009), para. 70. Kälin (2012), 26. O'Flaherty (2006), 32. 
in subsequent chapters, it is not uncommon for some treaty bodies or country rapporteurs to have a draft of the $\mathrm{COs}$ before the actual dialogue with the state. ${ }^{23}$

COs are a relatively recent phenomenon. The CESCR decided to adopt countryspecific comments in 1990, subsequent to the dialogue with the state party as collective appraisals of the entire committee. ${ }^{24}$ The other treaty bodies followed suit rather quickly. ${ }^{25}$ The CEDAW Committee was the last to embrace the practice of issuing 'concluding comments' in 1994. Before that, the constructive dialogues had basically 'no conclusion' and experts of the various treaty bodies tried 'to avoid evaluation at all costs'. ${ }^{26}$ Some individual members made a couple of 'disparate, sometimes inconsistent' observations. ${ }^{27}$ The adoption of country specific recommendations was blocked. This was the result of a fierce debate among treaty body members, especially those from the HRC, as to whether there is a proper treaty basis for the adoption of COs which are targeted at a particular state. Several expert members from communist Eastern European countries argued that the treaties did not permit the adoption of observations with respect to individual states since this would go against the cooperative spirit of reporting. They based their arguments on a narrow textual interpretation of the treaties, especially Article 40(4) ICCPR. The relevant part of Article 40(4) stipulates: 'The committee shall study the reports submitted by the States parties to the present Covenant. It shall transmit its reports, and such general comments as it may consider appropriate, to the States parties'. Eastern European members argued that the reference to 'general comments' and 'the State parties' implied that the HRC could not single out specific states and should rather address states as a whole by focusing on thematic topics. ${ }^{28}$

\subsection{Objectives of reporting}

Reporting as an international mechanism of supervision serves different objectives. Alston distinguished between seven functions of reporting in 1989.29 These functions also mirror the seven objectives highlighted in the first General Comment

23 This was mentioned by Dutch officials in relation to CERD and CESCR in 2010. The author also saw draft COs lying on the desk of the country rapporteur of CESCR prior to the start of the dialogue with the Dutch government. See chapter V, section 3.2 and chapter VII, section 3.2.

24 O'Flaherty (2006), 30. UN Doc. HRI/ICM/2011/4 (2011), para. 74.

25 The HRC's first COs were from September 1992, while the CERD, CRC and CAT Committee issued their first COs in the current form in 1993. O'Flaherty (2006), 28-30.

26 For a good overview of the discussions, see Boerefijn (1999), 285-294.

27 Alston (1997a), para. 109. From 1985, observations of HRC members were, for example, included in the summary records and the annual reports to the General Assembly. Boerefijn (1999), 291. O'Flaherty (2006), 29.

28 Boerefijn (1999), 286-289.

29 The seven objectives are: initial review, monitoring, policy formulation, public scrutiny, evaluation, acknowledging problems, and information exchange. Alston (1989), para. 33. 
(GC) of CESCR of the same year. ${ }^{30}$ The objectives were largely reaffirmed in the harmonised guidelines on reporting of 2006. ${ }^{31}$ The objectives of reporting will be explicitly reflected upon in this research (see below and chapter I, section 4.1).

One key objective of reporting is to provide a regular and periodic comprehensive review by a state party of the state of implementation of human rights, progress achieved and obstacles encountered. This gives an opportunity to reflect on the measures necessary to improve the human rights situation. As the harmonised guidelines stipulate, reporting should be used as 'an opportunity to take stock of the state of human rights protection within their jurisdiction for the purpose of policy planning and implementation'. ${ }^{32}$ Another objective is to provide an opportunity for 'constructive engagement with relevant actors of civil society'. ${ }^{33}$ Reporting could thus offer a 'platform for national dialogue on human rights' and to encourage and facilitate public scrutiny and discussion with civil society and NGOs about treaty implementation and government policies. ${ }^{34}$ In this way, the process can bring different domestic stakeholders together and encourage communication between them, while it also raises awareness about the treaty. ${ }^{35}$ The process, hence, aims 'to promote social mobilisation'. ${ }^{36}$ Alston observed that the role of the treaty bodies is, thus, 'essentially catalytic and secondary' as monitors of domestic monitors. The primary role in the protection of human rights is for domestic stakeholders 'with the strongest stake in the outcome and the best knowledge and understanding of the situation'. ${ }^{37}$

The extent to which these objectives of reporting are realised in practice depends upon how serious the state party takes the process. Alston argued that the process should be 'an integral part of a continuing process designed to promote and enhance respect for human rights rather than an isolated event absorbing precious bureaucratic resources solely to satisfy the requirements of an international treaty [...]. The process should be treated as an opportunity, rather than a chore or formality'. ${ }^{38}$ As will be presented in section 4.1, this research will examine whether reporting has indeed fulfilled the above-mentioned objectives in the three countries and whether it has been used as an opportunity for human rights review and dialogue.

30 Note that this GC and Alston's description predate the formulation of COs. CESCR, General Comment No. 1 on reporting by states parties, third session (1989).

UN Doc. HRI/MC/2006/3 (2006).

UN Doc. HRI/MC/2006/3 (2006), para. 9.

UN Doc. HRI/MC/2006/3 (2006), para. 10.

UN Doc. HRI/MC/2006/2 (2006), para. 8. Lansdown (2000), 114.

Kälin (2012), 39.

Lansdown (2000), 114.

Alston (1993), para. 95.

Alston (1997b), 20. 
Introduction

\subsection{The legal status of COs}

This section will briefly address the legal status of the COs, since this issue has already been addressed in-depth elsewhere. ${ }^{39}$ At a first and quick glance it seems easy to argue that the COs are, in principle, not legally binding but advisory. This can be derived from the recommendatory wording of the COs and the fact that the treaties do not provide the treaty bodies with the power to determine violations. This is further supported by the fact that the COs frequently relate to issues beyond the scope of the treaty and the constructive and non-adversarial nature and limited length of the dialogue. ${ }^{40}$ The view that COs do not impose a legal obligation per se is also shared by most state parties, their government and/or domestic courts, as will be discussed in subsequent chapters as well. ${ }^{41}$

Nonetheless, several observers argue that the status of COs goes beyond this simple portrayal and that COs can constitute authoritative statements or interpretations which cannot easily be ignored by states. Dimitrijevic, for example, argued that COs 'cannot remain without consequences', while Steiner stated that they constitute a 'special claim for attention'. ${ }^{42}$ The International Law Association (ILA) also observed that treaty body pronouncements are 'more than mere recommendations that can be readily disregarded'. ${ }^{43}$ O'Flaherty also stated that COs 'are not without some special status' and 'have a notable authority'. There are some judgments of national courts which give support to a stronger status of COs, because the COs were accorded persuasive or moral authority. ${ }^{44}$ The latter also happened indirectly in the ICJ's Advisory Opinion in the Legal consequences of the construction of a wall in the Occupied Palestinian Territory in which the ICJ relied upon the COs of the HRC and CESCR for its conclusion that the ICCPR and ICESCR apply to acts done by a state in the exercise of its jurisdiction outside its own territory. ${ }^{45}$ In the Ahmadou Sadio Diallo case, the ICJ attached 'great weight' to the interpretations of the HRC (Views and GCs), although it noted that it 'is in no way obliged [...] to model its own interpretation of the Covenant on that of the Committee, ${ }^{46}$ According to several scholars, the principle of good faith in Article 26 of the Vienna Convention on the Law of Treaties (VCLT) at least implies

\footnotetext{
39 See especially International Law Association (2004), O'Flaherty (2006) and Kälin (2012).

40 O'Flaherty (2006), 33 and 36-37.

41 International Law Association (2004), para. 16. O’Flaherty (2006), 33-34.

42 Dimitrijevic (2001), 198. Steiner (2000), 52.

43 International Law Association (2004), para. 15.

44 See the references to the jurisprudence of New Zealand and Irish courts in International Law Association (2002), para. 32-33.

45 Legal consequences of the construction of a wall in the Occupied Palestinian Territory (2004), ICJ Rep. 184, para. 110-113.

46 Ahmadou Sadio Diallo (Republic of Guinea v. Democratic Republic of the Congo) (2010), ICJ Rep. 639, para. 66.
} 
that states take note of and duly examine the COs and provide reasoning when they decide not to follow up on them. ${ }^{47}$

Several scholars make a distinction between, on the one hand, more compelling COs that relate to (clear violations of) treaty obligations that a state is required to comply with. ${ }^{48}$ On the other hand, they point to more advisory COs that go beyond such situations and relate to policy issues where the state has more freedom to choose the means through which it aims to realise or improve treaty compliance. O'Flaherty, for example, argued that COs especially have authority in situations where a treaty body determines that a state party's legislation, policy or practice is not in conformity with its treaty obligations. ${ }^{49}$ Scheinin held that because treaty bodies are the most authoritative bodies interpreting legally binding treaty obligations, a determination of a violation is an 'indication' that the state party is obliged to remedy the situation. ${ }^{50}$ The authority is less apparent when COs include 'general advice' or deal with matters which have little or nothing to with the treaty. ${ }^{51}$ This was also noted by Kälin who argued that COs relating to 'wider policy issues conducive to the full realisation of the treaty' are less authoritative and have less weight, because states have a wider margin. ${ }^{52}$ The last three authors, thus, stress the binding nature of the treaty standards upon which the treaty bodies base their pronouncement. They argue that noncompliance with a $\mathrm{CO}$ might lead to a violation of the underlying treaty obligation.

Another matter is whether the COs may constitute 'subsequent practice in the application of the treaty which establishes the agreement of the parties regarding its interpretation' or a 'supplementary means of interpretation' in the sense of Articles 31(3)(b) and 32 VCLT respectively. The ILA argued that the treaty body findings - which include COs - do not qualify as such, but that a supportive reaction or even the acquiescence by states in relation to the findings might constitute such subsequent practice. This reasoning was also based on the acknowledgement that human rights treaties are different from other international treaties and that subsequent practice might be broader than state practice 'and include the considered views of the treaty bodies adopted in the performance of the functions conferred on them by the States parties'. ${ }^{53}$ Some states, however, opposed this view of the ILA, including the US, the UK and Australia. ${ }^{54}$

Nollkaemper and Alebeek warned that endeavours to convert the views of treaty bodies into legally binding obligations are problematic and conflict with the intention of states as reflected in the text of the treaty and the dominant position in

Kälin (2012), 32. Keller and Grover (2012), 129.

See also International Law Association (2004), para. 15.

O'Flaherty (2006), 34-36.

Scheinin, as quoted in O'Flaherty (2006), 34.

O'Flaherty (2006), 36.

Kälin (2012), 56-57.

International Law Association (2004), para. 22.

Keller and Grover (2012), 130-131. 
state practice. ${ }^{55}$ This conclusion applies equally to the COs. ${ }^{56} \mathrm{Be}$ that as it may, the crucial point is that the above sketched ambiguity as to the precise legal status makes it important that COs are (seen as) persuasive, convincing and enjoy legitimacy in order for them to be effective (see chapter II, section 2.2).

\section{OVERVIEW OF THE DEFICIENCIES OF THE TREATY BODY SYSTEM}

The quotes in the beginning of this chapter already hinted at a heated discussion as to the significance of the treaty bodies. At one extreme are those who stress the great merits of the treaty bodies in a 'mantra-like' way and argue that they provide a 'valuable tool'. ${ }^{57}$ At the other extreme are those who argue that the system is 'an empty diplomatic ritual' which 'should be disbanded' ${ }^{58}$ Others are of the view that the "treaty bodies are becoming more and more peripheral's9 or that the "system is in crisis'. ${ }^{60}$ Somewhere in the middle is the view that the treaty body monitoring system 'has reached a critical crossroads', as Alston already concluded in 1989.61 Likewise, Keller and Ulfstein held that the system's credibility is 'seriously threatened'. ${ }^{2}$ Views also differ as to the reasons that have contributed to these problems. On the one hand, it is argued that the difficulty of the system is 'to a large degree a product of its success in attracting the participation and involvement of states and of other bodies'. ${ }^{6}$ On the other hand, there are those who argue that the deficiencies are the result of the persistent non-functioning of the system which has led to a vicious circle. ${ }^{64}$ The problems have become more severe as a result of the further growth of the treaty body system in recent years. Since 2004, the system has almost doubled in size. The number of treaty bodies went from six to ten and the number of experts increased from 97 in 2000 to 172 in $2012 .{ }^{65}$

\footnotetext{
$55 \quad$ Nollkaemper and Alebeek (2012), 385.

56 See also O'Flaherty's reservations as to the conformity of COs with principles of due process. O'Flaherty (2006), 36-37.

57 See, for example, the Dublin Statement: 'The treaty bodies have amassed many achievements and, severally and jointly, they have made a considerable contribution to the promotion and protection of human rights across the world'. Dublin Statement (2009), para. 2. Morijn (2011), 299. Connors (2000), 4.

58 Connors (2000), 4.

59 Clapham (2000b), 175.

60 The latter view as to a crisis situation and 'impending deadlock' of the treaty body system was already expressed by Glukhov in 1989 as quoted in Alston (1989), para. 7. Bayefsky (2000a), 315. Leckie noted that the system has become 'subject to a barrage of criticism in recent years, much of it justified'. Leckie (2000), 129.

$61 \quad$ Alston (1989), para. 8.

62 Keller and Ulfstein (2012), 425.

63 Crawford (2000), 3. See also Keller and Ulfstein (2012), 418.

64 Morijn (2011), 302 and 304.

65 Morijn (2011), 301. Pillay (2012), 17.
} 


\subsection{The treaty body reform discussion}

Leaving aside the severity and sources of the problems, the deficiencies in the functioning of the treaty bodies are rather well known and have been well documented over the past two decades. In 2007 O'Flaherty referred to 'a now wellworn litany of failings', which will be discussed below. ${ }^{66}$ The functioning of the treaty body system has been on the agenda since the end of the 1980s. At that time, Alston was appointed as an independent expert to study the functioning of the treaty bodies. His third and final report of 1997 concluded that the system is 'unsustainable and that significant reforms' and 'radical changes' are necessary 'if the overall regime is to achieve its objectives, ${ }^{67}$ Between 1999 and 2001, Bayefsky conducted a study entitled 'The UN human rights treaty system: universality at a crossroads' in cooperation with the Office of the High Commissioner for Human Right (OHCHR) which aimed to put forward suggestions for the enhancement of the treaty body system.

It was only when the Secretary General, Kofi Annan, raised the issue of treaty body reform in 2002 that concrete reform initiatives were discussed at the UN level. $\mathrm{He}$ advocated 'a more co-ordinated approach' and pointed to the need of a standardisation of reporting requirements and procedures. ${ }^{68}$ His suggestion of a single 'unified report' for all the treaty bodies as well as the proposal of the then High Commissioner for Human Rights, Arbour, in 2005 to create a unified standing treaty body were, however, rejected by several treaty bodies and NGOs. ${ }^{69}$ Despite some improvements made by treaty bodies themselves (chapter I, section 2.3), hardly anything has happened in terms of structural reforms addressing the more fundamental problems sketched below. ${ }^{70}$ According to O'Flaherty, the efforts had a rather limited scope and 'the need thus remains for a broader framework for overhaul of the system. ${ }^{71}$ The Dublin Statement also acknowledged that the process of harmonising the working methods 'is capable of addressing only a small number of concerns [...] at a slow pace'. ${ }^{72}$ In 2009, the High Commissioner for Human Rights Pillay initiated a process of reflection on how to further streamline and strengthen the treaty body system instead of reforming the system. This process consisted of several consultations with and written submissions and proposals of

66 O'Flaherty and O’Brien (2007), 158.

67 Alston (1997a), para. 10 and 80.

68 UN Doc. A/57/387, para. 52. O'Flaherty (2010), 118.

69 UN Doc. A/59/2005/Add.3, para. 147. UN Doc. HRI/MC/2006/2 (2006), para. 5. One important argument against was that such a body would entail the danger of losing the specificity of the treaties and, thus, reduce the attention paid to different rights holders, such as women and children. Schöpp-Schilling (2007), 203-211. For a discussion on the arguments in favour and against, see Johnstone (2007) and O'Flaherty and O'Brien (2007). and 307.

71 O'Flaherty (2010), 119.

72 Dublin Statement (2009), para. 4. 
different stakeholders, including the earlier mentioned Dublin Statement of current and former treaty body expert members. ${ }^{73}$ It culminated in a report by the High Commissioner of June 2012 which compiled various proposals, such as a comprehensive reporting calendar and a simplified and aligned reporting process in line with the LOIPR. ${ }^{74}$ An intergovernmental process was consequently launched in 2012 to conduct negotiations on the strengthening of the treaty body system. ${ }^{75}$

This process ended with the (draft) Resolution of the UN General Assembly (GA) of February 2014. The Resolution 'encouraged' treaty bodies and states parties to work with the simplified reporting procedure, while also encouraging the treaty bodies to have an aligned methodology for their dialogue with state parties and adopt 'short, focused and concrete' COs. ${ }^{76}$ The GA also 'decided' on word limits for documents prepared by treaty bodies and state parties and to provide additional meeting time to the treaty bodies on the basis of the number if reports and communications they receive. ${ }^{77}$ In addition, the Resolution focused on strengthening capacity building and technical assistance activities. ${ }^{78}$ Given that the GA primarily encouraged and invited the stakeholder to take certain measures, it remains to be seen what eventually will be implemented and whether the issues outlined below will be sufficiently addressed.

\subsection{The weaknesses in the treaty body system, the dialogue and the COs}

This section discusses the quality and professionalism of the treaty bodies in a general way, while subsequent chapters will focus on the differences between (and sometimes within) the six treaty bodies. The objective of this section is to show that there is considerable scepticism in the literature as to the functioning of the treaty bodies and whether COs are ever effective. ${ }^{79}$ As will be argued in chapter III,

73 For an overview of other statements, consultations and submissions, see <www2.ohchr.org/ english/bodies/HRTD/>.

74 Pillay (2012).

75 UN Doc. A/RES/66/254 (2012), para. 1.

76 This draft was submitted to the GA's budgetary committee for approval in March 2014. UN Doc. A/68/L.37 (2014), para. 1-2 and 5-6.

77 UN Doc. A/68/L.37 (2014), para. 15-16 and 26. Note that the joint statement of NGOs on this Draft argued that the GA cannot 'decide' on specific action, because it has no mandate to 'interfere' with the treaty bodies' working methods. 'Joint NGO statement', 20 February 2014, <www.ishr.ch/sites/default/files/article/files/2014-02-20-ngo_statement_on_tbsp_final.pdf>, accessed 12 March 2014.

78 UN Doc. A/68/L.37 (2014), para. 17-20.

79 The discussion is especially based on the abovementioned reports of Alston and Bayefsky as well as some edited volumes about the treaty bodies. Alston and Crawford (2000), Bayefsky (2000b), Bassiouni and Schabas (2011) and Keller and Ulfstein (2012). The rather critical discussion in the High Commissioner's Proposal for a unified standing treaty body in UN Doc. $\mathrm{HRI} / \mathrm{MC} / 2006 / 2$ (2006) is also noteworthy. For a good overview of the 'whole catalogue of concerns', see also Morijn (2011) and O'Flaherty (2010). 
section 1.1, this is an important reason for focusing on the most likely cases of established Western democracies.

It is not the aim of this section to unduly criticise or blame (individual) members of the treaty bodies. Many of the deficiencies described below are clearly beyond the power of the treaty bodies themselves. They are primarily a result of or affected by the limited financial resources of the treaty body system as well as the limited human and financial resources and support by the Secretariat of the OHCHR. ${ }^{80}$ It is commendable that the treaty bodies have largely managed to work with a system that has so many limitations. What is more, the dedication and commitment of many of the individual members of the treaty bodies is admirable. It is pitiable, however, that every treaty body has a couple of members who fail to live up the expected standards in terms of expertise, professionalism and independence. Such members have arguably received most of the attention in the literature. The functioning of such members also got disproportionate attention during interviews with domestic stakeholders. As will be discussed in subsequent chapters, several government officials focused on such members in order to discredit the whole treaty body and the treaty body system, despite the dedication and quality of the majority (chapter IV, section 4 and chapter XII, section 5.2).

The state parties are ultimately responsible for the functioning of the system, including its resources and other critical issues, such as the limited mandate and legal powers of the treaty bodies and the election of non-independent experts. ${ }^{81}$ Many state parties are reluctant to increase the effectiveness and enforcement capabilities of the system because they want to maintain their freedom of action as much as possible. ${ }^{82}$ It was (and is) not their intention to create a robust monitoring mechanism. A lot of the defects or weaknesses in the system are thus built into the treaties. ${ }^{83}$ Leckie expressed it rather aptly: 'How can it be, a lay observer might ask, that the procedures for securing compliance with major human rights treaties hinge upon a system that makes governments entirely responsible for reporting on themselves, once every five years, subject to soft questioning for a few hours by cautious committees, elected by those very government, and with almost no likelihood of serious censure or real sanctions' ${ }^{84}$

Another point which should be noted in this context is that many of the problems are the result of the rather ad-hoc development of the system from two treaty bodies

80 Alston (1989), para. 6 and 107-108. Alston (1997a), para. 7. Evatt (2000), 288. Crawford (2000), 6-7. Banton (2000), 71. Bustelo (2000), 100. Leckie (2000), 132-133. Bank (2000), 173. Clapham (2000b), 177 and 188. Schmidt (2000b), 481 and 494-495. Alston (2000), 502. UN Doc. HRI/ MC/2006/2 (2006), para. 18. O'Flaherty and O'Brien (2007), 142. Dublin Statement (2009), para. 5. O'Flaherty and Tsai (2011), 46. Gaer (2011), 112. Tyagi (2011), 633. Pillay (2012), 26-28. Keller and Ulfstein (2012), 425.

81 Alston (1993), para. 11.

82 Alston (2000), 502 and 522. Bayefsky (2001), 69. Heyns and Viljoen (2001), 517. Bassiouni (2011), 1.

83 Mutua (1998), 211-212. Leckie (2000), 130. Gaer (2011), 112. O'Flaherty and Tsai (2011), 42.

84 Leckie (2000), 130. 
in the $1970 \mathrm{~s}$ to the current coexistence of ten bodies. ${ }^{85}$ As a result, there is a considerable variance among the treaty bodies and their procedures, working methods and reporting guidelines, despite some improvement in recent years. ${ }^{86}$ Coordination between treaty bodies is still rather limited. This has several consequences. There is no division of labour but a considerable overlap in the questions and COs adopted. Because of this duplication, the total number of COs for a state party can range from 100 to 350 recommendations for a time period of four to five years. Such an amount is almost unmanageable. ${ }^{87}$

Most accounts on the functioning of the reporting system start by pointing to the problem of non-reporting by most of the states due to insufficient administrative capacity and expertise or a lack of political will. ${ }^{88}$ The Dublin Statement of 2009 even referred to 'escalating levels' of non-submission. ${ }^{89}$ In 2012 , only $16 \%$ of the state reports were submitted on time. ${ }^{90}$ On average, $23 \%$ of the state parties to one treaty have even never submitted a single report. ${ }^{91}$ Observers noted rather cynically that the present system is only able to continue functioning because of the nonparticipation of a significant number of states. ${ }^{92}$ When states do report, the quality of the reports varies widely and they are frequently inadequate or unsatisfactory. Reports are often self-serving, non-critical and descriptive and show a reluctance of states to reflect critically on their own performance. ${ }^{93}$ In addition, they do not contain adequate and detailed information on the law, practice and institutional human rights framework in the country. ${ }^{94}$

Observers also pointed to a reporting and evaluation fatigue on the part of the states. $^{95}$ The OHCHR noted that a state needs to submit twenty reports over a period of ten years when it has ratified the nine UN human rights treaties and the two optional protocols with a reporting procedure. ${ }^{96}$ This also means that states

85 Alston (1989) para. 21-25 and 35. Alston (2000), 522. UN Doc. HRI/MC/2006/2 (2006), para. 17 and 23. O'Flaherty and Tsai (2011), 37.

86 Tistounet (2000). UN Doc. HRI/MC/2006/2 (2006), para. 17, 19 and 23. Schöpp-Schilling (2007), 204. Bassiouni (2011), 6. Morijn (2011), 303 and 317. Keller and Ulfstein (2012), 424.

87 Pillay, as quoted in Kälin (2012), 18. Observers also pointed to the increased risk of contradictory remarks and interpretations among treaty bodies. Alston (1989), para. 128. Bank (2000), 150 and 152. Tistounet (2000), 390-394. Mechlem (2009), 908. Pillay, as quoted in Kälin (2012), 18-19. Alston spoke about 'chronic proportions'. Alston (1997a), para. 43 and 112.

Dublin Statement (2009), para. 5.

Pillay (2012), 9 and 20-23.

Pillay (2012), 94.

Alston (1997a), para. 48 and 113. Crawford (2000), 6. Kälin (2012), 45. Pillay (2012), 9.

Alston (1989), para. 6. Connors (2001), 10. Bayefsky (2000a), 317 and 323. Steiner (2000), 50. Leckie (2000), 130-131. Bank (2000), 147-148. Heyns and Viljoen (2001), 504-505 and 510. UN Doc. HRI/MC/2006/2 (2006), para. 16 and 24. Schöpp-Schilling (2007), 20-204. O'Flaherty and Tsai (2011), 46. Tyagi (2011), 308. Morijn (2011), 297. Kälin (2012), 46.

96 Pillay (2012), 21. 
often have to report on similar issues, because of rather similar and overlapping treaty provisions and duplicating requests of treaty bodies to provide information on these issues. ${ }^{97}$ Examples of issues that are included in almost every report and discussed with almost every treaty body are children's rights, women's rights, violence against women, non-discrimination, freedom of association, and illtreatment of persons. ${ }^{98}$ States are increasingly engulfed by a plethora of burdensome and often overlapping reporting requirements in other international and regional fora as well. ${ }^{99}$ Alston qualified this as 'the paper warfare against states'. ${ }^{100}$ It is therefore not surprising that reporting is not seen as a priority by many governments. Rather it is just another item to cross off the 'to do' list which includes many other items that compete for attention. ${ }^{101}$ Hence, it is approached without much engagement as a mere formality and bureaucratic exercise or a 'ritualistic routine'. ${ }^{102}$ Leckie referred in this context to the 'unwanted, boring and burdensome task of reporting. ${ }^{103}$ Reporting is also often done separate from day-to-day activities and is not seen as an element in policy making and NGO engagement. ${ }^{104}$

When states have submitted the report, there is usually a delay of a couple of years before the report is processed and discussed with the treaty body because of the backlog in the work of treaty bodies and the limited meeting time for treaty bodies. ${ }^{105}$ The consequence of this is that much of the information in the report is out of date at the time the report is considered. This situation has several implications. Backlogs could lead to a situation in which the work of the treaty bodies becomes rather irrelevant to states. ${ }^{106}$ Backlogs also weaken the opportunity to use the reporting process in a strategic way to raise awareness and create ownership with respect to the treaty and stimulate discussions with NGOs. ${ }^{107}$ The state is often required to present additional information in its replies to the LOI to update the state report. Such double work leads to a (further) disincentive to report. ${ }^{108}$

97 Mutua (1998), 217. Byrnes (2000), 310. Bayefsky (2001), 19. UN Doc. HRI/MC/2006/2 (2006), para. 17. Schöpp-Schilling (2007), 203. Johnstone (2007), 181-184. Morijn (2011), 297 and 303. Gaer (2011), 112. Pillay, as quoted in Kälin (2012), 18-19.

98 Tistounet (2000), 388. Alston (1989), para. 45-46.

99 Alston (1989), para. 6 and 36-42. Clapham (2000b), 196. Bayefsky (2001), 17-19. Kälin (2012), 17-18. Pillay (2012), 8.

100 Alston (1993), para. 19.

101 Woll (2000), 73 and 76. Heyns and Viljoen (2001), 508 and 519-520.

102 Norwegian Institute of Human Rights as quoted in Alston (1993), para. 9. See also Johnstone (2007), 180-181. Pillay (2012), 12.

103 Leckie (2000), 131.

104 Bayefsky (2001), 77.

105 Alston (1997a), para. 7. Crawford (2000), 4-5. Steiner (2000), 33. Bustelo (2000), 85-86. Lansdown (2000), 125. Bank (2000), 149. Bayefsky (2001), 17. Gras (2001), 125. UN Doc. HRI/ MC/2006/2 (2006), para. 19. Schöpp-Schilling (2007), 203. O’Flaherty and Tsai (2011), 46. Morijn (2011), 303. Kälin (2012), 42-45. Pillay (2012), 8 and 23-24.

108 Observation of the CEDAW Committee as quoted in Alston (1997a), para. 51. 
Another in-built weakness in the treaty body system is the lack of quality and expertise of some treaty body members. ${ }^{109}$ Steiner, for example, stated that the HRC has 'included a great range of members, from the exceptionally able to the mediocre, from the dedicated to the detached'. ${ }^{110}$ One quote by Mavrommatis, who served on the HRC for twenty years, is rather telling: 'The vast majority of the members of the [Human Rights] Committee were eminent jurists but there were and shall always be, a few passengers like the members whose largest and loudest contribution to our work was his snoring [...] and the other who before retiring admitted to me that his election was a mistake because it was thought that ours was a sort of economic committee and he was the person who was in Geneva looking after his dictator's, President-for-life's, investments in Switzerland. There was even a member who during each session only read a prepared ten-line text. Rumour had it that it was prepared by his wife'. ${ }^{111}$ A former member of the Committee on the Elimination of Racial Discrimination (CERD) likewise observed: 'It is not unusual for a member to be absent for part of meeting or even for several days, perhaps leaving Geneva to deal with governmental business elsewhere'. ${ }^{112}$ It is, hence, not surprising that two academics held that expert members should demonstrate greater self-discipline. ${ }^{113}$

The greatest concern relates to the lack of independence and impartiality. A significant part of the members of the treaty bodies consists of serving diplomats, ambassadors and members of government. Bayefsky found that in $200148 \%$ of the 947 elected treaty body expert members up to that date were employed in some capacity by their government. ${ }^{114}$ It should be noted that such a situation is almost unavoidable in an international organisation based on the equality of states which is subject to vote trading and politicised bargaining. ${ }^{115}$ Another factor that contributes to this situation is that the experts work on a part-time and unremunerated basis, in addition to having other demanding full-time jobs. ${ }^{116}$ This means that membership is often only possible for government officials and university professors who are paid or subsidised by their governments. Alston noted that this has repercussions for the independence of the experts. ${ }^{117}$

109 Leckie (2000), 131. Alston (2000), 502. UN Doc. HRI/MC/2006/2 (2006), para. 22. Johnstone (2007), 187. O'Flaherty and Tsai (2011), 46.

110 Steiner (2000), 42.

111 Mavrommatis (2001), 151.

112 Banton also referred to the occasion during which the draft COs were discussed by the CERD without the country rapporteur who had drafted them. Banton (2000), 61.

113 Keller and Ulfstein (2012), 424.

114 Bayefsky (2001), 108. See also Mutua (1998), 222. Clapham (2000a), 185. Clapham (2000b), 188 and 197. Connors (2000), 12. Crawford (2000), 9. Steiner (2000), 28. Leckie (2000), 131-132. Alston (2000), 502. Hakki (2002), 88-89. Johnstone (2007), 187-188. Mechlem (2009), 913 and 915. Dublin Statement (2009), para. 19.

115 Banton (2000), 74. Clapham (2000b), 188. Johnstone (2007), 187.

116 Connors (2000), 12-13. Clapham (2000b), 188, 193 and 195. Steiner (2000), 28. Evatt (2000), 289. Banton (2000), 71. Bayefsky (2001), 37. UN Doc. HRI/MC/2006/2 (2006), para. 22. Tyagi (2011), 633.

117 Alston (1989), para. 106. Alston (1997a), para. 84. 
Several observers pointed to the lack of preparation preceding the dialogue on the part of some expert members. ${ }^{118}$ This is not only related to their lack of motivation but also the 'explosion' of written information that is available and which is nearly impossible for members to be able to read it all. ${ }^{119}$ Keller and Ulfstein noted that in 2010, 139 state reports were submitted by 92 states with a total of 11,294 pages. These reports need to be translated into the three working languages of the treaty bodies. This often happens with significant delays, if at all. The latter consequently impedes the preparation of the expert members. ${ }^{120}$ It is, thus, not uncommon that treaty body members raise questions about issues which are already explained in the documents submitted to the treaty body. ${ }^{121}$

The quality of the dialogue has also been commented upon by many scholars. It has been described as 'often very poor', 122 'a strange diplomatic ritual'123 or 'a mere formality'. ${ }^{124}$ Several aspects have been noted in particular. Firstly, the superficiality of the discussion and the lack of focus in the questions or suggestions for future action have been noted. ${ }^{125}$ This is also because the members and the Secretariat of the OHCHR have limited familiarity and expertise with the circumstances, legal system and factual situation in the country under review. Secondly, the unstructured and sometimes undisciplined nature of the dialogue is noted. Some experts speak at excessive length. ${ }^{126}$ Others merely make a speech for the summary record or only raise questions because of their personal interest. ${ }^{127}$ The duplication of questions by experts is considerable as well. ${ }^{128}$ Thirdly, some argued that the dialogue has not really been a dialogue in the sense of a two-way flow or exchange, also as a result of excessive questioning. ${ }^{129}$ Requests and questions from government delegations to the treaty bodies for guidance or advice frequently remain unanswered. ${ }^{130}$ Neither is it seen as a constructive dialogue. Scholars pointed to the experience of state parties who feel that the process is rather adversarial or aggressive and that they are

118 Bank (2000), 153-154. O'Flaherty and Tsai (2011), 46.

119 Tistounet (2000), 394. Bayefsky (2001), 41. Kälin (2012), 61.

120 Keller and Ulfstein (2012), 418-419.

121 Gras (2001), 126.

122 Bayefsky (2000a), 320.

123 Clapham (2000b), 176.

124 Connors (2000), 11 and 13.

125 Bustelo (2000), 91. Schmidt, Bayefsky and Rodley (1997), 467. Alston (1997a), para. 83.

126 Banton (2000), 74. Bayefsky (2001), 63. Gras (2001), 126-127. Keller and Ulfstein, hence, proposed strict time management to prevent unnecessary interventions. Keller and Ulfstein (2012), 424. Note that embarrassing or controversial remarks of treaty body members are often omitted from summary records. Bayefsky (2000a), 320. Banton (2000), 62. Bayefsky (2001), 63-64. (2000), 74. Bustelo (2000), 91. Bank (2000), 150. Schmidt (2000b), 491. Bayefsky (2001), 63. 
unjustly criticised. ${ }^{131}$ In this context, the different standard of review was noted. It is not unusual that well-performing and diligent countries are constantly pressed to improve even more, whereas countries with a worse human rights record are merely encouraged for the sake of maintaining a dialogue. ${ }^{132}$ Fourthly, the dialogue usually consists of only two or three meetings of three hours. This means that a country report is often discussed for six hours, once every four or five years and often even on a less frequent basis. ${ }^{133}$ This limited time is not enough to answer the 'barrage of lengthy and complex requests' in an adequate way. ${ }^{134}$ Above all, this does not permit a thorough analysis or exchange of views. ${ }^{135}$ Neither does it enable the treaty body to fully comprehend the situation in a country and produce accurate COs that are of direct practical relevance for the state party. ${ }_{136}$

Another crucial element of the process is the quality of the COs in terms of their accuracy and the extent to which they reflect the needs and priorities of the country concerned. ${ }^{137}$ A great deal of criticism has been expressed in this context as to the variance in quality and specificity of COs. ${ }^{138}$ COs have often been described as vague, impractical, brief, general, and of little value because no specific measures are recommended. ${ }^{139}$ In the light of the earlier discussion as to the superficiality and limited time of the dialogue it is not surprising that the treaty bodies are hardly capable of absorbing the specific issues in each state to a sufficient degree so as to draft COs that are relevant. COs regularly recommend a state to simply intensify, strengthen or continue its efforts, without any suggestions for concrete measures. Such 'vague appeals' offer no useful guidance for states and are, hence, most likely being ignored. ${ }^{140}$ Leckie, for example, held that COs 'are so general as to lose any realistic hope of being taken seriously'. ${ }^{141}$ Likewise, Bayefsky argued that domestic stakeholders are frustrated by such 'extremely general' COs, because of the limited

131 Byrnes (2000), 304 and 310. Gras (2001), 123-125 and 128. Schöpp-Schilling (2007), 203. Alston also pointed to the danger of critical confrontations and a 'slinging match' procedure when treaty bodies rely too heavily on NGO material. Alston (1993), para. 231-236. Keller and Ulfstein referred to the 'filibustering' of delegations. Keller and Ulfstein (2012), 424.

132 Gaer (2011), 112. Keller and Ulfstein (2012), 423-424.

133 Schmidt, Bayefsky and Rodley (1997), 467.

134 Alston (1989), para. 112. Byrnes (2000), 310. Gras (2001), 123 and 126-127.

135 Bank (2000), 150 and 159. Clapham (2000b), 181 and 188. Bayefsky (2000a), 320. Gras (2001), $123-124$.

136 Schmidt, Bayefsky and Rodley (1997), 470. Clapham (2000a), 187-188.

137 Bayefsky (2001), 66-67. UN Doc. HRI/MC/2006/2 (2006), para. 25.

138 Bustelo (2000), 95. Bank (2000), 156. Gras (2001), 136-137. This variance depends very much on the country rapporteur. Bayefsky (2001), 37. O'Flaherty (2006), 32.

139 Alston held in 1997 that there is room for improvement in terms of the COs' 'clarity, degree of detail, level of accuracy and specificity': Alston (1997a), para. 109. Note that there have been some limited improvements in recent years. Kälin (2012), 62-63. For more criticism, see Evatt (2000), 288. Bayefsky (2000a), 321-322 and 335. Steiner (2000), 52. Bank (2000), 156-157. Gras (2001), 140. Heyns and Viljoen (2001), 511. Morijn (2009), 304. O’Flaherty and Tsai (2011), 46-47. Gaer (2011), 112. Pillay (2012), 60-61.

140 Morijn (2011), 304 and 313. Bank (2000), 157.

141 Leckie (2000), 132 and 136. 
possibility for them to be used as advocacy tools or to plan and implement reforms. ${ }^{142}$

COs are rarely backed up by substantive reasoning, if at all. ${ }^{143}$ They do not show that counterarguments expressed by the government delegation during the dialogue have been reflected upon by treaty body. ${ }^{144}$ Another problem is that not all treaty bodies (consistently) refer to the relevant underlying treaty provision in their COs. ${ }^{145}$ Hence, the relationship between the COs and the treaty is sometimes unclear. ${ }^{146}$ This is especially problematic when COs include issues that are marginal to the treaty or when COs go beyond the scope of the treaty. ${ }^{147} \mathrm{COs}$ are frequently based on rather progressive interpretations of the treaty beyond the plain text and original meaning. ${ }^{148}$ Especially in these two situations, there is a need for treaty bodies to provide a more elaborate motivation and an explicit legal basis.

Other comments about the COs have been targeted at their ad-hoc nature and selective focus on certain issues. ${ }^{149} \mathrm{COs}$ regularly fail to address the most pertinent problems. ${ }^{150}$ More critical, however, is that COs occasionally contain 'substantial errors' and show 'fundamental misunderstandings'. ${ }^{151}$ In addition, there have been COs on issues that have not been discussed (sufficiently) during the dialogue. This is something which undermines the reliability and persuasiveness of the treaty bodies. ${ }^{152}$ Another problematic issue is the (too) heavy reliance on information from NGOs. ${ }^{153}$ Some observers noted that the quality of this information varies enormously and is often far from objective. ${ }^{154}$ Treaty bodies and their members have no research capacity or possibilities for fact finding to assess the facts with a

142 Bayefsky (2001), 67.

143 Mutua (1998), 238. Evatt (2000), 292. Bayefsky (2000a), 328. Steiner (2000), 40-43. Bank (2000), 157. Gras (2001), 138. Hakki (2002), 97-98. Mechlem (2009). Baluarte and Vos (2010), 29. Keller and Ulfstein (2012), 422 and 425. Bank (2000), 158-159.

There has been an improvement in recent years. Currently, the HRC, CECSR and CAT Committee do so. Kälin (2012), 49-50.

Bank (2000), 160. O'Flaherty (2006), 33.

Bank, for example, argued that a justification for considering asylum policy in the context of CAT is necessary. Bank (2000), 152. Tistounet held that the CAT Committee cannot deal with ill-treatment by individuals, such as corporal punishment. Nonetheless, it has recently started doing so. Tistounet (2000), 386 and 393-394. See also Banton (2000), 55, 62 and 74. Kälin (2012), 57-59.

The HRC has frequently asked about economic, social and cultural rights. The HRC has, for example, interpreted the right to life to include housing, health and nutrition. This has been qualified as 'extremely expansive' by Khaliq and Churchill as quoted in Keller and Ulftein (2012), 416. Kälin (2012), 51-56.

Leckie (2000), 132. Bayefsky (2001), 68. Hakki (2002), 89.

Bank (2000), 150. Heyns and Viljoen (2001), 520. Hakki (2002), 89.

Bank (2000), 159.

Bank (2000), 158. O’Flaherty (2006), 38-41.

Leckie (2000), 133-134. Clapham (2000b), 177, 182 and 186-187. Alston (2000), 509-510. Bayefsky (2001), 46.

Bassiouni (2011), 7. 
high degree of accuracy. ${ }^{155}$ Some argued that the selective use of information gives rise to a perception of bias against states and might pose a danger to the impartiality and, hence, the effectiveness of the treaty bodies. ${ }^{156}$

Observers also pointed to the limited visibility of the system, which is hardly known outside a small circle of academics, government officials, specialised lawyers, and NGOs. ${ }^{157}$ Heyns and Viljoen even spoke about 'widespread ignorance'. ${ }^{158}$ The Secretariat described the system as 'disconnected from realities on the ground', while Clapham noted that the treaty bodies are splendidly isolated from the rest of the UN system. ${ }^{159}$

\subsection{Recent improvements}

Much of the critical and pessimistic literature discussed in the previous section stems from around the turn of the millennium. The treaty body system has evolved since then. Following the treaty body reform discussions which started in 2002 (chapter I, section 2.1), treaty bodies have taken measures to address some problems themselves. ${ }^{160}$ They undertook various attempts to harmonise their working methods and streamline reporting guidelines. These improvements were primarily the result of the increased cooperation of treaty bodies through (bi)annual InterCommittee Meetings. ${ }^{161}$ Another change includes the earlier mentioned LOIPR by some treaty bodies. In addition, the COs have become more detailed and more country specific in the last decade. This is illustrated by the increasing length of the COs. The most recent COs vary from five to 24 pages, while the length of the COs up to the mid-2000s seldom exceeded five pages. ${ }^{162}$

Several treaty bodies have also introduced written follow-up procedures. While Bayefsky observed in 2000 that follow-up is the 'key missing component of the implementation regime' and that treaty bodies only have 'rudimentary' follow-up procedures, there are currently four treaty bodies with a follow-up procedure. ${ }^{163}$ They

155 Alston (1989), para. 107. Banton (2000), 71. Bank (2000), 154. Bayefsky (2000a), 322. Hakki (2002), 88. Bassiouni (2011), 6-7.

156 Schmidt, Bayefsky and Rodley (1997), 468. Byrnes (2000), 309. Bayefsky (2000a), 324.

157 Mutua (1998), 229. Johnstone (2007), 181. O'Flaherty and O’Brien (2007), 143. Morijn (2011), 302. Kälin (2012), 69.

158 Heyns and Viljoen (2001), 518

159 UN Doc. HRI/MC/2006/2 (2006), para. 21. Clapham (2000b), 175 and 198.

160 See also Pillay (2012), 31-36. Hafner-Burton (2013), 124-127.

161 Since 1995, the Chairs of the treaty bodies have been meeting annually. Since 2002, these meetings have been broadened with two additional members per treaty body. They have been meeting twice a year since 2008. Morijn (2011), 306. Pillay (2012), 28.

162 O'Flaherty (2006), 30-31. UN Doc. HRI/ICM/2011/4 (2011), para. 76. There are notable differences among the treaty bodies. The CEDAW and CRC Committee rarely adopt COs of less than 10 pages. Recent COs of the CRC Committee sometimes even exceed 20 pages. See, for example, UN Doc. CRC/C/ALB/CO/2-4 (2012).

163 Bayefsky (2001), i-ii. Other scholars also noted that treaty bodies did not systematically check whether states have acted upon (all) the COs, if at all, even though states are supposed to report 
request the state party to provide information within one or two years after the issuance of the COs about the implementation of a few COs that deserve priority according to the treaty body. ${ }^{164}$ In addition, the HRC and CAT Committee have a special rapporteur for follow-up who reports to the wider committee whether follow-up answers were provided and considered adequate. Several scholars, however, noted the weaknesses of this follow-up procedure which is only limited to a few COs and based on the (written) information submitted by the state. ${ }^{165}$ Gaer criticised this procedure for considering the mere submission of information as satisfactory without examining whether the follow-up measures are substantively sufficient. ${ }^{166}$ The limited follow-up procedures have also not led to an increased discussion of the previous COs during the constructive dialogue. High Commissioner Pillay observed in 2012 that such discussions still 'remain marginal to the dialogue'.167

\section{OVERVIEW OF CONTEMPORARY RESEARCH ON THE EFFECTIVENESS of COs}

To date, academic research on the impact and effectiveness of COs has been limited. There is hardly any information about the actual impact of COs. ${ }^{168}$ Very few systematic in-depth studies have been conducted as to the effectiveness of the COs. Neither, have there been analyses from more theoretical and conceptual perspectives aimed at eliciting the factors which contribute to the (in)effectiveness of the UN human rights regime. ${ }^{169}$

On the one hand, many assertions about the achievements of the treaty bodies and the effectiveness of COs are largely grounded on anecdotal evidence. Several scholars stated that some countries changed their legislation or took some measures in response to the dialogue and COs, without giving any concrete examples. ${ }^{170}$ Others pointed to specific measures in certain countries which were allegedly taken as a result of the COs, but without an in-depth discussion of the causal relationship between the COs

in their subsequent state reports on the measures that have been taken in the interim period. Only the CRC and CEDAW Committee included an explicit section which assesses the level of implementation of some of the previous COs. Coomans (2000), 96. Evatt (2000), 290. Bank (2000), 161-162. Gras (2001), 127. O'Flaherty (2006), 41. 
and the measures. ${ }^{171}$ Many of these statements are made by those intimately involved in the work of the treaty bodies and, hence, 'insufficiently impartial and thus unable to judge $[. .$.$] whether the reporting system meets its goals'. { }^{172}$

On the other hand, statements as to the ineffectiveness of COs are also primarily based on (negative) perceptions, which might seem to follow logically from the deficiencies in the system outlined above. These scholars and observers note that COs are not followed up or are simply ignored. ${ }^{173}$ Several even spoke about 'chronic' or 'distressing' levels of non-compliance and an 'implementation crisis [...] of dangerous proportions'. ${ }^{174}$ Schmidt pointed in 2001 to a consensus among treaty bodies that the follow-up to COs is 'seriously flawed'. ${ }^{175}$ Even the Secretariat of the OHCHR concluded in 2006 that 'The treaty body system is rarely perceived as an accessible and effective mechanism to bring about change. [...] Governments frequently pay insufficient attention to the recommendations adopted by the treaty bodies, and lack of awareness or knowledge among national constituencies about the monitoring procedures and their recommendations, renders these invisible at the national level'. ${ }^{176}$ Some countries even downplay or disregard the treaty bodies altogether, while others see them as a 'bit of nuisance'. ${ }^{177}$ Noncompliance with COs is generally seen by states as 'harmless and cost-free negligence'. ${ }^{178}$ It is, thus, not surprising that scholars pointed to the low impact of the work of the treaty bodies and its irrelevance to the 'real' human rights work on the ground. ${ }^{179}$ Similar conclusions were made with respect to the Views of the treaty bodies in relation to individual complaints. A 2010 study of the Open Society Justice Initiative found that only $12 \%$ of the Views of the HRC have been implemented and that implementation had actually deteriorated over time. ${ }^{180}$

Only a handful of studies as to the actual effectiveness of COs have been conducted. Much of the research that is available was conducted in the early $2000 \mathrm{~s}$ and is, thus, rather outdated. One of the first studies was conducted in 1991 by

171 These accounts often simply note the difficulty of establishing causality. See, for example, Alston (2000), 508. Leckie (2000), 137-138 and 141. Tyagi (2011), 323-324 and 783.

172 Connors (2000), 8.

173 Schmidt, Bayefsky and Rodley (1997), 463. Schmidt (2000a), 244. Byrnes (2000), 308. Gras (2001), 141. O'Flaherty and O'Brien (2007), 143. Gaer (2011), 114.

174 Bayefsky (1996). Schmidt, Bayefsky and Rodley (1997), 470.

175 Schmidt (2001), 211.

176 UN Doc. HRI/MC/2006/2 (2006), para. 21 and 25.

177 Mavrommatis (2001), 152. See also Schmidt, Bayefsky and Rodley (1997), 464. Mutua (1998), 229. Schmidt (2001), 203.

178 Schmidt (2001), 215.

179 Bank (2000), 147. Clapham (2000b), 176.

180 This study was based solely on the annual report of 2009 of the HRC. Baluarte and Vos (2010), 119-120. Earlier, Bayefsky referred to a compliance rate of $21 \%$, while Schmidt argued that only $20-25 \%$ of the follow-up replies to the Views of the HRC could be deemed satisfactory. Bayefsky (2001), 33. Schmidt (2001), 203. The HRC estimated that only around $30 \%$ of follow-up replies show a willingness to implement the Views. UN Doc. A/64/40 (Vol. I) Supp No. 40 (2009), para. 230-236. 
Cohn. She made an 'early harvest' of the domestic legal changes as a result of the comments of individual members of the HRC. She found that 6 out of the 41 reported states had made changes in the light of the comments of the HRC. One drawback of this study is that the assessment was exclusively based on the information provided in state reports and no attempt was made to examine the truthfulness of the claims in the reports. ${ }^{181}$

The most systematic study was undertaken by Heyns and Viljoen from 19992001. They - in collaboration with the OHCHR - examined the impact of UN human rights treaties in 20 countries on the basis of national correspondents. Their primary conclusion was that the 'mechanisms used by the treaty bodies appear to have had a very limited demonstrable impact thus far'. ${ }^{182}$ COs are 'routinely ignored' when this is domestically convenient. ${ }^{183}$ They noted that the impact of the treaty body mechanisms varies enormously from country to country. They held that 'the enforcement system can and does have an impact' for the countries that are highly engaged with the system and submit substantial reports on time, especially when NGOs, newspapers and academics are also active. ${ }^{184}$ As a limiting factor, they pointed to the absence of a domestic human rights culture and 'domestic constituencies' in the form of active civil society actors and NGOs, an independent judiciary and a free press. ${ }^{185}$ Other factors enhancing the impact of the treaties and the COs include media coverage, reception by national courts and the development of human rights action plans. ${ }^{186}$ Note that the study was predominantly focused on the impact of the treaties as such, while only some attention was paid to both the process of reporting and the individual communications procedure. The actual level of implementation of COs is only briefly addressed and not in a very systematic way. ${ }^{187}$ Hardly any attempt was made to examine the causal relationship in relation to specific domestic policy changes supposedly made as a result of the COs. ${ }^{188}$ Niemi published a similar study in 2003 about the implementation of the COs, Views and GCs of the treaty bodies in six countries. Her study concentrated, first and foremost, on the institutions, structures and procedures in place for the implementation of treaty body findings and not so much on the (factors determining the) effectiveness of specific COs. She concluded that the degree of compliance with treaty body output is dependent upon the strength of domestic institutions. ${ }^{189}$

181 Cohn (1991), 298-300.

182 Heyns and Viljoen (2001), 488. Heyns and Viljoen (2002).

183 Heyns and Viljoen (2001), 488 and 511.

184 Heyns and Viljoen (2001), 488.

185 Heyns and Viljoen (2001), 488, 518 and 522.

186 Heyns and Viljoen (2001), 522-524.

187 The examination of the COs by the country correspondents in the individual chapters was not conducted in a systematic way and also varied widely. Heyns and Viljoen (2001), 511-512.

The authors merely acknowledged the difficulty in doing so. Heyns and Viljoen (2001), 486 and 512.

189 The countries in her study were Finland, Spain, Czech Republic, Australia, Canada, and Sweden. Except for the latter, all the countries were also included in the study of Heyns and Viljoen. Niemi (2003), 55. 
The ILA also issued a report in 2004 about the impact of the findings of the treaty bodies in the work of national courts and tribunals. The study concluded that the COs have been referred to on a relatively small number of occasions. ${ }^{190}$ By contrast, the Views of the treaty bodies, and especially the HRC, have become 'a relevant interpretive source for many national courts'. Nonetheless, the Views are hardly a decisive factor affecting the outcome of a court decision and play a smaller role than the jurisprudence of the ECtHR, even in countries which are not a party to the ECHR. ${ }^{191}$ Note that the ILA study is almost exclusively focused on the impact on courts. ${ }^{192}$

There have also been several studies as to the impact of the process of reporting under CRC and the COs of the Committee on the Rights of the Child (CRC Committee) across several countries. The CRC impact study 2000 found that the process of reporting under CRC was not used as a catalyst for domestic debate and policy change in the six countries included in the research. ${ }^{193}$ A subsequent study of Save the Children in 2009 arrived at the slightly more positive conclusion that the COs were implemented to a large extent. The study, however, did not try to uncover whether the COs were the reason for the legislative and policy measures. It simply noted that 'too many other factors are at play at [the] national level to determine cause and effect'. ${ }^{194}$ The limited specificity of the COs as well as budgetary state resources were said to be important factors complicating the impact of COs, while the use of COs by NGOs and UN agencies working at the national level is an enhancing factor. ${ }^{195}$ There has also been quite a large body of comparative research on the impact of CEDAW. These studies, however, focus primarily on the influence and domestic role of CEDAW as such and not so much the COs of the CEDAW Committee. 196

There have also been some individual country studies. The most notable is Byrnes' in-depth assessment of the impact of the process of reporting in Hong Kong in the 1990s. He noted that the response of the government to the COs was

190 International Law Association (2004), para. 176.

191 Treaty body output is primarily cited as additional support for a decision reached along with other international materials. International Law Association (2004), para. 175 and 179. International Law Association (2002), para. 18, 28 and 62.

192 The report only marginally touched upon the use of a treaty body by other national institutions in the Netherlands, the legislative process in Finland and the Australian human rights institution. International Law Association (2004), para. 156-174.

193 The six countries were Ghana, Yemen, Peru, Nicaragua, Sweden, and the Philippines. Woll (2000).

194 Theytaz-Bergman (2009), 39-40.

195 Theytaz-Bergman (2009), 40.

196 The first CEDAW impact study, for example, included ten countries. Only one of the 18 questions in the questionnaire distributed to the national correspondents was related to the implementation of the COs. McPhedran et al. (2000). See also Hellum and Aasen (2013). Zwingel examined national compliance processes in the context of CEDAW, with a particular focus on Finland and Chile. It is noteworthy that part of her analysis also included the reporting process. Zwingel (2005), 382-388. 
often rather negative. The common initial reaction was to disagree with the treaty bodies' analysis and dismiss COs as invalid on factual or legal grounds. ${ }^{197}$ Byrnes, nonetheless, concluded that the process of reporting and the COs can lead to government action when they are taken up by committed NGO activists, academics and legislators. COs can, hence, contribute to the domestic political struggle. ${ }^{198}$

\section{MaIn ReSEARCH QUESTIONS AND DEFINITIONS}

This research examines the domestic impact and effectiveness of the process of state reporting under the six main UN human rights treaties (ICERD, ICCPR, ICESCR, CEDAW, CAT and CRC). ${ }^{199}$ In order to address this question, three research questions were formulated:

(1) What has been the broader influence of the process of state reporting?

a. Has the reporting process been used domestically as an opportunity for human rights review and dialogue and, if so, in what way?

b. Has the reporting process led to a better understanding or increased awareness about the treaties and rights in question and, if so, in what way?

(2) How and in what way have domestic actors referred to, used and discussed the reporting process and the COs at the domestic level? (Impact)

(3) To what extent have policy, legislative or any other measures been taken at the domestic level as a result of the COs? (Effectiveness)

c. What factors have contributed to the (in)effectiveness of the COs?

The research questions and the main concepts used will be further explained and operationalised in chapter III, section 2. For all three questions it will be examined what the differences are between the six main UN human rights treaties and between the three countries, the Netherlands, New Zealand and Finland. Such a comparative exercise is particularly helpful in identifying factors that contribute to the (impact and) effectiveness of COs. For each country, there are roughly between 250 and 500 recommendations from the six treaty bodies since 1995, depending on how one counts. ${ }^{200}$

197 Byrnes (2000), 295-296 and 306-307. For similar observations, see Lansdown (2000), 123. Schmidt (2000a), 236. Clapham (2000b), 178.

198 Byrnes (2000), 311-312.

199 This research will not examine the reporting process under the two Optional Protocols to the $\mathrm{CRC}$ on the involvement of children in armed conflict and on the sale of children, child prostitution and child pornography.

200 This uncertainty as to the exact number of recommendations is because one paragraph in the COs often contains different recommendations. For the Netherlands, there have been between 250 and 550 recommendations adopted during 18 reporting cycles between April 1995 and November 2010. For New Zealand, between 250 and 500 during 17 cycles between March 1995 and May 2012. For Finland, between 250 and 500 during 21 cycles between January 1995 and 
Introduction

\subsection{Broader influence of the process}

The first research question deals with the broader influence of the reporting process. This refers to the more subtle and often indirect impact of the process of state reporting beyond specific COs. The first sub question investigates whether reporting has been used as an opportunity for human rights review and dialogue, or a so-called 'national human rights audit'. This question thus reflects on the extent to which the broader objectives of reporting are realised in practice (chapter I, section 1.2). The second sub questions examines whether the reporting process has led to a better understanding or increased awareness among various domestic stakeholders about the treaties and rights in question and, if so, in what way. This research question and the two sub questions were deliberately included to complement the rather narrow focus on COs as the main yardstick to measure the impact and effectiveness of the process of state reporting. The operationalisation of the broader influence of the reporting process will be further discussed in chapter III, section 2.1 .

\subsection{Impact}

The second research question dealing with impact relates to the way in which domestic actors have used the COs and the reporting process. The domestic actors included in this research are: the government, parliament, courts, national human rights and ombudsman institutions, NGOs, and the media. This means that this research will primarily focus on the role of COs in political decision making by the executive, the legislative process, litigation, and NGO lobbying. ${ }^{201}$ The following issues will especially be looked at: whether and how the government reflects and reacts to the COs and whether it refers to the COs in policy notes, Bills and during parliamentary debates. Another question is how parliament is informed about the process and the COs and whether the COs are tabled and discussed in parliament. It will also be examined whether Members of Parliament (MPs) submit (written) parliamentary questions, motions or legislative proposals as a result of or on the basis of the COs. In addition, the focus will be on whether and how NGOs use the COs in their domestic advocacy and litigation. Likewise, the role of COs in the work of national human rights and ombudsman institutions will also be examined.

June 2011. The website of the Netherlands Institute for Human Rights with all the COs of the six treaty bodies for the Netherlands since 1998 differentiated between 337 concerns and recommendations. The following filters were selected: CESCR, CEDAW, CAT, CRC, Mensenrechtencomité, CERD, Zorgpunt and aanbeveling <www.mensenrechtenkwesties.nl $>$, accessed 30 October 2013. Kälin held that states that have ratified all treaties and comply with their reporting requirements usually receive between 100 and 350 recommendations from the different treaty bodies they report to in a time period of four to five years. Kälin (2012), 18.

201 This definition mirrors the modalities of impact in Heyns and Viljoen (2001), 485-486, as well as Simmons (2009) who focuses on the executive and legislator in relation to policy and legislation, litigation and NGO advocacy and mobilisation (chapter II, section 1.2). 
Note that impact is closely linked to the concept of 'domestic mobilisation', which will be discussed in chapter II, section 1.2. The operationalisation of impact will be further discussed in chapter III, section 2.2.

\subsection{Effectiveness}

The third research question, regarding effectiveness, deals with the policy, legislative or any other measures which have been taken at the domestic level as a result of the COs. This definition implies that there are, in the words of Raustiala, 'changes in behaviour that otherwise would not have occurred'. ${ }^{202}$ This definition also reflects the idea that that COs have 'value if and only if they cause people to do things they would not otherwise do'. 203

A lot of research has focused on 'compliance' with international norms. Effectiveness is different from compliance in the sense that it refers to 'the extent to which it [the treaty] requires states to depart from what they would have done in its absence'. ${ }^{204}$ Compliance refers to 'a state of conformity or identity between an actor's behaviour and a specified rule'. ${ }^{205}$ There are several limitations to studying 'compliance' understood in this way. On the one hand, (full) compliance may not occur, even though a state has taken subsequent measures to address the issue. ${ }^{206}$ On the other hand, compliance may exist without a change and without any (additional) policy or legislative measures. Behaviour could simply be in line with or merely correspond to the COs without them having had any role whatsoever in policy decisions. Compliance, thus, does not tell us anything about the role or relative weight of the specific rule or recommendation, also because of other exogenous factors that could have contributed to the compliance. ${ }^{207}$ What distinguishes effectiveness from compliance is that effectiveness focuses on the causal relationship between legal rules or recommendations and the government's behaviour. $^{208}$

Effectiveness in the context of this research is thus understood as observable changes or actions that were (partly) the result of the COs. This refers to changes that can be attributed to the COs, because of a causal relationship between the COs

202 According to Raustiala 'an effective rule is simply a rule that leads to observable, desired behavioural change. Effectiveness is the measure of that change'. He argued that effectiveness is 'a means of measuring the extent to which compliance has achieved the desired change in behaviour'. Raustiala (2000), 394 and 396. For similar definitions, see Hathaway (2002), 1938. Gibson and Caldeira (1995), 460. Chayes and Chayes (1993), 176. Mitchell (1994), 425 and 429.

Downs, Rocke and Barsoom (1996), 383.

Raustiala (2000), 388 and 391-392. Compliance exists when 'the actual behaviour of a given subject conforms to prescribed behaviour, and noncompliance or violation occurs when actual behaviour departs significantly from prescribed behaviour'. Young (1979), 104. Jacobsen and Weiss (1995), 123.

Kingsbury (1998), 348.

Keohane (1997), 487. Raustiala (2000), 399-411. Martin (2013), 591 and 605. 
and the change. This change can take many forms (for a further discussion and operationalisation, see chapter III, section 2.3). One could think of (an adjustment of) policy or legislative measures, the establishment of an interdepartmental working group or committee to review the policy or legal framework, the commissioning of a report or evaluation, the establishment of a new institution or the allocation of extra budgetary resources. Effectiveness or change is not solely measured through the adoption of such new policy or legislative measures. COs can also be effective by thwarting an intended or desired change. This refers to a situation in which the government is precluded from taking measures that it would otherwise have taken, because they would go against the aim of COs. In such an instance, COs limit the policy options and courses of action available. One could also think of more subtle 'changes' of when COs put an issue on the political or legislative agenda or strengthen the arguments of domestic actors and, hence, shift the terms of the debate. Obviously, measuring the effectiveness of COs is an enormous challenge, especially in the light of a plethora of interacting domestic and international factors. This measurement challenge will be addressed in chapter III, section 2.4 .

\section{RESEARCH OBJECTIVES AND CONTRIBUTIONS}

The results of this research help to get better insight into the factors which contribute to the impact and effectiveness of COs at both the national and international level. By discussing these factors, lessons may be drawn and suggestions made on how to strengthen the effectiveness of COs. The examination of factors related to the operation and quality of the various treaty bodies also contributes to the burgeoning literature on the functioning of the UN human rights system and the treaty bodies. This is especially timely in the light of the recent discussions on the strengthening of the treaty bodies (chapter I, section 2.3).

Another objective of this research is to contribute to the literature of International Relations (IR) and International Law. This research offers insights into the factors contributing to the effectiveness and implementation of the COs, which are derived from and supported by theoretical and empirical studies (chapter II). In this way, this research makes it possible to confirm or reject the applicability of several underlying theories about the mechanisms through which international institutions affect the behaviour of states. ${ }^{209}$ Embedding the empirical research in a theoretical framework also allows for a more valid generalisation of the research findings. ${ }^{210}$ In doing so, this research also provides insights for sociological and political science studies that focus on the (crucial) role and contribution of domestic actors like parliament, national human rights and ombudsman institutions and especially NGOs in the protection and promotion of human rights.

209 Young and Levy (1999), 21. Nollkaemper (1992), 64. Landman (2009), 39.

210 Landman (2009), 27-29. 


\section{VALORISATION: SOCIETAL RELEVANCE OF THIS RESEARCH}

This research identifies the factors at the national and international level that contribute to the (in)effectiveness of the COs. Domestic stakeholders, such as government officials, NGOs and human rights and ombudsman institutions can 'learn' from this analysis. The conclusion of this book provides concrete policy recommendations for domestic stakeholders if they are willing to invest in the reporting process and strengthen its domestic impact and effectiveness (chapter XIV, section 6). Likewise, the findings might also be relevant for the treaty body strengthening debate (chapter I, section 2.1). The conclusion will therefore reflect on the future of reporting and include some concrete proposals which aim to strengthen the effectiveness of the treaty body system (chapter XIV, section 6).

The author already shared and discussed his findings with several stakeholders during the writing of his $\mathrm{PhD}$. In addition to the presentation of papers during academic conferences, the author gave several presentations and has held discussions with different Dutch domestic stakeholders who have been (in)directly involved in the reporting process. This, firstly, included presentations to several Dutch NGOs that have been most widely involved in the reporting process: the Dutch section of the International Commission of Jurists (NJCM), Defence for Children (DCI) who acts as a Chair of the Dutch Children's Rights Coalition and the Vereniging voor Vrouw en Recht (VVR), which is one of the most important NGOs of the Dutch CEDAW Network. ${ }^{211}$ Secondly, the author gave a presentation at the (future) Netherlands Institute for Human Rights during an internal brainstorming session about the (envisaged) role of the Institute with respect to (monitoring) follow-up to COs. ${ }^{212} \mathrm{He}$ was also a member of the sounding group for the first annual report of the Institute about the human rights situation in the Netherlands, where he could use the insights from this research (Klankbordgroep Jaarlijkse Rapportage, November 2012 - October 2013). ${ }^{213}$ The author, thirdly, discussed his findings for the three countries with government officials from the Constitutional and Legal Affairs Department when they were in the process of drafting the first national human rights action plan, which was presented in December 2013. ${ }^{214}$

211 Study evening about shadow reporting organised by NJCM (1 December 2011, The Hague). Lunch meeting at DCI about the reporting process under the CRC and the role of NGOs (3 June 2013, Leiden). Year conference of the VVR about the role of human rights in Dutch politics (9 October 2013, Utrecht). 25 January 2011, Utrecht.

213 Meetings in February, April and October 2013. The purpose of this group of three persons was to provide feedback on the plan, structure, themes and several draft chapters of this report. College voor de Rechten van de Mens (2013), 8. 
Introduction

\section{STRUCtURE OF THE BOOK}

Part A will provide the theoretical and methodological framework of this research. Chapter II gives an overview of the several theoretical models and causal mechanisms driving the impact and effectiveness of international (human rights) standards. On the basis of this overview, the chapter will present a theoretical framework that has inspired the methodologies for the empirical research. These methodologies for the establishment of the impact and effectiveness of the COs are presented in chapter III together with a justification for the countries selected.

Part B encompasses eight chapters on the Netherlands. It starts with chapter IV with a general introduction focusing on the role of human rights in the Dutch legal order and the organisation of the reporting process. This chapter will also present the (interview) findings as to the attitude of government officials towards the importance of reporting and their views about the functioning and quality of the treaty bodies, the constructive dialogue and the COs. The following six chapters (chapters V-X) each deal with one of the six main UN human rights treaties. These chapters are ordered on the basis of the date they were opened for signature, with the oldest treaty (ICERD) first and the most recent treaty last (CRC). Each chapter follows the same format. The impact of the COs is discussed in the first section, the effectiveness in the second section and the factors contributing to the (in)effectiveness in the third section. Part B ends with chapter XI which compares the findings from the six treaty specific chapters.

Part $\mathrm{C}$ includes the findings on the two other country studies, New Zealand and Finland (chapters XII and XIII). After outlining the legal and political system, the organisation of the reporting process and the views of government officials towards the value of reporting, these two chapters roughly follow a similar structure as the treaty specific chapters for the Netherlands.

Part $\mathrm{D}$ provides the conclusions on the research questions. It will compare and contrast the findings as to the impact and effectiveness of the COs in the three countries and present the most important factors that contribute to the (in)effectiveness of the COs. 


\section{Part A}

\section{TheORETICAL AND METHODOLOGICAL FRAMEWORK}




\section{Chapter II Theoretical Framework}

Research on the compliance with and effectiveness of international norms and their influence on the domestic level is burgeoning within the disciplines of International Relations (IR), International and European Law, Political Science, and even Sociology and Anthropology. Different concepts and questions are used in these fields, such as how norms 'influence', 'affect', 'diffuse to', or 'feed back into' national political systems or how changes at the domestic level can be attributed to or traced back to European or international norms, policies and processes. Other terms used are, for example, adaptation, domestic implementation, home-coming, transnational diffusion, appropriation, or norm realisation. At the heart of all these different approaches is, nonetheless, the recognition that international and domestic politics and processes are 'often somehow entangled', as Putnam observed.' Gourevitch argued in a similar way that international relations and domestic politics 'affect each other' and are 'so interrelated that they should be analysed simultaneously, as wholes'. 2

The following chapter will give a literature overview of the mechanisms that drive the influence, effectiveness of and compliance with international (human rights) norms which are identified in IR and International Law scholarship. ${ }^{3}$ The impact of and compliance with international norms is also studied in the context of so-called Europeanisation research on the impact of processes at the European level on domestic policies, institutions and political processes. ${ }^{4}$ Another rich field is international environmental law and regimes. ${ }^{5}$ This conceptual and theoretical framework will borrow from several insights derived from these fields as well. Note that this overview 'skims only the surface of deeply complex theories'. 6 Even though this research looks at effectiveness instead of compliance (as was discussed in chapter I, section 4.3), this chapter will sometimes refer to compliance, because this has been the term which is used most frequently in the literature.

1 Putnam (1988), 427. Putnam developed a two-level game to gauge the interaction of domestic and international factors in relation to international negotiations. National decision makers try to reconcile domestic and international pressures simultaneously. They play one game with domestic actors who pressure the government to adopt certain measures and another at the international level in order to enlarge their ability to please their domestic audience.

2 Gourevitch termed the impact of international structures and processes on the domestic level as the 'second image reversed'. The second image in IR assesses how domestic political forces and the internal structure of the state affect international relations and the international system, such as the occurrence of war. Gourevitch (1978), 882 and 911.

This overview largely follows Hathaway (2002) and Von Stein (2013).

Börzel and Risse (2012), 1.

Supra n. 169 in Chapter I. See also Young and Levy (1999).

Hathaway (2002), 1944. 
This theoretical overview serves two purposes, as is also illustrated by figure 2.1. Firstly, the several theoretical models have been instructive in guiding the empirical work to delineate what aspects to focus on. Secondly, as will be argued in chapter III, section 1, the theories have also been important for the country selection. The first three sections will briefly outline the content of several theoretical models and discuss their implications for this research. Section 4 will consequently present the theoretical framework used for this research. Note that final chapter XIV will reflect on the validity or operation of the several underlying theoretical models on the basis of the empirical findings. ${ }^{7}$

Figure 2.1. A theoretical overview with its implication for this research

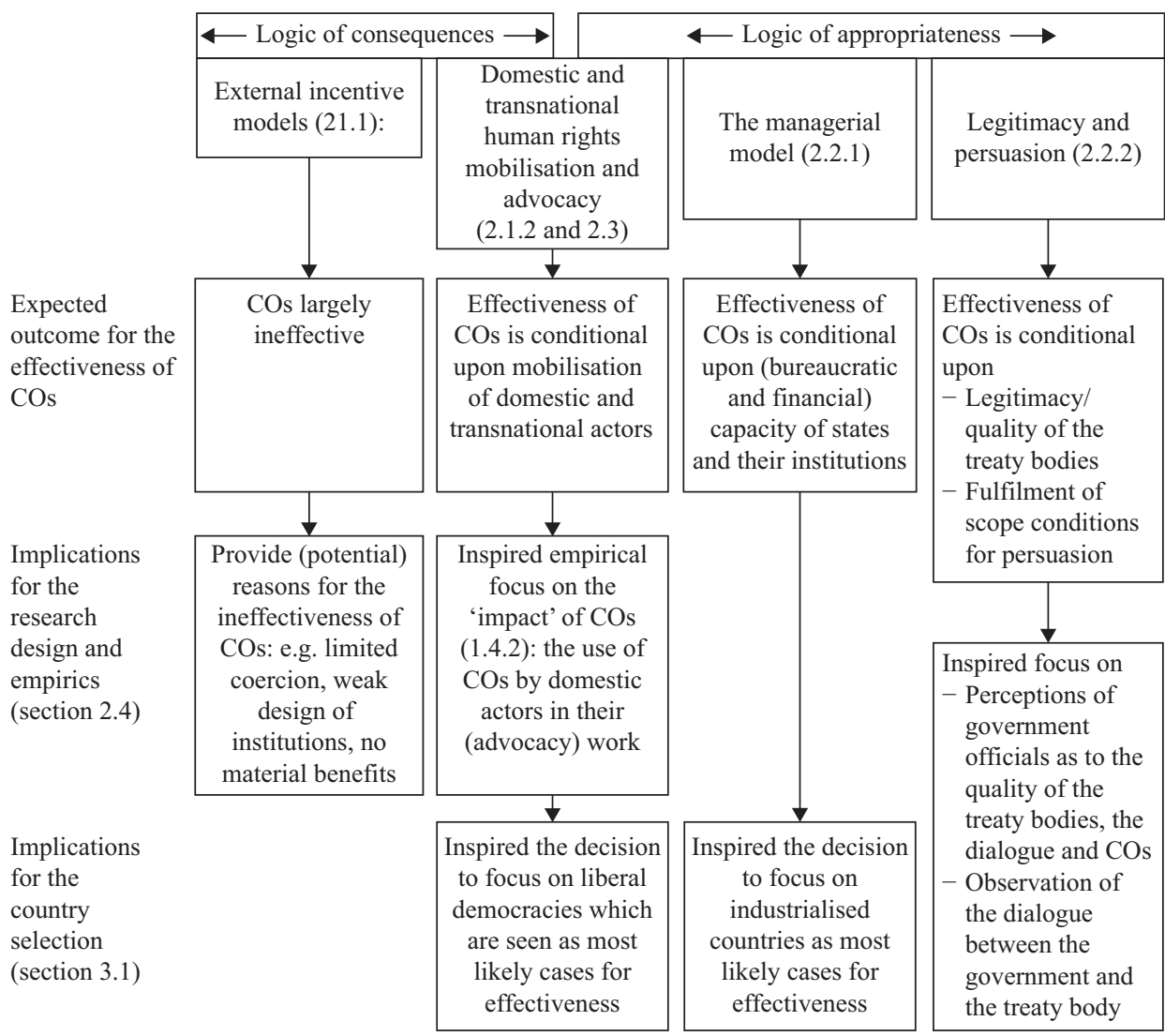

7 Note that this research is more inductive than deductive. The explicit choice was made not to test hypotheses or theories. One reason for this is that there had hardly been any research on the effectiveness of the recommendations of treaty bodies before. The research is at the same time not strictly inductive either. There has been a continuous interaction between theories and empirical observations. 
Theoretical Framework

\section{LOGIC OF CONSEQUENCES: INSTRUMENTALIST OR RATIONALIST MODELS}

Usually two different logics of action are distinguished with respect to an actor's behaviour. These two underlying logics are ideal types or stereotypes and, as will be discussed later, they often operate simultaneously. ${ }^{8}$ The first group of models posit that state behaviour is 'driven by a logic of anticipated consequences and prior preferences'. ${ }^{9}$ They treat actors as rational and self-interested strategic utility maximisers. Compliance decisions are the result of a reasoned weighing and calculation of the consequences and costs and benefits of alternative modes of action. ${ }^{10}$ Following this logic, actors comply with international norms for instrumental reasons, which relate to the international (section 2.1.1) or domestic level (section 2.1.2). Note that (neo)realist IR theorists downplay the relevance of international institutions and argue that human rights treaties hardly affect state behaviour, if at all. ${ }^{11}$

\subsection{External or international incentives models}

The following external incentive models see compliance with international human rights law as the result of international material inducements which manipulate the utility calculations of states. These compliance incentives arise out of the interaction between states. States comply when this furthers their self-interests and the benefits outweigh the costs of detection. States either comply to avoid punishment or retaliation by other more powerful states in the form of sanctions, reduction of development aid or in extreme cases (military) intervention. ${ }^{12}$ Or they comply to obtain (positive) rewards, such as aid, trade concessions, accession to an international organisation (conditionality), technical, and financial assistance. ${ }^{13}$ The extent to which states are willing to coerce other states to comply in the field of human rights is, however, limited. Scholars argue that these states usually do not have a strong interest in or incentive to enforce compliance with human rights in

Börzel and Risse (2012), 5.

March and Olsen (1998), 949.

10 March and Olsen (1998), 949-950. Hathaway (2002), 1944 and 1951. Tallberg (2002), 611-612.

11 They argue that compliance is not the result of international human rights law but merely happens when state interests simply coincide or correlate with international norms, because the norms reflect the interest of - especially the most powerful - states. Realists would argue that states will not comply with human rights treaties when it is not in their interest to do so. Considerations of power always triumph. Simmons (2009), 115. Hathaway (2002), 1944-1947. Mitchell (1994), 428. Keohane (1997), 489.

12 Guzman referred to the 'Three Rs of compliance': retaliation, reciprocity and reputation. Guzman (2008). The 'retaliation' model sees coercion, punishment or diplomatic pressure by more powerful and dominant states as the most important compliance mechanism. Simmons (2009), 114-115.

13 Schimmelfennig and Sedelmeier (2004), 671-672. Schimmelfennig (2005), 830. 
other states. ${ }^{14}$ States have only been willing to coerce other states in exceptional cases of the most flagrant violations of human rights. One important explanation for the limited occurrence of retaliation or coercion is that the principle of reciprocity does not work in the field of human rights. Human rights violations primarily affect the state's own citizens and, thus, do not harm the other (non-violating) state directly. The risk that the non-violating state consequently denounces the treaty is minimal. ${ }^{15}$ There is, thus, no direct consequence or deterrent for the reneging state. This compliance mechanism is of little value for this research, in particular, because there have been hardly any instances of coercion or cases in which other states have pressured or provided assistance to these more powerful (Western) countries to follow up on a CO. ${ }^{16}$

Several scholars have gone beyond material inducements to also include social rewards in the form of international recognition, public praise and reputation or 'soft sanctions' in the form of 'naming, shaming and faming'. ${ }^{17}$ These social inducements act as an indirect way of coercion. According to this model, states comply in order to avoid embarrassment and maintain their reputation for respecting international (human rights) law and keeping their promises. Damage to reputation can also have material repercussions, since a state's reputation or credibility might affect its ability to secure (future) cooperation in other issue areas and international investments. ${ }^{18}$ The reputational mechanism is, however, assumed to be of limited relevance for this research. Simmons argued that reputational costs are low in the field of human rights, because 'many violations are difficult to detect'. ${ }^{19}$ Hawkins and Jacoby also found that 'public shame' is rather limited in relation to noncompliance with judgments of the ECtHR and IACHR, because few actors pay attention to these judgments. ${ }^{20}$ This finding is even more true for the COs, which are hardly known outside a small circle of diplomats and government officials (chapter I, section 2.2). ${ }^{21}$

Another strand of rationalist literature, (neoliberal) institutionalism, takes international institutions and treaties into account and argues that they can potentially have an effect on state behaviour by manipulating states' incentives to

14 Reasons are, for example, that 'peers' are not affected by the violation or that other foreign policy concerns prevail. Hathaway (2002), 1938 and 1951. Simmons (2009), 113, 122 and 126. Dai (2013), 95-96.

15 Simmons (2009), 123 and 154. Koh (2005), 1134.

16 States rarely react to other states' failures to submit reports or implement COs, if at all. Crawford (2000), 10. Evatt (2000), 288. More in general, usually (Western) democracies coerce 'repressive' states with respect to human rights, and not the other way around. Risse and Ropp (1999).

17 Schimmelfennig (2005), 831-832. Zeitlin (2009), 226-227.

18 Keohane (1997), 490 and 494. Raustiala (2000), 402.

19 Simmons (2009), 124-125. Keohane also argued that violating norms only has consequences for reputation under certain conditions, which are frequently not fulfilled in world politics. Keohane (1997), 497.

20 Hawkins and Jacoby (2010), 41.

21 Steiner (2000), 38-39 and 51. 
comply. They focus on the 'design' of institutions and the characteristics which favour compliance. ${ }^{22}$ Design features of compliance systems that are studied are, among others, the 'direct punitive capacity' to enforce or the extent to which institutions can provide financial and technical assistance. ${ }^{23}$ Several empirical studies found that international human rights treaties and institutions are not strong enough to alter state behaviour and prompt state compliance. ${ }^{24}$ As was already discussed in the introduction, UN human rights treaties lack a (strong) enforcement mechanism (chapter I, section 2.2). Treaty bodies have no instruments at their disposal to compel states to comply with the COs through the adoption of sanctions or the withholding of benefits. Treaty bodies are, thus, 'weak by design', also because of limited resources. The treaty bodies or the Secretariat of the OHCHR are hardly able to provide financial assistance to strengthen the compliance capacity of states. ${ }^{25}$

While these international incentive models offer explanations for the ineffectiveness of COs, they are not very well placed in explaining compliance with and changes on the basis of international human rights treaties and especially the COs. ${ }^{26}$ On the basis of these models alone, one would not expect a change of state behaviour as a result of the COs. Other theories should, thus, be taken on board to account for the (potential) effectiveness of COs.

\subsection{Domestic politics, institutions and mobilisation}

Another rationalist strand of compliance research focuses on the domestic political level and largely falls within the liberalist IR tradition. Compliance decisions are said to be a function of the domestic self-interest of governments and their instrumental cost and benefit calculations about the domestic political constellation. The higher the domestic political adjustment costs and the more the difficult policy changes, the less likely compliance will be. ${ }^{27}$ Compliance with international norms is, thus, the result or 'by-product' of domestic politics and institutions. ${ }^{28}$ The domestic politics are construed as a political bargaining game about 'who gets what, how, and when' during which rational domestic actors, who act as utility

22 Helfer and Slaughter, for example, developed a checklist for effective supranational adjudication with institutional factors within the power of the state parties, including the tribunal's composition, its caseload and resources, its independent fact-finding capacity and its formal status. Helfer and Slaughter (1997), 298-323.

23 Finnemore and Sikkink (1998), 893. Mitchell focused on the extent to which institutions provide transparency and information about non-compliance. Mitchell (1994).

24 For a good recent overview of the literature, see Hafner-Burton (2013), 67-115. Keith (1999), 112. Hathaway (2002), 1938 and 1947. Neumayer (2005), 926-928. Hafner-Burton and Tsutsui (2005), 1384.

25 Hathaway (2002), 2020. Dai (2013), 95.

26 Simmons (2009), 121. Koh (2005), 979. Steiner (2000), 25. Bassiouni (2011), 1-3.

27 Schimmelfennig (2005), 828.

28 Hathaway (2002), 1952. 
maximisers and pursue their own interests, strategically interact, negotiate and form coalitions with each other. ${ }^{29}$ The following theories have quite a bit of overlap with constructive theories following the logic of appropriateness as will be discussed in chapter II, section 3.

The central tenet of this group of theories is that international institutions are able to change the behaviour of a state through domestic institutions, such as domestic courts, and by mobilising domestic advocacy groups, NGOs, and political parties that pressure governments to change behaviour. ${ }^{30}$ International pressure can be a necessary, but is not a sufficient, condition for policy change in itself. Domestic resonance and support is crucial for this change. ${ }^{31}$ Helfer and Slaughter focused on the ability of a supranational tribunal 'to secure such compliance by convincing domestic government institutions, directly and through pressure from private litigants, to use their power on its behalf' ${ }^{32}$ Moravcsik also held that international human rights institutions 'coopt' domestic actors who consequently pressure their governments for compliance 'from within'. International norms and institutions can subsequently shift the balance of power within and between domestic actors and prompt a change in coalitions and calculations underlying governmental policies, which might eventually lead to a policy change. ${ }^{33}$ A government or a government department might, for example, use international norms and pressures to increase their influence vis-à-vis domestic opponents and, hence, shift the balance of power in favour of the preferred policy. ${ }^{34}$ Likewise, Alter held that international courts can act as 'tipping point actors' by forwarding resources to and supporting compliance constituencies. In this way, they can tip the political balance in favour of policies in line with international norms. ${ }^{35}$ Norms and pronouncements of international courts can, thus, offer a (legal) justification to domestic actors and can frame a minority view in favour of compliance in more universal terms. They can also offer a tool to delegitimise the arguments of the opponents to compliance. ${ }^{36}$

Europeanisation research in particular has a principal focus on domestic politics, institutions and the constellation of actors and their strategies as a causal mechanism to compliance. ${ }^{37}$ Several studies concluded that domestic change on the basis of European norms is unlikely to happen, unless domestic actors take them up and demand change. ${ }^{38}$ European norms and processes are conceived as

March and Olsen (1998), 949-950. Hafner-Burton and Tsutsui (2005), 1380.

Hathaway (2002), 1954. Neumayer (2005), 930. Hafner-Burton and Tsutsui (2005), 1385.

Gourevith (1978), 911. Putnam (1988), 429-430.

Helfer and Slaughter (1997), 278.

Moravscik (1995).

Risse and Sikkink (1999), 33. Alter (2013), 17.

Alter (2012), 1 and 5. Alter (2013), 16-18.

Alter (2012), 5 and 8. Gurowitz (1999). Jacobsson and Vifell (2007), 181-182.

Saurugger and Radaelli (2008), 215. Heidenreich and Zeitlin (2009), 2. Mastenbroek and Keading (2005), 337-340.

38 Zeitlin found that 'creative appropriation' by domestic actors is the strongest mechanism for the Open Method of Coordination, which is a soft-law process of benchmarking and the exchange of 
political opportunity structures, whereby policy actors are confronted with incentives and resources, on the one hand, and constraints to their interests, on the other hand. ${ }^{39}$ Norms can empower domestic actors differently and strengthen their bargaining power vis-à-vis opponents by granting them additional resources to exert influence. ${ }^{40}$ The latter is referred to as a 'leverage effect', whereby domestic actors, such as interests groups, judges and litigants, utilise and exploit norms strategically as a resource to further their own objectives and legitimise their own preferences. $^{41}$ Europeanisation research has also looked at interdepartmental 'struggles' and how some ministries have used European processes to strengthen their policy influence and enlarge resources. ${ }^{42}$ European Union (EU) norms and processes can, thus, act as a 'selective amplifier' by legitimating and pushing through reforms. ${ }^{43}$

Europeanisation research has revealed an extensive list of important domestic mediating factors that facilitate change, including the relative power and capacity of domestic actors to exploit opportunities, the absence of powerful veto players, the presence of supporting institutions, a consensus-orientated decision-making culture, domestic pressure-by-supportive interest groups and voters and the responsiveness of domestic decision makers. ${ }^{44}$ Another factor relates to the salience and importance attached to certain norms or issues. ${ }^{45}$ 'Issue salience' refers to the relative importance of a certain topic in the light of other issues that compete for the limited policy makers' time and attention. Salience is found to affect the level of priority which is given to a certain policy issue and the extent to which it is put on the political or legislative agenda. ${ }^{46}$ Versluis distinguished between three indicators for salience: seriousness or risks of the issue addressed by a certain norm, the amount of political and media attention and the existence of disasters or scandals. ${ }^{47}$ Several scholars found that a low political salience results in less pressure or demands on decision and policy makers to transpose EU law into domestic law or apply it in practice and thus to inadequate compliance. ${ }^{48}$ Simmons (see further below) argued that there can be variances between certain categories of human rights as to their salience, also because some rights and issues are easier to get around. She argued that children's issues and rights are generally more salient,

best practices. He even stated that there is 'no impact of Europe without usage by domestic actors'. Zeitlin (2009), 231-233. Börzel and Risse (2012), 11. Jacobsson and Vifell (2007). Jacobsson and Vifell (2007), 165.

Börzel and Risse (2000), 2 and 6. Schimmelfennig and Sedelmeier (2004), 672.

Zeitlin (2009), 231. Mastenbroek and Kaeding (2006), 338-339. Heidenreich and Zeitlin (2009),

4. Saurugger and Radaelli (2008), 215.

Zeitlin (2009), 231-232.

Zeitlin (2009), 231-232. Vanhercke (2009), 13.

See, for example, Börzel and Risse (2000), 1. Falkner et al. (2005), 16-17.

Zeitlin (2009), 232. Mastenbroek and Kaeding (2006), 341.

For a good recent overview and more references, see Spendzharova and Versluis (2013).

Versluis (2003), 44-45.

Versluis (2003), Spendzharova and Versluis (2013). 
since they have a built-in pressure group and are seen as less controversial in principle than other rights. As a result, Simmons found more domestic effects for the CRC in some countries, than for other treaties. ${ }^{49}$

There are two theories of compliance with international human rights norms that deserve special attention. Firstly, there is Dai's theory on domestic compliance constituencies as 'decentralised enforcers'. ${ }^{50}$ These constituencies consist of elected executives, government officials, interest groups, lawyers and judges who use international norms for strategic reasons to press forward their agendas. Dai argued that international institutions have the potential to indirectly influence the government decision makers' compliance calculations through these procompliance constituencies. ${ }^{51}$ They can do so by, firstly, strengthening the leverage and empower these constituencies by legitimising their demands. International norms and institutions can, thus, create a focal point for domestic actors. ${ }^{52}$ Secondly, they can enhance their informational status so that these constituencies can mobilise further support and public concern and, hence, raise the salience of the issue. ${ }^{53}$ As a consequence, international norms can change the domestic balance of competing interests and reallocate domestic political resources. ${ }^{54}$

The second theory which discusses the specific pathways to compliance even more extensively is Simmons' domestic politics theory on compliance with human rights treaties. The central idea of her theory is that human rights treaties 'are causally meaningful to the extent that they empower individuals, groups, or parts of the state with different rights preferences that were not empowered to the same extent in the absence of the treaties' ${ }^{55}$ Simmons distinguishes three domestic processes in particular. Firstly, treaties can change political and legislative agendas and induce governments to put an issue higher on the agenda or empower the government to adopt certain measures. ${ }^{56}$ Secondly, treaties create possibilities for litigation by individuals and groups, who might use treaties to leverage their rights claims in domestic courts. Litigation is often part of a broader political strategy which aims to publicise and mobilise a cause. Litigation can further increase the political costs of non-compliance and, hence, influence a government's compliance calculation. ${ }^{57}$ Thirdly and in line with Dai, treaties act as a 'legitimate focal point' by encouraging domestic demands for the realisation of rights and offering 'a tool to support political mobilisation'. ${ }^{58}$ International treaties and institutions can also

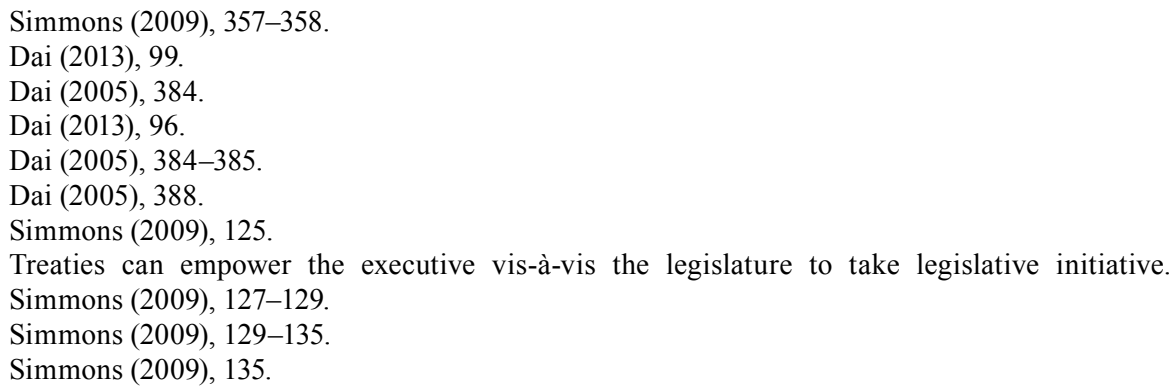


introduce (new) rights claims and a new set of ideas which may affect how individuals and groups define and understand their own rights, identities and interests. Ratified treaties offer domestic actors an indication of the acceptability of advancing certain rights claims. ${ }^{59}$ In addition, they raise the expected impact of political or social mobilisation and increase the likelihood of the success of mobilisation by providing a more favourable 'political opening'. ${ }^{60}$ The eventual success of mobilisation depends upon the extent to which outside norms are 'translated' into the 'local vernacular' by local agents. ${ }^{61}$ According to Simmons, an important precondition for the domestic impact of human rights treaties is the existence of domestic compliance constituencies, their willingness to be 'allies' and mobilise themselves as well as their relative strength and resource base. ${ }^{62}$ Simmons' theory allows for variances among countries, depending on the actual institutional and political conditions. ${ }^{63}$

These latter insights with respect to differences between countries and between human rights treaties make these liberal theories particularly suitable for this comparative research. By opening and unpacking the 'black-box' of the state, liberal theories are also well placed to study the great variety of domestic actors who often have different interests. They can also explain variation in state behaviour rather well. ${ }^{64}$ The implications of these theories will be discussed further in chapter II, section 4. Liberal theories have also (partly) inspired the decision to select established liberal democracies. This is based on the argument of the majority of liberal theorists that international human rights norms and treaties are most effective in established liberal democracies with strong traditions of rule of law, robust legal institutions and independent strong NGOs (for a further discussion see chapter III, section 1.1). ${ }^{65}$

\section{LOGIC OF APPROPRIATENESS: IDEATIONAL NORM-CENTRED APPROACHES}

The theories discussed above emphasise the concerns and strategic calculations of states about the international and domestic costs of non-compliance. Another group

59 Simmons (2009), 139-144.

60 Firstly, a ratified treaty positively affects the receptiveness of the government and legislature to the demand. Secondly, it can enhance the size of the pro-rights domestic coalition to include, for example, MPs or legal interest groups. Thirdly, it increases the intangible resources by legitimising domestic rights claims. Fourthly, it widens the scope of available (legal and political) strategies which can be used. Simmons (2009), 144-148.

61 Simmons referred in this context to Sally Engle Merry's study on gender violence. Simmons (2009), 140-142.

62 Simmons (2009), 140-142.

63 Simmons (2009), 148-154.

64 Raustiala (2000), 399 and 409.

65 Moravcsik (1995), 180. Raustiala (2000), 410-411. Hathaway (2002), 2020. Neumayer (2005). 
of theories goes beyond this perspective by pointing to the persuasive and transformative power and appeal of international norms themselves. These approaches emphasise persuasion and legitimacy as the main causal mechanisms through which international organisations and treaties have effect. The approaches see compliance as resulting from a normative belief that a norm ought to be obeyed. States have a propensity to comply because this constitutes proper and desirable behaviour and is, thus, the 'right thing to do'. ${ }^{66}$ States are socialised into following norms and have a sense of obligation and responsibility to meet social expectations. They, hence, follow a logic of appropriateness, according to which state behaviour is seen as rule based. States might even comply with norms when this would go against their own (material) interests. ${ }^{67}$ Some (constructivist) approaches furthermore posit that the effect of norms is more than shaping actual state behaviour. Norms can have a deeper normative and constitutive effect of actors' underlying beliefs, interests and identities.

\subsection{The managerial model}

One strand of the normative approaches is Chayes and Chayes managerial model. The central idea of this model is that states are generally willing to comply with international norms, because of a sense of obligation to obey. They argue that compliance problems do not reflect a deliberate decision of the state to disobey the norms, but that it is more a problem of management. They attribute noncompliance to, firstly, ambiguous and indeterminate treaty provisions. ${ }^{68}$ Secondly, noncompliance stems from limitations on the capacity of states in terms of expertise and resources. ${ }^{69}$ Thirdly, norms might be difficult to implement and require considerable time. ${ }^{70}$ According to Chayes and Chayes, these causes for noncompliance call for a managerial model of compliance. This model de-emphasises formal enforcement and coercive sanctions, but it includes non-coercive tools, such as reporting, verification, monitoring, technical and financial assistance, and capacity building. ${ }^{71}$ They argue that compliance can be encouraged by a cooperative, interactive and iterative process of persuasive discourse among the state parties and the treaty organisation. These interactive processes of norm interpretation would generate pressures to comply. ${ }^{72}$ The primary drivers in these processes are persuasion and argumentation (chapter II, section 2.2) ${ }^{73}$

\footnotetext{
See, for example, Franck (1990), 16.

March and Olsen (1998), 951.

See also Zohlnhöfer and Ostheim (2005), 149. Falkner et al. (2005), 286.

See also Börzel and Risse (2012), 11. Falkner et al. (2005), 24. Tallberg (2002), 613.

Chayes and Chayes (1993), 188 and 204.

Tallberg (2002), 613-614.

Chayes and Chayes (1993), 204-205. Koh (1997), 2601, 2627 and 2636-2638.

Downs, Rocke and Barsoom (1996), 381.
} 
The central tenet of the managerial model, that noncompliance often relates to the capacity of states, inspired the decision to select countries with an adequate bureaucratic and financial capacity to fulfil the rather burdensome reporting requirements and implement the COs (chapter III, section 1.1).

\subsection{Legitimacy and persuasion}

A second set of research within the normative approaches focuses on the qualities and legitimacy of international norms and institutions as an explanation for compliance and the norms' effectiveness. The logic runs that the norms' qualities and legitimacy determine the extent to which states take them seriously and change their behaviour accordingly. Legitimacy is especially crucial when courts or other institutions lack coercive means. ${ }^{74}$ Alvarez, for example, argued that: 'legitimacy is the missing link in solving the mystery of how the international system obliges without a coercive force' ${ }^{75}$ Franck defined legitimacy as 'a property of a rule or rule-making institution which itself exerts a pull towards compliance on those addressed normatively because those addressed believe that the rule or institution has come into being and operates in accordance with generally accepted principles of right process ${ }^{76}$ Others have also argued that legitimacy facilitates compliance and that a lack of legitimacy in the views of the addressees may hamper compliance. $^{77}$

Legitimacy strongly relates to the subjective perception and belief systems of actors. ${ }^{78}$ Hurd, for example, referred to a 'subjective feeling' and 'normative belief by an actor that a rule or institution ought to be obeyed. It is a subjective quality, relational between actor and institution, and defined by the actor's perception of the institution'. ${ }^{79}$ According to Franck, 'compliance is secured [...] by the perception of the rule as legitimate by those to whom it is addressed' ${ }^{80}$ Likewise, Çali et al. have used the attitudes and perceptions of domestic decision makers and stakeholders towards the ECtHR as an explanation for compliance with judgments of the ECtHR. ${ }^{81}$

Legitimacy based explanations focusing on subjective perceptions of domestic decision makers are rather consistent with the constructivist literature on persuasion. ${ }^{82}$ According to Checkel, persuasion is: 'an activity or process in which

78 Trimble (1990), 838 and 840. Alvarez (1991), 206. Helfer and Slaughter (1997), 284. Mastenbroek (2009), 10-12.

79 He argued that this perception is influenced by the substance of the rule and/or the procedure or source by which the rule has come into being. Hurd (1999), 381.

80 Franck (1988), 706. Franck (1990), 19.

81 Çali et al. (2011).

82 Raustiala and Slaughter (2002), 541. Brunnée and Toope (2013), 131. 
a communicator attempts to induce a change in the belief, attitude, or behaviour of another person... through the transmission of a message in a context in which the persuadee has some degree of free choice'. ${ }^{83}$ Actors, thus, change their attitudes, beliefs and preferences in the absence of clear material benefits and coercion. Checkel proposes several hypotheses or scope conditions when persuasion is more likely to take place. ${ }^{84}$ The first condition is somehow related to the notion of legitimacy and argues that persuasion can occur when the persuader is seen as authoritative. ${ }^{85}$ The second condition is when actors are in a new and uncertain environment or the norms deal with a new issue. Thirdly, this takes place when the actor has 'few prior, ingrained beliefs' that conflict with the persuader's view. The fourth condition is when the persuader does not 'lecture or demand' but relies on deliberative argumentation. Fifthly, it takes place when the interaction occurs in a less politicised environment. Finally, when there is a high degree of interaction between the actors and the persuader persuasion can occur.

As will be shown in chapter II, section 4, this research will combine legitimacy and persuasion based explanations by focusing on the perceptions and views of decision makers, gathered through interviews, towards the authority or legitimacy of the treaty bodies and the legal quality and persuasiveness of the COs. This research will also study whether Checkel's scope conditions for persuasion are met.

\section{COMBINING THE TWO LOGICS: TRANSNATIONAL HUMAN RIGHTS ADVOCACY}

There are several models which have combined the two underlying logics in an integrated way. This reflects the increased acknowledgement that both approaches are not mutually exclusive but complementary and able to operate simultaneously. ${ }^{86}$ Empirical findings also showed that state behaviour cannot solely be attributed to one logic alone. ${ }^{87}$ The most prominent example of a 'theory' that combines the two logics, although it is usually presented as a constructivist or normative model, is the theory of transnational human rights advocacy networks. ${ }^{88}$ The most prominent

83 Perloff (1993) as quoted in Checkel (2003), 212.

84 Checkel, thus, developed a middle-range theoretical approach which aims to uncover scope conditions for learning. It is not a substantive theory predicting it to occur. Checkel (1999), 549. Checkel (2001), 562-563. Checkel (2005), 813.

85 Other scholars also held that persuasion depends upon the content, appropriateness, legitimacy and quality of the norm and process. Schimmelfennig and Sedelmeier (2004), 676. Likewise, Trimble stated that 'legitimacy is the key to persuasiveness'. Trimble (1990), 835 and 845.

86 Koh (1998), 635. Börzel and Risse (2000), 2. Raustiala (2000), 399. Checkel (2001), 581.

87 March and Olsen (1998), 952.

88 Another example of a socialisation model focusing on 'transnational norm entrepreneurs' is Koh's 'transnational legal processes' as a 'complex process of institutional interaction whereby global norms are not just debated and interpreted, but ultimately internalised by domestic legal regimes'. Koh (1997), 2640 and 2645. Koh (1998). For a related theory, see the process of acculturation as define acculturation as developed by Goodman and Jinks. They referred to 
elaboration can be found in Risse, Ropp and Sikkink's five phase spiral model of human rights change. ${ }^{89}$ One of the central tenets of the spiral model is that the diffusion and domestic change in relation to human rights is dependent on the strength of transnational human rights pressures and policies and, above all, advocacy networks. ${ }^{90}$ Transnational human rights advocacy networks consist of international human rights NGOs, like Amnesty International and Human Rights Watch, domestic NGOs, political parties, the media, intellectuals and international institutions. ${ }^{91}$ These networks have three functions that are crucial for the process of socialisation. Firstly, they put an issue on the international agenda. Secondly, they empower and legitimise the claims of domestic movements and NGOs by providing them with "“ammunition" in the internal "argumentative wars". ${ }^{2}$ Thirdly, they enable pressuring states from above and from below. ${ }^{93}$ The model incorporates Keck and Sikkink's 'boomerang effect', which describes how domestic compliance constituencies and especially NGOs bypass their state to seek international support and link up with a transnational network to bring outside pressure on their states. These international linkages allows them to gain leverage by introducing new issues, norms and discourses into the debate and strengthening and amplifying their demands so that the terms of the debate can shift. ${ }^{94}$ The spiral model and boomerang effect build upon Finnemore and Sikkink's work that points to the important role of domestic 'norm entrepreneurs'. These entrepreneurs use international norms to reinforce their (minority) position in domestic discussions and act as 'agents of socialisation' by demanding a policy or legislative change. ${ }^{95}$

The main process through which human rights change takes place is 'norms socialisation', which is defined as 'the process by which principled ideas held by individuals become norms in the sense of collective understandings about appropriate behaviour which then lead to changes in identities, interests, and

acculturation as a complex social process by which actors 'adopt the beliefs and behavioural patterns of the surrounding culture [...] driven [...] by identification with a reference group which generates varying degrees of cognitive and social pressures to conform with the behavioural expectations of the wider culture'. Goodman and Jinks (2008), 726.

The five phases are repression, denial, tactical concessions, prescriptive status, and ruleconsistent behaviour. These phases apply to processes in repressive non-democratic states and their interactions with Western powers, who act as promoters of human rights. The five phases as such are not very relevant for this research, because the Netherlands, New Zealand and Finland are in the final stage of the model in which human rights are internalised. Risse and Ropp (1999), 235, 237 and 266.

$90 \quad$ Risse and Sikkink (1999), 4. Risse and Ropp (1999), 237.

91 These actors, who are working internationally on an issue, 'are bound together by shared values, a common discourse, and dense exchanges of information and services'. Keck and Sikkink (1999), 89.

92 Risse and Ropp (1999), 256.

93 Risse and Sikkink (1999), 5. Risse and Ropp (1999), 238.

$94 \quad$ Risse and Sikkink (1999), 18. Keck and Sikkink (1999), 90 and 93.

95 Finnemore and Sikkink (1998), 893 and 902. 
behaviour'. ${ }^{96}$ Three types of socialisation processes are distinguished. Firstly, there is adaptation and strategic bargaining. This type reflects rationalists' arguments and sees actors as expected utility maximisers who change their behaviour to obtain instrumental or material goals without necessarily accepting the validity of the norms (see also chapter II, section 1.2). Norm violating states, for example, make some tactical concessions or start bargaining with the international community or the domestic opposition. ${ }^{97}$ Secondly, there are processes of moral consciousnessraising, argumentative discourses, (moral) persuasion and shaming or embarrassing (see also chapter II, section 2.2). ${ }^{98}$ Thirdly, institutionalisation and habitualisation is 'the final stage in a socialisation process' when actors comply with the norms irrespective of individual beliefs about their validity but because it is the right thing to do. ${ }^{99}$

There is considerable overlap between these transnational advocacy models and the liberal theories on domestic mobilisation and politics. ${ }^{100}$ Both the spiral model and the boomerang effect include rationalist elements which mirror these liberal theories. As we have seen, the spiral model holds that the socialisation process consists of both strategic bargaining whereby domestic actors rally around human rights norms for instrumental reasons as well as discursive processes of persuasion and argumentation. ${ }^{101}$ Other scholars have also used both rationalist and constructivist approaches together. Checkel, for example, integrated both logics. In addition to social learning and persuasion, he focused on the way in which social protest by domestic actors can force national decision makers to adjust policy and legislation by exploiting international norms. ${ }^{102}$ Norms are, hence, used as 'an additional tool' or 'additional weapon for shaming' to increase the pressure on policy makers engaging in a cost/benefit analysis. ${ }^{103}$ This 'social sanctioning' mirrors the rationalist approach by focusing on how domestic actors use norms instrumentally and strategically to promote given interests and influence and

96 Risse and Sikkink (1999), 10.

97 Risse and Sikkink (1999), 11-12.

98 In this type of process, change agents or norm entrepreneurs try to 'teach' human rights norms and shape domestic actors' perceptions and persuade them to redefine their interests and identities through a process of social learning. Such a process is (conceptually) different from the rationalist view on domestic actors as mobilising to pressure decision makers by increasing the costs of noncompliance. Börzel and Risse (2000), 2 and 9. Risse and Ropp (1999), 271. Risse and Sikkink (1999), 13-14.

99 Risse and Sikkink (1999), 16-17.

100 Simmons explicitly presented her domestic mobilisation theory as 'a crucial supplement' to the writing on transnational advocacy networks. Simmons (2009), 126 and 372. Risse and Ropp similarly argued that at least two of the three domestic causal compliance mechanisms Simmons identified are consistent with the spiral model. Risse and Ropp (2013), 11.

101 Domestic actors do not necessarily have to believe in human rights when they use them. Risse and Sikkink (1999), 15-16 and 26.

102 Checkel (1999), 552-553. Checkel (2001), 557.

103 Checkel (2001), 569. 
constrain the views of decision makers. ${ }^{104}$ This also reflects what Finnemore and Sikkink called 'strategic social construction' whereby actors 'strategise rationally to reconfigure preferences, identities, or social context'. ${ }^{105}$

As will be discussed in chapter II, section 4, this research will combine both the rationalist and normative perspective on domestic actors, seeing them as strategic utility maximisers as well as norm entrepreneurs.

\section{THEORETICAL IMPLICATIONS FOR THIS RESEARCH}

The theoretical starting point of this research follows the observation that the rationalist external incentive mechanisms for compliance rarely works, if at all. COs are legally speaking non-binding and treaty bodies lack instruments to enforce and coerce compliance with the COs. This means that the effectiveness of COs primarily depend, firstly, on government officials and decision makers and, secondly, on the domestic and transnational mobilisation of actors.

The first mechanism that this research will incorporate combines legitimacy and persuasion based explanations (chapter II, section 2.2). Crucial for the effectiveness of COs is that government officials and decision makers are persuaded and feel bound to comply with the COs. This compliance pull is contingent on the legitimacy, usefulness, persuasiveness, and legal quality of the COs, as well as the authority of the Committee. ${ }^{106}$ Hakimi, for example, argued that it is unlikely that states accept as law the norms advanced by actors and institutions, such as the treaty bodies, if they consider them illegitimate or merely aspirational. ${ }^{107}$ Legitimacy is particularly crucial for UN human rights treaty bodies, since they lack coercive means and the COs are legally non-binding. ${ }^{108}$ Secondly, the COs often relate to policies and legislation adopted by a democratically elected parliament and an accountable government. It has been argued that legitimacy plays a crucial role in such instances. ${ }^{109}$ As will be further discussed in chapter III, section 2.5, based on these theoretical insights, this research focuses on the subjective perceptions of government officials as to the legitimacy of the treaty bodies and the legal quality and persuasiveness of the COs.

The second mechanism incorporated in this research deals with domestic and transnational human rights mobilisation and advocacy. This mechanism is grounded

\footnotetext{
104 Checkel (2001), 558.

105 They argued that norms and rationality are 'intimately connected'. Finnemore and Sikkink (1998), 888.

106 Mechlem argued, for example, that the impact of treaty bodies depends on a convincing and persuasive reasoning and a consistent interpretation method. Mechlem (2009). For a similar argument, see Steiner (2000), 52. UN Doc. HRI/MC/2006/2 (2006), para. 22. Keller and Ulfstein (2012), 421.

107 Hakimi (2009). See also Hafner-Burton (2013), 63-65.

108 Keller and Ulfstein (2012), 423. Keller and Grover (2012), 128-129.

109 Alter (2003), 73.
} 
on liberal theories on domestic politics and mobilisations (chapter II, section 1.2) and the transnational human rights advocacy network, such as the spiral model and boomerang effect (chapter II, section 3). As was mentioned before, the reliance on domestic actors is particularly crucial for international human rights, given the absence of an international enforcement mechanism and weak institutions. ${ }^{110}$ The idea behind focusing on domestic actors is that their involvement eventually affects and is decisive for the effectiveness of COs. This reflects the argument of Finnemore and Sikkink that 'international norms must always work their influence through the filter of domestic structure and domestic norms'. ${ }^{111}$ This research will approach domestic actors in both rationalist terms as strategic utility maximisers (chapter II, section 1.2) and in normative terms as norm entrepreneurs (chapter II, section 2.2). This combined perspective is in line with the literature discussed in chapter II, section 3. As will be explained in chapter III, section 2.2, this second mechanism is integrated in this research by focussing on the impact of the process of reporting at the national level in terms of the extent to which domestic actors have been involved in the process and have used the COs in their domestic work.

110 Dai (2013), 95-96.

111 Finnemore and Sikkink (1998), 893. See also Oomen (2011), 43. 


\section{Chapter III Methodological Framework}

The methodological framework of this research is presented in this chapter. The first section provides the justification for the selection of the Netherlands, New Zealand and Finland as the three country studies. The second section elaborates on the methodology used for the assessment of the broader influence, impact and effectiveness of the reporting process and the COs. It will also discuss the limitations in measuring (section 2.5) the latter as well as the methodology for the interviews (section 2.6).

\section{Country SELECTION}

\subsection{Western liberal democracies as most likely cases}

From the outset, two parameters were set for the selection of the two other countries. The first prerequisite was that the country should have participated regularly in the process of state reporting, in at least three cycles of reporting resulting in COs. This would allow the author to obtain a reliable picture of developments over time. In addition, a more pragmatic reason for this choice is that this regular reporting implies that a sufficient amount of information is available in the form of state reports, summary records and NGO parallel reports. The latter is essential for a proper study of the effectiveness of COs. The second requirement was that the country should have ratified all the six main human rights treaties. This would permit an examination of the differences among the different treaties.

Within these parameters, the decision was made to concentrate on 'most likely cases' 'where theory suggests the outcome is definitely meant to occur', in other words, where impact and effectiveness of COs could be expected. ${ }^{1}$ Hence, this research chose to focus on countries in which the process and the COs potentially 'work' instead of countries in which one would expect hardly any result from the outset. One important reason for this was that this research aims to study the mechanisms and conditions under which specific COs are or can be effective. ${ }^{2}$ Such an analysis also helps to confirm or deny the applicability of underlying theoretical models (chapter I, section 5). ${ }^{3}$ Focusing on 'least likely cases' would not be particularly fruitful for this endeavour. This is also because much has already been written about the limited impact and effectiveness of the reporting process

Landman (2009), 39.

Mahoney and Goertz (2006), 239. Zwingel (2005), 61.

Landman (2009), 38-39. 
and the deficiencies in the functioning of the treaty bodies (chapter I, sections 2.2 and 3). Thus, the factors explaining the ineffectiveness are particularly well known.

The first and most important characteristic of a most likely case is a country that takes the reporting requirement seriously and is willing to report (relatively) on time (see also chapter I, section 3). It is not unreasonable to expect that the COs are most effective in states that are committed to fulfilling their reporting requirement and, thus, comply with their treaty obligations. ${ }^{4}$ Alston, for example, pointed to a positive correlation between the effectiveness of the process of reporting and the extent to which states take their obligations to reports seriously. ${ }^{5}$ Timely reporting - and implementation of $\mathrm{Cos}$ - depends on the availability of adequate bureaucratic and financial capacity and knowledge about the process and the treaties. ${ }^{6}$ This expectation is inspired by the managerial model of compliance which attributes non-compliance to limitations on state capacity and sees sufficient resources and expertise as a prerequisite for COs' effectiveness (chapter II, section 2.1). ${ }^{7}$ Western industrialised countries have, generally speaking, the greatest capacity and most effective government structures. The compliance rate with the reporting requirements has also been found to be the highest among these countries. ${ }^{8}$

The second feature of a most likely country is the commitment to the rule of law and democracy. This assumption reflects a logic of appropriateness argument that mechanisms of persuasion are particularly effective in stable democracies, because human rights protection is considered to be the norm and the right thing to do and even reflective of a national identity as a liberal democracy (chapter II, section 2). ${ }^{9}$ This assumption is also based on liberal theories on compliance which argue that domestic mobilisation is more likely in liberal democracies (chapter II, section 1.2). Helfer and Slaughter, for example, noted that the states that are most likely to respond to international human rights regimes are 'states that arguably need them least' and 'with the least to hide'. ${ }^{10}$ In these countries, there is more potential for international organisations to 'recruit' domestic interest groups as compliance partners or allies. ${ }^{11}$ Democratic governments are also more responsive to claims of domestic actors and have more difficulty in hiding non-compliance. In addition, liberal states are (assumed to be) more willing to have their domestic laws and policies examined at the international level. The logic behind this is that liberal states 'willing to submit to the rule of law and civil society at the domestic level are

Connors (2000), 8-9. Heyns and Viljoen (2001), 488.

Alston (1989), para. 35.

Alston (2000), 524. Woll (2000), 73. Niemi and Scheinin (2002), 23 and 29. Niemi (2003), 55.

See also Risse and Ropp (2013), 4 and 15-18.

LeBlanc, Huibregtse, Meister (2010). Bayefsky also found that the number of overdue reports is larger for states ranked lower in the Human Development Index or with a lower GDP. Bayefsky (2001), 8-9. Niemi and Scheinin (2002), 7. 
more likely to submit to their analogues at the international level'..$^{12}$ Hafner-Burton also argued that democracies, by design, foster (public) dialogue, internal political contests and (electoral) accountability, which are prerequisites for human rights treaties to have effect. ${ }^{13}$ Some scholars recently argued that human rights treaties and norms have had the biggest effects in transitioning countries. The most prominent example is Simmons, who found empirical support for her conclusion that civil and political rights had most effect in less stable middle-ground countries, where political human rights mobilisation is higher. She argued that mobilisation in consolidated Western democracies was lower because the values implicit in human rights treaties are often already present and, thus, 'largely redundant'. ${ }^{14}$ It is unclear whether these observations also hold true for the reporting process and the COs.

The reason such transitioning countries were not selected was because the empirical research so far actually hints at a higher impact and effectiveness of the reporting process in Western liberal democracies (chapter I, section 3). ${ }^{15}$ The study conducted by Heyns and Viljoen, for example, found that COs especially have an impact in countries like Australia, Canada, South Africa, and Finland. These countries have a domestic human rights culture and 'domestic constituencies' in the form of active civil society actors and NGOs, an independent judiciary, and a free press as 'an enabling domestic environment'. ${ }^{16}$ Likewise, the 2010 Open Society Justice Initiative study found that Western European countries with a strong rule of law tradition and a strong civil society have been the most prompt and responsive in implementing the Views of the treaty bodies. ${ }^{17}$ Tomuschat, for example, observed that especially countries committed to the rule of law will evaluate and address the COs to the extent possible. ${ }^{18}$ Most of the treaty body expert members who have been contacted or interviewed also expected the COs to be most effective in Western liberal democracies. ${ }^{19}$ The ultimate choice for such countries was also inspired and supported by the views from several scholars and activists from different countries. ${ }^{20}$ They were asked about the (expected) effectiveness of COs in

12 Kupchan and Kupchan (1991) as quoted in Raustiala (2000), 410-411.

13 Hafner-Burton (2013), 64 and 71.

14 Simmons (2009), 149-153. See also Hafner-Burton (2013), 72.

15 Bayefsky observed that the public interest, media attention and NGO activity is significantly less for developing countries than developed countries. Bayefsky (1996), fn. 17-18. Peter likewise noted that there is a lack of awareness and participation of NGOs in reporting under CERD in developing countries. Peter (2011), 130. Steiner also referred to media dissemination and publicity of the Views of treaty bodies in countries like Australia, Canada and Finland. Steiner (2000), 36 .

16 Heyns and Viljoen (2001), 488, 518 and 522. Email from Frans Viljoen on 19 April 2011 in which he confirmed that this quote primarily applies to these countries.

17 Baluarte and Vos (2010), 28, 121 and 129.

18 Tomuschat (2008), 188.

19 Jaap Doek, Sir Nigel Rodley, Eibe Riedel, Cees Flinterman and Martin Scheinin.

20 The following people were contacted: Zambia (Misozi Lwatula and Bas de Gaaij Fortman), Kenya (Korir Singoei Abe, Felix Nhadinda and Phyllis Livaha), South Africa (Frans Viljoen), 
their country as well as the feasibility of doing research in their country in terms of availability of sources and the willingness of government officials to be interviewed.

\subsection{The Netherlands as the main case}

The original research proposal had the impact and effectiveness of reporting in the Netherlands as its starting point and main focus. The Netherlands is - at least at a first glance - a most likely case for the impact and effectiveness of COs. The Netherlands ranks high in democracy indexes and has a very open and favourable constitutional and political system for the reception of international (human rights) law (chapter IV, section 2). ${ }^{21}$ In addition, it is often seen by others - and it sees or presents itself - as a front runner or model when it comes to human rights. ${ }^{22}$ There is a strong idea or even missionary spirit among politicians and the wider public that the Netherlands is the most progressive country in the world and that it should act as a leading country (gidsland) and set an example. ${ }^{23}$ The website of the central government, for example, stipulated: 'Because the protection of human rights is well regulated in the Netherlands, the central government concentrates on the improvement of human rights abroad'. ${ }^{24}$ Former Minister of Foreign Affairs Verhagen held in 2008 that recommendations of UN treaty bodies are taken very seriously, also because this is of direct relevance to the credibility of the foreign policy on human rights. ${ }^{25}$ This book takes such statements and assumptions as the starting point and investigates whether the Netherlands indeed plays such an exemplary role when it comes to the domestic realisation of human rights and more specifically its participation in the reporting process and the implementation of the COs. There were also practical reasons for taking the Netherlands as the main case,

the Phillipines (Gilbert V. Sembrano), Indonesia (Byung Sook de Vries), Australia (Andrew Byrnes), New Zealand (Claudia Staal), Finland (Martin Scheinin), and Denmark (Anders Buhelt and Eva Maria Lassen).

21 See, for example, the Top 10 of The Economist Democracy Index 2012 which include all the five Nordic countries as well as New Zealand, Australia, Canada, the Netherlands and Switzerland. The Economist Intelligence Unit (2013), 3.

22 CESCR member Sadi, for example, referred to the Netherlands as a leader, serving as a good example to others. Personal observation of the dialogue. Not stated in UN Doc. E/C.12/2010/ SR.43 (2010), para. 26. Several HRC members also commended the international leadership role of the Netherlands with respect to human rights. UN Doc. CCPR/C/SR.2630 (2009), para. 24, 41 and 43.

23 Baehr et al. (2002), Kennedy (2006).1. Reiding (2007), 12-15. Oomen (2011), 2 and 9.

24 'Omdat de bescherming van mensenrechten in Nederland goed geregeld is, concentreert de Rijksoverheid zich op het verbeteren van mensenrechten in het buitenland'. 'Verslag NJCMseminar: het EU-Grondrechtenhandvest', NTM/NJCM-Bull. 37(2) (2012), 285. Quote is from the website $<$ www.rijksoverheid.nl/onderwerpen/mensenrechten/mensenrechtenbeleid $>$, which does not exist anymore.

'Dat Nederland zelf goed presteert op het gebied van mensenrechten is van direct belang voor de geloofwaardigheid van het internationale mensenrechtenbeleid. Aanbevelingen van VN-verdragscomités worden dan ook zeer serieus genomen'. TK 2007/08, 31263, nr. $10,1$. 
including language, affinity with the legal and political system and access to documents and interview participants.

It was decided to limit the research to the European part of the Kingdom of the Netherlands and exclude the overseas territories in the Caribbean. The first reason for this had to do with the constitutional reforms which took place on 10 October 2010. Up to that date, the Kingdom constituted of three countries; the Netherlands (the European part), Aruba and the Netherlands Antilles. Since 2010, the Netherlands Antilles has ceased to exist and was replaced by the two new countries of Curacao and Sint Maarten. ${ }^{26}$ These reforms and their timing would, thus, complicate this research and add an additional layer of complexity. The second reason is related to the fact that these overseas territories have not regularly reported or participated in the constructive dialogue (see chapter III, section 1.1). As a result, there are only a limited number of COs directly addressed to them.

\subsection{Two additional most similar countries: New Zealand and Finland}

Two additional countries were selected. The purpose was twofold. Firstly, comparing the Netherlands with two - rather similar - countries makes it possible to understand the Dutch case better (see below). Secondly, the comparison also allowed for a broader generalisation of the research findings, by examining to what extent the phenomena observed for the Netherlands hold true for other countries as well. The comparative element is of a more limited scope than the research on the Netherlands. It primarily focuses on the effectiveness of the COs and the factors contributing to the effectiveness of COs. The objective was not to give an exhaustive account of the impact of the COs of the specific UN human rights treaties and treaty bodies. The research on these two countries has therefore primarily been based on UN documents, academic literature and interviews.

In order to select the two other countries within the group of industrialised and developed Western liberal democracies, a literature scan was carried out for several countries to map differing variables. ${ }^{27}$ Two countries that are relatively similar to the Netherlands were ultimately chosen. ${ }^{28}$ The reason was to avoid too much variance, and thus limit the number of differing variables within the group of Western liberal democracies as far as possible. Comparing most similar countries with considerable commonalities better enables isolating the factors that might explain (the variation in) the effectiveness of COs. ${ }^{29}$ Such a most-similar-systems design would also enable coming up with insights and conclusions that are relevant for the Dutch context.

26 The so-called BES islands of Bonaire, Sint Eustatius and Saba are special municipalities of the Netherlands.

27 Countries included in this literature scan were Canada, Australia, New Zealand, Denmark, Sweden, Norway, Finland, Germany, Ireland, the United Kingdom, France, and Belgium.

28 For a similar reasoning, see also Niemi (2003), 8.

29 Landman (2009), 33-34. 
The most important selection criterion was to include a country that is, just like the Netherlands, a (decentralised) unitary state. Research has shown that human rights implementation in a federal state adds an additional layer of complexity, because both the federal state and the individual states have a role with respect to the implementation of human rights. ${ }^{30}$ In addition, another criterion was to include a country without a constitutional court, but one with a less powerful and more decentralised form of judicial review and a tradition of judicial restraint. ${ }^{31}$ One comprehensive study about the impact of the ECHR found that judges in countries with a powerful Constitutional or Supreme Court that primarily defend national human rights are reluctant to base their rulings on the ECHR as an independent source of law. As a result, such a strong national 'pre-existing human rights judicial tradition' in countries like Germany, Italy and Ireland was found to hamper the reception of ECHR and the jurisprudence of ECtHR. ${ }^{32}$

The monist or dualist nature of the legal system of a country was not used as a selection criterion. Several scholars have recently written about the irrelevance of this distinction. Von Bogdandy, for example, argued that monism and dualism are 'zombies of another time' that 'should cease to exist as doctrinal and theoretical notions for discussing the relationship between international law and internal law'. ${ }^{33}$ The monist or dualist nature does not say anything about the role of treaties in practice. On the one hand, in monist countries, such as the United States and the Netherlands, the role of international law in legal practice is limited by the doctrine of self-execution or the notion of direct effect. On the other hand, courts in dualist countries have made rather extensive use of treaties or even treaty body output to arrive at a treaty consistent interpretation. ${ }^{34}$

One notable differing variable was, however, incorporated in this research. The choice was made to include one country that is a member of the ECHR and another country that is not a member of a regional human rights system. This choice was inspired by preliminary findings for the Netherlands that UN human rights treaties and the COs are often overlooked because of the pervasiveness of ECHR and EU law and the stronger enforcement mechanisms in the form of the ECtHR and ECJ. There is preference for and focus on these regimes by domestic actors. These

30 For Canada it was concluded that the federal system is a problem for implementing international human rights treaties, because provinces have little interest in international instruments. Heyns and Viljoen (2002), 113-162, 160. Niemi (2003), 12.

31 According to Hirschl, the Netherlands, New Zealand and Finland fall into this category. Hirschl (2011), 454 and 459. Judicial restraint was also noted in relation to the Nordic countries and the Netherlands. Claes and Van der Schyff (2008), 136.

32 Keller and Stone Sweet (2008), 686. Helfer and Slaughter also noted that states with a strong domestic tradition of the rule of law, such as the US, Germany, Italy, and France, are less open to international supervision. Helfer and Slaughter (1997), 332-333. the division of powers between the judiciary and the legislature is more important than the formal status of a treaty. Van Dijk (1988), 631-632. Scheinin (2000), 231. International Law Association (2004), para. 181-182. 
findings correspond with Langford's 'displacement effect' where regional and domestic constitutional norms and courts diminish the impact of international human rights treaties. According to him: 'The adjudicatory function of international treaties, however, is partly lessened by the presence of strong regional variables [...] Regional standards may provide greater legitimacy and effectiveness than international law and dominate political discourse, policy practice and legal mobilisation'. ${ }^{35}$ Likewise, Heyns and Viljoen pointed to the 'widespread preference for regional systems above the UN system', because they are more accessible, more efficient, usually operate faster and result in binding decisions. ${ }^{36}$ By choosing a country which is not a member of a (strong) regional human rights system, this research seeks to 'test' whether COs have more of an impact and effectiveness in countries that are only part of the UN human rights machinery. New Zealand was selected out of the group of non-European Western democracies that also include Australia, Canada and the United States. New Zealand is not a member of a regional (human rights) system like Canada or the United States. ${ }^{37}$ Neither is it a federal state like Australia, Canada or the United States. Nor does New Zealand have a constitutional court like the United States.

The decision was also made to include one of the five Nordic countries (Norway, Iceland, Denmark, Sweden, and Finland). Firstly, they consistently rank high in democracy indexes. ${ }^{38}$ Secondly, in the Nordic countries, the process of reporting tends to have been integrated rather well domestically and views of NGOs have been taken into account during the compilation of the state report. ${ }^{39}$ Thirdly, they are regarded as consistent compliers with international norms. In EU compliance research it was, for example, found that Denmark, Finland and Sweden belong to the group of 'world of law observance', which include countries who dutifully implement EU Directives on time and correctly, even where conflicting domestic interests exist. ${ }^{40}$ One scholar even found empirical support for a 'distinct Nordic exceptionalism' in the implementation of EU law, which he attributed to a Nordic administrative style marked by a problem-solving or consensus-seeking approach that avoids (legal) confrontation and the use of courts. ${ }^{41}$ This political and legal culture is also similar to the Netherlands. ${ }^{42}$ The ultimate choice was made for Finland, primarily because of the availability of academic literature in English

\footnotetext{
35 Langford (2010).

36 Heyns and Viljoen (2001), 520-521. See also Steiner (2000), 34 and 38-39.

37 Both Canada and the United States are members of the Organisation of American States (OAS). They have, however, not ratified the American Convention on Human Rights or recognised the jurisdiction of the IACHR. They are, however, subject to the jurisdiction of the Inter-American Commission on Human Rights, which has adopted several decisions vis-à-vis both countries.

38 Supra n. 21.

39 Connors (2000), 10.

$40 \quad$ Falkner et al. (2005).

41 Nordic countries are among the best performing EU countries in transposition of EU law into national law. Sverdrup (2004).

42 Sverdrup (2004).
} 
about human rights and the impact of COs in particular. Finland was one of the 20 countries in the study of Heyns and Viljoen about the domestic impact of UN human rights treaties and one of the six countries in a similar study by Niemi in 2003. In addition, a lot has been published in English by scholars like Scheinin, Ojanen and Husa about human rights in Finland. ${ }^{43}$

Another similarity between the three countries is that they all have an active foreign human rights policy because they have a strong interest in promoting human rights abroad. This is what Brysk referred to as 'global good Samaritans' and Hafner-Burton labelled as 'steward states'. ${ }^{4}$

\section{Methodology}

This comparative country research will be mainly qualitative, even though it will also include some (semi)quantitative elements. A qualitative research design is well placed to determine the causal relation between COs and policy or legislative change and to identify the factors that contribute to the effectiveness of COs. ${ }^{45} \mathrm{Such}$ an endeavour is far from straightforward. Methodological and measurement difficulties can, however, be alleviated through the combination of several methodological strategies. ${ }^{46}$

The first strategy is a careful triangulation of data by having 'multiple points of observation' in order to compensate for sources of bias and arrive at valuable and reliable conclusions. ${ }^{47}$ Translated into more practical terms, this research is based on a document analysis of a diverse range of primary sources, including state reports, parallel reports, parliamentary papers, policy documents, court judgments, and media articles, and secondary (academic) literature. This is complemented with interviews with different actors in the three countries, including government officials and NGO representatives (Chapter III, section 2.6). In addition, this research also includes first-hand observations of the three constructive dialogues between the CEDAW Committee, CERD and CESCR and the Dutch government delegation in Geneva in 2010 and 2011.

The second approach is a systematic comparison of data in order to 'identify and explain both general tendencies and dimensions of variation'. ${ }^{48}$ For this purpose, this research will compare six different treaty bodies over a longer period of time involving at least three cycles of reporting and sets of COs for three different countries. This research will focus primarily on the period starting in the year 1995 .

43 Directly relevant for this research is, for example, Scheinin's contribution about the role of COs in the Finnish legislative process. International Law Association (2004), para. 158.

Brysk (2009). Hafner-Burton (2013).

Checkel (2005), 816. Martin (2013), 608.

Zeitlin (2009), 215-216.

Zeitlin (2009), 215. Checkel (2005), 817.

Zeitlin (2009), 216. 
At that point, all treaty bodies had adopted the practice of publishing a specific set of recommendations in writing (chapter I, section 1.1).

\subsection{The broader influence}

The first research question deals with the broader influence or more subtle impact of the process of state reporting. The 'concept' of 'broader influence' is, contrary to the other two concepts of impact and effectiveness, not defined in advance. It is intentionally formulated as a broad and open question which makes it possible to group various effects under it which go beyond the more concrete and measurable effects which are studied in relation to impact and effectiveness, This is, for example, visible in the open ended interview question to domestic stakeholders to describe the influence of the reporting process at the national level (see appendix 3 , under F).

Two aspects which relate to the broader influence of the process of state reporting will, nonetheless, be looked at in specific. Firstly, the extent to which reporting has been used as an opportunity for human rights review and dialogue. This question essentially deals with the (bureaucratic) organisation of the reporting process at the national level. Features that will be focused on include, among others, the department which is responsible for coordinating the compilation of the report, the level of consultation of and interaction with NGOs, the continuity in the involvement of government officials, and the presence of a procedure for follow-up to the COs. This analysis is primarily based on the information provided by states in their state reports and core documents as well as alternative NGO reports and secondary literature. In addition, government officials were asked during the interviews to give their opinion about the value and importance they place on reporting as well as the way in which reporting is organised in practice and what priority is given to it by the government and their ministry or department. In addition, they were asked to describe the level of interaction with and consultation of NGOs (see appendix 3, under B). These answers were complemented by the views of other domestic stakeholders who were asked to reflect on the way the government deals with reporting.

A second sub question is whether the reporting process has led to a better understanding or increased awareness about the treaties and rights in question and, if so, in what way. This question is primarily answered on the basis of secondary literature and interviews. In all three countries, domestic stakeholders were asked to give their views on the (wider) role of human rights (treaties) and the knowledge of domestic actors about the UN human rights treaties and the reporting process (see appendix 3, under D). In addition, for the Netherlands, this information was supplemented with a (database) search of parliamentary papers, court judgments and newspaper articles with a view of tracing the number of references to a certain human rights treaty over time (for a further description, see chapter III, section 2.2). 
There are close connections between the concept of 'broader influence' and the other two concepts of 'impact' and 'effectiveness'. Impact and effectiveness arguably depend upon the way in which the reporting process is organised (first sub question) and the level of awareness or knowledge among officials about the respective treaty and the reporting process (second sub question). ${ }^{49}$

\subsection{Domestic impact and domestic mobilisation}

The second research question deals with the domestic impact of the reporting process and the COs. Impact was defined as the way in which domestic actors have used and discussed the reporting process and the COs at the domestic level (chapter I, section 4.2). The definition of this concept closely resembles IR theories that focus on the level of domestic and transnational human rights mobilisation and advocacy (chapter II, section 4). Domestic impact will thus be treated as the degree or level of domestic mobilisation. The only difference between domestic mobilisation and impact is that impact also looks at the government attention to the reporting process and COs.

The impact of COs at the national level is likely to be related to the extent to which domestic actors like parliament and especially NGOs have been (directly) involved in the process of reporting by way of, for example, submitting alternative reports or presenting their views orally to the treaty bodies. That is to say, the domestic actors' involvement in the process and their interaction with each other and the treaty bodies is likely to affect their subsequent use of the COs. When they have been actively engaged in the process, they are probably more dedicated and committed to the process and, hence, more likely to use the COs in their subsequent domestic work. A (short) description of the level of involvement of domestic actors in the reporting process at the national and international level will, thus, be provided (see also table 3.1). ${ }^{50}$

Table 3.1 presents the modalities of impact and the more specific indicators that will be especially examined. The impact of the COs for the Netherlands will be measured in both a (semi-)quantitative and qualitative way relying on both the number of the above-mentioned documents in which the COs are referred to as well as the substance of these documents. This analysis is done on the basis of a (database) search of parliamentary papers, court judgments, newspaper articles, and NGO websites for the period 1 September 1995 until 31 August 2011 (see appendix 2 for the search terms used). ${ }^{51}$ In order to analyse the impact in a more qualitative sense, this database search is complemented by information from UN documents and academic literature. This document analysis is supplemented with the views

Supra n. 38 in Chapter I.

Zwingel (2005), 391.

Use was made of, respectively, Parlando/ Overheid.nl, rechtspraak.nl, Lexis Nexis and Google Search. 
from interviewed domestic actors about the impact and role of COs. For New Zealand and Finland, it is largely based on secondary literature and interviews (see appendix 1). For New Zealand, parliamentary papers are also searched to measure the governmental and parliamentary attention to the Cos, both quantitatively and qualitatively. ${ }^{52}$

\section{Table 3.1. Modalities of impact and their indicators}

\begin{tabular}{|c|c|}
\hline Modality of impact & Indicators \\
\hline Governmental attention & $\begin{array}{l}\text { - the number of parliamentary papers referring to the COs, including: } \\
\text { policy notes, (Explanatory Memoranda to) legislative proposals, } \\
\text { statements of ministers in parliament etc., } \\
\text { - the extent to which the government has informed parliament about the } \\
\text { reporting process and the resulting COs, } \\
\text { - the extent to which the government has sent a reaction to the COs to } \\
\text { parliament. }\end{array}$ \\
\hline Parliamentary scrutiny & $\begin{array}{l}\text { - the number of parliamentary papers referring to the COs, including: } \\
\text { written parliamentary questions, statements of MPs during parliamentary } \\
\text { debates etc., } \\
\text { - the extent to which parliament has debated the COs and the government } \\
\text { reaction thereto, } \\
\text { - the number of motions or legislative initiatives of MPs in which the COs } \\
\text { are explicitly mentioned. }\end{array}$ \\
\hline $\begin{array}{l}\text { Courts and } \\
\text { legal practice }\end{array}$ & - the number of court judgments referring to the COs. \\
\hline NGOs & $\begin{array}{l}\text { - NGOs' involvement in the reporting process by way of writing parallel } \\
\text { reports or attending a pre-session NGO briefing or the constructive } \\
\text { dialogue with the state, } \\
\text { - the extent to which NGOs have (systematically) monitored the } \\
\text { implementation of the COs by the government, } \\
\text { - the extent to which NGOs have used the COs in their lobby and advocacy } \\
\text { vis-à-vis the government or parliament, } \\
\text { - NGOs' level of interaction with and consultation by the government in the } \\
\text { context of the reporting process, } \\
\text { - the extent to which NGOs have used the COs in litigation. }\end{array}$ \\
\hline $\begin{array}{l}\text { Human rights and } \\
\text { ombudsman } \\
\text { institutions }\end{array}$ & - largely the same as under NGOs \\
\hline Media coverage & $\begin{array}{l}\text { - the number of newspaper articles about the reporting process, including: } \\
\text { the pre-session working group, the LOI, alternative NGO reports, the } \\
\text { constructive dialogue and the resulting COs. }\end{array}$ \\
\hline
\end{tabular}

52 On 14 June 2012, an advanced search was conducted on Hansard, which contains the transcript of debates in the New Zealand House of Representatives as well as written and oral questions since 1 January 2000. Search terms can be found in appendix 2 . 
There is a close connection between impact (or domestic mobilisation) and effectiveness. Several liberal compliance theories on domestic politics and mobilisation even noted that domestic mobilisation often acts as a precondition for the effectiveness of international norms (chapter II, section 1.1.2). It could thus be argued that in order for COs to be effective, domestic actors should use the COs and lobby and pressure the government to act upon them. ${ }^{53}$ This strong relationship between impact and effectiveness also means that the level of domestic mobilisation is first used to measure impact while it is at the same time used to explain the (in)effectiveness of COs (chapter III, section 2.5).${ }^{54}$ It should, however, not be ruled out in advance that a $\mathrm{CO}$ can have an impact without being effective in the sense of leading to any follow-up measures. Likewise, a $\mathrm{CO}$ might also be effective, without having had any notable impact and with hardly any domestic mobilisation in relation to the respective $\mathrm{CO}$.

\subsection{The effectiveness of $\mathrm{COs}$}

Effectiveness was defined earlier as the extent to which policy, legislative or any other measures are taken as a result of the COs (chapter I, section 4.3). This implies that something happens that would otherwise not have occurred. Effectiveness will, however, not only be measured through the adoption of such new policy or legislative measures. This is also made clear in table 3.2, which highlights that COs can be (partly) effective by, for example, preventing intended policy or legislative measures. In addition, COs can put an issue (higher) on the political or legislative agenda or lead to the commissioning of an evaluation report. With respect to the ineffectiveness of COs, a distinction will be made between COs that have been rejected and the COs that coincide with the standing policy which is already in line with the COs. Table 3.2 also provides the indicators that will be looked at when assessing and explaining the (in)effectiveness of COs. These indicators and the methodology for the assessment of the (in)effectiveness will be discussed more thoroughly in the rest of this section.

The assessment of the effectiveness of COs was conducted in two stages. During the first stage, an initial examination of potential effective COs was made on the basis of a document analysis and the examples given by interviewees of alleged effective COs. The second stage consisted of a thorough analysis of the causal relation between the COs and correlated policy and legislative measures. For a schematic portrayal of the methodology followed, see figure 3.3.

53 See, for example, Zohlnhöfer and Ostheim (2005), 149. Falkner et al. (2005), 24. Jacobsson and Vifell (2007). Zeitlin (2009), 226. For a similar reasoning as to the COs, see Alston (1993), para. 95.

54 In other words, impact or domestic mobilisation is both the dependent variable (the effect that is studied) as well as the intervening or intermediary variable explaining the other dependent variable of effectiveness. 
Table 3.2. Operationalising and measuring effectiveness

\begin{tabular}{|c|c|}
\hline Operationalising (in)effectiveness & Indicators \\
\hline $\begin{array}{l}\text { Ineffective COs. A distinction will be made } \\
\text { between: } \\
\text { - COs that have been (explicitly) rejected } \\
\text { - Standing policy and legislative measures that } \\
\text { are already in line with and simply coincide } \\
\text { with the COs }\end{array}$ & $\begin{array}{l}\text { Indicators that make a causal relationship between } \\
\text { COs and follow-up measures or actions less } \\
\text { likely: } \\
\text { - Government challenges COs on factual and/or } \\
\text { legal grounds } \\
\text { - No interviewees hold that the COs played a } \\
\text { (considerable) role in the follow-up measures } \\
\text { - No explicit link is made between COs and } \\
\text { measures in Bills, policy documents or reports } \\
\text { - 'Follow-up' measures were announced prior to } \\
\text { COs } \\
\text { - COs were not used by domestic actors in their } \\
\text { lobbying leading up to the measures }\end{array}$ \\
\hline $\begin{array}{l}\text { (Partly) effective COs. A distinction will be made } \\
\text { between the following modalities of effectiveness: } \\
\text { - Agenda setting: COs put an issue (higher) on } \\
\text { the political agenda or strengthen the } \\
\text { arguments of domestic actors and, hence, shift } \\
\text { the terms of the debate } \\
\text { - Study or evaluations: COs lead to the } \\
\text { commissioning of a report or the establishment } \\
\text { of an interdepartmental working group or } \\
\text { committee to review the policy or legal } \\
\text { framework } \\
\text { - COs lead to (or prevent) new or additional } \\
\text { policy measures or initiatives or the allocation } \\
\text { of extra budgetary resources } \\
\text { - COs lead to (or prevent) legislative changes }\end{array}$ & $\begin{array}{l}\text { Indicators that make a causal relation between CO } \\
\text { and follow-up measures or actions more likely: } \\
\text { - An explicit link is made between COs and } \\
\text { measures in Bills, policy documents or reports } \\
\text { - Measures are taken (shortly) after the COs } \\
\text { - COs were used by domestic actors in their } \\
\text { lobbying leading up to the measures (level of } \\
\text { domestic mobilisation) } \\
\text { - The number of interviewees who mention the } \\
\text { measures as an example of effectiveness }\end{array}$ \\
\hline
\end{tabular}

The preliminary estimation in the first phase was firstly undertaken on the basis of the primary and secondary sources. This review especially considered the government's reaction to the COs in UN documents, including state reports, replies to the List of Issues, Summary Records of the constructive dialogues, and NGO parallel reports. The assessment for the Netherlands was also based on the government reaction to the COs sent to parliament and discussion of and references to COs in other parliamentary papers. For New Zealand, internal memos about the follow-up to several COs were also used (chapter XII, section 2.1). For Finland, several policy documents in which a reflection was given on the COs were also available in English. ${ }^{55}$ On the basis of these documents an initial estimation of the effectiveness of COs was made by assessing the correlation between the COs and legislative or policy measures. A second way in which potential effective COs were identified was through

55 For example, the government reports to parliament on human rights. Formin (2004) and (2009). 
the interviews with domestic stakeholders. Interviewees were asked how they regard the effectiveness of COs in their country and their role in policy and legislative development. In addition, they were asked to give concrete examples of measures taken and changes made as a result of COs and specify the role or contribution of the COs in this regard. In this way, the interviews enabled the identification of COs that were effective and played some role in policy or legislative discussions, even though they were not explicitly referred to in government papers or policy documents.

Figure 3.3. Two-stage methodology for the establishment of the effectiveness of COs

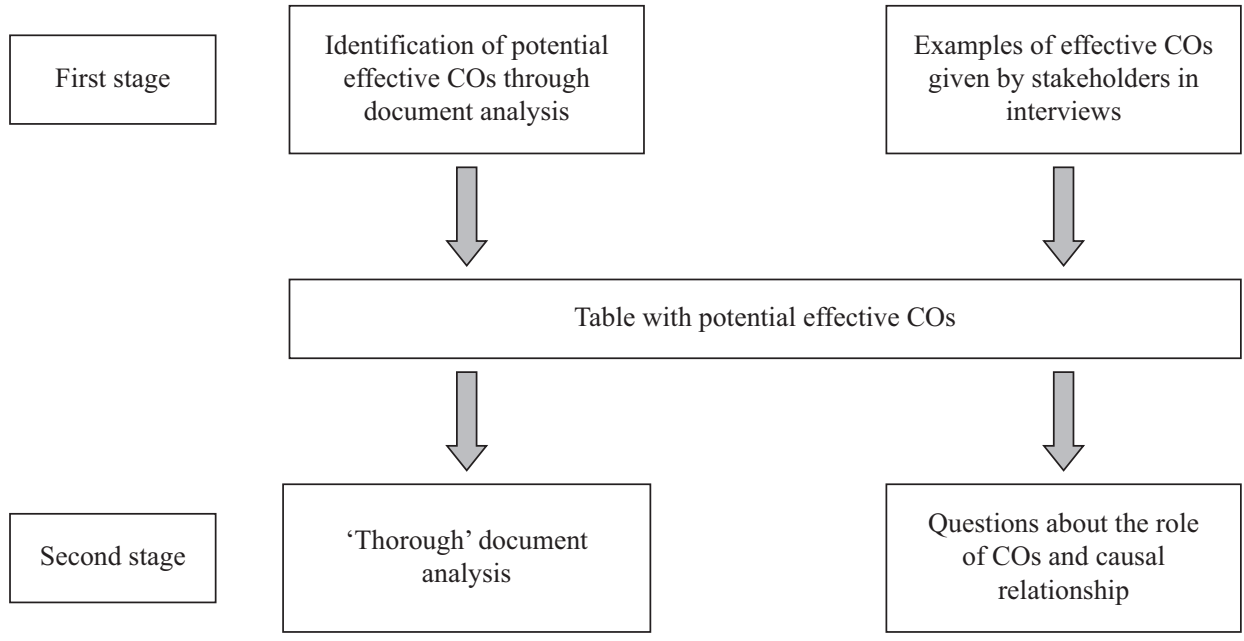

Based on both the document analysis and the interviews, a distinction was made between potential effective COs and seemingly ineffective COs. The former refers to COs that have possibly led to new or a change in policy or legislation, because the government explicitly claimed that the measures were taken as a result of COs or because there seemed to be a high degree of correlation between the COs and subsequent measures or (see below for some criteria). Seemingly ineffective COs are those COs that have not been acted upon and have not led to additional measures, because they are, for example, rejected. Hence, when the government rejected the $\mathrm{CO}$ by, for example, and challenged it on factual or legal grounds, this is treated as an important indication for limited effectiveness. ${ }^{56}$ Another category of seemingly ineffective COs are those that merely coincide with existing initiatives without a plausible causal relationship between initiatives and COs. At this stage it is assumed that COs that are rather general and do not prescribe specific courses of action or merely recommend the continuation of certain policy initiatives are especially when there is a strong domestic advocacy advocating for change in line with the CO. 
ineffective, unless the document analysis or interviews hinted at another conclusion. A table was made with potential effective COs identified through the document analysis and interviews.

This table served as a starting point for making the final and second stage assessment of the effectiveness of COs and establishing whether measures were 'really' taken as a result of $\mathrm{CO}$ and do not simply coincide with existing measures. The policy 'chain of events' was consequently examined more thoroughly in order to determine what factors have contributed to the decision underlying the policy or legislative measures. This also enabled distilling the specific role and contribution of the COs.

This second stage assessment was, first of all, based on a more thorough analysis of the above-mentioned primary and secondary sources. Several 'criteria' were used to establish the causal relationship (table 3.2). The following aspects are believed to make it more plausible that COs have been effective. Firstly, when an explicit link is made between COs and subsequent policy or legislative measures by the government or parliament in (the Explanatory Memoranda accompanying) Bills, policy documents or (evaluation) reports, it is more likely that there is a relationship between the COs and the respective measures. When the COs are only briefly or superficially addressed, the causal relationship is assumed to be less than when the specific content of the COs is discussed in depth. Secondly, the timing of the policy or legislative measure is important. When they were announced prior to the COs, this suggests the absence of a causal relationship..$^{57}$ By contrast, when the measures are announced or adopted (shortly) after the COs this could imply a relationship. Other aspects that at least imply a contributory role of the COs relate to the extent to which domestic actors have referred to or used the COs and the extent to which the specific treaty has played a role in relation to policy and public debates about the issue. This analysis was, second of all, complemented with and tested against data gathered through the interviews with domestic stakeholders. Interviewees were confronted with the potential effective COs identified in the preliminary assessment and questioned about the reasons for policy change and the causal relationship between subsequent measures and the COs. They were also asked to elaborate on the contribution of the COs in the light of other causal factors.

\subsection{Limitations to the measuring of effectiveness}

There are however several limitations to the above sketched methodology for the measurement of effectiveness. Firstly, it was at times difficult to get a complete overview of the process and chain of events and, thus, all factors that have an influence on the outcome. ${ }^{58}$ The documents outlined above are sometimes

\footnotetext{
57 This is not always the case. In some cases, however, measures might have been taken before and in anticipation of the COs. See, for example, chapter X, section 2.

58

Dür (2008), 563.
} 
insufficient to establish the effectiveness of each and every CO. This is aggravated by the fact that a reference is not always made to the COs or, when the COs are responded to, this is only done in rather general terms by outlining all policies in the respective area taken in the time period after the COs. Another important reason the effectiveness of COs is difficult to establish is that the COs are often rather broad and unspecific and do not prescribe any particular behaviour. This is especially the case where the COs recommend or encourage the state to continue with its policy ${ }^{59}$ and strengthen, intensify or increase its efforts. ${ }^{60}$ Hence, it is difficult to determine what behaviour is expected and to what extent subsequent measures are in line with the COs.

Secondly, because not all COs have been responded to by the government in state reports or parliamentary papers, interviews are sometimes the only source of information to get an insight into the reasons behind a policy or legislative change in the light of COs. The consequence of this is that triangulation of data is sometimes difficult to achieve in practice for each $\mathrm{CO}$. In addition, there are also problems with relying (too heavily) on interviews as a source. ${ }^{61}$ Statements made by interviewees are not always reliable, because they might have a reason to criticise and downplay the role of COs in order to give credit to domestic processes, a national institution or an individual minister. Conversely, government officials might have reason to exaggerate the impact and effectiveness of COs. Attributing a change to COs might be politically convenient, because it could shift blame for unpopular decisions on to an international entity. Another problem with interviews is the (un)conscious misrepresentation of developments and facts as a result of imperfect memories or biases in the recollection of past developments. This especially holds true for domestic stakeholders involved in the process of state reporting and the subsequent decision-making processes related to the implementation of the COs in the 1990s and early 2000s. With respect to these persons there is another difficulty of recruiting them (chapter III, section 2.6).

Thirdly, characteristic of social phenomena in general is the variety and interrelated set of conditions and factors jointly contributing to change. Hence, it is difficult to isolate the role or contribution of COs from other international and national processes. ${ }^{62}$ Heyns and Viljoen, for example, acknowledged that a limitation inherent in their study is the fact that a direct causal relationship between the treaty systems and domestic policy and legislative changes is hard to ascertain decisively, especially because several other factors also play an important role. ${ }^{63}$ What usually

59 See, for example, UN Doc. ICERD/C/64/CO/7 (2004), para. 11: 'The Committee encourages the state party to continue its efforts to combat this contemporary manifestation of racial discrimination.' measures to ensure proper representation of ethnic minority groups in the labour market.' UN Doc. ICERD/C/64/CO/7 (2004), para. 13.

61 Dür (2008), 563-564. Zeitlin (2009), 215.

62 Zeitlin (2009), 215 and 220.

63 Heyns and Viljoen (2001), 486. Connors (2000), 8. 
also happens is that the origins of change precede the COs. An illustration of this is the boomerang effect, which describes how domestic compliance constituencies and NGOs seek international support and link up with transnational networks to put pressure on their states from the outside (chapter II, section 3). NGOs often highlight issues in their parallel reports to the treaty bodies that they are already lobbying for domestically. They do this in order to obtain a useful and 'authoritative' recommendation that will give extra strength and legitimacy to their claims. COs, thus, act as 'resources' which can strengthen the arguments and position of domestic actors already advocating a certain change (chapter II, section 1.2).

This third limitation also suggests that COs are hardly ever a necessary or sufficient cause. A necessary cause refers to a situation in which policy and legislative measures would not have been taken without the $\mathrm{CO}$. When a CO is a sufficient cause, this means that the $\mathrm{CO}$ is able to produce a policy or legislative effect by itself. Rather, COs will almost always be a contributory cause among many other factors that jointly have an effect. ${ }^{64}$ Such contributory causes are neither necessary nor sufficient. Rival explanations and counterfactual reasoning to estimate how the behaviour would have been in the absence of the $\mathrm{CO}$ is not possible with multiple causes. ${ }^{65}$ It is also not easy to assess the precise and relative role and contribution of the COs and the other factors in the political decision. ${ }^{66} \mathrm{~A}$ distinction which will, nonetheless, be made is between, firstly, COs that have been used by the government to justify or give support to - an already intended - policy direction; secondly, COs that were just one of the many contributory factors that jointly led to a certain policy or legislative measure; and thirdly, COs that played a decisive or essential role in follow-up measures (see table 11.3 in chapter XI, section 3 for an illustration).

\subsection{Explaining the (in)effectiveness of $\mathrm{COs}$}

As was argued in chapter II, section 2.2 and II.4, this research incorporates two theoretical models to explain the (in)effectiveness of COs. The first is the constructivist literature on legitimacy and persuasion. As said, it is crucial for the effectiveness of COs that government officials are persuaded and feel compelled to comply. Such a compliance pull depends on the quality and authority of the treaty bodies and their COs in the eyes of officials. Therefore, this research focuses on the subjective perceptions of government officials and government ministers as to the legitimacy of the treaty bodies and the legal quality and persuasiveness of the COs. This is largely done through interviews with officials who were involved in the reporting process (chapter III, section 2.6) ${ }^{67}$ These interviews also serve to elicit the degree of engagement, ownership of and commitment to the process of reporting

64 Cohn (1991), 297. Kälin (2012), 64.

65 Goertz and Levy (2007), 15.

66 Dür (2008), 564. Mahoney and Goertz (2006), 235.

67 Mastenbroek and Kaeding (2006), 337-339. 
in order to determine whether officials are generally receptive and open to learning and persuasion. ${ }^{68}$ In addition, several constructive dialogues with treaty bodies were attended to observe the attitude of the government delegation in their interaction with the treaty body (see the introduction to chapter III, section 2). By focusing on all these elements in interviews and during the observation of the dialogue, this research examines whether Checkel's scope conditions for persuasion (chapter II, section 2.2) are met.

The second mechanism that is used to explain the (in)effectiveness of COs is domestic and transnational human rights mobilisation and advocacy (chapter II, section 4). This mechanism was integrated in this research by focusing on the impact of reporting and the COs, which was already discussed in chapter III, section 2.2.

This research also identifies other domestic factors, conditions or intervening variables that contribute to the (in)effectiveness of COs. ${ }^{69}$ This includes, among others, the bureaucratic capacity and organisation of reporting (chapter II, section 2.1 and chapter III, section 2.1), the salience of the respective rights and treaties (chapter II, section 1.2) and cultural, political and legal factors, such as the existence of a compliance culture and the way in which international treaties are incorporated into the domestic legal order.

\subsection{Interviews}

As was mentioned earlier, semi-structured interviews were conducted with domestic stakeholders (in)directly involved in the process of state reporting. This involvement could consist of drafting or contributing to state or NGO reports, attendance at the dialogue with the treaty bodies or persons who have used the COs in their domestic work. The domestic stakeholders that were interviewed were primarily government officials and NGO representatives, but they also included representatives from national human rights and ombudsman institutions, academic scholars, ministers, MPs, lawyers, and judges. In order to arrive at a comprehensive and reliable picture, domestic stakeholders in relation to all the six human rights treaties were interviewed and all the reporting cycles under the six treaties since the mid-1990s were covered. In addition, another aim was to interview officials from all the ministries involved in the reporting process.

Government officials were identified on the basis of the lists of the delegation consisting of the government officials who participated in the constructive dialogue. These lists are usually sent to the treaty bodies prior to the dialogue by the Permanent

68 Vanhercke (2009), 6 and 13. Hurd, (1999), 382 and 390. Beach (2005), 130.

69 The (theoretical) explanations relating to legitimacy and persuasion as well as domestic and transnational mobilisation and advocacy are primarily used to explain the (in)effectiveness of COs and not so much the impact of COs. However, some of these factors also affect the domestic impact of COs. It is, for example, not unlikely that the salience of a certain category of rights also contributes to the number of references by domestic actors to COs of a certain Committee. 
Mission in Geneva or New York. ${ }^{70}$ Relevant NGOs and human rights and ombudsman institutions were found on the basis of parallel reports on the website of the OHCHR and their own websites. ${ }^{71}$ Interviewees were sometimes also identified through academic literature. In addition, several contacts in New Zealand and Finland helped with the identification of relevant domestic stakeholders in the initial preparatory stage of the country visit. ${ }^{72}$ Moreover, the approach of snowball or chain-referral sampling was used by asking interview respondents via email and during interviews for recommendations of other relevant persons and organisations.

For each country, there were between 90 and 130 government officials who attended the constructive dialogues since the mid-1990s. The number of officials who were involved in the reporting process in one way or another is even higher. Some sort of 'selection' was thus necessary for the government officials. There was a preference for officials who have been involved in different reporting cycles. The rationale was that these officials were better able to compare between different dialogues and/or treaty bodies. There was also a preference for officials who have also been involved in the process of reporting in another capacity, for example, as Children's Ombudsman or NGO representative so that they were able to share their experience from different perspectives.

Respondents were informed that the data would be reported in aggregated form in such a way that individuals or organisations are not identifiable. It was made clear that when there was a need to attribute a particular quote to a participant, the participants' approval for attributing the quote would be sought. Respondents were also informed that their name and function(s) would be included in the appendix. For the Netherlands and Finland, the consent of the respondents was implied on the basis of their (voluntary) participation in the research in the light of the information provided in the interview request and the oral information at the beginning of the interview. ${ }^{73}$ The research stay as a visiting researcher at the Faculty of Law of Victoria University, Wellington, necessitated obtaining ethical approval from the Pipitea Human Ethics Committee for the interviews. Approval for the research was obtained in May 2012. The Committee considered it essential that informed consent would be obtained through a signed consent form, since this would provide proof that the interview participants agree to be interviewed on the terms explained to them.

70 These lists can be found on the website of the OHCHR. When no lists were available, especially for the dialogues in the 1990s, use was made of the summary records or press releases of the dialogues, which specify which officials were part of the government delegation. The contact details (email or LinkedIn) of the persons could often be found on the internet. Where this was not the case, another person was asked for the contact details.

71 These reports usually mention which organisations have written or contributed to the report. Sometimes they even mentioned the specific authors. If not, the organisations were contacted with the question about who had contributed to the report.

72 For New Zealand, these were Claudia Staal, Petra Butler and Peter Shuttleworth. For Finland, these were Martin Scheinin, Tuomas Ojanen and Miia Halme-Tuomisaari.

73 Use was made of a separate information sheet for the interview requests for New Zealand and Finland. 
Overall, domestic stakeholders were rather willing to be interviewed. Eventually 63 stakeholders were interviewed in the Netherlands, 62 in New Zealand and 50 in Finland (see appendix 1). There were only a handful of persons in each country who were not able or willing to be interviewed. They gave several reasons for this, such as time constraints or because they were of the opinion that they would not have much to contribute and, thus they recommended other colleagues. An even smaller group of people was made up of persons whose contact details could not be found or from whom no reply was received. ${ }^{74}$

The interviews were not taped, but extensive written notes were taken during the interview. ${ }^{75}$ An interview checklist was used to ensure that the same questions were asked to all interviewees (see appendix 3 for the checklist). ${ }^{76}$ As was mentioned already, the protocol included questions about the broader influence of the process of state reporting (chapter III, section 2.1), the impact of the COs (chapter III, section 2.2) and the effectiveness of specific COs (chapter III, section 2.3). In addition, interviewees were also asked about their views as to the importance and usefulness of the process of reporting. In order to determine whether a compliance pull exists and persuasion occurs (chapter II, section 2.2), questions were also raised about the quality of the constructive dialogue, the COs and the treaty bodies, including possible differences between treaty bodies and their COs (chapter III, section 2.5).

As said, the interview data are used in a non-attributable form in this book, by focusing on the commonalities between the several respondents. If there are significant contradictions, they are mentioned explicitly. When a view was put forward by only a couple of respondents, the following words are used, for example: 'some', 'several', 'a number of' or 'various'. ${ }^{77}$ When an issue was mentioned by almost all respondents, this is referred to as 'most' or 'almost all' respondents. When no pronoun is being used, this means that the view was expressed or shared by a considerable majority of the respondents.

74 The names of these persons could be retrieved from the author upon request.

75 These notes were typed out in Word, usually on the same day as the interview. The summaries of the interview reports can be accessed upon request. It was not felt necessary to record the interviews, since the interviews would be discussed and paraphrased in an aggregated way without literal quotes. The expectation was also that respondents would be more open and honest without a recorder.

76 This interview checklist was in principle not sent to the respondent prior to the actual interview. This was done in a few instances only when respondents requested this.

77 A reference to 'one' interviewee is only made when that person's view is related to its particular involvement or function. 


\section{Part B}

\section{The Netherlands}




\section{Chapter IV \\ The Role and Place of Human Rights and State Reporting in the Netherlands}

'The Netherlands will continue to fully cooperate with UN human rights treaty bodies by submitting timely periodic reports and acting on their concluding observations and recommendations promptly and in good faith.' [Ministry of Foreign Affairs in 2007] ${ }^{1}$

This chapter serves two objectives. Firstly, it provides a general introduction to the Dutch legal and political system (section 1) and it will discuss the role of human rights more generally in government bureaucracy, the parliament and legal practice (section 2). Secondly, it outlines the organisation of the reporting process within the government administration and the views of government officials towards the importance of reporting and the functioning of the treaty bodies (sections 3 and 4).

\section{BaCkground to The DUtCh legal AND POLitical SySteM}

The Netherlands is a country of the Kingdom of the Netherlands situated in North West Europe and bordering Belgium and Germany. ${ }^{2}$ It has a population of around 16.7 million. The Netherlands is a constitutional monarchy with a parliamentary democracy. Parliament, the States General (Staten-Generaal), consists of the House of Representatives with 150 seats, referred to as the Second Chamber or Lower House (Tweede Kamer or TK), and the Senate with 75 seats, the First Chamber or Upper House (Eerste Kamer or EK). The Netherlands has a multi-party system with many political parties represented in parliament as a result of a proportional voting system. This means that coalition governments have traditionally been the practice. Since 1980, governments have primarily consisted of at least two or three of the following four political parties, the centre-right Christian democrats (CDA), the centre-right liberal-conservatives (VVD), the centre-left social democratic Labour party (PvdA), and the centrist social-liberal party (D66). ${ }^{3}$

See the brochure 'The Netherlands, a committed candidate for the Human Rights Council' of March 2007 in the attachment to TK 2006/07, 30800 V, nr. 86, 4.

2 Note that the 'BES islands' of Bonaire, Sint Eustatius and Saba are special municipalities of the Netherlands since October 2010. As was stated in chapter III, section 1.2, this research focuses on the European part only.

3 The governments of Kok I (1994-1998) and Kok II (1998-2002) consisted of PvdA, VVD and D66. Balkenende I (2002-2003) was formed by CDA, VVD and LPF. Balkenende II (20032006) was a coalition government of CDA, VVD and D66. CDA and VVD continued with Balkenende III (2006-2007) when D66 left the government. This government was succeeded by a coalition between CDA, PvdA and the social Christian party CU, Balkenende IV (2007-2010). Rutte I (2010-2012) was a minority government of VVD and CDA which was supported by the right-wing PVV. Rutte II (2012-present) is formed by VVD and PvdA. 
The Netherlands ratified the six main UN human rights treaties within a considerable period of time after signing the treaties, from a little bit less than four years (CAT) to eleven years (CEDAW). ${ }^{4}$ The long time period can primarily be explained by the seriousness with which the government tends to take international obligations. A treaty will usually not be ratified until domestic legislation is fully amended to conform with the treaty standards. ${ }^{5}$ At the time of the ratification of the ICERD, ICCPR and ICESCR in the 1970s, both the government and the parliament expected these treaties to have little impact on the Dutch legal order, because there was an idea that national legislation was already in compliance with the treaties and contained sufficient safeguards. ${ }^{6}$

The Dutch Constitution contains a - rather limited - bill of rights. Many rights are excluded, including the right to a fair trial, the right to life, the prohibition of torture and the right to family life. ${ }^{7}$ The Constitution contains a bill of rights which also includes some social rights, albeit they have been formulated primarily as a 'duty of performance' (inspanningsverplichting) rather than as an individual right. ${ }^{8}$ The constitutional bill of rights has only had a limited impact in comparison with international human rights treaties. ${ }^{9}$ This is because international treaties have a strong formal status and get a 'generous reception' in the Dutch legal order. ${ }^{10}$ The Constitution has been qualified as 'one of the most völkerrechtsfreundliche'. ${ }^{11}$ This is because the Netherlands adopts a monist approach to international treaties, which automatically become part of the national legal order and do not need to incorporated or transformed into national legislation. This is provided by Article 93 of the Constitution. ${ }^{12}$ Article 94 of the Constitution even gives international law precedence over national law by allowing courts to hold domestic law provisions inapplicable when they are incompatible with treaty provisions. ${ }^{13}$

4 ICERD (signed on 24 October 1966 and ratified on 10 December 1971), ICESCR (signed on 25 June 1969 and ratified on 11 December 1978), ICCPR (signed on 25 June 1969 and ratified on 11 December 1978), CEDAW (signed on 17 July 1980 and ratified on 23 July 1991), CAT (signed on 4 February 1985 and ratified on 21 December 1988) and CRC (signed on 26 January 1990 and ratified on 6 February 1995).

$5 \quad$ Nollkaemper (2009). Heringa (1988), 104 and 121-122.

6 This observation was also made in relation to the ECHR which was ratified in August 1954. Swart (1999), 38. Zwaak (2001) 595. De Wet (2008), 504-505. Kuijer (2009), 52-53.

7 Articles 1-23. Oomen (2011), 22-23.

8 The first chapter on fundamental rights (article 1-23) was expanded during the 1983 Constitutional revisions.

$9 \quad$ Barkhuysen et al. (2009).

10 Claes and De Witte (1998), 187. Claes and Leenknecht (2011), 288. Van Dijk (1988), 639. Zwaak (2001), 597.

11 Fleuren (2010), 246.

12 'Provisions of treaties and of resolutions by international institutions which may be binding on all persons by virtue of their contents shall become binding after they have been published.'

13 'Statutory regulations in force within the Kingdom shall not be applicable if such application is in conflict with provisions of treaties or of resolutions by international institutions that are binding on all persons.' 
Articles 93 and 94, however, put a filter on the otherwise extreme monism. ${ }^{14}$ In this qualified monistic legal system, individuals can only directly derive rights from treaty provisions provided that they are 'binding on all persons'. This means that the nature and content of the treaty provision needs to be capable of judicial enforcement in the absence of further implementing measures. This is eventually something for national courts to decide. In practice, courts have used EC law criteria associated with the notions of 'direct effect' and 'direct applicability' to determine the self-executing character. ${ }^{15}$ The potentially great impact of treaties is more limited in practice, because courts apply strict criteria for establishing direct effect. ${ }^{16}$ In the view of Scheinin, the restrictive use of the criteria has led to an 'allor-nothing approach in which a treaty provision is either of decisive importance or is simply overlooked as irrelevant'. ${ }^{17}$ Dutch courts generally consider the ECHR and ICCPR and some provisions of the CRC and CEDAW to be 'binding on all persons', while the other UN human rights treaties are seen as lacking direct effect.

Article 90 of the Constitution provides that 'the government promotes the development of the international legal order'. This Article is illustrative of the strong missionary spirit to be a guiding country and set an example whereby human rights operate as 'a moral cornerstone' of foreign policy. ${ }^{18}$ There is great pride among politicians and government officials that they have The Hague as the 'legal capital of the world'. The idealist internationalist attitude 'to do good' is part of a historical tradition that goes back to the times of the Dutch jurist Hugo Grotius, but at the same time it reflects the national interest of a small and open trading country in international cooperation and law. ${ }^{19}$

\section{The ROle Of hUMAN RightS IN THE DUTCh LEGAL ORDER}

This section examines the role of human rights in the government administration, the parliament and in the legal practice before courts. It will also reflect on the legal

14 Besselink and Wessel argued that because of Article 94 and the judicial restraint, the Dutch system operates in practice primarily in a dualistic way. Besselink and Wessel (2009), 81.

15 The phrase 'binding on all persons' was intended to be a description of the doctrine of 'selfexecuting' provisions, a concept which is primarily used in the United States. TK 1955/56, 4133 (R 19), nr. 3, 5. Fleuren (2010), 248. Zwaak (2001), 598. De Wet (2008), 235.

16 The criteria that have been used by courts include, for example, the intention of state parties to make a provision self-executing, the wording of the provision and whether it is sufficiently concrete, the extent to which implementing measures are needed and the allowed room for discretion, whether gradual implementation is envisaged and whether it includes a positive obligation. The opinion of the government as to the effect of treaty provisions is not decisive, but it is taken into consideration as well. Fleuren (2010), 253-254. Alkema (2011), 417. Besselink and Wessel (2009), 49-50.

17 Scheinin (1991), 352.

18 Since March 2000, there has even been a human rights ambassador. Claes and De Witte (1998), 173 and 189. Baehr (2000), 51-52. Baehr et al. (2002), 1. Reiding (2007), 12-15. Oomen (2011), 9.

19 Claes and De Witte (1998), 189. Baehr (2000), 50. Oomen (2013a), 45-46. 
(human rights) culture and the relationship between the judiciary and the legislature. The concluding section 2.5 will also reflect on some recent developments.

\subsection{Government}

There has not been a comprehensive and coherent governmental strategy for the (domestic) implementation of human rights in the Dutch legal order. There have only been regular policy papers on the Dutch foreign policy on human rights. ${ }^{20}$ The first national human rights action plan was only presented in December 2013. Human rights, nonetheless, play a substantial part in the legislative process in which the government plays a dominant role. ${ }^{21}$ The Dutch instructions for legislation, for example, provide that during the legislative process it must be examined whether there are 'higher rules' that restrict the 'freedom of regulation'. The explanation to the guidelines details that higher rules include, among others, international or EU law. The ECHR and ICCPR are mentioned in particular. ${ }^{22}$ Almost all government Bills discuss the human rights aspects rather thoroughly and extensively in the Explanatory Memorandum. ${ }^{23}$ The Council of State (Raad van State), who gives advice on all Bills, also pays considerable attention to conformity with international law, especially to the ECHR and to a lesser extent the ICCPR. ${ }^{24}$ Its advice is nonbinding, but the government and the parliament will not disregard the criticism of the Council easily and will usually amend or withdraw the Bill. ${ }^{25}$ Nonetheless, especially when treaty provisions contain room for interpretation, the comments of the Council have sometimes been dismissed 'with rhetoric that pays lip-service' to the treaty. ${ }^{26}$

The ECHR is the main point of reference during the legislative process. Especially since the 1990s, government officials have 'almost routinely' paid

20 There have, however, been policy notes in specific areas, such as the note on fundamental rights in a multiform society. 'Grondrechten in een pluriforme samenleving' in TK 2003/04, 29614, nr. 1. Another example is privacy. TK 2011/12, 32761, nr. 1.

21 There is, however, no specific human rights impact assessment. Kuijer (2009), 56-59. Loof (2008), 89.

22 See Instruction 18 of Dutch instructions for legislation (Aanwijzingen voor de regelgeving). Instruction 11 and 166 also refer to the ICCPR in addition to the ECHR. See also the checklist on fundamental rights, referring to the six UN human rights treaties, as developed by the Knowledge Centre for Legislation (IAK) as part of the Integrated Assessment Framework for Policy and Legislation: 'Checklist toetsing (international) (klassieke) grondrechten', December 2012, <www.kc-wetgeving.nl/fileadmin/documents/IAK/IAK-toetsen/CZW-Checklist_ toetsing_wetgeving_dec2012.pdf $>$, accessed 6 August 2013.

23 Lawson (1999), 105. Loof (2008), 110. Note that this pre-legislative scrutiny has been characterised as not wholly unbiased, because there is a certain interest in an outcome in the form of the realisation of a policy goal. Peters (2009), 111. The examination of the other human rights treaties is intended but not necessarily exhaustive. Broeksteeg et al. (2005), 68 and 129. Loof (2008), 89.

25 Claes and Leenknecht (2011), 293.

26 De Wet (2008), 276 and 287. Loof (2008), 89. Redactioneel (1998a), 261. 
attention to the compatibility of legislative proposals with the ECHR. ${ }^{27}$ In this context, it has also been noted that the government has generally amended legislation in response to ECtHR judgments without significant problems, albeit sometimes with several years of delay. ${ }^{28}$ These amendments, however, often show a minimal and pragmatic reading of the judgment in order to downscale its impact. ${ }^{29}$ In addition, the government, but also courts, often see the ECHR as the (maximum) human rights standard, as was noted by several scholars. They hardly go beyond a minimalist interpretation of the ECtHR and are reluctant to provide a higher level of protection of human rights. ${ }^{30}$ This has, according to some, led to a 'chilling effect' on the protection of human rights. ${ }^{31}$ Loof also observed that because the Dutch legislator is focused on Strasbourg, it does not take into account that the obligations under other human rights treaties might be more demanding and far reaching. ${ }^{32}$

There are notable differences among political parties with respect to their stance on international human rights treaties and monitoring mechanisms, especially in recent years. The VVD, PVV and, to a lesser extent, CDA have sometimes been rather dismissive. ${ }^{33}$ Some political parties have traditionally had more favourable views towards international human rights law and are more prone to using it, including the green left party GL, the PvdA and D66 and to a lesser extent the socialist SP. ${ }^{34}$ These differences have obviously resulted in some variance between different governments as to their receptiveness towards international human rights. The purple coalition of Kok I and II (Pvda, VVD and D66) and the Balkenende IV government (CDA, PvdA and CU) have, for example, had a more international outlook and a more international (human rights) law friendly approach than centreright governments, such as Balkenende I (CDA, VVD and LPF), Balkenende III (CDA and VVD) and especially Rutte I (VVD, CDA and PVV) (see chapter IV, section 2.5). ${ }^{35}$

27 De Wet (2008), 274. Swart (1999), 39.

28 The President of the ECtHR, Costa, even referred to a 'very good record' of execution of judgments. Costa as quoted in Van Dam (2009), 2. See also Lawson (1999), 103. Zwaak (2001), 620-623. Emmerik (2008), 149. Kuijer (2009), 51. Claes and Gerards (2012), 5 and 22-23. Kuijer (2013). De Wit (2013), p. 218-219 and 229. It was noted that amendments were sometimes made after years of delay. De Wet (2008), 238-240, 257-261 and 268.

29 Claes and Gerards (2012), 23.

30 Loof (2008), 116. De Wet (2008), 276 and 287.

$31 \quad$ Claes and Leenknecht (2011), 302. Peters (2009), 109.

32 Loof (2008), 116-117.

33 Kamp (VVD), for example, noted that the reports of ECRI are one-sided, biased, include false conclusions and lack nuance. TK 2008/09, 30950, nr. 13, 4 and 6.

34 This has caused some to argue that human rights are increasingly seen as a leftist hobby. Van den Brink (2013), 489. Redactioneel (2011). Loof, for example, noted that the majority of written questions in relation to ECtHR judgments were raised by PvdA. Loof (2008), 102.

35 The international outlook has been particularly visible with respect to migration policies. See chapter $\mathrm{X}$, section 2.3.4. 


\subsection{Parliament}

Human rights are increasingly referred to in parliament. Oomen, for example, found that they were mentioned more often in 2010 than in $1995 . .^{36}$ There is, however, no structural or fundamental debate in parliament about the domestic human rights situation in the Netherlands. ${ }^{37}$ This means that human rights (treaties) are referred to on an incidental basis through written parliamentary questions primarily as a result of reports in the news. ${ }^{38}$ One scholar even referred to a 'drama-democracy' in which parliamentary attention is primarily driven by newspaper headlines. ${ }^{39}$ The great influence of the media was attributed to the information overload and lack of time for MPs and the pressure to attract media coverage. Because of the limited time of MPs, they, and especially members of the opposition, are generally eager to make use of commentaries and information from NGOs or professional organisations of judges or lawyers or comments of academics. ${ }^{40}$ Another element of the parliamentary scrutiny of human rights is that human rights have primarily been discussed in relation to other countries in the context of Dutch foreign policy. Almost $73 \%$ of the references to human rights in parliament dealt with foreign policy. ${ }^{41}$

Nonetheless, this does not mean that the human rights aspects of a Bill are completely ignored during the parliamentary discussion. ${ }^{42}$ There are considerable differences between the First and Second Chamber in terms of the attention paid to human rights. The Second Chamber barely conducts a thorough analysis of the constitutionality of Bills and their compliance with international and European law. ${ }^{43}$ It scarcely undertakes an examination of the necessity and subsidiarity of limitations on human rights itself. ${ }^{44}$ Hardly any amendments are proposed or adopted to remedy the tension with human rights in specific. ${ }^{45}$ This reflects more generally the ever-decreasing role of the Second Chamber as a co-legislator and the

36 Oomen (2011), 15. Oomen (2013a), 42 and 49. Baehr et al. were under the impression that MPs paid less attention to human rights in the (late) 1990s than in the 1970s or 1980s. Baehr (2000), 61. Baehr et al. (2002), 233.

College voor de Rechten van de Mens (2013), 34. The government sends yearly reports about the jurisprudence of the ECtHR to parliament. These are, however, not discussed and often merely taken note of. Emmerik (2008), 151. Kuijer (2009), 58.

Around $30 \%$ of the work of MPs is determined by media and newspaper articles. De Jong and Kummeling (2009), 72. Van Dam (2009), 120-121. Loof (2008), 103.

Loof (2008), 109-110. Oomen (2011), 39.

Oomen (2011), 39. See also Redactioneel (1998a). De Boer (2008), 51.

42 Some authors even pointed to the routine debate of human rights aspects of Bills. Loof (2008), 110. De Wet (2008), 274. Kuijer (2013), 107.

43 Claes and Leenknecht (2011), 292.

44 MPs often base their judgment on the information provided by the government. They are often satisfied with the promise of the restricted use of the competences in practice or a future evaluation of the new law. De Jong and Kummeling (2009), 83-84.

45 Loof (2008), 112-113. Criticism of the Council of State or other organisations does not always lead to critical reflection. De Jong and Kummeling (2009), 70, 83 and 85. 
limited attention to the legal quality of legislation. ${ }^{46}$ Explanations for the marginal human rights scrutiny and this wider phenomenon include the limited legal expertise to analyse jurisprudence and address the critical issues of a Bill, the great turnover and, hence, limited experience of MPs, the absence of a collective or institutional memory or the limited popularity of being involved in - the rather technical exercise of - legislation. ${ }^{47}$

By contrast, the Senate has traditionally paid special attention to conformity with international (human rights) law as a 'chamber of reflection'. The discussion of Bills is usually more intensive than in the Second Chamber. ${ }^{48}$ Nonetheless, the Senate can only adopt or reject the Bill and it lacks the power to introduce a legislative proposal or to amend it. As a consequence, it has been careful to reject a Bill, even when it had constitutional defects. Between 1956 and 2000, only 36 Bills were not adopted. This is less than $0.3 \%$ of the total number of Bills. ${ }^{49}$ Broeksteeg concluded that the Senate is not able to influence the legislative process in a fundamental and effective way, despite its powerful position on paper. Rather it frequently caves under the political pressure of the government and Second Chamber. ${ }^{50}$ Even when a Bill was met with fundamental human rights criticism in the Senate, political motives are more important than legal ones and the concern of governing parties to support government proposals almost always prevails. ${ }^{51}$ The latter is reflective of the functioning of both Chambers of parliament as partners instead of watchdogs of the executive. ${ }^{52}$ The governing parties in parliament usually operate in a monistic way without a clear distinction between them and the government and tend to vote in line with the coalition agreement.

\subsection{National courts and legal practice ${ }^{53}$}

Until the end of the 1970s, an appeal to an international human rights treaty was considered to be a 'sign of weakness' and was only made when there was no other

46 De Jong and Kummeling (2009), 71-72.

47 The average number of years in parliament of MPs decreased from 7.3 years in 1959 to 3.7 years in 2005. The number of lawyers has also decreased sharply. De Jong and Kummeling (2009), 67-68, 71-72 and 91. Peters (2009), 110. Loof (2008), 111-112.

$48 \quad$ Claes and Leenknecht (2011), 292. Gerards (2012), 2453.

49 In practice, the Senate has, however, claimed a 'veiled right of amendment' by informally requesting the initiator to amend the Bill with the threat of a rejection. From 1983 to 2000, only 20 Bills out of 4439 were adopted through this novel procedure. The majority deals with legal or linguistic changes only. Broeksteeg (2008), 94-96. Van der Schyff (2008), 232. Peters (2009), 105.

50 Broeksteeg (2008), 96-97.

51 Loof (2008), 113 and 123. De Jong and Kummeling (2009), 88 and 92. Ten Kate and Van Koppen (1994), 146.

52 Oomen (2011), 36.

53 Note that there are several courts which are the highest judicial authorities. The Supreme Court is the highest court in the field of civil, criminal and tax law. In the field of administrative law, the Administrative Jurisdiction Division of the Council of State exercises this function. The Central Appeals Tribunal is the highest authority in relation to social security and civil service issues. 
'reasonable argument'. ${ }^{54}$ Courts were reluctant to use international human rights treaties and to disapply national law in the context of Article 94 of the Constitution. ${ }^{55}$ Since the beginning of the 1980s, the attitude of several courts 'changed dramatically' and invoking human rights treaty provisions became normal for a lawyer. ${ }^{56}$ Van Dijk found a considerable increase in the number of references to human rights treaties by the Supreme Court since $1985 .{ }^{57}$ Since the 1980s, the ECHR in particular, has been a 'touchstone in all areas of jurisprudence' and has been applied on a daily basis. ${ }^{58}$ One reason why international human rights treaties have obtained a central position in the Dutch legal order, at least as far as they contain self-executing provisions, is the prohibition of constitutional review. ${ }^{59}$ As a result of Article 120 of the Constitution, courts cannot review the conformity of Acts of parliament with the constitution. ${ }^{60}$ As we have seen before, treaty review under Article 93 and 94 of the Constitution is allowed.

Nonetheless, courts have still been rather cautious and hesitant in their review of domestic law against human rights treaties and will not easily declare a violation. ${ }^{61}$ There have only been 28 cases between 11 January 1995 and 21 October 2008 in which an Act was held to be inapplicable. ${ }^{62}$ Claes and De Witte referred to the 'striking receptivity [of international law] in principle' which is coupled with 'cautious pragmatism in [its] application'. ${ }^{63}$ There is a preference among courts to avoid a conflict between the domestic law and treaties by employing a treaty conform interpretation. ${ }^{64}$ Courts are generally not eager to make political decisions

$54 \quad$ Zwaak (2001), 595. See also Swart (1999), 39. Peters (2009), 112.

55 Even the ECHR was ignored by the authorities and courts. Van Dijk (1988), 640. The absence of judicial activity was attributed to the limited familiarity of the judiciary. Zwaak (2001), 601-602 and 622 .

56 Van Dijk (1988), 649. Zwaak (2001), 602. There was also increased attention by academics and more training courses on human rights treaties, especially with respect to the ECHR. De Wet (2008), 302-303.

57 The total number of references to the five human rights treaties (ECHR, ESC, ICCPR, ICESCR and ICERD) was: 51 (1980), 54 (1981), 64 (1982), 65 (1983), 56 (1984), 121 (1985), 141 (1986). 37 violations were determined of the ECHR (35) and ICCPR (2). The ECHR was cited 391 times, ICCPR 145 times, ESC 8 times, ICESCR 7 times and ICERD only once. Van Dijk (1988), 641-643.

58 De Wet (2008), 285. Swart (1999), 39.

59 Uzman et.al concluded that it 'has led to a situation where international human rights law (most notably the ECHR) has taken over the role as most important civil rights charter for the Netherlands'. Uzman, Barkhuysen and van Emmerik (2010), 429, 432 and 436. Swart also argued that had there been a system of constitutional review, the ECHR would have played a smaller role. Swart (1999), 40.

60 'The constitutionality of Acts of parliament and treaties shall not be reviewed by the courts.' Courts can only review secondary legislative acts (Royal Decrees, ministerial, provincial and municipal by-laws) and administrative decisions/ordinances of lower public bodies. Claes and Leenknecht (2011), 291.

61 De Wet (2008), 241 and 254. Gerards (2008), 163. Swart (1999), 41.

62 Besselink and Wessel (2009), 52.

63 Claes and De Witte (1998), 188.

64 The Supreme Court held that Dutch courts 'should, as far as possible, construe and apply Dutch law in such a manner that the state complies with its treaty obligations'. Hoge Raad, 
The Role and Place of Human Rights and State Reporting in the Netherlands

between several alternatives that are equally consistent with the treaty provision. ${ }^{65}$ This is because courts are reluctant to interfere with the competence of the legislature. Courts justify this non-interference in legislative affairs by reference to the 'constitutional relations between the courts and the legislature', 'the courts' place in the constitutional setting' or the law/politics divide. 66

\subsection{The legal (human rights) culture}

The population values the importance of human rights at home and abroad. ${ }^{67}$ The Netherlands has the highest percentage of people being members of a human rights organisation, $24 \%$ in 1999, while the global average is $3 \% .{ }^{68}$ At the same time, rights consciousness is low in Dutch society. Oomen found that the knowledge about the Constitution and international human rights treaties is limited and lower than in other neighbouring countries. ${ }^{69}$ She and others argued that many important social issues are not framed or approached in terms of human rights. ${ }^{70}$ International human rights are often considered irrelevant in domestic political debates and public discourse. ${ }^{71}$ When issues are framed in terms of human rights, this can lead to surprised or even dismissive responses. ${ }^{72}$ Oomen referred in this context to 'human rights exportism' where treaties are considered as yardsticks for others. ${ }^{73}$ In this context, she quoted the Chairman of the 1956 Constitutional Commission who held that: 'the international conventions aim to elevate backward countries' ${ }^{74}$

16 November 1990, NJ 1992, 107 as quoted in Fleuren (2010), 259-261. Zwaak (2001), 623. Claes and De Witte (1998), 172. Peters (2009), 112. Alkema (2011), 417.

The Supreme Court emphasised that courts should be careful in reaching value judgments, especially when there are different possibilities and clashing interests which are of a more principled nature. Such decisions should be left to the legislature. Hoge Raad, 16 May 1986, NJ 1987, 251. Zwart (2001), 555-556. Fleuren (2010), 258-259 and 262. Uzman, Barkhuysen and van Emmerik (2010), 7 and 12-16. Van der Schyff (2010), 289. Alkema (2011), 410. Claes and Leenknecht (2011), 287. Claes and Van der Schyff (2008), 125, 129 and 141. De Wet (2008), 254. Peters (2009), 109 and 118. Alkema (2011), 417.

67 Reiding (2007), 36.

68 Oomen (2011), 34.

$6994 \%$ of the respondents of a representative survey knew hardly anything about the actual content of the Constitution. When asked about 'treaties or other documents in which fundamental rights are laid down', $20 \%$ of the respondents who answered mentioned the Constitution, $9 \%$ the UDHR, 5\% the CRC and only 4\% the ECHR. The Eurobarometer on the CRC showed that the Dutch youth ranked $24^{\text {th }}$ out of 27 countries in terms of awareness about children's rights. Oomen (2011), 30 and 33-34.

70 Oomen (2011), 2.

71 College voor de Rechten van de Mens (2013), 26-27. Oomen (2011), 7 and 15-17. Brenninkmeijer (2010). Redactioneel (1998a).

72 Oomen (2011), 8-9. Brenninkmeijer (2010), 277.

73 Oomen (2011), 3. Oomen (2013a), 45. See also Brenninkmeijer (2010), 277.

74 Oomen (2013a), 47. 
There has traditionally been a lack of human rights litigation, as was already noted in chapter IV, section 2.3. Human rights have primarily been realised and protected by political institutions through a political process instead of by judicial review by courts. ${ }^{75}$ There is considerable trust among the public in the political process and a democratically elected legislature and an accountable executive. ${ }^{76}$ This does not leave much room for 'activist' intervention by courts in political issues. ${ }^{77}$ In this context, Claes and Leenknecht pointed to the 'poor tradition of judicial fundamental rights protection' ${ }^{78}$ Finding negotiated solutions is valued over the idea of individual rights and the resolution of conflicts 'at the point of the law' ${ }^{79}$ Oomen noted in this context the fear of juridification and the rise of a claim culture in parliament. ${ }^{80}$ One illustration of the limited resonance of judicial review is that general administrative courts were only established in 1974. In addition, the Netherlands has, for example, less courts, judges and lawyers than its neighbour Germany ${ }^{81}$ Nonetheless, since the 1970s, there has been an increase of rights talk and litigation as a result of a process of emancipation and individualisation..$^{82}$ According to some, there has even been a shift to a 'lawyocracy' ${ }^{83}$ In more recent years, courts have played an important role in highly sensitive issues that were not addressed by the legislature at that moment, including wrongful life, wrongful birth, adoption and euthanasia. ${ }^{84}$

\subsection{Concluding remarks and recent developments}

The previous overview shows that it is especially the ECHR and the jurisprudence of the ECtHR that have been dominant in the Dutch legal order. ${ }^{85}$ Claes and Leenknecht held that the ECHR is "without a doubt the single most important

75 Van der Schyff (2010), 288. Claes and Gerards (2012), 3.

76 Claes and Van der Schyff (2008), 124 and 141. Van der Schyff (2008), 227. This was attributed to the relatively peaceful, liberal and tolerant history that did not necessitate the same fierce struggle for the protection of fundamental rights against a central government as in other countries and originally a rather homogeneous population. Claes and Van der Schyff (2008), 126. Oomen (2011), 30-31.

Claes and Van der Schyff (2008), 136 and 141. Oomen (2011), 35.

Claes and Leenknecht (2011), 306.

Swart (1999), 43. Oomen (2011), 35 and 37.

Oomen (2011), 30.

Oomen (2011), 35-36.

Kuijer (2009), 53. Oomen (2011), 35. Kuijer (2013), 104.

Van Waarden as referred to in Oomen (2011), 35.

Claes and Van der Schyff (2008), 125. Ten Kate and Van Koppen (1994), 144 and 146. The proactive role of the judiciary in relation to euthanasia, abortion and the right to strike was noted. Peters (2009), 117. Uzman et al. argued that Dutch courts have subjected executive action and Acts to 'rigorous fundamental rights review'. Uzman, Barkhuysen and van Emmerik (2010), 1 .

85 Domestic courts follow the 'incorporation theory', whereby interpretations of the ECtHR are read into the provision of the ECHR. The government also considered that the judgments of the 
The Role and Place of Human Rights and State Reporting in the Netherlands

treaty. ${ }^{86}$ Likewise, Swart noted that the impact of ICCPR has 'remained very modest' in comparison with the ECHR. ${ }^{87}$ The ECHR is regarded as the 'chief document for human rights protection' or even a 'substitute constitution'. 88 The ECtHR is seen as another instance of appeal or a 'substitute for a system of domestic constitutional review' ${ }^{89}$ Hence, the ECHR regime has had a profound influence on the administration of justice and the stronger rights culture. ${ }^{90}$

Several political parties and MPs have become more critical about international human rights treaties and monitoring in recent years. International human rights treaties are increasingly viewed as obstructing the implementation of intended policy initiatives, particularly in the field of immigration and integration. ${ }^{91}$ Then VVD Leader in the Second Chamber and the current Prime Minister, Rutte, even referred to 'outdated European treaties' that prevent putting an end to the big flow of migrants. ${ }^{92}$ Especially in the latter field, it has become easier to secure a parliamentary majority for policies and legislation which have been regarded critically from a human rights point of view. ${ }^{93}$ There is also growing criticism among politicians, both in parliament and in government, as to international intervention in domestic affairs as well as domestic court judgments in relation to human rights. ${ }^{94}$ Rutte (VVD) stated that the government should not execute the

\footnotetext{
ECtHR have direct effect as well. Lawson (1999), 99. De Wet (2008), 237. Alkema (2011), 423. Loof (2008), 95. Kuijer (2009), 51.

86 Claes and Leenknecht (2011), 301.

87 Swart (1999), 41.

88 Claes and Leenknecht (2011), 288 and 301. According to Swart, the ECHR is what the national Constitution is for the US and Germany. Swart (1999), 41. See also Peters (2009), 108-109. Kuijer (2009), 85.

89 De Wet (2008), 266. See also Uzman, Barkhuysen and van Emmerik (2010), 5.

$90 \quad$ Swart (1999), 39. Kuijer (2013).

91 Hirsch Ballin (2010). Claes and Gerards (2012), 43. Kuijer (2013), 114. See, for example, Stef Blok and Paul de Krom (VVD), 'Migratie vereist aanpassing internationale verdragen', de Volkskrant, 11 March 2009. Already in 2001, Kamp (VVD) proposed to change the Refugee Convention. TK 2001/02, nr. 21, 1476-1512, 1490. Visser (VVD) likewise noted that the increased internationalisation and treaties could limit the policy freedom of the Dutch legislature with respect to issues such as criminal law, student grants, the CRC and social security. TK 2006/07, 29861, nr. 15. See similar statements of Van Beeten (CDA) in EK 2005/06, nr. 12, 597$607,599-600$.

92 'We moeten een eind maken aan de grote stroom kansarme migranten die hier komen om vervolgens in de sociale zekerheid te belanden. De VVD wil verouderde Europese verdragen die dit belemmeren, veranderen.' Mark Rutte, 'Knok voor vrijheid. De staat moet de baas zijn', NRC Handelsblad, 31 May 2010, 6.

93 Gerards noted that several legislative proposals of the Rutte I government were at odds with human rights. Gerards (2012), 2453. See also Groenendijk in Van Dam (2009), xii. Loof (2008), $119-120$.

94 College voor de Rechten van de Mens (2013), 28. Kuijer (2013), 113. Oomen (2013b), 308. See also the criticism of the VVD as to the judgment of The Hague District Court that the Act which abolished the special social security for artists violated Article 1 Protocol 1 ECHR in Stef Blok, Klaas Dijkhoff and Joost Taverne, 'Verdragen mogen niet langer rechtstreeks werken', $N R C$ Handelsblad, 23 February 2012, 17. Likewise, Visser (VVD) criticised the judgment of the
} 
Salah Sheekh judgment of the ECtHR because other states are also not implementing the Court's judgments. ${ }^{95}$ More recently, the VVD and the PVV, and to a lesser extent the CDA, have been critical about the expansionist power and interpretation of the ECtHR. ${ }^{96}$ At the same time, there is also more and more criticism as to the openness of the Constitution for international developments. ${ }^{97}$ Recently, several liberal MPs from the VVD presented an initiative to prevent too broad an interpretation of human rights treaties by courts by amending Articles 93 and 94 of the Constitution. They proposed to give the government and parliament more possibilities to specify the effect of treaties in order to restore the balance between the legislature, executive and judiciary. ${ }^{98}$

There are several recent developments which have strengthened the domestic human rights infrastructure: firstly, the establishment of the Children's Ombudsman in April 2011; secondly, the Netherlands Institute for Human Rights which replaced the Equal Treatment Commission in October 2012; and thirdly, the first national human rights action plan, which will be published in December 2013. Chapter XI, section 2.2 will give a brief reflection on these developments.

\section{ThE BROADER INFLUENCE OF THE REPORTING PROCESS}

The first sub question under the first research question on the broader influence of the process of state reporting asks whether reporting has been used as an opportunity for human rights review and dialogue. In order to answer this question an overview will firstly be provided of the (bureaucratic) organisation of the reporting process at the national level (chapter IV, section 3.1). This is followed by an overview of the attitudes of government officials towards the value of reporting (chapter IV, section 3.2).

Central Appeals Tribunal that illegal children have a right to social security. He was critical about the political and activist role of the court and the too great an effect of international treaties. Cees van der Laan, "Dan moet de Bijstandswet maar aangepast' Bijstand illegale kinderen', Trouw, 12 August 2005, 4.

95 Rutte as quoted in Loof (2008), 119-120.

96 This discussion was to a large extent instigated by the opinion article of Thierry Baudet, 'Het Europees Hof voor de Rechten van de Mens vormt een ernstige inbreuk op de democratie', NRC Handelsblad, 13 November 2010, 1-2. See, for example, the motion proposed by Çörüz and Omtzigt (CDA) in which they determined that the ECtHR has drastically interfered in national legislation and that countries need room to make their own policy based on national singularities. TK 2010/11, 32500 VI, nr. 29. In a similar way, Stef Blok and Klaas Dijkhoff (VVD), 'Leg het Europees Hof aan banden', de Volkskrant, 7 April 2011, 28. Comparable criticism as to the ECtHR was expressed in the policy note on human rights in foreign policy of the Rutte I government. TK 2010/11, 31735, nr. 1.

97 Van Emmerik (2008), 145.

98 Stef Blok, Klaas Dijkhoff and Joost Taverne, 'Verdragen mogen niet langer rechtstreeks werken', NRC Handelsblad, 23 February 2012, 17. TK 2011/12, 33359-(R1986) nr. 3. 
The Role and Place of Human Rights and State Reporting in the Netherlands

\subsection{The organisation of the process of state reporting}

The Ministry of Foreign Affairs maintains a general overview of the international obligations to report under the UN human rights treaties. This means that the Ministry keeps the contact with and takes care of the correspondence with the treaty bodies and the Secretariat OHCHR in Geneva and also deals with the logistics involved in the sessions in Geneva. ${ }^{99}$ The Ministry of Foreign Affairs also coordinates the compilation of the actual state reports on the basis of the input of other ministries, except for CRC and CEDAW. The writing of the reports and the substantive preparation for the dialogue for these two treaties is undertaken by the Directorate Youth Policy and the Directorate Emancipation respectively. The latter was part of the Ministry of Social Affairs and Employment until 2007 and currently falls under the Ministry of Education, Culture and Science. More recently, the Legislative Department of the Ministry of Justice has increasingly become involved and, for example, conducted the substantive preparation for ICCPR 2009. This was also because the Minister of Justice, Hirsch Ballin, was the head of the delegation. Likewise, the Ministry of Social Affairs and Employment has become more active with respect to the coordination of the report for the CESCR discussed in 2010. ${ }^{100}$

State reports have generally been submitted with delays ranging from eight days (CEDAW 2000) to eight years (ICESCR 2005). Only the 2002 report for CRC was submitted without a delay. The reporting record is worse than in New Zealand and Finland. There has been some improvement since the mid-2000s as a result of a catch-up effort. ${ }^{101}$ The state reports for CRC and CEDAW have had the shortest delays. State reports - and also the COs - are not translated into Dutch, except for some of the state reports for CEDAW and CRC, the CRC COs 2009 and CEDAW COs 2010. ${ }^{102}$ Note that there has not been an update of the core document - which

99 Since 2012, this has been done by the Department of Human Rights and Political-Legal Affairs which is part of the Department of Multilateral Institutions and Human Rights. Before that it was the Human Rights Division (Directie Mensenrechten, Goed Bestuur en Humanitaire Hulp, afdeling Mensenrechten, DMH/MR) in cooperation with the United Nations Division.

100 The head of the delegation during the dialogue in 2010 was Lauris Beets, Director of International Affairs, Ministry of Social Affairs and Employment. The reaction to the COs 2010 was sent to parliament by the Minister of Social Affairs and Employment.

101 CAT 1994 (5 months), CAT 1999 (23 months), CAT 2004 (30 months) and CAT 2012 (5.5 months). ICCPR 1999 (7 years) and ICCPR 2007 (9 months). CEDAW 1998 (26 months), CEDAW 2000 (8 days), CEDAW 2005 (6 months) and CEDAW 2008 (3 months). ICERD 1997 (6 years), ICERD 1999 (28 months), ICERD 2003 (29.5 months), ICERD 2008 (12 months) and ICERD 2012 (due since January 2013). ICESCR 1996 (4 years), ICESCR 2005 (8 years) and ICESCR 2007 (12 months). CRC 1997 (9 days), CRC 2002 (on time), CRC 2007 (3 months) and CRC 2012 (due since March 2012).

102 The CRC state reports of 2003 and 2007 were published in Dutch as well. UN Doc. CRC/C/117/ Add.1 (2003), para. 10. CRC/C/NLD/3 (2008), paras. 18-19. A popular version of the initial state report under CRC was also made. TK 1998/99, 26200 XVI, nr. 5, 54-55. The second and third state reports for CEDAW (1999 and 2000) were written in Dutch. For the translation of CEDAW COs 2010 see the attachment to TK 2009/2010, 30420, nr. 154. 
outlines a country's general political structure and its legal framework for the protection of human rights - since December 1995 for the European part of the Kingdom. ${ }^{103}$

No public consultations with respect to the compilation of the state report have taken place on a formal or regular basis, as in Finland or New Zealand. This is the result of a clear separation between the state report - which is compiled by the government - and the parallel NGO reports. There is no direct input from NGOs in the state report itself and comments of NGOs or other organisations are not included in the state report. Some NGOs (representatives) emphasised that this strict division is crucial in the light of their different roles and is necessary to preserve their independence from the government. As will be discussed in subsequent chapters, NGOs and the government have sometimes discussed the alternative report and the government's state report prior to the dialogue with the treaty body. This has especially happened for the CRC and CEDAW. ${ }^{104}$ Note that some NGOs received funding from the government for the purpose of making a parallel report (in the case of CEDAW) or general funding for monitoring the implementation of the Convention (CRC).

It is noteworthy that the involvement of members of government as the head of the delegation of the Netherlands, during the dialogue with the treaty bodies, is relatively frequent in comparison with New Zealand and Finland. The delegation for CEDAW 2001, 2007 and 2010 and CRC 2004 and 2009 were headed by the Minister or State Secretary responsible for emancipation affairs and youth affairs respectively. ${ }^{105}$ As said before, the Minister of Justice led the delegation for ICCPR 2010. For the other treaty body sessions, the head of the delegation has traditionally been a diplomat from the Ministry of Foreign Affairs from The Hague or the Permanent Representative in Geneva or New York. More recently, delegations were led by high-ranking civil servants from another ministry. ${ }^{106}$ The continuity of government officials involved in the reporting process has been more limited than in Finland. There have only been ten officials who have attended more than three treaty body dialogues, while only two attended five sessions. ${ }^{107}$

103 UN Doc. HRI/CORE/1/Add.66 (1996).

104 For example, prior to the dialogue in 2006, the NGOs who prepared the shadow report to the third ICESCR report were invited by the government to get to know the government officials who were going to represent the government during the dialogue. Ideas were exchanged on the objectives, procedures and the follow-up of periodic state reporting as well as the content of the state report. This has also happened with the ICCPR report of 2009 and CEDAW 2010.

For CEDAW, State Secretary of Social Affairs and Employment Verstand-Bogaert in 2001, Minister of Social Affairs and Employment De Geus in 2007 and State Secretary of Education, Culture and Science Dijksma in 2010. For CRC, State Secretary of Health, Welfare and Sport Ross-van Dorp in 2004 and Minister for Youth and Families Rouvoet in 2009. For CERD 2010, Haimé, Director of Integration from the Ministry of Housing, Spatial Planning and the Environment. For CESCR 2010, Beets, Director of International Affairs, Ministry of Social Affairs and Employment.

107 The only two officials who attended five different sessions were: Claudia Staal (Ministry of Social Affairs and Employment): ICESCR 1998, ICCPR 2001, CRC 2001, CERD 2001 and 2004. 
There is no mechanism for structural follow-up to COs. All ministries themselves are responsible for follow-up measures. The coordinating ministry merely asks the other ministries for a (substantive) reaction to COs for the purpose of informing parliament. No further initiatives are usually undertaken in addition to this reaction. Interdepartmental meetings to discuss the COs are only convened on an ad-hoc basis 'if this is deemed useful'. ${ }^{108}$ In practice this has hardly ever happened. There is also no mechanism to check the follow-up to COs periodically. ${ }^{109}$ The Ministry of Foreign Affairs, who is the 'focal point' for the implementation of the COs for the treaties, except CRC and CEDAW, does not consider itself well placed to monitor whether and how the other ministries implement the COs that almost always deal with domestic issues. ${ }^{110}$ The Directorate Emancipation has also not exercised control over nor has it put pressure on the responsible ministries with respect to the actual implementation of COs of the CEDAW Committee. ${ }^{111}$

\subsection{The attitude of government officials towards the process of state reporting}

\subsubsection{The value of reporting}

During interviews, government officials were asked about their (individual) ideas concerning the importance of state reporting. The first view, which prevailed among officials from the Ministry of Foreign Affairs, is rather pragmatic. State reporting is primarily seen as a matter of compliance with an international obligation to report. Government officials who took this first view saw little reason to (critically) reflect upon oneself, at least in the context of state reporting. Some government officials even argued that UN human rights treaties and the process of state reporting are first and foremost (truly) relevant for other (developing) countries. Reporting is only seen as a necessary prerequisite for having other countries to be subjected to some form of international scrutiny. There is an idea that the Netherlands has to fulfil an exemplary function. Former Minister of Foreign Affairs Verhagen, for example, stated that: 'the good performance of the Netherlands in the field of human rights is of direct relevance to the credibility of

Robbert Moree (Ministry of Social Affairs and Employment): ICESCR 2006 and 2011, ICCPR 2009, CRC 2009, CEDAW 2010.

$108 \mathrm{UN}$ doc. CAT/C/NET/Q/4/Rev.1/Add.1 (2007), para. 83.

109 There is no permanent interdepartmental mechanism for screening ECHR and UN human rights jurisprudence. Loof (2008), 101-102. Kuijer (2009), 61.

110 UN doc. CAT/C/NET/Q/4/Rev.1/Add.1 (2007), para. 82.

111 It was noted that the Directorate Emancipation hardly 'monitors' follow-up. The Directorate does not have the power to overrule other ministries or to impose a specific course of action. 
the foreign policy on human rights. Recommendations of UN treaty bodies are therefore taken very seriously'. ${ }^{112}$

A slightly more ambitious view on the importance of reporting underscores the need for accounting for one's actions and explaining certain policy choices. Government officials who took this position mentioned that the process of state reporting forces the government to justify why certain policy choices were made and to reflect on the necessity of these policies in the light of other considerations. The state report gives a cross section or a snapshot in time of policy initiatives and legislation and the state of implementation of the treaty at the domestic level. The process of state reporting thus functions as a touchstone, whereby treaty bodies act as a mirror forcing one to reflect on and question self-evident notions. These government officials valued the confrontation with outsiders, at least in principle. They at least understood the need of explaining national policies and legislation at the international level, even though they are considered to be self-evident and indisputable domestically.

It is noteworthy that government officials of the Directorate Youth Policy, which is responsible for the coordination of the process of state reporting under the $\mathrm{CRC}$, were generally more positive about the importance of reporting. They, for example, emphasised that the process of reporting and the resulting COs are not seen as a critique alone but that they can be used as positive feedback to improve policies further. One explanation for the more positive view is that reporting under the CRC is relatively better embedded in a continuous and interactive process and dialogue between NGOs and the government at the national level. Another explanation for this more positive attitude might be that the officials of the Directorate Youth Policy are almost exclusively involved in reporting under this treaty and suffer less from evaluation fatigue. By contrast, Ministry of Justice officials, who are involved in the reporting for all UN human rights treaty bodies, were more negative. ${ }^{113}$ A few government officials expressed similar positive views in relation to reporting in the context of CEDAW in the end of the 1990s. These officials recognised the (strategic) value of CEDAW. In that period, national reports and in-depth studies were conducted on the implementation of CEDAW. According to officials, this national process meant that state reporting itself also had a clear purpose. ${ }^{114}$ This process

112 'Dat Nederland zelf goed presteert op het gebied van mensenrechten is van direct belang voor de geloofwaardigheid van het internationale mensenrechtenbeleid. Aanbevelingen van VN-verdragscomités worden dan ook zeer serieus genomen'. TK 2007/08, 31263, nr. 10, 1. Brenninkmeijer (2010), 277.

113 This reflects the fact that the great majority of the issues dealt with under the six treaties relate to the policy areas for which the Ministry of Justice is responsible. The Legislative Department responsible for the coordination of the input of the Ministry of Justice is primarily focused on the cases against the Netherlands before the ECtHR. Reporting under UN human rights treaties is done in between. It is therefore no surprise that reporting is primarily seen as an administrative burden.

114 A good illustration of this is the second state report, which was structured on the approach adopted by the Groenman Committee who drafted the first national report about the 
has had a more limited scope since 2004 (see chapter VIII, section 1). Government officials involved in the latest reporting cycles of CEDAW (2007 and 2010) were equally critical - and sometimes even more critical - about the importance, usefulness and contribution of state reporting. In sum, when the process of state reporting is integrated in a national process of reporting (CEDAW in the 1990s) or a continuous dialogue with civil society and parliament (CRC), government officials are more positive about the importance of the exercise of reporting.

\subsubsection{The importance given to reporting in practice}

The government officials that were interviewed admitted that the importance they attach to reporting is greater than it had actually been in practice. Reporting by and large does not receive the necessary political priority by members of governments leading the ministries, with some exceptions. ${ }^{115}$ It is seen by most departments as an administrative burden, a necessary evil or doing the chores. ${ }^{116}$ There is a considerable amount of evaluation fatigue. Almost all government officials lamented that the process of state reporting is extremely labour-intensive and an enormous amount of work. Government officials mentioned in this context the duplication of supervisory and monitoring mechanisms and overlapping obligations to report in the context of the EU, Council of Europe (CoE), ILO and other evaluation mechanisms at the UN level. Several interviewees pointed out the low priority given to state reporting by the Ministry of Foreign Affairs in particular. The task of reporting has shifted rather frequently over the years and has often been entrusted to interns. ${ }^{117}$ The institutional memory with respect to state reporting is consequently low. ${ }^{118}$ Another indication for the low priority accorded to state reporting is that, especially during the earlier reporting cycles, the exercise of compiling and coordinating the input of the state report was usually allocated to a junior clerk. Another reason for or illustration of the low priority given to reporting is that the actual reporting is often done by officials working in policy departments who are more focused on the national policy making domain. For substantive input, they are dependent on the cooperation of officials from other policy departments. The latter officials always give the domestic political process and parliament priority above the numerous reporting requirements at the international level. In

implementation of CEDAW. UN Doc. CEDAW/C/NET/2, 4-5. Van den Brink and Jacobs (1994).

115 Several government officials of the Ministry of Justice mentioned that Minister Hirsch Ballin (CDA) (2006-2010) and State Secretary Albayrak (PvdA) (2007-2010) highly valued the process of state reporting. They, for example, wanted to have the report submitted for approval in order to have the opportunity to pass comments, which they also did. With other members of government it was said to be more difficult to persuade them that the process is important and useful. approached as a burden (last). College voor de Rechten van de Mens (2013), 39-41.

117 See also Redactioneel (1998b), 421.

118 See also Redactioneel (1998b), 419. 
addition, these officials are seldom aware of the international obligations and the context and process of state reporting under the treaties.

Another difficulty inherent in the process of state reporting is that it is retrospective in nature. State reports are concerned with a certain period of time, often a couple of years ago. This conflicts with the orientation of government officials on current political events. The necessity of reflecting on certain problems that have already been solved long ago was often unclear for these officials. In addition, policy choices or the societal context might have changed altogether at the time of compiling the report. Hence, contributions for periodic state reports do not enjoy a high priority in the light of all the other activities and are often done in between.

As a result, compiling the report has often been a difficult logistic process for the coordinating government officials to get decent texts and the requested information in time. ${ }^{119}$ Deadlines have often not been met, which required coordinating officials to send reminders, sometimes several times. In practice reporting is usually a rushed job and primarily a copy and paste exercise of information which had already been sent to parliament or other international organisations before. Departments have often sent long and descriptive policy expositions that needed considerable rewriting to take into account the international context. This might explain why the great majority of state reports are primarily legalistic and descriptive. ${ }^{120}$ Reports have usually consisted of nothing more than a bare and random enumeration of policy and legislative initiatives which are linked to the treaty in an unclear and trivial way. ${ }^{121}$ Oomen noted that only in communications that have an international human rights monitoring mechanism are policy or legislative efforts 'brushed up and explicitly related to human rights'. ${ }^{12}$ Government officials made clear that there is no overarching idea behind the report. There has hardly been any integrated or interdepartmental discussion about the structure or content of periodic reports. Consequently, the way reporting is carried out means that there is no time or possibility to truly reflect on policies and legislation and no genuine willingness to learn. Government officials doubted whether the reporting process has been and could be used for in-depth and critical policy evaluations and an analysis of dilemmas and problems in the implementation of a treaty. ${ }^{123}$

119 Note that the great majority of government officials interviewed are working in departments responsible for international affairs and simply coordinate the input for the report for their entire ministry.

120 See also Coomans (1998), 941 and 945. Van Boven (2005), 117. Van den Brink and Jacobs (1994), $745-746$.

121 Van Dooren found that CERD and CEDAW have hardly been considered in policy and law making, but that the treaties are suddenly linked with national legislation in the periodic state report. Van Dooren (2007), 60. anyone reading documents such as the 2008 UPR report. Oomen (2013b), 299. 
The latter also illustrates that reporting has not been approached as a cycle. As was mentioned before, a structural mechanism of follow-up to COs is lacking. After one cycle of state reporting is completed, officials move on to other activities. There is an inclination to 'wake up' by the time the deadline for submission of the subsequent state report is approaching. An illustration of the course of events is that, at the time when the interviews were conducted in June 2011, one government official mentioned that it was discovered by chance that the deadline for the submission of the next report for CAT was due shortly.

The previous paragraphs beg the question whether reporting is taken seriously. The amount of time dedicated to the compilation of the state report and answering the LOI is significant. There is a clear willingness to provide the committees with the requested information and data and offer a comprehensive and proper explanation. In addition, the delegations are large which illustrate that all the ministries consider it important enough to delegate at least one official as a representative. As was mentioned before, a minister or state secretary has acted as the head of the delegation on several occasions as well. The preparation for the actual dialogue is also extensive. Delegates arrive with thick files with all the information that could be asked for. Q\&A's are prepared beforehand, often on the basis of the issues dealt with in the NGO reports. Government officials usually arrive one day before the actual dialogue to discuss the course of events and the most delicate issues with each other. During the days of the treaty body sessions, officials often work well into the night to answer the questions posed by committee members. Furthermore, colleagues in The Hague are on stand-by in case additional information and data is needed.

In this light it is not surprising that some government officials observed that the discussion of the state report in Geneva seems to be taken more seriously than the compilation of the state report itself. Obviously, the dialogue has more direct and immediate consequences for the COs. There is a clear and more urgent need to give good answers since not doing so will affect the tone of the COs. The aim of the dialogue is - according to government officials - to get as few critical and unpleasant COs as possible and avoid screaming headlines at the same time, since critique might have (domestic) political consequences for the members of government. The idea is that political damage in the form of negative attention in newspapers and parliament should be averted. ${ }^{124}$ Partly as a result of this intention to avoid that the government is put in bad light, the exercise of state reporting is not used for presenting the dilemmas the state is confronted with or for asking treaty

124 A manual ('Handleiding rapportages aan VN verdragcomités') compiled by the Legislation Department of the Ministry of Justice about reporting to the UN human rights treaty bodies for government officials of the Ministry of Justice explained the importance of reporting on time and thoroughly by pointing to the potentially big spin-off effect of the process of state reporting. According to the manual, COs are given attention in the media and are called upon by NGOs and MPs to put an issue on the agenda. It is noted in this context that poor reporting produces extra work and bad press. Dutch Ministry of Justice (2009), 1. 
bodies for suggestions. The government delegation also stated during the dialogue with CESCR that identifying the areas in which the government was encountering difficulties might not always be possible, because it is not natural for a civil servant to show his or her disagreements with the policy of his or her employer, the state. ${ }^{125}$ The dialogue with the treaty bodies is therefore primarily seen as a 'defence' or a 'country-examination', whereby the main objective is to give 'a good answer' to the critical questions of the Committee. ${ }^{126}$

\section{The VIEWS OF GOVERNMENT OFFICIALS ABOUT THE QUALITY OF TREATY BODIES AND THE COS}

This section will sketch the view of government officials concerning the process of state reporting and the performance of the committees. Some issues highlighted are structural deficiencies or limitations in the system, while other aspects relate more to the functioning of specific committees and expert members. Many of the views coincide with the critical aspects mentioned by other scholars and observers as discussed in chapter I, section 2.2. Note that this section does not assess whether the views expressed are fair and valid. The main idea behind focusing on the perception of government officials is to illustrate that officials are not persuaded to act upon the COs and that there is, hence, no compliance pull. The critical and sometimes dismissive views also demonstrate the earlier mentioned attitude of defensive self-righteousness rather than an open-minded attitude and a willingness to learn (chapter IV, section 3.2). Many of the issues discussed in the following subsections will be elaborated on in the six treaty specific chapters (chapters V-X).

Government officials were almost equally critical about the functioning of the six different UN human rights treaty bodies. That is to say, they were not significantly more positive about the functioning, quality or authority of one specific Committee. ${ }^{127}$ They primarily stressed the archaic, bureaucratic and inefficient procedures and the lack of uniform working methods between the several treaty bodies. Government officials did not focus on qualitative differences between committees, but they emphasised above all the differences between individual expert members within treaty bodies. Government officials distinguished between prominent scholars with a solid reputation, on the one hand, and the less qualified and ignorant members of the committees who were politically appointed, on the

125 UN Doc. E/C.12/1998/SR.14 (1998), para. 8 and 10.

126 This was also noted by NGO representatives. See also TK 2006/07, 30420, nr. 24. TK 2007/08, 30420 nr. 61, 7. TK 2008/09, 30420, nr. 136, TK II 2009/10, 30420 nr. 141.

127 Government officials were more critical of ICESCR 1998, CRC 1999, ICESCR 2010 and CEDAW 2010. Some government officials argued that the HRC is the best and most serious committee with the highest status. ICERD 1998 and 2000 were also singled out by some in terms of quality. 
other hand. ${ }^{128}$ The majority of government officials were able to put the latter into perspective by arguing that this is inherent in an international organisation with universal membership, but some dismissed the entire committee on the basis of only a couple of disputable expert members, questions or COs.

Some government officials were clearly more negative than others. There were hardly any noticeable differences between departments or ministries. Where opinions seem to be divided most is the issue of the level of preparation. Some government officials argued that treaty bodies were well prepared and had read all the documents, while others were more negative and pointed to the lack of preparation of the great majority of expert members. The former group of government officials showed their respect for the ability of some expert members to identify problematic issues and difficulties, especially in the light of the fact that treaty bodies have to acquaint themselves with a varied number of countries in a relatively short period of time. Other more critical government officials pointed to a couple of uninterested individual members that did not ask a single question and were above all busy with other issues such as submitting an expense account, reading a newspaper or drawing figures.

\subsection{The irrelevance of the dialogue}

Government officials were rather negative about the usefulness of reporting and the dialogue as a result of the structural backlog in consideration by the treaty bodies of the reports submitted by states. They pointed to the long time span between the submission of the report and the actual dialogue, during which a lot of new developments had taken place. Officials argued that when the dialogue and the COs are based on outdated and superseded information, this diminishes the value of the entire process. ${ }^{129}$ In this context, government officials gave the example of the combined seventeenth and eighteenth report of CERD, which covered the period between 2002 and 2006 and which was only discussed in 2010. This was also one of the reasons that the responsible minister for integration was not very eager to be the head of the delegation.

Government officials also mentioned the duplication of issues between the various treaty bodies, irrespective of the special focus of the respective treaty. ${ }^{130}$ Several examples were given of issues that were considered by all treaty bodies, such as domestic violence, human trafficking, violence against children and alien

128 Several government officials mentioned the lack of independence of a great number of expert members as a factor influencing the authority of the committees. It was noted that several members are former or sometimes even incumbent ministers or government officials, while other experts also have clear connections to a government. that this saves time and makes reporting and the dialogue with the Committee more focused.

130 It was, for example, noted that CERD is targeted at a specific issue, racial discrimination, but that this is broadly construed in practice. 
detention. Within less than two years, the Dutch government, for example, discussed almost all of these issues with five different treaty bodies: with the CRC Committee (January 2009), the HRC (July 2009), the CEDAW Committee (January 2010), CERD (February 2010) and CESCR (November 2010). Some officials argued in this context that treaty bodies at times stretch their mandates beyond the text of the respective treaty. An example given was the consideration of the asylum policy by the CERD. ${ }^{131}$

In addition, the dialogues were also said to focus sometimes on - at least for the Netherlands - irrelevant, minor or unproblematic issues instead of the dilemmas policy makers are confronted with. Almost all government officials showed their disappointment that the discussion often focuses on Dutch 'liberal' practices such as abortion, euthanasia, prostitution, same-sex marriages, and the drugs policy that are of a more political nature. ${ }^{132}$ Likewise, officials also considered that the discussion about breastfeeding that lasted a half an hour during CRC 2004 was not very useful. It was also mentioned that the dialogue often concentrates on current (political) affairs and not so much the (implementation of the) respective treaty and all the submitted information which required a lot of work. The discussion of these issues was considered to be a pity by officials and NGO representatives, since there were dozens of other issues that were at that moment more pressing to discuss. Government officials noted that the discussion of the Dutch 'liberal' issues is often rather emotional, because many of the practices are illegal in other countries. ${ }^{133}$ Several government officials, for example, qualified the questions posed by the American expert member during the dialogue with the HRC in 2009 about euthanasia as emotional and political. Not only did Wedgwood refer to her own demented father, but she also drew a parallel between the European criticisms of the EU on the death penalty in the US. According to government officials it is difficult to get such principled or political issues explained, because expert members are more led by prejudice and mistrust than facts and arguments. The feeling prevails among government officials that it is difficult or sometimes even nearly impossible to get Dutch policies or the national context explained, due to a lack of understanding on the part of the treaty body.

Another aspect which results in the reporting process being seen as lacking relevance is the view of government officials that the process is rather repetitive and predictable. They usually know beforehand what the questions and COs of the Committee will be on the basis of the parallel report and a compilation of previous

131 UN Doc. CERD/C/64/CO/7 (2004), para. 14. UN Doc. CERD/C/NLD/CO/17-18 (2010), para. 11.

132 Government officials mentioned these points especially in relation to CRC 1999, CRC 2004, ICCPR 2001 and ICCPR 2009. The issue of prostitution was also discussed extensively with CEDAW in 2001 and 2007.

133 It was also noted that with respect to these principled issues it is difficult to get closer to one another, since the policies have often been the result of compromises at the national level which were reached with difficulty. The government has, thus, made a conscious policy choice to do it differently so that there is hardly any room for arranging it differently, in line with the view of the treaty bodies. 
COs and the COs of other treaty bodies. Committees hardly raise any new issues or startling disclosures. The thorny issues have often already been discussed at the national level in parliament or with NGOs. The constructive dialogue has, in the view of government officials, hardly any added value in terms of enriching the discussion substantively or giving the delegation food for thought. It was said that the discussion focuses more and more on the same issues the government is unwilling to change. This means that the same answer is given over and over again to the treaty bodies. ${ }^{134}$ As a result of this, paper is being pushed around without any concrete result. The fact that several treaty bodies are seen as digging their heels in also precludes a real dialogue from taking place and decreases the importance and relevance government officials attach to state reporting. Officials argued that this has also negatively affected their enthusiasm. Especially in relation to CEDAW, it was mentioned that this repetitiveness and the standstill in discussions has led to negative energy.

\subsection{The superficiality of the dialogue}

It is not so much the (legal) expertise of the expert members that has been doubted by the interviewees but above all the limited time for experts to acquaint themselves with all the subtleties of the countries being reviewed, given their full-time jobs in addition to their work as experts. That is to say, government officials lamented the fact that several of the committees' questions were rather basic or showed a limited knowledge of the national context. ${ }^{135}$ This criticism should, however, be put into perspective. The Dutch government has not updated its core document outlining its general political structure and its legal framework for the protection of human rights since December 1995. ${ }^{136}$

Almost all government officials mentioned that a lot of committee members do not succeed in viewing the situation in the Netherlands dissociated from their own national context. Officials argued that it is difficult to have a proper discussion and truly understand each other as a result of cultural and legal differences and the fact that several concepts and notions have a different meaning depending on the national context. During the discussion with CEDAW in 2010, there was a question by the Chinese delegate about isolation problems among elderly rural women as a consequence of a lack of public transport and community involvement. ${ }^{137}$ This example was given by almost all government officials as an example of a question

134 One official noted that a rear-guard action (achterhoedegevecht) is fought on points were little political consensus exists to do it differently. Another government official also spoke about a 'paper tiger', whereby the discussion focuses more and more on the same issues that had been explained sometimes more than ten times by the government, because of a lack of understanding, knowledge, ignorance and bias on the part of the CEDAW Committee.

135 This was also noted by several NGO representatives. See also Dutch Ministry of Justice (2009), 9.

136 UN Doc. HRI/CORE/1/Add.66 (1996).

137 UN Doc. CEDAW/C/SR.917 (2010), para. 34. 
which allegedly shows a limited understanding of the Dutch context. Another example which was given several times were the questions posed by CERD about the situation of the Frisian minority. Another government official gave the example of a question by an expert from the Philippines during the dialogue with CEDAW in 2007 whether pregnant girls are expelled from school.

Related to this is the focus of committee members on their personal preferences and hobbyhorses. ${ }^{138}$ Several government officials noted that expert members frequently please their own agendas or ask questions for the sake of asking a question instead of monitoring whether the Netherlands is complying with its obligations. One government official gave the example of a great number of questions about social security itemised for each vulnerable group which necessitated an exposition of the entire Dutch social security system. After the dialogue, the expert member thanked him/her for this explanation and explained that she wanted to learn from it personally, since the social security system was not that well organised in her own country. Another government official referred to the Belarusian expert member of CESCR who only asked questions about human trafficking, in his/her view, to mask the absence of a human rights policy in Belarus by pointing to the alleged 'good' policy on human trafficking in his own country. The result of this focus on hobbyhorses is that an integral and comprehensive overview of the situation in a country is often lacking.

As a result of cultural differences, the lack of basic background knowledge and the hobbyhorses is that the dialogue often remains at a superficial level. Officials noted that a lot of time is often lost simply with the introduction, general country information and explanation of basic issues. This was not only considered a pity but also a waste of time. A complicating factor in this context is the language barrier, especially with respect to technical jargon and tricky issues in relation to which nuance is often indispensable in order to avoid misunderstandings. The command of English of some government officials is not always sufficient to explain details and subtleties.

Several government officials also pointed to the fact that committee members often have general human rights knowledge, but they lack (technical) expertise in the field of certain issue areas. Consequently, the criticism of treaty bodies concerning these issues is not seen as problematic. For example, CESCR's comments on social security, poverty reduction and labour standards are considered to be of limited value, especially compared with the level of detail of EU legislation or the expertise of the ILO. In this context, several government officials pointed to the CESCR expert member that did not want to talk about the 'labour market', because this concept is too capitalistic. Some government officials also pointed to the limited expertise of the CEDAW Committee with respect to labour market issues. 
The Role and Place of Human Rights and State Reporting in the Netherlands

\subsection{The absence of a constructive dialogue}

Almost all government officials noted that the delegation is usually bombarded with questions which often cover a broad and varied number of issues. ${ }^{139}$ Such a barrage of questions was seen as unproductive, since there was sometimes hardly any time to think over and get feedback from the department in The Hague. As a result, some answers were sometimes simply rattled off or answered with superficial generalities. ${ }^{140}$ At the same time, it was seen as practically impossible to have an answer for all questions asked, given the limited amount of time for the dialogue. This is further aggravated by the fact that often all questions had to be answered for all the three autonomous parts of the Kingdom of the Netherlands. Hence, the great number of questions and the 'dishing out of answers' has the result that a real dialogue and an interactive discussion is nearly absent in the view of government officials. Some even qualified the dialogue as an interrogation. Since discussions often focus on an great number of different issues, an in-depth debate on specific issues does not take place.

Another aspect which resulted in the dialogue not being constructive, according to government officials, is the over-critical approach of some treaty bodies. With respect to the session with the CRC Committee in 1999, officials noted a rather negative atmosphere in which the Committee approached the delegation in an undeservedly critical, tendentious manner and without respect. One official spoke about the sneering and conceited remarks about the 'rotten' policy in the Netherlands. Several officials specifically signalled out the attack of the Indonesian Chair, allegedly based on personal feelings owing to the colonial past. The CEDAW Committee was also said to be too negative, with a whole shopping list of complaints, while it had hardly any compliments, especially during the dialogue in 2010. In the view of government officials, this approach and the long length of the COs do not do justice to the reality that the Netherlands is still a model country with respect to the emancipation of women. A fierce and often prejudiced attitude and an alleged desire among members to close down on a rich country that is always beating the big drum was also noted by some officials with respect to the CRC 2004, ICESCR 2010 and to a lesser extent ICCPR 2001. The latter is also reflective of the feeling of almost all government officials that treaty bodies often adopt more rigorous standards for Western countries. There was some irritation about the focus of treaty bodies on details and a couple of remaining small issues, while the treaty obligations are largely complied with. Several government officials held that there are hardly any governmental measures that are a (clear) violation of a treaty. It was held that COs contain (complementary) suggestions, but that does not mean that the measures in certain policy areas are necessarily

139 This was also noted by several NGO representatives. See also Dutch Ministry of Justice (2009), 10.

140 Van Boven also noted that the answers of the delegation during the dialogue with CERD in 2004 were often couched in officials jargon and hardly served to give an insight into policy dilemmas and implementation problems. Van Boven (2005), 114 and 117. 
contrary to treaty. It was pointed out that with several of the points criticised by the committees it is often possible to hold different views that are also legally justified.

\subsection{The limited quality and specificity of COs}

Both government officials and NGO representatives mentioned the limited specificity of COs, which in their view would primarily explain their limited impact and effectiveness. COs are seen as sweeping statements of a general nature with which little can be done. It is often unclear what kind of measures treaty bodies have in mind and how a certain practice can be improved. Interviewees noted that COs are usually rather concise and lack argumentation and reasoning. They argued that COs should include a more careful outline of the problem and a more detailed explanation. COs should also indicate a specific course of action, include concrete and realistic suggestions and helpful advice, for example by pointing out best practices. COs should also give due account of and fit in with the specific national societal and policy context. Government officials stressed that COs are useful when they give concrete instead of abstract recommendations that are difficult to grasp. Both government officials as well as NGO representatives also argued that the government can easily set aside those general COs or it can simply claim that something is already done about it since COs allow for different interpretations. The government can also be held accountable by both the Committee as well as NGOs when COs are more specific.

What is more, government officials were often highly indignant about the COs. They had the feeling that they could not get some issues explained. In their view, this might be because committees simply have not listened to some of their answers. Another reason given is that committee members might not have understood everything correctly. Be that as it may, according to government officials, COs insufficiently render account of the position of the government since they simply repeat what treaty body members said during the dialogue. Officials had the idea that little is done with the dialogue and the information from the government. Officials sometimes had the impression that the COs were already completed before the actual dialogue. ${ }^{141}$ What was also considered questionable was that sometimes recommendations were given on points that were not discussed in Geneva. According to government officials, these aspects clearly diminish the quality, relevance and usefulness of COs.

Almost all government officials and NGO representatives noted the heavy - and sometimes almost exclusive - reliance of expert members on the information

141 This issue was especially raised in relation to CEDAW 2001, CEDAW 2007, ICCPR 2009, ICERD 2010 and ICESCR 2010. Several government officials mentioned that they had seen the draft COs of CERD 2010 lying on the desk of expert members and noted that - at least the first page - matched the final version of the COs. Government officials also had the idea that some concerns or conclusions were not recalled on the basis of the clarification offered by the governmental delegation. 
provided by NGOs in their parallel reports. This was attributed to the limited possibility and time for expert members to prepare themselves. Questions or recommendations of NGOs are sometimes even literally read out or included in the LOI or COs. Although this is understandable given the time constraints under which experts operate, officials, nonetheless, criticised the committees for taking over the criticism of NGOs too easily without questioning it or caring out their own research as to its accuracy. Government officials considered this to be problematic, because the information is regarded as one-sided and often representing only one interest. Some government officials consequently characterised some committees as rather activist and argued that they sometimes neglect the legal accuracy. This was especially said of these committees that focus on one clear target group, such as the CEDAW and CRC Committees. The CEDAW Committee was, for example, seen as holding 'a single issue campaign' by only adopting an empowerment and emancipation perspective.

Government officials also criticised the over-simplification and (legal) inaccuracy of some COs. COs sometimes contain clear factual errors despite clarifications during and after the dialogue. Several government officials made clear there is usually at least one purely factual error in the draft COs sent to the government for correction before their official publication on the website of the $\mathrm{OHCHR}$, and sometimes there are even two or three. The most extreme example is the recommendation of the CESCR in which it was concluded that the Dutch state pension is discriminatory against migrant workers and that there was a risk of poverty for pensioners. In a letter to the Committee, the head of the delegation expressed in rather strong words its 'deepest' and 'sincere' concerns about the way the Committee had arrived at its conclusions, which 'are based on a misunderstanding of the facts' and in relation to which 'no reasoning nor factual information' is provided. ${ }^{142}$ The head of the delegation further stressed that he was surprised that (additional) information sent by the delegation after having read the draft COs had not given rise to modification of the COs. The letter once again explained the Dutch pension system in order to show that there are "no objective factual grounds' for the COs and, therefore, asked the Committee to reconsider its COs. Government officials made clear that this 'incident' is fatal for the image of CESCR, since this is the only thing government officials, managing directors and members of government remember about the UN human rights treaty bodies in general and CESCR in specific. This was said to undermine the credibility of the instrument and lead to negative energy and emotions. These officials also noted that it was made more difficult for the coordinating Directorate to show the need and importance of participating genuinely in the process of state reporting. They argued that the authority and importance of the UN human rights treaty bodies was consequently difficult to convey to other government officials who did not form part of the delegation.

142 Letter sent by Beets on 6 December 2010: <www2.ohchr.org/english/bodies/cescr/docs/ CommentsNetherlands_Dec.2010.pdf>, accessed 31 July 2013. 


\section{Conclusion}

This chapter presented several preliminary findings which will be explored more thoroughly in the following treaty specific chapters. The first conclusion is that reporting enjoys a low priority in the Dutch government administration. There is a considerable evaluation fatigue as a result of overlapping reporting requirements in the context of the EU, CoE, ILO and the UN. Reporting is seen as a burdensome and labour-intensive task which is preferably entrusted to an intern. It is not approached as an opportunity for review and improvement. Reflective of this is also the absence of a mechanism which ensures or monitors follow-up to the COs. Many government officials see reporting as something which is primarily relevant for other countries with a worse human rights record. There have, however, been differences between several ministries and directorates with respect to the importance of reporting. Government officials from the Directorate Emancipation and the Directorate Youth Policy have attached more (strategic) value to, respectively, (reporting under) the CEDAW in the 1990s and the CRC in the late 2000 s. A second preliminary finding is that a compliance pull is generally absent for the treaty bodies and the COs as a result of which officials are not persuaded to act upon the COs. This is because Dutch government officials were rather negative about the quality and functioning of the six treaty bodies, the constructive dialogues in Geneva or New York and the COs. They, for example, pointed to the basic and limited knowledge of several treaty body members about the national context and the poor preparation of some members which consequently results in general and vague COs. They also noted the irrelevance and superficiality of the dialogue, which was not considered to be constructive either. Officials also lamented the onesided approach of treaty bodies and the fact that they easily take over the information and criticism of NGOs. A third preliminary finding is the dominance of the ECHR and 'Strasbourg' in the Dutch legal order. It would be interesting to examine whether the alleged chilling effect of the ECHR and the fact that it is seen as the (maximum) human rights standard also downplays the impact and effectiveness of UN human rights treaties and the COs of the treaty bodies. 


\section{Chapter V ICERD}

'Studies are constantly being published that accuse us of discrimination. But Dutch people are not at all likely to discriminate. We have been a welcoming people for centuries.'

[Former Minister of Immigration and Integration Verdonk in 2008] ${ }^{1}$

This chapter examines the impact and effectiveness of the COs of the CERD. The CERD has considered the implementation of ICERD by the Netherlands four times since 1995. ${ }^{2}$ The COs 1998, 2000, 2004 and 2010 addressed, among others, the situation of the only recognised official minority (the Frisians) and the unemployment among ethnic minority groups. ${ }^{3}$ Other issues that have been dealt with over the years include racial segregation in schools and neighbourhoods, the high number of minority people leaving the police forces, xenophobic, anti-Semitic and Islamophobic incidents, the civic integration examination and the asylum policy.

This chapter also shortly compares the findings for CERD with the three reports on the Netherlands by the European Commission against Racism and Intolerance (ECRI), a CoE institution established in 1994. ${ }^{4}$ ECRI issued several recommendations which are similar to the COs of CERD and cover more or less the same period (1998, 2001 and 2008). ${ }^{5}$ The government has provided a relatively extensive reply to some of ECRI's recommendations. This reply has also been used, among others, in the assessment of the effectiveness of CERD's COs.

\section{DOMESTIC IMPACT AND DOMESTIC MOBILISATION}

\subsection{Governmental attention}

The government has hardly informed parliament about the process of state reporting under ICERD. The Minister of Foreign Affairs sent the combined fifteenth and

1 'Er verschijnen steeds onderzoeken die ons van discriminatie beschuldigen. Maar Nederlanders hebben het helemaal niet in zich om te discrimineren. We zijn al eeuwenlang een gastvrij volk.' Verdonk as quoted in Witte and Scheepmaker (2012), 119.

2 This chapter is partly based on Krommendijk (2012c).

3 UN Doc. CERD/C/304/Add.46 (1998). UN Doc. CERD/C/304/Add.104 (2001). UN Doc. CERD/C/64/CO/7 (2004). UN Doc. CERD/C/NLD/CO/17-18 (2010).

$4 \quad$ ECRI consists of 47 expert members entrusted with the task of, among others, reviewing and monitoring Member States' legislation, policies and other measures to combat racism, racial discrimination, xenophobia, anti-Semitism and intolerance.

5 CRI (98) 49, 15 June 1998. CRI (2001) 40, 13 November 2001 and CRI (2008) 3, 12 February 2008. 
sixteenth periodic state report (2005) and the combined seventeenth and eighteenth report (2008) to parliament. ${ }^{6}$ The thirteenth and fourteenth periodic reports (2000) were, however, not sent to parliament. More striking, however, is the fact that the government has not always informed parliament about the COs. The COs of 1998 and 2000 were not sent to parliament at all. The Minister of Foreign Affairs did send a letter summarising the COs of 2004, but no substantive reaction to the concerns and recommendations was included. ${ }^{7}$ The COs of 2010 were sent to parliament as an attachment to a letter about racial discrimination, again without a substantive governmental response. ${ }^{8}$

In addition to these letters, the government has only referred to CERD's COs on five other occasions. Remarkably, all five references were in the period from September 2000 to March 2002. ${ }^{9}$ The COs were merely referred to in rather general terms, primarily highlighting the positive aspects noted by CERD. It is illustrative of the limited scrutiny of COs by the government that the occasions in which the government refrained from referring to the COs or even ICERD, although it would have been logical. For example, the 2004 National Action Plan against Racism and the subsequent evaluation reports on its progress did not mention the COs or ICERD. ${ }^{10}$ The COs or ICERD were also not referred to in the note laying down the integration policy for 2007-2011 and the letter on integration, which discussed the anti-discrimination and racism policy. ${ }^{11}$

Not surprisingly, ICERD is the least cited treaty of the six treaties in this research, with only 71 references between 1995 and 2011 by the government in parliamentary papers and during debates. This coincides with the finding of Van

TK 2002/03, buza030263. TK 2007/08, 30950, nr. 10.

TK 2003/04, $29200 \mathrm{~V}$, nr. 75.

TK 2009/10, 30950, nr. 18, 1 .

In the 2000 report about the integration policy of ethnic minorities, the government noted that the conclusions of CERD about the Dutch policy were generally positive. The concerns of CERD about racial discrimination in the areas of 'employment and the police' were mentioned only briefly. TK $2000 / 01,27412$, nr. 2, 17. Secondly, a memo about the final conference about the ILO project concerning the fight against discrimination of ethnic minorities in the labour market sketched several initiatives that were taken as a result of this conference, the reports of the Equal Treatment Commission, labour unions and LBR, as well as ECRI and the findings of CERD. TK 2000/01, 27223, nr. 11, 6. Thirdly, a report about the integration policy of ethnic minorities 2001 referred to the compliments of CERD and ECRI about the effective national combat of racism on internet sites and stated that the financing of the Dutch complaints bureau for discrimination on the internet, which plays an important role in this regard, will be maintained in 2002 . TK 2001/02, 28006, nr. 2, 54-55. Fourthly, the Ministers of Justice and the Interior referred to the progress noted by CERD in the handling of discrimination cases by the National Discrimination Centre within the prosecution service. TK 2001/02, nr. 628. Fifthly, the Minister of Urban Policy and Integration of Ethnic Minorities mentioned the 'support' of CERD to interpret the notion of 'national minorities' broadly. TK 2001/02, nr. 1058.

10 TK 2003/04, 29200 VI, nr. 121. TK 2004/05, 29800 VI, nr. 154. TK 2006/07, 30950, nr. 9.

11 TK 2007/08, 31268, nr. 2. For the letter on integration see TK 2009/10, 31268, nr. 25. 
ICERD

Dooren that ICERD has barely been considered in the context of law making and that hardly any connection is made between ICERD and substantive policy areas. ${ }^{12}$

\subsection{Parliamentary scrutiny}

The role of parliament in relation to the COs of CERD is also rather limited. The COs have never been tabled for a parliamentary discussion. MPs have very rarely taken action themselves on the basis of the COs. They have also not urged or pressured the government to do so. Only once did parliament adopt a motion about the accessibility of education, which mentioned the 'reprimand' of CERD in 2000 as one of the reasons 'for consideration of the deficiencies in the accessibility of the educational system'. ${ }^{13}$ This motion was adopted by 73 votes to 71 (for a further discussion, see chapter $\mathrm{V}$, section 2.3). ${ }^{14}$ The COs 2000, in relation to discrimination of minorities in the labour market, were also alluded to in the Explanatory Memorandum of the legislative proposal of the MPs Vos (GL) and Stuurman (PvdA) concerning the extension of the Employment of Minorities (Promotion) Act (Wet SAMEN). This Act aimed to facilitate multicultural personnel management of companies. ${ }^{15}$ The proposal mentioned the 'strong criticism' of CERD concerning the situation in the Netherlands with respect to the big difference in unemployment rates between ethnic minority groups and the native Dutch population. ${ }^{16}$ It seems that the reference merely served as a useful additional argument or justification among many other reasons which were sketched in the 17 pages. This is because the COs or ICERD were no longer used during the parliamentary discussion.

On five other occasions, MPs asked the government's opinion about the COs. Firstly, one written parliamentary question was raised by Singh Varma (GL) about the COs 1998 concerning the fight against racial discrimination by the police and the Public Prosecution Department and the delay in state reporting. ${ }^{17}$ Secondly, another question by Koenders and Valk $(\operatorname{PvdA})$ dealt with the existence of 'black'

12 She based this conclusion on a study of the role of ICERD during the legislative projects of the Employment of Minorities (Promotion) Act, the Equal Treatment Act, the Integration of Newcomers Act and a Bill concerning a regulation for integration in the Netherlands. Van Dooren (2007), 25-32.

13 Motion proposed by Lambrechts (D66), Hamer (PvdA) and Rabbae (GL). TK 2001/02, 28000 VIII, nr. 71.

14 TK 2001/02, nr 34, 2509-2512, 2512.

15 The Act entered into force on 1 January 1998 and ceased to be in force on 31 December 2003. It obliged companies with more than 35 employees to keep a register and submit reports about the number of staff from ethnic minorities and the measures taken and intended to be taken to further stimulate their recruitment. UN Doc. ICERD/C/452/Add.3 (2003), para. 90 and 91.

16 TK 2003/04, 29275, nr. 3, 9 and 14-15.

17 In its answer to this and the second question, the government made clear that it could not answer the questions substantively, because at that time it was not yet in possession of the COs 1998 . TK 1997/98, nr. 1148. 
and 'white' schools and the delay in state reporting. ${ }^{18}$ Thirdly, another question was raised by Lazrak (SP) about the closure of black schools, in which the 'advice' of CERD in 2000 about the reduction of de facto segregation and the promotion of a multicultural education system was alluded to. ${ }^{19}$ Fourthly, Hoekema (D66) referred to the criticism in the COs 2000 in the field of 'employment and the police' and subsequently asked the Minister about the current state of affairs with the police. ${ }^{20}$ Fifthly, Timmermans (PvdA) asked for a reaction to several COs 2010 in particular. ${ }^{21}$ Parliament also raised questions and made remarks about the more procedural aspects of the process of state reporting. ${ }^{22}$

ICERD is also by far the UN human rights treaty which is least referred to in parliament. Both NGO representatives and government officials also pointed to a lack of knowledge about ICERD and little interest in the subject matter among MPs. In their view, parliament has not or has insufficiently used the process of state reporting as an instrument to hold the government accountable. There have been many occasions during which it could have been relevant or useful for MPs to discuss or mention ICERD or the COs. ${ }^{23}$

\subsection{Courts and legal practice}

The COs have not been considered by national courts. National courts have only referred to ICERD 17 times since December 1999. ${ }^{24}$ This is the lowest number of references of all the six UN human rights treaties. Courts especially mentioned ICERD in relation to the treaty-conform interpretation of the notion of 'race' ${ }^{25}$ or the interpretation of Article 137(c) and (d) in the Dutch Criminal Code, which prohibit insulting a group and incitement of hatred, discrimination or violence. ${ }^{26}$

The most obvious explanation for the limited role of ICERD in legal practice is the limited knowledge among lawyers and judges about the ICERD. In addition, the

18 TK 1997/98, nr. 1283.

19 The government made clear that the COs 2000 are 'taken to heart' and incorporated in the policy on integration and ethnic minorities. TK 2001/02, nr. 1265.

20 TK 2000/01, 27412, nr. 3, 6.

$21 \quad$ TK 2010/11, 2011Z16502.

22 The delay of six years in reporting was noted by Rehwinkel (PvdA) shortly after a roundtable on ethnic minorities during which NJCM mentioned the delay. TK 1997/98, 25601, nr. 23, 3. See also Timmermans (PvdA) in TK 2010/11, nr. 3166.

23 For example, the parliamentary debate about segregation in primary education, TK 2007/08, 31293 , nr. 10, or the meeting about the evaluation of the Employment of Minorities (Promotion) Act (Wet SAMEN) and the several motions proposed in this context. TK 2003/04, nr. 39, 2872 2874 and TK 2003/04, 27223, nr. 49-51.

24 In the period between 1974 and 2000, the total number of times that courts considered the provisions of ICERD was 29. See the several volumes in the series of Rechtspraak rassendiscriminatie (Utrecht: Landelijk Buro Racismebestrijding and Lelystad: Koninklijke Vermande) for an overview of relevant jurisprudence in the area of racial discrimination.

25 See, for example, Hoge Raad, 23 March 2010, LJN: BK6331, para. 2.5.2.

26 See, for example, Hoge Raad, 28 August 2007, LJN: BA5618, para. 18-21. 
provisions of ICERD have been incorporated in the latter articles in the Criminal Code as a result of which courts can simply rely on these domestic provisions. ${ }^{27}$ Another explanation is that courts sometimes denied the ICERD having direct effect. ${ }^{28}$ What is more, courts primarily rely on the ECHR or even the ICCPR and the Constitution in relation to racial discrimination. ${ }^{29}$ The judgment of the Court of Appeal in Amsterdam ordering the criminal prosecution of the politician Geert Wilders is illustrative of the emphasis on other provisions. The Court only considered the following treaty provisions to constitute the framework for its judicial review; Articles 18, 19, 20, 26 and 27 ICCPR, Articles 9, 10, 14 and 17 ECHR and Articles 1 and 7 of the Constitution, in addition to the relevant provisions in the Dutch Criminal Code. ${ }^{30}$ Likewise, in its judgment, a court exclusively considered Article 1 of the Constitution when declaring that the investigations as to the actual residence and the rights to social security of people of Somalian descent constitutes racial discrimination. ${ }^{31}$

\subsection{NGOs}

The NGOs that coordinated the alternative reports under ICERD are the Dutch section of the International Commission of Jurists (NJCM) and the Dutch National Association Against Discrimination, until 1 January 2007 Landelijk Bureau Rassendiscriminatie (LBR) and now Article $1 .{ }^{32}$ Despite their involvement in the reporting process, these NGOs have hardly lobbied on the basis of the COs. The most noteworthy activities they employed were concentrated around the turn of the millennium and include two follow-up meetings in 2000 and 2004 (see also chapter

$27 \quad$ Van Dijk (1988), 643.

28 The Council of State concluded that Articles 1(2), 2(1), 4 and 5 ICERD do not have direct effect. See nrs. 31, 51 and 84 in the series of Rechtspraak rassendiscriminatie (Utrecht: Landelijk Buro Racismebestrijding and Lelystad: Koninklijke Vermande). Likewise, The Hague District Court held that the appeal to Articles 1, 2 and 5 ICERD in the Antillean Reference Index (Verwijsindex Antillianen) fails, because those provisions are exclusively directed towards the state party and do not lend themselves to direct effect. Rb. Den Haag, 26 July 2007, LJN: BB0711.

29 In the case about the Antillean Reference Index (Verwijsindex Antillianen), the Council of State, for example, considered in the following order: Article 14 ECHR, Article 1(1) Protocol 12 ECHR, Article 26 ICCPR, Articles 1(1) and 2(1) ICERD, Data Protection Directive 95/46/EC, Article 1 of the Constitution and the Data Protection Act. ABRvS, 3 September 2008, LJN: BE9698, para. 2.1.

30 The latter include Article 137(c), (d), (e), 147, 261, 262 and 266 of the Criminal Code. The Court also examined the jurisprudence of the ECtHR extensively. Hof Amsterdam, 21 January 2009, LJN: BH0496. In the final judgment of the District Court of Amsterdam, the court only mentioned that Article 137(d) Criminal Code was the result of ICERD. It did not touch upon ICERD itself. Rb. Amsterdam, 23 June 2011, LJN: BQ9001.

31 The Court considered whether there were objective and reasonable grounds for the infringement of the non-discrimination principle. Rb. Haarlem, 8 May 2007, LJN: BA5410.

32 Representatives of those NGOs have also been present during the constructive dialogue in order to explain the alternative report to the expert members of CERD. 
$\mathrm{V}$, section 2.3). ${ }^{33}$ In addition to these meetings and the issuing of press communiqués after the constructive dialogue, NGOs have hardly paid any attention to COs and the concerns of CERD in their (outside) lobby and advocacy activities and their letters to parliament or the government. ${ }^{34}$ Amnesty International has hardly paid any attention to the COs either, although it has started to pay more attention to (racial) discrimination in the Netherlands in recent years. ${ }^{35}$ Rather, it relied on ECRI, the European Commissioner for Human Rights, the ECHR, the ECtHR and EU legislation. ${ }^{36}$ One NGO representative also acknowledged that NGOs have lobbied not so much on the basis of COs as such, but primarily per issue area. Consultations between the coordinating NGOs and the government in relation to state reporting have also taken place, albeit on a rather ad hoc basis. ${ }^{37}$

There are several reasons why lobbying is practically non-existent in relation to CERD's COs. First of all, there is no NGO which is primarily focused on the (implementation of) ICERD as such. NJCM focuses on the full spectrum of human rights and Article 1 concentrates on discrimination at large. Note, however, that its predecessor, the LBR, dealt with racial discrimination alone. This might be a factor that has contributed to a bigger impact of COs in the beginning of the 2000s as will be elaborated on further below. Secondly, LBR/ Article 1 is primarily a national expertise centre and strictly speaking not an NGO focused on lobby. It was also mentioned that follow up to the COs 2010 was not a priority for Article 1 due to

33 On 9 November 2000, a roundtable follow-up meeting took place about the COs of CERD between representatives of NJCM, LBR, the Netherlands Institute of Human Rights (SIM) and several government officials. 'Rondetafelbijeenkomst follow-up 'concluding observations' Antiracismeverdrag', NJCM-Bulletin 26 (1) (2001), 136. LBR also organised a follow-up meeting to discuss the COs 2004 with NGOs and government officials. 'Follow-up bijeenkomst CERD op 28 oktober 2004', NJCM-Bulletin 30 (1) (2005), 131.

34 The exceptions to this are the two times that NCJM referred to the COs concerning de facto segregation and hence the legal obligation to prevent and abolish school segregation. Gerards, 'NJCM-commentaar inzake onderwijs, integratie en burgerschap', 10 January 2005: <www. njcm.nl/site/comments/list_all>, accessed 31 July 2013. 'Wijziging in het beleid inzake bestrijding van segregatie in het onderwijs', 26 April 2011: <www.njcm.nl/site/uploads/ download/423>, accessed 31 July 2013. NJCM also sent a letter to the Minister of Foreign Affairs in which it regretted the delay in sending a follow-up response to the HRC and CERD with respect to their COs of 2009 and 2010. 'Uitblijven van regeringsreacties op aanbevelingen van VN-verdragscomités', 23 May 2011: <www.njcm.nl/site/uploads/download/425>, accessed 31 July 2013.

35 The COs were referred to in Amnesty International, 'Kabinetsformatie', 5 August 2010: <www. amnesty.nl/sites/default/files/public/amnesty brief aan informateur opstelten 5 augustus_2010.pdf >, accessed 31 July 2013, 3 .

36 See, for example, Amnesty International, 'Etnische registratie van Roma', 24 September 2010: $<$ www.amnesty.nl/sites/default/files/public/1010_memo_etnische_registratie_roma_0.pdf >, accessed 31 July 2013.

37 After the dialogue and the COs 2000, 2004 and 2010, NJCM and LBR had a meeting with government officials at the Ministry of Foreign Affairs or the Ministry of Housing, Spatial Planning and the Environment in 2010. In addition, in 2004, NGOs also explained their alternative report in order to enable government officials to anticipate the issues to be addressed by CERD. In 2010, a similar meeting took place. 


\section{ICERD}

other concerns and internal affairs related to the discontinuation of the funding. NJCM has limited financial and bureaucratic resources to employ wider lobby and advocacy activities. It primarily consists of volunteers, who do their NGO work in their free time, often in addition to full-time jobs. Representatives of NJCM also pointed to the high turnover of volunteers. Parallel reports are usually compiled by students and recent graduates who often leave after a short period, as a result of which the institutional memory is also meagre. What is more, NJCM representatives regarded the exercise of compiling such a report primarily as an objective in itself. The parallel report is not seen as one step in a much longer political lobby process that takes place primarily at the national level. Thirdly, as will be discussed below, CERD's COs are broader and more unspecific than the COs of, for example, the CEDAW and CRC Committee, and, as a result, less useful for lobbying. ${ }^{38}$

\subsection{Media coverage}

Only eight articles have appeared in the printed press about the concerns and COs of CERD between 1995 and 2011. The attention and the extent to which the COs were picked up decreased over time. That is to say, the 'reprimand' and concerns of CERD in 1998 were mentioned in four articles ${ }^{39}$, and the dialogue and COs of 2000 were covered twice. ${ }^{40}$ Only one article appeared about the COs 2004 shortly after the COs were adopted. ${ }^{41}$ Some of the media attention for the dialogue and COs in 2000 and 2004, especially for the issues of the composition of the policy and the school segregation, seems to be the result of the involvement and work of LBR in particular. ${ }^{42}$ The COs 2010 were mentioned once in relation to educational segregation. ${ }^{43}$

\subsection{Conclusion}

To sum up, the impact of the COs of the CERD is limited, especially since the mid2000s. While parliament and the government paid some attention to the COs of

$38 \quad$ Infra n. 50-51.

39 See, for example, Willebrord Nieuwenhuis, 'Gevoelige vingertik van de VN', NRC Handelsblad, 28 March 1998, 3.

40 See, for example, 'Politie gaat slecht om met migrant; VN: verloop ligt aan korpscultuur', Het Parool, 11 August 2000, 3.

$41 \quad$ Marc Kruyswijk, 'VN kraakt beleid voor minderheden', Algemeen Dagblad, 27 March 2004, 2.

42 The Director of LBR Fermina, who attended the dialogue in Geneva in 2000, gave several (television) interviews to the media. See, for example, Frank Renout, 'Machocultuur bij de politie bestrijden', Algemeen Dagblad, 12 August 2000, 5. There was also an article about the delay in state reporting in 2002, which referred to the criticism of LBR. 'Buitenlandse zaken is laks', Algemeen Dagblad, 20 August 2002, 3. The criticism of NGOs in their alternative report 2000 was also dealt with once. Frank Renout, 'Te zonnig beeld van integratie; 'Rapport voor VN noemt alleen maatregelen, niet de resultaten', Algemeen Dagblad, 2 August 2000, 5.

43 Leonoor Kuijk Brussel, 'EU laakt segregatie Nederlandse scholen', Trouw, 16 June 2011, 9. 
1998 and 2000, the most recent COs of 2004 and 2010 were almost completely ignored. One important factor for the latter is the fact that NGOs barely used the most recent COs in their lobbying and advocacy. The media has also not paid serious attention to these COs. This might seem remarkable in the light of the salience of racial discrimination in the Netherlands. Racism, discrimination, xenophobia, integration, ethnicity, minority issues and Islamophobia, among many other things, have been high on the (political) agenda in the Netherlands, especially since the beginning of this new millennium.

Interestingly, the reports of ECRI, at least the second and third reports of 2001 and 2008, received considerable attention at the domestic level. The government informed parliament better about the reports of ECRI and it also sent a reaction about the concerns and recommendations of the second and third report. ${ }^{44}$ These reactions and ECRI's reports were also subsequently discussed during a parliamentary debate ${ }^{45}$ What is more, the number of substantive references by MPs to the recommendations of ECRI was almost three times higher than the COs. ${ }^{46}$ In addition, media coverage was almost five times higher. ${ }^{47}$ NGOs have also been more active in relation to the follow-up to ECRI's recommendations. ${ }^{48}$ Several government officials and NGO representatives also observed that reports of ECRI have had a greater impact, especially in parliament and the press, although this was not necessarily always a positive impact.

\section{Assessing the effectiveness of COs}

It is particularly difficult to establish the effectiveness of each and every $\mathrm{CO}$ of CERD. One reason for this is that the government has hardly given a reaction to the COs by, for example, sending a letter to parliament, nor has a parliamentary debate taken place about the COs (chapter V, sections 1.1-2). Only in some periodic state reports did the government respond to the COs in rather general terms by outlining

44 TK 2001/02, szw0001022. TK 2001/02, 28198, nr. 3. TK 2007/08, 30950, nr. 12. Houtzager (2010), 219-221.

45 TK 2001/02, 27223, nr. 22. TK 2008/09, 30950, nr. 13.

46 There were twenty references to the process of reporting by ECRI and the content and recommendations of the reports, in addition to the parliamentary debates specifically dedicated to ECRI. See, for example, Arib (PvdA) in TK 2007/08, nr. 52, 3777-3782, 3779. Searches for 'ECRI' (106 results) and 'Commissie tegen racisme en intolerantie' (48 results) in the period of 1-1-1995 until 30-3-2010 in Parlando.

47 The second and third report of ECRI were reported respectively 6 and 33 times. On 30 June 2010 a search was conducted for 'Europese Commissie tegen racisme en intolerantie' (44 results) and 'ECRI' AND NOT 'Europese Commissie tegen racisme en intolerantie' (3 results) for the period 1 September 1994 and 30 June 2010 in Lexis Nexis.

48 Supra n. 36. Article 1, for example, sent a letter with its reaction to the third report on 22 May 2008 (4.2.2.1/MM/0508/108): <www.art1.nl/scripts/download.php?document=315>, accessed 31 July 2013. 
the policies in the respective area. ${ }^{49} \mathrm{~A}$ second reason why it is difficult to establish the effectiveness of the COs of CERD in particular, is the fact that the COs are even more broad and unspecific than COs of the other treaty bodies, especially when it is simply recommending that the state continue with its policy ${ }^{50}$ and strengthen, intensify or increase its efforts. ${ }^{51}$

The only substantive reaction given to the COs was in the follow-up reply to CERD to some of the COs $2010 .{ }^{52}$ This reply illustrates the two most important categories of reactions to the COs that will be further elaborated upon in this section. First of all, the government showed its disagreement with the concerns and recommendations of CERD (chapter V, section 2.1). That is to say, in response to the $\mathrm{CO}$ urging the government to take effective measures to suppress racist speech emanating from 'a few extremist parties' and to improve the tone of the political debate, the government pointed to 'the free and open nature of society' and the importance of dialogue in a democratic state governed by the rule of law. It was furthermore stressed that politicians have more freedom and possibilities in public debate. ${ }^{53}$ Secondly, the government pointed to existing initiatives and measures which were not necessarily taken as a result of the COs (chapter V, section 2.2). The government, for instance, pointed to an action programme to combat discrimination. This programme was, however, primarily focused on anti-Semitism and was (most likely) not the result of the COs,${ }^{54}$ but of a motion passed during an emergency debate on anti-Semitism. ${ }^{55}$ ICERD or the COs did not play a role during the debate and were not mentioned in the motion. ${ }^{56}$

49 The seventeenth and eighteenth report did include a section with responses to the COs 2004. Nevertheless, the response failed to establish a true link with the COs given the fact that the COs are hardly considered nor explicitly mentioned. The fifteenth and sixteenth report included a similar section with a response to the COs 2000 but only with respect to the issues in relation to which the government was requested to provide further information. The thirteenth and fourteenth report did not react to the previous COs 1998.

50 See for example UN Doc. ICERD/C/64/CO/7 (2004), para. 11: 'The Committee encourages the state party to continue its efforts to combat this contemporary manifestation of racial discrimination'.

51 See for example UN Doc. ICERD/C/64/CO/7 (2004), para. 13: 'The Committee recommends that the state party take adequate policy measures to ensure proper representation of ethnic minority groups in the labour market'.

52 The government gave a similar reaction to a question by Timmermans (PvdA). TK 2011/12, nr. 196.

53 UN Doc. C/NLD/CO/17-18/Add.1 (2011), para. 2-4.

54 CERD recommended a plan of action while also recommending an appropriate balance between responsibilities of the state under ICERD and immigrant communities' own responsibilities. The latter was not addressed in the government's reply. UN Doc CERD/C/NLD/CO/17-18/Add.1 (2011), para. 1 and 9.

55 The motion requested the government to draw up an action programme on anti-Semitism. TK 2009/10, 32123 VI, no. 111. Another motion urged the government to request policy and justice authorities to again register complaints of anti-Semitism. TK 2009/10, 32123 VI, no. 113.

56 The programme mentioned the principle of equality as laid down in Article 1 of the Constitution and the inviolability of human dignity in Article 1 Charter for Fundamental Rights. The debate 
Both government officials as well as NGO representatives involved in the process of state reporting concerning ICERD could hardly give examples of COs, especially the most recent ones of 2004 and 2010, that led to measures or a change in policy or legislation (chapter $\mathrm{V}$, section 2.3). One NGO representative involved in several reporting cycles of different treaties noted that in comparison with other treaties hardly anything was done as a result of the COs, if at all. Van Boven also noted that there has not been a policy focused discussion as a result of the COs $2000 .{ }^{57} \mathrm{~A}$ government official also noted with respect to CERD in particular that, with 30 recommendations, there are usually 28 recommendations in relation to which one digs one's heels in or in relation to which a lot of measures are already in place. The official noted that it is exceptional that there are more than two COs that are concrete enough to follow-up on.

\subsection{COs that have been rejected}

The government disagreed with several COs of the CERD. This conclusion is especially based on an examination of the government's reply to rather similar recommendations of ECRI. ${ }^{58}$ Both ECRI 2008 and the COs 2010, for example, recommended to review the Civic Integration (Preparation Abroad) Act which requires 'non-Western' state nations to pass an exam before entering the country for family formation or unification. ${ }^{59}$ The responsible Minister argued that parliament and government had discussed 'endlessly' the conformity of the Act with the ECHR during the legislative process. She noted that various advice had been given and that parliament and government eventually established that the Act would not violate the ECHR. She simply argued that the Act reflects a clear policy choice, which remains unaffected by experts and lawyers, such as ECRI, arguing otherwise. ${ }^{60}$

The ineffectiveness of some COs can (partly) be explained by the fundamentally different positions of CERD and the government. CERD recommended in its COs 2010 to take special measures and policies aimed at specific groups. ${ }^{61}$ By contrast,

and the motion was first and foremost the result of new data showing the magnitude of the number of reports of anti-Semitism.

57 Van Boven (2005), 112.

58 In its response to the report of ECRI, the government stated that it did not share all the conclusions and recommendations of ECRI. Among other things, the tone of the political and public debate, the policy for Roma and Sinti, the Antillean Reference Index, the Urban Areas (Special Measures) Act, the scope of the Equal Treatment Act, education and awareness raising. CRI (2008) 3, 45-51. The government also made clear in its reaction to the report of the European Commissioner of Human Rights Hammarberg that it only took note of, but did not accept, the recommendation to recognise the Roma and Sinti as a minority. TK 2008/09, 31700 V, nr. 95, 14-15. See also Van Sasse van Ysselt (2003), 423.

TK 2008/09, 30950, nr. 13, 23.

Article 1(4) ICERD excludes special measures from the definition of racial discrimination, while Article 2(2) even obliges states to take affirmative action. CERD recommended the Dutch government to take special measures. UN Doc. CERD/C/NLD/CO/17-18 (2010), para. 6 and 12. 


\section{ICERD}

the delegation stressed that it would be wrong to take measures on specific groups, because this would lead to segregation. ${ }^{62}$ The Balkenende IV government therefore adopted a generic policy targeted at all Dutch citizens, irrespective of their gender, descent or religious and confessional beliefs. ${ }^{63}$ Similarly, it held that it does not take measures targeting specific forms of discrimination, including racial discrimination. ${ }^{64}$ The coalition agreement of the Rutte I government even provided explicitly that the policy on diversity and preferential treatment on the basis of gender and ethnicity would be terminated altogether. ${ }^{65}$

These observations illustrate that there often exists a divergence of views about the nature of some obligations under ICERD between the government and CERD. This divergence also relates to different views on the role and functions of the state in society and the way in which other clashing fundamental rights and freedoms, such as privacy and the freedom of expression, association, religion, and education, should be respected. As we have seen, the government made clear in its response to the COs 2010 that the tone of the political and public debate is related to the freedom of expression. Likewise, prescribing the way in which human rights are taught at Dutch schools should also be seen in light of the freedom of education, according to the government. In the context of those conflicting rights, the government seems to adopt a 'justified limitation approach' whereby measures that result in indirect discrimination could, nevertheless, be objectively and reasonably justified when they are legitimate, necessary and proportional. Implicit in the reasoning of the government is the approach by the ECtHR which leaves more margin of appreciation for national authorities to balance conflicting rights. ${ }^{66}$ By contrast, CERD focuses primarily on the (criminal) prohibition and criminalisation of racial discrimination while paying less attention to these other clashing human rights and public interests. ${ }^{67}$

62 UN Doc. ICERD/C/SR.1985 (2010), para. 3. The government considered that the improvement of the disadvantaged position of women belonging to ethnic minorities is 'their own responsibility to an important extent'. UN Doc. CEDAW/C/NLD/4 (2005), 23.

63 TK 2009/10, $32123 \mathrm{~V}$, nr. 90, 44. This also means that the government is not very willing to support affirmative action and positive measures. An indication of this is the repeal of the Employment of Minorities (Promotion) Act (Wet SAMEN) in 2003. Supra n. 15-16.

64 UN Doc. ICERD/C/SR.1985 (2010), para. 3.

65 In addition, the government put the responsibility for integration on the ethnic minorities themselves. TK 2010/11, 32824, nr. 1, 10.

66 See, for example, Timishev v. Russia, 13 March 2006, Application no. 55762/00 and 55974/00, and D.H. and others v. the Czech Republic, 13 November 2007, Application no. 57325/00.

67 From the point of view of CERD this is understandable, since its competence is limited exclusively to ICERD. CERD regards the prohibition of racial discrimination as a peremptory norm of international law in the sense of Article 53 VCLT. UN Doc. A/57/18 (2002), 107. Thornberry noted that the exceptions to the definition of discrimination are limited under ICERD. The only limitation clause in Article 1 deals with citizenship. Thornberry (2005), 249251. Meron noted that: 'the Convention does not indicate that states can invoke a range of considerations to justify failure to take immediate steps towards implementing the equal achievement goal and can balance that goal with other desired community goals'. He, furthermore, held that some members of CERD regarded Article 4 ICERD as more important 


\subsection{Standing policy measures in line with the COs}

Quite a lot of COs merely recommend or encourage the state to continue with its policy or efforts, ${ }^{68}$ and strengthen, intensify or increase its efforts. ${ }^{69}$ Likewise, CERD recommended to "take more effective measures" 70 or 'take adequate policy measures ${ }^{71}$ without suggesting concrete measures as examples or inspiration. Several COs also recommended to only 'review' certain laws without indicating specific aspects. ${ }^{72}$ Such Cos, which do not prescribe any concrete action, are not very helpful and frequently only endorse the current efforts of the government. One scholar, who also noted that CERD's COs are rather superficial, ill-informed, unspecific and void of any content, argued that these 'flimsy and ineffectual reports from CERD contribute to the sense of futility and cynicism concerning UN human rights efforts' ${ }^{73}$ One NGO representative also argued that merely recommending 'to undertake further measures to reduce de facto segregation and to promote a multicultural educational system', without suggesting certain effective measures, is superfluous, since it is a complex problem for both the government and NGOs who do not know how to tackle this problem exactly. ${ }^{74}$

\section{3. (Partly) effective COs}

Interviewees could only give a few examples of COs that had some role at the national level or had led to increased domestic attention (see right column of table 5.1). Table 5.1 shows that these examples coincide with the references made by the government and parliament in parliamentary papers as discussed in chapter $\mathrm{V}$, section $1.1-2 .{ }^{75}$

than freedom of expression and association, which caused opposition among other members and some Western states. Meron (1985), 289-290 and 298-301. 
ICERD

Table 5.1. Overview of (partly) effective COs of the CERD in the Netherlands.

As cited in parliamentary papers or mentioned in interviews.

\begin{tabular}{|l|c|c|c|c|}
\hline \multirow{2}{*}{ Policy issue/CO } & \multicolumn{2}{|c|}{$\begin{array}{c}\text { Impact: number of } \\
\text { references to COs }\end{array}$} & \multicolumn{2}{c|}{$\begin{array}{c}\text { Number of interviewees who } \\
\text { held that CO was effective }\end{array}$} \\
\cline { 2 - 5 } & Government & Parliament & $\begin{array}{c}\text { Government } \\
\text { official }\end{array}$ & $\begin{array}{c}\text { NGO } \\
\text { representative }\end{array}$ \\
\hline $\begin{array}{l}\text { Financing of the reporting centre for } \\
\text { discrimination on the internet }\end{array}$ & 2 & & & \\
\hline $\begin{array}{l}\text { Continuation national discrimination } \\
\text { centre within the prosecution service }\end{array}$ & 1 & 1 & & 1 \\
\hline Composition of police forces & 1 & 1 & & \\
\hline $\begin{array}{l}\text { Increased attention for de facto school } \\
\text { segregation }\end{array}$ & & 3 & & \\
\hline
\end{tabular}

The COs in the table primarily deal with the positive aspects noted by CERD in its COs 1998 and 2000 which acknowledged the government's efforts. The COs of CERD were not effective in the sense of driving the actual measures. Rather, the references to these COs have primarily been used by the government in a strategic way in communication vis-à-vis parliament in order to gather support for existing and intended initiatives and policy proposals. The continuation of the financing of the reporting centre for discrimination on the internet was justified by the government on the basis of the positive feedback by ECRI and CERD in its COs 2000. Likewise, one NGO representative mentioned that the appreciation of CERD in its COs 2000 and ECRI partly played a role as a support for the continuation of the national discrimination centre within the prosecution service, which was established in the autumn of $19977^{76}$

Another way in which the COs have been effective is by raising the prominence of an issue or putting it higher on the agenda. According to one NGO representative, the COs 2000 were one supporting factor for the increased (political) attention for the composition of the police forces and the recruitment of ethnic minorities by the Ministry of the Interior. ${ }^{77}$ LBR was rather active on this issue and also used CERD's CO in its lobbying on some occasions. ${ }^{78}$ Note that the issue was already on the national policy agenda before it was raised by CERD in the COs 2000, given the parliamentary and media attention before $2000 .{ }^{79}$ Part of this media attention was caused by an individual complaint lodged with CERD of a Dutch citizen of

76 ECRI also welcomed the establishment of this centre. CRI (2001) 40, para. 5.

77 This was also addressed in the first and second report of ECRI. CRI (98) 49, para. 12. CRI (2001) 40, para. 42 and 43.

78 The issue was, for example, discussed during the roundtable follow-up meeting about the COs 2000. Supra n. 33 and 42. See also Van Boven (2005), 116.

79 One example is the question of Scheltema-De Nie (D66) as a result of the article 'Discriminatie bij de politie' in the Haarlems Dagblad on 13 May 2000. TK 1999/00, 1412/1484. See also TK 2000/01, 26345, nr. 56. 
Surinamese origin concerning his discharge from the police academy. ${ }^{80}$ This illustrates that the COs were just one contributory element.

The COs concerning de facto school segregation and the existence of so-called 'black schools' is another illustration of how the COs can be one ingredient in national political discussions and are one of the many factors that contribute to the salience of an issue. As we have seen, parliament adopted a motion in which the 'reprimand' of CERD was mentioned as one of the reasons for requesting the government to reflect on the accessibility of the educational system (chapter V, section 1.2). This motion hinted at the COs 2000 recommending that the state party undertake further measures to reduce de facto school segregation. ${ }^{81}$ As a result of the motion, the government asked the Education Council (Onderwijsraad) for advice about the accessibility of the educational system and the other points mentioned in the motion and sent a reaction in the form of a letter about citizenship. Interestingly, two of the three studies conducted by the Education Council referred to ICERD and the COs about de facto segregation. ${ }^{82}$ Minister of Education Van der Hoeven made clear in her reaction to these studies that the government was aiming at making schools more mixed. ${ }^{83}$ Before that, the government had still held that it was difficult to take any measures against the segregation in education in the light of the freedom of education in Article 23 of the Constitution. ${ }^{84}$ One important starting point for this shift was the policy recommendation to take measures against segregation in schools done by the Blok Committee that presented its report about the Dutch integration policy since the 1970 s on 19 January 2004.85 The recommendation of the Blok Committee also reflects the increasing magnitude of

80 E.I.F. v. The Netherlands, 21 March 2001, Communication No. 15/1999, U.N. Doc. ICERD/ $\mathrm{C} / 58 / \mathrm{D} / 15 / 1999$. Three articles were published about this complaint in 1998. See, for example, Marije Vlaskamp, 'VN-proces wegens racisme bij politie', Het Parool, 2 May 1998, 1.

81 Supra n. 13. The motion hinted at UN Doc. ICERD/C/304/Add.104 (2001), para. 14. During the parliamentary debate, Lambrechts (D66) also mentioned the 'reprimand of the UN'. TK 2001/02, nr. 29, 2077-2089, 2081.

82 One study focused on Article 23 of the Constitution, also considering it in the light of international and European legal norms, including Articles 2(1)(a) and 5(d) and (e) ICERD. Onderwijsraad, 'Vaste grond onder de voeten' (The Hague, July 2002), 34-35 and 57. The other study was about citizenship and cohesion Onderwijsraad, 'Samen leren leven. Verkenning onderwijs, burgerschap en gemeenschap' (The Hague, December 2002), 32. Both studies mentioned that segregation along ethnic lines is generally valued negatively, in this context citing the CO 2000 in a footnote.

83 The government gave its reaction to these two studies on 23 April 2004 without mentioning ICERD or the COs. TK 2003/04, 29536, nr. 1.

84 Mark Duursma and Guus Valk, 'We moeten etnische tweedeling accepteren; Onderwijsminister Maria van der Hoeven', NRC Handelsblad, 28 October 2003, 1. The Blok Committee also stated that the government had hardly taken any measures to prevent segregation in education to that date. The government only acknowledged in 2000 that segregation was a problem. TK 1999/00, 27020, nr. 1. TK 2003/04, 28689, nr. 9, 340.

85 In its reaction to the report, the government announced its intention to stimulate the mixing of pupils. TK 2003/04, 28689, nr. 17, 17-18. The Blok Committee did not refer to ICERD in relation to de facto school segregation at all. It even stated at a later instance that it was not aware that 
this societal problem and public pressure exercised by the political parties in parliament, schools, interest groups and academics' ${ }^{86}$ The COs were not the primary or decisive factor but one of the many factors that indirectly contributed to the eventual change. That is to say, the issue of school segregation and the existence of black and white school had already been raised and discussed at the political level and in the media preceding the COs $1998 .{ }^{87}$ NGOs and some MPs used the COs as an additional argument to underline the salience and urgency of the issue. ${ }^{88}$ As we have seen, two written parliamentary questions were raised in 1998 and 2002 which mentioned the COs 1998 and 2000 in relation to this issue (chapter V, section 1.2). The COs might have, in one way or another, contributed to getting the problem higher on the policy agenda. ${ }^{89}$ Nevertheless, when the issue of segregation in education was eventually (higher) on the policy agenda, it was no longer considered in the light of CERD's COs, at least by MPs and the government. ${ }^{90}$ An explanation for this might be that, as we have seen, CERD did not recommend or suggest any concrete measures to reduce de facto segregation. Another indication of the limited effectiveness of COs is that the Rutte I government decided to abolish the policy to combat de facto school segregation and the existence of black schools. ${ }^{91}$

It could be argued that the COs that were (partly) effective could be attributed to ECRI as well. ${ }^{92}$ It is not unthinkable that the recommendations of ECRI not only had a bigger impact, as was set out in chapter $\mathrm{V}$, section 1.6 , but also that they were a more important factor for subsequent policy and legislative measures. An explanation for this are the country visits of ECRI with the objective of speaking to several stakeholders. In addition, the Dutch expert member of ECRI, Sorgdrager, explained and discussed the conclusions of ECRI's third report with government

the Netherlands would not act in conformity with ICERD by not tackling the existence of black schools. TK 2003/04, 28689, nr. 9, 537. TK 2003/04, 28689, nr. 14, 137.

NJCM and JWS (2006), 10.

See, for example, Rabbae (GL) in TK 1997/98, 1754-1801, 1784. In the report about the integration of ethnic minorities 2002 it was also mentioned that the issue of segregation demanded continuous attention. TK 2002/03, 28612, nr. 2, 21-22.

Quite a lot of attention has been paid to the issue by NJCM and LBR. The issue was, for example, discussed during the roundtable follow-up meeting in 2000. Supra n. 33-34. See also Van Boven (2005), 114.

Note that the issue was also included in ECRI's reports. CRI (98) 49, para. 13. CRI (2001) 40, para. 26-29.

Coomans (2004). ICERD let alone the COs were not touched upon in the policy note addressing segregation. TK 2007/08, 31293, nr. 3. The Education Council, nonetheless, discussed ICERD and the COs 2000 and 2004 in its advice. Onderwijsraad, 'Spreidingsmaatregelen onder de loep' (The Hague, May 2005), 34 and 134. Onderwijsraad, 'Bakens voor spreiding en integratie' (The Hague, May 2005), 19 and 25-30. The advice of the Equal Treatment Commission requested by the Education Council about the issue also mentioned the COs. Commissie Gelijke Behandeling, 'Spreidingsbeleid in het primair onderwijs' (2005-01).

91 Robin Gerrits and Ron Meerhof, 'Kabinet accepteert zwarte scholen CDA-minister Van Bijsterveldt breekt met rijksbeleid om segregatie te bestrijden', de Volkskrant, 7 February 2011, 1. Supra n. $76-77$ and 89. 
officials and MPs. ${ }^{93}$ One NGO representative attributed the bigger impact of ECRI not only to the country visit, but also to the more elaborate reports of ECRI that also include better substantiated and more specific recommendations. What is more, the reports of ECRI are more timely than CERD and often precede similar recommendations of CERD. The third report adopted on 29 June 2007 and published on 12 February 2008, for example, covered more or less the same period as the combined seventeenth and eighteenth report discussed two years later in 2010 with CERD, 2003-2007 and 2002-2006 respectively. As we have seen, government officials considered the COs 2010 a mere repetition of the recommendations of ECRI 2008.94 This hints at another factor explaining the limited impact and effectiveness and the redundancy of discussing CERD's COs in the light of the relatively extensive debate about the - often rather similar - conclusions and recommendations of ECRI.

\section{TReaty SPECIFIC REASONS FOR THE (IN)EFFECTIVENESS OF COS}

\subsection{Factors related to the domestic context}

The previous section showed that the (partly) effective COs were those of 1998 and 2000. The reason that the effectiveness of COs was almost confined to these 'early' COs is that the impact of and the domestic attention paid to the COs was relatively high in this period. As we have seen in chapter V, section 1, all the references to COs by the government were made in the parliamentary years 2000/01 and 2001/02. The references by MPs to the COs were also by and large concentrated in this period. In addition, there was a rather extensive media coverage of the COs 1998 and 2000, which stands in sharp contrast with the almost absent attention concerning later COs. Furthermore, as we have seen, a follow-up meeting was organised in 2000 by NJCM, the Netherlands Institute of Human Rights (SIM) and LBR. The latter NGO was, at that time, also specifically focused on racial discrimination. There was, thus, some domestic mobilisation in this period, albeit still rather limited.

The (impact and) effectiveness of the COs can also be explained by the increased attention to the issue of racism at the EU and international level, including the

93 She presented the third report during a conference about the fight against racism organised by the Ministry of Housing, Spatial Planning and the Environment (VROM) and the Association of Netherlands Municipalities (VNG) and Article 1 on 21 May 2008. She also met with members of the First and Second Chamber to explain the work(ing methods) and the results of ECRI. EK/TK 2008/09, 20043, nr. U/76.

94 Likewise, the country visit of ECRI in the context of the second report took place on 5-7 June 2000 , two months before the consideration of the combined thirteenth and fourteenth report. The second ECRI report covered the period between the adoption of the first report on 13 June 1997 and the adoption of the second report on 15 December 2000. By contrast, the combined thirteenth and fourteenth report considered in 2000 covered the period 1996 and 1997. 
World Conference against Racism, Racial Discrimination, Xenophobia and Related Intolerance which took place between 31 August and 7 September 2001 in Durban. It was as a result of this conference that a National Action Plan against Racism was drafted. ${ }^{95}$ Around this time, ECRI also published its first and second report for the Netherlands, in 1998 and 2001. These international developments coincided with an increased focus on this issue during the Kok II government in particular (19982002). ${ }^{96}$ One illustration and important reason for this heightened attention is that under Kok II a special Minister for Urban Policy and Integration of Ethnic Minorities, Van Boxtel (D66), took office for the first time. Hence, the fight against discrimination and intolerance was approached in a more structural way and also made the integration policy more visible. ${ }^{97}$ It was noted by some NGO representatives that this Minister was also personally interested in and committed to the issue of racial discrimination. Another illustration of the salience of the issue of racial discrimination in this period is the establishment of the National Platform for consultation and cooperation against Racism and Discrimination on 8 April 2002, which was announced during a conference on 18 April 2001 about cooperation between local authorities and partners. ${ }^{98}$

One reason for the diminished attention to and effectiveness of the COs after the year 2001/02 might be the 9-11 attacks and the heightened discussions about the multicultural society. This discussion grew even stronger in the build-up to the parliamentary elections on 25 May 2002 when Pim Fortuyn, who ran as party leader of a party with the same name (LPF), was assassinated shortly before the elections. ${ }^{99}$ The debate was further intensified by the murder of the director and filmmaker Theo van Gogh on 2 November 2004 by a Dutch-Moroccan Muslim. The societal climate concerning ethnic minorities has changed considerably since the beginning of the new millennium. ${ }^{100}$ It was noted that combatting racism has consequently also been approached more critically. ${ }^{101}$ The emphasis has been put on the freedom of expression to the detriment of the protection from discrimination and hate speech. ${ }^{102}$ In addition, the idea that the disadvantaged position of ethnic

\footnotetext{
95 Attachment to TK 2003/04, 29200 VI, nr. 121, 5. Van Sasse van Ysselt (2003), 411 and 415-416.

96 The fight against racism was a hot issue in the 1980s and 1990s. Witte and Scheepmaker (2012), $109-114$.

97 TK 2001/02, 28198, nr. 3, 3.

$98 \quad$ Staatscourant 2002, 75, 7.

99 Lijst Pim Fortuyn was founded in February 2002 by Fortuyn after he was sent away as party leader of Leefbaar Nederland because of his statements in a newspaper interview about Muslim migrants and Islam. Frank Poorthuis and Hans Wansink 'De islam is een achterlijke cultuur', de Volkskrant, 9 February 2002.

100 A policy based on respect for differences was replaced by one that emphasised a common form of citizenship. Reiding (2007), 333 and 339.

101 Witte concluded that racism and discrimination were no longer considered a 'hot' topic in the $21^{\text {st }}$ century. He noted that references to discriminatory or racist expressions were simply disposed of as 'old political correctness', especially after the appearance of Fortuyn in 2002. Witte (2010), 185.

102 Witte and Scheepmaker (2012), 119-120.
} 
minorities is primarily their own responsibility has become more accepted and preferential treatment has increasingly been called into question. This is also partly reflected in the governmental views on several COs as outlined in chapter $\mathrm{V}$, section 2.1. What is more, the fight against discrimination has become a non-issue or a taboo and the existence of discrimination is sometimes even denied. ${ }^{103}$ Witte and Scheepmaker observed that this has resulted in the absence of a substantive antidiscrimination governmental policy. ${ }^{104}$ NGO representatives noted that it was more difficult in the period after 2001/02 to get ICERD on the political agenda. ${ }^{105}$ This also corroborates the idea of government officials that NGOs had more influence in the preceding period. ${ }^{106}$ In this light, it is not surprising that one government official held that ICERD is a relatively old treaty which reflects a certain spirit of the times. ${ }^{107}$

Another explanation for the limited impact and effectiveness of CERD's COs is the dominance of the European human rights regime. ${ }^{108}$ As we have seen, national courts have primarily examined other provisions of human rights treaties instead of ICERD. In fact, governmental and parliamentary scrutiny, legal practice and scholarly writing in relation to issues that are also dealt with by CERD, focus primarily on the relevant provisions of ECHR, ${ }^{109}$ the jurisprudence developed by the ECtHR, EU legislation, as well as judgments of the ECJ. ${ }^{110}$ These sources are sometimes used to justify noncompliance with recommendations of ECRI or CERD in the field of racism. ${ }^{111}$ More importantly, this also implies that the government

103 Witte and Scheepmaker (2012), 118-120.

104 Witte and Scheepmaker (2012), 120-121.

105 One NGO representative also noted that the director of LBR/ Art. 1, Fermina, was a former MP of the same political party as the Minister for Urban Policy and Integration of Ethnic Minorities, Van Boxtel (D66) in the Kok II government. Hence, Fermina frequently went to parliament himself, also because he had easy access to his own political party, but he also had access to other parties.

106 This also because LBR was more widely known than Art. 1, which was established in 2007.

107 At the time of ratification in the $1970 \mathrm{~s}$, the idea was that the consequences of ICERD were minimal for the Netherlands and that racial discrimination did not exist. Redactioneel (1998b), 420.

108 For a similar argument, see Van Sasse van Ysselt (2003), 413.

109 Especially Article 14 ECHR and Article 1 Protocol 12. One example is the question by Strik (GL) about the Civic Integration (Preparation Abroad) Act and its conformity with the ECHR. EK 2008/09, nr. 2.

110 At the EU level, relevant legislation in the field of racial discrimination is the EU Directive 2000/43/EC implementing the principle of equal treatment between persons irrespective of racial or ethnic origin. In addition, the Council Framework Decision 2008/913/JHA on combating certain forms and expressions of racism and xenophobia by means of criminal law.

111 In response to a recommendation of the European Commissioner of Human Rights, Hammarberg, that mirrors recommendations made by CERD, to ensure that tests, fees and age requirements for family reunification and formation are not a disproportionate obstacle, the government stated that the requirements are in conformity with the EU Directive on family reunification. UN Doc. ICERD/C/NLD/CO/17-18, (2010), para. 5. TK 2008/09, 31700 V, nr. 95, $7-8$. 
is not eager to give up or change its policy on the basis of non-binding recommendations. Instead, it prefers an authoritative statement of the law through a definite binding judgment by a court. ${ }^{112}$ That is to say, if there is no judgment determining a violation of the ECHR or EU law, then the government almost automatically assumes that the standards in UN human rights treaties are also complied with. Nonetheless, many possible human rights problems and potential violations do not reach the ECtHR, ECJ or national courts. The view also neglects that treaty standards and the interpretation of these standards by international courts or committees may differ (see also chapter VII, section 3.1).

\subsection{The (perceived) quality of the CERD}

One important reason for the limited effectiveness of the COs is the limited legitimacy and persuasiveness of the CERD in the view of government officials. This means that a compliance pull and persuasion is largely absent. This section will address the functioning of CERD and the COs from the perception of government officials based on several interviews and the author's personal observations from the dialogue of CERD with the Netherlands in 2010.

Both government officials as well as NGO representatives were rather critical about the dialogue with CERD in 2010 and noted that expert members were not or were poorly prepared. It is noteworthy that government officials and NGO representatives were slightly more positive about CERD 2004 and especially the dialogues in 1998 and 2000. It was noted that the questions were more targeted at the situation in the Netherlands than during the dialogue in 2010 (see further below). One official argued that the mere presence of the Dutch expert member Van Boven (1992-1999) during the dialogue in 1998 already raised the stature and authority of CERD. With respect to CERD 2004 it was noted that the Austrian country rapporteur for the Netherlands, Herndl, was well prepared and informed about the Dutch situation and was caught up with the real issues. This might also be reflective of the fact that the government and delegation approached the issue of racial discrimination and the position of ethnic minorities more favourably in this period, as we have seen in the previous subsection. At the same time, this more positive stance towards the two dialogues (and COs) explains the concentration of references of the government to COs 1998 and 2000.

Several government officials mentioned that they had seen the draft COs CERD 2010 lying on the desk of expert members before the start of the dialogue. They noted that - at least the first page - matched the final version of the COs and criticised that the COs did not reflect the dialogue and did not take into consideration

112 See also Redactioneel (2012), 387. The government, for example, made clear that it was not willing to definitively give up the Antillean Reference Index (Verwijsindex Antillianen) as a consequence of the third report of ECRI. The government argued that the 'opinion' of ECRI that the index was not consistent with the ban on racial discrimination and is not supported by a judgment of The Hague District Court. Supra n. 28-29. 
the government's replies. Country rapporteur Lahiri presented his preliminary conclusions in his introductory statement. ${ }^{113} \mathrm{He}$ did not raise any questions in his intervention, nor did he ask the government for a reaction to his point of view. His conclusions at the end of the dialogue were more or less similar to his introductory words. Government officials argued that the delegation might just as well have stayed at home, because CERD seemed to have its conclusions ready before the dialogue. Dutch government officials argued that this diminishes the quality of the COs and negatively influences the authority of CERD.

With respect to CERD 2010, it was argued that the 'distance' or unfamiliarity of CERD with the Dutch context was even greater than the dialogue with CEDAW one month before (chapter VIII, section 3.2). Quite a few expert members of CERD hardly had any idea about the situation in the Netherlands. Hence, the national background of expert members could be clearly heard in the questions. Members from certain - mostly Arabic countries - focused, for example, very much on Islamophobia and racist and xenophobic speech of certain politicians. Others asked questions about the Frisian minority. ${ }^{114}$ One government official argued that someone who is familiar with the Dutch context knows that there are hardly any problems with the Frisians. One NGO representative also observed that CERD members were ill-informed about details in legislation and current discussions in parliament. The questions and statements of the expert members not only reflected but also explicitly included personal opinions and backgrounds. ${ }^{115}$ Furthermore, in contrast with CEDAW, experts frequently included anecdotes in their statements. ${ }^{116}$

In general, the dialogue was not structured on the basis of the articles of ICERD, as was the case with the dialogue with the CEDAW Committee. There were few references to previous COs, and the articles of the ICERD were not referred to. ${ }^{117}$ Expert member Prosper even said that the government may do what they like with

113 He rather easily concluded that the shift in policy concerning the integration of minorities had led to increased anti-immigrant sentiment, hate speech and Islamophobia, without elaborating upon the assumed causal relationship. Likewise, he concluded that because the overseas integration test only applies to nationals of non-Western countries and had led to a significant reduction from especially Morocco and Turkey it is racially discriminatory. UN Doc. ICERD/C/ SR.1985 (2010), para. 17-18. UN Doc. ICERD/C/SR.1985 (2010), para. 23 and 32.

115 Amir, for example, stated that he would like to see culture dominating politics and politics becoming more multicultural. Prosper made clear that he personally agreed with the government's integration policy. Diaconu spoke about his opinion that he expressed during the dialogue but also in writing about the importance of respecting the principle of equality. UN Doc ICERD/C/SR.1986 (2010), para. 37.

116 Amir spoke about the maritime power of days gone by. He also referred to the fight of the Helvetians against Caesar and quoted Caesar in this regard. Also Avtonomov mentioned the historical role of the Netherlands conquering the sea and emphasised the close ties that exist between Russia and the Netherlands. Ewomsan elaborated upon the fact that the Dutch are well known for trade and that their products are of better quality. Prosper mentioned that he visited the Netherlands and that this visit was reasonably pleasurable and that he had never had any problems. Most notably, there were questions about the Employment of Minorities (Promotion) Act (Wet SAMEN), without mentioning the COs of 2004 and 2001. 
the COs. Remarkably, there was no time limit for expert members of CERD. The consequence of this is, for example, that the expert from Algeria had the chance to take the floor for 18 minutes with a tirade against measures of the Western world against 'countries of Muslim faith' at international airports. He argued that measures against terrorism that punish and humiliate a whole people constitute a violation of ICERD. He also highlighted that he himself is a Muslim and that 'we' (the Muslim world) love art, noting that calligraphy was brought from the Muslim world to Europe. He acknowledged that his concern was not directed at the Netherlands, but that the problem is much larger. ${ }^{118}$

This statement is illustrative of the dialogue in which a lot of experts made statements which were not directly related to the (particular) situation in the Netherlands but more generally to Europe and Western countries and the challenges they are facing in light of immigration and integration. ${ }^{119}$ Several expert members mentioned that they did not want to question the government's policies, but rather that they wanted to understand what the government is doing so that CERD can learn from this. Especially the second round of questions consisted more of a general philosophical debate about integration, assimilation, the right to identity, diversity, and universality of values. ${ }^{120}$ Expert member Lindgren, for example, elaborated upon the right to identity, generally and in abstract terms, but not at all related to the situation in the Netherlands. ${ }^{121}$ Hence, the answers of the government also focused on this broader discussion about integration and assimilation, as a result of which specific questions about the situation in the Netherlands were largely left unanswered. One expert member of CERD explained that because of the fact that a lot of expert members are from non-Western countries, the discussion in CERD is usually rather broad. ${ }^{122}$ The general discussion with a lot of personal reflections might also be the result of the fact that CERD members were not very well prepared in comparison with CEDAW. ${ }^{123}$

118 See UN Doc. ICERD/C/SR.1985, para. 21. Interestingly, this paragraph is only a very small reproduction of the statement Amir delivered during the dialogue.

119 Prosper, for example, discussed the 'rhetoric in Europe about promoting multiculturalism and ethnic integration'. UN Doc. ICERD/C/SR.1985 (2010), para. 26. See also the statements by Kut concerning the racist and xenophobic political discourse in Europe. UN Doc. ICERD/C/SR.1985 (2010), para. 55.

120 Diaconu referred to the dilemma those countries have in the light of their multicultural society between identity versus diversity and mentioned Charles Taylor and also referred to the situation of Aboriginals in Australia. Avtonomov also observed that CERD had started a general discussion about integration himself, referring to the situation of indigenous people in Guatemala. Lahiri was also fascinated about where the debate was going, mentioning the references to multiculturalism, Pushkin and Othello. Also the government noted that the discussion sometimes went beyond the situation in the Netherlands. Personal observation of the dialogue. Note that these statements are not reported in the summary records.

122 Personal observation in the margin of the session.

123 This was also noted by an NGO representative. Prosper, for example, remarked at the beginning of his statement that he was not sure what his questions were. 
Government officials also pointed to the irrelevance of the dialogue which primarily centred on the period 2002-2006. This means that certain policies and legislation and consequent COs were already obsolete. This 'delay' was also one of the reasons that the responsible Minister was not very eager to be the head of the delegation, according to some government officials. Several questions were about issues that were from years earlier. ${ }^{124}$ One expert wanted to know again the rationale for the adoption of the Employment of Minorities (Promotion) Act in 1998 and its abolition in December 2003, although this had already been addressed in the context of the discussion of previous reports. ${ }^{125}$ Another question dealt with the judgment of the Court of Appeal of 29 April 2003 sentencing the Chair of the Nederlandse VolksUnie (NVU) to imprisonment for racist insults. ${ }^{126}$ Likewise, the government was asked for an explanation as to the assassinations of Fortuyn and Van Gogh in 2002 and 2004. ${ }^{127}$ These antiquated issues were discussed despite the LOI which was sent to the state party only shortly before the dialogue, which could also have addressed such issues. ${ }^{128}$

Government officials also lamented the fact that because the Netherlands reported in a good way, it was approached more critically. It was, for example, argued that the relatively high number of racism reported to the police was the result of the accessible nationwide network of anti-discrimination services and the national anti-discrimination campaigns. According to these officials, this did not necessarily reflect an increase in the extent of racial discrimination, as suggested by CERD during the dialogue and in the COs 2010. Likewise, officials argued that CERD primarily adopts a strictly legal view primarily focused on the treaty, without considering actual possibilities, the societal context and the dilemmas the government is confronted with. Similarly, CERD was said to neglect other conflicting obligations and interests and does not take into account that it is not up to the government to encourage a certain tone of the political debate in the light of the freedom of expression (see chapter V, section 2.1). Furthermore, it was noted that positive special measures are not always possible or difficult to justify in the light of EU legislation which is more restrictive. It was noted that ICERD deals with the very specific issue of racial discrimination, but that CERD interprets this broadly and sometimes goes beyond the actual treaty. An example given of an issue that is not related or does not directly flow from ICERD was the consideration of the asylum policy by CERD. ${ }^{129}$

Lahiri lamented the fact that the coverage of the period 2002-2004 in the report was not complete and remained rather sketchy. UN Doc. ICERD/C/SR.1985 (2010), para. 15. 


\section{ICERD}

\section{Conclusion}

CERD's COs have had a limited impact in the Netherlands, especially since the mid-2000s. Many of CERD's COs, especially those of 2004 and 2010, have remained ineffective and have not led to new initiatives or changes in policy or legislation. Nonetheless, two of the COs 2000 have been effective in the sense that they were used as a justification by the government to continue with certain policies (the reporting centre for discrimination on the internet and the discrimination centre within the prosecution service). The COs 2000 also contributed - together with many other domestic and international factors - to increased domestic attention for the issues of school segregation and the ethnic composition of the police. The effectiveness of the latter two COs can also be attributed to the advocacy of several domestic actors in relation to the COs in the period 1998-2002. That is to say, MPs, the government, NGOs, and the media occasionally referred to the COs in this period. The salience of the issue of racial discrimination was also higher in this period. 


\section{Chapter VI ICCPR}

'The human rights treaty, that we signed, does not oblige us to amend national legislation when the HRC has criticism.'

[Spokesperson of former Minister of Foreign Affairs Van Aartsen in 2001] ${ }^{1}$

This chapter considers the impact and effectiveness of the COs of the HRC. ${ }^{2}$ Since 1995, the HRC has considered the implementation of ICCPR by the Netherlands twice, in 2001 and 2009. The primary concern of the HRC on both occasions was related to the practice of euthanasia and the Medical Research (Human Subject) Act. The Termination of Life on Request and Assisted Suicide (Review Procedures) Act, which came into force on 10 April 2001, legalised physician assisted suicide and/or euthanasia on the explicit and repeated request of a patient who is hopelessly and unbearably suffering. The HRC recommended in its COs 2001 and 2009 that this law be re-examined. In addition, the HRC made clear, among other things, that the government 'must ensure that the procedures employed offer adequate safeguards against abuse or misuse, including undue influence by third parties' and that the 'ex ante control mechanism should be strengthened'. ${ }^{3}$ With respect to the Medical Research (Human Subject) Act, ${ }^{4}$ the HRC also recommended that the government reconsider this Act and 'remove minors and other persons unable to give genuine consent from any medical experiments which do not directly benefit these individuals (non-therapeutic medical research)' .5 Other COs dealt with, among others, the prevalence of child abuse, trafficking and sexual exploitation as well as gender equality and the discrimination of ethnic minorities. The HRC also expressed its concern about the asylum protection of women who fear genital mutilation in 2001 and the short duration of the accelerated asylum procedure in 2009. On both occasions, the use of anonymous witnesses and the long duration of pre-trial detention was criticised as well.

1 'Het mensenrechtenverdrag dat wij hebben ondertekend, verplicht ons niet de nationale wetgeving aan te passen als het comité kritiek heeft.' Elaine de Boer, 'VN moeten weten: euthanasiewet is Nederland', de Volkskrant, 30 July 2001, 2.

2 This chapter is partly based on Krommendijk (2013a) and (2011a). The latter pays more attention to the role of the ICCPR in the Dutch legal order and also contains more references to parliamentary papers, court judgments, media articles, and NGO information.

3 UN Doc. CCPR/CO/72/NET (2001), para. 5. UN Doc. CCPR/C/NLD/CO/4 (2009), para. 7.

4 The Medical Research (Human Subjects) Act lays down several substantive norms and procedural rules as to the protection to research subjects in medical research. It also established a central committee for medical research involving human subjects.

5 UN Doc. CCPR/CO/72/NET (2001), para. 7. UN Doc. CCPR/C/NLD/CO/4, (2009), para. 8. 
Chapter VI

\section{DOMESTIC IMPACT AND DOMESTIC MOBILISATION}

Before turning to the impact of the COs of the HRC, it is important to pay some attention to the rather considerable impact of the ICCPR in the Dutch legal order of the Netherlands in the 1970s and 1980s. Already in the 1970s the government recognised that a lot of the provisions in the ICCPR would be 'binding on all persons' in the sense of Articles 93 and 94 of the Constitution. As a result, these provisions would have 'direct effect' and could be applied immediately by national courts without any implementing legislation. ${ }^{6}$ The ICCPR has indeed been applied extensively by national courts since its ratification. The abundant jurisprudence in relation to the principle of non-discrimination, which is laid down in Article 26 ICCPR, is especially noteworthy in this context. ${ }^{7}$

The most prominent period for the ICCPR was at the end of the 1980s, especially as a result of the Views of the HRC in Broeks v. the Netherlands and Zwaan-de Vries v. the Netherlands. ${ }^{8}$ As a result of these Views, the Central Appeals Tribunal revised its stand on the direct effect of Article 26 ICCPR. ${ }^{9}$ Consequently, the Tribunal applied Article 26 in relation to legislation providing for social security (and thus the rights contained in ICESCR) and concluded in several cases that women were wrongfully denied social security benefits. According to the government, these judgments in relation to social security would have far-reaching budgetary implications. The government consequently considered denouncing the ICCPR and acceding to it again with a reservation to the application of the treaty. ${ }^{10}$ The latter never happened. Ironically, the Views and the judgment of the Tribunal were actually inspired by the recognition of the Dutch government itself during the dialogue with the HRC about its first state report that 'direct application of Article 26 in the area of social, economic and cultural rights' might be possible. ${ }^{11}$

6 TK 1975/76, 13932, nr. 3, 13.

7 For an extensive elaboration on the developments in the interpretation and application of Article 26 ICCPR by national courts see Woltjer (2002), 175-284. Heringa observed that more than half of the 65 judgments from 1978-1986, in which only the ICCPR (and not the ECHR) was invoked by the applicant, dealt with Article 26. Heringa (1988), 108 and 133-135.

8 In these cases, the HRC concluded that Article 26 ICCPR was violated since women were denied social security benefits on an equal footing with men. That is to say, in order to receive unemployment benefits, a married woman had to prove that she was a breadwinner, a condition that did not apply to married men. For the Views, see Broeks v. The Netherlands, 9 April 1987, Communication No. 001/1984, U.N. Doc. CCPR/C/OP/2 at 196 (1990) and F. H. Zwaan-de Vries v. the Netherlands, 9 April 1987, Communication No. 182/1984, U.N. Doc. CCPR/C/OP/2 at 209 (1990).

9 The revised stance brought the Tribunal in line with the approach of the Supreme Court and the Administrative Law Division of the Council of State, who had already determined that Article 26 ICCPR had direct effect in the beginning of the 1980s. CRvB, 14 May 1987, AB 1987, 543. Heringa (1988), 124. Woltjer (2002), 175-284. Besselink and Wessel (2009), 23 and 51.

$10 \quad$ Van Emmerik (2008), 148.

11 Olde Kalter in UN Doc. CCPR/C/SR.325 (1981), para. 50 as quoted in Broeks v. the Netherlands, 9 April 1987, Communication No. 001/1984, U.N. Doc. CCPR/C/OP/2 at 196 (1990), para. 5.4. 
ICCPR

\subsection{Governmental attention}

The government sent the periodic state reports and the HRC's COs 2001 and 2009 with a governmental reaction to parliament. ${ }^{12}$ The government also sent its reaction to these COs. The Minister of Health even found it necessary to inform parliament separately about the COs 2001 concerning euthanasia and the Medical Research (Human Subjects) Act. ${ }^{13}$ The government has, however, only referred to the COs of the HRC once in other parliamentary papers or during parliamentary debates. This was a reference to the COs 2001 concerning the Medical Research (Human Subjects) Act. ${ }^{14}$

The few references to COs contrasts with the relatively extensive number of references to the ICCPR in parliamentary papers (354 in total). The ICCPR is the most cited UN human rights treaty after the CRC. Legislative proposals are also tested against the ICCPR more often than the other UN human rights treaties. That is to say, the number of references to the ICCPR in Explanatory Memoranda attached to the Bills tabled in parliament is rather considerable (100 times). ${ }^{15}$ Compared with the ECHR, the consideration of the ICCPR by the government has, however, still been rather limited. ${ }^{16}$ The government made clear, for example, that proposed measures and legislation should primarily be tested against the ECHR. ${ }^{17}$ Often only conformity with the ECHR is discussed in depth during the legislative process, while the ICCPR is only briefly mentioned. ${ }^{18}$ The ICCPR is often only referred to with the statement that the material discussion is (almost) similar to the discussion of the conformity of the policy measure or legislative proposal with the ECHR and/or the Constitution. ${ }^{19}$ Government officials admit that ICCPR is seldom considered separately. An important reason for this is the availability of

12 The third periodic report was only sent after the dialogue with a brief outline of the COs 2001 . TK 2000/01, buza000451. The government also sent its replies to the COs in the context of the follow-up procedure. TK 2002/03, buza030180. For the fourth report, see TK 2006/07, $30800 \mathrm{~V}$, nr. 90. The LOI and the answers of the government thereto have not been sent to parliament.

13 TK 2000/01, 26691/22588, nr. 42. The government only gave a substantive reaction to the other COs after a request of parliament. TK 2001/02, 28000 VI, nr. 54. The Minister of Justice gave a reaction to the COs 2009 in TK 2009/10, 32123 VI, nr. 11.

14 This reference was made in the Memorandum of Reply about proposed amendments to the Act for the implementation of the EU Council Directive 2001/20/EC. TK 2002/03, 28804, nr. 5, 5.

15 The Dutch instructions for legislation provide that during the legislative process it must be examined whether there are 'higher rules' that restrict the 'freedom of regulation'. The instructions mention ECHR and ICCPR in particular. See Instruction 18 of Dutch instructions for legislation (Aanwijzingen voor de regelgeving). Instructions 11 and 166 also refer to ICCPR in addition to ECHR.

16 Krommendijk (2013a), 216-217.

17 See, for example, TK 2000/01, 27605, nr. 3, 11.

18 The government, for example, justified the lawfulness of the Termination of Life on Request and Assisted Suicide Act on the basis of Art. 2 ECHR and argued that this reasoning applies mutatis mutandis for the other provisions of international law, including Articles 7 UDHR and 14 ICCPR. EK 2000/01, 26691, nr. 137b, 40-41.

19 See, for example, TK 1998/99, 26735, nr. 3, 22. 
jurisprudence in relation to the ECHR, which is also seen as more authoritative. Likewise, the Council of State also paid more attention to the ECHR than ICCPR. ${ }^{20}$

\subsection{Parliamentary scrutiny}

Parliament has hardly discussed or referred to the COs of the HRC. No parliamentary debate has taken place on the basis of the COs. ${ }^{21}$ There were two written question rounds about euthanasia and the Medical Research (Human Subjects) Act, in which the COs 2001 played a considerable role and were referred to by several political parties. ${ }^{22}$ MPs have only addressed the late submission of the state report or the delay in sending a follow-up response to the COs to the HRC sporadically. ${ }^{23}$

MPs alluded to the COs on seven occasions. MPs have never introduced a legislative proposal or motion to give effect to the COs. Remarkably, five of the seven instances in which the COs were addressed explicitly dealt with the issue of euthanasia. All five times, the question or statement was made by a member of one of the two opposition parties with a Christian profile, the ChristenUnie (CU) or the reformed political party SGP. ${ }^{24}$ In November 2009, Van der Staaij (SGP), for example, inquired why the government sidestepped the criticism of 'the UN' concerning euthanasia so easily, given its reaction to the COs sent to parliament. ${ }^{25}$ The government pointed to its earlier letter with the reaction to the COs 2009 and the coalition agreement, simply stating that it had nothing to add to this at that moment. ${ }^{26}$ As will be elaborated upon further below, this answer implies that the government is willing to put aside criticism of the HRC on the basis of a government programme which is backed by a parliamentary majority. Another way in which members of government have avoided addressing specific COs in parliament is

20 See, for example, TK 2006/07, 30901, nr. 4, 8-11.

21 Minister of Justice Hirsch Ballin, nevertheless, stated that he expected that a parliamentary debate would be held on the basis of the government reaction to the COs 2009. This debate, however, never took place. TK 2009/10, nr. 21, 1755-1785, 1782.

22 TK 2001/02, 26691, nr. 43 and TK 2001/02, 26691/22588, nr. 45.

23 On three occasions questions were raised about the delay in state reporting under ICCPR. Van Oven (PvdA) and Blaauw (VVD) in TK 1996/97, nr. 131. Timmermans (PvdA) asked twice about the delay in the follow-up response to the COs 2009, probably as a result of a letter sent by NJCM on 23 May 2011 about the delay. TK 2010/11, nr. 3166.

24 Van Dijke (CU) in TK 2001/02, nr. 2, 4-70, 17-18 and 68. Rouvoet (CU) and Van der Vlies (SGP) in TK 2004/05, nr. 515. The SGP in TK 2010/11, 32500 VI, nr. 11, 9-10 and TK 2010/11, 32500 XVI, nr. 125, 18-19.

25 TK 2009/10, nr. 20, 1609-1636, 1628.

26 Because Van der Staaij considered this answer to be unsatisfactory, he proposed a motion in which the government was asked for a further substantive reaction to the 'serious concerns' of the HRC as well as the possibilities to give in to those objections. Van der Staaij withdrew his motion as a consequence of the promise of the Minister that another letter would be sent to parliament and that the matter could be discussed during another meeting. TK 2009/10, nr. 21, 1755-1785, 1776 and 1782. TK 2009/10, nr. 21, 1788-1800, 1800. 


\section{ICCPR}

when they pointed to another occasion during which all the COs could be discussed integrally or when they advised that the matter should be discussed with another member of government. The latter, for example, happened when Pechtold (D66) asked the Minister of Foreign Affairs about his opinion on the 'criticism' of the $\mathrm{HRC}$ in the LOI with regard to the asylum policy and anti-terrorism legislation during a parliamentary debate about the budget of the Ministry. ${ }^{27}$ The Minister did not give an answer to this question but only mentioned that he assumed parliament would continue the discussion about this with the State Secretary of Justice. ${ }^{28}$ This eventually did not happen.

In addition to these five references to the COs dealing with euthanasia, two other COs 2010 were mentioned on two occasions. Timmermans (PvdA) asked how the government was planning to publish and make the COs widely available and whether the government was willing to withdraw the reservation to Article 10 ICCPR as recommended by the HRC. ${ }^{29}$ Furthermore, during a parliamentary debate about anti-terrorism measures, Senator Berndsen (D66) referred to the COs 2009 and the conclusion of an evaluation study that there is a very considerable risk that the ECtHR would not regard the application of personal disruption measures as necessary in a democratic society. ${ }^{30}$ The reference to the COs was the result of the legal evaluation which assessed the legality of several anti-terrorism measures, also in the light of the COs (for a further discussion see chapter VI, section 2.3). ${ }^{31}$

\subsection{Courts and legal practice}

The COs for the Netherlands have not been explicitly referred to by national courts. ${ }^{32}$ Even though this research has not examined the impact and effectiveness of Views of the HRC in individual communications, it would, nonetheless, be peculiar not to devote some words to the impact of the Views of the HRC, which have had considerably more impact than the COs. The Views were mentioned in at least 48 judgments. ${ }^{33}$ In addition to the Broeks and Zwaan cases discussed in the

27 TK 2008/09, nr. 24, 1933-1944, 1943.

28 TK 2008/09, nr. 24, 1933-1944, 1943.

29 In its reply, the Minister of Foreign Affairs stated that the COs are placed on the website of the OHCHR and that they were sent to parliament together with a reaction. The reply did not mention any further initiatives to make the COs widely available. Concerning the withdrawal of the reservation to Article 10 ICCPR, the Minister made clear that he would again consider this. TK 2011/12, nr. 196.

30 TK 2010/11, 29754, nr. 202, 7.

31 See infra n. 86.

32 In one case the defendant, for example, brought up the COs about Algeria. Rb. Den Haag, 6 October 2008, LJN: BF9079, para. 3.10. In another, the defendant submitted a Tanzanian shadow report under ICCPR. Rb. Den Haag, 2 March 2010, LJN: BL7397.

33 In general, Dutch courts have used these Views mainly to confirm their own conclusions or support jurisprudence of national courts or the ECtHR. Rb. Den Haag, 21 December 2006, LJN: AZ5335. At other times, however, courts dismissed the Views of the HRC invoked by the 
introduction to this section, the Views of the HRC seem to have been of overriding importance on other occasions as well. The Central Appeals Tribunal, for example, adjusted its jurisprudence with respect to surviving dependants' benefits in line with the View of the HRC in Derksen v. the Netherlands. ${ }^{34}$ It was in response to this View that the Tribunal recognised that, although the HRC's Views are, formally speaking, non-binding, they should generally be regarded as being 'an authoritative opinion' and having 'special importance'. This means that, according to the Tribunal, national judicial authorities can only deviate from these Views when this is justified by weighty reasons. ${ }^{35}$ As a result of this judgment, the organisation implementing national insurance schemes (Svb) only granted Derksen her surviving dependants' benefits as from March 2006 while it denied her claim to benefits as from 1 July 1996. The Tribunal considered the latter denial to be in violation of Article 2(3) ICCPR since the Svb had not (fully) enforced the judicial remedies as granted in the Views. ${ }^{36}$

\subsection{NGOs}

NGOs have hardly used COs in their lobbing and advocacy work, which means that the extent to which NGOs have exerted pressure on the government and parliament by criticising the policies of government on the basis of COs is limited. Very few documents could be found in which the COs or the concerns of the HRC were alluded to. ${ }^{37}$ One exception is a follow-up meeting about the COs 2001 on 27 February 2002 organised by NJCM, which has so far coordinated the shadow

applicant. Hof Den Haag, 16 February 2005, LJN: AS6769, para. 9. Courts also considered that the Views are not 'newly emerged facts or changed circumstances' within the meaning of Article 4:6 of the General Administrative Law Act (Awb) as judgments of the ECtHR and the ECJ are. Rb. Zutphen, 2 February 2009, LJN: BH3039, para. 4.4.

34 The HRC concluded that the distinction under the new Surviving Dependants Act (ANW) between 'children born, on the one hand, either in wedlock or after 1 July 1996 out of wedlock, and, on the other hand, out of wedlock prior to 1 July 1996, is not based on reasonable grounds' and, thus, constituted a violation of Article 26 ICCPR. That is to say, the latter were denied benefits under the new ANW. The HRC was of the opinion that the government could have easily terminated this form of discrimination by extending the application of the new Act. Derksen v. the Netherlands, 1 April 2004, Communication No. 976/2001, U.N. Doc. CCPR/ C/80/D/976/2001 (2004), para. 9.3.

35 The Tribunal eventually determined that there were no valid weighty reasons for the government to deviate from the Views of the HRC. CRvB, 21 July 2006, LJN: AY5560. De Vries, Councillor of the Tribunal noted that this judgment was, to his knowledge, the only instance in which the jurisprudence of the Tribunal was changed as a result of the Views of the HRC. De Vries (2007), 83. CRvB, 4 May 2011, LJN: BQ3522, para. 4.1-4.6.

37 NJCM did send a letter to the Minister of Foreign Affairs in which it regretted the delay in sending a follow-up response to the HRC and CERD with respect to their COs of 2009 and 2010. The letter did not discuss any specific COs. NJCM, 'Uitblijven van regeringsreacties op aanbevelingen van VN-verdragscomités', 23 May 2011: <www.njcm.nl/site/uploads/ download/425>, accessed 31 July 2013. 


\section{ICCPR}

reports for ICCPR. ${ }^{38} \mathrm{NGOs}$ have also been consulted infrequently and on an ad hoc basis by the government in relation to state reporting. ${ }^{39}$

The lack of monitoring of follow-up in the context of ICCPR was also brought up by several representatives of the NGOs themselves. NJCM representatives acknowledged that NJCM could do much more with respect to follow-ups to the COs of the HRC and the other treaty bodies. One representative stated that in terms of follow-up, nothing happened. One reason that NGOs were not eager to start a follow-up and lobby process on the basis of the COs 2009 was the weak and general nature of the $\mathrm{COs}$ and the fact that a lot of recommendations were already superseded by the time they were published. ${ }^{40}$ One NGO representative explained that he/she had been involved in the process of drawing up a shadow report since May 2007 and that only after two years this resulted in something that did not go beyond mere generalities. This also makes clear why the focus of many NGOs was not so much on the slow process of state reporting but first and foremost on the more dynamic national level. Another explanation for the limited lobbying on the basis of COs is the limited number of NGOs with a civil rights focus in the Netherlands. ${ }^{41}$ There is also no NGO centred around the implementation of ICCPR as such. ${ }^{42}$ The NGO which has been most involved with respect to ICCPR, NJCM, focuses on the full spectrum of human rights and especially pays attention to the ECHR and CoE human rights regime (for more explanations see chapter $\mathrm{V}$, section 1.4).

38 During this meeting organised together with SIM, compliance with treaty obligations and reporting about this to the treaty bodies was discussed with government officials. The meeting was held in the parliamentary building as a result of which also some MPs were present, including two from the PvdA, one from CU and one from VVD. See the draft year report of NJCM April 2002 - April 200: <www.njcm.nl/site/uploads/download/88>, accessed 31 July 2013, 6 .

39 NGOs were consulted prior to the constructive dialogue with the HRC in order to discuss the LOI on 27 March 2009 at the Ministry of Foreign Affairs. No meeting took place, however, after the COs 2009.

40 It was noted that in order to lobby, a CO should be specific and of current interest. The generality of this $\mathrm{CO}$ easily allows the government to claim that the legislative proposal on the improved asylum procedure qualifies as such. The example was given of the CO 2009 recommending the state party 'to ensure that the procedure for processing asylum applications enables a thorough and adequate assessment by allowing a period of time adequate for the presentation of evidence. The state party must, in all cases, ensure respect for the principle of non-refoulement.' UN Doc. CCPR/C/NLD/CO/4 (2009), para. 9.

41 Recently, several smaller NGOs were founded, such as Bits of Freedom, Privacy First, and the Platform Protection of Civil Rights. These NGOs are primarily issue driven and focused on privacy and internet freedom.

42 A government official also noted that during the consultation prior to the dialogue in 2009 , a great number of NGOs were present that were all active in relation to one specific subject. As a result, it is difficult to maintain a dialogue, as is for example the case with respect to CRC. 


\subsection{Media coverage}

There was considerable media attention with respect to both dialogues with the HRC and resulting COs. Ten articles in the major newspapers alluded to the dialogue and the COs of 2001. The media focused almost exclusively on the issue of euthanasia. ${ }^{43}$ The media also actively sought a reaction of several MPs to the criticism of the HRC on the Dutch practice of euthanasia. ${ }^{44}$ The considerable media attention on this issue also explains the parliamentary scrutiny of the COs. Nine articles appeared in the major newspapers between 13 July and 4 August 2009 and the discussion and COs were referred to on three later occasions as well. Two journalists even attended the dialogue with the HRC in $2009 .{ }^{45}$ The articles especially focused on the criticism of the HRC concerning euthanasia and the storage of fingerprints on passports. ${ }^{46}$ Despite considerable media attention, the COs 2009 were not referred to in parliament in this period. The reason these articles led to little parliamentary scrutiny might simply be because parliament was in summer recess. ${ }^{47}$

\subsection{Conclusion}

In sum, the impact of the COs of the HRC has been rather limited. Both parliament and the government have hardly paid any attention to the COs, although several articles appeared in the press about the concerns of the HRC. The HRC's COs that had at least some notable impact were the COs about euthanasia and to a lesser extent the Medical Research (Human Subject) Act. Nonetheless, these COs were only given attention by the two opposition parties with a Christian profile, the CU and SGP. One important factor for the lack of parliamentary scrutiny is the fact that NGOs did not use COs in their lobby and advocacy.

43 See, for example, Frank Kuitenbrouwer, “Krachtige” vragen van VN over euthanasie', NRC Handelsblad, 30 July 2001, 3.

44 Several articles mentioned the response of MPs from CDA and the smaller political parties with a Christian profile and the fact that they wanted a response from the government. See, for example, 'Kamerleden willen reactie VN-kritiek', NRC Handelsblad, 31 July 2001, 3. Barbara Rijlaarsdam (NRC Handelsblad) and Gerard Beverdam (Nederlands Dagblad). The latter newspaper is not accessible via LexisNexis. The latter journalist wrote four articles about the criticism of the HRC on euthanasia, the SGP and the storage of fingerprints. See, for example, 'Kritiek VN op beleid euthanasie' / 'Scepsis bij VN over opslag vingerafdrukken', Nederlands Dagblad, 15 July 2009, 1 and 3.

46 See, for example, Barbara Rijlaarsdam, 'Buitenlandse kritiek op SGP en euthanasie; Minister voor VN-mensenrechtencommissie', NRC Handelsblad, 2.

47 Note that questions were asked to the European Commission by a Dutch member of the European Parliament, Hennis-Plasschaert, about the storage of fingerprints on passports on 5 August 2009. In her question, she referred to statements of the Minister of Justice during the dialogue with the HRC. E-3962/09. Böhre (2010), 114-120. 


\section{ICCPR}

\section{Assessing the effectiveness of COs}

This section will sketch the effectiveness of COs on the basis of the reaction of the government in its letters to parliament ${ }^{48}$ and in the documents sent to the HRC. ${ }^{49}$ This section calls into question the extent to which legislative or policy changes have been made as a result of the HRC's COs. The government rejected several recommendations (chapter VI, section 2.1) or it argued that the legislative or policy framework already addressed the concerns of the HRC sufficiently (chapter VI, section 2.2). Further support for the ineffectiveness of the COs of the HRC is that government officials and NGO representatives could not give examples of COs that were (partly) effective. It is therefore not surprising that the 2008 NGO report provided that 'NGOs doubt whether the government feels obliged to implement these Observations' ${ }^{50}$

Although the COs might not have led to a (fundamental) change in policy or legislation, this does not mean that the government has not taken the process of state reporting and the COs seriously. Government officials argued during interviews that COs have been seriously examined and discussed even though they have not resulted in actual policy or legislative changes. The government made clear, for example, that it would take another look at whether the reservation to Article 10 could be withdrawn in its reaction to the COs $2009 .{ }^{51}$ As we have seen, the government paid attention to the concerns of the HRC, especially with respect to euthanasia and medical research as well (chapter VI, section 1.1). In addition, the euthanasia review committees were informed of the COs 2001 and the government's reaction. ${ }^{52}$ Likewise, the government asked the Central Committee on Research Involving Human Subjects (CCMO) 'to pay close attention to compliance with the law in the case of non-therapeutic research involving minors and/or decisionally incapacitated adults.'.53

\subsection{COs that have been rejected}

The government has disagreed with several COs and justified why it has chosen not to act upon them. The government has, firstly, argued that the criticised policy or legislative practice is already subject to adequate safeguards and is, hence, already addressing the concerns of the HRC sufficiently. In these instances, the government

Supra n. 12-13.

UN Doc. CCPR/CO/72/NET/Add.1 (2003). UN Doc. CCPR/C/NET/4 (2008).

NJCM (2008), 1. Note, however, that the alternative report did not assess the level of compliance with specific COs 2001. The report did, however, refer to COs of the CEDAW Committee 2007, CRC 2004 and CAT 2007. The same holds true for the Addendum to the Commentary. NJCM (2009a).

$51 \quad$ TK 2009/10, 32123 VI, nr. 11, 2.

52 TK 2001/02, 26691/22588, nr. 45, 5.

53 UN Doc. CCPR/C/NET/4 (2008), para. 76. 
contrasts the HRC's considerations with its own appraisal and concludes that the practice is already in conformity with the ICCPR. These arguments were, for example, used in relation to the COs with respect euthanasia, ${ }^{54}$ the Medical Research (Human Subjects) Act ${ }^{55}$ and the trial of suspects within a reasonable time instead of the two years that pre-trial detention may last. ${ }^{56}$

A second way of justifying noncompliance with $\mathrm{COs}$ is by referring to the ECHR and especially the jurisprudence of the ECtHR. ${ }^{57}$ A good example of this is the reaction of the government to the HRC's COs with respect to the maximum of 3 days and 15 hours which may lapse between a suspect's arrest and being brought before a judge. ${ }^{58}$ The HRC considered that this period does not satisfy the requirement in Article 9(3) ICCPR of being 'promptly' brought before a judicial authority. The Minister was, however, of the opinion that there is sufficient reason to speak about 'promptly', also with a view on the jurisprudence of the ECtHR. ${ }^{59}$ The Minister referred to Brogan in which the ECtHR concluded that the Dutch regulation did not violate the requirement of being 'promptly' brought before a judicial authority. ${ }^{60}$ Likewise, in reaction to the recommendation of the HRC to ensure that all persons are tried within a reasonable time, the Minister mentioned that the ECtHR has examined the Act several times, without concluding that it violated the ECHR. ${ }^{61}$ A third example is the reaction to the CO 2001 concerning the too broad use of anonymous witnesses, in which the Minister of Justice argued that the government has made use of the margin left in the 'standard jurisprudence' of the ECtHR. In this context, two judgments of the ECtHR against the Netherlands were mentioned. ${ }^{62}$

A third argument used by the government is the extensive domestic discussion whereby the conformity of policy and legislation was carefully reviewed. With respect to the HRC's recommendation regarding Medical Research (Human

54 TK 2000/01, 26691/ 22588. nr. 42, 2-3. TK 2009/10, 32123 VI, nr. 11, 3.

55 UN Doc. CCPR/CO/72/NET (2003), para. 7. TK 2001/02, 26691/22588, nr. 45, at 3. TK 2009/10, 32123 VI, nr. 11, 3-4.

56 UN Doc. CCPR/C/NLD/CO/4 (2009), para. 12. The Minister of Justice concluded that the Dutch criminal procedural system does contain sufficient safeguards that are in line with the recommendation of the $\mathrm{HRC}$, that intend to realise that suspects are tried within a reasonable time. TK 2009/10, 32123 VI, nr. 11, 5.

57 In addition to the ECHR, the government also pointed to other international obligations. The government, for example, argued that the Medical Research (Human Subjects) Act is in conformity with EU legislation and the Convention on Human Rights and Biomedicine. TK 2009/10, 32123 VI, nr. 11, 3-4.

58 UN Doc. CCPR/CO/72/NET (2003), para. 13.

59 UN Doc. CCPR/C/NET/4 (2008), para. 127.

60 TK 2001/02, $28000 \mathrm{VI}, \mathrm{nr} .54,7$.

61 TK 2009/10, 32123 VI, nr. 11, 5-6.

62 UN Doc CCPR/CO/72/NET (2001), para. 12. In these cases, the ECtHR considered that the use of statements made by anonymous witnesses is not incompatible with the ECHR under all circumstances. Doorson v. the Netherlands, 26 March 1996, Application no. 20524/92. Van Mechelen and others v. the Netherlands, 30 October 1997, Application no. 21363/93, 21364/93, 21427/93, 22056/93. 


\section{ICCPR}

Subjects) Act, the government, for example, underlined that parliament had discussed the arguments for medical experiments extensively during the consideration of the legislative proposal. ${ }^{63}$ It held that after weighing all the arguments carefully a choice was made by both government and parliament with an overwhelming majority. The government also held that the 'Dutch legislator' regarded this choice to be in compliance with treaty requirements. ${ }^{64}$ With respect to the Termination of Life on Request and Assisted Suicide Act, the government likewise underlined that the concerns which were later expressed by the HRC were already at the forefront during the preparation of the legislative proposal and the parliamentary discussion. ${ }^{65}$ In addition, the government simply pointed to the coalition agreement determining that no amendments would be made in the period of office. ${ }^{66}$

The reference to the extensive and careful discussion, the parliamentary approval of legislation and the coalition agreement mirror statements of government officials that COs are simply taken note of when they relate to clear and deliberate policy choices backed up by a parliamentary majority. Officials made clear that the difficulty with the implementation of COs is that policy and legislation is often fixed in the coalition agreement for the period of office of the government. Hence, both MPs and government officials simply 'agree to disagree' with treaty bodies on these points. Several government officials argued that euthanasia is a political nonissue in the Netherlands given the political consensus in favour of the policy. As will be discussed in the next section, government officials regretted that the discussion with the HRC focused on issues that 'we cannot get explained anyway' like the policy on euthanasia, while there were a lot of other issues that could have better be discussed.

\subsection{Standing policy and legislative measures in line with the COs}

The government did not disagree with all COs. That is to say, several recommendations were supported and the government made clear in its reaction that measures were taken in line with the COs. Nevertheless, even when measures have allegedly been taken in line with COs, one could question whether the measures were also taken as a result of the COs. It could be argued that COs simply coincide with measures which had already been in place or foreseen, especially because several COs have been rather general. This was also made clear by several government officials themselves who argued that the COs simply reflect existing initiatives and standing policy and legislative measures. The government, for example, referred to several initiatives that had been employed 'already' in the

63 Almost all political groups asked a question about the conformity of the proposed Bill with Article 7 ICCPR. See, for example, TK 1995/96, 22588, nr. 7, 39 and 44-45.

64 TK 2001/02, 26691/22588, nr. 45, 6-7. UN Doc. CCPR/C/NET/4 (2008), para. 71-75.

65 TK 2000/01, 26691/ 22588. nr. 42, 2.

66 TK 2009/10, 32123 VI, nr. 11, 3. 
preceding years in reply to the CO 2001 to continue the development of strategies designed to prevent child abuse. ${ }^{67} \mathrm{In}$ its reaction to the recommendation to standardise the systems and measures employed by its advisory centres dealing with child abuse, the government also stated that the methods of working were 'already' protocolled. As a result, the government took the view that it had already acted upon the recommendation of HRC sufficiently. ${ }^{68}$

Similarly, the letter sent to parliament with a reaction to the COs 2009 primarily enumerated initiatives and measures which had already been taken. ${ }^{69}$ The Minister of Justice, for example, referred to several existing and intended measures with respect to the right to contact counsel in the context of a police interrogation and the lawyer-client confidentiality of telephone conversations. ${ }^{70}$ That is to say, the Minister had already sent a letter to parliament prior to the dialogue with the HRC in which a probable legislative change was announced as a consequence of two judgments of the ECtHR about suspects' right to access to a lawyer (for a further discussion see chapter IX, section 2.1). ${ }^{71}$

\section{3. (Partly) effective COs}

As was said before, government officials and NGO representatives could not give many examples of COs that were (partly) effective. Only two COs were mentioned. One government official and one NGO representative both pointed to media coverage of the dialogue with the HRC in 2009 that had - in their view - as a result that the issue of central storage of fingerprints was put on the agenda. ${ }^{72}$ The Act providing for such a national database for biometric data was adopted by the Senate shortly before the dialogue with the HRC on 9 June $2009 .{ }^{73}$ NGOs strategically used the process of state reporting to raise the matter and generate publicity for this Act. ${ }^{74}$ The NGOs managed to have the HRC raise a question about this during the dialogue. The issue was also picked up by the media (chapter VI, section 1.5). Remarkably, the issue was not included in the COs, although a question was asked

\footnotetext{
67 UN Doc. CCPR/CO/72/NET (2001), para. 9.

68 TK 2001/02, 28000 VI, nr. 54, 2-3.

69 See, for example, the measures that were outlined in relation to the labour market participation of women and discrimination of ethnic minorities in the labour market. TK 2009/10, 32123 VI, nr. 11 .

$70 \quad \mathrm{CCPR} / \mathrm{C} / \mathrm{NLD} / \mathrm{CO} / 4$ (2009), para. 11 and 14.

71 TK 2008/09, 31700 VI, nr. 117. UN Doc. CCPR/C/NLD/Q/4/Add.1 (2009), para. 90.

72 'Organisaties protesteren bij VN tegen bewaren paspoortgegevens voor opsporingsdoeleinden', Het Parool, 13 July 2009, page unkown. Barbara Rijlaarsdam, 'Vingerafdruk wellicht weg uit paspoort; Minister na kritiek op privacy', NRC Handelsblad, 15 July 2009, 3. Max Snijder, 'Wat wil Hirsch Ballin met de Paspoortwet? Reactie op minister op kritiek van VN-comité roept vragen op; privacy nog steeds in het geding', NRC Handelsblad, 24 July 2009, 7.

73 Only D66, GL and the SP voted against the Bill.

$74 \quad$ NJCM (2009a), 1.
} 
by Sir Rodley during the dialogue. ${ }^{75}$ Despite considerable media attention, the criticism of the HRC as to the storage of fingerprints was not picked up and explicitly referred to by parliament.

In April 2011, the government decided to suspend the storage of fingerprints. ${ }^{76}$ This decision was influenced by the increased media attention, political debate and civil society involvement together with concerns expressed at the municipal level and the court cases. It is difficult to assess what the contribution of the (media coverage of the) HRC's criticism to this national discussion was and whether it indeed had an agenda-setting function as some claim. ${ }^{77}$ An argument against this position would be that the issue of storage of fingerprints was already given attention in the media before the dialogue with the HRC. ${ }^{78}$ Nonetheless, the fact that the media picked up the issue might in any case have kept or put the issue of storage of finger prints higher on the agenda. This means that the comments of the HRC were at least one contributory element.

A government official and NGO representative also mentioned the withdrawal of the Bill on Administrative Measures for National Security as an example of a measure in relation to which the COs have played a role, albeit a minimal one. This Bill contained provisions that restrict the freedom of movement and privacy of persons suspected of being 'associated with terrorist activities' ${ }^{79}$ The government had already requested before the dialogue with the HRC that the Senate hold over the legislative proposal pending the results of a comprehensive evaluation of the package of counterterrorism measures. ${ }^{80}$ This decision to postpone the consideration of the Bill was taken on the basis of the report of the Committee on the Evaluation of Counterterrorism Policy (Suyver Committee) in 2009. ${ }^{81}$ Minister

75 UN Doc. CCPR/C/SR.2630 (2009), para. 27. When asked about the reasons for this, Sir Rodley stated: 'reasons could range from accidental oversight to lack of agreement (which may be deep or merely a matter of uncertainty that there isn't enough time to talk through) about the existence or nature of a problem under the ICCPR'. Böhre (2010), 115.

76 The letter announcing this decision did not refer to the ICCPR, ECHR, human rights, or the issue of privacy. TK 2010/11, 25764, nr. 46, 3-4. For the government Bill, see TK 2012/13, 33440-(R1990) nr. 2.

77 Böhre (2010), 114-120.

78 Some examples are Barbara Rijlaarsdam, 'Verzet tegen digitaal hamsteren', NRC Handelsblad, 10 June 2009, 2. Jeroen Trommelen, 'Maatschappelijk belang gaat bij paspoortwet voor de privacy', de Volkskrant, 12 June 2009, 3. For more references to articles in the printed press see Böhre (2010), 113 and 141. This study mentioned that the first wave of critical media coverage started at the end of June 2009. Another study, however, noted that agenda setting developments in the media and by civil society started already in 2008. Koops (2011), 176-177.

79 UN Doc. CCPR/C/NLD/CO/4 (2009), para. 10.

80 Parliament was informed about this request on 9 July 2009, five days before the dialogue with the HRC. TK 2009/10, 29754, nr. 164, 3. Note that the ICCPR was not considered during the parliamentary discussion about the Bill by both the government and parliament, except one slight reference to Art. 12 ICCPR in the Explanatory Memorandum and the VDD in the Senate. EK 2005/06, 30566 nr. 3, 10. EK 2005/06, 30566 nr. 5, 7.

81 This temporary Committee was established on 1 October 2008 in response to a motion proposed by Pechtold (D66) asking the government how an evaluation of terrorism measures could be 
of Justice Opstelten eventually decided to withdraw the Bill on the basis of the comprehensive evaluation of 2011. ${ }^{82}$ The letter which announced this decision did not refer to the HRC or the ICCPR. ${ }^{83}$ A strong causal relation seems, thus, absent. This was also confirmed in interviews during which the Suyver Committee was mentioned as the crucial factor in the decision to withdraw the Bill, as well as the criticism of the Senate. ${ }^{84}$ Nonetheless, the CO played a small role in the legal background study which was part of the 2011 evaluation. ${ }^{85}$ This study analysed the legality of six anti-terrorism measures, including the Bill, in the light of national jurisprudence, jurisprudence of the ECtHR and the recommendations of the HRC and the European Commissioner on Human Rights. The $\mathrm{CO}$ was used to offer additional legal support for the conclusions together with the output of other international monitoring bodies. As we have seen, the $\mathrm{CO}$ was also mentioned by a Senator, probably as a result of its inclusion in the legal study (chapter VI, section 1.2). ${ }^{86}$

\section{TREATY SPECIFIC REASONS FOR THE (IN)EFFECTIVENESS OF COS}

\subsection{Factors related to the domestic context}

One important reason for the limited effectiveness of the COs of the HRC is the almost complete absence of domestic mobilisation and lobbing in relation to the COs. One explanation for the latter is the dominance of the better known ECHR and the ECtHR which issues binding judgments. As a result, parliament, the government, the media, legal practice, academic literature, and NGOs are primarily geared towards this regional regime to the exclusion of the ICCPR and the HRC. This difference between the ICCPR and ECHR is also illustrated quantitatively by table 6.1.

designed. TK 2007/08, 31200 VI, nr. 79. The report of the Suyver Committee only considered ECHR and not ICCPR. Rapport van de Commissie evaluatie antiterrorismebeleid, 'Naar een integrale evaluatie van antiterrorismemaatregelen', The Hague, 2009.

82 TK 2010/11, 29754, nr. 199, 2.

83 It only mentioned the conclusion of the study that the six anti-terrorism measures examined do not violate the ECHR. The most important reason for the withdrawal of the Bill was that administrative counterterrorism measures had become outmoded since procedural powers in criminal cases had already been expanded. EK 2010/11, 30566, nr. E.

84 EK 2006/07, 30566, nr. B. EK 2007/08, nr. C and D.

85 The COs were also considered in relation to the Detention and Prosecution of Terrorist Crimes Act, the Protected Witnesses Act and the Personal Disruption Measure. UN Doc. CCPR/C/ NLD/CO/4 (2009), para. 12, 13 and 15. For the legal study see Van Kempen and Van de Voort, 'Nederlandse antiterrorismeregelgeving getoetst aan fundamentele rechten. Een analyse met meer bijzonder aandacht voor het EVRM', Radboud Universiteit Nijmegen, Nijmegen, 2010. This study is added as attachment $\mathrm{H}$ to the evaluation itself. 'Antiterrorismemaatregelen in Nederland in het eerste decennium van de 21e eeuw', The Hague, 2011.

Supra n. 31 . 
Table 6.1. References to the ICCPR and ECHR in the Netherlands (1995-2011) ${ }^{87}$

The number of parliamentary papers and court judgments in which the ICCPR or ECHR was mentioned. 'Media' relates to the number of newspaper articles which referred to the HRC or the ECtHR.

\begin{tabular}{|l|c|l|}
\hline & ICCPR & ECHR \\
\hline Government & 354 & $5261^{88}$ \\
\hline Parliament & 186 & 5261 \\
\hline National courts & 1279 & $16138^{89}$ \\
\hline Media & $50($ HRC) & $806^{90}$ (ECtHR) \\
\hline
\end{tabular}

One government official admitted that the added value of ICCPR is consequently limited and is primarily of a symbolic value. Participation in the process of state reporting under ICCPR is done largely out of foreign policy considerations. As we have seen, non-compliance with COs of the HRC has sometimes been justified with reference to the jurisprudence of the ECtHR or the ECJ (chapter VI, section 2.1). ${ }^{91}$ A government official noted that this is the best and most legitimate argument against implementing certain 'opinions' of the HRC, since judgments of the ECtHR (and ECJ) are binding. The jurisprudence of the ECtHR has been prioritised over the HRC by national courts and in academic literature. ${ }^{92}$

One important factor for the ineffectiveness of the COs is, thus, the dominance of the ECHR and the ECtHR in the Dutch legal order. As a result, the ICCPR and the HRC, as well as other UN human rights treaties and treaty bodies are often overlooked, as was also already noted with respect to CERD (chapter V, section

87 For a further discussion of this table, see Krommendijk (2013a), 215-217 and 223-224.

88 Searched with 'EVRM' [ECHR] in the period of 1 September 1995 until 31 August 2011 in parliamentary papers via zoek.officielebekendmakingen.nl. The papers were not screened for their relevance, nor was a distinction made between references by the government and parliament.

89 Searched with 'EVRM' [ECHR] in the court judgments until 31 August 2011 on www. rechtspraak.nl.

90 Searched with 'Europees Hof voor de Rechten van de Mens' [ECtHR] in the period of 1 September 1995 until 31 August 2011 in LexisNexis. The number of articles referring to the 'Europees Verdrag voor de Rechten van de Mens' [ECHR] was 761.

91 This argument is also used sometimes in the government's reaction to the Views of the HRC. See, for example, the reaction to Derksen $v$. the Netherlands in which the jurisprudence of the ECtHR was relied upon. Government Gazette (Staatscourant) 2004, 165. Likewise, the government alluded to the jurisprudence of the ECJ in its reaction to Vos v. the Netherlands, 26 July 1999, Communication No. 786/1997, UN Doc. CCPR/C/66/D/786/1997 in Government Gazette (Staatscourant) 1999, 214.

92 See, for example, a case in which a court dismissed the statement of the applicant with an appeal to the comments of the HRC by pointing to a judgment of the ECtHR and the Supreme Court. Hof Amsterdam, 23 September 2010, LJN: BN8613. 
3.1). ${ }^{93}$ During interviews, government officials contrasted the binding - and in their view more authoritative - judgments of the ECtHR with the non-binding COs which is seen as noncommittal 'advice' or mere 'opinions' that can easily be rejected ${ }^{94}$ Officials argued that the legally binding character of the judgments of the ECtHR does not only clearly affect the authority of the Court positively, but that it also increases the impact of its judgments..$^{95}$ The government has pointed to the non-binding nature of COs as a reason for non-compliance on several occasions..$^{96}$ Likewise, the government made clear that the HRC 'is not a judge' and that the consideration of individual complaints does not result in a legally binding judgment but an opinion. The government, hence, stated that appropriate measures may be taken on the basis of such an opinion. ${ }^{97}$ The Minister of Justice also held that it is primarily up to the national judge to decide legally whether certain acts or regulations are in conformity with the fundamental rights in the ICCPR with respect to the COs about the Medical Research (Human Subjects) Act. ${ }^{98}$

Above all, there seems to be the idea in government circles that if one complies with the ECHR and EU law, then one also automatically complies with the standards in UN human rights treaties. This view, however, neglects that treaty standards, ${ }^{99}$ but above all, the interpretation of these standards by international courts or committees, may differ. As was mentioned already in relation to ICERD, it appears that the government gives preference to the more precise obligations in

93 The Minister of Foreign Affairs, for example, stated that the procedures before the ECtHR are by far the most important in comparison with proceedings under other human rights treaties. TK 1999/00, 26800 V, nr. 19, 55-56. Loof also observed that the Dutch legislator is focused on Strasbourg and does not take into account that the obligations under other human rights treaties might be more demanding and far reaching. He gave the example of the time between a suspect's arrest and brought before a judge, Article 5 (3) ECHR and Article 9 (3) ICCPR, citing also the Brogan judgment and COs 2001 to show a divergence in views between the ECtHR and the HRC. Loof (2008), 116-117.

94 See Article 46(1) ECHR. The re-opening of criminal trials is limited to the binding judgments of the ECtHR and not the Views of the HRC. EK 2001/02, 27726, nr. 216b. Van Emmerik (2008), 134. Loof (2008), 102-103. Supra n. 33.

95 Government officials noted that a state could expect to be rapped over the knuckles by these Courts almost on a daily basis. This has an effect on parliamentary scrutiny as parliament is often right on the ball and frequently summons the Minister to the weekly question time in parliament. In addition, judgments of the ECJ and ECtHR are applied by domestic courts who feel obliged to follow legal precedents. See also Van Dam (2009), 104-106 and 110-111.

96 Supra n. 1. TK 2001/02, 26691/22588, nr. 45, 6-7. TK 2002/03, 28100, nr. 7, 8. TK 2007/08, 31263 , nr. 9, 37.

97 TK 2002/03, nr. 1639. TK 2002/03, 28600 VI, nr. 38, 2. See also Redactioneel (2012), 387.

98 TK 1996/97, nr. 36, 7341-7354, 7352.

99 One major difference between ICCPR and ECHR used to be Article 26 ICCPR, but this has been overruled by Protocol 12. The only remaining material difference with ECHR is perhaps the right to appeal under Article 14(5) ICCPR. The HRC concluded in an individual communication that this article is violated since the right to appeal in less serious criminal cases is limited by means of a system of leave. Mennen v. the Netherlands, 24 August 2010, Communication No. 1797/2008, UN Doc. CCPR/C/99/D/1797/2008. 
ICCPR

the context of the ECHR and the EU and that it often wants to have an authoritative statement of the law through a definite binding judgment by a(n inter)national court.

\subsection{The (perceived) quality of the HRC}

Interviewees were rather critical about the functioning of the HRC. Government officials especially regretted the general and superficial nature of the dialogue with the HRC. It was lamented that a lot of time was simply lost with general country information and the explanation of basic issues, which was seen as reflective of a lack of basic background knowledge. Remarkably, the delegation had to respond orally to the questions in the LOI at the start of the dialogue in 2001 and 2009, although the replies had already been provided in written form in advance. This was considered a pity in the light of the elaborate preparation by the government delegation. Several interviewees wondered whether the HRC truly understands the situation in the Netherlands, also given the questions on irrelevant or marginal issues for the Netherlands. An NGO representative also argued that the HRC was hardly prepared, if at all. An example is the question of Bhagwati whether the risk of being subjected to genital mutilation in the country of origin constitutes grounds for granting asylum, although this issue was discussed in the state report. He also raised a question about legal aid for asylum seekers despite information in the report. 100 Another issue which was considered damaging for the authority and professionalism was the fact that one older expert member was continuously drawing pictures and when speaking was only babbling in an inarticulate way.

Government officials also regretted that the discussion with the HRC in 2001 and 2009 was dominated by more principled issues such as euthanasia, abortion and prostitution. ${ }^{101}$ Several government officials qualified the questions posed by the American expert member Wedgwood about euthanasia in 2009 as emotional and political. This is because she referred to her own demented father and drew a parallel between the European criticisms on the death penalty in the US. ${ }^{102}$ Interviewees considered the focus on these principled ethical issues a pity, first of all, because they had the idea that they cannot get these policies explained to expert members from countries with a different cultural and legal system. Officials noted an almost insurmountable difference in views between the government and the HRC in this context. Secondly, it was noted that the practice of euthanasia was not

100 UN Doc. CCPR/C/SR.2630 (2009), para. 23. For the information, UN Doc CCPR/C/NET/4 (2008), para. 23 and 191.

101 During the dialogue in 2001, five expert members asked questions about euthanasia. UN Doc. CCPR/C/SR.1929 (2001), para. 25, 30-31, 34, 36 and 38-39. UN Doc. CCPR/C/SR.1930 (2001), para. 57. Likewise, three members asked questions about the Medical Research (Human Subject) Act. UN Doc. CCPR/C/SR.1929 (2001), para. 26 and 32-33. UN Doc. CCPR/C/SR.1930 (2001), para. 57. During the dialogue in 2009, three expert members asked questions about euthanasia. UN Doc CCPR/C/SR.2630 (2009), para. 37. UN Doc. CCPR/C/SR.2631 (2009), para. 24, 69. 
necessarily contrary to ICCPR. Thirdly, it was considered that there were a lot of other issues that would have been better to discuss. In general it was observed that the dialogue with HRC was more political and emotional than other treaty body dialogues. Expert members were also said to primarily ride their hobbyhorses and put forward a question for the mere sake of asking something more often.

Interviewees also noted the enormous diversity of matters raised in relation to ICCPR during the dialogue in 2009. The HRC was said to ramble from one subject to another. As a result of the tornado of questions and the limited time, answers were simply rushed through as a result of which important issues were or could not be mentioned. Government officials also noted the overlap between several committees and, hence, argued that several issues could have been dealt with better under other UN human rights treaties, such as employment and the situation of minorities. ${ }^{103}$ Another official pointed to the difference between committees with respect to the COs. While the HRC commended the Netherlands on its policy on human trafficking, CEDAW raised its concerns and had several recommendations in 2010 .

Interestingly, one HRC expert member held in 2001 that 'there were clearly more issues for concern in the Netherlands Antilles than there were in the European territory of the Netherlands. ${ }^{104}$ Nonetheless, the subsequent COs 2001 contained ten paragraphs with subjects of concern and recommendations for the European Part and only six for the Netherlands Antilles and three for Aruba. The COs 2009 even contained sixteen recommendations for the Netherlands, only five for the Netherlands Antilles and only one for Aruba. In this light it is, therefore, not surprising that government officials had the idea that the more developed countries are monitored more rigorously. It is noteworthy that one expert member of the HRC also warned against 'the tendency to hold certain countries to higher standards than those required under the Convention', which in his view could turn out to be counterproductive. ${ }^{105}$ This remark was also referred to by a government official during the interview.

As was already mentioned, several interviewees noted the weakness and generality of the COs 2009 and the fact that many of them were already superseded by the time they were published. ${ }^{106}$ Some government officials had the idea that the

103 For questions related to the position of women, see UN Doc. CCPR/C/SR.2630 (2009), para. 41. UN Doc. CCPR/C/SR.2631, para. 56-57 and 61. Questions about ethnic minorities in UN Doc. CCPR/C/SR.2630 (2009), para. 54, 59 and 61. See also the COs 2009. UN Doc. CCPR/C/NLD/ $\mathrm{CO} / 4$, (2009), para. 5, 6 and 19.

Solari Yrigoyen in UN Doc. CCPR/C/SR.1930 (2009), para. 25. Likewise, several expert members commended the international leadership role of the Netherlands. Amor held that: 'the Netherlands contributed significantly to the protection and promotion of human rights and it was therefore all the more disconcerting when marginal issues arose.' UN Doc. CCPR/C/SR.2630 (2009), para. 71. See also UN Doc. CCPR/C/SR.2630 (2009), para. 24, 41 and 43.

106 One official also noted that the dialogue in 2001 was superseded, because the of the time span between the submission of the report and its consideration. The discussion of the consolidated 
COs were already completed before the actual dialogue, while also noting that several recommendations were simply taken over from NGOs without conducting their own investigation. Government officials noted that exactly because of the broader range and variety of issues covered, the ICCPR and the HRC's COs have less impact and are less effective.

The HRC has hardly monitored the implementation of its COs in the LOI, ${ }^{107}$ during the constructive dialogue ${ }^{108}$ or in the COs, besides the written follow-up procedure in which the government is asked to reply to some of COs. ${ }^{109}$ This is even more striking given the fact that the government showed its open and explicit disagreement with the HRC in its state reports or follow-up replies to the COs. The government, for example, held in relation to the time period between the arrest of a suspect and his/her appearance before a judge that 'while recognising the Committee's concerns, the government continues to maintain that the period referred to in Article 59a of the Code of Criminal Procedure is sufficiently prompt." 110 This issue was not included in the LOI, nor was it picked up by the HRC during the dialogue in 2009. Likewise the LOI did not raise a question about the Witness Identity Protection Act, although the government stated in its fourth report that it regretted the concerns of the HRC, because it held the opinion that the Act 'incorporates adequate safeguards.' 111 It is therefore unclear whether the HRC actually does something with the follow-up to the replies of the government to the COs, if at all.

\section{Conclusion}

Except for the COs about euthanasia and the Medical Research (Human Subject) Act, the COs of the HRC have been given little attention by parliament, the

third report was postponed several times. The third report, which was submitted on 28 July 2000, was a consolidation of reports submitted earlier, in 1995, 1997 and 1998. The report covered the period September 1986 to January 1996. The introduction to the third report provided that 'due to variety of reasons, considerable time has lapsed between the submission of this report in 1997 and its publication'. UN Doc. CCPR/C/NET/99/3 (2000), para. 1.

107 While the LOI to the third report did not discuss previous COs, the LOI to the fourth report only mentioned earlier COs twice, in relation to the Netherlands Antilles and more generally the involvement of civil society in the implementation of the COs. UN Doc. CCPR/C/NLD/Q/4/ (2008), para. 21 and 27.

108 The only exception is the statement made by Wedgwood concerning the medical experiments. She held: 'By deciding to disregard the Committee's recommendation, did the Netherlands not run the risk of giving too much latitude to the medical profession?' UN Doc. CCPR/C/SR.2630 (2009), para. 38 .

109 The COs 2001 do not mention previous COs at all, whereas those of 2009 only refer to earlier observations with respect to euthanasia and medical experimentation. UN Doc. CCPR/C/NLD/ $\mathrm{CO} / 4$ (2009), para. 7-8.

110 UN Doc. CCPR/C/NET/4 (2008) para. 127.

111 UN Doc. CCPR/C/NET/4 (2008) para. 192. 
government and NGOs. The COs of the HRC have by and large remained ineffective partly as a result the absence of domestic mobilisation. The only $\mathrm{CO}$ that has played some role at the national level is the concern of the HRC as to the central storage of fingerprints. The media attention for the critical questions of the HRC about the issue kept or put the matter higher on the political agenda. One factor that has contributed to the ineffectiveness of many of the other COs is the exclusive focus of domestic actors on the ECHR. In addition, there is an idea in government circles that the Netherlands is in compliance with the ICCPR when it conforms to the ECHR and the judgments of the ECtHR. 


\section{Chapter VII ICESCR}

'The Covenant came about under great pressure of the former communist countries.

We believed that we could not distance ourselves too much because of the attempts to build bridges between countries.' [Former Minister of Education Ritzen in 1996] ${ }^{1}$

The impact and effectiveness of the COs of CESCR is the focus of this chapter. The implementation of ICESCR in the Netherlands has been discussed three times by CESCR since 1995. The major concern of CESCR in its COs of 1998, 2006 and 2010 was related to the fact that Dutch courts and the government do not consider the provisions of ICESCR to have direct effect, which means that they cannot be applied by courts. ${ }^{2}$ CESCR has also issued recommendations in relation to, among others, racial discrimination, gender equality, violence against women and the increase of tuition fees at the end of the 1990s.

\section{DOMESTIC IMPACT AND DOMESTIC MOBILISATION}

\subsection{Governmental attention}

The government has only minimally informed parliament about the process of state reporting under ICESCR. Parliament was not informed about the state report of 1996 or the COs 1998. Although the third state report of 2006 was sent to parliament, it was only provided with a short letter summarising the issues that were raised by the CESCR during the dialogue in 2006, with the COs 2006 attached. The letter did not contain a substantive reaction to the COs $2006 .{ }^{3}$ Although the combined fourth and fifth report of 2008 was sent to parliament, the LOI and the replies of the government were not forwarded. It is noteworthy that an extensive reaction to the most recent COs of 2010 of 20 pages was sent to parliament by the Minister of Social Affairs and Employment. ${ }^{4}$

1 'Het verdrag tot stand is gekomen onder grote druk van de toenmalige communistische landen. Wij vonden dat wij daarvan, in termen van het proberen creëren van bruggen tussen landen, niet al te veel afstand konden nemen'. EK 1995/96, nr. 23, 1305-1322, 1318 and 1331.

2 UN Doc. E/C.12/1/Add.25 (1998), para. 21. UN Doc. E/C.12/NLD/CO/3 (2006), para. 19. UN Doc. E/C.12/NDL/CO/4-5 (2010), para. 6.

3 It was only mentioned that a response to the COs 2006 would be included in the subsequent report which would be submitted to the CESCR. TK 2005/06, buza060088. TK 2007/08, 31200 V, nr. 82 .

4 TK 2010/11, nr. 2729. 
The government has never referred to the COs in other policy notes, legislative proposals and parliamentary papers on other occasions than in these letters. ${ }^{5}$ CESCR's COs are, thus, worst off of all the six treaty bodies. This also reflects the limited role of ICESCR in the government bureaucracy more generally. After ICERD, ICESCR has been the least mentioned UN human rights treaty in governmental papers (123 references). ICESCR has also hardly been considered and tested against policy and legislative proposals. Only in thirteen Explanatory Memoranda has the ICESCR been referred to. ${ }^{6}$ When ICESCR is cited, the government often emphasises the absence of direct effect of the provisions of ICESCR, ${ }^{7}$ as well as the generality of the provisions. ${ }^{8}$ In order to substantiate this lack of direct effect and the alleged margin of appreciation for the authorities, the government usually points to the jurisprudence of the Supreme Court (section 1.3). ${ }^{9}$

\subsection{Parliamentary scrutiny}

The COs or the implementation of ICESCR has never been tabled in parliament. ${ }^{10}$ Parliament has never introduced a motion or a legislative proposal to give effect to COs. Moreover, the considerable delay in reporting on the part of the government has not been addressed by parliament either. Only on four occasions were rather noncommittal questions raised or statements made with respect to the COs. This means that only the COs of the CAT Committee have been mentioned less by MPs. First, Rabbae (GL) submitted a written parliamentary question about the 'judgment' of the CESCR in 1998 that the Dutch policy with respect to tuition fees was in violation of ICESCR. ${ }^{11}$ It seems likely that this question was the consequence of

5 There was one reference to the COs 2007 for the Netherlands Antilles welcoming the measures aimed at increasing the duration of compulsory education and combating school dropout. TK $2007 / 08$, nr. 815 .

6 Interestingly, eight are related to the right to education in Article 13 ICESCR. See, for example TK 1996/97, 25321, nr. 3, 3-4.

7 See, for example, the Explanatory Memorandum to the Bill regulating prostitution and abuse in the sex industry referring to Article 6 ICESCR. TK 2009/10, 32211, nr. 3, 23. See also EK 2006/07, 30308, nr. F, 47 and TK 2008/09, nr. 466.

8 The government, for example, argued that Article 13(2)(b) ICESCR merely encompassed a 'duty of care' instead of an 'unimpaired right' to access to education. TK 1995/96, 24233, nr. 3, 31 . See also TK 2008/09, 311775, nr. 3, 9. UN Doc. E/C.12/1998/SR.13 (1998), para. 25.

9 See, for example, the Explanatory Memorandum to the Bill Amending the Tuition Fees Act and the Study Cost Allowances Act. TK 1996/97, 25321, nr. 3, 3-4. See also TK 1995/96, 24233, nr. 6, 53 .

10 Note that the letter, with the combined fourth and fifth report attached, was - together with many other documents - on the agenda of a debate about the human rights foreign policy. The letter and the report were not discussed. TK 2007/08, 31263, nr. 17.

11 Minister of Education Ritzen stated that the Committee had not determined a violation of ICESCR but had only expressed its concern at the consequences of the Tuition Fees Act. TK 1997/98, nr. 1485. 
an article in the printed press (section 1.5). ${ }^{12}$ Rabbae referred for a second time to the fact that the Dutch National Student Association had 'summoned' the Minister of Education before the CESCR more than two and a half years later. ${ }^{13}$ Thirdly, there was a question by several Senators about a judgment of the ECJ. ${ }^{14}$ The Senators asked why the person in question could not be expelled from the Netherlands on the basis of Article 3 ECHR while he was denied the necessary means of support at the same time. They subsequently enquired whether this is in conformity with the fundamental rights guaranteed in the ESC, the ECHR and the Charter for Fundamental Rights. In this context they also asked about the applicability of Articles 9 and 11 ICESCR and GC 19 and the concern of the CESCR in the COs 2006 that the ICESCR cannot be applied directly. ${ }^{15}$ Fourthly, Spekman and Timmermans (PvdA) requested a response to the COs 2010 and also asked the government for a reaction to several recommendations specifically. ${ }^{16}$ This question was the direct result of a conversation with professor Oomen, who was the president of the Netherlands Platform of Human Rights Education and who was present during the dialogue with CESCR in 2010. It is noteworthy that, Spekman, who dedicates himself especially to the rights of undocumented migrants and children, had never heard of ICESCR nor the COs before this conversation. ${ }^{17}$

The latter anecdote illustrates that MPs have only limited knowledge about the ICESCR. This was also noticed by NGO representatives who also argued that only one or two MPs are interested in the subject matter, and often only marginally. The latter is illustrated by the fact that the ICESCR is the least cited treaty after ICERD (77 references). ${ }^{18} \mathrm{~A}$ great number of these references relate to the (ratification of

12 The question was submitted on 5 June 1998. The day before, one article addressed the concern of the Committee with respect to the increase of tuition fees. "VN-comité bezorgd over hoogte collegegelden', de Volkskrant, 4 June 1998, 3.

13 Rabbae noted that 'he had understood' that ICESCR did not have a binding character and therefore emphasised the moral force of the Covenant. TK 2000/01, nr. 38, 3063-3098, 3080. Minister of Education Hermans talked about 'Article 13 of the European Convention' in his answer and confirmed that his predecessor was indeed summoned but not 'sentenced', because the Views of the Committee were not binding. The Minister also held that free did not mean zero. TK 2000/01, nr. 38, 3063-3098, 3086.

14 EK 2009/10, nr. 5. Case T-341/07 Sison v. Council, 30 September 2009.

15 UN Doc. E/C.12/NLD/CO/3 (2006). The government answered that the person in question could not return to his country of origin, but that the person had the obligation to leave and go to a third country. It made clear that lawful residence is a prerequisite for social services, except for necessary medical care and legal aid. It underlined that such a restriction for illegal persons is in conformity with international law and that ICESCR leaves room for such an interpretation (chapter VII, section 3.1).

16 The question required a reaction to the COs concerning the status and direct effect of ICESCR, discrimination of migrant and ethnic minorities, the detention of asylum-seekers and unaccompanied minors, and the ratification of the Optional Protocol. TK 2010/11, nr. 2729.

17 Email from Hans Spekman to author of 28 May 2011 and email from Barbara Oomen of 14 June 2011.

18 The greatest attention has been paid to Article 13 ICESCR. 33 out of the 77 parliamentary papers in which MPs made a reference to ICESCR were related to the right to education. MPs 
the) Optional Protocol establishing an individual complaint mechanism under ICESCR (see chapter VII, section 3.1). ${ }^{19}$

\subsection{Courts and legal practice}

Interestingly, the COs have been explicitly invoked by applicants before national courts in four instances. ${ }^{20}$ All four cases were before the Central Appeals Tribunal and dealt with social security. It is noteworthy that, in three of the four cases, the applicant was represented by the same lawyer, Fischer. ${ }^{21}$ In all four cases, the Tribunal started its assessment by stating that the provisions in ICESCR relied upon by the claimant do not have direct effect in the sense of Article 94 of the Constitution. ${ }^{22}$ The Tribunal was of the opinion that the articles of ICESCR only encompass generally formulated 'social objectives' from which no unconditional and precise subjective rights could be derived in the sense of a (justiciable) claim to assistance. ${ }^{23}$ In all four cases, the Tribunal concluded that the COs formed an 'insufficient basis for a divergent viewpoint' as to the direct effect of the articles in ICESCR. ${ }^{24}$

made several references to Article 13 ICESCR with respect to the obligation to introduce free secondary and higher education progressively. See, for example, EK 2000/01, 27414, nr. 204a, 1, 2 and 5 .

19 See for example Strik (GL) in EK 2008/09, nr. 41, 1908-1939, 1915 and 1926.

20 It might be that the COs have been appealed to on more occasions, because in other cases courts have referred to 'several documents that were submitted' in rather general terms. Also with respect to these documents, courts concluded that they constituted an 'insufficient basis for a divergent viewpoint' as to the direct effect of the articles in ICESCR. See, for example, CRvB, 11 June 2009, LJN: BI9325, para. 3.

21 W.G. Fischer works for Fischer Advocaten in Haarlem. This law firm focuses specifically on human rights and economic, social and cultural rights in particular. In addition, the firm cooperates with NGOs, like DCI, and has taken the initiative to establish a working group on social and economic rights within NJCM.

22 The Tribunal based its conclusions on the wordings and purpose of ICESCR as well as the Explanatory Memorandum to the Act ratifying ICESCR. In one case, the appellant who lived in Curacao invoked Article 9 ICESCR and argued on the basis of the COs 1998 that the European part of the Kingdom of the Netherlands is also responsible for the implementation of ICESCR in the overseas territories. CRvB, 24 July 2008, para. 3.2 and 4.9. See also CRvB, 22 December 2008, LJN: BG8789, para. 3.2 and 4.2. CRvB, 22 December 2008, LJN: BG8776, para. 3.2 and 4.4. CRvB, 26 January 2010, LJN: BL1686, para. 4.8 and 4.9.

23 In other judgments, the Appeals Tribunal also argued that the provisions of ICESCR encompass generally formulated social objectives rather than a right which citizens can appeal to 'right away'. CRvB, 21 November 2007, LJN: BB9625, para. 3. The formulation by the Tribunal has also been adopted by other courts which referred to the Tribunal's 'standard jurisprudence'. Rb. Leeuwarden, 5 July 2010, LJN: BN0391, para. 4.4.

24 See also the court case about the measure that increased the university tuition fees for students who incur a study delay of more than a year (langstudeerdermaatregel) in which the COs 2010 about the justiciability of the ICESCR were invoked by the Dutch National Students Association (ISO). Rb. Den Haag, 11 July 2012, LJN: BX0977, para. 5.11. 
The government held in 2011 that there were no known court judgments in which direct effect is imputed to provisions of ICESCR. ${ }^{25}$ Both the Supreme Court and the Administrative Law Division of the Council of State have considered the provisions of ICESCR not to have direct effect. ${ }^{26}$ The Council of State has simply reasoned that these provisions are 'not sufficiently concrete' and need more detailed working out in domestic laws. ${ }^{27}$ In this context, courts considered that it is not the responsibility of the judge to give such further details to the general formulations. ${ }^{28}$ The conclusion of Craven from the beginning of the 1990s that Dutch courts have 'tended to rely upon a superficial and monolithic interpretation' of ICESCR seems thus still applicable. ${ }^{29}$

\subsection{NGOs}

Lobbying on the basis of CESCR's COs by NGOs is limited. NGOs have not given a reaction to the COs or the response of the government thereto. The only exception is the roundtable meeting about follow-ups to the COs 1998 which was organised by NJCM and the Netherlands Institute of Human Rights (SIM) on 15 June 2000, more than two years after the COs were adopted. ${ }^{30}$ At the same time, the COs have hardly been mentioned or referred to in letters and commentaries in relation to specific issue areas. Coomans also observed that there are few NGOs that demand attention for the COs or test the government's policy against ICESCR. ${ }^{31}$ One NGO representative also held that besides NJCM, which has hardly been involved in follow-up, there is no other NGO that is concerned with the (monitoring of) compliance with COs. Remarkably, the two biggest trade unions, FNV and CNV, have not used the COs nor ICESCR in their work. Instead, they have focused on EU legislation, the ECHR and especially the ILO. NJCM has only referred to the COs twice until 15 September 2011. ${ }^{32}$ It is noteworthy that the COs 2010 have recently

25 TK 2010/11, nr. 2729.

26 In the 'Harmonisatiewet arrest', the Supreme Court concluded that Article 2(1) and Article 13(1) and (2)(c) and (e) do not have direct effect. It based its determination on the wording of ICESCR and the fact that the provisions cannot function without further implementing measures. In addition, the Explanatory Memorandum to the Acts ratifying ICESCR provided that, 'in general', the provisions in the Covenant would not have direct effect. Hoge Raad, 14 April 1989, NJ 1989, 469, para. 5.3.

27 See, for example, ABRvS, 19 April 2004, LJN: BA4289, para. 2.5.2.

28 See, for example, Rb. Den Haag, 6 September 2000, LJN: AA7019, para. 3.11.

29 Craven (1993), 404.

30 NJCM's annual report of April 2001-April 2002: <www.njcm.nl/site/uploads/download/87>, assessed 31 July 2013, 2.

31 Coomans (2007), 748.

32 A letter of 15 January 2007 to the person charged with forming a new government underlined the importance of compliance with the obligation to report and follow-up to COs. The COs 2006 were attached to the letter and were shortly referred to: <www.njcm.nl/site/uploads/ download/30>, accessed 31 July 2013. Another letter of 26 May 2011 quoted the COs regarding the completion of apprenticeships of undocumented children enrolled in vocational training: 
been mentioned more frequently by NJCM and some other NGOs. Amnesty International referred to the COs 2010 about alien detention together with similar criticism of other (inter)national organisations in a letter to the members of the parliamentary Committee for Immigration and Asylum. ${ }^{33}$ In addition, the Dutch CEDAW Network mentioned the COs 2010 regarding domestic workers twice. ${ }^{34}$

The government has rarely consulted NGOs in the context of the process of state reporting, before or after the dialogue. Prior to the dialogue in 2006, the NGOs who prepared the parallel report to the third report, NJCM and the Johannes Wier Stichting (JWS), ${ }^{35}$ were invited by the government to get to know the government officials who were going to represent the government during the dialogue. ${ }^{36}$ Ideas were exchanged on the objectives, procedures and follow-up to periodic state reporting as well as the content of the state report. ${ }^{37}$ But after the COs 2006 were issued, no contact took place. No meetings prior to and after the discussion in 2010 took place between NGOs and the government. ${ }^{38}$

\subsection{Media coverage}

The reporting process under ICESCR has received the least media coverage of all the UN human rights treaties. The process of state reporting and the resulting COs have hardly been covered in the media. Only once, an article mentioned the 'complaint' made in April 1998 to CESCR by the Dutch National Student

$<$ www.njcm.nl/site/uploads/download/430>, accessed 31 July 2013. Note that NJCM has referred to some of the COs 2010 more often since 15 September 2011. See, for example, the letters 446 (14 November 2011), 484 (20 September 2012) and 488 (29 October 2012).

33 Letter sent on 20 January 2011, Eb/pol/2010, 30: <www.amnesty.nl/sites/default/files/public/ eb-pol-2010-30 ao vreemdelingendetentie.pdf $>$, accessed 31 July 2013.

34 Letter sent to the Minister and Parliamentary Committee of Social Affairs and Employment on 29 March 2011: <www.vrouwenrecht.nl/opinie/commentaar-vvr/>, accessed 31 July 2013. Position Paper of 25 May 2011, <www.vrouwenrecht.nl/category/hoorzitting-hhp/>, accessed 31 July 2013.

35 JWS is primarily focused on the implementation of the right to health in practice. Its activities are largely targeted at health care professionals. JWS has organised several follow-up meetings to inform professionals in the health care about the international legal obligations. Sometimes, attention has been paid to the COs of UN human rights treaty bodies, especially CESCR and the CRC Committee.

36 One NGO representative gave the parallel report 2006 as an example of how it should not be. The cooperation between the NGOs was not very good and there was a limited amount of time to compile the actual report.

37 Coomans (2007), 747.

38 The government had approached the NGOs for a meeting prior to the dialogue with the CESCR to hear about their reports. The main reason that no such meeting took place was that NGOs themselves were still busy with internal communication and the compilation of the parallel report. There was also a concern about the utility of the meeting at that point, since the government had already submitted its own report to CESCR. 
Association concerning the increase of tuition fees. ${ }^{39}$ As we have seen, the article was the reason for Rabbae (GL) to raise a question about the 'judgment' of the CESCR (section 1.2). ${ }^{40}$

\subsection{Conclusion}

This section showed that both COs as well as ICESCR are nearly absent in national policy making and legal practice. In fact, as was pointed out already several times, ICESCR and the COs of CESCR have been the worst off of the six treaties in this research. The limited impact was attributed to the absence of direct effect. Another important reason for the limited impact is also that the ICESCR is rather unknown. ${ }^{41} \mathrm{NGO}$ representatives pointed to the limited knowledge of government officials and MPs about ICESCR which give rise to exaggerated fables or fairy tales, as if ICESCR would force us to completely change our social security policy. NJCM concluded that the government does not consider ICESCR to be a 'touchstone' against which measures are tested that are likely to have an influence on the rights in the Covenant. ${ }^{42}$ It is noteworthy that the idea of minimum core obligations, which was put forward by CESCR in GC 3 and further developed in subsequent Comments, does not play a part in case law or parliamentary papers. ${ }^{43}$ It is therefore not surprising that NGOs noted in their parallel report that Dutch judges and lawyers are not aware of the progressive developments in relation to ICESCR since the 1990s. ${ }^{44}$

Another aspect which has limited the impact of economic, socials and cultural rights is the different nature of social rights. An evaluation study about the Dutch Constitution also concluded that social constitutional rights have not played a steering role in working out the level of social provisions, nor have social rights prevented intervention and austerity measures in relation to the system of social security, medical expenses and legal aid. Likewise, it was concluded that social rights have hardly been addressed in the context of the development of legislation and parliamentary debates. ${ }^{45}$ What is more, since 1983 , there have only been four

39 'VN-comité bezorgt over hoogte collegegelden', de Volkskrant, 4 June 1998, 3. The article referred to the concern that the increases of tuition fees are contrary to the principle of equality of opportunities. UN Doc. E/C.12/1/Add.25 (1998), para. 19 and 27. This CO was the result of the alternative information presented by a delegation of Dutch National Student Association (ISO) in writing and during the hearing with CESCR on 27 April 1998. The ISO also published a press release and the issue was also covered in several university papers. Coomans (1998), 940 and 945.

$40 \quad$ Supra n. 11.

41 Coomans (2007), 752-753.

$42 \quad$ NJCM and JWS (2006), 2.

43 The only reference to the concept of core obligations was by the Advisory Council on International Affairs. Adviesraad voor International Vraagstukken (2008), 24.

$44 \quad$ NJCM (2009b), 8.

45 Barkhuysen et al. (2009), 59-61. 
court judgments in which it was concluded that a social constitutional 'duty of performance' (prestatieplicht) was violated. ${ }^{46}$ Chapter VII, section 3.1 will examine these factors more closely.

\section{Assessing the effectiveness of COS}

This section examines the effectiveness of COs. There are, however, hardly any instances in which the government reflected upon COs. As we have seen, no reaction was sent to parliament to the COs 1998 and 2006. Both the third and the combined fourth and fifth periodic state reports contain a separate section with a response of the government to the previous COs 1998 and 2006, but this response consists primarily of an enumeration of policy measures and initiatives in relation to which no connection to the articles of ICESCR is made. ${ }^{47}$ This was also noted by NGOs in their parallel report, in which it was argued that it remained unclear how the measures outlined in the state report fulfilled the $\mathrm{COs}^{48} \mathrm{~A}$ further complicating factor for the analysis of the effectiveness of COs is that NGOs in their parallel report rarely assess the implementation of COs by the government. ${ }^{49}$

The extensive reaction of the government to the COs 2010 is nonetheless quite revealing. ${ }^{50}$ Broadly speaking, the government either (explicitly) rejected the criticism of the CESCR (section 2.1) or pointed to existing policy initiatives that result in the $\mathrm{CO}$ already being sufficiently complied with, in the view of the government (section 2.2). It is noteworthy that the reaction includes rather bold language, reflecting an increased assertiveness of the government in talking back to the committees. Only in a few cases did the government show its willingness to take some steps on the basis of COs. ${ }^{51}$

46 In other cases in which social constitutional rights were referred to, courts have considered these rights as 'instruction norms' that were not directly applicable. Barkhuysen et al. (2009), 62-63.

47 For example, the response to the CO 1998 recommending to 'continue its endeavours' with respect to racial discrimination in the labour market filled 18 pages. The Lisbon objectives in the European Employment Strategy and the coalition agreement were mentioned as the major reasons for measures taken to increase the employment rate of ethnic minorities. UN Doc. E/1994/104/Add.30 (2005), para. 4-109 and 489, 11-79. UN Doc E/C.12/NLD/4-5 (2009), para. $5-123$.

48 NJCM and JWS (2006), 2.

49 The parallel report of 2006, for example, only reflected upon the government's response to CO about the applicability of ICESCR. NJCM and JWS (2006), 1.

50 TK 2010/11, 26150, nr. 100.

51 Most notably, the government stated that it intended to examine in more detail whether a national human rights action plan could have added value. For a further discussion see chapter IV, section 2.5. The government also held that it would bring the concern of the Committee that training programmes for practitioners do not cover ICESCR to the notice of training institutions. At the same time, the government was unwilling to prescribe the actual content of the training programmes of these institutions, since this is their own responsibility. In addition, in response to the concern that human rights education is not provided for in national school curricula, the government promised to ask the Education Council whether further stimulation of citizenship is 
One hint for the ineffectiveness of ICESCR's COs is the fact that both government officials and NGO representatives involved in the process of state reporting in relation to ICESCR could not give any examples of COs that have played some role at the national level. One NGO representative involved in several reporting cycles under different treaties even observed that the effectiveness of the COs is worse than ICCPR and ICERD.

\subsection{COs that have been rejected}

As mentioned before, quite a number of COs have been dismissed by the government. Government officials also mentioned several COs that could or were not complied with during interviews, including the status and direct effect of ICESCR, discrimination against migrant workers with regard to pension rights and access to health care of undocumented migrants.

The Minister of Education, Science and Culture made clear that he did not share the conclusion of the CESCR in 1998 that the increase in tuition fees is contrary to the principle of equality of opportunities. ${ }^{52}$ According to the Minister, this view simply passed over the balanced retribution system that includes special regulations for the financially weak ensuring the accessibility of higher education. Hence, he did not agree with the recommendation of the Committee to take appropriate steps to alleviate or eliminate the adverse effects of the Tuition Fees Act. ${ }^{53}$ The Minister simply argued on the basis of the travaux préparatoires that the phrase 'free education' did not imply that higher education should be free of charge in all cases. He proposed further reflection on the question whether the wording of Article 13(2) (c) ICESCR is sufficiently clear in the light of its primary aim to guarantee the accessibility of higher education. He suggested considering whether there is reason to give - within the framework of ICESCR - expression to the fact that the financing of higher education in the Netherlands and other neighbouring countries is not in breach of ICESCR and its spirit. ${ }^{54}$

The government also rejected the Committee's reiterated recommendation to reassess the extent to which the provisions of ICESCR might be considered to have direct effect. 55 This was justified on the basis of the independence of national judges deciding in concrete cases about the direct effect of provisions of

possible and desirable and what the role of the central government could be in this regard. Simultaneously, the government itself made clear that it was of the opinion that human rights education already takes place in different ways and that, hence, treaty obligations are already complied with. TK 2010/11, 26150, nr. 100, 4 and 18.

52 UN Doc. E/C.12/1/Add.25 (1998), para. 19 and 27.

53 TK 1997/98, nr. 1485.

54 In this context, the Harmonisatiewet judgment of the Supreme Court and the Flinterman ruling were referred to. Hoge Raad, 14 April 1989, NJ 1989, 469 and AB 1989, 207. Rb. Den Haag, 14 November 1990, 89/7932 and 90/659.

55 UN Doc. E/C.12/1/Add.25 (1998), para. 11 and 21. UN Doc. E/C.12/NLD/CO/3 (2006), para. 19. UN Doc. E/C.12/NDL/CO/4-5 (2010), para. 6. 
international treaties (chapter VII, section 1.3). ${ }^{56}$ In addition, it was stated that most provisions of ICESCR cannot be applied directly given the nature of the Covenant and the unspecific and imprecise wording of the rights, which require intervention from the national legislature. ${ }^{57}$ In response to the CO 2010, the government also held that it is only obliged under ICESCR to create a situation complying with the Covenant and that ICESCR does not specify how this should be realised. It is up to states themselves to determine, depending upon their national constitutional system, whether this should be realised through treaty provisions having direct effect or indirectly via implementing legislation and policy measures. ${ }^{58}$ The government has also steadfastly discarded the $\mathrm{CO}$ requesting the Kingdom of the Netherlands, as the state party to ICESCR, to be responsible for the Covenant's implementation in the constituent countries. ${ }^{59}$ The fact that the dialogue in 2006 only covered the European part of the Kingdom of the Netherlands is illustrative of the complete disregard of this $\mathrm{CO} .{ }^{60}$

The Committee also urged the government in its COs 2010 to meet its 'core obligations' under ICESCR and ensure that the minimum essential level relating to the right to housing, health and education for undocumented migrants, since the latter cannot have access to health care and education in practice, although they are formally entitled to both. ${ }^{61}$ In its reaction to this $\mathrm{CO}$, the government merely emphasised the formal legal possibility by stressing that under the Benefit Entitlement (Residence Status) Act (Koppelingswet) undocumented migrants benefit from necessary medical treatment in urgent situations and compulsory education until the age of $16 .{ }^{62}$ This shows, first of all, that the government adopts a narrower and formalistic approach, focused more on the de jure situation, whereas the Committee also considers the de facto enjoyment of rights. What is more, this disagreement between the government and the CESCR hints at a fundamental different outlook on the scope of the rights in ICESCR. The Committee, on the one hand, holds the view that the rights under the Covenant are 'enjoyed by all individuals within its territory or under its jurisdiction', including non-nationals, such as 'refugees, asylum-seekers, stateless persons, migrant workers and victims of international trafficking, regardless of legal status and documentation'. ${ }^{63}$ The

\footnotetext{
56 TK 1997/98, nr. 1485.

57 UN Doc. E/1994/104/Add.30 (2005), para. 4-9. UN Doc. E/C.12/NLD/4-5 (2009), para. 10 and 11 .

58 TK 2010/11, 26150, nr. 100, 3.

59 The government of the European part of the Kingdom made clear that it is not responsible for the implementation of ICESCR in Aruba and the Netherlands Antilles, but that the governments of the overseas territories are responsible for this. UN Doc. E/1994/104/Add.30 (2005), para. $108-109$.

60 UN Doc. E/C.12/NLD/4-5 (2009), para. 7-9.

61 UN Doc. E/C.12/NDL/CO/4-5 (2010), para. $25 \mathrm{sub}$ b.

62 TK 2010/11, 26150, nr. 100, 1 June 2011, 14.

63 General Comment No. 1 on reporting by states parties, third session (1989). General Comment No. 20 on Discrimination in Economic, Social and Cultural Rights (art. 2(2)), UN Doc. E/C.12/ GC/20 (2009), para. 30.
} 
government, on the other hand, is in principle opposed to rights to benefits for persons without lawful residence status, since they are obliged to leave the country. ${ }^{64}$ The head of the delegation made clear that the extension of benefits would go against this policy, would give rise to a pull-factor for migrants and, hence, result in budgetary problems. ${ }^{65}$ There is, thus, a difference in views as to the range of ICESCR in terms of its beneficiaries between the government and the Committee, the latter adopting a more progressive and far-reaching interpretation of ICESCR.

At other times, the government hinted at a misunderstanding on the part of the Committee. The government, for example, held that, contrary to the statements of the Committee in its COs 1998, which pointed to a reduction of budgetary allocation for social welfare programmes, social assistance benefits had not been reduced, but they had actually increased in line with the statutory minimum wage. ${ }^{66}$ In addition, in its response to the COs 2010, the government stated that it could not understand the 'remarks' of the Committee recommending that the necessary measures be taken to increase the number of trained mental health personnel in penal institutions or to guarantee appropriate treatment in the light of the legislative amendments that were being made. The government, therefore, concluded that the remarks were based on incorrect facts (see also chapter VII, section 3.2). ${ }^{67}$

\subsection{Standing policy and legislative measures in line with the COs}

A significant number of CESCR's COs are extremely vague, broad and unspecific, ${ }^{68}$ often only recommending that the government 'intensify its efforts', 'continue its endeavours' 69 , 'to implement adopted measures' or even 'continue to strengthen its efforts' ${ }^{70}$ These COs have remained largely ineffective. This is because they have often only supported existing policies without requiring or recommending any additional measures or a change of policy and/or legislation. One example is the CO 1998 that recommended in rather broad terms that 'more clearly targeted policies be adopted to protect the welfare of the family'. Several measures were outlined in response to this $\mathrm{CO}$ in the third periodic report especially focusing on violence against women and children. ${ }^{71}$ Any causal link between these

\footnotetext{
64 UN Doc. E/C.12/NLD/Q/4-5/Add.1 (2010), para. 127-132. TK 2003/04, 19637, nr. 826, $13-14$.

65 Personal observation of the dialogue. Not stated in UN Doc. E/C.12/2010/SR.44 (2010), para. 9.

66 UN Doc. E/C.12/1/Add.25 (1998), para. 16 and 25. UN Doc. E/1994/104/Add.30 (2005), para. 84.

67 TK 2010/11, 26150, nr. 100, 17.

68 See for example the references to 'appropriate steps' and 'more clearly targeted policies'. UN Doc. E/C.12/1/Add.25 (1998), para. 26 and 27.

69 The government was recommended to 'intensify its efforts' to guarantee equal wages and access to employment for men and women and to 'continue its endeavours' with respect to racial discrimination in the labour market. UN Doc. E/C.12/1/Add.25 (1998), para. 22 and 23. UN Doc. E/C.12/NDL/CO/4-5 (2010), para. 10, 13, 16 and 23.

70 UN Doc. E/C.12/NLD/CO/3 (2006), para. 23 and 28. See also para. 21, 22, 24, $26-27$ and 30.

71 UN Doc. E/1994/104/Add.30 (2005), para. 87-105.
} 
measures and the COs seems absent for the following two reasons. Firstly, the third report made no connection whatsoever between the policy measures and the COs, but mentioned other factors or actors as policy drivers. ${ }^{72}$ Secondly, neither the ICESCR nor the COs had ever been discussed or referred to in the context of (domestic) violence or abuse of children. Such broad COs, thus, do not have any impact or effectiveness at the national level.

\section{TReATY SPECIFIC REASONS FOR THE (IN)EFFECTIVENESS OF COS}

\subsection{Factors related to the domestic context}

The most important reason for the almost complete ineffectiveness of CESCR's COs is the absence of domestic attention and mobilisation as outlined in chapter VII, section 1. Another important factor explaining the limited impact and effectiveness of COs, but also ICESCR at large, are the views of the government (officials) as to the relevance and character of the rights in ICESCR. Some politicians and government officials do not consider ICESCR to be relevant (any more). The remark of the MP Boorsma (CDA) that he could imagine that the Minister of Education regarded the 'old' Covenant 'out of date' with respect to the obligation to introduce free higher education progressively is illustrative, because the Netherlands was doing quite a lot in this respect and had a 'luxury system'. ${ }^{73}$ Minister of Education Ritzen made clear that it is indeed a good idea to consider how to continue with ICESCR in the long term and whether there is a reason for amending ICESCR so as to bring it more in line with the position of the Netherlands and other countries. In this context, the Minister pointed to the fact that ICESCR had come about in 1966 under great pressure of the former communist countries. At that time, the government was of the opinion that it could not distance itself too much given the attempts to 'build bridges between countries' ${ }^{74}$ One government official also stressed that ICESCR is an old-fashioned and out-dated treaty reflecting the spirit of the 1970s. In this period a dominant, central and protecting position of the authorities was valued and there was a strong belief in the makeability of the society. In recent years, however, individual responsibilities have been emphasised more expressly. ${ }^{75}$

Although the government underlines the complementarity and the interdependence of human rights, it makes clear that this does not mean that civil and political rights and economic, social and cultural rights can be implemented, fulfilled and enforced in the same way. ${ }^{76}$ The government itself acknowledged that

UN Doc. E/1994/104/Add.30 (2005), 87-89. UN Doc. E/1994/104/Add.30 (2005), para. 102-105. EK 1995/96, nr. 23, 1306-1307.

EK 1995/96, nr. 23, 1305-1322, 1318 and 1331.

Barkhuysen et al. (2009), 55 and 60.

UN Doc. E/C.12/2006/SR.33 (2006), para. 3 and 4. For a historic discussion of the (gradually changing) views of the Dutch government since the 1950s, see Reiding (2012). Reiding (2007), 131-135. 
there is a contradiction in such a position. ${ }^{77}$ Nevertheless it emphasised that economic, social and cultural rights can 'exclusively' be realised progressively and that there are differences between states as to what constitutes a satisfactory fulfilment of these rights. ${ }^{78}$ The government highlighted that economic, social and cultural rights are not formulated as obligations that could be directly invoked before court but merely as an obligation of conduct (inspanningsverplichting). ${ }^{79}$ Rather, the implementation of economic, social and cultural rights is a political question between various equally possible policy choices and requires government action. ${ }^{80}$ The government stressed in this context that the question as to whether or not such democratically legitimated policy choices, which inevitably affect several groups, are in conformity with human rights, is difficult to answer on the basis of an individual case. ${ }^{81}$

The government has also held that the objective of ICESCR is not so much the laying down of minimum requirements but more so the definition of objectives state parties should aspire to. ${ }^{82}$ The government has even argued that international minimum standards in relation to economic, social and cultural rights are absent. ${ }^{83}$ This implies that the government does not accept the idea of 'minimum core obligations' as developed by the CESCR in its GC 3. Another indication for this is that this idea of core obligations is not referred to by the government in parliamentary papers (chapter VII, section 1.6). Van Hoof also observed that the government takes a rather minimalist position with respect to the effective implementation of the provisions in ICESCR ${ }^{84}$ During interviews, government officials argued that politicians do not regard economic, social and cultural rights as true fundamental human rights in a legal sense. For them, human rights deal with fundamental issues, such as freedom of expression and torture. Likewise, an NGO representative stated that there is (still) an idea that the 'rights' included ICESCR do not entail true legal obligations. This means that the importance and political sensitivity of ICESCR is also limited. Reiding attributed these views on the legal character of the ICESCR and the 'rights' included therein to the 'traumatic' and

77 UN Doc. E/C.12/2006/SR.33 (2006), para. 47.

78 TK 2005/06, 26150, nr. 39, 3. TK 2006/07, nr. 1352. Minister of Foreign Affairs Bot also stated that there is no hierarchy between these rights, but that there are, nevertheless, 'great differences' in the implementation. TK 2005/06, 26150, nr. 37, 4.

79 TK 2001/02, 27742, nr. 4, 5. TK 2001/02, 27742, nr. 2, 35. During the dialogue with the Committee, the Dutch delegation stated that civil and political rights are in essence rights orientated, while economic, social and cultural rights concern first and foremost obligations of the state. UN Doc. E/C.12/1998/SR.13 (1998), para. 25 and 28. See also Coomans (1998), 942.

80 UN Doc. E/C.12/1998/SR.13 (1998), para. 10, 11 and 25. UN Doc. E/C.12/2006/SR.33, para. 47.

81 TK 2007/08, nr. 2015.

82 TK 2005/06, 30300 IV, nr. 26, 8.

83 TK 2003/04, $29800 \mathrm{~V}$, nr. 50, 18. TK 2000/01, $27400 \mathrm{~V}$, nr. 63, 11. TK 2001/02, 27742, nr. $2,36$. The head of the delegation, Potman, also held in 1998 that the obligations of civil and political rights were clear, whereas this was less so for economic, social and cultural rights. UN Doc. E/C.12/1998/SR.13 (1998), para. 10. 
'unnerving experience' of the late 1980s during which courts applied Article 26 ICCPR to social security issues (chapter VI, section 1). As a result of this experience, government officials are conscious of the potential risks of justiciable economic, social and cultural rights and are, hence, reluctant to acknowledge the direct effect of ICESCR. ${ }^{85}$

These thoughts might indeed explain why ICESCR is the penultimate treaty in terms of parliamentary and governmental attention. What is more, when the actual treaty is seen primarily as aspirational it is not surprising that the non-binding COs are seen as even more noncommittal. Furthermore, this view clarifies the reluctance of the government towards the ratification of the Optional Protocol to ICESCR. ${ }^{86}$ The government was of the opinion that an individual right to complaint would not lead to a better implementation of these rights. In addition, such a right to complaint would only raise unrealistic expectations, also because these rights are not directly enforceable and minimum standards are absent. ${ }^{87}$ The government also pointed to the difficulty of measuring violations in the individual enjoyment of these rights. ${ }^{88}$ It also pointed to the duplication of and conflict with good functioning national policy mechanisms. ${ }^{89}$ Underlying these arguments is the idea that a full recognition of the obligatory nature of the rights in ICESCR would entail significant financial resources. ${ }^{90}$ Given these objections, it is not surprising that the government advocated the possibility of excluding several rights in ICESCR from the individual complaints procedure during the negotiations about the Optional Protocol. ${ }^{91}$ Nonetheless, the Netherlands eventually voted in favour of the Optional Protocol, because of the 'conviction' that economic, social and cultural rights are on equal terms with civil and political rights and in order to meet the wishes of other states and societal organisations. ${ }^{92}$ The government is, however, still of the opinion that not all economic, social and cultural rights lend themselves to a right to complaint. ${ }^{93}$

The main reason for signing the Protocol seems to be inspired by foreign policy considerations. The account below also applies more generally to reporting under ICESCR and the COs and illustrates that reporting is also something which has

\footnotetext{
85 Reiding (2012), 132-133. Reiding (2007), 200.

86 For an extensive discussion of the Dutch position as to the Optional Protocol, see Reiding (2007), 141-148.

87 TK 2003/04, $29800 \mathrm{~V}$, nr. 50, 18.

88 The government also pointed to the many practical objections without making these explicit. TK 2003/04, $29800 \mathrm{~V}$, nr. 50, 18. TK 2000/01, $27400 \mathrm{~V}$, nr. 63, 11.

89 TK 2005/06, 26150, nr. 37, 4.

$90 \quad$ Reiding (2012), 136.

91 TK 2007/08, nr. 2015. Reiding (2012), 137.

92 TK 2008/09, 31263, nr. 27, 59. EK 2007/08, nr. 33, 1366-1411, 1392.

93 Minister for Development Cooperation Koenders stressed that the economic, social and cultural rights, which do not lend themselves to a right to complaint, should not be 'internationalised', because they are the result of policies and democratic decision making at the national level. EK 2007/08, nr. 33, 1366-1411, 1392. TK 2008/09, 31263, nr. 27, 59.
} 
largely a symbolic value (see also chapter VI, section 3.1). Minister of Foreign Affairs Verhagen explicitly stated that the Netherlands was among the first states that had signed the Protocol, because economic, social and cultural rights can support the realisation of poverty reduction by giving a voice and means to the population to demand the fulfilment of their rights. Hence, a complaint mechanism might play a stimulating part in countries in which politics is not directed towards the fulfilment of these rights and social justice..$^{94}$ The Ministry of Foreign Affairs, thus, considered it important to show the Dutch goodwill towards the Protocol..$^{95}$ This rationale can be compared to the motives for the government's recognition of the right to water as a human right. The Minister of Foreign Affairs argued that recognition would give the Netherlands the legitimacy to point to duties of the government and the rights of the population in the course of the policy dialogue with partner countries. At the same time, the Minister acknowledged that this recognition would have no domestic legal consequences and was, thus, primarily of international political importance. ${ }^{96}$ This overview illustrates that the latter Ministry was considerably more positive about the Optional Protocol than the other ministries who are responsible for its implementation and its financial consequences. ${ }^{97}$

Another reason for the (perceived) irrelevance of ICESCR in the Dutch legal order is that other international treaties related to economic, social and cultural rights are (considered) more important. The ILO, for example, seems to carry more weight in relation to employment-related matters. An illustration is the discussion in the context of maternity benefits for self-employed female entrepreneurs. Minister of Social Affairs and Employment De Geus simply held that the relevant provisions in ICESCR were derived from ILO Treaties. In the light of the parliamentary discussion about, among others the question whether a distinction should be made between with women with an employment contract and selfemployed women, the Minister sought advice from the two institutions who could give 'an authoritative opinion', the Equal Treatment Commission and the ILO. ${ }^{98}$ Likewise, an Advisory Committee about the legal status of political office holders held that the ILO has the richest tradition in the interpretation and application of the

94 TK 2010/11, 32735, nr. 26, 42. EK 2007/08, nr. 33, 1366-1411, 1392. It is noteworthy that the Advisory Council on International Affairs also recommended that the Optional Protocol be ratified exactly for these foreign policy reasons, stressing that ratification would give an important signal to developing countries that the Netherlands is taking economic, social and cultural rights seriously. The Council also hinted that ratification of the Protocol would also raise the credibility of the Netherlands when criticising the human rights situation in other countries. Adviesraad voor International Vraagstukken (2008), 34.

95 Reiding (2012), 138.

96 The right to water was recognised as a human right by the UN Human Rights Council in 2008. TK 2007/08, 31250, nr. 15, 2-3.

97 Reiding (2007), 146-148. Reiding (2012), 136.

98 EK 2003/04, nr. 37, 2037-2050, 2039-2040. 
norms related to freedom of association and collective bargaining. ${ }^{99}$ The ESC seems to be regarded as more pertinent and important as well. The government, for instance, exclusively pointed to the ESC in relation to the right to strike, arguing that the conditions for the exercise of the right to strike developed in case law adequately implement the normative framework of the ESC. ICESCR was not mentioned at all in this context. ${ }^{100}$ In the same way, Article 11 ECHR and the Protocol 12 ECHR and the jurisprudence of the ECtHR are relied upon and discussed in relation to the right to form and join trade unions and the right to education more frequently and extensively than their counterparts in the ICESCR. ${ }^{101}$

Another factor which explains the ineffectiveness of $\mathrm{CO}$ is the idea of the government that the Netherlands complies with its treaty obligations under ICESCR. ${ }^{102}$ The government held that 'all of the obligations under the Covenant are adequately incorporated in national legislation'. ${ }^{103}$ This view was also put forward by CESCR in 1998 when it concluded that the Netherlands 'has to a considerable extent met its obligations with respect to the protection of the rights set out in the Covenant'. ${ }^{104}$ During the dialogue 2010, one expert member also mentioned that some questions are also raised because the Committee considers the answers helpful for other countries in terms of best practices. ${ }^{105}$

\subsection{The (perceived) quality of the CESCR}

One of the most important reasons for the limited effectiveness of the COs is the limited legitimacy and persuasiveness of the CESCR in the eyes of government officials. This section will address the authority of CESCR and the COs on the basis of the views of government officials expressed in interviews and the author's personal observations from the dialogue of CESCR with the Netherlands in 2010. It is quite revealing that a former member of CESCR, Philip Alston, also indicated dissatisfaction with the outcome of the consideration of state reports by CESCR which he suggested was sometimes 'almost amateurish' and falling short of 'the highest professional standards'. ${ }^{106}$ One result, in his view, is that COs are sometimes

99

100

101

The relevant ILO treaties are 87 and 98. Attachment to TK 2006/07, 28479, nr. 32, 29.

TK 2010/11, 26150, nr. 100, 11.

See, for example, the attachment to TK 2006/07, 28481, nr. 4. Rb. Den Haag, 11 July 2012, LJN: BX0977.

TK 1997/98, nr. 1485.

UN Doc. E/C.12/NLD/Q/3/Add.1 (2006), para. 1. UN Doc. E/C.12/2006/SR.33 (2006), para. 4. The Committee also noted the 'long tradition of respect for human rights'. UN Doc. E/C.12/1/ Add. 25 (1998), para. 3 and 4.

Personal observation of the dialogue. Not stated in UN Doc. E/C.12/2010/SR.44 (2010), para. 13 (Kedzia).

He also noted that the very short time available, combined with the high volume of materials to be digested, meant that expert members were not always able to be adequately prepared and that the Secretariat lacked the resources and the specialist expertise to be able to provide the sort of 
not adequately explained or reasoned, nor sufficiently well focused or targeted, and are thus of limited utility at the national level.

CESCR is generally regarded as one of the weakest of the UN human rights treaty bodies by government officials, who were rather critical about the dialogue with CESCR in 1998 and 2010. Officials from the Ministry of Social Affairs and Employment were especially negative. CESCR is seen as 'an amateurish Committee that made arbitrary decisions. As compared to, for instance, the ILO institutions, it functioned as a kangaroo court'. ${ }^{107}$ The dialogue with CESCR in 1998 was considered significantly less authoritative than ICERD in the same year. One official noted the great distance between CESCR and the government that was almost impossible to overcome, since it turned out especially difficult for the former to understand the specific national context, as a result of which it was not easy to have a (true) dialogue. Some officials observed a desire among expert members to close down on a rich country during the dialogue in ICESCR 2010. Expert member Sadi indeed stated that more is expected from the Netherlands than other countries. He referred to the Netherlands as a leader, serving as a good example to others. ${ }^{108}$ Government officials lamented that the Netherlands is approached as critically as, for example, Zimbabwe. Several government officials had also seen the draft versions of the COs on the desk of the country rapporteur during the dialogue 2010, as a result of which they wondered what the point of having a constructive dialogue was. The author also saw the COs lying on the desk, close to the entrance of the room.

One government official counted CESCR, together with the CRC and CEDAW Committees, among the 'activist' treaty bodies that do not always keep a close eye on legal accuracy and hardly consider the budgetary implications of their recommendations. In this context it was also noted that an almost endless range of widely varying issues were brought up by the Committee. One official pointed to the danger of inflation of human rights. Another official argued that it is unfeasible for a Committee to be well informed about all the issues raised, forcing expert members to rely primarily on NGO input. Related to this is the observation of the Minister of Foreign Affairs that some of the questions of the Committee during the dialogue 2006 went beyond the main obligations in ICESCR. ${ }^{109}$ Another official referred to the questions of the Belarusian expert member of CESCR as an example of how expert members sometimes primarily address their own agendas. This expert member only asked questions about human trafficking, according to this official, in order to mask the absence of a human rights policy in Belarus by

in-depth analysis that would be desirable in such situations. Statements made during a meeting on 20 January 2011 at Maastricht University. Permission to attribute these quotes was given on 6 December 2013 via email.

Van Blankenstein, International Affairs Division of the Ministry of Social Affairs (1967-1992) as quoted in Reiding (2007), 146.

Personal observation of the dialogue. Not stated in UN Doc. E/C.12/2010/SR.43 (2010), para. 26. TK 2006/07, 30800 V, nr. 100. 
pointing to the alleged 'good' policy on human trafficking in his own country. Several government officials pointed to the CESCR expert member - with a legal background - who did not want to talk about the 'labour market', because he considered this concept too capitalistic and meaningless since everybody has a right to work. ${ }^{110}$ One official stated that as a result of such 'nonsense' he/she lost his/her 'rag'.

Sometimes questions were asked about certain issues, the answers to which were already provided in the documents submitted by the state. ${ }^{11}$ At other times, rather basic questions were put forward. ${ }^{112}$ Most remarkably, country rapporteur Pillay was not aware of and did not have the previous COs for the European part of the Kingdom at his disposal in 2010. ${ }^{113}$ Not only does this show that the monitoring of follow-ups to COs is imperfect, but it is also illustrative of the unprofessionalism of the CESCR. ${ }^{114}$ Another example of the lack of follow-up is the question by Barahona Riera as to whether or not domestic violence is specifically criminalised. ${ }^{115}$ In this context, she did not refer to the previous COs urging the government to adopt specific legislation on domestic violence, neither did she mention the response of the government in the state report which showed that it was not in favour of adopting such specific legislation. ${ }^{116}$

It is noteworthy about the dialogues in 1998 and 2006 that a lot of moral and ethical issues were considered instead of the implementation of ICESCR as such. Coomans, who attended the session in 2006, observed that the emphasis was placed

110 See the statements by Abdel-Moneim mentioning that he did not like the word labour supply, because labour involves human beings. This is not stated in UN Doc. E/C.12/2010/SR.43 (2010), para. 62.

111 See, for example, the question by Barahona Riera as to whether or not child pornography is criminalised. Martynov even suggested that legislation did not criminalise child pornography. UN Doc. E/C.12/2010/SR.44 (2010), para. 46 and 50. For the answer, see UN Doc. E/C.12/ NLD/4-5 (2009), para. 109-112.

112 See for example the question by Kerdoun on what the state religion is. UN Doc. E/C.12/2010/ SR.45 (2010), para. 2. See also Coomans (1998), 941 and 945.

113 Pillay explicitly cited paragraph 9 (direct effect of ICESCR), 23 (training for judges and lawyers) and 41 (national plan of action against poverty) of the COs. He asked the state party, including the government of the European part, whether it was considering to act upon these recommendations. When personally asked by the author during the session to which COs he was referring, he showed the document with COs for the Netherlands Antilles. UN Doc. E/C.12/ NLD/CO/3/Add.1 (2008). He argued that the COs for the Netherlands Antilles were also applicable to the European part of the Kingdom. Pillay was not aware of the COs of 2006 for the European part, which he did not have in his file.

114 The COs 1998 were not referred to in the LOI, the dialogue or the COs 2006. Surprisingly, the recurrent issue of status and direct effect of ICESCR was addressed in the COs 2006, without linking it to the COs 1998. UN Doc. E/C.12/NLD/CO/3 (2006), para. 4. The only previous CO 2006 that was alluded to by two experts (Atangana and Abashidze) related to the status of ICESCR. UN Doc. E/C.12/2010/SR.43 (2010), para. 19 and 23. It was also mentioned in the LOI. UN Doc. E/C.12/NLD/Q/4-5 (2009), para. 3.

115 UN Doc. E/C.12/2010/SR.44 (2010), para. 46.

116 UN Doc. E/C.12/NLD/4-5 (2009), para. 99. 
on subjects in relation to which opinions often diverge because of principled reasons. The subjects he referred to were those in which the Netherlands played a progressive part, like prostitution, as well as sensitive and difficult issues like domestic violence, sexual exploitation and abuse of women and children. ${ }^{117}$ The head of the delegation noted in his final statement in 2006 that there had been 'numerous questions relating to the family, marriage, sexual relations and sexual exploitation' and that policy choices in the Netherlands with respect to these issues had often been the result of lengthy social debate, underpinned by human rights considerations. ${ }^{118}$

CESCR member Sadi stated in 1998 that he regarded the fact that couples living in a registered partnership were treated equally as married couples as 'questionable' and as going against the articles in ICESCR protecting the family. ${ }^{119}$ Grissa asked whether 'homosexual couples had the right to adopt children and, if so, whether steps were taken to protect the children against possible sexual abuse'. ${ }^{20}$ The head of the Dutch delegation, Potman, made clear that he found it inappropriate to have a discussion of morality. ${ }^{121}$ After questions by both Sadi and Adekuoye as to whether or not the method used to calculate income tax was the same for married couples, unmarried couples and homosexual couples, CESCR member Texier rightly stressed that the mandate of the Committee was to monitor the implementation of ICESCR instead of talking about such moral issues. ${ }^{122}$ Likewise, in reply to a question about the policy on drugs, the delegation made clear that it was not able to reflect on the political aspects of this policy, which also went beyond the scope of ICESCR. ${ }^{123}$ In 2006, there was once again a question by Sadi, this time as the country rapporteur for the Netherlands, about same-sex marriage and its conformity with the right to found a family which is only recognised for 'men and women'. In this context he referred to the right as laid down in Article 23 ICCPR instead of a provision in ICESCR. ${ }^{124}$

117 Coomans (2007), 751. See also Coomans (1998), 942-943.

118 UN Doc. E/C.12/2006/SR.35 (2006), para 38.

119 The same member also questioned the legalisation of prostitution. See also the statements by Antanovich about the cost effectiveness of 'such liberal policies' in the light of the purpose of Article 10 ICESCR, the protection of the family. UN Doc. E/C.12/1998/SR.14 (1998), para. 17-19 and 34.

120 UN Doc. E/C.12/1998/SR.14 (1998), para. 22.

121 He also stated that the legalisation of prostitution was not in breach of international treaties. He also did not find it appropriate to discuss whether it was humiliating for a prostitute to display herself in a window. UN Doc. E/C.12/1998/SR.14 (1998), para. 24.

122 UN Doc. E/C.12/1998/SR.14 (1998), para. 32 and 37.

123 UN Doc. E/C.12/1998/SR.15 (1998), para. 6 and 7.

124 The same expert member wondered why a person below the age of 18 , who is not allowed to sign a contract, is nevertheless authorised to consent to sexual relations from the age of 16 . He also considered prostitution a violation of fundamental rights of the person concerned and deplored the fact that prostitution is not only legalised but also facilitated and even encouraged. UN Doc. E/C.12/2006/SR.34 (2007), para. 15 and 16. 
Government officials also pointed to the irrelevance and generality of several COs. Several COs lack a motivation or reasoning, which is especially striking in the light of the sometimes far-reaching determinations. An example of the limited motivation in COs is the CO 2010 in which the Committee concluded that compulsory labour for prison inmates exists in contravention of Article 6 ICESCR without explaining or justifying this conclusion sufficiently. ${ }^{125}$ Government officials also noted that the broadness of COs explains why they hardly have an impact at the national level. The limited focus in the COs was also attributed to a lack of expertise on the part of the Committee. Several government officials put forward that the comments of the CESCR on social security, poverty reduction and labour standards are of limited value, especially compared with detailed EU legislation or the expertise of the ILO and - to a lesser extent - the ESC monitoring bodies. It was observed that the CESCR, consisting of human rights law generalists, approaches the subject primarily from a human rights and legal point of view. The ILO, on the other hand, is much more practically orientated while it also has detailed knowledge with respect to specific policy areas such as leave and pay. These views corroborate with Reiding who noted that the government has been rather positive about the ILO-system and has referred to it as 'undoubtedly the most effective [...] among the worldwide systems' and 'doing a great job in the field of realising economic and social rights'. ${ }^{126}$

The most extreme example of the limited expertise, according to government officials, is the recommendation of the CESCR in which it was concluded that the Dutch state pension is discriminatory against migrant workers and that there was a risk of poverty for pensioners. In a letter to the Committee, the head of the delegation expressed in rather strong words its 'deepest' and 'sincere' concerns about the way the Committee had arrived at its conclusions, which 'are based on a misunderstanding of the facts' and in relation to which 'no reasoning nor factual information' is provided. ${ }^{127}$ The head of the delegation further stressed that he was surprised that (additional) information sent by the delegation shortly after having read the draft COs had not given rise to a modification of the COs. The letter once again explained the Dutch pension system in order to show that there are 'no objective factual grounds' for the COs and, therefore, asked the Committee to reconsider its COs. Government officials made clear during the interviews that this 'incident' undermined the credibility of the CESCR and had led to negative energy and emotions within their department. Officials also held that this incident was fatal for the image of $\mathrm{UN}$ human rights treaty bodies, since the undeserved

125 UN Doc. E/C.12/NLD/CO/4-5 (2010), para. 11. A comparable case is the CESCR's concern about 'the living conditions of asylum seekers in some reception centres in the country'. This $\mathrm{CO}$ does not make clear on what source the conclusion is based or how the Committee had verified information it received about the living conditions. UN Doc. E/C.12/1/Add.25 (1998), para. 18. 


\section{ICESCR}

recommendations would be the only thing that government officials, managing directors and members of government remember about treaty bodies in general and ICESCR in specific. The government officials noted that they found it difficult as a result of the incidence to convey the authority and importance of the treaty bodies to other government officials, especially those not forming part of the delegation. Hence, it was said to be more difficult for the coordinating Directorate to show the need and importance of participating genuinely in the process of state reporting.

\section{Conclusion}

CESCR's COs have almost completely escaped the attention of domestic actors. Their impact has been negligible and the lowest of all the six UN human rights treaties in this research. Not surprisingly, the COs - which have been considerably more general and vague than those of other treaty bodies - have also remained ineffective. There has not been even one CO that has, in one way or another, contributed to political discussions or policy and legislative making. The limited effectiveness is closely related to the absence of mobilisation and lobbing by domestic actors as well as the negative views of government members and officials as to the legal nature and character of the rights protected under ICESCR, which are seen as programmatic and aspirational. Another explanation is the limited authority and quality of the COs and CESCR, which is seen as one of the weakest of all the treaty bodies. 


\title{
Chapter VIII CEDAW
}

\author{
'Sometimes the situation in the Netherlands is so specific that it is as it is.' \\ [Former State Secretary for Education, Culture and Science Dijksma (PvdA) \\ during the dialogue with the CEDAW Committee in 2010] ${ }^{1}$
}

The CEDAW Committee has discussed the Dutch state reports three times since 1995, in 2001, 2006 and 2010. ${ }^{2}$ On all three occasions, the CEDAW Committee expressed its concern as to the existence of the reformed political party, SGP, which excluded women from membership (until 2006) and excluded women from being eligible for election (until 2013). ${ }^{3}$ The CEDAW Committee also determined three times that the Dutch Law on Names continues to contravene the basic principle of the CEDAW regarding the equality of men and women. The Law on Names provides that, where the parents cannot reach an agreement as to the name of a child born in wedlock, the father has the right to make the ultimate decision. ${ }^{4}$ Other issues that have been commented upon critically by the CEDAW Committee include the gender neutral wording of the policy on violence against women, the abolishment of maternity benefits for self-employed women, the overrepresentation of Dutch women in part-time employment and lifting the ban on brothels.

\section{DOMESTIC IMPACT AND DOMESTIC MOBILISATION}

Before examining the impact of the COs of the CEDAW Committee, it is crucial to mention the national reporting process of the implementation of the CEDAW. This national reporting is the result of a 'unique provision' in the Act ratifying CEDAW, which obliges the government to send a report to parliament about the implementation of CEDAW in the Netherlands every four years. ${ }^{5}$ In 1997 the first national report of the Groenman Committee was issued. ${ }^{6}$ In addition, five in-depth studies about

\footnotetext{
Personal observation during the dialogue.

Parts of this chapter were published earlier in Krommendijk (2011b) and Krommendijk (2012b). UN Doc. A/56/38(SUPP) (2001), para. 219-220. UN Doc. CEDAW/C/NLD/CO/4 (2007), para. 25-26. UN Doc. CEDAW/C/NLD/CO/5 (2010), para. 10.

4 Note that a child born out of wedlock receives the name of the mother when there is a disagreement. The CEDAW Committee pointed in particular to Article 16 (g) CEDAW. UN Doc A/56/38(SUPP) (2001), para. 223-224. UN Doc. CEDAW/C/NLD/CO/4 (2007), para. 33-34. UN Doc. CEDAW/C/NLD/CO/5 (2010), para. 10.

Van den Brink (2013), 482.

The report contained 65 recommendations. Het Vrouwenverdrag in Nederland anno 1997. Verslag van de commissie voor de eerste nationale rapportage over de implementatie in Nederland van het Internationaal Verdrag tegen Discriminatie van Vrouwen (February 1997). On the occasion of this report, a conference was held in Nijmegen on 17 October 1997 during
} 
thematic parts of the CEDAW have also been conducted. ${ }^{7}$ The national reporting process has become considerably less ambitious since 2004. The last in-depth study, for example, appeared in January 2004. The third and fourth national report issued in 2006 and 2011 only had a thematic focus instead of the a focus on the implementation of the (entire) CEDAW in the domestic legal order, as the first and second report did. What is more, both reports hardly linked up with CEDAW, if at all. ${ }^{8}$

The government explicitly acknowledged that the first Groenman report resulted in a higher visibility of the CEDAW in terms of its meaning for the legal order and social and political developments and consequently a higher priority on the political agenda. ${ }^{9}$ The national reports and studies have not only contributed to the visibility of the CEDAW in general, but they have also strengthened the impact of COs, at least at the end of the 1990s and the beginning of the 2000s. ${ }^{10}$ Several in-depth studies and especially the second national report referred to and discussed several of the COs 2001. State reporting was also clearly linked to the national reporting process in this period. The second and third reports were, for example, structured on the basis of the Groenman report. ${ }^{11}$ As was mentioned in chapter IV, section 3.2, government officials attached more (strategic) value to CEDAW and were more positive about the importance of state reporting partly. This was also because state reporting was embedded in a national (reporting) process and, thus, had a clearer purpose. These developments also coincided with the increased attention and momentum for women's rights at the international level. The most prominent illustration of this is the fourth - and last - world conference on women in Beijing in 1995 which resulted in the Beijing Platform for Action.

which several priorities were established. TK 1997/98, 25893, nr. 2. The second national report contained a thematic part about the position of migrant and refugee women (TK 2002/03, just030524) as well as a general part examining the implementation of the entire Convention by Marchand (2003) in TK 2003/04, szw0400002.

7 These studies were about CEDAW in the Dutch legal order, the significance of Article 12 CEDAW for the Netherlands, the effect of CEDAW on the legal position of pregnant women and young mothers, the implications of the CEDAW for the Netherlands concerning the prevention and elimination of violence against women and Article 5 CEDAW. Krommendijk (2012b), 491.

8 The third national report focused on a distinction in education in relation to Articles 5 and 10 CEDAW. CEDAW was only mentioned in the first chapter outlining the background to the study. Rapportage ongezien onderscheid in het onderwijs in TK 2007/08, 30420, nr. 47, 6-7. The fourth report was devoted to the health situation and labour market participation of migrant women. CEDAW was only touched upon in the foreword and in a footnote. Keizer and Keuzenkamp, Moeilijk werken; gezondheid en de arbeidsdeelname van migrantenvrouwen (SCP, The Hague, February 2011), 7 and 17.

9 TK 1997/98, 25893, nr. 2, 2.

10 The comments of several NGOs about the government reaction to the second national report referred to several COs 2001. These COs were consequently also mentioned by some MPs and the government. TK 2003/04, 27061, nr. 23. TK 2003/04, 29200 XV, nr. 37, 5. Krommendijk (2012b), 491.

11 The submission of the second report was delayed due to the 'very scale of the operation' of the first national Groenman report. UN Doc. CEDAW/C/NET/2 (1999), 3-5. UN Doc. CEDAW/C/ NET/3 (2000). Van den Brink (2013), 487-488. 


\section{CEDAW}

\subsection{Governmental attention}

The government has kept parliament informed about the process of state reporting under CEDAW on a rather structural basis. The process of informing parliament in relation to CEDAW is the best of all the six UN human rights treaties. Not only have the periodic state reports been sent but also the LOI with the answers of the government were sent. The government has also consistently given a reaction to the COs. ${ }^{12}$ It is noteworthy that the COs 2010 were even translated into Dutch for the first time. ${ }^{13}$ The government referred to the COs on ten other occasions in the period 1995-2011. These references include, among others, violence against women (2), the SGP case (1) and the Law on Names (1). ${ }^{14}$ Although this is still rather minimal in absolute terms, it should be noted that it is relatively frequent in comparison to the other treaties discussed so far. Be that as it may, COs have not been mentioned in the notes, memoranda and letters laying down national policies in the field of emancipation.

The number of references to the COs is reflective of the limited role of CEDAW at the governmental level. When the government refers to CEDAW, this is often in a rather general way, whereby it is only mentioned that CEDAW is a point of reference for the Dutch emancipation policy, without discussing or mentioning substantive provisions of CEDAW. ${ }^{15}$ Moreover, in recent years the CEDAW (and also the obligation to report) has often been referred to only in the context of the Dutch international emancipation policy. ${ }^{16}$ The discussion about preferential treatment is illustrative of the limited role of CEDAW. Minister of Social Affairs and Employment De Geus stated that CEDAW does not have any added value in the Dutch context in relation to a discussion about preferential treatment. ${ }^{17}$ These findings as to the limited attention given to COs and CEDAW coincide with the

12 It is noteworthy that the letter of 2001 is only two and a half pages long and only marginally addresses some recommendations, whereas the letter concerning the COs 2007 is nine pages and the letter responding to the COs 2010 even 24. TK 2001/02, szw0000825. TK 2006/07, 30420, nr. 46. TK 2009/10, 30420, nr. 154.

13 TK 2009/10, 30420, nr. 154.

14 Krommendijk (2012b), 490. The Plan of Action for domestic violence, for example, mentioned the United Nations who urged the government to review the gender-neutral wording of the policy. The COs 2007 were referred to in a footnote. See the attachment to TK 2007/08, 28345, nr. $70,8$.

15 This is especially the case for the most recent letters and notes laying down the emancipation policy. The letters and notes between 1997/98 and 2001/02 did discuss the CEDAW in relation to specific policies on a more frequent basis. See also Van Den Brink (2013), 502.

16 TK 2007/08, 30420, nr. 50. The budget for the Ministry of Education, Culture and Science of 2011 even stated that Article 19 TFEU and the Dutch Equal Treatment Act constitute the legal framework for the emancipation policy. CEDAW was only additionally mentioned as being important. TK 2010/11, 32500-VIII, nr. 2, 161.

17 TK 2005/06, 27223, nr. 75, 2 and 6. The policy document about preferential treatment did discuss Article 4(1) CEDAW but not GR 25 or relevant COs of the CEDAW Committee. TK 2004/05, 28770, nr. 11, 4. 
conclusions of the Netherlands Emancipation Review Committee of 2007. The Committee considered that the examination of laws for compatibility with the CEDAW is marginal, only when there 'is reason to' and it is recommended that this test should be conducted more structurally. ${ }^{18}$ Similarly, van Dooren found that the CEDAW is rarely considered in the context of law making and that hardly any connection is made between the CEDAW and substantive policy areas. ${ }^{19}$ Van den Brink also noted that CEDAW seems to play a more important part in Dutch foreign policy than in relation to domestic policies. ${ }^{20}$

\subsection{Parliamentary scrutiny}

The role of parliament in relation to CEDAW and the process of state reporting is rather limited, although this is considerably better than the other UN human rights treaties, with the exception of CRC. The COs 2001 and 2007 and the government's reaction were discussed during a parliamentary debate with the State Secretary or Minister responsible for emancipation affairs. ${ }^{21}$ Although several specific COs were discussed, the main talking point during these debates was the attitude of the government towards the process of state reporting and the CEDAW Committee. ${ }^{22}$ The debates in 2001 and 2007 consisted primarily of a noncommittal exchange of ideas. No motions were adopted by parliament. An explanation for this - as government officials pointed out - is that the reaction of the government usually only encompasses information on standing policy that the parliament already knows about, because it was involved in the decision-making process of the respective legislation and policy. What is more, those meetings about the COs are often not the appropriate place to discuss specific policies substantively. During the debate about the COs 2007, the Minister responsible for emancipation affairs, for example, mentioned that the Minister of Justice would send parliament an evaluation concerning the law abolishing the ban on brothels and that this would be the appropriate moment to

Visitatiecommissie Emancipatie (2007c), 7-8.

Van Dooren (2007).

She noted that the impact of CEDAW on legislation has been 'very disappointing'. Van den Brink (2013), 486 and 502-504.

21 TK 2001/02, 28009 nr. 7. TK 2007/08, 30420, nr. 98. The COs 2010 were not discussed in parliament. A complicating factor was that the Balkenende IV government tendered its resignation on 20 February 2010 and that a new government assumed office on 14 October 2010. The reaction of the previous government was tabled among several other parliamentary papers during a debate about the outlines of the new emancipation policy 2011-2015. The COs were, nonetheless, not mentioned explicitly. CEDAW was only briefly mentioned by Van Gent (GL). TK 2010/11, 30420, nr. 158.

22 In 2001, some MPs were of the opinion that the government always reacts in a forced way to criticism of the UN. Bussemaker (PvdA) and Van Vliet (D66) noted that the government merely stated that it did not share the 'opinion' of the CEDAW Committee and that the reaction contained the same arguments provided to the Committee. See the reactions of. TK 2001/02, 28009 , nr. 7, 7 and 9. 
discuss the related COs. ${ }^{23}$ Nevertheless, both in the letter that was attached to the second evaluation and the reaction of the government, the COs were not referred to. ${ }^{24}$ As a result, the discussion in parliament about (the evaluation of) the prostitution policy did not address the concerns of the CEDAW Committee at all.

The COs have been referred to on 21 occasions by MPs, in addition to the debates about the COs. This is considerably more than the references to the COs of the other treaty bodies discussed so far. Parliament has also raised relatively a lot of questions related to the more procedural aspects of the process of state reporting, such as the delay in reporting or the way in which parliament is informed about the process. ${ }^{25}$ MPs also questioned the way in which the government addressed the concerns and carried out the COs. ${ }^{26}$ The COs that have had the highest impact were the Law on Names and SGP, which were alluded to eight and three times respectively. ${ }^{27}$ One MP even proposed, albeit unsuccessfully, an amendment to the Law on Names on the points that CEDAW expressed its concerns (chapter VIII, section 2.3.2). The Explanatory Memorandum to the Bill highlighted that the Netherlands had been given 'a rap on the knuckles' by the CEDAW Committee. ${ }^{28}$ Other COs that were alluded to more than once are those related to the prostitution policy ${ }^{29}$ and violence against women, ${ }^{30}$ three and two times respectively.

Even though parliamentary scrutiny of the COs and the process of reporting under CEDAW is relatively considerable in comparison to the other UN human rights treaties, it is, nonetheless, still rather minimal. ${ }^{31}$ Illustrative of the limited and unstructured attention to COs is the fact that the COs 2007 were not touched upon during the discussion in parliament of the emancipation note for the period of 2008-2011. During this parliamentary debate, the same MPs were present as during the discussion of the COs 2007, which took place only one month earlier. ${ }^{32}$ Another recent example is the parliamentary debate about the judgment of the Supreme Court in the SGP case during which the COs did not play a role. ${ }^{33}$ This also illustrates that the real political debate takes place on the basis of the government's

TK 2007/08, 30420, nr. 98, 8 .

TK 2007/08, 28684, nr. 119.

On 17 December 2008, the parliament discussed its involvement in the process rather extensively. TK 2008/09, 30420, nr. 13. See also TK 1995/96, 24406, nr. 3, 5. TK 1998/99, 26206, nr. 2, 3 and 4. TK 1998/99, 25893, nr. 6. TK 1999/00, 26814, nr. 3, 3-4.

33 TK 2010/11, 28481, nr. 15, 7 June 2011, 23. TK 2010/11, nr. 99, 94-97.
} 
policy notes about its emancipation policy. The limited role of parliament in relation to CEDAW and the process of state reporting has also been acknowledged by several government officials. They noted that parliament does not always establish a link between specific policy areas and CEDAW or the COs.

Figure 8.1. Parliamentary references to CEDAW and the COs of the CEDAW Committee in the Netherlands (1995-2011)

The number of parliamentary papers in which the CEDAW or the COs of the CEDAW Committee are mentioned by MPs.

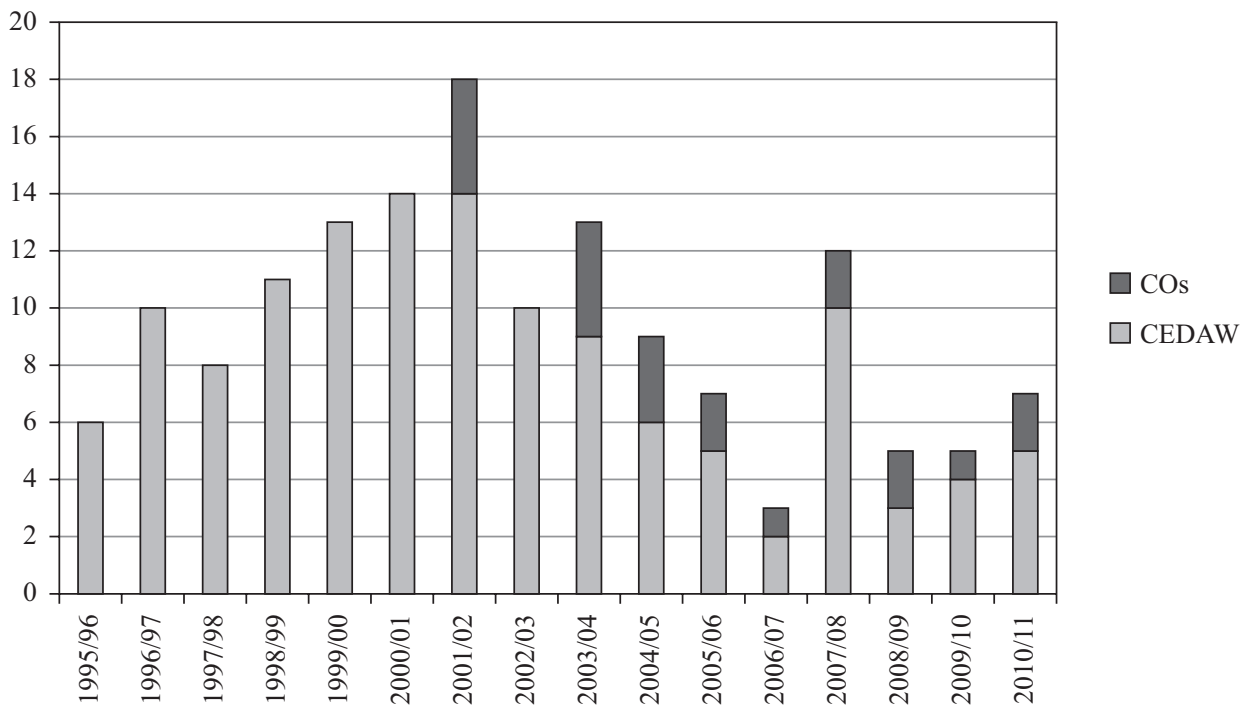

It is interesting to examine the parliamentary scrutiny of CEDAW more closely. Figure 8.1 shows that parliamentary attention to CEDAW was concentrated in the period 1999-2003. Six out of the nine motions that explicitly mentioned CEDAW were also proposed in this period. ${ }^{34}$ Parliament also discussed the substantive content of the second state report in May $1999^{35}$ and the parallel reports to the second and third report in February $2001 .{ }^{36} 15$ out of the 25 written parliamentary questions in which CEDAW was mentioned were raised in the parliamentary years 1999/00 $2002 / 03$. The number of questions raised by Bussemaker (PvdA) is interesting. Between 8 June 1999 and 25 September 2002, she raised 11 parliamentary questions in which CEDAW was referred to. One question also referred to the COs 2001.37 This illustrates that the attention of MPs for the CEDAW and the COs depends to a

\footnotetext{
34 For a discussion of the motions, see Krommendijk (2012b), 494.

35 TK 1998/99, 26206, nr. 10.

36 Visser-van Doorn (CDA) and Bussemaker (PvdA) referred to the newspaper article 'Emancipatie is doorgeschoten' devoted to the parallel report. TK 2000/01, 27061, nr. 12.

37 TK 2001/02, nr. 708. Krommendijk (2012b), 493.
} 
large extent upon the interests of individual MPs. This overview suggests that the visibility of the CEDAW was higher in this period. As we have seen, it was in this period that nearly all national reports and in-depth studies were conducted (see the introduction to chapter VIII, section 1). The majority of the motions were indeed a reaction to national reports, the in-depth studies or parallel reports. ${ }^{38}$

\subsection{Courts and legal practice}

The COs of the CEDAW Committee have been explicitly mentioned in court judgments on at least five occasions. This is the greatest number among the six UN human rights treaties. Two of those five cases deal with the SGP. ${ }^{39}$ This SGP case was taken to court by the test case fund Clara Wichmann and approximately ten other NGOs in 2003 because the government was unwilling to act upon the COs 2001 in which it was recommended to 'take urgent measures' in relation to the SGP's exclusion of women from membership. ${ }^{40}$ After almost seven years of litigation in several instances, the case was eventually decided by the Supreme Court in 2010 . The Court ruled that the fact that a political party excludes women from being eligible for election cannot be accepted in the light of the prohibition of discrimination and Article 7 CEDAW in specific. According to the Court, the government is obliged to take effective measures to address this situation. ${ }^{41}$ What is especially interesting is that the fund and the NGOs used the COs 2001 during the legal proceedings. As a result, courts also paid attention to them. ${ }^{42}$ The Court of Appeal referred to the CEDAW Committee's 'judgment' to confirm its own conclusion. ${ }^{43}$ The COs 2001 were also reproduced entirely on the advice of the Solicitor General to the Supreme Court. $^{44}$ The Supreme Court itself, however, did not refer to CEDAW or the COs in its judgment. The judgments of the Council of State and the courts of first instance

38 The Explanatory Memorandum to the proposal by Van Wijmen and Ross-van Dorp (CDA) about the inheritance of noble titles through the female line, for example, paid attention to CEDAW and the critique of the Groenman Committee. TK 2000/01, 27074, nr. 5.

39 In a case about the Law on Names, the 'bibliography' of the conclusion of the Solicitor General of the Supreme Court referred to academic literature in which the COs 2001 are discussed. Hoge Raad, 14 April 2006, LJN: AU9239. Another reference was to the COs 2001 concerning the position of prostitutes without a valid residence permit. Rb. Amsterdam, 3 June 2002, LJN: AE4749. For the third case, see infra n. 50.

40 The 'Proefprocessenfonds Clara Wichmann' is a test case fund for cases in the field of discrimination of women and women's rights. They started civil proceedings against the SGP and the state. Rb. Den Haag, 7 September 2005, LJN:AU2091. For a discussion of other court cases, see Janse and Tigchelaar (2010), De Boer (2012), Van den Brink (2013), 494-501.

41 According to the Supreme Court, these measures should at the same time constitute the least infringement of the fundamental rights of freedom of religion and association of the members of the SGP. Hoge Raad, 9 April 2010, LJN: BK4547, para. 4.5.5, 4.6.1 and 4.6.2.

42 See also Janse and Tigchelaar (2010), 314.

43 Hof Den Haag, 20 December 2007, LJN: BC0619, para. 5.10.

44 It is remarkable that the Solicitor General did not refer to the most recent COs of 2007. Conclusion by Langemeijer in Hoge Raad, 9 April 2010, LJN: BK4547, para. 1.4, 2.20 and 2.21. 
also did not mention the COs. ${ }^{45}$ Several interviewees referred to the judgment as an example of influence of the process of state reporting. For a further discussion of the effectiveness of the COs with respect to the SGP, see chapter VIII, section 2.3.1.

The CEDAW as such, however, does not have a prominent position in legal practice. Courts have only touched upon CEDAW 39 times since December 1999. Apart from the SGP case, Dutch courts have rarely scrutinised the CEDAW on its merits. ${ }^{46}$ Dutch courts also disagreed whether certain provisions of CEDAW have direct effect. In the SGP cases, the courts granted Article 7 direct effect. ${ }^{47}$ At other times, courts expressed their doubts as to the direct effect. That is to say, in the case about maternity benefits for self-employed women, several courts and the Central Appeals Tribunal considered Article 11(3)(b) CEDAW to be 'an instruction norm', because this provision does not include an immediate and unambiguous obligation, but instead it endows states with a margin of discretion. ${ }^{48}$ In addition, both the Court of Appeal and the Supreme Court considered this article to be formulated too generally and insufficiently precise, since it does not specify the modalities of maternity leave as to its duration, configuration and the amount of benefits. Hence, this provision could not have direct effect in the view of both courts. ${ }^{49}$ The Solicitor General to the Supreme Court in this case disregarded the appeal to COs 2007 and 2010 in which the CEDAW Committee called upon the state to reconsider its position as to the direct effect of the provisions of the CEDAW. He considered this 'standpoint' of the Committee not to be directly applicable in the Dutch legal order, since the legislature should act first before the judge can apply the standpoint. Nor does the standpoint offer the judge a basis to concretise the provision as to the form and amount of benefits. ${ }^{50}$ For a further assessment of the effectiveness of this $\mathrm{CO}$ concerning maternity benefits, see chapter VIII, section 2.3.3.

\subsection{NGOs}

The NGO which has been most active in relation to CEDAW is the Dutch CEDAW Network. This Network is an open form of cooperation between several women and human rights organisations with the objective of monitoring and evaluating the governments' compliance with its obligations under CEDAW. ${ }^{51}$ The fourth and

45 Rb. Den Haag, 7 September 2005, LJN:AU2091. Rb. Den Haag, 30 November 2006, LJN: AZ5393. ABRvS, 5 December 2007, LJN: BB9493.

46 See also Van den Brink (2001), 1074-1075. De Boer (2008), 51.

47 Hoge Raad, 9 April 2010, LJN: BK4547, para. 4.4. Hof Den Haag, 20 December 2007, LJN: BC0619, para. 4.1-4.7. ABRvS, 5 December 2007, LJN: BB9493. Rb. Den Haag, 7 September 2005, LJN: AU2088, para. 3.15.

48 The test case fund Clara Wichmann, the trade unions confederation FNV and seven individuals claimed a violation of CEDAW. Rb. Den Haag, 25 July 2007, LJN: BB0334.

49 Hoge Raad, 1 April 2011, LJN: BP3044, para. 3.3.1-3.3.3. Hof Den Haag, 21 July 2009, 105.007.459/01, para. 3.3.

50 Conclusion of Langemeijer in Hoge Raad, 21 January 2011, LJN: BP3044, para. 3.15-3.18.

51 This network consists of a core group of nine (previously ten) Dutch NGOs and several individual specialists of the CEDAW, of which the Clara Wichmann Instituut, an expertise 
fifth parallel reports were written on behalf of the Network in 2006 and 2009.52 It is noteworthy that the government subsidised these parallel reports. ${ }^{53}$

The Network and individual women's rights NGOs have used the COs in their domestic lobbying rather extensively. ${ }^{54}$ After the publication of the COs, NGOs have usually discussed the priorities in the COs, the division of tasks between the NGOs and the formulation of concrete action points for their advocacy. ${ }^{55}$ Sometimes an MP or even the responsible member of government also participated in such meetings. ${ }^{56}$ The Network has also started to monitor the implementation of the COs and, thus, the follow-up at the national level more closely, especially after the COs 2007. The Network, for example, sent a detailed analysis and commentary about the governmental reaction to the COs 2007 to parliament for the purpose of the parliamentary debate about the COs. ${ }^{57}$ The COs 2010 were even published in a comprehensive brochure by E-quality on behalf of the Network. ${ }^{58}$ The Network also sent parliament a point by point commentary to the government's reaction to the COs 2010. ${ }^{59}$ The COs 2010 were also given some attention during a discussion

centre for women and rights (until 1 October 2004) and the Vereniging voor Vrouw en Recht Clara Wichmann (VVR) (from 22 April 2004) and E-Quality are most directly involved in the monitoring of the CEDAW. Other members are Aletta, Justitia et Pax, Movisie, St. Emancipatie Online, SIM, Tiye-International, Vluchtelingenorganisaties Nederland and, until 25 February 2011, Aim for Human Rights.

52 Margreet de Boer en Marjan Wijers, Taking women's rights seriously (NJCM and Dutch CEDAW Network, 15 June 2006). Leontine Bijleveld and Linda Mans, Women's rights. Some progress, many gaps (Dutch CEDAW Network, 2009). The parallel report to the second and third state report discussed in 2001 was published by E-Quality and NJCM.

53 UN Doc. A/4938 (1994), para. 253. UN Doc CEDAW/C/NLD/5 (2008), 12.

54 Almost all the commentaries in which the COs are mentioned are written by or on behalf of the Vereniging voor Vrouw en Recht Clara Wichmann and/or the Network. For a good overview: $<$ www.vrouwenrecht.nl/opinie>, accessed 31 July 2013.

55 After the COs 2007, there was, for example, a public meeting on 23 March 2007 to deliberate on the way in which the COs could contribute to better policies for women. Action points for the new emancipation note of the government and for the participating NGOs themselves were formulated.

56 State Secretary Verstand and an expert member of the CEDAW Committee attended a follow-up meeting organised by E-Quality and the Clara Wichmann Institute on 16 April 2002. Boerefijn et al. (2003), 125-126. Karabulut (SP) participated in the public meeting about the COs 2007. The result of this is that she mentioned the COs 2007 more often and more specifically than other MPs. TK 2007/08, 30420, nr. 98, 2-3 and 9. During a similar meeting in 2010, Senator Strik (GL) was present. As a result, GL asked a question about prostitution in which the COs 2010 were referred to. TK 32211, nr. B, 8.

57 Netwerk VN-Vrouwenverdrag (2008). As a result, many of the issues were also highlighted by MPs in the debate, including the requests to be informed about the division of responsibility and coordination of emancipation affairs and the legal status of CEDAW. TK 2007/08, 30420, nr. 98. TK 2007/08, 30420, nr. 97 and 106. Van den Brink (2013), 493.

58 E-Quality, 'Vrouwenrechten in Nederland anno 2010', April 2010: <www.atria-kennisinstituut. nl/epublications/IAV_B00103409.pdf>, accessed 31 July 2013.

59 This commentary was sent twice, on 6 September 2010 and 31 May 2011. The latter was sent with a view on the parliamentary debate about the policy note about emancipation on 8 June 2011: <www.vrouwenrecht.nl/opinie/vvr/brieftkcobs_juni2011>, accessed 31 July 2013. 
organised by E-Quality about emancipation with several MPs which took place before the parliamentary elections. ${ }^{60}$

The lobbying on the basis of the COs has had a real impact on parliament in particular. MPs have asked the government to give a reaction or more information on the points raised by the NGOs. ${ }^{61}$ The commentaries and opinions of NGOs are often explicitly mentioned by MPs. ${ }^{62}$ The government has also felt it necessary to react to the points raised by NGOs. ${ }^{63} \mathrm{NGO}$ lobbying is, thus, an important mediating factor for parliamentary and governmental attention to CEDAW and the COs. This means that NGOs are important for 'translating' COs for the domestic context and making MPs aware of the COs. This role of NGOs was also noted by several government officials.

Consultation meetings between NGOs and the government have increasingly taken place since the fifth reporting cycle and before and after the dialogue with the CEDAW Committee in 2010. ${ }^{64}$ This enhanced involvement of NGOs was attributed to the UPR 2008, during which NGOs were also more closely involved. Note that the meetings took place primarily on an ad hoc basis. Both NGO representatives and government officials were less positive about this consultation than, for example, the cooperation between the Children's Rights Coalition and the government (chapter X, section 1.4). Government officials mentioned the sometimes very negative and critical approach of NGOs and the 'us vs. them' relationship. They also referred to angry remarks made by NGO representatives on their blog about the statements of the Dutch delegation during the dialogue with the CEDAW Committee in 2010. In addition, government officials pointed to the same issues that were constantly repeated by NGOs. It was also noted that the reasoning on the part of NGOs is abstract and legal and almost exclusively based on CEDAW instead of being realistic. NGOs, on the other hand, argued that the government finds it difficult to deal with criticism.

NGOs have also been active in relation to litigation. That is to say, the test case fund Clara Wichmann took several matters related to discrimination of women and

60 The discussion note for this meeting analysed four issues in the election programmes of the several political parties partly in the light of the most recent COs. The meeting took place on 3 June 2010. Several MPs were present, including Karabulut (SP), Hamer (PvdA), Van der Burg (VVD), Van Dijk (CDA), Van Gent (GL). The four issues were childcare, tax, social security and labour law, and integration: Zijspiegel. Verkiezingsprogramma's bekeken op emancipatie-effecten, May 2010: $<$ www.atria-kennisinstituut.nl/atria/content/163323/politiek_50__ 50>, accessed 31 July 2013.

61 See, for example, TK 2008/09, 30420, nr. 136. Supra n. 57. De Boer (2007), 1225-1226.

62 Supra n. 56. See also the question of the SP in the context of the prostitution policy referring to the COs 2010 which reflect the comments of the Vereniging voor Vrouw en Recht. TK 2009/10, 32211 , nr. 5, 4. For the comments: <www.vrouwenrecht.nl/2009/12/01/commentaar-wetsvoorstelprostitutiewet-32-211-1-december-2009/>, accessed 31 July 2013.

63 See, for example, the reaction to the Monitor about the implementation of the COs 2007. EK 2008/09, 30420, nr. A and TK 2008/09, 30420, nr. 129.

64 There was a meeting on 23 June 2009 about the LOI during which the NGOs informed the government about their remarks about the fifth state report. Another meeting between NGOs and governmental officials from different departments took place in mid-December 2009. Another meeting to discuss the COs 2010 took place on 19 April 2010. 
women's rights to court (chapter VIII, section 1.3). In several of these cases, the fund claimed a violation of provisions of CEDAW. This included, among others, the cases earlier discussed related to the SGP (chapter VIII, section 2.3.1) and maternity benefits for independent entrepreneurs (chapter VIII, section 2.3.3).

NGOs involved in the process of parallel reporting under CEDAW also used their involvement to define their work and to stimulate cooperation among each other. One representative of the Netherlands Centre for Social Development (Movisie), which is focused on domestic and sexual violence, stated that the human rights perspective has become stronger in their agenda setting and advisory work at the national level, as a consequence of their involvement in the reporting process. Some NGO representatives also mentioned that the compilation of a parallel report offered the possibility for NGOs to get in touch with each other, enabling future ways of cooperation. During the latest reporting cycle, the Federation of Dutch associations for the integration of homosexuality (COC Netherlands) was also involved in the parallel reporting process and one representative was also present in Geneva in 2010. It is noteworthy that the choice of COC to participate actively in the process was also motivated by the wish that LGBT issues would be given attention and recognised at the international level within the context of CEDAW. ${ }^{65}$ In addition, its involvement was also based on national considerations related to domestic political lobbying. ${ }^{66}$

In sum, the extent of domestic mobilisation of NGOs with respect to CEDAW and the COs of the CEDAW Committee is considerable in comparison to the other treaties discussed so far. The Dutch CEDAW Network has specifically used the COs in its political lobbying and litigation. Representatives of the Network saw the reporting process as part of a wider political lobby. The most important reason for submitting shadow reports is to generate COs that will strengthen the domestic lobby. By contrast, as we have seen in the previous chapters about ICCPR and ICESCR, other NGOs such as NJCM see the parallel report primarily as an exercise in itself.

\subsection{Media coverage}

The parallel report and the COs 2001 were picked up by the media and covered rather extensively. There were 24 newspaper articles that referred to the COs $2001 .^{67}$ No less than 14 articles referred to the COs 2001 in relation to the SGP case, whereby

65 The CEDAW Committee included a reference to the issue of forced sterilisation of transgenders and the reimbursement of breast implants for transgender women in its COs 2010. The fact that the COs dealt with this sensitive issue was primarily the result of the lobbying of the COC and the Network and the willingness of the Dutch delegation to raise this issue in its opening statement. UN Doc. CEDAW/C/NLD/CO/5 (2010), para. 47.

66 Especially the $\mathrm{CO}$ recommending the reimbursement of breast implants was used in advocacy as an additional argument and a means of putting political pressure on parliament and the government. See, for example: $<$ www.coc.nl/dopage.pl?thema=politiek\&pagina=viewartikel\&a rtikel_id=3432>, accessed 31 July 2013. This lobby was of no avail, since the Minister decided not to follow the CO. TK 2009/10, 30420, nr. 154, 22.

67 See, for example, Herman Staal, 'Emanciperen via VN', NRC Handelsblad, 1 February 2001, 2. 
it was stated that the CEDAW Committee 'lectured the government', 'rapped the government over the knuckles', 'called the government to order' or appealed or condemned the situation as to the existence of the political party. ${ }^{68}$ Attention in the press was also paid to the COs concerning the Law on Names. ${ }^{69}$ No attention was, however, paid to the COs 2007 and 2010. The increase in the number of articles in which CEDAW was mentioned in relation to several court judgments in the SGP case after 2005/06 is illustrative of the lack of attention paid to the COs. Nonetheless, only 1 of the 75 articles also made a reference to the CEDAW Committee. ${ }^{70}$

\subsection{Conclusion}

The reporting process under CEDAW and the COs of the CEDAW Committee has had the biggest impact of the six treaties in this study, except for the CRC. This section showed that the COs have sometimes been discussed, invoked or referred to in parliament and by the government. At the same time, COs have been considered by national courts and picked up by the press. The COs that have received the most attention were the COs with respect to the Law on Names and SGP. One reason that these COs were mentioned relatively frequently might be that these COs were the most specific and clear. That is to say, the wording chosen by the Committee in these paragraphs is more forceful in comparison to the other COs. Not only is the language stronger ('contravenes the basic principle of the Convention' and 'is a violation'), but it is only with respect to these issues that the Committee refers to specific provisions in the CEDAW.

It is noteworthy that the attention paid by parliament and the government to the national reports and in-depth studies was - at least until 2004 - more frequent and extensive in comparison to COs. ${ }^{71}$ The media has also paid attention to the reports and in-depth studies. ${ }^{72}$ This could possibly be attributed to the fact that those national reports are more visible, thorough and contain a more comprehensive analysis. In addition, they also have a better understanding of the national context, given the fact that they are written by nationals (see also chapter VIII, section 3.2). Furthermore, those reports are written in Dutch, whereas the COs 2001 and 2007 were not translated into Dutch. ${ }^{73}$

68 See, for example, Tom Kreling, 'SGP en staat voor de rechter gedaagd', NRC Handelsblad, 13 November 2003, 1.

69 See, for example, 'Minister Donner bekijkt praktische uitwerking; "het naamrecht is anno 2005 niet geëmancipeerd"', Het Parool, 22 April 2005.

70 Marijn Kruk, 'Inperking van de islam treft ook andere religies', Trouw, 17 November 2005, 5.

71 The reactions to the first and second national report were 59 and 68 pages long. TK 1997/98, 25893, nr. 2 and the annex to TK 2003/04, szw0400002. See also the 62 detailed and specific questions in parliament about the recommendations of the third in-depth study. TK 1998/99, 25893, nr. 6, 1-10. Van den Brink (2013), 482.

72 See, for example, 'Vrouwen in Nederland nog steeds achterop', Het Parool, 19 March 1997, 1 and 2. Krommendijk (2012b), 496.

73 Note that the second and third state reports of 1999 and 2000 were written in Dutch. 


\section{Assessing The efFectiveness of COs}

This second section analyses the effectiveness of the process of state reporting in terms of the extent to which the Netherlands has taken measures as result of and in line with the COs. As with the other treaties, this appraisal is based on the documents in which the reaction of the government to COs in parliamentary papers ${ }^{74}$ state reports ${ }^{75}$ the replies to the LOI and the summary records. Furthermore, NGO parallel reports and the national reports were considered. ${ }^{76}$ The analysis in this section is also based on the examples given by quite a few government officials and NGO representatives of COs that were partly effective (see table 8.2). This section will investigate whether these COs were indeed effective.

In general, the initial reaction of the government to the COs sent to parliament is rather dismissive and defensive. COs are either refuted (chapter VIII, section 2.1) or the reaction refers to existing and intended policy measures and initiatives already in place (chapter VIII, section 2.2). In particular the reaction to the COs 2010 was dismissive. In response to several COs, the government held that it had already explained its position to the Committee several times. At other times, the government argued that it had made a deliberate policy choice or that it had a different assessment and argues that it considered its efforts or policies sufficient. Note that the government unsuccessfully tried to get several (factual) errors in the COs 2010 rectified. ${ }^{77}$ In terms of effectiveness, the reaction did not include proposals for new policies and legislation since the Balkenende IV government was outgoing at that time. Parliament requested the Rutte I government to give a further policy reaction to the COs 2010, since the reaction of July 2010 did not include any proposals for new policy measures. The government, however, considered the initial reaction to be sufficient. ${ }^{78}$

\section{$74 \quad$ Supra n. 12.}

75 By and large, the fourth report hardly responded to the previous COs 2001. Only in two instances was there a reference to the COs, concerning the participation of representatives from the overseas territories and the SGP. This was despite the fact that the report provided that it 'takes a closer look at the recommendations and conclusions under the relevant articles'. One government involved in the coordination of the fourth report also mentioned that the COs 2001 were hardly used when writing the subsequent fourth report, because of the long time interval due to the delay in reporting. UN Doc. CEDAW/C/NLD/4 (2005), 3 and 47. The COs 2007 were responded to in the fifth report in the context of the specific provisions of CEDAW. UN Doc. CEDAW/C/NLD/5 (2008).

76 Especially the parallel report of 2006 referred to the previous COs 2001, while the report of 2009 did so to a lesser extent. Supra n. 52. The government reacted to the national report of 2003 in TK 2003/04, szw0400002.

77 The government sent its comments to the CEDAW Committee on 11 February and 9 April 2010 with respect to para. 12, 26, 28, 29, 41 and 46 of the COs 2010. See 'Comments of the Kingdom of the Netherlands on the Concluding observations dated 5 February 2010 to be taken into consideration by the Committee and to be referred to by the Committee', 9 April 2010, unpublished.

78 TK 2009/10, 30420, nr. 154, 1. TK 2010/11, 27017, nr. 74, 4. 


\subsection{COs that have been rejected}

Government officials gave many examples of COs that were rejected or considered a bridge too far during the interviews, as table 8.1 shows.

\section{Table 8.1. Overview of ineffective COs of the CEDAW Committee in the Netherlands}

The number of times that COs were mentioned by government officials as examples of an ineffective $\mathrm{CO}$. The respective footnotes and following section discuss the reasons given for not acting upon the COs.

\begin{tabular}{|l|c|}
\hline The limited legal status and lack of direct effect of CEDAW & 7 \\
\hline The overrepresentation of women in part-time employment & 4 \\
\hline The autonomous status of the overseas territories ${ }^{79}$ & 3 \\
\hline Lifting the ban on brothels $^{80}$ & 2 \\
\hline Funding of NGOs $^{81}$ & 1 \\
\hline Temporary special measures, including quota & 1 \\
\hline Compensation for the cost of contraception for women & 1 \\
\hline One single government department responsible for coordination gender-mainstreaming $^{82}$ & 1 \\
\hline Domestic violence as a ground for asylum $^{93}$ & 1 \\
\hline The possibility of victims of trafficking to be offered protection and a residence permit & 84 \\
\hline
\end{tabular}

79 The government considered the overseas territories are fully autonomous in their domestic affairs, which means that the government of the Netherlands 'has no authority to impose any policy' concerning the implementation of international human rights instruments. UN Doc. CEDAW/C/SR.513 (2001), para. 12.

80 State Secretary Verstand remarked that the Netherlands has chosen to abolish the ban on brothels 'with good intentions', where other countries, such as Sweden, choose an absolute ban in order to protect prostitutes, or others criminalised the 'use' of the services of prostitutes. TK 2001/02, 28009 nr. 7, 12.

81 The government preferred to fund the knowledge infrastructure for emancipation in general as well as 'output and results' and local initiatives on the ground instead of funding the monitoring of compliance with CEDAW. It argued that the subsidising of the parallel report is sufficient. UN Doc. CEDAW/C/NLD/Q/4/Add.1 (2006), para. 20. UN Doc CEDAW/C/NLD/5 (2008), 12.

82 During the parliamentary debate about the COs 2007 the Minister said that he would support other ministries' process of emancipation, but that he will not have a 'designating competence'. TK 2007/08, 30420, nr. 98, 8.

83 Government officials argued that it had been explained over and over again to the CEDAW Committee that this is already legally provided for. In its comments to the COs 2010 it held: 'The assumption that domestic violence is not formally recognised as a ground for asylum is not correct.' Supra n. 77.

84 Government officials argued that it had been explained over and over again to the CEDAW Committee that this is already legally provided for in the Alien Circular. In its comments to the COs 2010 it held: 'The Netherlands asked the Committee to rectify the sentence [...] however the Committee was not forthcoming to do so. The assumption that victims who do not cooperate are excluded from help is incorrect.' Supra n. 77. 
Officials frequently noted that they could not have these issues explained or that the CEDAW Committee simply did not (want to) understand. This means that the government often reproduces the same story that was included in the state report, the answers to the LOI or it reiterates what has been told during the dialogue and what the Committee did not consider satisfactory or sufficient. ${ }^{85}$ The COs of the CEDAW Committee are seen as mere opinions. It was made clear, for example, that the political appraisal as to the implementation of the COs is ultimately made in the Netherlands. ${ }^{86}$ During the parliamentary debate about CEDAW COs 2001, the State Secretary emphasised that neither the COs nor the CEDAW Committee need to be viewed as a timetable. ${ }^{87}$ Another government official spoke about a 'wish list' implying that what the government is already doing is not necessarily in violation of the recommendation. Several government officials also highlighted that 'we' have our own vision and 'they' (the CEDAW Committee) their interpretation. The government, for example, held in its fourth report: 'although the Convention states that the member states should combat the exploitation of prostitution, the Netherlands takes a different view. ${ }^{88}$ Officials spoke about 'agree to disagree' points encompassing clear and deliberate policy choices backed by a parliamentary majority that is prepared to put up with the fact that such a policy might be in conflict with human rights standards. Several government officials and also an MP even questioned why the CEDAW Committee meddled in domestic affairs. ${ }^{89}$ In response to questions of Committee expert members in 2010 about the Law on Names, the State Secretary simply stated that it is in our culture. ${ }^{90}$

As was mentioned in relation to CERD, COs are often not complied with because of a fundamental irreconcilable difference of opinion between the government and the Committee (chapter V, section 2.1). In the case of CEDAW, the disagreement is essentially the result of the divergence of views about the nature of the obligations under the CEDAW. Whereas the CEDAW Committee interprets the CEDAW broadly and progressively, the government adopts a more restrictive view

85 Van den Brink (2001), 1073. De Boer (2007), 1220 and 1223. Bussemaker (PvdA) in TK 2001/02, 28009, nr. 7, 7 and 16.

86 TK 2007/08, 30420, nr. 98, 7-8. See also Janse and Tigchelaar (2010), 314-315.

87 The State Secretary used the word 'spoorboekje' (railway timetable). She argued that states have a certain margin for their own interpretation. TK 2001/02, $28009 \mathrm{nr}$. 7, 12. Similarly, during the debate about the COs 2007, the Minister recognised that the CEDAW Committee's 'advice' is taken seriously, but that this does not mean that all the advice and comments will be adopted one-on-one. TK 2007/08, 30420, nr. 98, 7-8.

88 The Netherlands does not have any reservations under CEDAW. UN Doc. CEDAW/C/NLD/4 (2005), 4 .

89 Middelkoop (CU) questioned the fact that the Committee meddles in issues that are the result of local culture, such as low labour market participation and discrimination in pay. As a result, he argued for assertiveness in answering criticism. TK 2001/02, $28009 \mathrm{nr}$. 7, 11. Reading out some COs, one government official reacted by saying 'what do they (the CEDAW Committee) know about it' and 'why should they meddle in' and 'not all countries have to be like Sweden'.

Personal observation of the dialogue in 2010. 
about the obligations under the CEDAW. ${ }^{91}$ This divergence is for example reflected in the discussion about the status and the direct effect of the CEDAW. ${ }^{2}$ The government argued in a similar way as with ICESCR that CEDAW contains obligations of conduct rather than obligations of result (chapter VII, section 3.1). It held that CEDAW is not giving an unambiguous framework because of the different national contexts in which it needs to be implemented. ${ }^{93}$ During an individual complaint before the CEDAW Committee, the government even stated that Article 11(2)(b) CEDAW cannot be invoked directly by individuals, because it entails 'an obligation to pursue, rather than to achieve, a certain goal (inspanningsverplichting), with states parties being allowed certain discretionary powers'. Accordingly, the government is thus of the opinion that the provision is not 'formulated so precisely that rights necessarily ensue from it unambiguously and without the need for any further action to be taken by the national authorities' ${ }^{94}$

A related issue is the disagreement about the form of equality that should be achieved on the basis of the CEDAW, whether it is merely de jure or also de facto. The government, for instance, rejected the recommendation about the accessibility of pensions and health care for elderly women, because these facilities are at least formally equally accessible. ${ }^{95}$ Another example of this is the reasoning that the obligation in Article 5 CEDAW concerning the elimination of stereotypes has been fulfilled, because the Equal Treatment (Full-time and Part-time Workers) Act avoids any reference to full-time or part-time employees. ${ }^{96}$ Similarly, the government and especially the Ministry of Justice deems the gender-neutral wording of policy to be the correct starting point, for example in the context of domestic violence, human trafficking or the integration courses. ${ }^{97}$

This divergence of views also boils down to differences in how the government and the CEDAW Committee see the role and functions of the state in society vis-àvis individual responsibilities. ${ }^{98}$ CEDAW and the CEDAW Committee call for an active role of the state to realise equality and equal opportunities in practice by, for example, taking temporary special measures for specific (vulnerable) groups of women and minorities. The Dutch government is not in favour of such measures, at

\footnotetext{
91 Acar, former Chair of the CEDAW Committee, stated that the Committee is 'famous for integrating progressive standards into its interpretation of the Convention' and that the views expressed by experts during the dialogue 'bear testimony to a remarkably bold interpretation of the Convention'. Acar (2007), 242.

92 UN Doc. CEDAW/C/NLD/CO/4 (2007), para. 11 and 12. UN Doc. CEDAW/C/NLD/CO/5 (2010), para. 8, 12 and 13 .

93 TK 1997/98, 25893, nr. 5, 6 .

94 Nguyen v. the Netherlands, 14 August 2006, Communication No. 3/2004, UN Doc. CEDAW/ $\mathrm{C} / 36 / \mathrm{D} / 3 / 2004$, para. 6.9 and 6.10 .

95 TK 2001/02, szw0000961, 1.

96 UN Doc. CEDAW/C/NLD/4 (2005), 62.

97 Visitatiecommissie Emancipatie (2007c), 7. UN Doc. CEDAW/C/NLD/5 (2008), 27.

98 Krommendijk (2012b), 506.
} 
least in the sense of the CEDAW. ${ }^{99}$ It considered that the improvement of the disadvantaged position of women belonging to ethnic minorities is primarily 'their own responsibility to an important extent'. ${ }^{100}$ The government also downplayed the role of the state by emphasising the freedom of individuals with respect to the great number of women employed in part-time jobs. According to the former Minister of Social Affairs and Employment De Geus, this is not undesirable, because the freedom to choose whether or not to work should be respected. ${ }^{101}$ Government officials also argued that women should not be forced to work against their will. They considered this freedom to be an achievement in the Netherlands instead of something unwanted. Officials criticised the 'the worn idea' of the CEDAW Committee that all women should work, preferably full-time. In this context it was also mentioned that the Netherlands does not strive for a CEDAW police state. ${ }^{102}$

These divergent views often boil down to clashing obligations under international and European law, encompassing different standards of equality. ${ }^{103}$ The government has frequently referred to other international obligations or jurisprudence of other international courts in order to justify non-compliance with COs. ${ }^{104}$ For example, with respect to the Law on Names, the government pointed to the ECtHR that ruled in a case against the Netherlands that the difference in treatment is reasonable and proportional. ${ }^{105}$ In the context of the $\mathrm{CO}$ about the discrimination part-time workers are facing in relation to overtime, the government mentioned the ruling of the ECJ that it was not discriminatory to deny overtime pay to a part-time worker.' 106 Similarly it was argued that the jurisprudence of the ECJ has curtailed the possible forms of preferential treatment. ${ }^{107}$

\subsection{Standing policy and legislative measures in line with the COs}

Several COs of the CEDAW Committee are very broad and unspecific. This is especially the case with the COs about measures in the socio-economic field

99 The government said that it was against legal quotas for women holding public office or political positions because positions in the Ministry were filled on the basis of qualifications, irrespective of gender. UN Doc. CEDAW/C/SR.767(B) (2007), para 6 and 45. Krommendijk (2012b), 506507.

100 UN Doc. CEDAW/C/NLD/4 (2005), 23.

101 UN Doc. CEDAW/C/SR.767(B) (2007), para. 7. Krommendijk (2012b), 507.

102 Janse and Tigchelaar also argued that judges might see the CEDAW Committee as a one-issue party that does not carefully balance conflicting human rights. Janse and Tigchelaar (2010), 315.

103 Holtmaat and Tobler (2005).

104 During the dialogue in 2007 it was stated that the B-9 arrangement was in line with EU guidelines for residence permits for victims who cooperated with the authorities. CEDAW/C/ SR.767(B) (2007), para. 62.

105 Bijleveld v. the Netherlands, 27 April 2000, Application no. 42 973/98.

106 UN Doc. A/56/38(SUPP) (2001), para. 214. UN Doc. CEDAW/C/SR.512 (2001), para. 47.

107 TK 2004/05, 28770, nr. 11, 4. 
related to the labour market participation of women and the position of immigrant, refugee and minority women. ${ }^{108}$ Those $\mathrm{COs}$ are rather undetermined and aspirational referring to 'greater efforts', 'additional programmes', 'sufficient childcare places', 'relevant follow-up steps', and the increase, intensifying or strengthening of efforts. Given the fact that the measures prescribed are general and do not outline a specific course of action, it is unclear what kind of measures the CEDAW Committee has in mind and how the state could intensify its efforts. As a result, it might be uncertain what the contribution and the usefulness of the COs is, also in the light of the fact that the government frequently seems to support the lofty sweeping statements of the Committee. Broad COs have led to little reflection as to whether the measures in the policy areas covered by the COs are indeed sufficient or proper. Another illustration of the limited usefulness is the limited impact at the domestic level and the fact that they are rarely picked up by domestic actors such as parliament or NGOs. Government officials mentioned that these broad COs often reflect what the government is already doing. They gave several examples of COs that could be easily parried, since a lot of policy measures are already employed. Officials mentioned COs with respect to the increase of the labour market participation of women, women in high-ranking posts in politics, in the private sector and in academia, human trafficking and domestic violence. ${ }^{109}$

The government has sometimes claimed that it has taken a certain measure in response to the criticism of the Committee. The following examples show that it is important to scrutinise these claims carefully in order to determine whether there is indeed such a causal relation between the COs and alleged follow-up measures. During the parliamentary debate about the COs 2007, the Minister responsible for emancipation affairs enumerated several measures allegedly taken in response to the COs 2007, including several fiscal measures. ${ }^{110}$ Nevertheless, the Minister of Finance had held earlier that the 'advice' of the Committee in the COs 2007 did not have any practical consequences for the policy of the Ministry of Finance. ${ }^{111}$ This implies that the (fiscal) measures were already planned irrespective of the COs and not taken as a result of the COs. Likewise, the Minister of Education presented the decision to include compensation for the cost of contraception in the basic health insurance package as an example of a measure taken to follow-up on the COs 2007..12 Nevertheless,

108 See, for example, UN Doc. A/56/38(SUPP) (2001), para 203-206, 213-214 and 216-218. UN Doc. CEDAW/C/NLD/CO/4 (2007), para 17-18, 27-30.

109 The Dutch CEDAW Network noted that new or additional policies had been developed for human trafficking, domestic violence, the maternity benefits for self-employed women and family reunification, but that no link was made with CEDAW or the COs. Netwerk VN-Vrouwenverdrag (2008), 13. 
the measure was already announced in the new coalition accord on 7 February 2007, while the COs were only adopted by the Committee five days earlier. ${ }^{113}$ What is more, this decision was already reversed after three years, despite the COs. ${ }^{114}$

Two NGO representatives gave the example of the evaluation of the income requirement for family reunification as a measure taken as a result of the COs 2007. ${ }^{115}$ In these COs, the Committee urged the government to withdraw the severe requirements for family reunification constituting a breach of Article 16 CEDAW. ${ }^{116}$ Nonetheless, the evaluation was the result of a motion proposed by Azough (GL) requesting the government to conduct an independent evaluation of the (lawfulness) of the increase of the income requirement. The parliamentary debate during which the motion was proposed took place before the dialogue with the CEDAW Committee on 17 and 18 January $2007 .{ }^{117}$ In addition, the motion only mentioned the right to family life laid down in the ECHR. ${ }^{118}$ There is, thus, no causal relationship between the COs and the motion requesting the evaluation. One government official also pointed out that the evaluation was not the direct consequence of the COs but of a request of parliament.

\section{3. (Partly) effective COs}

This section examines seven (partly) effective COs. As was mentioned before, several interviewees could give examples of COs that were acted upon. Table 8.2 shows that these examples also mirror the COs that were mentioned in parliamentary papers by the government and MPs. The remainder of this section examines these seven COs more in depth.

\footnotetext{
113 TK 2006/07, 30891, nr. 4, 32.

114 TK 2009/10, 29689, nr. 303, 5.

115 'Internationale gezinsvorming begrensd? Een evaluatie van de verhoging van de inkomens- en leeftijdseis bij migratie van buitenlandse partners naar Nederland' as attachment to TK 2008/09, 30573, nr. 43.

116 UN Doc. CEDAW/C/NLD/CO/4 (2007), para. 42 and 43.

117 The motion was the result of a joint action by the political party GL and Stichting Buitenlandse Partner (Foundation Foreign Partners). During the debate, Azough did not refer to CEDAW. TK 2006/07, nr. 32, 2011-2032 and 2094-2110, 2026. Nonetheless, Azough held earlier that the proposed income requirement would violate CEDAW, because women are indirectly discriminated. TK 2004/05, 19637, nr. 873, 6.

118 TK 2006/07, 30800 VI, nr. 57.
} 
Table 8.2. Overview of (partly) effective COs of the CEDAW Committee in the Netherlands As cited in parliamentary papers or mentioned in interviews.

\begin{tabular}{|l|c|c|c|c|}
\hline \multirow{2}{*}{ Policy issue/ CO } & \multicolumn{2}{|c|}{$\begin{array}{c}\text { Impact: number of } \\
\text { references to COs }\end{array}$} & $\begin{array}{c}\text { Number of interviewees who } \\
\text { held that CO was effective }\end{array}$ \\
\cline { 2 - 5 } & Government & Parliament & $\begin{array}{c}\text { Government } \\
\text { official }\end{array}$ & $\begin{array}{c}\text { NGO } \\
\text { representative }\end{array}$ \\
\hline SGP case & 1 & 4 & 5 & 1 \\
\hline Law on Names & 1 & 8 & 2 & 2 \\
\hline $\begin{array}{l}\text { Reinstatement of maternity benefits for } \\
\text { self-employed women }\end{array}$ & & 1 & 1 & 3 \\
\hline $\begin{array}{l}\text { More attention to the gender aspects of } \\
\text { domestic violence }\end{array}$ & 1 & & 1 & 2 \\
\hline Exit programmes for prostitutes & & 1 & & 1 \\
\hline $\begin{array}{l}\text { Evaluation gender dimension asylum } \\
\text { policy }\end{array}$ & 1 & & & \\
\hline Uninterrupted long school day & 1 & & & \\
\hline $\begin{array}{l}\text { Evaluation increase income requirement } \\
\text { for family reunification }{ }^{119}\end{array}$ & & & & \\
\hline
\end{tabular}

\subsubsection{The SGP case}

The CEDAW Committee already determined three times that the existence of the political party SGP, represented in the parliament, is a violation of Article 7 CEDAW, because the SGP excluded women from membership until 2006 and continued to exclude women from being eligible for election until 2012. The CEDAW Committee also held that funding of the SGP by the state violates CEDAW. The CEDAW Committee recommended that the state take urgent measures to address this situation through the adoption of legislation. ${ }^{120}$ The government argued that in spite of the conclusion of the CEDAW Committee, the government is of the opinion that the current legislation meets the obligations of Article 7 CEDAW. ${ }^{121}$ The government also refused to withdraw its appeal against the judgment of the Court of Appeal, as recommended by the CEDAW Committee, because it considered the matter to be very principled since several fundamental rights and the relationship between the legislature and the judiciary were at stake. ${ }^{122}$

It was only after the judgment of the Supreme Court in 2010, discussed in chapter VIII, section 1.3, that the government was willing, albeit reluctantly, to take

This CO was ineffective as argued in chapter VIII, section 2.2, supra $\mathrm{n} .115-118$.

UN Doc. A/56/38(SUPP) (2001), para. 219-220. CEDAW/C/NLD/CO/4 (2007), para. 25-26.

$\mathrm{CEDAW} / \mathrm{C} / \mathrm{NLD} / \mathrm{CO} / 5$ (2010), para. 10.

121 TK 2001/02, szw0000961, 2. UN Doc. CEDAW/C/NLD/4 (2005), 47-48.

UN Doc. CEDAW/C/NLD/5 (2008), 66-67. UN Doc. CEDAW/C/SR.916 (2010), para. 75. 
measures. ${ }^{123}$ Nonetheless, when the SGP filed an appeal before the ECtHR, the Rutte I government decided to await the judgment of the ECtHR before taking any further definitive (legislative) measures. ${ }^{124}$ When the ECtHR deemed the application of the SGP inadmissible in 2012, the SGP eventually changed its regulations allowing women to be placed on the list of candidates for elections. ${ }^{125}$ Minister of the Interior Plasterk found that the change was sufficient to comply with the judgment of the Supreme Court and was of the opinion that no further measures were necessary. ${ }^{126}$ Lilian Janse was the first woman in the history of the SGP to be elected during the municipal elections of March 2014 in Vlissingen.

The COs of the CEDAW Committee were an essential factor in the entire SGP saga. Five government officials pointed to the SGP case as an example of an effective $\mathrm{CO}$. It was noted that the COs gave an important impulse and provided a good anchor and strong arguments for initiating a court case by NGOs (chapter VIII, section 1.3). NGOs have also used the COs rather frequently in their political lobbying vis-à-vis the government and parliament. MPs have also discussed or mentioned the COs concerning the SGP several times, especially in the light of the several cases before court (chapter VIII, section 1.2). The photo in the top left corner of the book cover illustrates the extensive level of domestic mobilisation in relation to the SGP case.

\subsubsection{Law on Names}

The CEDAW Committee determined three times that the Law on Names continues to contravene the basic principle of the CEDAW regarding equality of men and women and, hence, recommended that the law should be amended. ${ }^{127}$ The Law provides that when the parents cannot reach an agreement as to the name of a child, the child will automatically receive the name of the father. The government made clear that it did not share the CEDAW Committee's opinion that the Law on Names contravenes the CEDAW. ${ }^{128}$ As elaborated upon earlier, an MP proposed an amendment to the Law on Names on the points on which the CEDAW Committee expressed its concerns (chapter VIII, section 1.2). ${ }^{129}$ In its opinion to this proposal,

123 In the television programme NOVA on 9 April 2010, then Minister of the Interior and Kingdom Relations Hirsch Ballin stated that the judgment of the Supreme Court is fully respected and that new legislation is needed.

124 Minister of the Interior Donner considered the judgment of the ECtHR necessary for arriving at a final opinion in this complex case. Interestingly, the Minister characterised the discussion not only in terms of clashing fundamental rights but also as one of conflicting treaty provisions in CEDAW and ECHR. TK 2010/11, nr. 10, 93-97, 96. TK 2010/11, 28481, nr. 8. TK 2010/11, 28481, nr. 9-14.

125 SGP v. the Netherlands, 10 July 2012, Application no. 58369/10, para. 78 and 77-79. See also Van den Brink (2013), 499-500.

126 TK 2012/13, 28481, nr. 20.

127 Supra n. 4.

128 As support, the government pointed to the jurisprudence of the ECtHR, which ruled in a case against the Netherlands that the difference in treatment is reasonable and proportional. Bijleveld v. the Netherlands, 27 April 2000, Application no. 42 973/98. TK 2001/02, szw0000961, 3. TK 2003/04, 29353, nr. 5, 3.

129 This proposal mentioned that the Netherlands was given a rap on the knuckles by the CEDAW Committee, but it did not explicitly reproduce the COs. The proposal also referred to a study 
the Council of State stated that the CEDAW Committee reproduced the Law on Names incorrectly. ${ }^{130}$ In addition, the Council of State remarked in its opinion that the CEDAW Committee did not provide a further explanation as to the question whether an objective and reasonable ground exists concerning the preference in the Dutch Law for the family name of the father when parents cannot reach an agreement as to the name of a child. It also referred to the 'margin of appreciation' for states under the CEDAW and the fact that this subject is defined by national traditions and that there exists a clear preference of the Dutch population. ${ }^{131}$ Minister of Justice Donner shared this advice and the opinion that the Law is not incompatible with the CEDAW. He argued that he had doubts about whether the CEDAW Committee rightly established a conflict. ${ }^{132}$ The amendment was eventually withdrawn. ${ }^{133}$

Nonetheless, the $\mathrm{CO}$ has not remained completely ineffective, since a working group considering the Law on the Names was also asked to consider the COs. This working group was established by Minister of Justice Hirsch Ballin in 2008. ${ }^{134}$ The promise of having this working group reflect on the COs was the result of persistent questions and references to the COs by Senator Strik (GL). ${ }^{135}$ As was mentioned before, the COs have also been mentioned on seven other occasions by MPs. ${ }^{136}$ Two government officials argued that the consideration of the issue by a working group is an example of effectiveness. The COs were one reason to scrutinise the issue again by way of a study. It was noted that the COs have also contributed to the salience and politicisation of the issue. The report of the working group referred to the COs. It gave two options for changing the Law on the aspect criticised by the CEDAW Committee. ${ }^{137}$ Several governments have, however, not deemed legislative changes to the Law on Names necessary, because no big and urgent problems were found to exist. ${ }^{138}$

which concluded that the Law is not in conformity with the CEDAW. TK 2005/06, nr. 29353, nr. 18, 4. Supra n. 28. TK, 2005/06, 29353, nr. 20, 3.

131 The Council put forward that the ECtHR did pay attention to this question and that the ECtHR had concluded that discrimination is out of the question. TK 2005/06, 29353, nr. $20,3$.

132 TK 2005/06, 29353, nr. 20, 4.

133 The amendment was withdrawn on 6 February 2008 since it was critically received by CU, SP and VVD. TK 2007/08, nr. 50, 3677-3684, 3684.

134 The Minister of Justice promised to set up this working group during a debate on 6 February 2008. During this meeting Pechtold (D66) reminded the Minister of the COs. TK 2007/08, nr. 50, 3677-3684, 3681 . EK 2008/09, nr. 3, 132-138, 134. EK 2008/09, nr. 3, 164-170. TK 2009-10, 32123 VI, nr. 2, 211. Supra n. 27.

137 Maintaining the name of the father in the case of disagreement between parents and reinforcing the position of the mother or making double-barreled surnames in alphabetical order possible. The report was sent to parliament on 27 July 2010, although it was already finalised in April 2009. Werkgroep liberalisering naamrecht, Bouwstenen voor een nieuw naamrecht (The Hague, April 2009), 19, 38-40 and 47-51.

138 TK 2009/10, 32123-VI nr. 121, 1. The Rutte II government gave priority to other (legislative) issues. An illustration of the low priority of the matter is that parliament submitted questions on 29 October 2010, which were only answered on 17 December 2012. TK 2012/13, 33400 VI, nr. 84, 7. 


\subsubsection{Reinstatement of maternity benefits for self-employed women}

In its COs 2007, the Committee called upon the state to reinstate maternity benefits for all women in line with Article 11(2)(b) CEDAW. ${ }^{139}$ The maternity and pregnancy benefits for self-employed women were abolished in 2001 and women were referred to private insurance. The government eventually decided to reinstate the benefits, because of the health of the mother and child and the 'disadvantage' of women compared to men. ${ }^{140}$ The government Bill entered into force in June 2008. The CO was, thus, eventually complied with. It is therefore important to consider the causal relationship between the $\mathrm{CO}$ and the change in policy. It is important in the first place that the coalition agreement of 7 February 2007 already provided that the possibility of introducing a public provision would be considered. ${ }^{141}$ It is questionable whether the inclusion of this intention is (primarily) the result of the dialogue with the Committee on 24 January 2007 and the COs which were adopted only on 2 February 2007. There was a parliamentary majority in favour of the reintroduction of the benefits already before the COs 2007, given the several motions adopted by parliament. ${ }^{142}$ This wish of parliament, made explicit through several motions, was considered by the government as one of the most important reasons for the change. Another reason was the advice of the Equal Treatment Commission of June 2007 in which it was noted that the Netherlands is the only country in the EU that does not have a public provision concerning maternity benefits. The advice concluded that the government is obliged to introduce a public provision of maternity benefits for self-employed persons on the basis of Article 11 CEDAW. ${ }^{143}$ Another argument against a causal relationship between the COs and the reinstatement is that the government emphasised that CEDAW does not encompass an obligation to instate a public provision of maternity benefits for self-employed women. ${ }^{144}$ Neither CEDAW nor the COs were mentioned in the Explanatory Memorandum to the legislative proposal. ${ }^{145}$

CEDAW and - to a lesser extent - the COs 2007, nonetheless, played a role in the political process. ${ }^{146}$ The advice of the Equal Treatment Commission of 2007, for

139 UN Doc. CEDAW/C/NLD/CO/4 (2007), para. 30.

140 TK 2006/07, 30420/31070, nr. 49.

141 'Coalitieakkoord tussen de Tweede Kamerfracties van CDA, PvdA en ChristenUnie': <www. parlement.com/9291000/d/coalitieakkoordcdapvdacu.pdf>, accessed 31 July 2013, 29.

142 See, for example, the motion proposed by Van Gent (GL) and Verburg (CDA) in TK 2006/07, 30800 XV, nr. 48. Cremers-Hartman (2007), fn. 4.

143 TK 2006/07, 30420, nr. 49, 1-2.

144 As support, the letter referred to the judgment of The Hague District Court that there is no legal necessity for a public provision of these benefits. Rb. Den Haag, 25 July 2007, LJN: BB0334. TK 2006/07, 30420, nr. 49, 2. TK 2007/08, 30420, nr. A, 2.

145 TK 2007/08, 31366, nr. 1-4.

146 See also Van den Brink (2013), 500-501. Cremers-Hartman (2007), fn. 3-7, 28-29 and 38. 
example, referred to the COs and CEDAW. ${ }^{147}$ CEDAW was mentioned frequently during parliamentary discussions about the termination of maternity benefits for self-employed women on earlier occasions. ${ }^{148}$ There were repeated questions in parliament about the legality of the previous Act, which abolished the maternity benefits for self-employed women. As a result, Minister of Social Affairs and Employment De Geus asked the ILO for an informal opinion about the Act's conformity with ILO Convention 121 and CEDAW. ${ }^{149}$ One important factor for the legislative change was the considerable lobby by NGOs vis-à-vis parliament and international organisations. ${ }^{150}$ NGOs used CEDAW as one element in their lobby and litigation. ${ }^{151}$ The test case fund Clara Wichmann and the trade unions confederation FNV initiated several court cases in which they claimed a violation of CEDAW. ${ }^{152}$ They also lodged an individual complaint with the CEDAW Committee, albeit unsuccessfully. ${ }^{153}$ NGO representatives, however, noted that their lobbying was not always clearly related to the CEDAW Committee and the COs.

In sum, there was an extensive social and political discussion that included lobbying by NGOs, litigation and parliamentary attention. The combination of these forces eventually caused the decision to reinstate maternity benefits for selfemployed women. In terms of the COs' effectiveness, the reporting process under CEDAW and the COs were certainly not the decisive factor, but one of the many factors that jointly played a role.

\subsubsection{More attention to the gender aspects of domestic violence}

The CEDAW Committee expressed its concern that the framework for combating domestic violence is couched in gender-neutral wording in its COs 2007 and $2010 .{ }^{154}$ In its reaction to the COs, the government mentioned that it had explicitly

147 Van der Burg and Keizer, 'Advies Gelijke behandeling van zwangere zelfstandigen. Aanbevelingen voor een gelijkebehandelingsbestendig stelsel van zwangerschaps- en bevallingsuitkeringen', Commissie Gelijke Behandeling 2007/04, June 2007, 4, 16 and 19.

148 The proposal of Smeets (PvdA) and Vendrik (GL) to maintain the public provision mentioned that its aim was to be in keeping with Article 11(2)(b) CEDAW. The amendment was, however, eventually not adopted. TK 2003/04, 29497, nr. 9. 
chosen a gender-neutral formulation of the framework in order not to exclude men from the policies targeting domestic violence. Nevertheless, the way to deal with this problem is gender specific where possible and the main focus in on female victims, since they form the vast majority of victims of domestic violence. ${ }^{155}$

Although the CO 2007 might not have been complied with sufficiently, according to the CEDAW Committee and NGOs, it seems that the CO has not remained completely without effect. The government acknowledged that, partly as a result of the COs, it is being examined whether gender specific language of the policy on domestic violence is desirable and has added value for more effectively combating this form of violence. The government therefore commissioned a gender analysis of the plan of action known as 'The Next Stage' and the Ministry of Justice held interdepartmental information and training sessions to promote increased knowledge of the gender-associated character of domestic violence. ${ }^{156} \mathrm{~A}$ government official also pointed out that the policy on domestic violence had been gender-neutral for a long time and that, although the government had not come around completely, there is at least more attention for the gender-based character of domestic violence. NGO representatives argued that the message implicit in the COs has at least been received. The scholar Römkens also observed that a change had taken place in the government's thinking about violence against women. She pointed out that the Ministry of Health, Welfare and Sport now uses the term violence in relations of dependence, thereby pointing to the balance of power between men and women, instead of the general term domestic violence. Likewise, the Ministry of Justice is speaking about differences in power that are gender related. ${ }^{157}$

It is, however, difficult to assess the actual contribution of the COs in the change in the way of thinking and policy approach of the government. This is because similar concerns were voiced by, for example, the Dutch Emancipation Review Committee ${ }^{158}$ and UN Special Rapporteur on Violence against Women Ertürk who visited the Netherlands in July 2006. ${ }^{159}$ It seems that the concerns and recommendations of the latter were more decisive than the CEDAW Committee's COs, also because the Special Rapporteur elaborated more extensively on the problems inherent in the policy. ${ }^{160} \mathrm{~A}$ further indication of this is that the periodic

155 The reaction to the COs 2007 outlined several aspects of the policy showing this, including the consultation of an expert advising how gender could be even further integrated. TK 2007/08 31263 nr. 9, 7.

156 TK 2007/08, 31263 nr. 9, 7.

157 Römkens (2008), 14-15.

158 Attachment to TK 2005/06, 30420, nr. 7, 7-9.

159 UN Doc. A/HRC/4/34/Add.4 (2007), para. 49-42, 88 and 91.

160 In his statement to the UN Human Rights Council on 20 March 2007, Minister of Foreign Affairs Verhagen stated that: 'Ms Ertürk concluded that our approach to domestic violence is not gender-specific enough. My government takes this assessment very seriously, and will follow up on her observation.' The human rights ambassador stated in his response that 'the Netherlands Ministry of Justice will examine its policy which is formulated in gender neutral 
state report submitted to the HRC merely pointed to the concern expressed by 'several UN treaty bodies (CEDAW, CESCR and CAT) [...] about aspects of Dutch domestic violence policy', without elaborating on these aspects. The report, however, went into detail concerning the report of the Special Rapporteur and explicitly mentioned her criticism as to the gender-neutral formulation and subsequently stated that it would be considered whether a gender-specific formulation of policy is advisable. ${ }^{161}$ The latter suggests that the COs were one contributory factor among many other domestic and international factors.

\subsubsection{Evaluation gender dimension asylum policy}

In its COs 2007, the Committee recommended that impact assessments of laws and policies affecting immigrant and refugee women be conducted and to include information about this in the subsequent state report, specifically about the number of women who were granted residence permits and refugee status on the grounds of domestic violence. ${ }^{162}$ The government conducted such an evaluation of the gender dimension of the asylum policy. ${ }^{163}$ State Secretary of Justice Albayrak mentioned the questions of the CEDAW Committee as the 'direct starting point' for the evaluation. ${ }^{164}$ The evaluation included data for several gender-related subjects, including domestic violence, honour-related violence, victims of human trafficking and female genital mutilation. The choice for these issues was also influenced by CEDAW and the COs. One government official also confirmed that the evaluation was the direct consequence of the requests of the CEDAW Committee. It was primarily conducted to prevent that the delegation would be standing there dumbstruck during a subsequent dialogue with the CEDAW Committee. He/she made clear that it was his/her personal initiative. The evaluation was, however, also for national use given the demand for information by parliament and several government departments. This official characterised the evaluation as a matter of killing three birds with one stone. He/she allegedly used the COs as a 'threat' and 'to cut in on the action' in order to obtain the cooperation of the Immigration and Naturalisation Service that had conducted the actual evaluation.

terms in the light of the Special Rapporteur's recommendation on gender specificity.' See the attachments to TK, 2006/07, $30800 \mathrm{~V}$, nr. 86.

UN Doc. CCPR/C/NET/4 (2008), 13. The State Secretary of Justice held during the UPR of the Netherlands that 'partly due to the recommendations made by treaty bodies and the Special Rapporteur on violence against women, the government is considering whether a genderspecific formulation of policy is advisable.' UN Doc. A/HRC/8/31 (2008), para. 18. UN Doc. CEDAW/C/NLD/CO/4 (2007), para. 27 and 28.

163 IND Informatie- en Analysecentrum, 'Evaluatie gendergerelateerd vreemdelingenbeleid in Nederland. Uitvoeringsbeleid, praktische invulling en gevolgen voor de vreemdeling', July 2008, 11. 


\subsubsection{Uninterrupted long school day}

The COs 2001 recommended that the government ensure an uninterrupted long school day. ${ }^{165}$ Interestingly, the government referred to this $\mathrm{CO}$ out of its own motion in a document outlining the standpoint of the government concerning the combination of employment and care. It was provided that the Netherlands is one of the few European countries that has an interrupted school day. ${ }^{166}$ Several measures were subsequently taken in relation to this uninterrupted school day. ${ }^{167} \mathrm{~A}$ government official stressed that the basis for these measures were laid by the Committee on the Combination of Care and Paid Work (Commissie Dagindeling) in the period November 1996 and April 1998. This Committee also advised on the provision of childcare before and after a school's teaching period. ${ }^{168}$ The official emphasised that this was a contentious issue at the end of the 1990s which was also dependent upon the type of government. ${ }^{169}$ Everything that could support the intended policy measures was thus used in communication vis-à-vis parliament in order to accelerate the adoption and implementation of the policy measures. The CO of the CEDAW Committee was primarily used, albeit once, to support intended policy measures.

\subsubsection{Training and education for prostitutes leaving their profession}

In its COs 2001, the CEDAW Committee urged the government to provide training and education to prostitutes. The initial reaction on the part of the government was dismissive, making clear that the Dutch policy is targeted at fighting excrescences in prostitution and not prostitution as such. ${ }^{170}$ The government did not see it as its task to stimulate prostitutes to leave prostitution or to choose another occupation. Nonetheless, the government changed its stance and decided to give the foundation the Red Thread a project subsidy to support locally the occupational change of several lower-educated prostitutes in 2003. ${ }^{171}$ This change was the result of a motion adopted in parliament requesting the government to take away obstacles for prostitutes to leave the profession through, among other things, encouraging and/or

165 UN Doc. A/56/38(SUPP) (2001), para. 204.

166 The government underscored the importance of the provision of care at noon for the labour market participation of women and referred to several measures that would be taken in this regard. TK 2003/04, 29769, nr. 1, 6 .

167 With respect to the long uninterrupted school day, legislative changes were introduced that made elementary schools responsible for the provision of care at noon. Similarly, in autumn 2006, an Act was adopted on 1 August 2007 that made elementary schools responsible for providing after-school childcare. combination of work and care through several experiments. TK 2003/04, 29769, nr. 1, 2.

170 Annex 2 to TK 2002/03, just030524, 7.

171 Marchand (2003), 48. 
facilitating so-called 'exit programmes' targeted at prostitutes leaving the profession. ${ }^{172}$ Although, in terms of effectiveness, no references were made to the COs or CEDAW in the motion or during the parliamentary debate, a similar motion which was proposed before the COs 2001 did not get enough support in parliament. The CEDAW Committee's (legal) endorsement in the COs might have prepared MPs for something that they initially opposed. This was also noticed by the initiator of the earlier motion, Van der Staaij from the reformist political party SGP, who argued that his earlier motion about assistance to prostitutes could now possibly get enough support as a result of the COs. ${ }^{173}$

\section{TREATY SPECIFIC REASONS FOR THE (IN)EFFECTIVENESS OF COS}

\subsection{Factors related to the domestic context}

The previous section illustrated that the implementation of COs often requires a long political process lasting years. Domestic actors need to (be willing and able to) pay attention to and constantly come back to the issue over a long period of time. Essential intervening variables for the COs' effectiveness are parliamentary attention and the sustained lobbying by NGOs, as well as a court judgment in the case of the SGP. As chapter VIII, section 1 outlined, there has been a relatively extensive level of domestic mobilisation in relation to CEDAW.

Nonetheless, at the same time, a great number of COs have remained ineffective (chapter VIII, sections 2.1-2). One explanation for this is, first of all, that the idea prevails that the Netherlands is already fulfilling its obligations under the CEDAW. ${ }^{174}$ During the parliamentary debate about the COs 2007, the Minister remarked that the CEDAW obliges legislation and policy to eradicate discrimination against women and asks for 'appropriate measures' to promote women's development. In his opinion, the Netherlands fulfils this obligation. ${ }^{175}$ The Minister therefore did not agree with the conclusion that the Netherlands failed the test or was given a clip round the ear, because, in contrast with other states, the Netherlands 'did not break the regulations'. During interviews, several officials pointed to the pioneering work of the Netherlands and the fact that the Netherlands is a vanguard in terms of human rights and emancipation. ${ }^{176}$ An

172 Motion proposed by Van der Staaij (SGP), Rouvoet (CU), Halsema (GL), Van de Camp (CDA), Albayrak (PvdA), Dittrich (D66) and De Wit (SP) in TK 2002/03, 28600 VI, nr. 66.

173 TK, 2001/02, $28009 \mathrm{nr}$. 7, 3. The respective motion was proposed by Van der Staaij (SGP) during a debate about the emancipation policy in TK 2000/01, 27061, 8. This motion was only supported by the SP, RPF, GPV, SGP and CDA.

See, for example, TK 2003/04, 27061, nr. 23, 3-4 and 7.

TK 2007/08, 30420, nr. 98, 6. TK 2007/08, 30420, nr. 65.

Officials supported this statement by, for example, pointing to the Global Gender Gap, in which the Netherlands is in the top five, or by mentioning that the Netherlands scores well in the emancipation monitor, comparable to the Scandinavian countries. 
official also stated that the Netherlands was, for $95 \%$, in compliance with the CEDAW at the moment when it was ratified in 1991. Similarly, another government official noted that there is an idea that everything is arranged fantastically in the Netherlands and that the UN is not there for a country like the Netherlands. ${ }^{177}$ This self-satisfied and arrogant attitude was also explicitly mentioned by several government officials. The consequence of this idea that almost all parts of the CEDAW are already implemented is that CEDAW does not play a substantial role in government thinking (chapter VIII, section 1.1). Given the government's own assessment of its compliance with the CEDAW, it comes as no surprise that the government sees the dialogue with the CEDAW Committee as a defence, whereby the main objective is to give a good answer to the critical questions of the CEDAW Committee. ${ }^{178}$

Another second important factor that has hampered the impact and effectiveness of the process of state reporting under CEDAW is the diminished strength of the national machinery. The Netherlands Emancipation Review Committee concluded in 2007 that the interdepartmental supporting structure has functioned insufficiently since 2001. ${ }^{179}$ Similarly, a (comparative) study concluded that the national machinery has weakened since the 1990s. ${ }^{180}$ Examples illustrating this point further are the abolishment in 1995 of the All Parties Women's Caucus (Kamerbreed Vrouwenoverleg) which consisted of informal consultative meetings between MPs of different political parties. In addition, the Emancipation Council, a specific advisory council in the field of emancipation, also terminated its operation on 1 May 1997. Since 2002, NGOs operating in the field of emancipation have also been increasingly confronted with budget cuts.

A third factor which has contributed to the ineffectiveness of several COs is the division of responsibilities among the ministries and members of government. The coordination function of the Directorate Emancipation as the central policy unit has decreased over the years. Government officials of the Ministry of Social Affairs and Employment, to which the Directorate Emancipation belonged until February 2007 , even advocated the abolition of the coordination function altogether. ${ }^{181}$ The Minister for Emancipation is only responsible for the general framework and has primarily an agenda-setting role, while the substantive and primary responsibility for specific policy areas lies with other ministries. ${ }^{182}$ This is also reflected in the limited control and pressure exercised by the Directorate in relation to the follow-up and implementation of the COs vis-à-vis the responsible ministries (chapter IV,

\footnotetext{
177 See also De Boer (2008), 50-51.

178 TK 2006/07, 30420, nr. 24. TK 2007/08, 30420 nr. 61, 7. TK 2008/09, 30420, nr. 136, TK 2009/10, 30420 nr. 141.

179 Visitatiecommissie Emancipatie (2007a), 7-8 and 11-12. De Boer (2008), 51.

180 Outshoorn (2007).

181 See the speech of Lodders-Elfferich during the closing conference of the Netherlands Emancipation Review Committee on 16 April 2007: <www.emancipatie.nl/_documenten/ vce/2007/slottoespraak_Tineke_Lodders.pdf>, accessed 31 July 2013.

182 TK 2007/08, 30420, nr. 61, 1-2.
} 
section 3.1). A government official also noted that the national momentum to do something with the COs comes to a standstill because of this. ${ }^{183}$ The latter has also been complicated by the several changes in the portfolio of the administrator of emancipation over the past years, as a result of which CEDAW has not had a permanent and clear place within one department. ${ }^{184}$

A fourth factor that has complicated follow-up to COs is the lack of gender expertise and knowledge among government officials about the CEDAW and the reporting process. ${ }^{185}$ During the discussion of the second and third report in 2001, the government itself stated that it was 'by no means satisfied' that the CEDAW was known well enough. ${ }^{186}$ Several government officials also lamented the lack of knowledge about the CEDAW among government officials. The lack of sufficient expertise is also caused by the rapid turnover of staff in the Directorate Emancipation since the 1990s. Nowadays, government officials change function more often and are, as a result, less committed to and knowledgeable about the subject area. Several observers noted that there is a tendency to overlook or disregard the fact that there are international obligations which affect the emancipation policy. ${ }^{187}$ One illustration of this is the Dutch report in the context of the $15^{\text {th }}$ anniversary of the Beijing Declaration, which provided that the government has 'no special actions aimed at human rights at women'. ${ }^{188}$ Another explanation for the unawareness about the legal dimensions within the field of emancipation might be that the sheer majority of MPs and government officials dealing with emancipation are non-lawyers. At the same time, the legal institutions that have scrutinised the CEDAW, such as the Council of State and national courts, have been reluctant to give importance or direct effect to the CEDAW. ${ }^{189}$

These developments reflect a fifth factor which is the decrease in attention for the issue of emancipation of women over the years. This observation also corresponds with the conclusion that the impact of CEDAW has diminished since 2003/04 (chapter VIII, section 1). It is not surprising that several government officials stated that emancipation is not regarded as a priority and that there is a lack

183 The coordinating Minister for emancipation is only a key maker but is not directly responsible for the substantive policy areas. During parliamentary debates, the minister can only promise parliament that he/she will speak to his/her colleague. See also De Boer (2008), 53. Affairs and Employment until February 2007 and subsequently part of the Ministry of Education, Culture and Science.

185 Visitatiecommissie Emancipatie (2007b), 28 and 33. De Boer (2008), 51. Janse and Tigchelaar (2010), 313.

186 UN Doc. CEDAW/C/SR.512 (2001), para. 14

187 De Boer and Van de Brink noted that the government regards CEDAW as containing mere policy objectives instead of human rights. De Boer (2008), 48-49. Van den Brink (2013). 493 and 503. 
of interest among the official and political leadership. ${ }^{190}$ One NGO representative even argued that specialising in emancipation could negatively affect the career of government officials. Government officials also noted that MPs are less interested in gender issues than, for example, children's rights. There seems to be currently an idea among the public, government officials and MPs that emancipation of women is already achieved. ${ }^{191}$ Some officials held that women are not considered to be a vulnerable group (any more) in the Netherlands. Likewise, several government officials noted that CEDAW is rather outdated since it reflects 1970 s views about the makeability of the society with a proactive state.

A sixth factor that might account for the ineffectiveness and limited impact of several COs is the focus on norms and processes at the European and international level that are considered more important and decisive. ${ }^{192}$ Government officials stressed that the 'core business' is formed by the more specific European legislation and especially the jurisprudence of the ECJ and ECtHR in relation to sex-equality and other policy areas covered by CEDAW. With respect to violence against women and human trafficking, several government officials pointed, for example, to EU Directives $^{193}$ or the CoE Convention on preventing and combating violence against women and domestic violence. It is not unreasonable to argue that the relevance and usefulness of broad and unspecific COs is limited in the light of other more pertinent initiatives and legal instruments at the regional and international level. In fact, non-compliance with COs has sometimes been justified on the basis of these other international obligations (chapter VIII, section 2.1).

\subsection{The (perceived) quality of the CEDAW Committee}

One big obstacle for the effectiveness of COs are the not so positive attitudes and ideas of government officials about the authority and persuasiveness of the CEDAW Committee. This section will address the subjective views of government officials as to the stature and quality of the CEDAW Committee and COs coupled with some personal observations from the dialogue of the CEDAW Committee with the Dutch government delegation in 2010. This section aims to illustrate that there is no compliance pull from the COs because of the rather negative perceptions of government officials.

190 Van den Brink noted that in the period before and shortly after the ratification of the CEDAW there was 'ample attention' for the CEDAW in the 'heyday of the second feminist waves', with a significant number of studies, journal and expertise centres. Since then, there has been a diminished feeling of urgency regarding gender equality. See also Van den Brink (2013), 505-508.

191 One official, for example, mentioned that girls are currently performing better at schools than boys. See also De Boer (2008), 47.

192 There are numerous activities and initiatives in the field of equal treatment and employment at the EU, ILO and CoE level. See also Janse and Tigchelaar (2010), 314. Van den Brink (2013), 496 and 502 .

193 See, for example, the EU Directive on preventing and combating trafficking in human beings and protecting its victims, 2011/36/EU, 5 April 2011. 
Government officials, first of all, lamented the fact that several of the CEDAW Committee's questions were rather basic and/or showed a limited knowledge about the national context. There was a question by the Chinese delegate about isolation problems among elderly rural women as a consequence of a lack of public transport and community involvement. State Secretary Dijksma responded by saying that 'I do not know whether you have visited our country', because it is two hours from border to border. She also stated that this is not the biggest problem the Netherlands is currently facing. ${ }^{194}$ This example was given by almost all government officials as an example of how the mind frame and cultural background of experts can be clearly heard in their questions, thereby showing a lack of understanding and knowledge about the Dutch context. Another government official gave the example of a question by an expert from the Philippines during the dialogue with the CEDAW Committee in 2007 whether pregnant girls are expelled from school.

Several government officials observed that a number of expert members were not or were not well prepared. In its comments sent to the CEDAW Committee about the COs 2010, the government, for example, noted that: 'several of the Committee members clearly were not aware of the report of the Immigration and Naturalisation Service (IND) 'Evaluation of Gender-Related Immigration Policy in the Netherlands', which was made available to the Committee on $7^{\text {th }}$ October 2008. As a result, these members had an incorrect and/or incomplete view of the attention paid to women and gender aspects in Dutch asylum and immigration policy, which unfortunately is reflected in the recommendations regarding asylum and immigration policy'. 195

It was also noted that experts have to rely on the information provided by NGOs in their parallel reports, because of the limited possibility and time to prepare themselves. Officials criticised that the CEDAW Committee easily takes over the criticism of NGOs without question. ${ }^{196}$ In the eyes of officials, the CEDAW Committee attaches more value to the information of NGOs than the information from the Government and the dialogue. The problem with this is, according to government officials, that NGOs often represent only one audience and at the same time lose sight of the economic reality. The criticism provided by the NGOs is therefore seen as one-sided or only partially true. Some officials argued that relatively small problems based on complaints of only a couple of women are blown up by NGOs. One official pointed to the emotional role of NGOs suggesting that everything that is wrong is meant to discriminate against women. Another official spoke about NGOs using the process of state reporting as a vehicle for debate with Dutch NGOs and pointed to the risk of undemocratic societal discussions if the parallel report is written by NGOs with a particular bias. Government officials

194 UN Doc. CEDAW/C/SR.917 (2010), para. 34.

195 Supra n. 77.

196 Several authors noted that the NGO information could be clearly heard in the questions and COs of the Committee. Van den Brink and Jacobs (1994), 745. Van den Brink (2001), 1071. De Boer (2007), 1225. 
argued that the government has to consider and weigh several interests which necessitates nuance and different points of view. This is insufficiently taken into account by the CEDAW Committee, which is seen by some government officials as holding 'a single issue campaign' by only adopting an empowerment and emancipation perspective, without considering that the reality is often more unmanageable. ${ }^{197}$ That is to say, the CEDAW Committee does not consider budgetary implications, economic interests, clashes with democracy, and other fundamental rights and the legal dimensions, such as EU Law. One official qualified the recommendation of the CEDAW Committee to consider withdrawing its appeal against the judgment of the District Court in the SGP case as clearly damaging for the authority of the Committee, since this recommendation would counter the idea of a constitutional state in which the defending party, in this case the state, always has a right to appeal.

Government officials characterised the CEDAW Committee as droning on and being too negative, with a whole shopping list of complaints without any positive remarks. ${ }^{198}$ This was especially said about the session in 2010 . The critical approach, according to government officials, did no justice to the reality that the Netherlands is still a model country with respect to the emancipation of women. ${ }^{199}$ Another point of concern is that the CEDAW Committee only has two male members. Government officials noted that the stature of the CEDAW Committee would improve if there would be more male experts, because there is a risk that the Committee is seen as a biased club of feminist lawyers. ${ }^{200}$ Some government officials explicitly mentioned the lack of expertise and understanding of the CEDAW Committee concerning labour market issues, reflected in the COs, as compared to the ILO and the EU, which are deemed to be more relevant (see also chapter VIII, section 3.1). It was argued that the government did not lose any sleep over the CEDAW Committee's criticism concerning labour market issues as a result of its limited expertise in this field.

197 Officials argued that the easiest and most important steps required by CEDAW have already been taken, given the extensive equal treatment framework. What are left are processes the government could hardly steer and influence, such as the glass ceiling that exists for women or the labour market participation of women.

198 The CEDAW Committee was indeed more critical than, for example, the CERD a month later. Whereas the CERD frequently emphasised the non-adversarial and constructive nature of the dialogue, this was hardly done by the CEDAW Committee. In addition, the CERD gave the Dutch delegation a considerable number of compliments while also mentioning several times that it could learn from the Netherlands. See chapter V, section 3.2.

199 One official, for example, observed that the COs for the Netherlands were longer and more detailed than those of Chili.

200 Former member Flinterman also noted that the almost exclusive female membership of the Committee confirms the stereotypical view of most, if not all states, that the fulfilment of equality between men and women is first and foremost something that is of concern to women. Flinterman (2011), 8. 
Government officials were also critical about the quality of the COs. In its reaction to the COs 2010, the government pointed to several factual errors ${ }^{201}$ or mentioned that the COs relate to issues that were not discussed in the LOI or during the dialogue. ${ }^{202}$ Other COs were said to lack foundation. ${ }^{203}$

\section{Conclusion}

The COs of the CEDAW Committee have had considerably more impact than the COs of the other treaty bodies discussed so far. The government, parliament, NGOs and the media have discussed and used some of the COs at several occasions. While several COs have been rather forcefully dismissed by the government, others have been (partly) effective, albeit often with a considerable delay. Some COs led to a study or evaluation (Law on Names and the gender dimension of the asylum policy), while others were used in litigation and, hence, impacted on court judgments and eventually on the policy of a political party (SGP case). There were also other occasions during which the COs were a contributory cause among several other factors in policy decisions or legislative changes, such as the reinstatement of maternity benefits for self-employed women and some (discursive) changes in relation to the gender aspects of the policy on domestic violence. The effectiveness of these COs are not the result of a compliance pull from the COs, because government officials were rather critical about the CEDAW Committee and its COs. Rather is should be attributed to the mobilisation and lobby of women's rights NGOs and the relatively considerable attention in parliament to the COs.

\footnotetext{
$201 \quad$ Supra n. 77.

202 The government pointed to the joint plan for parenthood and the segregation in the field of education. TK 2009/10, 30420, nr. 154, 11 and 20.

203 In its comments to the COs 2010, the government stated that 'Maternal mortality risk for female asylum-seekers however was not discussed. The Ministry of Health, Welfare and Sport would like to be informed about the source of this information.' Supra n. 77. TK 2009/10, 30420, nr. $154,21$.
} 


\section{Chapter IX CAT}

'Combating torture globally is a fundamental objective of Dutch human rights policy. [...] I can assure you that, in the government's opinion, all the obligations under the Convention have been adequately incorporated into national legislation.' [Former Human Rights Ambassador De Klerk in his introductory statement before the CAT Committee in 2007] ${ }^{1}$

This chapter takes stock of the impact and effectiveness of the COs of the CAT Committee. The implementation of the CAT has been considered four times since 1995 by the CAT Committee in 1995, 2000, 2007, and 2013. The COs of 1995 and 2000 merely required additional information or statistics and hardly contained any recommendations that would require (changes in) policy or legislative measures. ${ }^{2}$ It was only with the COs 2007 that the CAT Committee came with more substantive recommendations for the Netherlands in relation to access to a lawyer during the initial period of interrogation, the accelerated asylum procedure and the detention of unaccompanied children and young asylum seekers. In addition, the CAT Committee recommended that the government reconsider its position on the role of medical investigations and integrate medical reports into the asylum procedure, while also encouraging the application of the Istanbul Protocol and the provision of training about this Protocol. ${ }^{3}$ Almost all these issues came back during the most recent consideration of the Dutch report on the basis of the LOIPR in May 2013. ${ }^{4}$ Note that the impact and effectiveness of the COs 2013 has not been examined, because empirical data for the Netherlands was only gathered until August 2011.5

$1<$ www.government.nl/documents-and-publications/speeches/2007/05/07/introductorystatement.html>, accessed 31 July 2013.

2 In the COs 1995, the government was only requested to provide additional information concerning compensation for victims of torture and whether the Public Prosecutors had initiated an investigation to prosecute General Pinochet. UN Doc. A/50/44(SUPP) (1995), para. 131. In 2000 , the state was requested to provide 'relevant statistics' by gender and geography. UN Doc. A/55/44(SUPP) (2000), para 188 sub d.

3 UN Doc. CAT/C/NET/CO/4 (2007), para. 8. The Istanbul Protocol is the 'Manual on the Effective Investigation and Documentation of Torture and Other Cruel, Inhuman or Degrading Treatment or Punishment'. This manual, drafted by physicians and human rights organisations, contains guidelines and best practices for the investigation of cases of alleged torture and mistreatment with a view to ensuring that the documentation could serve as evidence in court.

4 UN Doc. CAT/C/NLD/CO/5-6 (2013).

5 As said in chapter III, section 2.2, the database search of parliamentary papers, court judgments, media articles, and NGO websites was conducted for the period between 1 September 1995 and 31 August 2011. The last interviews with government officials were held in June 2011. 
Chapter IX

\section{DOMESTIC IMPACT AND DOMESTIC MOBILISATION}

\subsection{Government informing parliament}

The government has informed parliament in a rather minimal way. While some of the reports and COs were sent to parliament, no substantive reaction has been given to the COs. ${ }^{6}$ the government only referred once to the COs on its own motion. That is to say, Minister of Foreign Affairs Verhagen mentioned the discussion with the CAT Committee in 2007 during a parliamentary meeting between delegations from the various parts of the Kingdom of the Netherlands. After mentioning COs in relation to the situation of detainees in Aruba and the Netherlands Antilles, the Minister referred to the criticism with respect to the Dutch accelerated procedure under the Aliens Act 2000.

\subsection{Parliamentary scrutiny}

There have been no parliamentary debates about the dialogue with the CAT Committee and the COs. Only once has an MP raised a question in relation to (the delay in the) reporting. ${ }^{8}$ Parliament has only alluded to the COs in relation to the Netherlands twice. The COs of the CAT Committee are, hence, the least referred to of all the six treaty bodies. Van Oven (PvdA) shortly mentioned that the government was called to account by the CAT Committee in 1995 with respect to the lack of initiation of an investigation to prosecute General Pinochet when he was on Dutch territory in $1994 .{ }^{9}$ In the context of the discussion of amendments to the Aliens Act, the parliamentary groups of D66 and GL in the Senate asked whether the intention to introduce medical investigations for asylum seekers addressed the criticism of the CAT Committee in its COs 2007. ${ }^{10}$ It was in relation to the latter issue of medical information in the asylum procedure that MPs have also referred to the 'jurisprudence' of the CAT Committee and the jurisprudence of the ECtHR. ${ }^{11}$

6 The second periodic state report, which was discussed in 1995, and the resulting COs were not sent to parliament. Both the third periodic state report as well as the fourth report were sent to parliament. TK 1999/00, buza000127. TK 2004/05, buza040328. The COs 2000 and 2007 were both sent to parliament by the Minister of Foreign Affairs in an attachment to a letter that also included a short report about the dialogue and the questions raised by the Committee. These letters shortly mentioned the issues discussed with the CAT Committee and the COs. TK 1999/00, buza000420. TK 2006/07, $30800 \mathrm{~V}$, nr. 100.

7 TK 2006/07, 30945, nr. 6.

8 Timmermans $(\mathrm{PvdA})$ asked whether the sixth report of CAT had already been submitted given the deadline of 30 July 2011. TK 2010/11, 2011Z16502.

9 TK 1998/99, 26262, nr. 3, 1-2.

10 TK 2009/10, 31994, nr. B, 4.

11 The PvdA, for example, asked for a reaction to the jurisprudence of CAT and ECtHR. TK 2003/04, 19637, nr. 825, 21-22. TK 2004/05, 19637, nr. 903 3EH, 2-3, 7 and 12. The references were primarily the result of the analysis of international legal documents by NGOs and the 


\section{CAT}

De Wit (SP) even proposed a motion which requested the government to make it possible that medical reports are taken into account during the asylum procedure in the light of the 'jurisprudence' of the CAT Committee. ${ }^{12}$ The effectiveness of the COs concerning the issue of medical reports will be discussed in chapter IX, section 2.2.

\subsection{Courts and legal practice}

Courts have only touched upon the COs in relation to the Netherlands once. ${ }^{13}$ In an asylum case, the applicant of Zimbabwean origin, submitted the COs 2007 in order to support his claim arguing that it was wrongful that no attention was paid to his medical situation. The Court ruled that a reference to the Cos, without substantiating the applicant's individual situation, was insufficient in itself to conclude that there had been a deficiency in caution. ${ }^{14}$

\subsection{NGOs}

The NGOs who have coordinated the parallel reports in the context of CAT are NJCM and the Johannes Wier Foundation (JWS). Besides the writing of parallel reports, lobbying on the basis of COs by these NGOs has been limited. No reaction to the COs or the response of the government thereto has, for example, been sent to parliament or the government. ${ }^{15}$ Consultative meetings have also not taken place between NGOs and the government in the context of CAT 2007. Several NGO representatives also noted that the COs were given hardly any attention by NGOs, if at all. Representatives of NJCM acknowledged that NJCM had not employed any

Smeets Committee, which recommended that the government no longer exclude medical information during the asylum procedure or designate it as irrelevant. Landelijke Commissie Medische Aspecten van het Vreemdelingenbeleid, 'Medische aspecten van het Vreemdelingenbeleid', 2004, 27-31 and 52. TK 2003/04, 19637, nr. 806. Infra n. 17.

12 TK 2004/05, nr. 14, pag 769-777, 770.

13 The COs in relation to other countries have sometimes been submitted by applicants facing expulsion or extradition, often together with several other reports about the human rights situation in the respective state. See, for example, the COs about the Czech Republic submitted by the application together with several other reports by the US State Department, Human Rights Watch and the HRC about the situation of Roma. Rb. Den Haag, 10 March 2004, para. 11. The District Court in The Hague, for example, sought alignment with the conclusions of the CAT Committee and the Committee's evaluations of state reports of different countries for the interpretation of the component parts of the crime of torture in the Dutch Torture Convention Implementation Act in the case of the Rwandan Joseph M. Rb. Den Haag, 23 March 2009, LJN: BI2444, para. 9.

14 Rb. Den Haag, 5 July 2007, LJN: BB1326.

15 One letter of NJCM quoted several of the COs 2007 about the accelerated procedure in footnotes, together with similar critique of Human Rights Watch and the comments of UNHCR: $<$ www.njcm.nl/site/uploads/download/303>, accessed 31 July 2013. 
follow-up activities with respect to the COs $2007 .{ }^{16}$ Neither did a follow-up meeting take place around the COs 2000, in the period that similar meetings were organised around the COs of CERD, ICCPR and ICESCR.

Interestingly, Amnesty International and the Dutch Refugee Council have used the COs 2007 in their lobby concerning the role of medical reports in the asylum procedure. These NGOs contributed to the parallel report on this issue, because they were of the opinion that this could strengthen their domestic lobby. The issue of medical report serves as a good example to illustrate the potential of interaction between the national and international level, whereby domestic NGOs deliberately seize the opportunity to voice their demands at the international level in order for them to get an authoritative pronouncement that could strengthen their arguments. Their previous domestic lobby activities were initially insufficient to bring about a change in the government's policy on the issue. That is to say, NGOs (and MPs) had already been pressuring the Dutch government to take medical reports into account since the early 2000s ${ }^{17}$ Especially Amnesty International had already been active with respect to this issue for a long time. ${ }^{18}$ Amnesty, for example, initiated the CARE FULL project together with the Dutch Refugee Council and Pharos in 2006 'to enhance the protection of survivors of torture and ill-treatment who ask for asylum by giving due weight to medico-legal reports in the asylum procedure. ${ }^{19}$ In addition, several meetings had taken place between the Minister of Immigration and Integration and Amnesty International to discuss the matter. ${ }^{20}$ Not surprisingly, Amnesty's letters and commentaries, which were sent after the dialogue in 2007, referred to the COs 2007 of the CAT Committee concerning medical reports (chapter IX, section 2.2). ${ }^{21}$

16 The person who coordinated the report for NJCM became active for another working group within NJCM shortly after the dialogue with the CAT Committee.

17 De Wit (SP) mentioned in 2004 that the issue of medical care for asylum seekers had been discussed in parliament several times before. TK 2004/05, nr. 14, 769-777, 770. A letter of Amnesty of 2004 referred to several earlier letters in which it had disputed the standpoint of the government with respect to medical reports. Letter of 6 April 2004 (dir/dv/2004/037). Subsequent letters referred to several Communications of the CAT Committee as well as judgments of the ECtHR. For the other letters see 18 June 2004 (dir/hh/2004/071), 28 October 2004 (dir/hh/2004/105), 1 November 2005 (dir/hh/2005/200).

18 Already since 1977, the Medical Examination Group of Amnesty International has carried out medical examinations of asylum seekers allegedly having experienced torture or ill-treatment in their country of origin. Physicians examine the relationship between physical and/or psychological complaints and possible torture or ill-treatment.

19 This initiative was the result of an international expert meeting organised by the three NGOs on 14 and 15 November 2006 in Amsterdam. Amnesty International, Dutch Council for Refugees and Pharos, CARE FULL, Medico-legal reports and the Istanbul Protocol in asylum procedures: principles and recommendations (Amsterdam/Utrecht, 2007).

20 There were meetings on 7 March 2005 and 14 November 2005. TK 2005/06, 19637, nr. 999, 3 and 10 . TK 2005/06, nr. 1358 .

21 See, for example, the letter of Amnesty International of 2 March 2009 (Dir/en/2009/134): <zoek. officielebekendmakingen.nl/kst-31994-3-b8.pdf>, accessed 31 July 2013. 


\section{CAT}

\subsection{Media coverage}

Media coverage of the process of reporting under CAT has been minimal. Only the COs of CESCR have been given less attention. No more than five newspaper articles addressed the COs in one way or another. The request of the Committee in the COs 1995 for additional information on whether or not the public prosecutor initiated an investigation to prosecute General Pinochet was mentioned twice. ${ }^{22}$ The dialogue and the resulting COs 2000 were, however, not reported. One journalist attended the session in Geneva in 2007 and wrote two articles devoted to the dialogue with the CAT Committee. ${ }^{23}$ Another opinion article, written by the prospective Senator Strik (GL), made a passing reference to the pressing recommendation about compliance with CAT without elaborating on it further. Interestingly, she stated that discussion of reports by, for example, the CAT and CEDAW Committee does not come off and that there is a lamentable lack of attention for international human rights treaties in parliament. ${ }^{24}$

\subsection{Conclusion}

Except for the COs concerning medical reports in the asylum procedure, the COs of the CAT Committee have received little attention from domestic actors. Only the COs of CESCR have had less impact. Chapter IX, section 3.1 will try to explain the absence of domestic mobilisation.

\section{AsSeSSING THE EFFECTIVENESS OF COS}

This section addresses the (in)effectiveness of the COs of the CAT Committee. Two complications need to be mentioned in this context. Firstly, as we have seen, the government has almost not given a reaction to or discussed the COs in parliamentary papers or in its state reports. ${ }^{25}$ The government also did argue that

22 See, for example, Christa Meindersma, 'Pinochet had al lang in Nederlandse cel kunnen zitten', de Volkskrant, 24 October 1998. It is not unthinkable that the media attention on this issue explains the reference to the COs 1995 by Van Oven. Supra n. 9.

23 Caroline de Gruyter, 'VN-comité bezorgd over asielprocedure in Nederland', NRC Handelsblad, 19 May 2007, 1 and 3. Caroline de Gruyter, 'In Nederland duurt 48 uur ruim vijf dagen; Martelexperts VN bezorgd over versnelde Nederlandse procedure voor asielzoekers', 9 May 2007,3 .

24 Tineke Strik, 'Tweede Kamer wil geen greep krijgen op Europa', Trouw, 12 June 2007.

25 The third state report included a reaction to the COs 1995 with respect to compensation for victims of torture, while no information was provided as to the investigation to prosecute General Pinochet. UN Doc. CAT/C/44/Add.8 (2000), para. 2. UN Doc. CAT/C/SR.426 (2001), para. 12. The fourth state report contained a separate section with responses to the COs 2000. This section was surprisingly short with one sentence only: 'The definition of torture as laid down in the Convention has been fully incorporated into Dutch law. For current developments in 
certain measures were taken as a result of or in order to comply with COs. Consequently, it is more difficult to assess and establish the effectiveness of COs than for the COs of the other treaty bodies. Secondly, as was mentioned in the introduction, hardly any recommendations were made in the COs 1995 and 2000 that would require (changes in) policy or legislative measures. ${ }^{26}$ The only recommendation that might have implied further measures to be taken was the recommendation in 2000 'to fully incorporate the Convention in domestic law, including adopting the definition of torture contained in Article 1 of the Convention'. ${ }^{27}$ No substantive changes took place concerning the definition of torture and the incorporation of CAT. ${ }^{28}$ The remainder of this section will, thus, primarily reflect on the (in) effectiveness of some COs 2007.

\subsection{Standing policy and legislative measures in line with the COs}

There have been several improvements in line with the COs of the CAT Committee. These have, however, not necessarily been the result of or influenced by the COs. Rather other domestic and international factors were the (primary) cause. This section will discuss two examples as an illustration.

One government official gave the improvement of the accelerated asylum procedure as an example of a $\mathrm{CO}$ that played a role at the domestic level. ${ }^{29}$ The COs 2007 highlighted several issues that should be considered by the government when revising its asylum procedures, including the 48 -hour timeframe of the accelerated asylum procedure. The COs in relation to the asylum procedure were, however, not effective in the sense of prompting a policy change. This is because the plans for improving the asylum procedure were already referred to during the dialogue with the CAT Committee, which was also noted by the CAT Committee in its COs. ${ }^{30}$ The improvements made to the asylum procedure and the 48-hour timeframe of the accelerated asylum procedure were primarily the result of a political decision of the

this respect see Article 11'. The report did not contain the statistics requested by the CAT Committee. CAT/C/67/Add.4 (2005), para. 4.

26 Supra n. 2.

27 UN Doc. A/55/44(SUPP) (2000), para 188 sub a.

28 TK 1999/00, buza000420, 2. UN Doc. CAT/C/67/Add.4 (2005), para. 4. Note that the 1988 Act which implemented the CAT was repealed with effect from 1 October 2003 and the criminal offences of torture defined in that Act were transferred to the new International Crimes Act. The definition was, however, not substantively changed in the period after the COs 2000. UN Doc. CAT/C/SR.763 (2007), para. 3.

29 These improvements were also noted by the CAT Committee. UN Doc. CAT/C/NLD/CO/5-6 (2013), para. 7(f) and 11.

30 UN Doc. CAT/C/NET/CO/4 (2007), para 7. During the dialogue, the head of the delegation made clear that the government was 'committed to reviewing the procedure so as to address any concerns'. UN Doc. CAT/C/SR.763 (2007), para. 6. After the dialogue, he made clear that the government was already thinking about this and that the critique of the CAT Committee fitted in very well. Caroline de Gruyter, 'In Nederland duurt 48 uur ruim vijf dagen; Martelexperts VN bezorgd over versnelde Nederlandse procedure voor asielzoekers', 9 May 2007, 3. 


\section{arr}

Balkenende IV government, which took office in February 2007, and which included the issue in the coalition agreement. ${ }^{31}$ One important reason for this and other improvements to the asylum procedure was the evaluation of the Aliens Act 2000 by the Commission Scheltema. ${ }^{32}$ In addition, several political parties and MPs (and NGOs) had been pleading for an improvement of the procedure for years. They relied on the criticism of several national and international organisations, like Human Rights Watch, UNHCR, ACVZ, the Dutch Refugee Council, and Amnesty International. ${ }^{33}$ One NGO representative observed that NGOs lobbied hard on this point but hardly or not at all on the basis of the COs of the CAT Committee. NGOs primarily focused on the conclusions of the Commission Scheltema and judgments of the ECtHR in their lobbying activities. ${ }^{34}$ Another indication of the limited role of the COs is that neither CAT nor the COs have been substantively considered in parliamentary debates or papers about the asylum procedure, except for one short reference to the COs by the Minister of Foreign Affairs (chapter IX, section 1.1). ${ }^{35}$

The COs 2007 also recommended that government guarantee access to a lawyer to persons in policy custody during the initial period of interrogation. In April 2009 , a change in legislation and policy was announced. Nonetheless, in terms of effectiveness, this legislative change was primarily the result of two judgments of the ECtHR about the suspects' right of access to a lawyer. ${ }^{36}$ During the interviews, government officials also mentioned the judgment of the ECtHR as the starting point for the legislative change, as well as the repeated criticism of the ECPT since

31 TK 2008/09, 31994, nr. 3.

32 TK 2006/07, 30976, nr. 5, 4. The coalition agreement of 2007 stated that the (accelerated) asylum procedure would be improved in the light of the recommendations of the Commission Scheltema. TK 2006/07, 31070, nr. 1, 80. See also TK 2007/08, 29344, nr. 67, 2 and 4. TK 2008/09, 31994, nr. 3, 1-2.

33 References to these organisations were, for example, made by the PvdA. TK 2006/07, 30976, nr. 4, 3 and 4. MPs from D66 even introduced a Bill to improve the legal protection of asylum seekers. Their proposal referred to the Dutch Refugee Council and Amnesty International as well as several cases before the ECtHR. TK 2006/07 30830, nr. 3, 1.

34 See, for example, the letter sent by Amnesty International on 3 October 2008 (EB-pol-2008-32) which mentioned the CAT Committee's concerns with respect to the accelerated asylum procedure together with the criticism expressed by other international organs, including the UNHCR, Human Rights Watch, judgments of the ECtHR, advice by the Advisory Committee on Migration Affairs and reports of the Ombudsman. The COs were only shortly referred to in a footnote. By contrast, some of the conclusions of the Commission Scheltema, which evaluated the Aliens Act 2000, were reproduced entirely: <www.amnesty.nl/sites/default/files/public/ eb-pol-2008-41_begrotingsbrief_justitie_0.pdf $>$, accessed 31 July 2013.

35 Supra n. 7.

36 Salduz v. Turkey, 27 November 2008, Application no. 36391/02. Panovits v. Cyprus, 11 March 2009, Application no. 4268/04. Interestingly, the letter of the Minister of Justice also referred to the views of the ECPT. TK 2008/09, 31700 VI, nr. 117, 4-5. UN Doc CAT/C/NLD/5-6 (2012), para. 4. Already before the judgment of the ECtHR, there was a pilot programme running from 1 May 2008 until 1 May 2010 in which the counsel for the defence was allowed to attend a police interrogation in the case of a suspicion of a crime against someone's life. The pilot programme was the result of a motion proposed by Dittrich (D66), Wolfsen (PvdA) and Weekers (VVD). TK 2005/06, 30300 VI, nr. 138 and 149. 
the beginning of the 1990s. ${ }^{37}$ Another indication for the limited effectiveness of these COs is that the COs or CAT have not played a role in the discussion of the access to a lawyer during the initial period of police interrogation.

\section{2. (Partly) effective COs}

The COs relating to the integration of medical reports in the asylum procedure received some attention at the domestic level, as was shown in chapter IX, section 1. While the government still held that medical information about traumas and scars should not play a role in the assessment of asylum applications during the dialogue in 2007, it changed its stance partly shortly after the COs. ${ }^{38}$ That is to say, State Secretary of Justice Albayrak requested the Advisory Committee on Migration Affairs (ACVZ) to concretise its proposal made earlier to integrate medical examinations and apply the Istanbul Protocol in the asylum procedure ${ }^{39}$ Although the request did not refer to the COs, it is noteworthy that the request was made on 13 August 2007 while the dialogue with the Committee was held on 7 and 8 May and the COs were adopted on 14 May 2007. The subsequent advice of the Advisory Committee reproduced the relevant recommendation in the COs 2007 in addition to discussing the Istanbul Protocol and referring to the jurisprudence of the ECtHR, GC 1 and several Views of the CAT Committee. ${ }^{40}$ Hence, in view of these developments, the Advisory Committee did consider it relevant to implement the Istanbul Protocol in the asylum procedure. The State Secretary subsequently made clear that she was willing to reconsider the possibility of integrating medical aspects as 'supporting evidence' during the examination of the asylum application. ${ }^{41}$ The State Secretary subsequently discussed the way in which medical circumstantial evidence and the Istanbul Protocol could be integrated with several NGOs in the context of the revision and improvement of the asylum procedure. ${ }^{42}$ The Aliens Act implementation guidelines (Vreemdelingencirculaire) were eventually amended in

37 The ECPT had already recommended this in 1993, 1998, 2002 and 2007. CPT/Inf (93) 15, para. 41. CPT/Inf (98) 15), para. 34. CPT/Inf (2002) 30, para. 24. CPT/Inf (2008) 2, para. 21.

38 For a good summary of the initial reasons against including medical reports in the asylum procedure, see UN Doc. CAT/C/NET/Q/4/Rev.1/Add.1 (2007), para. 9 and 10.

39 In February 2007, the Advisory Committee on Migration Affairs issued an advice on its own initiative with a proposal for a new asylum procedure. The Committee proposed, among other things, a general medical check for asylum seekers in the initial stage of the procedure. Among the objectives of this check, the advice referred to the insights such a check can give about medical problems that are relevant for the asylum procedure in the light of the Istanbul Protocol. Adviescommissie voor Vreemdelingenzaken, 'Secuur en snel. Voorstel voor een nieuwe asielprocedure', February 2007, 31-34.

40 Adviescommissie voor Vreemdelingenzaken, 'Medische aspecten asiel/regulier', April 2008, 22 and 23.

41 She made clear that this was done only when a violation of Article 3 ECHR could occur. It is noteworthy that the State Secretary only referred to the ECHR without mentioning CAT. TK 2008/09, 29689, nr. 243, 4-5.

42 TK 2009/10, 19637, nr. 1305, 5-6. 


\section{CAT}

order to allow for circumstantial evidence submitted by the asylum seeker, such as the reports of the Medical Examination Group of Amnesty International, to be taken into consideration in the assessment of all the facts. ${ }^{43}$ Despite this change, the COs have not (yet) been fully effective, since medical reports are (still) not decisive on their own and the Istanbul Protocol is hardly used in practice. ${ }^{44}$

The question is what the role or contribution of the COs was in this policy change. One argument hinting at a limited role is that neither the COs nor CAT were explicitly mentioned by the government and parliament in parliamentary papers subsequent to the dialogue in 2007, except for one reference by D66 and GL in the Senate (chapter IX, section 1.2). ${ }^{45}$ There were many possibilities for both the government and parliament to do so, because the issue of medical reports and the Istanbul Protocol was discussed in parliament on several occasions and the State Secretary of Justice also sent several letters to inform parliament about the issue. ${ }^{46}$ It is, nonetheless, not wholly unlikely that the COs were a contributory cause among many other international and domestic factors, most notably the long national lobby and the crucial role of NGOs like Amnesty International and Pharos. ${ }^{47}$ The COs strengthened the arguments of domestic actors like NGOs and MPs. One government official held that in this way, the COs might have given a nudge in the right direction. The COs might also have contributed to keeping the issue on the agenda or raising its salience. Some NGO representatives also noted that even though the COs might not have been of overriding importance in the decision to integrate medical examinations in the asylum procedure, the COs were one of the many factors that played a role.

\section{Treaty SPECIFIC REASONS FOR THE (IN)EFFECTIVENESS OF COS}

\subsection{Factors related to the domestic context}

Except for the issue of medical reports, the COs of the CAT Committee have had a limited impact and have largely remained ineffective. The first explanation for the sparse attention to COs might be the limited importance and issue salience of torture in the Dutch context. The immediate relevance of CAT for the Netherlands

43 TK 2009/10, 19637, nr. 1305, 5-6.

44 The state report merely provided that the Netherlands is 'acting in the spirit of the Istanbul Protocol more than ever before'. UN Doc CAT/C/NLD/5-6 (2012), para. 43-47. See also the criticism of the NGO report and the CAT Committee. NJCM (2013), 13 and 15-16. UN Doc. $\mathrm{CAT} / \mathrm{C} / \mathrm{NLD} / \mathrm{CO} / 5-6$ (2013), para. 12.

45 Supra n. 10.

46 See, for example, TK 2008/09, 29689, nr. 243. TK 2009/10, 19637, nr. 1305, 5-6.

47 The commentaries and reports of NGOs about medical reports were mentioned by several MPs. The SP, for example, mentioned the criticism of the Dutch Refugee Council, Amnesty International and Pharos. TK 2004/05, 19637, nr. 903 3eH, 2-5. See also de Vries (PvdA) in TK 2005/06, nr. 1358 and Spekman (PvdA) in TK 2009/10, 31994, nr. 25, 19, 20 and 32. 
seems to be overlooked, because actual acts of torture are almost never committed in the territory of the Netherlands, at least in the European part. This issue was indeed brought forward by several government officials and NGO representatives who considered torture and CAT as something that does not concern them. This view is not completely unjustified, because hardly any true recommendations were made for the European part of the Kingdom in the COs 1995 and 2000 that would require a change in policy or legislation. As said, the COs 1995 and 2000 only required additional information or statistics. ${ }^{48}$

Note that the recommendations for the other parts of the Kingdom, Aruba and the Netherlands Antilles, were more substantive of nature. Interestingly, the COs for these overseas territories were referred to more often (three times) by Dutch MPs than the COs concerning the European part of the Kingdom. ${ }^{49}$ Likewise, the COs related to other countries were referred to more frequently in parliament and in the Dutch media. ${ }^{50}$ That is to say, nine articles appeared about the concerns of the CAT Committee regarding the United States and Israel, Saudi Arabia, Switzerland, China, Russia and Austria. ${ }^{51}$ The COs about other countries were also invoked more often by applicants in court. ${ }^{52}$

This might warrant the conclusion that CAT is seen by Dutch policy makers and stakeholders as not directly relevant for the Netherlands but first and foremost for other countries. This is also illustrated by the introductory statement of the head of delegation during the dialogue in 2007 which started with the Dutch foreign policy concerning torture instead of the situation in the Netherlands (see the opening quote of the chapter). ${ }^{53}$ Government officials acknowledged that CAT does not have a prominent place within national policy making. In addition, at the time when the interviews were conducted in June 2011, one government official mentioned that it was discovered all of a sudden that a deadline for the submission of a periodic state report was shortly due for CAT. ${ }^{54}$ This anecdote illustrates that state reporting in the context of CAT is poorly embedded in the national policy processes.

Another matter which shows that torture is primarily seen in relation to other countries is the delay in ratification of the Optional Protocol to the Convention Against Torture and other Cruel, Inhuman or Degrading Treatment or Punishment (OPCAT) which created a stronger monitoring mechanism at the international level.

Supra n. 2.

TK 2007/08, 30945, nr. 9, 5 and 8. TK 2006/07, nr. 1962. TK 1995/96, nr. 14, 3224-3227.

See, for example, the references by D66 and SP to the concerns of the CAT Committee with respect to the prison system in Spain and about Greece respectively. TK 2003/04, 29042, nr. 5, 13.

51 See, for example, 'VN maant Rusland over Tsjetsjenië', 25 November 2006, NRC Handelsblad, 4.

Supra n. 13.

UN Doc. CAT/C/SR.763 (2007), para 3.

The official explanation was that the government had tried to submit the report on time, but that it had not succeeded because of the extensive interdepartmental process involving several departments and the four countries of the Kingdom. TK 2011/12, nr. 196. 


\section{CAT}

The OPCAT was adopted by the General Assembly on 18 December 2002. The Dutch government only signed it on 3 June 2005 and ratified it on 28 September 2010. This delay stands in sharp contrast with the forceful lobby campaign by the Netherlands and the EU to create a strong inspection mechanism. ${ }^{55}$ An explanation for this contradiction is that the lobby and negotiation of OPCAT was led by the Ministry of Foreign Affairs, while the other ministries are responsible for the actual incorporation of the treaty at the national level, which in the Netherlands precedes ratification. There was a divergence of views among the Ministry of Foreign Affairs (and parliament), on the one hand, and the Ministry of Justice and also the Ministry of Health, Welfare and Sport, on the other hand. ${ }^{56}$ The Ministry of Foreign Affairs emphasised foreign policy considerations and stressed the importance of the Optional Protocol for countries in which there was no active regional supervisory mechanism. ${ }^{57}$ It, thus, welcomed the several motions of parliament requesting that the government ratify OPCAT with the utmost dispatch in the light of the exemplary function of the Netherlands in relation to the elimination of torture worldwide. ${ }^{58}$ MPs argued that the Netherlands should set a good example for others with respect to the application of international law, since it is the host country of the legal capital of the world. ${ }^{59}$ Other ministries brought forward domestic policy-related concerns. The Minister of Justice had, for example, worries as to the duplication of workload in the light of the ECPT. ${ }^{60}$ A worry of the Ministry of Health, Welfare and Sport was the disclosure of medical files of patients. ${ }^{61}$

A second explanation for the limited impact and effectiveness of the COs of the CAT Committee is the limited knowledge of domestic actors about this UN procedure. Domestic actors are more aware of other mechanisms in relation to torture and inhuman and degrading treatment, such as the ECHR and judgments of the ECtHR as well as the ECPT. ${ }^{62}$ The editorial of the NTM/NJCM Bulletin also noted

55 In the beginning of the negotiations, the Netherlands was not a proponent of an Optional Protocol. It, nonetheless, participated actively in the Working Group that was responsible. Attachment to TK 2005/06, 30300 V, nr. 132, 151-152. TK 2003/04, 26150, nr. 10, 7. EK 2000/01, 26732, nr. 5d, 29-30. TK 2000/01, nr. 18, 1287-1308, 1299.

56 This reflects that the Ministry of Foreign Affairs is generally more inclined to take human rights into consideration than the other ministries. Reiding (2007), 37 and 69-71. Baehr et al. (2002), $230-232$.

57 TK 2004/05, nr. 1138.

58 TK 2007/08, 31263, nr. 15.

59 TK 2005/06, 30300 V, nr. 105. TK 2004/05, 29800 V, nr. 88. Cörüz (CDA) in TK 2004/05, nr. 66, 4239-4242, 4239-4230. Van der Laan (D66) in TK2004/05, 29800 V, nr. 97, 4.

60 TK 2004/05, nr. 1138. TK, nr. 66, 4239-4242, 4241.

61 In the view of this Ministry, ratification would necessitate a legislative change on this point. TK 2007/08, nr. 78, 5519-5522, 5221. This was also an issue during earlier visits of ECPT. CPT/Inf (2008) 2, para. 6 .

62 The 2012 state report under CAT explicitly mentioned twice that policy or legislation was adopted 'in response to' or 'following' the report of the ECPT, while the previous COs of the CAT Committee were not referred to. UN Doc CAT/C/NLD/5-6 (2012), para. 57 and 193. Supra n. 36-37. 
that the findings of the ECPT are always taken seriously while this has been less the case with the UN human rights treaty bodies. This was attributed to the thorough and factual foundation of the report and the fact that it does not give a judgment about matters outside the mandate of the ECPT. ${ }^{63}$ One illustration of the focus of the government on the ECPT is its rather elaborate response to the 2007 report which can be contrasted to the absence of any substantive response to the COs of the CAT Committee. ${ }^{64}$ The almost exclusive consideration of ECHR was also noted by the Chair of the CAT Committee. He stressed that universal human rights treaties were of 'equal importance and also merited reference'. ${ }^{65}$ The government, for example, referred to the prohibition of non-refoulement in Article 3 ECHR in its replies to the LOI without mentioning Article $3 \mathrm{CAT}^{66}$ In its explanation, the head of the delegation argued that this was 'because many decisions had been handed down by the European Court of Human Rights on cases of relevance to the Netherlands, and those decisions served as a reference for the courts throughout the Kingdom'.67 In addition, the government has often referred exclusively to Article 3 ECHR in relation to the prohibition of non-refoulement. ${ }^{68}$ State Secretary of Justice Albayrak, for example, only referred to Article 3 ECHR in relation to revisions of the Aliens Act in order to make a more effective and careful asylum procedure. She made clear that there had been long discussions in parliament about the conformity of the Aliens Act with the ECHR and that the ECHR is constantly tested against. ${ }^{69}$ Even in relation to the role of medical reports in the asylum procedure, often the ECHR alone was mentioned..$^{70}$ As was already mentioned in relation to ICCPR, there is an idea among government members and officials that policy and legislation are in line with the CAT when they are in compliance with the ECHR (see chapter VI, section 3.1).

Similar conclusions as to the dominance of the ECHR and ECPT can be drawn with respect to national courts ${ }^{71}$ and parliament. ${ }^{72}$ The Explanatory Memorandum to

63 Redactioneel (2012), 389.

64 The reaction was 16 pages long, addressing all recommendations substantively. TK 2007/08, 24587 and 31200, nr. 245.

65 UN Doc. CAT/C/SR.763 (2007), para. 16.

66 UN Doc. CAT/C/NET/Q/4/Rev.1/Add.1 (2007), para. 10, 15 and 16.

67 UN Doc. CAT/C/SR.766 (2008), para. 3 and 4.

68 See, for example, the discussion in the context of the amendments to the Aliens Act 2000 implementing EU Directive 2004/83/EC. EK 2007/08, 30925, nr. E, 9. TK 2005/06, 19637, nr. 999. TK 2005/06, nr. 1358.

69 TK 2009/10, 31994, nr. 25, 38.

70 See, for example, TK 2008/09, 29689, nr. 243, 4-5.

71 The District Court in Amsterdam, for example, passed over consideration of CAT in an extradition case in which the applicant invoked both Article 3 ECHR, Article 37 CRC and CAT. The reason for this was that the court considered that the applicant had not made clear that there would be an imminent violation of his rights which are not protected under the ECHR while they are so in CAT. $\mathrm{Rb}$. Amsterdam, 15 July 2010, LJN: BM8538, para. 5. This focus on the ECHR is the result of the rather extensive jurisprudence of the ECtHR in relation to Article 3 ECHR. Another explanation as to the courts' focus on ECHR is the fact that many applicants often only invoke the ECHR. See, for example, Ross-van Dorp (CDA) in TK 1998/99, 26262, nr. 3, 4. 
the legislative proposal by D66 to improve legal protection of asylum seekers is illustrative of this and stated that the most well known prohibitions of non-refoulement are Article 33 of the Refugee Convention and Article 3 ECHR. The legislative proposal was consequently discussed in the light of these articles and the jurisprudence of the ECtHR and the Administrative Law Division of the Council of State. The Explanatory Memorandum also shortly referred to CAT, but it stated that the prohibition of nonrefoulement in CAT played a smaller role than those in the ECHR. ${ }^{73}$ The primary focus on ECHR has a self-reinforcing effect, because the government, parliament and courts refer and react to each other. ${ }^{74}$ When courts exclusively consider the ECHR, parliament will often only mention or discuss the ECHR. ${ }^{75}$

\subsection{The (perceived) quality of the CAT Committee}

Remarkably, government officials rarely referred to the (dialogue with the) CAT Committee during interviews. They were not significantly more critical or positive about the functioning of the CAT Committee in comparison to the other treaty bodies. ${ }^{76}$ Several government officials were positive about the LOIPR 2011 that replaced the compilation of the sixth state report. It was argued that this makes the reporting more focused and would result in saving time.

One issue which was noted by a government official was that the CAT Committee stretched its mandate by also focusing on the treatment of asylum seekers. This was already observed by the head of the delegation who noted that the connection between the questions about violence in Dutch society and the CAT was 'tenuous. ${ }^{77}$ When asking for more information about international cooperation in the context of human trafficking, the member of the Committee acknowledged that this issue was 'somewhat on the periphery of the Committee's direct concerns, but which, given its scope, deserved to be addressed'. ${ }^{78}$ There were also several other questions related to which the link with CAT is not straightforward. ${ }^{79}$ The letter

73 The ECHR is referred to 9 times, the ECtHR 13 times. TK 2006/07 30830, nr. 3, 1.

74 Judgments of courts often lead to questions in parliament. See, for example, the references by Karimi (GL) to the judgment of the Court of Appeal in the Bouterse case about the December Murders. TK 2000/01, nr. 54, 3962-3982, 3981. At the same time, the government refers to the (absence of) jurisprudence of courts to support its policy. See, for example, TK 2001/02, nr. 1289.

75 See for example de Vries (PvdA) in TK 2004/05, nr. 758.

76 Only four officials were interviewed who attended the dialogue with the CAT Committee in 2000 (two) and 2007 (two).

77 UN Doc. CAT/C/SR.766 (2008), para. 18.

78 UN Doc. CAT/C/SR.766 (2008), para. 60.

79 See, for example, the questions about sexual tourism, the juvenile justice system, corporal punishment, sexual exploitation of children and violence against women. Even more surprising is the question as to which measures the government had taken to prevent anti-Semitic and antiIslamic incidents. UN Doc. CAT/C/SR.763 (2007), para. 35, 40 and 44. There was also a question about the COs 2004 of the CRC Committee in relation to prejudices and discrimination against children of ethnic minorities and refugee children. This member also stated that the fact that the 
about the COs 2007 also mentioned that the questions of the Committee went beyond the core obligations of CAT and the observance of these obligations by the Kingdom. ${ }^{80}$

\section{Conclusion}

The COs of the CAT Committee have had little impact, except for the integration of medical reports in the asylum procedure. The process of reporting under the CAT has received the least domestic attention of all the six treaties after ICESCR. This is also reflective of the limited salience of the issue of torture and inhuman treatment in the Dutch context. The COs that contained substantive policy recommendations, those of 2007, have also largely remained ineffective. The only exception is the CO 2007 about medical reports which was used by several NGOs in their lobbying as an argument to strengthen their claim. In this way, the COs were one element among many others that eventually led to a policy change. This chapter also attributed to the limited impact and effectiveness of the almost exclusive focus on the ECtHR and ECPT. 


\section{Chapter X CRC}

'I sometimes say, the Convention on the Rights of the Child, that is my Convention. With this I mean that the Convention serves as the basis for everything what I do as Minister for Youth and Families. It is the foundation for the policy of this government. [...] I am the joint-owner of this Convention.'

[Former Minister for Youth and Families Rouvoet in 2009] ${ }^{1}$

This last treaty specific chapter for the Netherlands examines the impact and effectiveness of the COs of the CRC Committee. ${ }^{2}$ Dutch state reports about the implementation of the CRC, which was (only) ratified in 1995, were considered by the CRC Committee in 1999, 2004 and 2009. ${ }^{3}$ In its COs, the CRC Committee recommended, among many other things, the establishment of a Children's Ombudsman, the prohibition of corporal punishment, the introduction of human rights education and improvement with respect to the position of minors in the asylum procedure.

\section{DOMESTIC IMPACT AND DOMESTIC MOBILISATION}

\subsection{Government attention}

The government has been relatively active in informing parliament about the reporting process and paying attention to the COs in its parliamentary papers, especially in recent years. The government only sent the first state report and the COs of 1999 with its reaction to parliament as a consequence of a parliamentary question. ${ }^{4}$ The second periodic state report was sent to parliament before the dialogue with the CRC Committee. ${ }^{5}$ The COs 2004 were, however, not sent to parliament. Nor did the government react separately to the COs 2004, although this

1 'Ik zeg wel eens: het kinderrechtenverdrag, dat is mijn verdrag. Ik bedoel dan dat het Verdrag inzake de Rechten van het Kind de basis is voor alles wat ik als Minister voor Jeugd en Gezin doe. Het ligt ten grondslag aan het beleid van dit kabinet. [...] Ik ben daarom mede-eigenaar van het verdrag.' Rouvoet (2009b).

2 Parts of this chapter will also be published in Krommendijk (2014a).

3 UN Doc. CRC/C/15/Add.114 (1999). UN Doc. CRC/C/15/Add.227 (2004). UN Doc. CRC/C/ $\mathrm{NLD} / \mathrm{CO} / 3$ (2009).

4 The question was raised by Hoekema (D66) and Albayrak (PvdA) as a consequence of the article 'VN: opvang asielmeisjes gebrekkig', de Volkskrant, 9 October 1999, 7. TK 1999/00, nr. 210. In addition, two letters were also sent on 7 October and 17 November 1999 about the CRC Committee (VWS-99-1511 and VWS-99-1779). The two letters could not be retrieved through Parlando or via the OHCHR Secretariat.

5 TK 2001/02, buza020166. 
was promised by State Secretary of Health, Welfare and Sport Ross-van Dorp. ${ }^{6}$ The COs 2004 were, however, addressed in the National Plan of Action for Children $2004 .^{7}$

The government has especially kept parliament involved and informed with respect to the third reporting cycle. The government sent a Dutch version of the third periodic report to parliament and a Dutch translation of the COs 2009 with its reaction. ${ }^{8}$ The third cycle largely coincided with the Balkenende IV government (2007-2010) during which there was a separate Ministry for Youth and Families (2007-2010) and the policy on youth and families was a spearhead of the government. ${ }^{9}$ Minister for Youth and Families Rouvoet recognised the CRC as the starting point for his youth policy immediately after he had taken office. ${ }^{10}$ The CRC was explicitly regarded as the foundation for the Policy Programme of Youth and Families 'All chances for all children'. ${ }^{11}$ As the opening quote of this chapter highlights, Rouvoet even spoke about 'his' Convention and called himself the 'jointowner' of the CRC. ${ }^{12}$ Before and after the 2007-2010 period, youth policy was just one of the portfolios for the Minister or State Secretary, in addition to sport and/or welfare and health. The separate Ministry has clearly contributed to a higher visibility of the reporting process (see also chapter $\mathrm{X}$, section 3.1).

It is noteworthy that the government also referred to the COs on 24 other occasions. This is more than the number of references to the COs of the other five treaty bodies combined and two times more than the COs of the CEDAW Committee, which ranks second. The COs about the prohibition of corporal punishment and the imposition of a life imprisonment on anyone between the age of 16 and 18 were even reproduced in the Explanatory Memoranda to the Bills amending the legislation in line with the COs (see chapter X, sections 2.3.5 and 8). For an overview of the issues in relation to which the COs were invoked, see table 10.1. Another interesting way in which the COs have played a role is when they have been used by the government to make clear that more 'drastic' measures could not be taken, since the existing policies and legislation are already met with substantial criticism of the CRC Committee. ${ }^{13}$

6 The government only provided the hyperlink through which the COs were accessible as a result of a question of parliament. TK 2003/04, 29540, nr. 89, 43. TK 2003/04, 28606, nr. 15, 28.

TK 2003/04, 29284, nr. 3.

TK 2006/07, 31001, nr. 17. TK 2007/08, 31001 and 26150, nr. 40. TK 2008/09, 31001, nr. 66.

EK 2007/08, nr. 18, 784-809.

TK 2006/07, 31001, nr. 1, 1.

'Alle kansen voor alle kinderen. Programma Jeugd en Gezin 2007-2011' attachment to TK 2006/07, 31001, nr. 5, 9, 38 and 47.

Rouvoet (2009b).

13 See, for example, the rather dismissive reaction of State Secretary of Justice Albayrak to the legislative proposal of De Roon (PVV) to enlarge the possibilities to try minors as adults. She noted that the Netherlands was already criticised by international organisations on its reservation to Article $37 \mathrm{CRC}$ as a result of which 16 and 17 years old could be tried as adults. She stated that the proposal of De Roon would even go further than this. TK 2009/10, nr. 48, 4512-4524, 4522. TK 2006/07, 30332, nr. 10, 8. 
Table 10.1. References to the COs of the CRC Committee by the government and parliament in the Netherlands $(\mathbf{1 9 9 5}-2011)^{14}$

\begin{tabular}{|c|c|c|}
\hline & $\begin{array}{c}\text { No. of parliamentary } \\
\text { papers in which the COs } \\
\text { were mentioned by the } \\
\text { government }\end{array}$ & $\begin{array}{l}\text { No. of parliamentary } \\
\text { papers in which the COs } \\
\text { were mentioned by } \\
\text { parliament }\end{array}$ \\
\hline Administration of juvenile justice & 6 & 6 \\
\hline Life imprisonment minors & 3 & 2 \\
\hline $\begin{array}{l}\text { Detention of juvenile offenders with } \\
\text { children institutionalised for } \\
\text { behavioural problems }\end{array}$ & 2 & 3 \\
\hline $\begin{array}{l}\text { The possibility of trying children as } \\
\text { adults }\end{array}$ & 1 & 2 \\
\hline Violence and abuse & 6 & 9 \\
\hline Corporal punishment & 4 & 4 \\
\hline Asylum seeking and refugee children & 3 & 12 \\
\hline Unaccompanied minors & 2 & 2 \\
\hline Children awaiting expulsion & & 4 \\
\hline Detention of minors & & 3 \\
\hline Accelerated asylum procedure & & 1 \\
\hline Children's Ombudsman & 2 & 18 \\
\hline Other issues & 7 & 14 \\
\hline $\begin{array}{l}\text { The withdrawal of reservations to } \\
\text { Articles } 37 \text { and } 40 \text { CRC }\end{array}$ & 3 & 1 \\
\hline The National Action Plan & 3 & \\
\hline Promotion of breastfeeding & & 1 \\
\hline Human rights education & & 2 \\
\hline $\begin{array}{l}\text { Dissemination and awareness raising } \\
\text { CRC }\end{array}$ & 1 & \\
\hline The availability of foster care & & 1 \\
\hline $\begin{array}{l}\text { The availability of space for playing } \\
\text { outside }\end{array}$ & & 1 \\
\hline The budget of youth organisations & & 1 \\
\hline The age of recruitment for the army & & 1 \\
\hline
\end{tabular}

The relatively high impact of the $\mathrm{COs}$ on the government also reflects the increasing influence of the $\mathrm{CRC}$ in general. Until the turn of the millennium, the

14 Note that on some occasions, different COs were mentioned at the same time. As a result, the numbers do not add up. 
CRC was hardly examined on a structural basis in the context of legislation. From 1995/96 until 2002/03, the CRC was only examined in ten Explanatory Memoranda by the government, while it has been considered in relation to 36 Memoranda since 2003/04. . $^{15}$ The statement of the State Secretary of Health Ross-van Dorp and Minister of Justice Donner that the right to youth care, as introduced by the Bill is not foreseen in the CRC, is illustrative of this marginal role of the CRC. ${ }^{16}$ The legislative changes in the fields of family and youth law, child protection and juvenile justice were hardly meant to bring legislation in line with the CRC even though they affected the rights of the child. ${ }^{17}$ Such legislative measures or policies were primarily taken because they were seen as desirable in themselves. $^{18}$

Figure 10.1 shows that the CRC has started to play a bigger role in policy notes and letters of the government since the parliamentary years 2003/04. ${ }^{19}$ The role of the CRC in policy notes and parliamentary papers especially increased under the Balkenende IV government with the separate Ministry for Youth and Families (2007-2010). ${ }^{20}$ Bruning observed that the CRC is increasingly used as a starting point for policy and practice and stated that the implications of the CRC are nowadays 'always' scrutinised when Acts relate to issues affecting children. ${ }^{21}$ The CRC has especially received increased attention in the field of asylum, immigration and integration (see also chapter $\mathrm{X}$, section 2.3.4). ${ }^{22}$ NGOs, however, argued that the CRC has received less governmental

15 Possibly as a consequence of this, the Council of State has also started to pay more attention to the CRC in its advice to legislative proposals from 2004/05. From 1995/96 until 2003/04, the CRC was only touched upon three times by the Council of State. Since 2004/05, the CRC has been scrutinised 18 times.

16 The Explanatory Memorandum did discuss Articles 2, 3, 5, 12 and 18 CRC, while Articles 19, 20 and 37 were left unaddressed. TK 2001/02, 28168, nr. 3, 8. This analysis was the result of the questions by MPs. TK 1999/00, 26816, nr. 25, 8-9 and 24.

17 Doek (2004), 4-5.

18 The government, for example, held that the CRC did not oblige youth care to be provided to children who have no valid legal status. Children have, nonetheless, access to youth care, because the government thought it irresponsible to withhold children with severe problems from youth care. EK 2003/04, 28168, nr. B, 36.

19 It was noted by several interviewees that more attention has been paid to youth issues and the CRC as a result of 'Operation Young' (2003-2006) which aimed to ensure cohesion in the youth policy.

20 The Minister of Justice, for example, stated that the pedagogic character of juvenile justice is grounded on the CRC. TK 2008/09, nr. 1470. TK 2008/09, 28684, nr. 203, 32. The Minister of Justice also expressed his intention that child protection legislation would be reconsidered and, if necessary, amended to bring it in conformity with Article 3 CRC. TK 2003/04, 28606, nr. 19, 4.

21 Bruning (2010), 4.

22 The 2010 working group reconsidering the governmental policies on asylum, immigration and integration in the light of the necessary austerity measures cited the CRC among the policy's starting points, in addition to the Refugee Convention, ECHR and EU legislation. Interestingly, other UN human rights treaties, including CAT and ICCPR, were not mentioned in this context. See the attachment to TK 2009/10, 32359, nr. 1, 19 and 23. Likewise, the government stated that the CRC is part of the legal framework for family reunification, together with the EU directive 
attention after the change of government in 2010, which is also reflected in figure $10.1 .^{23}$

Figure 10.1. The impact of the CRC and the COs of the CRC Committee on the Dutch government (1995-2011)

The number of parliamentary papers in which the CRC or the COs of the CRC Committee are mentioned by the government

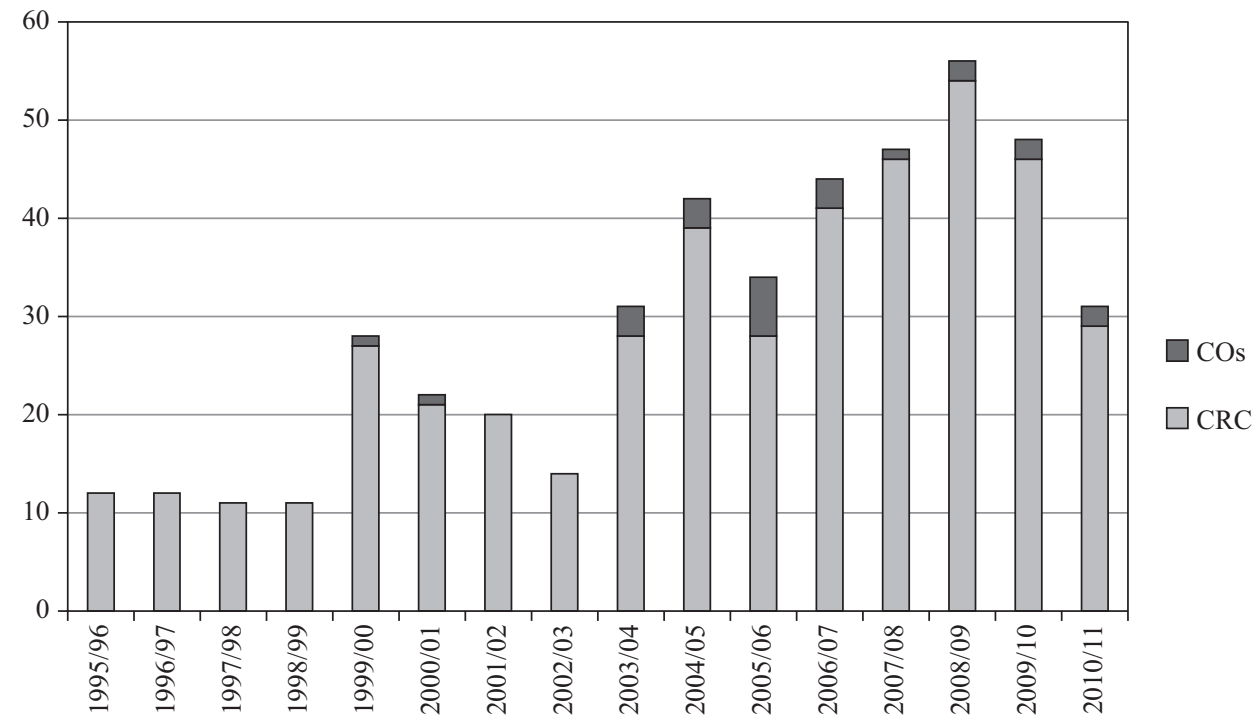

\subsection{Parliamentary scrutiny}

Several of the COs and some of the state reports have been tabled in parliament. This, however, does not mean that the COs of the CRC Committee have received in-depth attention or have led to any tangible results, in the form of motions. Only two MPs, for example, mentioned the COs briefly during a debate about the COs 1999 and several other policy notes about the youth care and youth participation. ${ }^{24}$ The COs 2004 were not tabled at all. The COs were, however, referred to by several

on this matter and the ECHR. TK 2008/09, 30573, nr. 13, 27. The State Secretary of Justice also wanted to make the basic principles in the CRC more explicit and visible in the policy on the detention of asylum-seeking children. TK 2007/08, 29344, nr. 66, 1-2.

23 Kinderrechtencollectief (2012), 11-12.

24 Örgü (VVD) referred to the concerns of the CRC Committee and the Children's Rights Coalition about the position of foreign children, the policy on child abuse and the long waiting lists in youth care. Kant (SP) also mentioned the criticism of the ' $\mathrm{UN}$ ' as to the policy on child abuse and asked whether the Youth Care Act would include a right to report. TK 1999/00, 26816, nr. 5 , 2 and 13. 
MPs during a debate about the 2007 state report. ${ }^{25}$ The reaction of the government to the COs 2009 was tabled for discussion with the Minister for Youth and Families as well as the State Secretary of Justice. ${ }^{26}$ This debate was rather noncommittal and without consequences, as was also noticed by government officials. MPs avoided any reference to the COs and discussed other issues instead. ${ }^{27}$ Only Dijsselbloem (PvdA) scrutinised some COs in substantive terms. ${ }^{28}$ Langkamp (SP), for example, stated that she was not going to pay attention to several COs 2009, such as those concerning youth care and child abuse, because they were already being discussed frequently. According to her, this would not imply that no improvements are needed, but that with respect to these issues, parliament is already right on the ball. ${ }^{29}$ Minister for Youth and Families Rouvoet also stated several times that it would be better to address issues in the context of other meetings. ${ }^{30}$ Nonetheless, one of his predecessors had stated earlier that COs should be discussed in their entirety and not by highlighting only some of them during specific policy debates. ${ }^{31}$ These statements reflect the problem of compartmentalisation (verkokering) within parliament and the fact that children's issues are spread over different ministerial portfolios (see also chapter VI, section 1.2 and chapter VIII, section 1.2).

The number of other occasions during which MPs have mentioned the COs of the CRC Committee is relatively high, with 56 occasions. ${ }^{32}$ By contrast, the COs of the CEDAW Committee, which occupy a second place, have been mentioned 21

25 Bouchibti (PvdA), Sterk (CDA) and Langkamp (SP). TK 2007/08, 31001 and 26150, nr. 40, 1-2.

26 TK 2008/09, 31001, nr. 66.

27 Madsen-van Stiphout (CDA), for example, only once referred to the 'human rights commission'. This was, however, in relation to the issue of institutionalisation of children with behavioural problems who should, according to CDA, be placed in their own region. The Committee had, however, not issued any recommendations about the placement in the region. Likewise, Langkamp (SP) remarked that several issues remained unaddressed in the reaction to the recommendations. She subsequently gave some examples, like the availability of space for playing outside and leisure and the use of mosquitoes which emit a sound with a high frequency in order to tackle loitering problems. These issues were, however, not addressed in the COs, but by the European Commissioner for Human Rights (mosquitoes) and the reaction of the Children's Rights Coalition to the COs 2009 (playing).

28 Dijsselbloem, first of all, pointed to the improvements since the COs 2004, such as the prohibition of corporal punishment, the efforts to avoid detention of juvenile offenders with children institutionalised for behavioural problems and the legislative proposal for a Children's Ombudsman. He subsequently addressed the COs that were not complied with: the inclusion of human and children's rights in school curricula, waiting lists in the youth care, the withdrawal of reservations to the CRC and the obligation to report child abuse. TK 2008/09, 31001, nr. 69, 6-7.

29 TK 2008/09, 31001, nr. 69, 3.

30 TK 2008/09, 31001, nr. 69, 13-14.

31 This was mentioned by State Secretary of Health, Welfare and Sport Ross-van Dorp in response to a question of Kant (SP) about the COs concerning the Children's Ombudsman during a debate about youth care. TK 2003/04, 28606, nr. 15, 28.

32 This includes five written questions in which the COs were mentioned, often on the basis of an article in the press. See, for example, the question of Vos and Karimi (GL) which refers to the article of Sheila Kamerman and Derk Stokmans, 'Nederland schendt VN-kinderverdrag', NRC Handelsblad, 26 October 2004. TK 2004/05, nr. 557. See also Hoekema (D66) and Albayrak 
times. The COs were also alluded to in two adopted motions and a legislative proposal with respect to the establishment of a Children's Ombudsman (chapter X, section 2.3.1). ${ }^{33}$ In addition, three other motions were proposed in relation to the care of asylum-seeking children in which the CRC and the COs were mentioned among the considerations. All three motions were, however, not adopted (chapter X, section 2.3.4). ${ }^{34}$

This account illustrates that parliament has increasingly taken up a role of domestic supervisor of the process of state reporting, as was also mentioned by several government officials. Parliament has requested several times to be informed about the reporting process and especially the COs and the government reaction thereto. ${ }^{35}$ This, however, still does not mean that parliament is monitoring the implementation of the CRC or the COs of the CRC Committee on a structural basis. This discussion shows that MPs tend to use the COs primarily in an opportunistic way as an additional argument for their position. Both government officials and NGO representatives attributed the absence of an in-depth discussion to the limited knowledge of MPs about the CRC and the process of state reporting. ${ }^{36}$ It was noted by an NGO representative that COs make a deep impression on MPs, exactly because their (legal) knowledge about the system of reporting and its (legal) status is limited. COs, thus, have a bigger impact on parliament than lawyers who emphasise their non-binding nature. NGO representatives noted that the limited awareness provides an opportunity for NGOs to influence MPs by providing them with ready-made questions and motions. They also noted that MPs are dependent on information provided by NGOs and have to be supplied with ready-to-hand information, because otherwise little will happen. The legislative proposal establishing a Children's Ombudsman was, for example, written by Arib (PvdA) with the advice of representatives from UNICEF and DCI.

Interviewees noted that the knowledge about the CRC has improved over the years. It was mentioned that UNICEF gave every MP a blue booklet about the CRC in 2010. The result was that several MPs held up and expressly quoted from the CRC during parliamentary debates since then. ${ }^{37}$ The latter also reflects that the impact of the CRC has grown considerably in recent years, as figure 10.2 shows. There have been 379 references between 1995 and 2011, while the second most-

(PvdA) in TK 1999/00, nr. 210. Kant (SP) in TK 1999/00, nr. 297 and 435. Dibi and Azough (GL) in TK 2008/09, nr. 1851.

33 Motion proposed by Arib (PvdA) and Ravenstein (D66) in TK 1999/00, 26816, nr. 7. Motion proposed by Van der Laan (D66), De Wit (SP), Wolfsen (PvdA) and Vos (GL) in TK 2003/04, 29200 VI, nr. 52.

34 Infra n. 154.

35 Parliament, for example, requested the COs 2009 and a governmental reaction. TK 2008/09, 31001 , nr. 66.

36 Supra n. 27.

37 Voordewind (CU) and Spekman (PvdA) 'waved' with the CRC during a debate about immigration. TK 2010/11, nr. 28, 28-56, 29 and 42. Spekman showed the 'blue booklet' of UNICEF. TK 2010/11, 19637 nr. 1388, 17. 
cited treaty in parliament, ICCPR, was mentioned 186 times. Especially since the parliamentary years 2003/04, the number of references to the CRC has increased to an average of 32 references a year, while this was only around 12 references in the years until 1998/99 and 23 between 1999/00-2002/03. A further rise took place in the period 2007/08-2010/11, during which the CRC and COs were mentioned 43 times a year on average. One illustration of the increased attention in this period are the two policy notes proposed by Spekman and Van Dijken (both PvdA) about shelter for asylum-seeking children and irresponsible parenthood respectively in which the CRC played a considerable role. ${ }^{38}$ Minister for Youth and Families Rouvoet also noted that parliament is keeping the government on its toes regarding the improvement of children's rights. ${ }^{39}$ The latter might be explained by the Permanent Standing Committee for Youth and Families in parliament which existed between 2007 and 2010 under the Balkenende IV government because of the Separate Ministry for Youth and Families.

Figure 10.2. The impact of the CRC and the COs of the CRC Committee on the Dutch parliament (1995-2011)

The number of parliamentary papers in which the CRC or the COs of the CRC Committee are mentioned by MPs

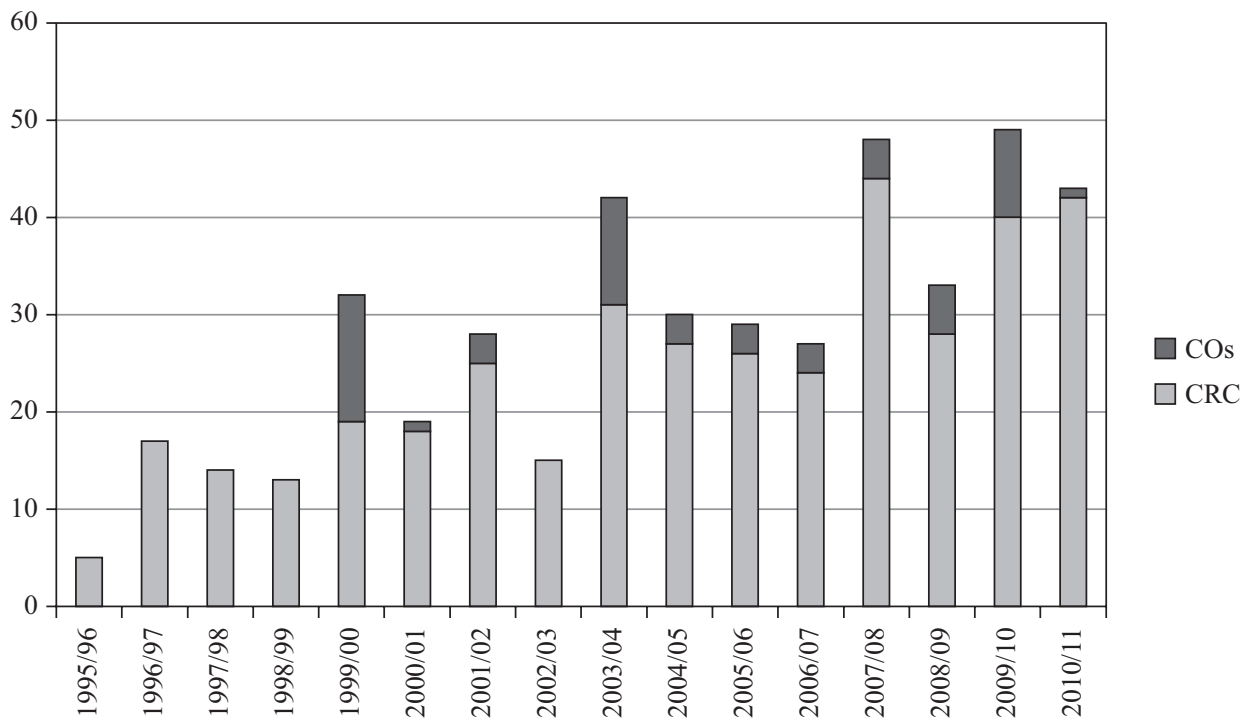

38 'Altijd onderdak voor kinderen' and 'Onverantwoord ouderschap'. TK 2010/11, 32566, nr. 2. TK 2009/10, 32405 nr. 2.

39 TK 2008/09, 31001, nr. 69, 7. 


\subsection{Courts and legal practice}

COs have hardly been scrutinised or touched upon by national courts in their judgments. The COs mentioned only once in the advice of the Solicitor General in a case before the Supreme Court concerning corporal punishment. ${ }^{40}$ One court has 'used' the COs in another interesting way by interpreting the absence of criticism of the Committee in the COs with respect to the DNA Testing (Convicted Persons) Act as an indication or support for the view that this Act is in conformity with CRC. ${ }^{41}$

The minor role and limited attention paid to COs contrasts with the considerable legal practice in relation to the CRC. The CRC has become well known for lawyers and judges, who have started to make use of the CRC increasingly in their work. In the period 2006-2009 there were approximately 70-80 (published) judgments per year in which the CRC is being dealt with, whereas this was only 75 in total for the period from 1995 until 2001, 11 cases per year on average. ${ }^{42}$ Figure 10.3 shows that this number has increased even further to around 150 since the parliamentary year 2009/10. The CRC is applied most often in relation to asylum matters and the law of persons and family law and to a lesser extent juvenile justice. ${ }^{43}$ National courts, however, differ in their opinions as to whether the provisions of the CRC have direct effect. ${ }^{44}$ Whereas the Central Appeals Tribunal has cautiously accepted the direct effect of (some) provisions of the $\mathrm{CRC},{ }^{45}$ the Administrative Law Division

40 The Solicitor General considered that chastisement as a defence was not excluded in Dutch law, although he recognised that this might change in the future given a Bill proposing to ban parental violence. He subsequently touched upon international developments in this direction, including Article $19 \mathrm{CRC}$ and para. 44 (d) of the COs 2004. Conclusion of the Solicitor General Jörg, nr. 03011/04, para. 33-41 in Hoge Raad, 4 October 2005, LJN: AU1657.

41 The applicant argued that the legislator had taken the interests of the child into account insufficiently when drafting the DNA Testing (Convicted Persons) Act. In this context, he appealed to Articles 3, 16 and 40 CRC. The District Court, however, held that the legislator had not lost sight of the position of the child and had made an appraisal of interests between societal interests and the interests of the convicted minors, because it had obtained advice from the Dutch Bar Association, the Attorney General and the Council for the Administration of Criminal Justice and Protection of Juveniles. The Court also considered that it has not been shown that the Netherlands was given a rap over the knuckles by the CRC Committee in its COs 2009 with respect to the Act or the treatment of minors in this context. Rb. Maastricht, 24 February 2009, LJN: BH4137, para. 4.4.

42 For a good analysis of jurisprudence until 2001 see Ruitenberg (2003), 215. For a study of the period between 2002 and 2005, see Van Emmerik (2005). The most recent study analysed 1028 judgments in which the CRC was mentioned in the period of 1 January 2002 until 1 September 2011. De Graaf (2012).

43430 judgments deal with asylum and refugee issues and 324 with family law. De Graaf (2012), 278.

44 De Graaf (2012), 275-276. Pulles (2011). TK 2005/06, nr. 1036. Ruitenberg (2003), 30-35.

45 CRvB, 5 August 2005, LJN: AU0687. In another judgment, the Tribunal ruled that Article 18 $\mathrm{CRC}$ is a generally formulated social objective from which no unconditional and specific subjective rights can be derived. CRvB, 20 October 2010, LJN:BO3580. Pulles (2011), 231-232. 
of the Council of State has been considerably more reluctant. ${ }^{46}$ In a great number of cases, courts have, however, examined the CRC in one way or another, leaving aside the question of direct effect or simply assuming implicitly direct effect. ${ }^{47}$

\section{Figure 10.3. The impact of the CRC on Dutch courts (1995-2011)}

The number of judgments in which the CRC is cited

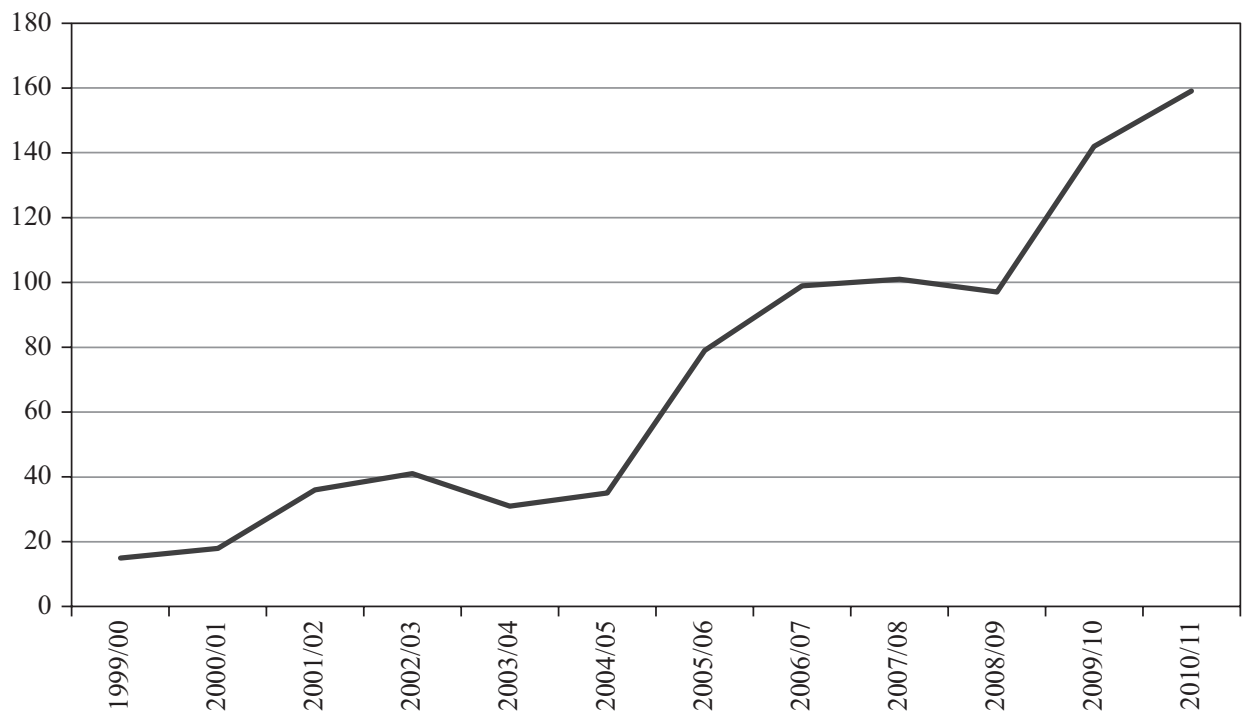

An appeal to the CRC seems to have been more successful in the period after 2001, especially before lower courts. ${ }^{48}$ The CRC has especially led to positive results in poignant situations, especially in the context of family law and to a lesser extent in the field of asylum and social security law. By contrast, the CRC has almost not had

46 The Administrative Law Division of the Council of State has frequently pointed to the insufficient concrete formulation of the provision in the CRC. See, for example, ABRvS, 9 April 2009, LJN:BC9087. De Graaf (2012), 276.

47 Courts have used the CRC to interpret national legislation by means of a so-called treaty conform interpretation or they have used the CRC among the considerations or as a supporting argument. The Hague Court of Appeal, for example, held that several provisions in the CRC have 'reflexive effect' as a result of which they have to be taken into account when interpreting norms, irrespective of their direct effect. Hof Den Daag, 27 July 2010, LJN: BN2164, para. 3.4. De Graaf (2012), 275-276. Van Emmerik (2005), 700, 705 and 714.

48 Van Emmerik gave two reasons. Firstly, given the more stringent immigration laws, there is more reason for the judge to apply the CRC and to tone down this policy a bit. Secondly, the CRC has become more well known. Van Emmerik (2005), 706-707. 
any impact in the field of criminal law. ${ }^{49}$ The more recent judgments of higher courts in relation to 'illegal' children, who are unlawfully present in the Netherlands, for example, because their asylum application had failed are especially noteworthy. ${ }^{50}$ The Central Appeals Tribunal, for example, held that these children have a right to assistance for the fulfilment of their basic needs, which include housing, food and clothes..$^{51}$

\subsection{NGOs}

The Dutch Children's Rights Coalition is the most important non-governmental actor involved in the process of state reporting under the CRC. The coalition was founded in 1995 and acts as a platform for several independent NGOs and civil society actors, including UNICEF and Defence for Children (DCI). The latter acts as Chair. The objectives of the Coalition are the promotion of cooperation between organisations involved in the rights of the child, the promotion of education on CRC and monitoring of the implementation of the CRC in the Netherlands. ${ }^{52}$ The Coalition has received a structural annual subsidy of the government to increase awareness of the CRC through, among other things, organising a Children's rights festival and publishing information about the CRC in brochures and on the internet. The Coalition has also developed training material for lawyers, judges and teachers. ${ }^{53}$

The coalition submitted separate alternative reports for the reporting cycles in 1999, 2004 and 2009. These reports were written prior to or at the same time as the state report and are, hence, not a commentary on or reaction to the state report. Contrary to other NGOs involved in reporting under other treaties, the NGO representatives of the Coalition see the alternative report and their involvement in the wider process of state reporting merely as a step in a larger and continuous political lobbying process at the national level. The Coalition has used the process of reporting strategically and has embedded the process in its broader political lobbying at the national level. The motto of NGOs is that the alternative report which is sent to Geneva is above all a message for The Hague. This explains why the Coalition

49 De Graaf (2012), 276-277.

50 See, for example, Hoge Raad, 21 September 2012, LJN:BW5328. Hof Den Haag, 27 July 2010, LJN: BN2164, para. 3.6. and 3.8. De Graaf (2012), 282-283. Krommendijk (2014a). Infra n. 71.

51 The Tribunal considered that Article 2(1) CRC has direct effect. CRvB, 24 January 2006, LJN: AV0197.

52 The other members are Jantje Beton, Bernard van Leer Association, the National Youth Council (NJR), the Augeo Foundation and the Foundation for Children's Welfare Stamps, Terre des Hommes, the Dutch Council of the Chronically ill and the Disabled (CG-Raad) and the Netherlands Youth Institute as an advisory member.

53 TK 2007/08, 31001 and 26150, nr. 40, 6. The government even argued that the Coalition is responsible for the implementation of Article 42 CRC. See the attachment to TK 2004/05, 29800 VIII, nr. 187, 15. The government also subsidised youth reports which are part of the alternative report of the Coalition. TK 2001/02, buza020166. 
always publishes a Dutch version of the alternative report which is also sent to parliament and political parties. ${ }^{54} \mathrm{NGO}$ representatives also argued that the process of state reporting and the resulting COs can be used as additional arguments making the NGOs' own views and recommendations stronger. The Coalition, for example, presented a ten point plan in parliament with proposals for an improvement of the Dutch youth policy. This plan was based on, among other things, the COs 2009. ${ }^{55}$

The Coalition, but also its members and other NGOs, have used the COs extensively in their lobbying work at the national level. ${ }^{56}$ Since 2008, UNICEF and DCI have started to monitor the CRC and the implementation of COs even more closely by publishing annual reports (Jaarberichten). In these reports, the Dutch situation in certain areas is tested against the CRC, whereby use is made of the COs. The Coalition also organised a meeting about follow-up to the COs 2009 shortly after the dialogue. Several MPs and Minister for Youth and Families Rouvoet were present. ${ }^{57}$

The latter also reflects the rather frequent interaction between the Coalition and the government. Since 28 June 2000, half-yearly meetings have taken place between the Dutch Children's Rights Coalition and an interdepartmental working group on children's rights. The contacts between NGOs and the government have also become more constructive over the last years. ${ }^{58}$ Several government officials noted that in the beginning, around the consideration of the initial state report in 1999 and to a lesser extent 2004, the interaction with some NGOs was ponderous. This was because NGOs approached the government primarily in a negative way and were not very willing to listen to the arguments put forward by the government. ${ }^{59}$ Government policies and ideas were seen as wrong from the very start. At the same time, NGO representatives pointed to the unwillingness and defensiveness on the side of the government (chapter X, section 3.1). As a result, a true dialogue did not take place. ${ }^{60}$

54 The second alternative report was, for example, completed before the second state report and presented to parliament in June 2002 as a contribution to the discussions in the context of the parliamentary elections. Meuwese (2004), 11-12.

$55<$ www.defenceforchildren.nl/p/53/1884/mo89-mc21/mo124-m0/mo125-cg193\%7C24=*/ aanbieding-tienpuntenplan-in-tweede-kamer>, accessed 31 July 2013.

56 Other NGOs, such as Amnesty International and NJCM, have also used the COs of the CRC Committee in their letters and lobbying activities on a few occasions.

57 The Coalition also wrote a note commenting on the government reaction to the COs 2009 with a view on the parliamentary debate about the COs: $<$ www.defenceforchildren.nl/images/20/884. pdf $>$, accessed 31 July 2013.

58 This was mentioned by several NGO representatives. See also Meuwese (2003), 4.

59 This was also implicitly acknowledged by NGOs. The Director of DCI stated that the press release of the Coalition about the COs 2004 'fell on stony ground' and was critically received by the interdepartmental working group on children's rights, since the tone was rather biting. The headline of the press release stated that the policy on children is incoherent and in violation of the CRC. Meuwese (2004), 14.

60 This was also given as a reason for the negative atmosphere during the dialogue with the CRC Committee in 1999. NGOs made the most of the fact that the delegation was not that well prepared during the dialogue in 1999. The latter was the result of the flooding of the basement of the Ministry of Justice. One NGO representative admitted that this was widely propagated vis-à- 
The contact has improved since 2004. Government officials and NGO representatives stressed that especially under Rouvoet (2007-2010) a true dialogue was sought. ${ }^{61}$ Government officials showed their appreciation for this and spoke about a true interaction, reflected in the numerous moments of contact during the whole process of state reporting. NGO representatives also highlighted the excellent contacts and attempts to create a partnership. The relatively extensive consultations between NGOs and the government in the context of the compilation of the state report, the answers to the LOI and the follow-up to the COs are good examples of this process with exchanges at regular intervals. An illustration of the latter is that at the time of the interviews in June 2011, a meeting had already taken place between NGOs and the government concerning the next state report to be submitted in March 2012.62 Another explanation for the improved interaction is that the government realises that the CRC Committee usually bases its questions and COs to a large extent on the information presented by NGOs in their alternative report. Hence, through consulting the NGOs in advance, it would be easier for the government to anticipate questions and COs of the Committee.

In addition to the relatively frequent interaction between children's rights NGOs and the government, there are also rather close contacts between NGOs and several MPs. The Coalition had, for example, an introductory talk with the Permanent Parliamentary Committee for Youth and Families in October 2007 about the work of the coalition, the third NGO alternative report and future cooperation between the Coalition and the Parliamentary Committee. The MPs made clear that they wanted specific 'ammunition' for a parliamentary debate about child abuse. ${ }^{63}$ Another example is the lobby meeting between one MP and DCI where it was agreed that DCI would raise publicity for a child that was about to be expelled and would also take care of the substantive input for written parliamentary questions. ${ }^{64}$ As was mentioned before, representatives from UNICEF and DCI also provided input and advice to Arib's (PvdA) legislative proposal that proposed the establishment of a Children's Ombudsman. Likewise, the policy note proposed by Spekman (PvdA) about shelter for asylum-seeking children was partly inspired by the note prepared

vis the media in order to weaken 'the opponent' and strengthen the NGOs' own position with a view of getting strong(er) recommendations.

Government officials noted that NGOs have also recently started to name more positive aspects in Dutch policy, especially during the third reporting cycle. Minister for Youth and Families Rouvoet and the Minister of Justice and Development Cooperation as well as Her Majesty the Queen were, for example, present during the closing of the event organised by UNICEF and the Dutch Children's Rights Coalition to celebrate the 20th birthday of the CRC in 2009.

62 The NGOs do not wait until the government has submitted its own state report. Already on 3 May 2011, a first meeting was organised by the Coalition in the build-up to the submission of the fourth report for which the deadline is March 2012.

Letter from the Children's Rights Coalition of 16 October 2007: <ecpat.sitespirit.nl/ images/42/670.pdf >, accessed 31 July 2013.

DCI, 'Verslag van activiteiten en financiën 2008': <www.defenceforchildren.nl/images/31/949. pdf $>$, accessed 31 July 2013, 26. 
by the Coalition 'Stop eviction of undocumented children in the Netherlands' ${ }^{65}$ Another example is the membership of senator Quick-Schuit (SP) of the expert panel for UNICEF and DCI's year report on children's rights $2008 .{ }^{66}$ These close contacts have influenced MPs, because they have often mentioned the commentaries of NGOs when referring to COs. ${ }^{67}$ In addition, parliament has also requested that the government react to the commentaries of NGOs on several occasions. ${ }^{68}$

Several children's rights NGOs have been quite active in the field of litigation with respect to children's rights as well. DCI, for example, has initiated cases before Dutch courts claiming a violation of CRC. ${ }^{69}$ In addition, DCI has regularly expressed its standpoints as an expert in children's rights. ${ }^{70}$ DCI also lodged a complaint with the European Committee of Social Rights in 2008 about the fact that children not lawfully present in the Netherlands are excluded from the right to housing. ${ }^{71}$

\subsection{Media coverage}

There have been 37 articles in the printed press devoted to the COs of the CRC Committee and the dialogue between the CRC Committee and the government delegation. Another 12 articles reported about the pre-session working group meeting, the LOI or the alternative report of NGOs. ${ }^{72}$ Fourteen articles appeared in the printed press about the COs 1999. The issues that were especially highlighted were the concerns of the Committee as to the situation of unaccompanied asylumseeking minors (4), child abuse (3) and the fact that the delegation was not very

65 In this policy note, Spekman also referred to the successful campaign which was started by DCI with support of the PvdA. TK 2010/11, 32566, nr. 2, 10 and 14.

66 It is, therefore, not a coincidence that the SP raised a question in the Senate about the COs concerning the withdrawal of reservations to the CRC. EK 2008/09, 31436, nr. D, 2-3. A colleague of Quick-Schuit, Slagter-Roukema (SP) also referred to the year report children's right 2008 in addition to the COs 2004. EK 2007/08, nr. 18, 748-770, 759.

67 De Vries (PvdA) and Vos (GL), for example, referred extensively to the COs 2004 in relation to asylum-seeking children. Two motions, which explicitly mentioned the COs, were proposed by them. Both members explicitly referred to DCI. TK 2003/04, 19637, nr. 833, 834 and 847. See also the references to the opinions of DCI, the Coalition and UNICEF by Hamming-Bluemink (VVD) and Dijsselbloem (PvdA) during the debate about the COs 2009. TK 2008/09, 31001, nr. 69, 4, 5 and 7.

Minister for Immigration and Integration Verdonk was, for instance, asked to react to DCI's five action points which were partly based on the COs 2004 about minor asylum seekers. TK 2003/04, 19637, nr. 823, 3-4.

69 DCI, for example, claimed on behalf of 2,100 asylum-seeking children that the state should make it possible that asylum-seeking children obtain a residence permit after five years of staying in the Netherlands. Rb. Den Haag, 11 July 2007, LJN:BB3303. DCI has also spent considerable time on legal assistance and advice to lawyers and social workers in individual cases. present in ABRvS, 29 January 2001, LJN: AF4218.

71 DCI v. the Netherlands, 29 October 2009, Complaint No. 47/2008. Krommendijk (2014a).

72 See, for example, Frank Renout, 'VN wil opheldering over Nederlands jeugdbeleid', Algemeen Dagblad, 11 September 1999, 5. 
well prepared (3). ${ }^{73}$ Twelve articles addressed the COs 2004. The majority of the articles focused on the detention of refugee children awaiting expulsion (7). ${ }^{74} \mathrm{It}$ is noteworthy that a radio channel also reported directly from Geneva. ${ }^{75}$ The COs 2009 were mentioned 11 times. During the dialogue, several journalists were actually present in Geneva. ${ }^{76}$ The emphasis in the articles was put on the Children's Ombudsman (5) and the possibility of trying children as adults (3). ${ }^{77}$

In sum, media attention of the process of state reporting and COs under CRC is considerable, particularly in comparison with the other treaties. This can be attributed to the salience of the issue of children's rights in society and politics (chapter X, section 3.1). Another reason for this interest is that a youth delegation went to Geneva for the pre-session working group meeting with the CRC Committee and the dialogue with government delegation. Both government officials and NGO representatives acknowledged that this delegation is an important trump card which generates substantial media attention. ${ }^{78}$ What might also explain the rather extensive media coverage was that a Dutchman, Doek, has been a member (1999-2007) and Chair (2001-2007) of the CRC Committee for several years. In this period he has been quite approachable for the media, which is illustrated by the several articles about the reporting process under the $\mathrm{CRC}$ and which also included his opinion. ${ }^{79}$ Another explanation is that NGOs have been active in seeking media attention. ${ }^{80}$ Several (opinion) articles have also been written by NGO representatives. ${ }^{81}$

\subsection{The broader influence of the reporting process under the CRC}

As was outlined in this section, the COs of the CRC Committee has had by far the biggest domestic impact of all the six UN human rights treaties ratified by the

See, for example, 'Kritiek VN-comité op Nederland', Algemeen Dagblad, 7 October 1999, 5.

74 See, for example, 'Uitbrander VN over jeugdbeleid', Algemeen Dagblad, 31 January 2004, 3. Note that two articles appeared as a result of the first year report of UNICEF and DCI. See, for example, 'Nederland leeft rechten kind slecht na; Eerste jaarbericht UNICEF en DCI', NRC Handelsblad, 21 January 2008, 1.

75 Meuwese (2004), 11

76 For example, Antoinette Reerink, 'Rouvoet op matje VN voor naleving kinderrechten', $N R C$ Handelsblad, 16 January 2009, 3.

77 See, for example, 'Hulpeloos achter slot en grendel; "Kwalitatief goede gesloten jeugdzorg leidt tot meer vraag”, Het Parool, 22 January 2009, page unknown. Iris Pronk, “'Ombudsman voor kind is luis in pels"; vijf vragen', Trouw, 23 April 2010.

78 Six articles paid attention to the reports of the Dutch Youth Council and its presentation during the session in 1999. See, for example, 'Nederlandse jeugd rapporteert aan VN', Algemeen Dagblad, 7 June 1999, 3.

79 See for example: 'Pleidooi raadgever kinderen', NRC Handelsblad, 15 September 1999, 5.

80 See also the several references to the CRC Committee in the appendix about media contacts in the year report 2009 of DCI: <www.defenceforchildren.nl/images/31/1195.pdf>, accessed 31 July 2013, 36-40.

81 See, for example, Stan Meuwese, 'Wie reageert op noodkreet gesloten wereld?', de Volkskrant, 17 December 2004, 15. 
Netherlands. Both the government and parliament have referred to the COs on various occasions. The previous subsections also showed that the reporting process under CRC has been used as an opportunity for human rights review and dialogue more than the reporting under the other five treaties. NGOs, and more recently also the government, have deliberately used state reporting to create a moment of (media) attention for children's rights. Reporting has been embedded in a relatively continuous and interactive process and dialogue between NGOs and the government at the national level. One government official even argued that the interaction with NGOs in the process of reporting at the national level is much better, more interactive and responsive than the process in Geneva. ${ }^{82}$ The Minister for Youth and Families acknowledged the involvement in and knowledge of the CRC of several NGOs, such as UNICEF, DCI and other partners in the Dutch Children's Rights Coalition. ${ }^{83}$ Likewise, one MP even stated that UNICEF is the watchdog of the CRC. ${ }^{84}$

Both government officials and NGO representatives pointed to the broader influence of reporting under the CRC. They argued that reporting has contributed to the increasing influence of and attention to the CRC by both the government and parliament, especially in recent years. ${ }^{85}$ The third state report, for example, provided that as a consequence of the $\mathrm{CRC}$ and the COs of the Committee, increased consideration was given to the interests of the child in matters concerning children. ${ }^{86}$ One NGO representative also noted that both the government and NGOs had come to realise, especially as a result of the dialogue and the COs 1999, that the $\mathrm{CRC}$ not only requires legislation, but that it also requires policy measures and the realisation of rights in practice. The CRC has had a substantial influence on setting the (political) agenda and has given rise to an environment in which children's rights are taken into consideration. ${ }^{87}$ Halsema (GL) noted that the idea of the child as an independent subject of law was being recognised more than in the beginning of the 1990s, partly as a result of the growing importance of the CRC in society and politics. ${ }^{88}$ The Children's Rights Coalition observed that the awareness of children's rights has increased and that the concept of children's rights has been adopted more often. ${ }^{89}$

82 Another indication of the crucial function of NGOs is the government reaction to NGOs reports, which is often more extensive than the reaction given to the COs. The reaction to the COs 2009 is, for example, slightly less than 4.5 pages, while the reaction to the report of UNICEF about children in asylum seeking centres was 16 pages. Attachment to TK 2010/11, 19637, nr. 1406.

The Minister thought that these people have the CRC on their bedside table and that they would be able to reproduce the content of the Convention if they were called during the night. Rouvoet (2009a).

84 Hamming-Bluemink (VVD) in TK 2009/10, nr. 66, 5778-5788, 5780.

85 See also UNICEF and DCI, 'Jaarbericht kinderrechten 2008', January 2008: <www. defenceforchildren.nl/images/20/339.pdf $>$, accessed 31 July 2013, 5.

UN Doc. CRC/C/NLD/3 (2008), para. 38-40.

Bruning (2010), 4.

TK 2000/01, nr. 41, 3260-3278, 3263.

Kinderrechtencollectief (2008), 7. 
The growing attention paid to CRC by both the government and parliament is also the result of the ever more extensive legal practice in relation to CRC and the readiness of courts to consider CRC and rule in favour of the child. The rising number of (successful) court cases creates an awareness that the CRC is of considerable importance and encompasses more than mere programmatic and generally formulated policy objectives, as is, for example, the view of courts and the government with respect to ICESCR. The government is, thus, more and more compelled to examine policies and legislation seriously in the light of the CRC given the possibility of courts testing these laws against the CRC and declaring them inconsistent with the CRC. The growing latitude of courts to rely on the CRC may be (partly) the result of the growing number of references to the CRC in legislative and policy documents reflective of the acknowledgement of the executive and legislature of the significance of the CRC. The increasing role of the CRC in both legal practice and the political process has, thus, a mutually reinforcing effect, as figure 10.4 also illustrates.

Figure 10.4. The growing impact of the CRC in the Netherlands (1995-2011)

The total number of parliamentary papers/judgments in which the CRC is mentioned

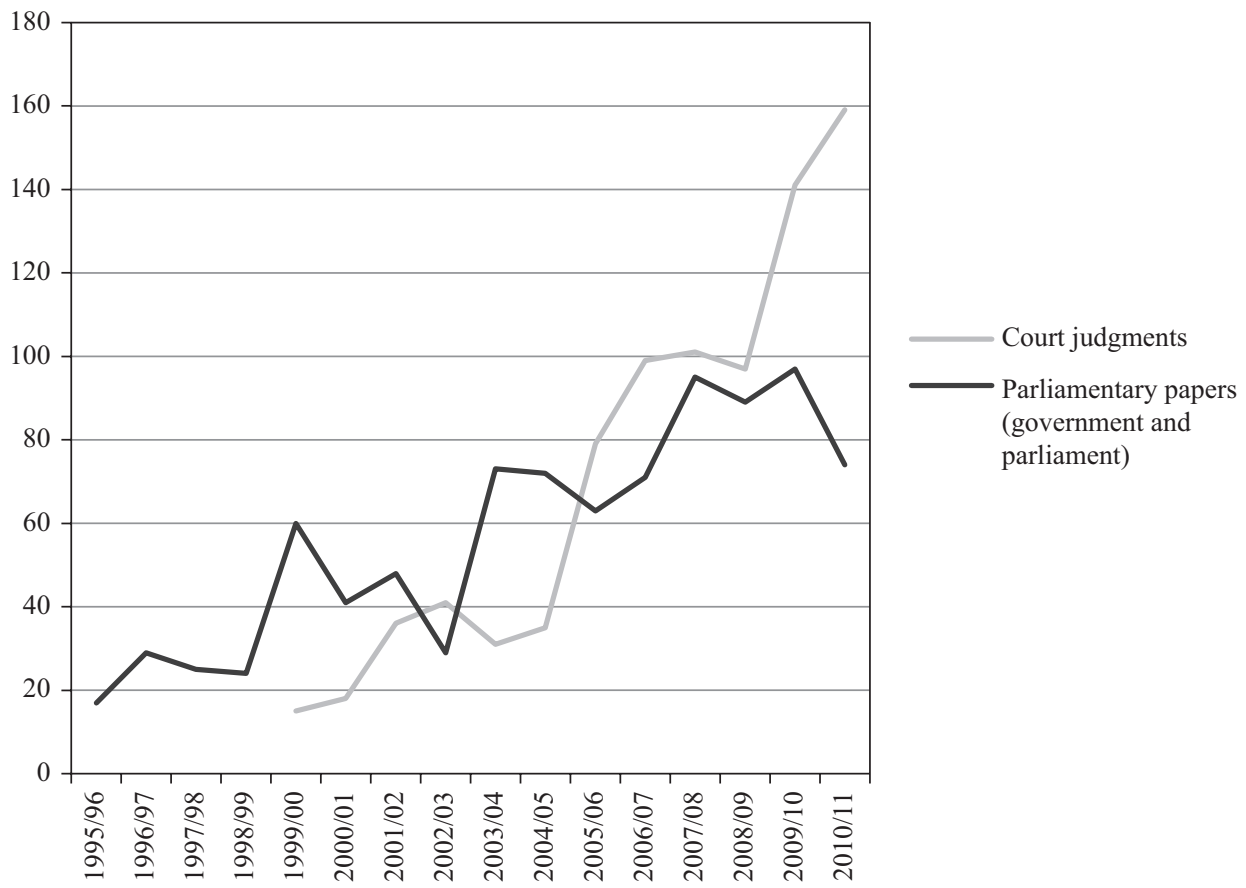




\section{Assessing THE efFectiveness of COS}

This section takes stock of the effectiveness of the COs. This appraisal is, first of all, based on the author's own research of the many documents in which the reaction of the government (and MPs) to the COs is included and reflected upon, including parliamentary papers, ${ }^{90}$ state reports ${ }^{91}$ and NGO alternative reports..$^{92}$ Secondly, another important source of information for this appraisal was provided by the examples of (partly) effective COs given by NGO representatives and governmental officials. It is noteworthy that almost all of the officials and representatives interviewed could give examples of COs that had allegedly led to a change in policy or legislation (see the scheme below). This section examines whether the measures mentioned in parliamentary papers and during interviews were indeed taken as a result of COs.

As with several of the COs of the other UN treaty bodies, some COs of the CRC Committee have also been rejected (chapter X, section 2.1). Other COs have sometimes simply coincided with measures already in place. This means that the COs as such have not been effective since these measures were not taken as a result of the COs (chapter X, section 2.2). Nevertheless, a relatively great number of COs seems to have played a noticeable role in national policy making while some COs have even been effective (chapter X, section 2.3).

Some government officials and NGO representatives observed that the influence of state reporting was primarily in the period between the submission of the state report in May 2007 and the dialogue in 2009 and not so much after the COs 2009. Some measures were allegedly taken in anticipation of the comments of the CRC Committee on the basis of the previous COs of 1999 and 2004 and the LOI of October 2008. One example was the national public campaign against child abuse. According to an NGO representative this campaign was intentionally decided upon in anticipation of the dialogue in 2009, because it was hoped that NGOs would depict the government less critically, also with the aim of not losing face before the Committee and avoid screaming headlines. ${ }^{93}$ One NGO representative also mentioned the detention of juvenile offenders together with institutionalised children (chapter X, section 2.3.2). Further support for the conclusion that the COs 2009 hardly led to new initiatives or policy or legislative changes is that the COs were simply put in a big pile of paper after the parliamentary debate about the COs 2009 , according to one government official. The COs would only be pulled out in

90 TK 2003/04, 29284, nr. 3. TK 2008/09, 31001, nr. 66. TK 2007/08, 31001 and 26150, nr. 40. TK 2008/09, 31001, nr. 66.

91 Both the second as well as the third report responded to the previous COs of 1999 and 2004.

92 The alternative report of 2003 and 2008 included a section which addressed the (implementation of the) previous COs of 1999 and 2004. Kinderrechtencollectief (2003), 47-62. Kinderrechtencollectief (2008), 69-76.

93 During the dialogue, Rouvoet mentioned that this campaign would begin in 2009. UN Doc. CRC/C/SR.1377 (2009), para. 83. 
anticipation of the fourth periodic state report. In addition, interviewees gave very few examples of effective COs 2009 during the interviews, except for the reconsideration of the withdrawals of reservations to Articles 37 and 40 CRC and the renewed consultations about foster care (chapter X, section 2.3.9). The limited effectiveness of the COs 2009 is also reflected in the consideration of the Minister for Youth and Families, Rouvoet that the COs primarily offer support for existing or intended policy and legislative measures (chapter X, section 2.2). ${ }^{94}$ The Minister argued that the COs make clear that the government is working on the right issues and that it has not forgotten anything, also because there were no surprises among the COs. He also stated that the COs 2009 underpin the continuation of the Dutch policy for children and, where necessary, a reinforcement of efforts. ${ }^{95}$

\subsection{COs that have been rejected}

As was mentioned in the introduction of this section, several COs have been rejected. Minister for Youth and Families Rouvoet admitted that not all COs are immediately and directly taken up, because the government might have very good arguments to deviate from what the CRC Committee recommends. ${ }^{96}$ The government, for example, made clear that the recommendation to establish a systematic assessment of the impact of budgetary allocations on the implementation of children's rights could not be met, given the decentralised nature of governmental administration and because no specific target groups are identified within budgetary policy. ${ }^{97}$ In its response to the CO 1999, the government made clear that it was not in favour of the recommendation of the CRC Committee to conclude bilateral agreements with states that are not parties to the multilateral conventions dealing with child adoption. ${ }^{98}$ The government also did not support the recommendation to adopt legislation with extraterritorial reach in relation to female genital mutilation. ${ }^{99}$ In addition, the government made clear that no changes had been made to the Dutch euthanasia legislation since the COs 2004 and that it was not considering revising this legislation in future either. ${ }^{100}$ The government has also rejected the COs to reconsider withdrawing the reservations to the Articles 26, 37 and $40 \mathrm{CRC}$ several times, even though it was willing to reconsider the arguments for and against withdrawal carefully on some occasions. ${ }^{101}$ State Secretary for

\footnotetext{
94 TK 2008/09, 31001, nr. 66. Rouvoet (2009a).

95 TK 2008/09, 31001, nr. 66, 2 and 5.

96 He, nevertheless, stressed that all points raised by the CRC Committee deserve careful attention. Manon Eijgenraam, 'Interview met Minister Rouvoet: "Kinderrechten zijn de bouwstenen voor mijn beleid", Tijdschrift voor de Rechten van het Kind (April 2009), 25-27, 27.

$97 \quad$ Kinderrechtencollectief (2003), 51.

98 UN Doc. CRC/C/117/Add.1 (2003), para. 84.

99 UN. Doc. CRC/C/RESP/48 (2003), 22.

100 UN Doc. CRC/C/SR.1377 (2009), para. 38.

101 The government reconsidered its reservations after the COs 2009. TK 2009/10, 31001, nr. 76, 3.
} 
Security and Justice Teeven (VVD), for example, argued against withdrawal of the reservation to Article 37(c) CRC, because he considered the possibility of trying children older than 16 on the basis of adult law desirable. ${ }^{102}$ Government officials stressed the importance of having the possibility of trying 16 and 17 years old as adults and made clear that a withdrawal is, hence, highly unlikely.

\subsection{Standing policy and legislative measures in line with the COs}

The second and largest category of COs includes the undetermined and aspirational COs. Several COs of the CRC Committee merely recommended that the government 'continue its efforts', ${ }^{103}$ 'strengthen measures', 104 'continue and further strengthen its efforts', ${ }^{105}$ and even 'further strengthen the measures already taken'.106 Other COs recommended to 'take all necessary measures' ${ }^{107}$ or 'take all appropriate measures', 108 without including concrete suggestions. These general COs have generally remained ineffective because they simply corresponded to existing policy and legislative initiatives and were, thus, interpreted as support for the continuation of these measures without requiring any follow-up efforts. Any causal relationship between the measures and the COs is, thus, absent. A joint vision of the central, provincial and municipal levels of government in relation to youth policy was, for example, presented as a result of the COs 1999, although it was already foreseen in the coalition agreement of $1998 .{ }^{109}$ Another example is the second state report of 2003 which provided that 'in response to recommendation 18 of the Committee, various campaigns have been run in recent years.' The examples given were a bilingual campaign in 1996 and 1997 and a project of 1999, which were both initiated before the COs $1999 .{ }^{110}$ Similarly, the third periodic report mentioned that 'partly' in response to the COs 2004, the Netherlands had introduced universal HIV testing of pregnant women. ${ }^{111}$ Nevertheless, in terms of effectiveness, this measure entered into force on 1 January 2004, before the dialogue with the Committee. ${ }^{12}$ As was mentioned in section 10.2, the reaction to

102 TK 2010/11, 28741 nr. 17, 5-6. Earlier, State Secretary of Justice Albayrak (PvdA) mentioned that this reservation was entered into consciously. TK 2007/08, 24587, nr. 287, 7. The VVD was fervently against withdrawal. TK 2009/10, 32123 V, nr. 90, 10-11. 
the COs 2009 mainly referred to existing policy initiatives. It was, for example, stated that the $\mathrm{CO}$ to reduce waiting lists in youth care perfectly links up with the Minister's policy priorities and initiatives which were already started before the COs 2009. ${ }^{113}$

\section{3. (Partly) effective COs}

This section examines ten of the eleven (partly) effective COs of the CRC Committee. ${ }^{114}$ As was mentioned before, a great majority of interviewees could give examples of (partly) effective COs. Table 10.2 shows that these examples often mirror the COs that were referred to by the government and/or MPs in parliamentary papers.

\section{Table 10.2. Overview of (partly) effective COs of the CRC Committee in the Netherlands}

As cited in parliamentary papers or mentioned in interviews

\begin{tabular}{|c|c|c|c|c|c|}
\hline \multirow[t]{2}{*}{ Policy issue/ CO } & \multicolumn{2}{|c|}{$\begin{array}{l}\text { Impact: number of } \\
\text { references to COs }\end{array}$} & \multicolumn{3}{|c|}{$\begin{array}{l}\text { Number of interviewees who held that } \\
\text { CO was effective }\end{array}$} \\
\hline & Government & Parliament & $\begin{array}{l}\text { Members of } \\
\text { govern- } \\
\text { ment }^{1309}\end{array}$ & $\begin{array}{l}\text { Government } \\
\text { officials }\end{array}$ & $\begin{array}{l}\text { NGO } \\
\text { representatives }\end{array}$ \\
\hline $\begin{array}{l}\text { The establishment of a } \\
\text { Children's Ombudsman }\end{array}$ & 2 & 19 & 2 & 4 & 5 \\
\hline $\begin{array}{l}\text { The separate housing of } \\
\text { juvenile offenders }\end{array}$ & 2 & 3 & 1 & 2 & 5 \\
\hline $\begin{array}{l}\text { Increased dissemination } \\
\text { and raising awareness } \\
\text { about the CRC }\end{array}$ & 1 & & 2 & 1 & 3 \\
\hline $\begin{array}{l}\text { Improvements in the } \\
\text { asylum procedure for } \\
\text { children }\end{array}$ & 3 & 12 & & 1 & 3 \\
\hline $\begin{array}{l}\text { The prohibition of corporal } \\
\text { punishment }\end{array}$ & 4 & 4 & 2 & 2 & 1 \\
\hline
\end{tabular}

113 TK 2008/09, 31001, nr. 66, 2.

114 The eleventh (partly) effective CO is the campaign against child abuse in 2009. Supra n. 93.

115 State Secretary of Health, Welfare and Sport Ross-van Dorp gave several examples of specific follow-up measures taken as a result of the COs 1999 in her introductory statement during the dialogue with the Committee in 2004. During the dialogue with the Committee in 2009, Minister for Youth and Families Rouvoet also highlighted several previous COs that had an impact on the child and youth policy in the Netherlands. He also mentioned previous recommendations which have partly contributed to changes in policy and legislation in his reaction to the COs 2009. TK 2008/09, 31001, nr. 66, 2. 
Chapter X

\begin{tabular}{|l|c|c|c|c|c|}
\hline $\begin{array}{l}\text { Improved interaction } \\
\text { between NGOs and the } \\
\text { government }\end{array}$ & & & 1 & 2 & 2 \\
\hline $\begin{array}{l}\text { Initiatives in the context of } \\
\text { human rights education }\end{array}$ & & 2 & & 1 & 1 \\
\hline $\begin{array}{l}\text { The abolishment of life } \\
\text { imprisonment for minors }\end{array}$ & 3 & 2 & 1 & 1 & \\
\hline $\begin{array}{l}\text { Renewed consultations } \\
\text { about foster care }\end{array}$ & & 1 & & & \\
\hline $\begin{array}{l}\text { The promotion of } \\
\text { breastfeeding }\end{array}$ & 3 & 1 & & & 1 \\
\hline $\begin{array}{l}\text { Examination of the with- } \\
\text { drawal of reservations to } \\
\text { the CRC } 116\end{array}$ & & & & & \\
\hline $\begin{array}{l}\text { The campaign against } \\
\text { child abuse 2009 }\end{array}$ & & & & & \\
\hline
\end{tabular}

\subsubsection{The establishment of a Children's Ombudsman}

The CRC Committee has recommended the establishment of a Children's Ombudsman three times to monitor the implementation of the CRC at the national level. ${ }^{117}$ In the beginning, the government and especially the Ministry of Justice were opposed to another Ombudsman. The government did not see the need for another ombudsman, because several of its potential activities were already being undertaken by other institutions. In addition, the government pointed to budgetary constraints. The government also held that the CRC also does not oblige appointing another Ombudsman. ${ }^{118}$ Nonetheless, the first Children's Ombudsman eventually took office on 1 April 2011.

The establishment of the Children's Ombudsman was the direct result of a legislative proposal by the MP Arib (PvdA). Arib made clear that her legislative proposal stemmed from the recommendations of the CRC Committee. ${ }^{119}$ It is noteworthy that on nineteen occasions, several other MPs than Arib also mentioned the COs as a reason for the establishment of the Children's Ombudsman. ${ }^{120}$ The

117 UN Doc. CRC/C/90 (1999), para. 12. UN Doc. CRC/C/15/Add.227 (2004), para. 8, 20 and 21. UN Doc. CRC/C/NLD/CO/3, para. 8, 16 and 17 .

118 UN Doc. CRC/C/117/Add.1 (2002), para. 31. TK 2003/04, 29200 VI, nr. 21, 85. TK 2003/04, 29200 VI, nr. 96, 5. Doek as quoted in Boerefijn and Kuijer (2005), 697.

119 The initial proposal was already submitted by Arib and Van Vliet (D66) in 2001. The proposal was, however, not considered until Arib took up the issue again in 2009. TK 2001/02, 28102, nr. 3. TK 2009/10, 31831, nr. 1-3 and nr. 9, 20. Liefaard also mentioned the Ombudsman as an example of effectiveness. Liefaard (2013), 479. See for example the statements made by Slagter-Roukema (SP), De Vries-Leggedoor (CDA) and Hamer (PvdA). EK 2009/10, nr. 32, 1373-1376, at 1373-1375. See also the references made by Langkamp (SP). TK 2009/10, nr. 79, 6765-6777, 6765. 
COs were also mentioned twice in parliamentary motions. ${ }^{121}$ As was mentioned before, the media also paid considerable attention to these COs. ${ }^{122}$ This illustrates that the COs gave the last and necessary push and offered additional support for Arib's proposal and to the arguments of other proponents. The COs were even said to have been an essential or decisive factor. One interviewee, for example, argued that the Children's Ombudsman would not have been established, had the Committee not recommended it in its COs 1999. One NGO representative also mentioned that NGOs would not have been so wound up about the issue, had the Committee not emphasised this issue so much.

Government officials and NGO representatives stressed the crucial role of the pressure and political interest of parliament for the COs to be effective. ${ }^{123}$ The role of NGOs was also identified as an important factor. As was mentioned before, Arib was advised by two NGOs representatives from DCI and UNICEF. ${ }^{124}$ In addition, the specificity of the COs was highlighted as a factor facilitating the COs' effectiveness. It was also considered important that the Minister for Youth and Families, Rouvoet (2007-2010), eventually supported the establishment of the Children's Ombudsman. ${ }^{125}$

\subsubsection{The separate housing of juvenile offenders}

The CRC Committee recommended in its COs 2004 to avoid the detention of juvenile offenders with children institutionalised for behavioural problems. ${ }^{126}$ Shortly after the dialogue with the CRC Committee in 2004, it was indeed decided to house these two categories of minors separately. ${ }^{127}$ The government argued in its 2008 state report that the decision was made 'partly in response' to the CO. ${ }^{128}$ Minister of Justice Donner also held that this change would 'at the same time' implement the CO. ${ }^{129}$ It took until 1 January 2010 before the process of separate

121 Supra n. 33.

122 The COs were mentioned in nine newspaper articles. See, for example, Tonny van der Mee, 'Wetsvoorstel van PvdA krijgt steun van een kleine kamermeerderheid. Ombudsman voor kinderen', Algemeen Dagblad, 20 November 2008, 6.

123 Note that the establishment of a Children's Ombudman was already propagated before the COs 1999 by several political parties, including PvdA and D66. 'Pleidooi raadgever kinderen', NRC Handelsblad, 15 September 1999, 5. Respectively Carla van Os and Majorie Kaandorp.

125 TK 2009/10, nr. 32, 1385-1392, 1387-1388.

126 UN Doc. CRC/C/15/Add.227 (2004), para. 59(d).

127 Minister of Justice Donner announced the decision only two weeks after the dialogue and only four days after the adoption of the COs 2004. TK 2003/04, 28741, nr. 6, at 4-5 and 7. He did not refer to the COs, neither did the Explanatory Memorandum to the Bill refer to the COs 2004, nor the CRC. The Memorandum emphasised the changed societal views and a study of the Verwey Jonker Institute as a starting point for the Bill. TK 2005/06, 30644, nr. 3.

128 UN Doc. CRC/C/NLD/3 (2008), para. 271-275. Liefaard also mentioned this issue as an example of effectiveness. Liefaard (2013), 479.

129 TK 2004/05, 28741, nr. 12, 2. 
housing was eventually completed. In this period, various domestic actors kept pressure on the government to expedite this process.

Interviewed government officials and NGO representatives stated that the CRC and the $\mathrm{CO}$ were one of the many contributory factors that played a role in (accelerating) the process of housing the two categories of minors separately. International criticism coincided with national politics and the broad wish among the government, parliament and societal actors to terminate the practice. That is to say, joint detention had already been an issue that was widely discussed since the end of the 1990s. ${ }^{130}$ There were considerable discussions and political resistance in parliament. ${ }^{131}$ In addition, the media also paid considerable attention to the issue and especially to children with behavioural problems who were allegedly unlawfully detained. ${ }^{132}$ More and more critique was expressed from various sides, including parental organisations and magistrates in juvenile courts who presented a manifesto concerning this issue. ${ }^{133}$ Children's rights NGOs were also right on the ball and lobbied a lot. The CRC and the $\mathrm{CO}$ were used as a supporting argument by many of these domestic actors. ${ }^{134}$ Another factor that facilitated the effectiveness of this CO was the separate Minister and Ministry for Youth and Families (2007-2010) who regarded the issue as important.

\subsubsection{Increased dissemination and raising awareness about the CRC}

The CRC Committee recommended in its COs 1999 that the government start disseminating information and develop training programmes for practitioners with a view to raising awareness about the CRC. ${ }^{135}$ As we have seen, the Dutch Children's Rights Coalition has been granted an annual subsidy for the

130 The issue of joint detention has been talked about since the end of the 1990s when the Youth Custodial Institutions Act was passed. TK 1997/98, 26016 B, 1 and 2. See also Bruning (2004), 1072-1073.

131 Already in March 2000, a motion proposed by Duijkers (PvdA) was adopted by parliament stating that it is undesirable that these two groups of children are housed together. The government was requested to set up an investigation as to the possibilities to address this situation. TK 1999/00, 26016, nr. 13. Since this motion, the issue was discussed several times in parliament. TK 2003/04, 28741, nr. 8. In another motion, parliament stressed the need to speed up the construction of facilities for the institutionalisation of minors with behavioural problems. The COs were not mentioned in this motion. TK 2006/07, 30800 XVI, nr. 98.

See, for example, the front page article Frederiek Weeda, 'Anouk zit onterecht in de cel', NRC Next, 2 September 2009, 1 and 4-5. The COs were mentioned in at least three articles. See, for example, Frank Kuitenbrouwer, 'Onschuldig in de jeugdgevangenis', NRC Handelsblad, 23 December 2008, 7.

Raad voor de rechtspraak, 'Kinderrechters in Nederland luiden de noodklok', 10 February 2004: $<$ www.nieuwsbank.nl/inp/2004/02/10/R243.htm>, accessed 31 July 2013. nr. 48, 2. Voordewind (CU) referred to the 'request' of the CRC Committee as well. TK 2009/10, 31839, nr. 54, 12. 
dissemination of information. ${ }^{136}$ Several publications have also been funded by the government in order to improve the implementation of the CRC by professionals. ${ }^{137}$ One example is the research project subsidised by the Ministry of Justice about the CRC in Dutch legal practice. This project indeed mentioned the COs as the direct starting point. ${ }^{138}$ Dissemination and raising awareness has been further improved by the Ministry for Youth and Families (2007-2010). ${ }^{139}$ During the children's rights summit on 20 November 2009, Minister for Youth and Families Rouvoet announced the launch of a public campaign about children's rights with messages on the radio and a renewed website. ${ }^{140}$ Three government officials confirmed that more effort was made to disseminate information about the CRC following the COs 1999 and the process of state reporting. Three other NGO representatives also gave this as an example of a $\mathrm{CO}$ that has been effective, even though they argued that the subsidies are still not sufficient to meet the obligations under Article 42 CRC. ${ }^{141}$

\subsubsection{Improvements in the asylum procedure for children}

The Committee also expressed its concern about refugee and asylum-seeking children in 1999, 2004 and 2009, particularly with respect to unaccompanied minors, the 48-hour accelerated asylum procedure and detention of children. ${ }^{142}$ These COs have received considerable attention by MPs, especially from left-wing opposition parties. It seems easy to simply conclude that these COs have remained ineffective since they were often disregarded, especially by the centre-right governments of Balkenende I-III (2002-2007). These governments have been reluctant to change the legislation on the basis and result of (non-binding) COs. ${ }^{143}$ Minister for Immigration and Integration Verdonk (VVD), for example, simply referred to the coalition agreement spelling out a restrictive immigration policy in her response to the COs $2004 .{ }^{144}$ She saw no reason whatsoever for a legislative change, because the Netherlands had already drafted its laws in conformity with international law. ${ }^{145}$ In response to the CO 2004, which recommended that it

136 Supra n. 53. The second and third report further enumerated several measures taken to increase awareness and disseminate information about the COs. UN Doc. CRC/C/117/Add.1 (2003), para. 10, 15 and 30. UN Doc. CRC/C/NLD/3 (2008), para. 14-17.

UN Doc. CRC/C/NLD/3 (2008), para. 16-17.

Ruitenberg (2003), 21.

139 TK 2007/08, nr. 36, 2887-2896, 2893.

140 Rouvoet (2009b).

141 It was also noted among the positive developments since the COs 1999 by the Director of the Dutch Children's Right Coalition. Meuwese (2003), 4. See also Bruning (2004), 1068 and 1073.

142 UN Doc. CRC/C/15/Add.114 (1999), para. 28. UN Doc. CRC/C/15/Add.227 (2004), para. 53 and 54. UN Doc. CRC/C/NLD/CO/3 (2009), para. 67 and 68.

143 Minister for Development Cooperation Van Ardenne, for example, held that the Dutch migration policy with respect to minors is in conformity with the CRC. TK 2003/04, 26150, nr. 12,8 .

144 TK 2003/04, nr. 33, 1801-1812, 1812.

145 In order to further justify this rejection, the conclusions of the Advisory Committee on Migration Affairs, that Dutch immigration laws should be deemed to be in conformity with the CRC, were referred to. TK 2003/04, 19637, nr. 847, 7 and 11. 
should be ensured that the detention of minors is used as a measure of last resort, for example, Verdonk stressed that this is 'already' limited as far as possible and only used when strictly necessary. ${ }^{146}$ She argued that the immigration laws had been drafted together with the parliament. If parliament considers amendments necessary, it should make this explicit.

Nevertheless, several improvements were eventually made with respect to the asylum policy and procedure, especially under the Balkenende IV government (2007-2010). Van Os (DCI) concluded that there had been a big shift towards less detention of minors at both the political level and in practice. ${ }^{147} \mathrm{~A}$ new policy was developed on the basis of the principles of the CRC and with the aim to reduce the probability of the detention of minors. ${ }^{148}$ This policy change was the result of a parliamentary majority in favour of a motion of De Vries (PvdA) which requested that government consider alternatives for parents with children in detention. ${ }^{149}$ The motion mentioned, as reasons for this request, the report of the Inspectorate for Sanction Administration and the opinion of the UNHCR. A subsequent motion proposed by Van Fessem (CDA) and Visser (VVD) requested that government take several measures to minimise or even terminate the detention of children. ${ }^{150}$ Another important reason for the policy change was the considerable NGO lobby. ${ }^{151}$ In particular, the NGO Coalition 'No child in a cell' (Geen kind in de cel) has had an impact. ${ }^{152}$ In addition, there was significant media coverage of the issue, with the eight-year-old Chinese boy Hui in detention as a figurehead. ${ }^{153}$

146 TK 2003/04, nr. 91, 5847-5852, 5851-5852.

147 Smits-Baauw and Van Os (2007), 2.

148 This intention was already expressed by Minister Verdonk under Balkenende II before the government fell. The letter did not refer to the CRC. TK 2005/06, 29344, nr. 57. State Secretary of Justice Albayrak announced a new and improved policy framework on 29 January 2008. She made clear that the principles of the CRC need to be expressly visible in policy. TK $2007 / 08$, 29344 and 27062, nr. 66. Minister for Immigration and Asylum Affairs Leers (Rutte I) promised to work this out and limit the detention of unaccompanied minors further.

149 TK 2005/06, 29344, nr. 54.

150 The motion did not refer to the advice or recommendations of (international) organisations. TK 2006/07, 19637, nr. 1085 .

151 The national report for the UPR provided that 'in part in response to interventions by UNICEF, NGOs for the rights of the child, and the Dutch parliament, the government has decided to limit the detention of children to a maximum of two weeks.' See the attachment to TK $2007 / 08$, 26150, nr. 54, 15-16.

On 22 June 2006, 138,212 signatures collected by nine societal organisations were presented to the MPs Van Fessem (CDA), de Vries (PvdA), Huizinga-Heringa (CU), de Wit (SP), van Gent (GL), and Dittrich (D66) to mark the end of the campaign against the detention of asylumseeking children. Maybe it was because of this that a motion was proposed by Van Fessem (CDA) and Visser (VVD) in which the government was requested to take measures to minimise or even terminate the detention of children. Supra n. 150.

153 The first article in the printed press appeared on 20 September 2006, 6 days before the motion was proposed. 'Kinderen Olympiaschool protesteren tegen uitwijzing van hun schoolgenoot; Jonge moeder werd misbruikt en hier gedropt', Het Parool, 20 September 2006, 15. Subsequently, in less than one month, 25 articles appeared in national newspapers about Hui. 
This discussion makes clear that the intended and proposed policy and legislative changes were primarily the result of factors other than the COs of the CRC Committee. This conclusion is further confirmed by the fact that the COs have rarely been mentioned explicitly by the government in its policy letters. This position, however, overlooks that relatively extensive attention was paid to the COs by the media and parliament on other occasions, such as the three motions that explicitly referred to the COs. ${ }^{154}$ This shows how complicated it is to establish the role of COs, especially because critique is usually expressed by several actors and (international) institutions over a long period of time. When the COs were explicitly referred to, this was often done together with the wider critique about the Dutch asylum policy, expressed by, among many others, UNHCR, the ECtHR, the CoE Parliamentary Assembly, the Advisory Committee on Migration Affairs, Human Rights Watch, Amnesty International, DCI, the Dutch Refugee Council, or NJCM. ${ }^{155}$ There is, thus, continuous attention and criticism of political opposition parties and extensive lobbying on the part of NGOs who sometimes organised themselves in Coalitions. ${ }^{156}$ In this political game, MPs and NGOs have made use of everything in their power to realise a policy and legislative change. ${ }^{157}$

As a consequence, it is difficult to single out the impact and role of the criticism of one organisation or actor, although judgments of national courts seems to have been of overriding importance for changes concerning asylum policy. ${ }^{158}$ The criticism of many international and domestic actors is interrelated and has a mutually reinforcing effect. The criticism and recommendations combined had kept

Search of Lexis Nexis newspaper search engine with Hui for the period 20 September 2006 and 20 October 2006 (25 results).

154 Two motions were proposed by Vos (GL) and De Vries (PvdA). TK 2003/04, 19637, nr. 833. One requested that the government draw up rules guaranteeing that detention of children is used only as measure of last resort. The other requested relief for minor asylum seekers until their return to their country of origin. TK 2003/04, 19637, nr. 833 and 834. Another motion proposed by Vos (GL) and Huizinga-Heringa (CU) asked the government to keep up the provision of relief for children. TK 2004/04, 29344, nr. 16.

155 See, for example, TK 2003/04, 19637, nr. 847, 1. TK 2006/07, 30800 VII, nr. 8, 162 and 163. TK 2007/08, 30846, nr. 2, 14-15. TK 2006/07, 29344, nr. 58, 6. TK 2004/05, nr. 72, 4408-4412, $4111-4112$.

156 The Coalitions 'Stop eviction of undocumented children in the Netherlands' (Geen kind op straat) and 'No child in a cell'.

157 Often only the criticism of other actors was relied upon and not the COs. See, for example, the reference of De Wit (SP) to the report of Human Rights Watch and the advice of the Advisory Committee on Migration Affairs. Some motions proposed by Vos (GL) dealing with detention of minors only mentioned a report of the Inspectorate for Sanction Administration or no specific institution at all. TK 2005/06, 29344, nr. 49 and 50.

158 Some interviewed officials also noted that change is primarily the result of binding judgments of courts. One example is the decision of Minister of Justice Hirsch Ballin not to terminate care for families with children in regular asylum-seeking centres whose return to their countries of origin could not be realised immediately. This decision was the result of an interim judgment of The Hague Court of Appeal. Hof Den Haag, 27 July 2010, LJN:BN2164, para. 3.6. and 3.8. TK 2010/11, nr. 1136. Krommendijk (2014). 
the issue on the agenda and further increased the pressure on the government. Government officials and NGO representatives also argued that the COs concerning the detention of minors were often only just one of the many factors that contributed to changes in asylum policy. ${ }^{159}$ It was mentioned that if all the criticism had not been there, a change would probably not have occurred.

\subsubsection{The prohibition of corporal punishment}

The CRC Committee recommended that Dutch government take legislative measures to explicitly prohibit corporal punishment in its COs 1999 and 2004. ${ }^{160}$ On 28 September 2005, a Bill was submitted and consequently adopted by parliament which banned parental violence, including corporal punishment, psychological abuse and degrading treatment. ${ }^{161}$ The relevant CO 2004 was entirely reproduced in the Explanatory Memorandum to the legislative proposal. ${ }^{162}$ Minister of Justice Donner made clear that the Bill would implement the CO 2004 as well as similar recommendations of the European Committee of Social Rights (ECSR) and the Parliamentary Assembly of the CoE. ${ }^{163}$ In order to establish the CO's effectiveness and the causal relationship between the $\mathrm{CO}$ and the legislative change, it is necessary to focus more closely on the timeline. In a letter of 25 June 2003, the Minister of Justice made clear that he was (still) not in favour of a legal prohibition. ${ }^{164}$ During the dialogue with the Committee on 15 January 2004, the Dutch delegation made clear that the government was of the opinion that the existing provisions in the Civil Code were sufficient. It did, however, mention that the issue was heavily debated at the domestic level and that the position was not definitive and could change. ${ }^{165}$ On 13 February 2004, less than a month after the dialogue, the Minister of Justice made clear that he had changed his opinion. ${ }^{166}$

What is then the actual role of the COs in the legislative change? On the one hand, it was mentioned several times by members of government that the proposed legislative change would implement the CO. ${ }^{167}$ MPs have also extensively referred to the $\mathrm{CO} 2004$ during the discussion of the Bill prohibiting corporal

159 In this context it was noted that even when COs were not explicitly mentioned, they have had a certain role in policy discussions in the background.

160 UN Doc. CRC/C/90 (1999), para. 17. UN Doc. CRC/C/15/Add.227 (2004), para. 44(d).

161 UN Doc. CRC/C/NLD/3 (2008), para. 144.

162 TK 2005/06, 30316, nr. 3, 1-2.

163 TK 2005/06, 30316, nr. 4, 3. Minister of Justice Donner also mentioned that GC 8 was an important international signal that a legal prohibition is desirable. TK 2005/06 nr. 106, 6487$6500,6496-6497$.

164 TK 2002/03, just030599.

165 UN Doc. CRC/C/SR.929 (2004), para. 72.

166 No reference was made to the COs in relation to this announcement. TK 2003/04, 28345, nr. 8, 2.

167 Minister of Youth and Families Rouvoet made clear that the proposed legislative change implemented the COs. TK 2006/07, 31015, nr. 1, 2 and TK 2003/04, 29284, nr. 3, 1. Liefaard also mentioned this legislative change as an example of effectiveness. Liefaard (2013), 479. 
punishment. ${ }^{168}$ On the other hand, the Minister of Justice, Donner, stated that the recommendations of the CRC Committee, ECSR and the Parliamentary Assembly were not the most important reason for the Bill, but above all the prevention of child abuse. ${ }^{169}$ On a later occasion, the Minister noted that the legislative change was 'partly' the result of the recommendations of several international organisations. ${ }^{170}$ Whereas one interviewee held that the ban would not have been established had the Committee not recommended it, most government officials argued that the legislative proposal was not directly the result of the CO. They pointed to the national (parliamentary) debate since the end of the 1990s. ${ }^{171}$ In their view, the CO primarily supported the introduction and eventual adoption of the Bill. One government official also pointed to the important role of an official of the Ministry of Justice who was personally dedicated to the issue and had tried to convince the Minister of Justice to introduce a legal prohibition. What was also considered important was the fact that the issue was given extensive attention both at the regional and international level at the same time. This account suggests that a combination of factors led to the legislative change and the $\mathrm{CO}$ was one of the contributory factors. The $\mathrm{CO}$ and other recommendations, thus, bolstered the arguments of the proponents, thereby creating a window of opportunity for and accelerating the introduction of the Bill.

\subsubsection{Improved interaction between NGOs and the government}

The COs 1999 encouraged the government to involve NGOs in a more systematic way throughout all the stages of the implementation of the CRC. ${ }^{172}$ Chapter $\mathrm{X}$, section 1.5 already concluded that the contacts and interaction with NGOs have become more structural and have improved since the discussion of the initial state report in 1999. ${ }^{173}$ Both NGO representatives and government officials attributed this improvement to the dialogue and COs 1999 and the process of state reporting. ${ }^{174}$

168 References by PvdA, VVD and CDA to the COs. TK 2005/06, 30316, nr. 5, 2-3 and 10. Several MPs noted that the Netherlands would finally comply with the CRC. TK 2005/06, nr. 106, 6487$6500,6489$.

169 TK 2005/06, 30316, nr. 6, 2. Likewise, the Minister did not point to the COs during the discussion of the Bill in parliament, but only mentioned the $2006 \mathrm{GC}$ of the CRC Committee as well as the recommendation of the CoE Parliamentary Assembly. TK 2005/06, nr. 106, 6487$6500,6495-6497$.

170 EK 2006/07, 30316, nr. B, 2.

171 The discussion as to whether corporal punishment should be prohibited already started in the mid-1990s and was put forward by several NGOs and academics. In 2001, MPs, for example, asked whether corporal punishment should be explicitly prohibited. TK 2001/02, 27842, nr. 5, 1. See also Bruning (2004), 1070.

172 UN Doc. CRC/C/90 (1999), para. 8.

173 See also Bruning (2004), 1068 and 1073.

174 See also Meuwese (2004), 11. 


\subsubsection{Initiatives in the context of human rights education}

The government rejected the recommendation of the CRC Committee to introduce human rights and child rights education into school curricula three times. During the dialogue with the Committee in 2009, the freedom of education of parents and schools was pointed to and it was made clear that human rights education was not envisaged to be 'a specific subject' ${ }^{175}$ In addition, the government argued that the way in which schools interpret these primary targets is the school's own responsibility. The central government 'can and will not' prescribe any programmes, because this would violate Article 23 of the Constitution. ${ }^{176}$ In addition, the government is reluctant to charge schools with ever more tasks and prefers to give schools the freedom to make their own choices. It is therefore not surprising that the Minister of Education herself wrote that the CRC has been promoted in a relatively passive way in the educational sector. ${ }^{177}$ The national action plan for human rights education, which was already promised to the UN in 2005, has still not been put in place yet. ${ }^{178}$ The government, however, does not consider it to be completely undesirable to integrate human rights in primary and secondary education. ${ }^{179}$ It simply argued that attention can already be paid to human rights in the context of various other subjects. ${ }^{180}$

Although no 'fundamental' change has yet taken place, the government has taken some additional measures in line with the COs. ${ }^{181}$ This was also noted by an NGO representative who held that despite the repeated dismissive reply to the COs by the government, some measures had been taken (partly) in response to the COs, but also similar recommendations by several $\mathrm{CoE}$ institutions, such as the European Commissioner for Human Rights. On 26 March 2007, the Ministry of the Interior, for example, organised a conference on education in human rights. In May 2007, Minister of Education Plasterk sent a letter to several educational institutions,

175 UN Doc. CRC/C/SR.1377 (2009), para. 81.

176 See the attachment to TK 2003/04, 29284 and 26150, nr. 3, 19.

177 TK 2007/08, nr. 36, 2887-2896, 2893. See the attachment to TK 2004/05, 29800 VIII, nr. 187, 15.

178 Oomen (2013a), 44.

179 The Minister for Youth and Families made clear that he considered it to be important that children are familiar with the CRC, but that it is not that obvious to lay this down in school curricula. TK 2008/09, 31001, nr. 66, 2.

180 Since 1 February 2006, schools are legally obliged to promote active citizenship and social integration. Human rights can be given attention in relation to the subjects of equal treatment and participation in the democratic constitutional state. Human rights also come up explicitly in the guidelines about active citizenship developed by the national institute for curriculum development (SLO). The government also pointed to the teaching packages about human rights developed by NGOs. TK 2007/08, nr. 36, 2887-2896, 2893. TK 2008/09, 31700, nr. 72, 2-3.

181 For a good overview of the 'politics of implementing human rights education' see Oomen (2013b). Oomen argued that very little has actually happened, even though she highlighted several developments and a wide variety of domestic actors involved in the implementation of the issue over the past few years. 
referring to the COs 2004, to request attention to be devoted to the CRC. ${ }^{182}$ The government also showed its willingness to discuss further how human rights can be stimulated without adopting new legislation. It referred to the concerns of civil society and international human rights mechanisms in this context. ${ }^{183}$ In addition, the Netherlands Institute for Curriculum Development (SLO) received the assignment to develop examples of curriculum guidelines for human rights education in the context of citizenship education 'because of international intentions and pressure'. ${ }^{184}$ The Minister of Foreign Affairs explicitly referred to the CRC Committee and the $\mathrm{CoE}$ during a roundtable meeting about human rights education in 2009. ${ }^{185}$ This short overview illustrates that the COs of the CRC Committee were one of the many factors contributing to such initiatives. The relatively extensive lobbying by several NGOs such as Amnesty International, the Platform Human Rights Education, DCI and UNICEF was crucial for these steps. ${ }^{186}$

\subsubsection{The abolition of life imprisonment for minors}

Both the COs 1999 and 2004 recommended that state party outlaw the possibility of imposing a life imprisonment on minors. ${ }^{187}$ A Bill was consequently proposed by the government that excluded the possibility of imposing such a life imprisonment. ${ }^{188}$ The Explanatory Memorandum to the legislative proposal referred to the COs and mentioned that the Bill was proposed to conform to the CRC. ${ }^{189}$ The government also explicitly referred to the COs in relation to the amendment on other occasions. ${ }^{190}$ One government official, who was closely involved in the drafting of the Bill, stated that the legislative amendment was a clear

182 Kinderrechtencollectief (2008), 61-62.

183 TK 2008/09, 31700, nr. 72, 6. For further initiatives taken after this letter, see TK 2009/10, 32123 V, nr. 90, 19-21.

184 The SLO consequently referred to (inter)national recommendations. Thijs and De Ridder, 'Burgerschaps- en mensenrechteneducatie. Leermiddelenanalyse' (SLO, Enschede, 2012), 5. Bron and Thijs (2011), 131.

$185<$ www.cmo.nl/pmre/downloads/verslag_rondetafelbijeenkomst mensenrechteneducatie_10122009.pdf $>$, accessed 31 July 2013, 7 .

186 See, for example, the study conducted by the Platform Mensenrechteneducatie, 'Gemiste Kansen? Aandacht voor Mensen- en Kinderrechten in het Nederlandse Onderwijs', 2008 : $<$ www.cmo.nl/pmre/downloads/Rapport-PMRE-Najaar2008.pdf $>$. This study was also referred to by several MPs. TK 2009/10, 32123 V, nr. 90, 4.

187 UN Doc. CRC/C/90 (1999), para. 30. UN Doc. CRC/C/15/Add.227 (2004), para. 59.

188 For the Bill amending the Criminal Code, the Code of Criminal Procedure and the Youth Care Act, see TK 2005/06, 30332.

189 TK 2005/06, 30332, nr. 3, 19. In its state report under CAT, the government also held that the Bill was submitted 'in compliance with' the COs of the CRC Committee. UN Doc. CAT/C/ NLD/5-6 (2012), para. 15 and 99.

190 Minister for Youth and Families Rouvoet held that the government had amended its legislation in accordance with the COs. UN Doc. CRC/C/SR.1376 (2010), para. 42. Minister of Justice Hirsch Ballin mentioned the CO during the discussion of the Bill in the Senate. EK 2007/08, nr. 15, 637-651, 638 . 
result of the COs, flowing from a personal initiative to take up this issue because he/ she saw the COs passing by for the umpteenth time. The official perceived political room for his/ her proposal and anticipated that both the responsible Minister and parliament would agree with it. ${ }^{191}$ The official argued that agreement would be easy to secure because it was a relative non-issue in the Netherlands. This is because life imprisonment of minors was only a theoretical possibility and had never been applied in practice. ${ }^{192}$ Implementation of these COs was, thus, primarily seen as a symbolic act without actual (political) costs and consequences. Be that as it may, the Bill would probably not have been adopted if the CRC Committee had not recommended this, exactly because it was not considered to be problematic in the Netherlands. The COs were, thus, an essential or decisive factor for this legislative change.

\subsubsection{Renewed consultations about foster care}

The CRC Committee recommended three times that increased attention should be given to alternatives to residential institutions for children deprived of a family, in particular foster family care. Several improvements have been made since the COs 1999, which were also noted by the Committee. ${ }^{193}$ In terms of effectiveness, however, the recommendation of 1999 simply coincided with measures which were already being announced and developed and did not bring about additional initiatives. ${ }^{194}$ Likewise, the COs 2004 concurred with increased attention and discussion at the national level as a result of television reports. ${ }^{195}$ An indication of the limited role of the COs in the policy measures is the fact that the COs have not played a role in parliamentary debates or in policy papers since $2000 .{ }^{196}$

Nevertheless, one government official mentioned with respect to the COs 2009 that they provided an occasion for having renewed consultations with several domestic actors. The COs created a good starting point and frame of reference for a

191 Bouchibti (PvdA) noted that this legislative change does justice to the rights of child in the CRC, while de Wit (SP) even stated that the CO had been followed up. TK 2006/07, nr. 56, 3197-3205, 3198, 3199 and 3203. Liefaard also mentioned this legislative change as an example of effectiveness. Liefaard (2013), 479-480.

TK 2005/06, 30332, nr. 3, 19.

193 The third report mentioned improvements in relation to foster care. UN Doc. CRC/C/NLD/3 (2008), para. 269 and 270. The CRC Committee also noted the successful initiatives to recruit more foster parents. UN Doc. CRC/C/NLD/CO/3 (2009), para. 41.

TK 1999/00, 26800 VI, nr. 6, 49. In addition, a Foster Care Innovation Project was initiated in 1998. Likewise, additional funds for the creation of 120 extra places were already announced before the COs 1999. TK 1998/99, 26211, nr. 5, 12-13.

195 Several parliamentary questions were asked, for example, about the shortage of foster care places as a result of the RTL news of 24 January 2004. TK 2003/04, nr. 884, 885 and 886. See also TK 2002/03, nr. 1119.

196 See, for example, the letter of the State Secretary of Health that outlined several measures. TK 2006/07, 29815, nr. 94. The initiative note on foster care, presented by CDA, also did not address the CRC, or the COs. TK 2007/08, 31279, nr. 2. 
new impulse and to come up with extra efforts. It was stressed that this did not mean that no policy measures had been in place before, since foster care has always been considered an important issue. Additional policy measures, however, were allegedly accelerated as a result of the COs 2009. In subsequent policy discussions, the COs were abandoned and did not play a substantive role.

\subsubsection{The promotion of breastfeeding}

The CRC Committee recommended that the government undertake breastfeeding promotion campaigns in its COs $1999 .{ }^{197}$ In response to a question whether the government was willing to follow up on the CO 1999 to promote breastfeeding, the Minister of Health made clear that she had agreed with the Netherlands Nutrition Centre to intensify the Centre's activities aimed at the promotion of breastfeeding. ${ }^{198}$ When asked about this CO, two government officials made clear that the COs might have partly played a role, but the $\mathrm{CO}$ was certainly not decisive. The $\mathrm{CO}$ coincided with a discussion and studies conducted at the national (and international) level. ${ }^{199}$ They argued that the $\mathrm{CO}$ was primarily used by the government as an additional argument to justify the need for promoting breastfeeding. Officials stressed that the attention of parliament for the issue was crucial to increase the activities of the Nutrition Centre. ${ }^{200}$

\section{TReaty SPECIFIC REASONS FOR THE (IN)EFFECTIVENESS OF COS}

The previous section showed that there have been a number of COs of the CRC Committee that have been effective. This raises the question as to what determines that the effectiveness of the COs is considerably higher for CRC than for the other treaty bodies. This section will locate the factors contributing to the COs' effectiveness at the national level.

\subsection{Factors related to state level}

The most important explanation for the fact that there have been more effective COs of the CRC Government than other treaty bodies is the higher level of domestic mobilisation in relation to the COs. As chapter X, section 1 showed, the COs have

\footnotetext{
197 UN Doc. CRC/C/15/Add.114 (1999), para. 20.

198 TK 1999/00, nr. 435.

199 This includes a TNO study about breastfeeding, the International Code of Marketing of Breast milk Substitutes and several resolutions of the World Health Assembly in relation to this Code. TK 1999/00, nr. 435.

200 The question of Kant (SP), in which the CO 1999 were referred to, mentioned a television programme broadcasted on 26 October 1999 as a starting point for the question. TK 1999/00, nr. 435. 1998/99, nr. 970.
} 
been used quite frequently by MPs and NGOs. Government officials also noted in interviews that changes as a result of COs were often only made possible by considerable and sustained lobbying by NGOs and extensive attention and pressure by parliament. NGOs were regarded as a crucial factor determining the impact and effectiveness of COs. The COs that have led to some changes or increased attention mirror the policy issues that NGOs have lobbied on. ${ }^{201}$

There are several other explanations for the higher (impact and) effectiveness of the COs of the CRC Committee. First of all, as was pointed out in chapter IV, section 3.2, government officials of the Directorate Youth Policy, responsible for the coordination of the process of state reporting under CRC, have been more positive and have attached more importance to the purpose of reporting. This is especially true since the discussion of the second report and particularly when there was a separate Minister and Ministry for youth affairs (2007-2010). ${ }^{202}$ This is also reflected in the fact that the reports for CRC were submitted relatively on time and with the least delays of all the other treaties. Only two of the three were submitted with a delay of less than three months. ${ }^{203}$ Reporting was approached in a more substantive way and embedded in a (more) interactive and responsive process at the national level. It is noteworthy that the coordination of the state report was undertaken by a trainee together with a senior with considerable experience with the reporting process and the CRC. Interestingly, government officials also emphasised that the process of state reporting and the resulting COs are not seen as critique alone but that they can be used as positive feedback to improve policies further, or provide a stimulus or even an impetus to act. ${ }^{204}$ This seems to hint at some sort of willingness to learn on the part of government officials. State reporting is not seen and approached as a snapshot in time, but it is a continuous and interactive dialogue between the most important domestic actors, government and NGOs (see chapter X, section 1.5). The Directorate has also used the interaction with the CRC Committee

201 Kaandorp (UNICEF) outlined several issues which were lobbied on by the Coalition at the national level and which were raised before the CRC Committee. Five of the six issues concern COs that have been effective in one way or another, including the Children's Ombudsman, the joint housing of juvenile offenders and children institutionalised for behavioural problems, the prohibition of corporal punishment, the asylum procedure and dissemination and training. Kaandorp (2004), 35.

The initial report was still coordinated by the Ministry of Foreign Affairs. Both government officials and NGO representatives noticed that this exercise had a limited set-up and was primarily approached as a defence. See also Bruning (2004), 1073.

203 The initial report was due on 6 March 1997 (submitted on 15 May 1997), the second report on 6 March 2002 (submitted on 6 March 2002) and the third on 6 March 2007 (submitted on 22 May 2007). Note that the fourth report, which was due on 6 March 2012, was only formally submitted for the Kingdom as a whole on 25 November 2013. An informal version for the European part of the Kingdom was already sent to the Dutch parliament on 4 July 2012. Liefaard (2013), 473.

This was also mentioned by several NGO representatives who argued that the initial report served primarily to argue that the existing legislative framework was in conformity with the $\mathrm{CRC}$, whereas subsequent reports were approached more as an opportunity to learn and further improve children's rights. 
in a more strategic way. It has deliberately used state reporting to create a moment of (media) attention for and raise awareness about children's rights. What is more, government officials of the Directorate Youth Policy also mentioned that reporting was done out of enlightened self-interest to legitimise the Ministry of Youth's own agenda and position. The process and the COs could be strategically used as an argument vis-à-vis parliament or the coalition partners to get support and more acceptance for certain policies or to increase budgetary resources.

A second important factor influencing the higher impact and effectiveness of state reporting under $\mathrm{CRC}$ is the salience and topical interest of the issue of children's rights, both at a political level as well as for society at large. Nobody wants to be seen as not being in favour of children's rights. Children's rights are, thus, less controversial and contested and there seems to be almost unanimous consensus that children's rights are good. At least this consensus is unanimous in general on an abstract level, because when it comes down to actual issues and the details, there is often more divergence, as chapter X, section 2 also showed (for a further discussion see chapter XI, section 2.1).

A third factor is the relative newness of the CRC. The CRC was the last of the six major UN human rights treaties, adopted on 20 November 1989. A consequence of this is that the CRC reflects the spirit of the times better than, for example, CERD and ICESCR, which were both adopted in 1966 (chapter VI, section 3.1 and chapter VII, section 3.1). Because the CRC was - at least relatively - recently ratified by the Dutch government (6 February 1995), there might simply have been more policy and legislative lacunae in its implementation, which would require improvement. Another consequence is that so far only three cycles of state reporting have been concluded. There was less tiredness and negative energy among government officials involved in state reporting under CRC than the other treaties. Several government officials mentioned that there was a tendency among other treaty bodies to constantly repeat and focus on only a couple of remaining issues in relation to which little political consensus exists to do it differently on the part of the state. This was observed less frequently in relation to the CRC Committee.

A fourth reason for the higher impact and effectiveness of CRC is the absence of another more prominent or authoritative international treaty or supervisory mechanism in the field of children's rights. The CRC is, thus, the unrivalled frame of reference for children's rights. The consequence of this is that domestic actors, and especially NGOs, are almost exclusively focused on the UN system and couch their demands in the language of children's rights under the CRC (for a further discussion see chapter XI, section 2.1).

A fifth crucial factor for the effectiveness of COs of the CRC Committee is the personal commitment of the ministers responsible for the youth policy. NGO representatives also noted that especially in the period of Rouvoet (2007-2010), COs were carefully scrutinised and implemented. ${ }^{205}$ The compilation and discussion 
of the third report took place at the time the Balkenende IV government took office and a separate Ministry for Youth and Families was created. As we have seen, the policy on youth and families was one of the spearheads of the government while the CRC was recognised as the starting point for the youth policy by Minister for Youth and Families Rouvoet. Reporting was seen as an inspiration and a boost instead of a burden by both Rouvoet and government officials from the Directorate Youth Policy. In addition to the personal interest of members of government, the role and commitment of government officials is also essential. During interviews it was noted that government officials have created awareness about CRC and have promoted the issue of children's rights. The previous section also showed that the effectiveness of some COs was sometimes the result of the dedication and efforts of individual government officials (chapter X, sections 2.3.5 and 8).

There have also been COs that have remained ineffective (chapter X, section 2.1-2). One mitigating factor for the effectiveness of COs of the CRC Committee, but also the other treaty bodies, is the idea expressed by members of government and government officials that the Netherlands is already in compliance with the CRC. ${ }^{206}$ This attitude was especially apparent during the dialogue in 1999. The government saw no need for amending legislation when ratifying the CRC on 6 February 1995, because the legislation at that time - given the pending Bills - was deemed to be in conformity with the CRC. ${ }^{207}$ This was based on the idea that the ratification process had taken a long time because all the legislation had to be tested against CRC. Not surprisingly given this attitude, the Committee noted that description prevailed over analysis and self-criticism. ${ }^{208}$ The dialogue in 1999 was, thus, primarily a defence. The delegation was shocked to realise that not everything was in order as expected, but that it was actually met with considerable criticism by the CRC Committee. As was mentioned before, this defensive attitude was less apparent during subsequent reporting cycles. Nevertheless, the government was clearly of the opinion that its asylum and immigration policy complied with CRC irrespective of the Committee's Views and, hence, spoke about 'defending' its policy during the dialogue in 2004. ${ }^{209}$ This attitude also reflects the idea among government officials and members of government that the situation of children in the Netherlands is almost perfect and that the CRC Committee primarily focuses on details. Rouvoet, for example, remarked that the dialogue with the CRC Committee had given the

206 See also Doek as quoted in Boerefijn and Kuijer (2005), 697.

207 TK 1992/93, 22855, nr. 6, 4. Ruitenberg (2003), 35 and 39-40.

208 UN Doc. CRC/C/SR.578 (1999), para. 8, 14 and 17. Hence, it was regretted that there was no real dialogue. UN Doc. CRC/C/SR.580 (1999), para. 59. Ruitenberg (2003), 48.

209 See, for example, the 'Q\&A tricky issues UN-Committee on the Rights of the Child' coincidentally included in the introductory statement of the State Secretary. In the answer to a question about the conformity of the Dutch asylum policy with the CRC, the government pointed to the judgment of the Council of State that the Dutch policy does not breach the CRC. Minister Verdonk also spoke about 'defending' this policy in the CoE. TK 2003/04, nr. 33, 18011812, 1812. 
delegation a good feeling, not despite but exactly because of the critical comments. He touched upon the fact that the Chair of the CRC Committee had mentioned that the Netherlands has a strong exemplary function with respect to children's rights and that because of that more is expected from the Netherlands. ${ }^{210}$ Country rapporteur Herczog stated that the Netherlands 'had an impressive record of achievement in the various areas related to the rights of the child' and that it was, thus, useful that the government would share it expertise and experience. ${ }^{211}$ The Minister also pointed to a study conducted by UNICEF which had concluded that the Dutch youth is the happiest of all western countries, which was also attributed to the implementation of children's right. ${ }^{212}$

Another factor that has hampered the effectiveness of (some) COs is the limited (in-depth) knowledge of government officials about the CRC. Government officials and NGO representatives noted the differences among government officials in this context. There are officials who are generally aware of children's rights and the CRC, including officials from the Directorate Youth Policy and the Ministry of Justice and Foreign Affairs, where officials tend to have a legal background or whose work has considerable international dimensions. By contrast, the knowledge of officials focused primarily on the national policy-making process is more limited and requires a basic explanation of UN and the CRC. Government officials acknowledged that a more in-depth knowledge about children's rights is limited, with some individual exceptions. This was also attributed to the large turnover. NGO representatives also noticed that there were a lot of changes among the government officials present during the half-yearly interdepartmental meetings and that usually in particular interns were present.

\subsection{The (perceived) quality of the CRC Committee}

In the light of the relatively high effectiveness of COs of the CRC Committee, the fact that government officials were as critical or sometimes even more critical about the functioning of the CRC Committee is remarkable. This finding supports the conclusion that the effectiveness of some COs should primarily be attributed to factors related to the national context instead of the compliance pull or persuasiveness of the CRC Committee and its COs.

Officials were especially critical about the sessions in 1999 and 2004. They highlighted the negative atmosphere with the CRC Committee in 1999, during which the Committee approached the delegation in an undeservedly critical, tendentious manner and without respect. One official spoke about the sneering and conceited remarks about the rotten policy in the Netherlands. Several officials specifically singled out the attack of the Indonesian Chair, allegedly based on

\footnotetext{
210 TK 2008/09, 31001, nr. 69, 7. Rouvoet (2009a).

211 UN Doc. CRC/C/SR.1377 (2009), para. 93.

212 TK 2008/09, 31001, nr. 69, 8.
} 
personal feelings owing to the colonial past. In addition, it was noted that the great majority of expert members had not read the report and did not seem interested in the discussion but primarily in other issues, such as their return flight or the submission of their expense account. It was noted that this was slightly better in $2004^{213}$ and significantly improved in 2009. One government official attributed this difference to the presence of a member of government in the Dutch delegation, as a consequence of which the Committee expert members were better prepared.

Almost all government officials showed their disappointment that the discussion in 1999 and 2004 also focused on issues that were not related to the CRC, such as homosexuality, abortion, euthanasia, same-sex marriage, and the drugs policy. One expert member, for example, called on the delegation to confirm or reject whether $2.5 \%$ of all new teacher enrolments were reserved for homosexuals. ${ }^{214}$ Not only did the discussion focus on these moral issues but also on - in the view of officials irrelevant, minor or unproblematic issues, such as the discussion for half an hour about breastfeeding in 2004. It was also noted that the discussion centred on current (political) affairs instead of the (implementation of the) CRC and the state report and extensive data into which a lot of work was put. The discussion of moral and minor issues was considered to be a pity since there were - according to interviewees - dozens of other issues to discuss that were more pressing at that moment. The dialogue in 2009 focused less on these moral issues. ${ }^{215}$

Government officials and NGO representatives lamented the absence of a substantive in-depth discussion. Former Chair of the Committee Doek also noted that the Committee does not have the time and resources to go deeply into the details and subtleties of national legislation, policies and practices. As a result, it is difficult for the Committee to enter into details in its COs and draft specific recommendations. ${ }^{216}$ Government officials also argued that several COs are unclear, broad and unspecific. ${ }^{217}$ In addition, several COs are surprisingly short and lack reasoning. The COs 2009 included, for example, the following concern and recommendation: 'The Committee is concerned about the access to health care for migrant children without a residence permit. The Committee recommends that the state party take appropriate measures to make sure that all children in its territory

213 Nonetheless, some experts already gave their conclusions before hearing the delegations' replies. Kotrane, for example, stated that legislation had not yet been brought into line with the CRC. Liwski stated that the Council of State had interpreted the Aliens Act in such as way as to deny the rights of children of illegal residents. UN Doc. CRC/C/SR.928 (2004), para. 9 and 11.

214 UN Doc. CRC/C/SR.579 (1999), para. 64. There was considerable discussion about euthanasia for children over 12 years. UN Doc. CRC/C/SR.579 (1999), para. 30, 44, 45, 49 and 56. UN Doc. CRC/C/SR.580 (1999), para. 5. UN Doc. CRC/C/SR.928 (2004), para. 9, 17, 20, 24, 46-47 and 49-52. For the questions about same-sex partnerships see UN Doc. CRC/C/SR.928 (2004), para. 17, 64 and 67. UN Doc. CRC/C/SR.929 (2004), para. 2 and 51. 
have access to basic health care.' 218 In addition, the government was recommended to 'continue to take measures to bring its legislation in line with the Convention', without specifying which legislation is not in conformity with CRC. ${ }^{219}$ One interviewee also pointed to the concern of the CRC Committee that the principle of the best interests of the child is not always integrated into legislation affecting children without specifying the relevant legal provisions. Another example given by several NGO representatives is the recommendation of the CRC Committee to review the Aliens Act of 2001 and its application. It is unclear whether the government is merely recommended to have another look at the Act or also to revise or adjust the Act. ${ }^{20}$ The government can, thus, easily claim the former. In order to avoid such a formalistic reading, the Committee could have indicated which particular areas it considered not to be in conformity with CRC.

Some government officials also argued that the CRC Committee is rather activist since this Committee focuses on one clear target group. It was also noted that because of this the discussion with the CRC Committee is usually more emotional and that the national background of expert members and hobbyhorses are more apparent than with other treaty bodies. The consequence is that legal accuracy and other conflicting interests might sometimes be neglected. ${ }^{221}$ Several government officials also noted that, especially with CRC, the backlog is chronic and considerable with a large time span between the submission of the state report and the consideration by the Committee. The state reports submitted so far by the Netherlands were considered on average two years after their submission. ${ }^{222}$ Rouvoet stated the dialogue with the Committee in January 2009 focused primarily on the period before he took office in February 2007. ${ }^{223}$ The CRC Committee has hardly monitored the implementation of COs in a structural way. Very few references to previous COs were actually made in the LOI or during the dialogue. ${ }^{224}$

218 UN Doc. CRC/C/NLD/CO/3 (2009), para. 51-52.

219 UN Doc. CRC/C/NLD/CO/3 (2009), para. 12.

220 The Director of DCI argued that the diplomatic jargon in the COs disguises the core of the matter and leaves (too) much room for interpretation. He mentioned that the COs 2004 included several recommendations that the Coalition considered less relevant, such as those about vaccination and euthanasia. Meuwese (2004), 13-14.

221 The delegation pointed to the difficulty of striking a balance between the freedom of expression and the protection of children in relation to the transmission of violence and pornography through the media and the internet. UN Doc. CRC/C/SR.57(1999), para. 20. The government also noted conflicting interests with respect to youth protection. On the one hand, the right to respect for private and family life on the basis of Article 8 ECHR and the right of parents to raise their children in the way they want. On the other hand, the rights of the child to protection and well-being under the CRC. TK 2008/09, 32015, nr. 3, 2.TK 2007/08, 31001, nr. 37, 1-2.

222 The third report was submitted on 22 May 2007 and only considered on 15 January 2009. Likewise, the second report was submitted on 6 March 2002 and discussed almost two years later on 19 January 2004. The initial report was even sent to the CRC Committee on 15 May 1997 and was only tabled for discussion on 4 and 5 October 1999. TK 2008/09, 31001, nr. 69, 8.

224 In its LOI 2003, the Committee requested information on four previous COs 'which have not yet been implemented'. During the dialogue in 2004 there were only two references to previous 


\section{Conclusion}

The COs of the CRC Committee have without doubt had the biggest impact and have been most effective of all the six treaties considered so far. The COs have played an essential and decisive role on some occasions, such as the establishment of the Children's Ombudsman and the abolition of life imprisonment. The COs also were one factor that led to the prohibition of corporal punishment and the decision to house juvenile offenders separately from minors with behavioural problems. The process of state reporting under CRC has also contributed to the increasing role and visibility of the CRC in the political and bureaucratic processes and the legal practice before courts. The effectiveness of $\mathrm{COs}$ is not the result of the persuasiveness and authority of the CRC Committee and a compliance pull from the COs. Rather, the almost exceptional position of the CRC and the COs of the CRC Committee should be attributed to the crucial role of domestic NGOs who organised themselves in the Dutch Children's Rights Coalition. Other important factors include the receptiveness of and attention paid by MPs, the positive views and commitments of government officials and some ministers towards reporting and the salience of children's rights. The role of the Ministry for Youth Affairs led by Minister Rouvoet (2007-2010) is particularly noteworthy for the impact of the $\mathrm{CRC}$ and the reporting process. Reporting, the CRC and the COs were approached more as sources of inspiration than an administrative burden in that period.

COs. UN Doc. CRC/C/SR.928 (2004), para. 19 and 53. The LOI 2008 made no reference to the COs 2004. The COs 2004 were only mentioned three times during the dialogue in 2009. UN Doc. CRC/C/SR.1376 (2010), para. 34 and 36. UN Doc. CRC/C/SR.1377 (2009), para. 5 and 44. 


\section{Chapter XI \\ COMPARISON OF THE FINDINGS \\ FOR THE NETHERLANDS}

'Not so long ago, I was called to account by a lofty person in the field of human rights in Geneva [...] who dared to say that a few things are not that well here. Well, I said, shall we first determine that what you hold against us is of an entirely different order than what happens in countries where they do not care a straw for human rights.'

[Former Minister of Foreign Affairs Rosenthal in 2011] ${ }^{1}$

'We are open for business, 24/7, to hear your complaints, to respond to them, and if we are corrected, we will accept that correction by the judges who will apply that correction.'

[Minister of Foreign Affairs Timmermans in 2013] ${ }^{2}$

The objective of this chapter is to compare the findings from the previous six treaty specific chapters on the Netherlands in terms of differences and similarities between the broader influence, impact and effectiveness of the reporting process under the six treaties and the COs of the six different treaty bodies (sections 1-3). This comparison enables the identification of the factors contributing to the (in)effectiveness of COs (sections 4 and 5).

\section{THE BROADER INFLUENCE OF THE REPORTING PROCESS}

The first research question relates to the broader influence of the reporting process. Two sub questions were distinguished, Firstly, whether reporting has been used as an opportunity for human rights review and dialogue. Secondly, whether reporting has led to a better understanding or awareness about the respective treaties and rights.

\subsection{Reporting as an opportunity for reflection?}

The compilation of the state reports has received a low priority in practice in the Netherlands and has primarily consisted of a copy and paste exercise without any immediately visible willingness to learn (chapter IV, section 3). Reporting has not

1 'Niet zo lang geleden werd ik in Genève nog aangesproken door een hoogmogend iemand op het gebied van mensenrechten, de naam zal ik niet noemen. Die bestond het te zeggen dat een paar dingen hier ook niet best zijn. Nou, zei ik, zullen we eerst vaststellen dat wat u ons verwijt van een heel andere orde is dan wat in de landen gebeurt waar ze zich niets aan de mensenrechten gelegen laten liggen?'. Michiel Zonneveld, 'Het interview', Wordt Vervolgd 6 (2011), 14-17, 16.

2 Town Hall meeting on human rights, Maastricht University, 17 April 2013: <um-web-video. maastrichtuniversity.nl>, accessed 27 May 2013. 
been used by the government as an opportunity to reflect or discuss certain policies in an integrated way from a human rights point of view. The actual compilation of reports has also not led to a dialogue. Timely reporting and participation in the process has primarily had a symbolic value and has largely been done out of foreign policy considerations (see chapter IV, section 3, chapter VI, section 3.1 and chapter VII, section 3.1). ${ }^{3}$ Oomen referred, in this context, to a 'highly ritualised exchange'. ${ }^{4}$ The reporting process under CRC has come closest to such a dialogue, since it has been embedded in a relatively continuous and interactive process and dialogue between NGOs and the government at the national level. NGOs, and more recently also the government, have deliberately used state reporting to create a moment of (media) attention for children's rights. A similar process happened for CEDAW with the national reports around the turn of the millennium.

Although the compilation of the actual report has not been used or led to a dialogue, some stimulus for human rights review, albeit still rather limited, has been provided by the dialogue with the treaty bodies and especially the COs (chapter IV, section 3.2.2). Although some government officials stated that the COs have hardly been talked about or have led to a new discussion among government officials, a greater number of government officials maintained that COs have been taken to heart even though they might not have been explicitly mentioned in policy documents and parliamentary papers. That is to say, COs have allegedly been examined and discussed, whereby it has been looked at whether they could be fitted in with the existing (and intended) policies and legislation and political priorities. ${ }^{5}$ There has, according to officials, thus, been some reflection about whether the way things are organised in the Netherlands is logical and good and whether certain practices are in conformity with human rights obligations or not. Several government officials spoke about the function of COs as a mirror in this context, whereby COs compel national policy makers at least to examine certain policies or laws once more and form an opinion about COs. As will be outlined in chapter XI, section 3, this examination does not preclude that domestic reasons eventually prevail and that COs remain unaddressed and ineffective. COs have also not had a concrete effect on the actual content or direction of policy and legislation.

Several government officials highlighted the contribution to the interdepartmental relations, because both the preparation in The Hague, as well as the session in Geneva, led to discussions, idea sharing and follow-up appointments. In a similar fashion, the process of reporting has also worked as a 'lubricant' for relations between the government and NGOs, especially in relation to CEDAW and CRC. State reporting has also had positive effects for NGOs themselves. NGO

See also Janse and Tigchelaar (2010), 314.

Oomen (2013a), 70.

According to government officials, the fact that COs are taken seriously also stems from the well-founded arguments provided in case of non-compliance in a letter to parliament and/ or in subsequent state reports. 
representatives mentioned that the compilation of a parallel report has offered NGOs the possibility to get in touch with each other, thereby also offering future ways of cooperation. Some NGOs also noted that the human rights perspective has become stronger in their work as a consequence of their involvement in the process.

\subsection{Increased understanding or awareness?}

Several government officials hinted at a broader and more subtle indirect impact of the reporting process. They mentioned that the reporting process and especially the dialogue with the treaty body has reminded officials of international obligations. The process has kept the treaty somehow on the agenda. Some government officials even argued that without the process, several UN human rights treaties would have fallen into oblivion, because attention is almost exclusively focused on the ECHR and the ECtHR. The process has, thus, promoted some awareness and knowledge about the respective rights and treaties among government officials and members of government. Especially the fact that colleagues in The Hague were on stand-by during the constructive dialogue, in case additional information and data was needed, has also ensured that the process and treaty has become wider known. It was only the reporting process under the CRC that was found to have had a noticeable impact on the awareness and understanding about children's rights and the CRC among officials and politicians (see chapter X, section 1.6).

\section{THE DOMESTIC IMPACT OF THE REPORTING PROCESS AND THE COS}

The second research question on impact relates to the way in which domestic actors have used, discussed, referred to and invoked the process of state reporting and in particular the COs at the domestic level.

\subsection{The impact of $\mathrm{COs}$}

The previous chapters showed that the reporting process and the COs have had little impact in the Netherlands, except for the COs of the CRC Committee and - to a lesser extent - the COs of the CEDAW Committee. Table 11.1 shows that the COs of the CRC Committee have been mentioned in more parliamentary papers by the government (24) than the COs of the five other treaty bodies together (on 17 occasions). The same holds true for parliament, with 56 parliamentary papers in which the COs of the CRC Committee were referred to as opposed to only 41 for the other treaty bodies. Media coverage of the reporting process under the CRC has also been significantly higher. The COs of the CEDAW Committee have also had a relatively large impact in comparison with the COs of the other four treaty bodies. the impact of the COs with respect to SGP in legal practice is especially noteworthy. 
Chapter XI

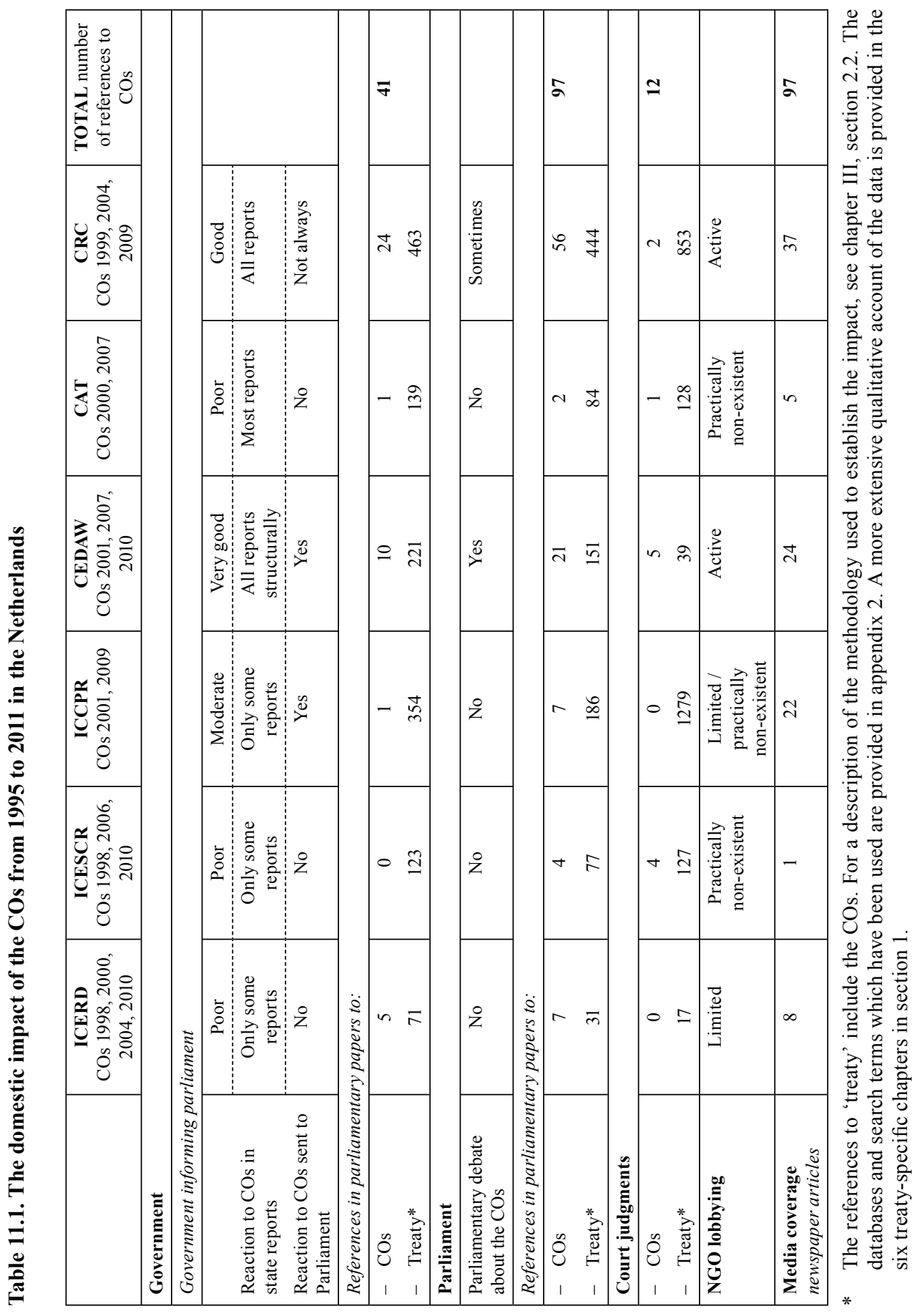


The exceptional position of the COs of the CRC Committee can especially be attributed to the relatively active and professional Dutch Children's Rights Coalition. This Coalition sees the parallel report and its involvement in the reporting process merely as a step in a larger process. The primary purpose is political lobbying at the national level. This means that its lobbying activities have primarily concentrated on follow-up at the national level and the government's implementation of the COs. The Dutch CEDAW Network, which has been smaller than the Coalition and primarily volunteer based, has operated in a similar way. Both the Coalition and the Network have, for instance, sent commentaries to the government's reaction to the COs to parliament and the responsible minister. They have also organised conferences and seminars to discuss follow-up with MPs or sometimes even with the responsible minister. In addition, they have started legal proceedings on the basis of the Conventions and/or relevant COs. In addition, meetings have taken place between the Coalition and Network and governmental officials about the implementation of the Conventions and the reporting process. With respect to the CRC, there have even been structural half-yearly meetings between the Coalition and the interdepartmental working group on children's rights. Lobbying by these NGOs on the basis of the COs has also been effective. NGOs' comments are often explicitly mentioned or reacted to by MPs during parliamentary debates. The NGO lobby has often been a major reason for MPs to allude to COs or to even put forward a legislative proposal, as was the case with the Children's Ombudsman.

One explanation for the exceptional position of the CRC is the salience of and topical interest in the issue of children's rights. It is widely acknowledged that children are in a vulnerable position. Children's rights meet a clear response in the wider society. Children's rights and the CRC have by definition a large constituency: children. This means that there is a large number of active specific interest groups and NGOs working in the field of children and children's rights. By contrast, other human rights treaties often have only one small group of interested people. Government officials also noted that MPs are more interested and committed to children's rights than, for example, gender and women's rights. As argued in chapter VIII, section 3.1, there is an idea that emancipation has already been achieved and that women are not a disadvantaged group (any more). Likewise, it has been argued that political polarisation and politics play a smaller role in the context of children's rights than racial discrimination. ${ }^{6}$ Government officials also mentioned that the government attaches considerable (political) weight to children's rights and devotes itself wholeheartedly to the cause of children's rights, contrary to, for example, ICESCR and CAT. In chapter X, section 3.1 several other explanations were given for the greater impact and effectiveness of the CRC and the COs of the CRC Committee, including the relative newness of the CRC.

6 See the statements made by Doek in Caroline de Gruyter, 'Papierstroom VN is niet bij te fietsen; Jaap Doek vertrekt bij VN-kinderrechtencomité', NRC Handelsblad, 13 March 2007, 4. 
Another reason for the 'CRC exception' is that there are no regional equivalents for the $\mathrm{CRC}$ as a result of which it is the most important point of reference for children's rights. The mobilisation of domestic actors is, thus, mainly targeted at the $\mathrm{CRC}$ and the reporting process under the CRC. ${ }^{7}$ Note that the latter also holds true for CEDAW, but to a lesser extent, because there are more (specific) EU legislation and $\mathrm{CoE}$ standards in the field of gender equality for issues like trafficking in women and violence against women. By contrast, for the other four UN human rights treaties there are European equivalents that are stronger, more specific and more authoritative. The 'substitute' of CAT and the CAT Committee is the ECPT, which pays country visits and comes with more concrete recommendations. Likewise, the equivalent of ICCPR is the ECHR and the ECtHR in Strasbourg, for ICERD there is an abundance of EU legislation and more specific $\mathrm{CoE}$ monitoring bodies, such as ECRI. The ESC and ILO Conventions outweigh ICESCR. The government, parliament, the media, NGOs, academic literature, and legal practice are primarily focused on these treaties and mechanisms. ${ }^{8}$

The latter is reflected in the marginal way the government has informed parliament about the process of state reporting and the COs of the CERD, CESCR, HRC, and CAT Committee, although this has somewhat improved since the beginning of 2000. The parliament has also discussed or referred to these COs sporadically. The media has paid serious attention to the COs of these four treaty bodies. ${ }^{9}$ At the same time, COs have been practically absent in legal practice and NGOs or other litigants have hardly made use of COs in court proceedings. ${ }^{10}$ NGOs have hardly lobbied on the basis of the COs. Most attention was paid to follow-ups to the COs of the four treaty bodies in the period 2000-2002 when three roundtable meetings were organised to discuss the COs of the CESCR, CERD and HRC. ${ }^{11}$ All these aspects are obviously interrelated. That is to say, the marginal way in which the government has informed parliament, the limited media coverage and the near absence of NGOs' lobbying has also affected the limited parliamentary scrutiny of the COs.

There are also several general observations to be made. Firstly, there is no structural interest in parliament in monitoring the implementation of human rights

7 This does not mean that children's rights NGOs have not used the European human rights mechanisms. As was mentioned in chapter X, section 1.3, DCI lodged a complaint to the ECSR in 2008. Cases have also been submitted to the ECtHR by children advocates.

8 Van Dam found that the CoE human rights monitoring mechanisms were given more attention in the media, in parliament and during political debates. Van Dam (2009), 116 and 120.

9 In her study, Van Dam also found that the COs in relation to migration, asylum and integration policy had completely escaped the notice of MPs and that the media paid little to no attention to the COs. Van Dam (2009), 116 and 120. Houtzager (2010), 221.

10 This corroborates the finding of the ILA that the reference to the treaty body output is haphazard and extremely limited in comparison to the jurisprudence of the ECtHR. International Law Association (2004), para. 168.

11 NJCM, who has been the major actor in the preparation of the parallel reports for these four treaties, has hardly lobbied on the basis of COs (since then). Reasons for this are provided in chapter $\mathrm{V}$, section 1.5 . 
treaties, the instrument of state reporting or the COs (chapter IV, section 1.2). ${ }^{12}$ MPs often use COs only incidentally in an opportunistic way as an additional argument or as support for their position with a reference to an 'authoritative' Committee. MPs usually get worked up about a certain point only when it conforms with their political objectives. This means that MPs primarily ask the government for a reaction to newspaper headlines, without reading the actual report and without knowing anything about the process. When a CO is not in the MP's direct line of interest it is simply ignored. What is more, MPs - especially those of the governing parties - have no incentive to use COs that relate to deliberate policy and legislative choices approved or taken by a parliamentary majority. COs are, thus, often invoked by MPs from the opposition, as in the case of the COs of the HRC in relation to euthanasia. Another practical difficulty is that COs often relate to a diverse range of issues which are spread over different ministerial portfolios. As a result of a compartmentalisation in parliament, because of its different subcommittees, a complete overview is lacking among MPs. In addition, it has sometimes been difficult to discuss the implementation of a certain human rights treaty or COs in an integrated way (chapter VI, section 1.1, chapter VIII, section 1.1 and chapter X, section 1.1$) \cdot{ }^{13}$

Secondly, the COs that have had the biggest impact were the most concretely formulated COs, such as the COs of the CEDAW Committee about the SGP. ${ }^{14}$ Hardly any attention has been paid to COs which were rather broad and unspecific and did not outline a specific course of action for the government. Such general and broad COs have also not offered an effective lobby tool for NGOs. The weakness and generality of the HRC's COs 2009 was, for example, the reason that NGOs were not eager to lobby on the basis of the COs, also because a lot of recommendations were already superseded. Several government officials noted that especially the COs of the HRC and the CESCR have had less impact given their wide reach. As a result, they appeal less to the imagination than the COs of, for example, the CRC and CEDAW Committees or CERD, which all have a clearer focus.

\subsection{Recent developments which might strengthen the impact of the COs}

There have been several recent developments with respect to Dutch human rights infrastructure, including the establishment of the Children's Ombudsman in April 2011 and the replacement of the Equal Treatment Commission by the Netherlands Institute for Human Rights in October 2012. In addition, the Ministry of the Interior started preparing the first national human rights action plan in the beginning of

See also Redactioneel (2002).

See also Rondetafelbijeenkomst Follow-up IVBPR, NJCM-Bulletin 27(4) (2002), 520-521, 520.

See also Van Dam (2009), 111 and 124. 
2013 'partly in response to international recommendations'.15 These developments have the potential of strengthening the impact (and effectiveness) of the COs. Note that these developments have not been systematically analysed through a (database) search of parliamentary papers, court judgments, newspaper articles, and NGO websites, since this search was finalised in August 2011 (chapter III, section 2.2).

It is not unreasonable to expect the impact of the reporting process and the COs to increase in future as a result of the developments. Firstly, the Institute for Human Rights has become more active with respect to reporting. It sees a clear and more structural role for itself with respect to reporting, also because there is a sincere belief that the reporting process can contribute to domestic reflection. ${ }^{16}$ Representatives of the Institute, including its Chairwoman, have, for example, attended all dialogues with the treaty bodies since 2010. They have provided (informal) statements to the treaty bodies, in addition to the submission of written information. ${ }^{17}$ The Institute has also made the COs more accessible by creating a website which organises the COs by theme, group or right holder and treaty body. ${ }^{18}$ It is also (planning to become) more active with respect to (monitoring) the follow-up to the COs by having consultations with government officials after the adoption of COs. Likewise, it intends to organise roundtable meetings with government officials, NGOs and other domestic stakeholders to discuss the follow-up to COs. ${ }^{19} \mathrm{COs}$ are also integrated in the Institute's annual human rights reports. ${ }^{20}$ They have also been cited in position papers and letters to the government or parliament. ${ }^{21}$

A second development which might (further) strengthen the impact of the COs of the CRC Committee is the establishment of the Children's Ombudsman. The precise involvement of the Ombudsman in the reporting process has not fully

15 Invitation via email sent by Marjolein Molenaar on 13 May 2013 for an expert consultation meeting on 28 May 2013.

16 The 2012 annual human rights report gave the UN human rights treaty bodies a rather prominent place and noted that international (reporting) procedures should be approached as a chance instead of a burden. College voor de Rechten van de Mens (2013), 11, 31 and 39-41. The importance of the reporting mechanism was also mentioned during the presentation of the Chair Koster during the conference 'Mensenrechten - vrouwenrechten in Nederland' organised by the Vereniging voor Vrouw en Recht (VVR) on 9 October 2013 in Utrecht.

17 CEDAW 2010, CERD 2010, CESCR 2010 and CAT 2013. Note that the Commission also submitted reports to CERD 1998 and 2004 and CEDAW 2006.

$18<$ www.mensenrechtenkwesties.nl>, accessed 8 October 2013.

19 A first roundtable meeting to discuss the COs CAT 2013 took place on 8 April 2014.

20 The 2012 annual human rights report mentioned the recommendations of international monitoring bodies among its sources. It explicitly mentioned the COs of the CEDAW Committee in relation to the gender specific nature of domestic violence, the COs of the CERD in relation to racial discrimination and the COs of both Committees with respect to the position of Roma. College voor de Rechten van de Mens (2013), 8, 97, 118-119 and 143.

21 See, for example, the advice with respect to the Bill amending the Medical Research (Human Subject) Act which referred to the COs of the HRC of 2001 and 2009. <www.mensenrechten.nl/ sites/default/files/advies-wet-medisch-wetenschappelijk-onderzoek-met-mensen-12sept2013. pdf $>$, accessed 8 October 2013. 
crystallised yet, because the fourth report under the CRC will probably only be considered by the CRC Committee in 2015 or even 2016. The Ombudsman is, however, closely following the reporting process at the (inter)national level and it has regular exchanges and meetings with NGOs and the government about this and many other issues. The fourth state report was, for example, discussed 'several times' with the Ombudsman. ${ }^{22}$ The Ombudsman is also planning to be directly involved by way of submitting an alternative report to the CRC Committee. In addition, it has used the - most recent - COs 2009 in its work. The COs were, for example, used as criteria to identify the themes to be included in the first yearly Children's Rights Monitor of 2012. ${ }^{23}$ The COs were also mentioned quite frequently as an additional argument for the position or recommendation of the Ombudsman. ${ }^{24}$ In addition, the Ombudsman presented - together with the State Secretary of Education, Culture and Science - a plan of action against bullying (partly) in order to implement the CO 2009 to ensure that children have access to safe schools. ${ }^{25}$

Several government officials have recently become slightly less negative about the importance of reporting, especially under CEDAW. This was mentioned by several domestic human rights stakeholders during informal meetings or discussions since mid-2011. One illustration of the positive change is the invitation of the 2010 country rapporteur of the CEDAW Committee for the Netherlands, Neubauer, with a view to improving the preparation of the next periodic report. The change was attributed to the new Minister responsible for emancipation affairs, Bussemaker (PvdA). As an MP, she has always been a promoter of women's rights and has had a relatively large interest in CEDAW (chapter VIII, section 1.2). In addition, the rather sceptic Director Emancipation was replaced in August 2011. The Constitutional and Legal Affairs Department of the Ministry of the Interior, who has coordinated the drafting of the 2013 human rights action plan, has also become increasingly involved in reporting. Government officials from this Department have been relatively less negative about reporting. It remains to be seen whether these recent developments indeed have a positive effect on the impact and effectiveness of the COs.

\section{EfFectiveness of the COs}

The third research question deals with the extent to which policy and/ or legislative measures have been taken as a result of the COs. The previous chapters showed that the majority of COs have largely remained ineffective. Generally speaking,

\footnotetext{
22 TK 2011/12, 26150, nr. 123, 1.

23 Kinderrechtenmonitor 2012, <www.dekinderombudsman.nl/ul/cms/fck-uploaded/documents/ 0515-Kinderrechtenmonitor2012web.pdf>, accessed 15 October 2013, 13.

24 The Ombudsman, for example, urged the government in line with the CRC Committee to withdraw its reservations. Ibidem, 62.

25 Attachment to TK 2012/13, 29240, nr. 52, 1.
} 
measures have not been taken as a result of COs. ${ }^{26}$ This is either because the government rejected the concerns and recommendations of the treaty body or because the COs were rather broad and unspecific and did not outline a specific course of action.

When COs were dismissed, the government frequently pointed to other international obligations, budgetary restraints or simply argued that it does not agree with the assessment of the treaty body and that, for example, sufficient safeguards are already in place. ${ }^{27}$ Likewise, other clashing human rights considerations were sometimes seen as a reason to justify non-compliance. Government officials also mentioned that some COs or the desired and recommended results are difficult to implement and realise in practice. Furthermore, some COs were not considered a real issue, since they relate to something which is considered irrelevant, minor or unproblematic in the Dutch context. These COs were, thus, not acted upon either. This is also the case for COs related to deliberate political choices of a democratically elected legislature, such as euthanasia, abortion and the lifting on the ban of brothels. These policies have been based on a clear appraisal of interests and an extensive discussion undertaken by a certain government on the basis of a coalition agreement and backed by a parliamentary majority. COs that were related to those points have simply been taken note of. Government officials spoke about 'agree to disagree' points and an irreconcilable (fundamental) difference of opinion. In sum, when there has been a clear political consensus and a majority against the measures prescribed by COs, COs have not been acted upon.

Another important category of ineffective COs are the general COs that recommend, for example, 'greater efforts', 'additional programmes', 'relevant follow-up steps', and increasing, intensifying or strengthening efforts. In the case of such undetermined and aspirational COs, it has not only been unclear what measures could and should be taken by the government, but it has also enabled the government to assert that it is complying with the COs. The government has usually made it clear that measures had (already) been taken that are in line with or address the COs sufficiently and reflect what the government is constantly doing. Even if measures seemed to have been taken in line with the COs, this was simply because COs coincided with standing policy and legislative measures.

During interviews, a great number of government officials could not give any examples of policies or legislation that were changed (partly) as a result of the COs. These officials gave several reasons for this. Firstly, some simply argued that COs

26 For a similar conclusion for the COs of different treaty bodies in relation to asylum, see Houtzager (2010), 221-222.

27 Reiding also pointed to major financial costs as a major explanation for the Dutch government to accept new international human rights standards and supervisory mechanisms. In addition, the government has tended to avoid norms that were contrary to existing laws and policies and would, hence, require their amendment. Reiding (2007), 414-416. Doek likewise noted the petit bourgeois mentality (kruideniersmentaliteit) and the economic and minimalistic approach to human rights implementation. Doek as quoted in Boerefijn and Kuijer (2005), 698. 
seldom lead to a change in policy and or legislation. The policy implications of COs were considered almost nil and it was mentioned that COs are not used in government officials' daily work. Likewise it was admitted that COs have not been used as a direction for Dutch policy and that they have not had an agenda-setting function, since they rarely contained new issues and often simply reflected a(n earlier) national discussion. COs have, thus, had a rather small role and have hardly been taken into account in policy making. Secondly, for several government officials, their involvement in the process of state reporting was too long ago to give concrete examples. Thirdly, officials from the Ministry of Foreign Affairs indicated that they and the Ministry have not followed or monitored the follow-up to the COs, which almost always deal with domestic issues. It is noteworthy that almost all of the examples that were given by government officials, but also by NGO representatives, relate to the COs of CRC and - to a lesser extent - CEDAW. For the four other treaties, government officials could give few examples of COs that have led to a change in policy. Likewise, only a few NGO representatives concerned with the four other treaties could give examples, because they were under the impression that very little is done with the COs by the government and that COs are simply put under a big pile of paper.

Only a rather limited number of COs (24) have been effective. Table 11.2 shows that the majority of effective COs were from the CRC Committee (11) with the COs of the CEDAW Committee (7) ranking second. There have been less effective COs from the other four treaty bodies together ( 6 in total).

Table 11.2. Quantitative overview of the number of COs that have been effective in the Netherlands

\begin{tabular}{|c|c|c|c|c|c|c|}
\hline CRC & CEDAW & ICERD & CAT & ICCPR & ICESCR & Total \\
\hline 11 & 7 & 4 & 1 & 1 & 0 & 24 \\
\hline
\end{tabular}

As table 11.3 shows, some COs have put an issue (higher) on the political agenda and/or have led to increased attention or discussions about the matter. Some COs (partly) led to the establishment of a committee or working group or the commissioning of an evaluation study to take a closer look at a certain issue. Other COs have led or contributed to policy measures or a legislative change. Table 11.3 also demonstrates that the COs of the CRC Committee have been more decisive and have led more often to legislative changes than the COs of the other treaty bodies (see the follow-up measures in the column on the right and in the lowest row). 


\section{Table 11.3. Overview of (partly) effective COs in the Netherlands}

This table is based on an analysis of a wide range of documents (above all, UN documents and parliamentary papers) and interviews. For a discussion of the methodology, see chapter III, section 2.3. The previous chapters discussed the effectiveness of specific COs more in-depth in section 2.

\begin{tabular}{|c|c|c|c|}
\hline & $\begin{array}{l}\text { COs used as support by } \\
\text { the government for } \\
\text { already intended } \\
\text { initiatives }\end{array}$ & $\begin{array}{l}\text { COs as a contributory } \\
\text { cause among many other } \\
\text { factors }\end{array}$ & $\begin{array}{l}\text { COs as an essential } \\
\text { or decisive factor }\end{array}$ \\
\hline $\begin{array}{l}\text { Agenda } \\
\text { setting } \\
\text { function }\end{array}$ & & $\begin{array}{l}- \text { Central storage of } \\
\text { fingerprints (ICCPR) } \\
- \text { School segregation } \\
\text { (CERD) } \\
- \text { Composition police } \\
\text { (CERD) }\end{array}$ & $\begin{array}{r}\text { - Renewed consultations } \\
\text { about foster care (CRC) }\end{array}$ \\
\hline $\begin{array}{l}\text { Studies or } \\
\text { evaluations }\end{array}$ & & $\begin{array}{l}\text { - Evaluation gender } \\
\text { dimension asylum policy } \\
\text { (CEDAW) }\end{array}$ & $\begin{array}{c}\text { - Working group Law on } \\
\text { Names (CEDAW) }\end{array}$ \\
\hline $\begin{array}{l}\text { Policy } \\
\text { measures or } \\
\text { initiatives }\end{array}$ & $\begin{array}{l}\text { - Promotion of } \\
\text { breastfeeding (CRC) } \\
\text { - Uninterrupted long } \\
\text { school day (CEDAW) } \\
\text { - Financing of the } \\
\text { reporting centre for } \\
\text { discrimination on the } \\
\text { internet (CERD) } \\
\text { - Continuation of the } \\
\text { national discrimination } \\
\text { centre within the } \\
\text { prosecution service } \\
\text { (CERD) }\end{array}$ & $\begin{array}{l}\text { - Initiatives in the context } \\
\text { of human rights } \\
\text { education (CRC) } \\
\text { - Exit programmes for } \\
\text { prostitutes (CEDAW) } \\
\text { - More attention for the } \\
\text { gender aspects of } \\
\text { domestic violence } \\
\text { (CEDAW) }\end{array}$ & 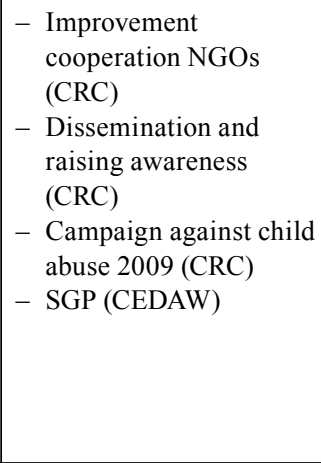 \\
\hline $\begin{array}{l}\text { Legislative } \\
\text { changes }\end{array}$ & & $\begin{array}{l}\text { - The prohibition of } \\
\text { corporal punishment } \\
\text { (CRC) } \\
\text { - Housing juvenile } \\
\text { offenders separately } \\
\text { (CRC) } \\
\text { - Improvements to the } \\
\text { asylum procedure for } \\
\text { minors (CRC) } \\
\text { - Integration of medical } \\
\text { reports in asylum } \\
\text { procedure (CAT) } \\
\text { - Reinstatement of } \\
\text { maternity benefits for } \\
\text { self-employed women } \\
\text { (CEDAW) }\end{array}$ & $\begin{array}{l}\text { - The abolishment of life } \\
\text { imprisonment for } \\
\text { minors (CRC) } \\
- \text { The establishment of a } \\
\text { Children's Ombudsman } \\
\text { (CRC) }\end{array}$ \\
\hline
\end{tabular}


The role or weight of the COs in these effective follow-up measures and initiatives varies. The COs have never been sufficient on their own. That is to say, there were very few measures, if any, which have been solely taken as a result of the COs. Rather, COs have often been a contributory cause or a factor among many other international and national factors that have jointly led to a certain policy or legislative change (column in the middle in table 11.3). There have been some COs which were an essential or even decisive factor in certain follow-up measures (right column in table 11.3). COs have primarily supported, legitimised or strengthened the arguments of domestic actors in debates. In such a context, COs have created a political momentum for change and, hence, have acted as a catalyst. In this way, they have pushed or accelerated the adoption of policy or legislative measures.

Some government officials of the Directorate Emancipation and Youth Policy also argued that COs have been used strategically by these coordinating directorates in relation to other ministries or parliament to start or to reinvigorate a discussion or to raise (additional) money. COs have, thus, offered a helping hand in discussions with opponents to a certain plan as an additional argument or to put pressure on other ministries to move in the direction of the recommendation. ${ }^{28} \mathrm{COs}$ have sometimes been used by the government to justify or give support to - an already intended - policy direction, especially when the policy was still in the developmental phase (left column in table 11.3). COs have, thus, been used to confirm the government's views that it needs to continue with a certain policy initiative when the COs highlighted that the result is not yet fully realised.

\section{FaCtors OBSTRUCTING THE EFFeCTIVENESS OF COS}

A sub question to the second research question relates to the factors that contribute to the (in) effectiveness of COs. There are several factors that have obstructed the effectiveness of COs. Firstly, the non-binding nature of COs is one such factor. The government has frequently used this argument to dismiss the COs (see especially chapter VII, section 3.1). Government officials characterised COs as 'mere remarks', 'opinions' or a noncommittal 'general critique' of committees at a distance. Some officials qualified the COs as a 'wish list' and stated that what the government is already doing is not necessarily in violation of the COs, because often different interpretations and policy choices are also legally viable under the respective treaty. A manual compiled by the Legislation Department of the Ministry of Justice about reporting to the UN human rights treaty bodies for government officials of the Ministry of Justice also stated that the persistence of a difference of opinion is not

28 Government officials mentioned the difference of opinion between the Directorate Emancipation and the Ministry of Justice with respect to the gender neutral formulation of the policy on domestic violence. Likewise, officials from the Directorate Youth Policy were in favour of withdrawing at least one reservation to $\mathrm{CRC}$. 
insurmountable. ${ }^{29}$ The government also stated on several occasions that the COs do not have to be adopted indiscriminately. Government officials argued that COs could easily be disregarded given their legally non-binding character and the fact that they are not legally enforceable. They argued that there is "no imminent danger', such as sanctions, when COs are not complied with, both at the international as well as the national level.

Secondly, another factor hampering the effectiveness of the COs is the idea among government members and officials that the Netherlands is already in compliance with the respective treaties. The process of reporting is primarily seen as relevant for others, as was discussed in relation to the ICCPR, CEDAW and CAT (7.3.1, 8.3.1 and 9.3.1). Several government officials argued that the Netherlands is not only seen as but also is one of the best students in class. There is a prevalent view that the government is doing enough and that policies and legislation, although they are perhaps not in line with COs, are nevertheless still seen as being in conformity with the respective treaties. The idea is that all obligations under the treaties are complied with, because human rights treaties are only ratified when policy and legislation is (almost) completely in conformity with the respective treaty. Some officials spoke about a self-satisfied attitude and noted that it is typical of Dutch policy makers that they consider everything well-organised in the Netherlands. They argued that in the Netherlands everything is thought through carefully and discussed extensively by numerous domestic institutions, including parliament. Dutch policy and legislation is often down to the smallest detail. By contrast, treaty bodies only consider a multitude of different issues within a couple of hours and only in a superficial way without knowing all ins and outs. This view explains why COs are sometimes seen by officials as 'vague moaning' or qualified as lingering too much over details.

Thirdly, another factor that has worked against the effectiveness of COs is the status, character and salience of the rights and issues addressed by the treaty and treaty bodies. The provisions of ICESCR are, for example, not seen as true human rights and as outdated reflections of previous times by some government members and officials (6.3.1). The latter view was also expressed by some officials about ICERD and CEDAW. Related to this latter point is the decreasing political and public salience of racial discrimination and the empowerment of ethnic minorities and the emancipation of women in the Netherlands. This has not only affected the impact of the COs of the CERD and the CEDAW Committee, but has also contributed to the ineffectiveness of some of their COs. The latter was also attributed to a divergence of views among these committees and the government about the form of equality to be protected and, for example, the need to take special preferential measures for certain groups (5.2.1 and 8.2.1). with the ECtHR and the ECJ, which both issue binding judgments. Officials made clear that the legally binding character of the judgments of the ECtHR clearly affects the authority of the Court and the impact of its judgments positively. 
Fourthly, the almost exclusive focus on the ECHR and EU legislation has also affected the effectiveness of COs negatively, as was also highlighted in chapter XI, section 2.1. There is an idea in government circles that if one complies with these international obligations, then one also automatically complies with the standards in UN human rights treaties. This idea also affects the effectiveness of COs. Noncompliance with COs of the HRC, CERD and the CEDAW Committee has sometimes been justified on the basis of the ECHR and especially the jurisprudence of the ECtHR.

Fifthly, one of the biggest important obstacles for the effectiveness of COs are the negative views and perceptions of government officials as to the quality, authority and persuasiveness of the treaty bodies. As was discussed in the theoretical chapter, a potential explanation for the effectiveness of international norms would be the presence of a persuasive compliance pull (chapter II, section 2.2). This pull has been absent for all the six treaty bodies and their COs (see chapter IV, section 4 and section 3.2 of the chapters V-X). Several issues were mentioned as especially prejudicial for the authority of the treaty bodies. This is when treaty bodies convey the impression that they have already made up their mind by having their conclusion and the COs already completed before the actual dialogue. Such a biased or prejudiced attitude, consisting of leading questions and not listening to the explanation of the government was seen as harmful. Government officials also argued that the negative and unwarrantedly critical approach of the treaty bodies is detrimental for the confidence in and authority of the treaty bodies. Furthermore, when the dialogue is based on emotions and preconceptions of Committee members, instead of facts and arguments, this prevents the discussion from being conducted in a professional way. It was noted that with such hobbyhorses and personal obsessions it often does not matter what arguments or facts you give as a delegation. Officials also noted that manifestly unfounded COs which are based on a misunderstanding of the facts are detrimental to the authority of treaty bodies.

Government officials were almost equally critical about the functioning of the several UN human rights treaty bodies. They were not significantly more positive about the functioning, quality or authority of the CRC or CEDAW Committee and their COs. The greater effectiveness of these COs can, thus, not be attributed to the existence of a compliance pull and the fact that these two committees are seen as more authoritative and persuasive than other committees. Rather, the effectiveness of these COs should primarily be explained by domestic factors, most notably the mobilisation of domestic actors.

\section{FACTORS CONTRIBUting to THE EFFECTIVENESS OF COS}

The higher effectiveness of the COs of the CRC and CEDAW Committee is largely to be attributed to the lobby and advocacy of domestic actors. As sketched out in the beginning of this chapter, the COs of the CRC Committee and - to a lesser extent - the CEDAW Committee have had the biggest impact and have been used 
most frequently in the lobbying and work of domestic actors (table 11.1). By contrast, the ineffectiveness of the majority of COs, especially those of the other four treaty bodies, has been facilitated by the near absence of societal and political pressure. The result of this is that the government could easily sit back and do nothing. The limited attention paid by parliament to the process of reporting and the COs has influenced the low priority that government officials attach to the process of state reporting and follow-up to the COs. Government officials argued that it is primarily up to national politicians and especially parliament to press for change. They reasoned that if parliament does not get upset about it, and raise its voice, then very little will happen on the basis of the COs.

Subsequent measures and initiatives as a result of the COs have often been the result of considerable and sustained lobbying by NGOs and extensive attention and pressure by parliament, as was also acknowledged by government officials. Many of the COs that have eventually triggered a change were initially disregarded by the government. International supervision is, thus, not sufficient in itself to prompt a change. Usually a long and slow political process needs to be followed to convince the government of the necessity of change. This means that domestic actors, such as NGOs, parliament and the media, need to (be willing to) spend attention on and constantly come back to the issue over a long period of time.

NGOs, most notably the Dutch Children's Rights Coalition and, to a lesser extent, the Dutch CEDAW Network, have especially been a crucial factor contributing to the impact and effectiveness of COs. ${ }^{30}$ NGOs have employed different tactics, often at the same time. They have, for example, lobbied the government directly to act upon the COs. More indirect strategies have often been necessary. NGOs have initiated court proceedings (as with the SGP case) or they have tried to capture the attention of the media (as with the detention of asylum seeking minors). NGOs have also 'used' parliament to exercise (additional) pressure on the government or - more exceptionally - to introduce a parliamentary Bill. As was sketched earlier in chapter XI, section 2.1, MPs depend upon NGOs to bring the COs into the spotlight since they are often unaware of the reporting process. The NGO lobby is often a major reason for MPs to allude to COs as an additional argument. There is, thus, a mutual dependency whereby both actors can reinforce their demands and, hence, the likelihood of success. The most prominent example of this cooperation is the legislative proposal for a Children's Ombudsman which was drafted by an MP with considerable advice from NGOs.

A second crucial factor that affects the COs' effectiveness is the international outlook of a member of government and the extent to which they are human rights orientated and whether they take notice of (international) critique. ${ }^{31}$ The individual

30 This mirrors the conclusion of Baehr et al. that pressures of NGOs were sometimes important in influencing MPs, the media and (eventually) the Dutch government's foreign human rights policy. Baehr et al. (2002), 228-230. See also Oomen (2013a), 54-55.

31 The willingness of government officials to head the delegation is also indicative of this international outlook. Both Minister of Justice Hirsch Ballin (CDA) and State Secretary 
views of ministers and state secretaries are also to a large extent dependent upon the government in power. As was discussed in chapter IV, section 2.1, the purple coalition of Kok I and II and the Balkenende IV government have, for example, had a more international outlook and more international (human rights) law friendly approach than other governments. This has also resulted in a greater effectiveness of COs. There was, for example, an increased focus on the issue of racial discrimination during Kok II (1998-2002). As a result, several COs of the CERD were one element contributing to heightened attention for issues such as school segregation and the composition of the police. In addition, almost a majority of the effective COs are from the Balkenende IV period (2007-2010). Examples are the integration of medical reports in the asylum procedure or greater attention to the gender aspects of domestic violence (see table 11.3).

Related to this are, thirdly, the role and personal interests of government officials and their views as to the usefulness of reporting. ${ }^{32}$ Sometimes follow-up measures to COs appear to have been instigated by individual government officials and the result of their dedication and efforts. Examples include the initiative of a government official to request an evaluation of the gender dimension of the asylum policy (partly) as a consequence of a CO of the CEDAW Committee and the abolition of life imprisonment for minors and the prohibition of corporal punishment following COs of the CRC Committee.

The last two personal factors were primarily present for the CRC (see 4.3 and 10.3.2). Former Minister for Youth and Families Rouvoet (2007-2010) based his policy (agenda) explicitly on CRC. He was also personally involved in the process of state reporting and approached reporting as an inspiration and a boost instead of only a burden. NGO representatives also noted that in the period of Rouvoet, COs were carefully scrutinised and implemented. In addition, government officials of the Directorate Youth Policy also promoted the issue of youth policy and created awareness about the CRC, especially when there was a separate Ministry for Youth and Families (2007-2010).

Albayrak (PvdA) of the Balkenende IV government headed the Dutch delegation during the dialogue with the HRC in 2009 and UPR in 2008.

32 See also Baehr et al. (2002), 230. Reiding (2007), 37-38. Oomen (2013a), 54 and 70. 


\section{Part C}

New Zealand And Finland 


\section{Chapter XII New Zealand}

'Our record on human rights is among the best in the world.'

[Former Minister of Justice Power 2008] ${ }^{1}$

'This is a Committee on the outer edges of the UN system. It is not a court. It did not follow any rigorous process as we would understand one. In fact, the process itself would not withstand scrutiny at all [...] Well, I think I have a somewhat better understanding of the UN system than they do.'

[Former Prime Minister Clark in 2005 about the CERD] ${ }^{2}$

This chapter examines the impact and effectiveness of the process of state reporting under UN human rights treaties in New Zealand. ${ }^{3}$ The previous chapters showed that the process has had a limited impact and has been largely ineffective in the Netherlands, except for the CRC and to a somewhat lesser extent CEDAW. One important explanation for the ineffectiveness of the majority of COs in the Netherlands has been the dominance and pervasiveness of a strong regional human rights mechanism. Domestic mobilisation, litigation and policy and legislative processes in the Netherlands have been predominantly orientated towards the ECHR, ECtHR and other CoE monitoring bodies, as a result of which COs are often overlooked. One objective of this chapter is to examine whether UN human rights treaties and COs have had more impact and have been more effective and in a country that is not a member of a regional human rights organisation and only part of the UN human rights system (chapter III, section 1.3).

This chapter is based on a document analysis of primary sources, including parliamentary papers, state reports and alternative NGO reports, as well as academic literature (see chapter III, section 2 for an outline of the methodology). In addition, 62 interviews were held with domestic stakeholders who have been (in) directly involved in the reporting process in New Zealand in June and July 2012. This includes government officials from different ministries ${ }^{4}$ and NGO

1 Simon Power 'Speech to Bill of Rights Act Symposium', 11 November 2010: <www.beehive. govt.nz/speech/speech-bill-rights-act-symposium>, accessed 31 July 2013.

2 Clark as quoted in Charters and Erueti (2005), 258 and 286.

3 The impact and effectiveness of the COs of the CEDAW Committee is addressed more in depth in Krommendijk (2013b). For a further reflection on the role of the New Zealand Bill of Rights Act of 1990 (NZBORA) and judicial review in New Zealand, see Krommendijk (2012a).

4 From the Ministry of Social Development, Justice, Women's Affairs, Youth Affairs, Foreign Affairs and Trade, Health, the Department of Labour, the Department of Corrections and the Office of Ethnic Affairs. 
representatives ${ }^{5}$ as well as representatives from the New Zealand Commission of Human Rights and the Children's Commissioner, academics, MPs and judges (see appendix 1 for an overview).

\section{BaCkground: The NeW ZeAland Legal AND POlitical SYSTEM}

New Zealand (or Aotearoa in Maori) is situated in the south western Pacific Ocean and consists of two islands. It has a population of around 4.5 million. Almost onefifth of the population is comprised of the indigenous Maori population. ${ }^{6}$ New Zealand is a former colony and dominion of the British Empire. Until the establishment of the Supreme Court in 2004, the highest court was still the Privy Council in London. Traditionally, New Zealand has not had a codified written constitution. ${ }^{7}$ New Zealand is a parliamentary democracy with a small unicameral legislature with 120 members, the House of Representatives.

New Zealand ratified the six main UN human rights treaties more or less around the same time as the Netherlands and Finland. ${ }^{8}$ It adopts a dualist approach to international treaties. ${ }^{9}$ This means that treaties are not recognised and cannot be given direct effect by courts in the domestic legal order, unless they are directly incorporated into domestic legislation. The $\mathrm{UN}$ human rights treaties have not been incorporated into New Zealand law. In 1990, a Bill of Rights Act (NZBORA) was adopted. This Act includes civil and political rights which mirror the ICCPR. Although the Act has as its objective 'to affirm New Zealand's commitment to the' ICCPR, the ICCPR is not directly incorporated and can therefore not be given effect by courts. NZBORA prohibits courts from declaring legislative enactments that are inconsistent with NZBORA (and international human rights treaties) invalid. ${ }^{10}$ NZBORA has therefore been characterised as a 'parliamentary Bill of Rights'

5 From the National Council of Women, Human Rights Foundation, Maori Women's Welfare League, Action for Children and Youth in Aotearoa Incorporated (ACYA), Amnesty International, Aotearoa Indigenous Rights Trust, Peace Movement Aotearoa, UNICEF, Save the Children and End Physical Punishment of Children (EPOCH).

6 Their relationship with 'the Crown', the New Zealand state, is governed by the 1840 Treaty of Waitangi, which is considered to be the founding document of New Zealand.

7 Nonetheless, the main constitutional elements can be found in the Treaty of Waitangi and parliamentary statutes like the Constitution Act 1986 and the New Zealand Bill of Rights Act 1990. Hopkins (2011), 429.

8 ICERD (signed on 25 October 1966 and ratified on 22 November 1972), ICESCR (signed on 12 November 1968 and ratified on 28 December 1978), ICCPR (signed on 12 November 1968 and ratified on 28 December 1978), CEDAW (signed on 17 July 1980 and ratified on 10 January 1985), CAT (signed on 14 January 1986 and ratified on 10 December 1989) and CRC (signed on 1 October 1990 and ratified on 6 April 1993).

9 Note that New Zealand adopts a monist approach when it comes to customary international law.

10 Section 4 NZBORA: 'No court shall, in relation to any enactment [...] (a) hold any provision of the enactment to be impliedly repealed or revoked, or to be in any way invalid or ineffective; or (b) decline to apply any provision of the enactment - by reason only that the provision is inconsistent with any provision of this Bill of Rights.' Courts have generally been averse to 
which is realised through political rights review in parliament instead of judicial review. ${ }^{11}$

The latter also reflect that New Zealand is strongly committed to the notion of parliamentary supremacy and the idea that 'parliament can do anything.' ${ }^{2}$ In practice, the principle of parliamentary sovereignty has resulted in an 'executive paradise' given the 'nearly complete fusion' of the legislative and executive branch. ${ }^{13}$ One contributory factor for this is the traditionally rather large oneparty government ('Cabinet') with around 25 or 30 ministers, who remain MPs during their term in office. ${ }^{14}$ This executive dominance has recently been alleviated to a certain extent as a result of the replacement of the first-past-the-vote election system by a more proportional voting system in 1996. As a consequence, New Zealand transformed from a two-party system with either the social democrats (Labour) or the centre-right liberal conservatives (National) in power into a multiparty system. The latter also necessitated the formation of coalition and/or minority governments. ${ }^{15}$

As in the Netherlands and Finland, there is a true commitment to multilateralism and an internationalising impulse to be part of the world in New Zealand. ${ }^{16}$ There is real pride in New Zealand being part of and contributing to advances in the international legal system, such as the ICJ judgments in relation to nuclear weapons. ${ }^{17}$ Politicians - especially those of Labour - emphasise their internationalist tradition and like to see themselves as a good international citizens acting in accordance with international law. There is also a strong belief in New Zealand that the country is playing a leading role in the world when it comes to human rights. ${ }^{18}$ The government underlined, for example, that 'New Zealand was one of a small number of states which presented concrete proposals to include

challenging the intention of parliament and have granted them considerable deference. Geiringer (2008), 70-71. Geiringer (2009), 646. Geddis (2009), 481. Kelly (2011), 304.

11 Geddis and Fenton (2008), 735. Kelly (2011), 308. P. Butler (2006), 31.

12 Ridley (1988) as quoted in Hopkins (2011), 429.

13 Waldron (2005), 444. M. Palmer (2006), 602. Hopkins (2011), 429-430.

14 Waldron (2005), 444.

15 Before 1996, National held office since 1990 and Labour from 1984 until 1990. From 1996 until 1999 the first National/ New Zealand First coalition government was in power. From 1999 until 2008, there were Labour led governments with Helen Clark as Prime Minister. From 1999 until 2002, there was a minority coalition government with the left-leaning Alliance which was supported by the Green Party through so-called confidence and supply agreements. From 2002 until 2008, Labour formed a government with the Progressives with the support of the centrist party United Future. Since 2008, there has been a National government supported by the Maori Parties, United Future and ACT.

16 Dunworth (2005), 141-142. Goff (2004).

17 In 1973 and 1995, New Zealand and Australia, for example, brought proceedings against France.

18 Hopkins (2011), 430. During the dialogue with the CESCR in 2012 the delegation held: 'New Zealand is proud of its record as a contributor, nationally and internationally, to human rights': $<$ www2.ohchr.org/english/bodies/cescr/docs/statements/StatementNewZealand48.doc $>$, accessed 31 July 2013, 4 and 9. 
'respect for' and 'the protection of' human rights as a principle of the United Nations during the drafting of the UN Charter in 1945. ${ }^{19}$

New Zealand has had a Human Rights Commission since 1977 and a Children's Commissioner since 1989. It is especially interesting to examine the role of these institutions in relation to the process of reporting, because such institutions were only recently established in the Netherlands (2012 and 2011 respectively) and Finland (2011 and 2005).

\section{The BROADER INFLUENCE OF THE REPORTING PROCESS}

The first sub question under the first research question on the broader influence of the process of reporting asks whether reporting has been used as an opportunity for human rights review and dialogue. In order to answer this question an overview will be provided of the (bureaucratic) organisation of the reporting process in New Zealand (chapter XII, section 2.1). This is followed by an overview of the attitudes of government officials towards the importance of reporting (chapter XII, section 2.2). Chapter XII, section 2.3 consequently examines the second sub-question which deals with the extent to which reporting has led to an increased understanding or awareness about the respective rights and treaties.

\subsection{The organisation of the process of state reporting}

Until 2006, the organisation of the process of reporting was roughly similar to that in the Netherlands. The Ministry of Foreign Affairs and Trade has been responsible for the 'overall coordination' of the preparation of state reports. ${ }^{20}$ Until 2006, it also prepared the reports for ICCPR, ICESCR, CAT and CERD, while the Ministry of Women's Affairs and the Ministry of Youth Affairs ${ }^{21}$ were responsible for the reports for CEDAW and CRC respectively. The Ministry of Foreign Affairs sometimes contracted external independent advisors to write the report. ${ }^{22}$ Since 2006, the Bill of Rights/ Human Rights Team of the Ministry of Justice has become more directly involved in the process and has taken over the responsibility of the

19 Clark (2008), 5-6. New Zealand also played 'an important role' in the drafting and adoption of the UDHR and subsequent negotiations for ICCPR and ICESCR. A. Butler and P. Butler (2005), para. 3.6.2 and 3.6.23.

20 UN Doc. HRI/CORE/NZL/2010 (2010), para. 237.

21 From October 2003, this Ministry has been a division of the Ministry of Social Development and was renamed as Ministry of Youth Development in order to ensure better coordination between various government departments. This chapter will refer to the Ministry of Youth Affairs in order to avoid confusion. Responsibility for the compilation of the CRC report shifted to the Ministry of Social Development during the writing of the combined third and fourth report in 2008. UN Doc. HRI/CORE/NZL/2010 (2010), para. 237.

22 The 2001 reports under ICCPR and ICESCR were written by Petra Butler, Victoria University Wellington. 
Ministry of Foreign Affairs for preparing the reports for ICCPR, ICESCR, CAT and CERD. ${ }^{23}$

The organisation of the process of reporting has improved since the Ministry of Justice became more involved since the mid-2000s. This is especially visible in the reduction of the delay in the submission of the reports to treaty bodies. The state reports that were submitted at the beginning of the millennium (between January and October 2001) had significant delays: CRC (9 months), CERD (21 months), CAT (36 months), ICCPR (72 months) and ICESCR (74 months). The report of CEDAW was submitted in October 2002 with a delay of 'only' 8 months. New Zealand subsequently made a catch-up effort to get completely up-to-date with its reporting obligations. ${ }^{24}$ Several treaty bodies facilitated this effort and were lenient with the submission dates of subsequent reports. ${ }^{25}$ As a result of this, New Zealand was able to submit its next reports on time (CAT 2007 and CRC 2008) or with relatively small delays of a couple of months (CEDAW 2006 and 2010; 2 and 3 months, ICCPR 2007; 5 months, CERD 2006 and 2011, 5 and 2 months, ICESCR 2009, 10 months). Another illustration of the improved reporting practice are the regular updates of the Core Document, which outlines a country's general political structure and its legal framework for the protection of human rights. ${ }^{26}$ Overall, the reporting record of New Zealand is better than the Netherlands, but it is worse than Finland.

It is common practice in New Zealand that the government circulates a draft version of the state report for public comment. This is similar to Finland, but it is different from the Netherlands. Submissions of NGOs, but sometimes also individuals, academics, and MPs, are subsequently considered in the preparation of the final text of the report. The consultation process has, however, been rather minimal in practice, except for CRC and CEDAW. ${ }^{27}$ Several NGO representatives argued that they should be better informed in all phases of the reporting process and argued that their involvement in the follow-up phase is especially limited. The government admitted that the involvement and regular consultation of civil society in the process of reporting and follow-up to the COs could be improved. ${ }^{28}$ It was felt by some NGO representatives that the Bill of Rights/ Human Rights Team of the Ministry of Justice has recently been more willing to interact with and listen to NGOs. Dissemination of the state reports and COs has gotten slightly better as well.

23 UN Doc. HRI/CORE/NZL/2010 (2010), para. 237. UN Doc. HRI/CORE/NZL/2006 (2006), para. 132.

24 UN Doc. CCPR/C/SR.2015 (2002), para. 48.

25 UN Doc. CRC/C/15/Add.216 (2003), para. 63.

26 The two latest updates are: UN Doc. HRI/CORE/NZL/1 (2006) and HRI/CORE/NZL/2010 (2010).

27 The Ministry of Justice, for example, organised a consultation meeting about the 2012 CERD draft report and the withdrawal of the reservation to Article 14 allowing for individual communications, but only one NGO representative turned up. 
The Ministry of Justice created a comprehensive website with information and most of the documents sent to and received from the treaty bodies. ${ }^{29}$

Another improvement since the mid-2000s is the increased involvement and participation of members of government, in the same way as in the Netherlands. ${ }^{30}$ (Associate) Ministers for Women's Affairs had already been the head of the delegation since the discussion of the second report with the CEDAW Committee in 1994. ${ }^{31}$ The delegation to the HRC in 2010 was headed by Minister of Justice Power. Almost all government officials mentioned his close personal interest and noted that his attendance raised the importance of reporting. The other delegations were headed by the Permanent Representative of New Zealand to the UN Office at Geneva $^{32}$ or the Chief Executive of the Ministry of Youth Affairs/ the Ministry of Social Development in the case of CRC in 2003 and 2011.33

Several observers noted the absence of clear leadership in the implementation of international human rights treaties in general and the COs in specific. ${ }^{34}$ The role of the Ministry of Foreign Affairs in relation to follow-up has been limited. There is no formal permanent interdepartmental or inter-agency network of government officials for international human rights issues which could facilitate the preparation of state reports and the implementation of COs. ${ }^{35}$ Especially for the COs of the beginning of the 2000s, several officials could not remember that these COs were analysed to see whether additional measures or a change in policy or legislation were needed. ${ }^{36}$ The Ministry of Justice confirmed this and stated that 'there was no formal consideration of concluding observations between 2003 and 2008'.37 Greatrex argued that COs are hardly recognised as important and that they 'are not being taken as seriously as they could be'. She referred to the problem that COs 'tend to go on the shelf until just before the next reporting round for a treaty', when an urgent message is sent in which the various departments are asked what they

29 <www.justice.govt.nz/policy/constitutional-law-and-human-rights/human-rights>, accessed 31 July 2013. The Ministry of Foreign Affairs has a website as well, but this contains hardly any explanation of the process and the documents are also less complete than the Ministry of Justice website: <www.mfat.govt.nz/Foreign-Relations/1-Global-Issues/Human-Rights/Treaties/index. php $>$, accessed 31 July 2013.

30 NZ Human Rights Commission (2010), 22-23. Race Relations Commissioner (2011), 6.

31 O'Regan (1994), Morris (1998), Dyson (2003), and Dalziel (2007).

32 Keating (ICCPR 1995), Caughley (ICCPR 2002, CERD 2002, ICESCR 2003 and CAT 2004), and MacKay (CERD 2007 and CAT 2009). The researcher was unable to retrieve the function or capacity of the head of delegation to CAT 1998 (Mr. Farrell), CRC 1997 (Ms. Gibson) and CERD 1995 (Mr. Armstrong).

33 Carter (2003) and Mackwell (2011).

34 See the reference to the suggestion of Chief Commissioner of the NZ Human Rights Commission Noonan and the general discussion during the NZ Diversity Forum in 2009. Greatrex (2010), 113 and $175-176$.

35 Cooper et al. (2000), para. 229. Greatrex (2010), 96 and 114.

36 This was mentioned in relation to CAT 1998, ICCPR 2002 and ICESCR 2003.

37 This observation was made in relation to ICESCR COs 2003. It was also noted that the Ministry of Justice 'does not have any formal process for responding' to the COs of CERD 2007, CAT 2009 and ICCPR 2009. Illingsworth (2012), infra $\mathrm{n}$. 40. 
have done to fulfil or implement the recommendations. ${ }^{38}$ Government officials also observed a similar tendency and argued that COs do not get proper attention and do not have much of an impact on government officials directly. The COs are, thus, often considered to be the end of the process. It seems, however, that more recent COs have been taken more seriously and considered more thoroughly, even though a formal process for responding to COs is still absent and remains largely ad hoc and responsive. Officials, for example, provided the Minister of Justice with briefings about the CAT COs 2009 and ICCPR COs 2010 and the extent to which (new) action was required in response to the COs. ${ }^{39} \mathrm{~A}$ similar assessment was made for CEDAW COs 2007 and CRC COs 2011. These briefings were obtained under an Official Information Request and are examined and discussed in chapter XII, section $4 .{ }^{40}$

A more systematic and continuous approach for follow-up was in place for the COs of the CRC Committee from 2000 until 2008. This practice is rather exceptional, because such an approach has been absent in the Netherlands and Finland. In order to strengthen the implementation of the COs of the CRC Committee, so-called CRC Work Programmes were developed with concrete targets or milestones for policy or legislative action. ${ }^{41}$ The Programmes were deliberately tabled in Cabinet in order to obtain the approval of other ministers and to get various policy and legislative intentions in the Work Programmes of other ministries. The latter was considered essential because most of the issue areas covered in the COs and the Work Programme were the responsibility of other

38 Greatrex (2010), 126, 129-130, 136.

39 Illingsworth (2012), infra n. 40.

40 A request under the Official Information Act 1982 was sent by Peter Shuttleworth to the Ministry of Justice via email on 23 April 2012. For the reply, see the letter from Fiona Illingsworth (Acting Manager of Bill of Rights and Human Rights, Ministry of Justice) of 22 May 2012. The following documents were attached: 'Response to Concluding Observations of the United Nations Human Rights Committee', 11 March 2011, HUM-06-02-03 and 'Responses to Recommendations Arising from the Convention Against Torture Presentation', 26 August 2009, HUM-06-14-02. Deb Moran (Policy Director, Ministry of Women's Affairs) replied separately with a letter dated 31 May 2012. Attached was the document 'Overview of the recommendations of the Committee on the Elimination of Discrimination Against Women', 31 March 2008, PIN-02-2007. Another request was sent by Shuttleworth to the Ministry for Social Development and Employment on 5 June 2012 about the COs 2011 of the CRC Committee. For the reply, see the letter from Sue Mackwell (Deputy Chief Executive, Ministry for Social Development) of 6 July 2012 with the attachments 'Debrief on New Zealand's examination before the United Nations Committee on the Rights of the Child', 3 February 2011, A5296830. 'United Nations Committee's Concluding Recommendations on implementing UNCROC following our 19 January 2011 examination', 14 July 2011, A5324854.

41 The last Work Programme covered a period of five years (2004-2008) and primarily addressed the most recent COs of 2003. These Programmes are called 'UNCROC Work Programmes', because in New Zealand the abbreviation UNCROC is used for CRC. The programmes and progress reports are available on: <www.msd.govt.nz/what-we-can-do/children-young-people/ uncroc/how-uncroc-is-improving-the-rights-of-children-and-young-people-in-nz.html>, accessed 31 July 2013. 
departments. Progress in the implementation of these items was also reported to Cabinet every year. There was (still) no Work Programme for the most recent COs of 2011 in August 2013.42

As was mentioned before, the (organisation of the) reporting process has improved since the mid-2000s. There are several factors that have contributed to this improvement. First of all, as some government officials pointed out, New Zealand intended to become a member of the UN Security Council in October 2014. This intention was already expressed in 2004. Hence, reporting was said to be taken more seriously in order to underline the history of engagement with the multilateral system. Secondly, some officials also argued that the UPR process in 2009 forced people to sit up and caused a more dedicated approach, also with respect to reporting. This was because there was an idea that New Zealand's reputation could be negatively affected if the process was not conducted in a right way. Officials, but also several other interviewees, argued that this UPR process led to a greater awareness of international (UN) treaties and processes and was a trigger for many domestic orientated departments to start to pay more attention to them. Another important factor was also the fact that Minister of Justice Power, went to the UPR in 2009 and the HRC in 2010 as the head of the delegation, which made it clear to officials that reporting was considered important.

\subsection{The attitude of government officials towards the process of state reporting}

The attitude of New Zealand government officials towards the (value of the) process of reporting is rather similar to the views of Dutch officials, but it is slightly different from its Finnish counterparts. Several officials stated that they considered reporting (potentially) important. They argued that it provokes a useful reflection and that it focuses officials' minds on important domestic human rights issues. Other officials held that it provides an oversight of human rights in New Zealand or that it serves as a benchmarking exercise. Government officials were, however, sceptical about the extent to which the process of reporting has realised this potential in practice. They argued that reporting has not been given the priority it should have. Writing or compiling (parts of) the state report has often been entrusted to junior officials. Coordinating government departments noted a difficulty in collecting information on time from departments which are more focused on domestic priorities. Almost all government officials lamented the burden of reporting, also as a result of the duplication and overlap between the several state reports. They held that the process is time consuming and a 'demanding chore', especially for a small country like New Zealand.

42

The CRC Monitoring Group received indications from the Ministry of Social Development that the government may establish a CRC Work Programme in the near future. Email from John Hancock of 8 August 2013, replying to a question from the author. See also A5324854 (2011), para. 6 and 30 . 
In addition, the process has primarily been approached as a compliance exercise instead of an opportunity to learn. There is a strong impulse among officials to defend and justify the government's policy and to avoid adverse publicity. Some even talked about an 'oral exam' and 'interrogation'. Nonetheless, compared with the Netherlands, the more recent state reports have been relatively honest and frank. This was also noted by several interviewees who argued that the more recent reports are less defensive than they used to be and try to provide an honest and complete overview. While the earlier reports of 2001 and 2002 were primarily good news stories, the New Zealand government now admits more openly that there might still be difficulties in relation to the implementation of human rights. ${ }^{43}$

The preparation for the dialogue with the treaty bodies in Geneva or New York has especially been taken rather seriously. This is in particular because of foreign policy considerations and concerns about New Zealand's position in the world. Politicians and government officials want New Zealand to be seen as a good international citizen and even a human rights leader. ${ }^{44}$ Human rights compliance is seen as a key component of New Zealand's reputation. Seen in this vain, bad preparation of the treaty body questions might have a negative influence on New Zealand's image. In a draft Cabinet paper, the Ministry of Foreign Affairs held that a breach of human rights treaties 'would do serious damage to our international reputation. It would bring forward criticism from UN committees and would give many countries (e.g. Nigeria, Cambodia, Myanmar, etc.) whom we are trying to influence cheap ripostes to any representations we might make on their human rights records. ${ }^{45}$ There is a strong tendency, especially among government officials from the Ministry of Foreign Affairs, not to undermine the UN human rights regime, because of its potential to encourage other countries to improve their human rights record. This view is also apparent in the statement of Minister of Justice Power, who stressed the importance of reporting: 'It's important to front up with our own situation so we can credibly discuss the challenges facing us and other countries. 46

Several government officials mentioned that the picture is different for reporting under the $\mathrm{CRC}$, which is valued more for domestic political reasons as the CRC Work Programmes also already illustrated. This was especially the case when it was coordinated by Ministry of Youth Affairs until 2008. ${ }^{47}$ This is similar to the Netherlands, especially when there was a separate Ministry responsible for youth affairs (2007-2010). The New Zealand Ministry also had 'ownership' over the CRC

43 The delegation recognised, for example, during the dialogue with the CESCR in 2012 that 'there will always be challenges'. Supra n. 18, 9-10.

$44 \quad$ Supra n. 1 and 17-20.

45 G. Palmer (1998), 69-70.

46 'Minister presents report to Human Rights Committee', 17 March 2010: <www.beehive.govt.nz/ release/minister-presents-report-human-rights-committee>, accessed 31 July 2013.

47 This standalone Ministry in New Zealand was established in 1988 to provide a youth perspective on governmental policies. UN Doc. CRC/C/NZL/3-4 (2008), para. 56. 
and an entrenched interest in reporting under the CRC. ${ }^{48}$ As the smallest and according to some 'the least listened to' Ministry, reporting was one of the biggest and most visible things they had to do. Officials from this Ministry were rather interested in and enthusiastic about reporting and they tried to give a fair picture and acknowledge deficiencies in the reports. ${ }^{49}$ The Ministry also used the process of reporting as a way to foster a dialogue and cooperate with NGOs, the Children's Commissioner and the NZ Human Rights Commission as well as children and young people themselves. ${ }^{50}$ Both government officials and NGO representatives felt that the process under the CRC has stimulated the relations between NGOs and the Ministry of Youth Affairs.

There are several reasons for the greater enthusiasm of the Ministry of Youth Affairs and its officials for reporting. First of all, many officials and some ministers from the Ministry of Youth Affairs had a personal interest in CRC and some were keen children's rights advocates themselves. ${ }^{51}$ They tried to push the children's rights agenda in their interactions with other departments. Secondly, these officials also acknowledged that $\mathrm{CRC}$ was useful to help advance domestic issues, because the CRC was considered to be consistent with that which the Ministry of Youth Affairs was advocating for. The process of state reporting was, thus, used in a strategic way to realise (domestic) priorities. The CRC and the COs were used as 'a tool to help develop child and youth policy' and to stimulate a wider understanding of children's rights and to develop a framework for considering them in policy making. ${ }^{52}$ This was primarily done through the Work Programmes in the period between 2000 and 2008. This was very much a bottom-up exercise and primarily driven by government officials with a view to strengthening the implementation of the COs and raising the profile of youth issues and the CRC. The Ministry of Youth Affairs tried to secure the commitment of other ministries and push the policy and legislative work of other departments through this Work Programme, especially because most of the issues in the Programme were the responsibility of other departments. The CRC and the COs were used as leverage and to strengthen

$48 \quad$ Cooper et al. (2000), para. 230.

49 State reports tend to mention the criticism of NGOs and individuals rather extensively. The 2001 state report, for example, admitted frankly that there is a lack of information and understanding of the $\mathrm{CRC}$ and that $\mathrm{CRC}$ is insufficiently used in legislative and policy development. UN Doc. CRC/C/93/Add.4 (2001), para. 111-112.

50 UN Doc. CRC/C/NZL/3-4 (2008), para. 19.

51 (Former) government official Jamison was, for example, a member of the establishment group of the NGO End Physical Punishment of Children (Epoch). Minister of Youth Affairs Harr (19992002) is seen as a proponent of children's rights, CRC and the prohibition of corporal punishment and also exerted strong political leadership. She also had good working relations with NGOs.

52 The Ministry of Youth Affairs took several initiatives to improve the integration of CRC in governmental processes and has used the process of reporting as a basis for doing so. The Ministry did this by creating a forum or network (Child Policy Reference Group) where government officials discussed, shared information on and helped each other with children's rights in relation to policy making. The forum also aimed at raising awareness of the CRC. UN Doc. CRC/C/93/Add.4 (2001), para. 52 and 108. 
arguments in this context. A number of interviewees noted the lower priority given to the CRC and reporting, since responsibility for CRC shifted from the Ministry of Youth Affairs to the Ministry of Social Development in 2008. ${ }^{53}$

\subsection{Increased understanding or awareness?}

The previous two sub section showed that - except for the CRC - reporting in New Zealand has hardly been used as an opportunity for review and dialogue, even though there has been some improvement in recent years. Reporting under the CRC stood out positively until 2008 because of its embeddedness in domestic procedures of review and dialogue.

Another matter is whether the reporting process has led to an increased awareness about human rights (treaties). Several interviewees pointed to such a broader influence of the process of state reporting. They noted that the process of reporting has helped to create a better understanding of (international) human rights obligations as a result of the participation of various government departments. ${ }^{54}$ It has also prompted some officials to reflect on certain issues and has reminded them of human rights implications of policies. Several interviewees argued that especially the process of reporting under CRC has contributed to an increased acceptance and prominence of children's rights. Various interviewees noted that there is more awareness among civil society and the wider public about the CRC than 10 or 15 years ago and that the CRC is regularly referred to in Cabinet Papers. ${ }^{55}$ Children's issues in general have also become more prominent. There has been a shift in thinking from thinking about children in terms of wellbeing to viewing them as having rights. ${ }^{56}$ It was acknowledged by interviewees that reporting has been an important factor, because of the way it has been (strategically) used by the Ministry of Youth Affairs with the CRC Work Programme. ${ }^{57}$ The shift in thinking was also attributed to the lobbying of NGOs and the Children's Commissioner and the debate about the prohibition of corporal punishment (chapter XII, section 4.1).

53 Interviewees argued that reporting is more approached as a compliance exercise, in line with the other treaties. Another difference with the 2000 state report was that the former was a big publication that was disseminated widely, while the 2008 report was merely put online. Several interviewees also noted that that the 2008 report was not as honest and open as the 2000 report.

54 Geiringer and Palmer some (analytical) capacity has been built up through the participation of government officials in the process of state reporting. Geiringer and M. Palmer (2007), 33-34. Officials from other departments also started to mention the CRC increasingly in policy documents and used the CRC as an argument to promote a certain policy. 'After a slow start', the CRC was taken very seriously by government departments and professionals, especially in the context of family law. Smith et al. (2003), 203. Several pieces of legislation in this period have considered the CRC more extensively, including the Care of Children Act 2004 and the Children's Commissioner Act 2003. In June 2002, the Government published the Agenda for Children, which aimed to encourage a new child approach which was partly based on the CRC as well. The Agenda also mentioned some of the concerns of the CRC Committee in the COs 1997. Wood et al. (2008), 53.

Supra n. 41. 


\section{DOMESTIC IMPACT AND DOMESTIC MOBILISATION}

The NZ Human Rights Commission concluded in 2010 that international human rights have 'a growing visibility' in New Zealand and that specific treaties are increasingly referred to in law, although this still happens on a largely ad hoc basis. ${ }^{58}$ Other reports and scholars have been more negative and argued that human rights issues are only considered rather superficially and relatively late within government departments. ${ }^{59}$ The expertise and familiarity with international human rights obligations is also said to be rather limited, especially in policy orientated departments. ${ }^{60}$ Many scholars also noted that parliament has hardly discussed or paid attention to domestic bill of rights aspects of legislation, let alone UN human rights treaties. ${ }^{61}$ By contrast, human rights treaties have had an increasing impact in legal practice, even though they have not been incorporated. ${ }^{62}$ Waters characterised this as a 'departure from dualism', while Hopkins referred to 'a modified monism [...] [of a] judge-made nature'. ${ }^{33}$ Several authors noted that the Views of the HRC have been relatively extensively discussed in judgments of majority and dissenting judges in New Zealand in comparison with other Commonwealth countries. ${ }^{64}$ This section will examine whether various domestic actors have referred to or used the COs in New Zealand.

\subsection{Governmental attention}

The COs have only been sporadically referred to by (members of) the government. Ministers have almost never held in parliament that a certain policy or legislation

$58 \quad$ NZ Human Rights Commission (2010), 13.

59 Cooper et al. (2000), 13 and para. 209 and 214. For a further discussion see Krommendijk (2012a), 583-587.

60 Geiringer and Palmer referred to a 'checklist approach' to human rights protection whereby it is checked whether the Bill does not contravene international obligations. Geiringer and M. Palmer (2007), 33-34.

61 Waldron (2005), 441. Kelly (2011), 309-310. Charters (2006), 656-657. Geddis (2011). Krommendijk (2012a), 591.

62 Hopkins (2011), 446-447. Geiringer pointed to the move from distrust to considerable receptivity to international law, which she labelled as a quiet revolution. Geiringer (2006), 300, 309 and 321.

63 Hopkins (2011), 446-447. Waters (2007), 688. The Court of Appeal, for example, sturdily discarded the dualist approach invoked by the government in relation to ICCPR and CRC which it considered to be 'an unattractive argument, apparently implying that New Zealand's adherence to the international instruments has been at least partly window dressing'. Tavita $v$. Minister of Immigration [1994] NZFLR 97 (CA).

64 Low noted that the discussion is not limited to a couple of individual judges only as in Australia. Low (2008), 4 and 39-42. Harrington found that the New Zealand courts have been more open to discussing the ICCPR and the interpretation of the HRC than Canadian courts. Harrington (2007), 233-234. 
needed to be taken as a result of criticism or recommendations of treaty bodies. ${ }^{65}$ On the contrary. Ministers have been remarkably dismissive in public about the recommendations and decisions of the treaty bodies. The most well-known example is the decision of the CERD in the context of the early warning procedure as a result of the submissions of Maori organisations in relation to the Foreshore and Seabed Act $2004 .^{66}$ The Act was enacted to address the fears following a court's judgment that the indigenous Maori might be able to successfully claim possession of large parts of the coastline and thereby limit public access to beaches. ${ }^{67}$ With the Act, the government wanted to safeguard this access by conferring the ownership of the Foreshore and Seabed to the Crown, the New Zealand state. Maori tribes and groups argued on the other hand that they were the rightful owners based on historical possession. CERD concluded in 2005 that the Act contained 'discriminatory aspects' against Maori. It requested the government to monitor the Act's implementation and its impact on the Maori population as well as to mitigate its negative effects. ${ }^{68}$ CERD repeated its recommendations in its COs 2007.69

The day after the CERD made its decision, Prime Minister Clark referred to CERD as 'a Committee on the outer edges of the UN system' (see the quote in the beginning of this chapter). ${ }^{70}$ She further held that the decision did not stipulate that there was a breach of any international convention and pointed to the 'great majority of New Zealand' that supported the law. ${ }^{71}$ Deputy Prime Minister Cullen concurred with the Prime Minister and added: 'A relatively small number of New Zealanders took that particular claim to that particular Committee' ${ }^{72} \mathrm{He}$ also

65 There was only one legislative change for which this was done. Dalziel (Minister of Women's Affairs) quoted the COs 2003 and held that the women in armed forces amendment Bill is doing precisely what we were asked to do by the CEDAW Committee. Goff (Minister of Defence) stated something similar (4 April 2007) 638 NZPD 8678 and 8684 . The COs were mentioned as a contributory factor on two other occasions. Finlayson mentioned that the HRC commended the Immigration Act 2009 in reaction to references by Locke (Green Party) and Katene (Maori Party) to the COs 2010. Finlayson (3 March 2010) 661 NZPD 10104. He also referred to the decision of CERD in relation to the Foreshore and Seabed Act. Finlayson (15 March 2011) 67 NZPD 17181.

66 The following Maori organisations requested the CERD to consider the Act 2004: Tranaki Maori Trust Board, Te Runanga o Ngai Tahu and the Treaty Tribes Coalition. CERD was chosen because of a rather similar and successful case in relation to Australia in which CERD adopted a progressive stance on indigenous rights. CERD/C/53/Misc.17/Rev.2. (1998).

67 The Act was enacted as a result of a court judgment which concluded that the Māori Land Court has jurisdiction to assess claims of customary ownership to the foreshore and seabed. Court of Appeal in Attorney-General v Ngāti Apa [2003] 3 NZLR 643. For a good and detailed discussion of the process and claims before the CERD, see Charters and Erueti (2005).

68 The Committee further noted the 'apparent haste' of its enactment and the insufficient consideration given to alternative viewpoints. UN Doc. CERD/C/66/NZL/Dec.1 (2005), para. 4, 6 and 8.

69 UN Doc. CERD/C/NZL/CO/17 (2007), para. 19.

70 Supra n. 2.

71 Charters and Erueti (2005), 286.

72 Cullen (23 November 2005) 628 NZPD 395. 
noted that several countries represented on the CERD do not have thorough legislative processes as in New Zealand. ${ }^{73}$ Several oppositional parties voiced similar criticism. ${ }^{74}$

Several interviewees noted that the public response of the government to COs has become more careful, diplomatic and sophisticated in tone after 2006. The government has adopted a 'more low-key approach' by giving less publicity to negative decisions, probably because it realised that such a strategy is more effective to silence opposition and that 'complaining about Geneva's intrusion' only added fuel to the flames and further politicised it. ${ }^{75}$ Hence, ministers responded more in substantive terms to questions in parliament about the COs. Minister of Labour Mallard (Labour), for example, pointed to the 'fundamental difference' in views between 'some people at the United Nations' and New Zealand with respect to absence of a minimum age of employment. ${ }^{76} \mathrm{He}$ referred to the majority of the public who think that some work is not harmful for children and stated that health and safety rules for workplaces are most important. ${ }^{77}$

Government officials noted that COs are hardly examined on a structural basis in policy making or legislative development. International human rights treaties also do not play a significant role in policy making and legislative development. ${ }^{78}$ Most of the government officials and ministers also noted that references to UN human rights treaties in Cabinet papers and policy documents are rare and that they are hardly used as a way of guiding policies. They argued that the consideration of these treaties is primarily a tick the box exercise or afterthought that does not involve any true consideration of possible human rights implications, especially in relation to the less obvious human rights inferences. Only occasionally have ministers made references during parliamentary debates to the obligations under UN human rights treaties and the need to act consistently with them. ${ }^{79}$ New

73 Cullen (9 November 2004) 621 NZPD 16708.

74 See, for example, Gerry Brownlee, 'UN assumptions biased presumptions', 25 November 2005:

<www.scoop.co.nz/stories/PA0511/S00387.htm >, accessed 31 July 2013.

75 These quotes were made in relation to Australia who had reacted forcefully to negative Views of treaty bodies as well. Charlesworth et al. (2006), 88.

76 This was a response to a question by Bradford (Green Party) in which she alluded to the CRC COs. UN Doc. CRC/C/15/Add.71 (1997), para. 19 and 31. CRC/C/15/Add.216 (2003), para. 47 and 48.

77 Mallard (21 November 2007) 643 NZPD 13275. Likewise, Minister of Justice Burton (Labour) responded to Flavell's (Maori Party) references to the COs CERD 2007 that the non-binding nature of the recommendations of the Waitangi Tribunal deprives claimants of an effective remedy by stating that: 'I do not share the committee's view, nor do I think the committee necessarily demonstrated in those remarks a complete understanding of the role and the jurisdictional differences between the tribunal and those of a court, for instance.' Burton (23 August 2007) 641 NZPD 11421.

$78 \quad$ Supra n. $59-62$.

79 See, for example, Minister of Immigration Coleman (National) who referred to the codification of procedural elements of CAT and ICCPR in the Immigration Bill (22 September 2009) 657 NZPD 6757. 
Zealand differs in this respect markedly from the Netherlands and Finland where the role of (UN) human rights (treaties) is significantly greater.

\subsection{Parliamentary scrutiny}

The government has not involved the parliament in the reporting process or in the follow-up to the COs. ${ }^{80}$ State reports and COs are not sent to or tabled in parliament. ${ }^{81}$ Individual MPs have occasionally picked up some of the COs. The most far-ranging way in which parliament has acted upon the COs is the introduction of a Private Members Bill to prohibit corporal punishment by Bradford (Green Party) directly in response to the COs (chapter XII, section 4.1).

Table 12.1. Number of occasions during which MPs referred to various treaties, treaty bodies and COs in New Zealand (2000-2012)

\begin{tabular}{lccc}
\hline & Treaty or committee & $\begin{array}{c}\text { Process of state } \\
\text { reporting }\end{array}$ & COs \\
\hline CAT & 23 & 1 & 9 \\
ICERD & 24 & 0 & 13 \\
ICESCR & 6 & 1 & 0 \\
CRC & 72 & 4 & 6 \\
CEDAW & 7 & 6 & 5 \\
ICCPR & 50 & 1 & 2 \\
\hline
\end{tabular}

COs have been referred to on a number of occasions as well. MPs have particularly referred to COs when they were already campaigning for a certain issue. There were, for example, 18 references to the 2005 decision of the CERD in relation to the Foreshore and Seabed Act. ${ }^{82}$ Table 12.1 shows that the highest number of references to COs is for CERD, 13 in total (see appendix 2 for the search terms used). Almost all of these references were by MPs from the Maori Party. This is not surprising, since the political party was founded in 2004 as a result of the controversy over the Foreshore and Seabed Act and the opposition of Maori to this Act. The Maori Party was also directly involved in the process of state reporting by way of submitting an alternative report to the CERD in May 2007. In addition to the Maori Party, another political party that has frequently alluded to COs and UN

\footnotetext{
80 The government considers the periodic reports to be government reports that do not require the approval of the House of Representatives. UN Doc. CEDAW/C/SR.805 (2007), para. 48.

81 Illingsworth (2012).

826 out of these 18 references were made prior to the final decision on 11 March 2005 and were more procedure related. References were primarily made by Maori Party MPs, but also Turei and Kedgley (Green Party) and Fairbrother (Labour).
} 
human rights treaties is the Green Party. ${ }^{83}$ Especially for these smaller parties, a reference to UN human rights treaties and COs can give them some authority and an additional lever in the debate. They have also used them as a political tool to portray their party as rights friendly. ${ }^{84}$

The relatively high number of references to CAT COs is also remarkable, 9 times (see table 12.1). Several factors might have contributed to this. Firstly, the parliamentary discussion of the Crimes of Torture and Amendment Act in the context of the ratification of OPCAT offered an opportunity for MPs to allude to the most recent CAT COs. During all three readings of the Act, CAT COs 2004 were addressed by Sharples and Flavell (Maori Party) and Locke (Green Party). ${ }^{85}$ Secondly, following OPCAT's ratification, annual reports of the NZ Human Rights Commission about its monitoring of places of detention are also sent to parliament. This has also been a good occasion to discuss the COs of the CAT Committee.

It is noteworthy that, contrary to the Netherlands or Finland, quite a number of MPs referred to the criticism or recommendations of the treaty bodies with disapproval. ${ }^{86}$ Hughes (Labour) noted, for example, that: "people at the fringes of politics have become very excited about a report from a United Nations committee regarding the Foreshore and Seabed Act. But I think it is very important to put on the record that that overseas committee considered that important matter for simply 35 minutes, and that it was not a committee made up of countries that we could say have a better race relations record than New Zealand does.' 87 Hayes (National), for example, held that the 'treaty committee system [...] is expensive and it is not delivering an iota of value to the people whom I represent in the Wairapa.' 88 Ryall (National) argued in similar fashion that: 'New Zealand has made it quite clear to all the international agencies that we will not follow their rules as we have our own rules' ${ }^{89}$ Future Minister of Justice Power (National) was also critical about MPs who would like to have the recommendations of the HRC implemented 'lickety-

83 In a study conducted by Butler about the references to the domestic Bill of Rights Act (NZBORA), she pointed to the following quite active MPs: Tanczos, Bradford and Locke (Green Party) and Mapp (National). P. Butler (2011), 45.

$84 \quad$ P. Butler (2011), 51. Geddis (2011), 471.

85 Sharples (21 November 2006) 635 NZPD 6685. Locke and Flavell (6 November 2006) 635 NZPD 6272 and 6274. Sharples (28 March 2006) 630 NZPD 2214.

86 These negative reactions primarily come from MPs of small parties like ACT and NZ First and to a lesser extent from the conservative National party. Sometimes Labour MPs were also critical about the treaty bodies and their COs or decisions, especially when the COs criticised policy and legislation championed by the Labour government (1999-2008). See, for example, some critical remarks of Fairbrother (Labour) in relation to the Foreshore and Seabed Act 2004. Fairbrother (23 November 2005) 628 NZPD 422. More unconditional support for the treaty bodies and their criticism comes from the Green Party and the Maori Party.

87 Hughes (16 March 2005) 624 NZPD 19241.

88 He also noted that New Zealand has a leadership role in relation to human rights and it is already complying with the obligations under OPCAT. Hayes (21 November 2006) 630 NZPD 2218 and (7 November 2006) 635 NZPD 6270.

$89 \quad$ Ryall (12 May 2005) 625 NZPD 20555. 
split'.90 Franks (ACT) went even further by stating that 'this government now claims, absolutely falsely, that we are obliged by the United Nations Human Rights Committee, the members of which are appointed by some of the most disgusting, vile, and cruel dictators on this earth. Mr Mugabe has a nominee on the United Nations Human Rights Committee, as does the Sudan - a country that is arresting people who are reporting mass rape - and this government says we kowtow, in this country, to the United Nations Human Rights Committee!'91 The latter quote also illustrates that MPs often confuse the HRC with the UN Human Rights Council or the former Commission.

Most interviewees noted the limited role of parliament in relation to the reporting process and the COs. Similar observations were made to UN human rights treaties. Table 12.1 shows that the number of references to UN human rights treaties in parliament is indeed rather limited as well. ICERD, ICESCR and CEDAW have been referred to only on one occasion every two years. CRC is discussed and referred to most extensively, because it is more frequently referred to in submissions of NGOs and academics to parliament. ${ }^{92}$

Interviewees gave several explanations for the limited parliamentary attention to human rights treaties in general and COs in particular. First of all, there is no inbuilt interest and commitment to international human rights obligations. Interviewees noted that the awareness and knowledge of MPs of these processes was fairly limited and, thus, depends very much upon individual MPs. Secondly, when the COs or UN human rights treaties are not reported in the media (chapter XII, section 3.6), it is often difficult for MPs to use COs or to put them on the agenda. Thirdly, and most important, is the absence of information coming from the government. The MP Locke (Green Party) held that had NGOs not been involved in the process or been to Geneva, no information would get through to New Zealand. References were often the result of work by NGOs or interested individuals and lawyers who alerted MPs to the COs. A recent example of the latter is the media release of Logie (Green Party) in which she highlighted the criticism of the CESCR on welfare reforms. ${ }^{93}$ The criticism was brought to her attention by the NGO Peace Movement Aotearoa. ${ }^{94}$ Likewise, Turia (Maori Party) referred to the fact that barrister Tony Ellis drew attention to the CAT COs 2004 in relation to compensation of prisoners.

$90 \quad$ Power (14 October 2003) 612 NZPD 9158.

91 Franks (1 June 2005) 626 NZPD 2097 and 21023. On an earlier occasion he held: 'The international bureaucrats, and the torturers, the robbers, and the tyrants who put people on to the United Nations Human Rights Committee, have said that New Zealand cannot do it.' Franks (12 May 2005) 625 NZPD 20564.

92 Hassall and Davies (2003), 34.

93 See, for example, Radio New Zealand, 'The United Nations has criticised New Zealand's proposed welfare reforms for breaching human rights', 22 May 2012: <www.radionz.co.nz/ news/national/106441/un-critical-of-nz-welfare-reforms>, accessed 31 July 2013.

94 Email from Jan Logie of 14 June 2012, replying to a question from the author how the criticism had come to her attention. 
During the same debate, Clendon (Green Party) referred to a report of the Law Society that also addressed the COs. ${ }^{95}$

\subsection{Courts and legal practice}

Although international human rights law in general has had an increasing impact, as was noted in the introduction to chapter XII, section 3, COs have hardly played a role in legal practice, if at all. The only case known to the author are the COs 2004 of the CAT Committee which were invoked before the Supreme Court, albeit with no result. ${ }^{96}$

A study conducted by Allan et al. in 2007 only found 17 cases in which the Views of the HRC were cited to date, even though the Court of Appeal held that its decisions are of 'considerable persuasive authority'. ${ }^{97}$ On a later occasion, the Court of Appeal repealed the judgment of the High Court that the HRC constituted a 'judicial authority', because it was not called a court or tribunal in the ICCPR or the travaux préparatoires and because its procedures are not those of a Court of tribunal-like body. ${ }^{98}$ The two UN human rights treaties that have been addressed most often by courts between 20 December 1999 and 30 June 2010 were CRC 99 and ICCPR, 163 and 164 times respectively. ${ }^{100}$ Only sporadically have courts referred to the other four treaties. ${ }^{101}$

Allan et al. also found that the judgments of the ECtHR and Canadian and American courts have been cited more often than the HRC. ${ }^{102}$ One reason for this is, firstly, the unfamiliarity of judges with and the limited access to the work and output

Turia and Clendon (22 June 2010) 664 NZPD 12065 and 12087.

The COs were invoked by barrister Tony Ellis. Note that CJ Elias referred to the CAT Committee as the 'Committee for the Prevention of Torture', thereby mixing it up with the ECPT. Taunoa and others $v$ Attorney-General and others [2008] 1 NZLR 429 (SC), para. 31, 59, 77-78, 80-82, 84-85 91, 93, 102, 104 (Elias CJ).

97 The Court consequently made clear that it favoured an interpretation that is consistent with the HRC's jurisprudence. R. v. Goodwin (No 2) [1990-92] 3 NZBORR 314, 321. The CRC Committee and CESCR were both cited once. Allan et al. (2007), 438.

98 The Court argued that it was not a 'judicial authority' in the sense of s19(1)(e) of the Legal Services Act as a result of which legal aid could not be provided to claimants making use of the individual communication procedure. Wellington district legal services committee $v$. Tangiora [1998] 1 NZLR 129, 134-136.

One explanation for the prominent role of CRC in legal practice is the Tavita case of 1994, which rather extensively discussed CRC as well as ICCPR. The Court of Appeal even held the CRC to be a mandatory consideration for state officials when they exercise discretion in matters affecting children. Supra n. 63.

Gobbi as referred to in Krommendijk (2012a), 593.

CAT (9 times), ICESCR (8), CEDAW (1) and CERD (0).

Allan et al. (2007), 438. Earlier, Butler and Butler concluded in 1999 that the number of references to the Views of the HRC is still minimal with only five cases. They also noted that the number of references to the jurisprudence under the ECHR was four times higher. A. Butler and P. Butler (1999), 184. A. Butler and P. Butler (2005), para. 4.5.2. 
of the HRC. ${ }^{103}$ Secondly, another reason for the limited reliance on treaty bodies is the way judges see themselves as being part of a court that follows legal precedents and adopts a judicial method. It was noted by several interviewees that treaty bodies hardly operate as courts, given the absence of oral hearings and their composition which includes non-judicially trained people, including former diplomats. Above all, the Views of treaty bodies were not considered very useful, because they are often rather short and declarative and hardly provide any reasons. ${ }^{104}$ This limits their applicability in other cases. New Zealand judges feel more comfortable with or prefer decisions from courts they are familiar with and which have a similar style of reasoning that is more discursive or explanatory, such as those from the ECtHR or courts from overseas jurisdictions. One judge, for example, held that the judgments of the ECtHR are 'a more appropriate reference point, since those decisions more often concern countries that have governmental and social similarities to New Zealand and with which this country would like to compare itself'. ${ }^{105}$ Thirdly, lawyers hardly invoke the ICCPR and the HRC as well as other UN human rights treaties because of a limited awareness and expertise. ${ }^{106}$ An illustration of the limited familiarity with the UN system is the relatively small number of individual communication under ICCPR. After ratification of the Optional Protocol under ICCPR on 26 May 1989, there have only been 20 communications which were considered by the HRC. By contrast, for the Netherlands there have been 70 cases since then, although the Netherlands is subject to the ECHR regime as well. ${ }^{107}$

\subsection{Human Rights Commission and Office of the Children's Commissioner}

The NZ Human Rights Commission has started to be more involved in the reporting process since the mid-2000s. Since 2007, it has started to submit alternative information to various treaty bodies and representatives of the Commission have also been present during dialogues with the committees. ${ }^{108}$ The government has

103 See also Geiringer (2006), 321.

104 Allan et al. argued that HRC's lower number is not surprising, because in their view it is common knowledge that the quality of decisions of the HRC is defective, because they frequently merely enumerate facts and submissions while proclaiming the HRC's conclusion in a superficial way. Allan et al. (2007), 6-7. Erdos (2007), 367-368. M. Palmer (2007), 580 and 582.

105 Taunoa and others $v$ Attorney-General and others (2008) 1 NZLR 429 (SC), para. 213 (Blanchard J). A. Butler and P. Butler (2005), para. 4.5.3.

106 A. Butler and P. Butler (2005), para. 4.5.2 and 35.10.3. Illustrative of this is that there are also few lawyers (Tony Ellis and John Steven Petris) who have brought more than one case before the HRC under the individual communications procedure.

107 Neither were there any communications under CAT and CEDAW. By contrast, the number of communications from the Netherlands for CAT is 13 and 2 for CEDAW out of a total of 14 cases. <sim.law.uu.nl/sim/Dochome.nsf>, accessed 16 July 2012.

108 An alternative report was submitted for CERD 2007, CAT 2009, ICCPR 2010, ICESCR 2012 and CEDAW 2012. Race Relations Commissioner De Bres was present during CERD 2007. Former Chief Human Rights Commissioner Noonan attended CAT 2009, UPR 2009 and CRC 
also consulted the Commission to discuss draft versions of periodic state reports several times. ${ }^{109}$ The NZ Human Rights Commission has increasingly referred to UN human rights treaties and COs in its submissions to parliament. ${ }^{110}$

The NZ Human Rights Commission consists of eight Commissioners, including the Chief Commissioner, the Equal Employment Opportunities Commissioner and the Race Relations Commissioner. It is especially the latter which deserves explicit discussion, because it is the Commissioner which has been the most widely involved in the reporting process. Following the CERD COs 2007, the Race Relations Commissioner organised a meeting with several government departments to facilitate a government response to the COs. ${ }^{111}$ In addition, the Commissioner started to monitor the implementation of COs 2007 in its annual race relations report which examines the progress in realising racial equality. ${ }^{112}$ The Commissioner has received assistance from the Ministry of Justice to collect information from various departments about the developments in relation to the COs. ${ }^{113}$ Note, however, that this joint monitoring mechanism is not seen as a programme for advocating the implementation of COs as such. De Bres, who was the Race Relations Commissioner from 2002 - 2012, said that the COs were used to inform the Commissioner's thinking and general prioritisation and back-up as a source of data in the annual reports and action plans of the Commissioner and the NZ Human Rights Commission and to make these reports more evidence based. ${ }^{114}$ This means that the Race Relations Commissioner has not lobbied for the implementation of COs as such. Rather, COs were used as additional support and to reinforce the priorities that were identified earlier. ${ }^{115}$ One explanation for the relatively extensive use of the reporting process and the COs by the Commissioner was that he was invited by the Secretariat of the CERD to attend and speak during the 2007 dialogue.

Special mention should also be made of the role of the NZ Human Rights Commission under OPCAT to monitor places of detention. Since 2007, the Commission has operated as the central preventive mechanism and has coordinated and liaised with the other national preventive mechanisms. It was acknowledged by interviewees that although this mechanism has not yet developed into an instrument

2011. Current Commissioner Rutherford, and one senior staff member, Beri, attended the dialogue with the CESCR in 2012. Equal Employment Opportunities Commissioner McGregor attended ICCPR 2010 (together with Bell) and CEDAW 2012. Commission to discuss the draft of the fifth periodic report under ICCPR. UN Doc. CCPR/C/ NZL/Q/5/Add (2010), para. 154. The Commission contributed to the sixth CEDAW report of 2006. UN Doc. CEDAW/C/SR.806 (2007), para. 2. Commissioner (2010), 6 .

111 Race Relations Commissioner (2009), 18.

112 The reports of 2010 and 2011 assessed the implementation of CERD COs 2007 in a table.

113 UN Doc. CERD/C/NZL/20 (2012), para. 14.

114 Interview 13 June 2011, Wellington, New Zealand.

115 Race Relations Commissioner (2008), 7. 
of regular monitoring of follow-up to COs, the COs are nonetheless discussed during the regular roundtable meetings which take place four to six times a year.

Another important actor is the Office of the Children's Commissioner, which has been involved in the process of reporting for a rather long time. ${ }^{116}$ It has paid extensive attention to the CRC and the COs of the CRC Committee in its work, especially in its lobbying and advocacy work (see, for example, chapter XII, section 4.1-2). ${ }^{117}$ The Children's Commissioner has also taken the initiative to set up a 'CRC monitoring group' to monitor the implementation of the CRC and COs after the COs 2011.118 The members of the group include the NZ Human Rights Commission and several children's NGOs. This group usually meets every three or four months and sometimes with senior government officials. ${ }^{119}$ An explanation for the relatively large involvement of the Commissioner in the process of reporting, both at the international and domestic level, is that the Commissioner has been entrusted to monitor and raise awareness about CRC since 2003. ${ }^{120}$

\subsection{NGOs}

NGOs have also increasingly become involved in the reporting process since the mid-2000s. Several new human rights NGOs with a domestic focus have been established since 2000, while other NGOs have strengthened their participation in the process. The Human Rights Foundation Aotearoa was, for example, founded in 2001, because it was felt that there was not really an NGO with a general human rights perspective. In addition, the New Zealand section of Amnesty International, UNICEF and Save the Children created a domestic advocacy function five to ten years ago and strengthened their involvement in relation to the process of reporting. An illustration of the enhanced participation is that no alternative reports were submitted to the HRC in 2002 and that for ICESCR in 2003 only a report about

116 It submitted alternative information for CRC 2003 and 2011 while it contributed to both the 1997 state report and the alternative report drafted by Action for Children in Aotearoa (now ACYA). Barrington (2004), 66.

117 Hollingsworth found that the Commissioner had principally acted as a children's advocate instead of holding the government to account by monitoring the implementation of the CRC. Hollingsworth (2004), 601.

118 This renewed commitment to monitoring the CRC was attributed to Hancock who started working at the Children's Commissioner in February 2011 after having been involved in the process of reporting with ACYA.

119 The group has met with the Deputy Chief Executives Social Sector Forum. This Forum has been in place since 2008 and meets monthly to address cross-sectoral youth issues and to coordinate work programmes of different government departments. It is chaired by the Chief Executive of the Ministry of Social Development. UN Doc. CRC/C/NZL/Q/3-4/Add.1 (2010), 3.

120 This is laid down in the Commissioner for Children Act 2003, which also appends to the text of the CRC. Several Commissioners based their work on the CRC before the 2003 Act. Barrington (2004), 47-48, 65 and 114. 
housing in New Zealand was submitted. ${ }^{121}$ By contrast, four and six alternative reports by New Zealand based NGOs were submitted for ICCPR $2010^{122}$ and ICESCR 2012.123 Likewise, the involvement of NGOs in relation to CERD in terms of the submission of alternative reports has grown considerably since the from an NGO point of view successful - decision of the CERD in relation to the Foreshore and Seabed Act. ${ }^{124}$ Several individual human rights lawyers have also become more active in recent times and have submitted alternative reports in relation to ICCPR 2010 and CAT 2009.125

NGOs can have a crucial role at the domestic level after the COs have been published. As was sketched in chapter XII, section 2.1, the domestic involvement of NGOs by way of consultation by the government has been rather minimal. This also holds true for lobbying for the implementation of COs. Although women's rights NGOs have been involved in the international reporting process, they have not used the COs of the CEDAW Committee very much in their lobby at the domestic level. ${ }^{126}$ Some COs have occasionally been referred to in submissions to parliament or in media releases.

The picture is different for CRC. For CRC there is a coalition of more than 100 NGOs, individuals and families interested in children's rights, Action for Children and Youth in Aotearoa Incorporated (ACYA). Its objectives are all explicitly centred on CRC and the COs of the CRC Committee. ${ }^{127}$ In addition, both UNICEF and Save the Children have become more involved in domestic advocacy since ten years. Hence, several interviewees argued that the children's rights NGOs have

121 Human Rights Foundation Aotearoa, 'Housing in New Zealand', <humanrights.co.nz/current/ UNHousingReportFinal.doc $>$, (accessed 26 September 2012).

122 Alternative reports were submitted by the following New Zealand based NGOs or individuals: ACYA, Andrew Butler as convener of the Human Rights Committee of the New Zealand Law Society, Peace Movement Aotearoa, Barrister of the High Court Tony Ellis, AIR Trust and Human Rights Foundation Aotearoa.

123 Alternative reports were submitted by the following New Zealand based NGOs: AIR Trust, Amnesty International NZ, Peace Movement Aotearoa and Human Rights Foundation Aotearoa.

124 No alternative report for CERD 2002 could be found. The report of the Race Relations Officer of 2010 pointed to the bigger involvement of civil society and increased input in the reporting process. Race Relations Commissioner (2011), 6. In addition to the NGOs with a general human rights focus (PMA and Human Rights Foundation Aotearoa) as well as children's rights (ACYA), the following Maori iwi submitted an alternative report to the CERD in 2007: Aotearoa Indigenous Rights Trust made up of Maori individuals with close associations with their tribes, Treaty Tribes Coalition iwi representing $15-20 \%$ of the Maori Population and a collective of four iwi Maori /indigenous peoples' Authorities in Tai Tokerau.

125 Alternative reports were submitted by Tony Ellis and Antony Shaw, Barristers of the High Court and the lawyer Sonja Cooper. ACYA and Human Rights Foundation Aotearoa also wrote a report. Krommendijk (2013b), 12-13.

ACYA was the Action for Children in Aotearoa until 2001. ACYA's objectives are: firstly, promoting the understanding and implementation of CRC. Secondly, encouraging action on the basis of the COs of the CRC Committee. Thirdly, submitting alternative reports to the CRC Committee: 'ACYA aims and objectives': <www.acya.org.nz/?t=8>, accessed 31 July 2013. 
grown stronger over the last decade. Government officials, especially those from the Ministry of Youth Affairs, acknowledged the important role and contribution of the active NGO sector and the 'ongoing interest and pressure' from NGOs to address specific COs. ${ }^{128}$ They noted the close interaction between the Ministry of Youth Affairs and even some Ministers of Youth Affairs with NGOs. One official from the Ministry of Youth Affairs was, for example, also a member of the group that established the NGO End Physical Punishment of Children (EPOCH). ${ }^{129}$ After the COs 2003, a CRC Advisory Group was set up which consisted of members of the Children's Commissioner, the NZ Human Rights Commission and representatives from several NGOs (UNICEF, Save the Children and ACYA). This Group met at least twice a year with government officials between January 2004 and 2008. ${ }^{130}$ (Former) officials from the Ministry of Youth Affairs stated that they often had similar views as NGOs and noted that the NGOs were helpful in raising issues that government officials could not put forward themselves.

NGOs or individual child or youth advocates have relied relatively heavily on the CRC or the COs of the CRC Committee in their submissions to parliament. As a result, some MPs have sometimes also referred to the COs. ${ }^{131}$ Government officials pointed to several instances in which the COs of the CRC Committee were used by NGOs to push things, including the prohibition of corporal punishment and the removal of reservations to the CRC (see chapter XII, section 4). The COs have empowered the NGOs and have given weight to their arguments. Some NGO representatives even held that COs give them a mandate or a strategy to formulate and measure the effectiveness of their work. They considered COs one of the most useful and powerful tools and leverage for civil society to hold the government accountable.

\subsection{Media coverage}

Almost all interviewees noted the lack of media coverage with respect to the process of state reporting. Some government officials considered this to be a success since there was no attention on the negative aspects of the performance of the government. Some interviewees pointed to occasional instances in which there was a short reference in the media. It was felt that the attendance of the dialogue by a minister has led to a higher interest of news media because ministers gave some

\footnotetext{
128 A5324854 (2011), para. 20.

129 Supra n. 51.

130 The Group provided advised and assisted in CRC related initiatives and it was offered the possibility to provide feedback during the preparation of the state report. UN Doc. CRC/C/ NZL/3-4 (2008), para. 13.

131 Bradford (Green Party), for example, mentioned the comments of UNICEF and the Children's Commissioner in relation to the prohibition of corporal punishment and the CRC COs 2003. (11 May 2004) 617 NZPD 12754. She also referred to recommendations of the 2003 report of ACYA in relation to child poverty and budget allocations. (18 June 2003) 609 NZPD 6386.
} 
interviews about their experience. A quick scan of $\mathrm{NZ}$ newspapers shows that newspapers have given more attention to CRC, ICCPR and CAT and the COs of the respective committees than to the other treaties. ${ }^{132}$ In addition, there was also significant media coverage of the high profile cases of the prohibition of corporal punishment and the Foreshore and Seabed Act 2004 and the treaty bodies' COs or decision (chapter XII, section 4.1 and 3). ${ }^{133}$

\section{Assessing the effectiveness of COS}

This section addresses the effectiveness of the COs. This section is first of all based on an analysis of documents in which a reaction to the COs is provided, in particular the periodic state reports, annual progress reports of the CRC Work Programme as well as reports from NZ Human Rights Commission and NGOs. In addition, use was made of internal briefings of the Ministry of Women's Affairs, Justice and Social Development about CEDAW 2007, CAT 2009, ICCPR 2010 and CRC 2011. ${ }^{134}$ This document analysis was complemented with interviews. Interviewees were, first of all, asked to give examples of effective COs themselves (see table 12.2). Secondly, the author questioned the interviewees about policy and legislative measures that in his view could have been potentially (partly) influenced or caused by COs. As explained in chapter III, section 2.3 on the methodology, it was consequently examined more thoroughly whether the measures mentioned during interviews were indeed taken (partly) as a result of COs.

132 There was, for example, some media coverage of the dialogue with the CRC Committee in 2011. A5296830 (2011), para. 15. A search was performed of NZ newspapers. See appendix 2 for the search terms used. 
New Zealand

Table 12.2. Examples of COs that were (partly) effective or played a noticeable role in New Zealand

\begin{tabular}{|c|c|c|c|c|}
\hline \multirow[t]{2}{*}{ Policy or legislative measure } & \multirow[t]{2}{*}{$\mathbf{C O}$} & \multicolumn{3}{|c|}{$\begin{array}{l}\text { No. of interviewees who } \\
\text { mentioned the } \mathrm{CO} \text { as effective }\end{array}$} \\
\hline & & G & $\mathbf{N}$ & $\mathbf{R}$ \\
\hline $\begin{array}{l}\text { The prohibition of corporal punishment/repeal of } \\
\text { section } 59\end{array}$ & CRC 97/03 & 8 & 7 & 1 \\
\hline $\begin{array}{l}\text { Measures to avoid age mixing in prison (steps to } \\
\text { withdraw reservation Article } 37 \text { (c) CRC) }\end{array}$ & CRC 97/03 & 4 & 3 & 1 \\
\hline The repeal of Foreshore and Seabed Act 2004 & CERD 04/07 & 2 & 2 & 3 \\
\hline Introduction of paid parental leave & CEDAW 94/98 & 4 & 1 & 1 \\
\hline $\begin{array}{l}\text { Education for unlawfully present children (steps } \\
\text { to withdraw reservation Article } 2 \mathrm{CRC} \text { ) }\end{array}$ & CRC 97/03 & 3 & 2 & \\
\hline $\begin{array}{l}\text { Child poverty on the agenda/Green Paper for } \\
\text { vulnerable children }\end{array}$ & CRC 11 & 1 & 3 & 1 \\
\hline $\begin{array}{l}\text { Strengthened employment position of children } \\
\text { (steps to withdraw reservation Article } 32 \text { CRC) }\end{array}$ & CRC 97 & 3 & 1 & \\
\hline $\begin{array}{l}\text { Withdrawal reservation CEDAW concerning } \\
\text { women in armed forces }\end{array}$ & CEDAW 94/98 & 3 & & 1 \\
\hline Measures to address inconsistencies in age limits & CRC 97 & 2 & 1 & \\
\hline $\begin{array}{l}\text { Measures to strengthen the independence of the } \\
\text { Police Conduct Authority }\end{array}$ & CAT 09 & 1 & & 1 \\
\hline $\begin{array}{l}\text { Improved collection of data on children } \\
\text { (well-being and health) }\end{array}$ & CRC 97/03 & 1 & 1 & \\
\hline Youth Suicide Prevention Strategy of 1998 & CRC 97 & 2 & & \\
\hline Young Persons and their Families Bill (No 6) & CRC 97/03 & 1 & & 1 \\
\hline Human rights training Corrections Department & CAT 09 & 1 & & 1 \\
\hline $\begin{array}{l}\text { Strengthened position of the Children's } \\
\text { Commissioner ( } 2003 \text { Act) }\end{array}$ & CRC 97/03 & 1 & & \\
\hline $\begin{array}{l}\text { More attention for double bunking during prison } \\
\text { inspections of the Ombudsman }\end{array}$ & CAT 09 & & 1 & \\
\hline $\begin{array}{l}\text { Overrepresentation of Maori in prisons higher on } \\
\text { the political agenda }\end{array}$ & CERD 07 & & 1 & \\
\hline $\begin{array}{l}\text { Public education campaign on corporal } \\
\text { punishment }\end{array}$ & CRC 97/03 & & & \\
\hline Translation CEDAW in Maori & CEDAW 98 & & & \\
\hline $\begin{array}{l}\text { Incorporation of the prohibition of non- } \\
\text { refoulement }\end{array}$ & CAT 04 & & & \\
\hline
\end{tabular}

$135 \mathrm{G}=$ government officials, $\mathrm{N}=\mathrm{NGO}$ representatives, $\mathrm{R}=$ rest, including representatives from the Human Rights Commission, Children's Commissioners, MP judges and academics. 
The majority of COs have remained rather ineffective. Generally speaking, hardly any measures have been taken as a result of COs. This is, first of all, because the concerns and recommendations of the treaty bodies often coincide with existing policy and legislative measures. The internal briefing of the Ministry of Justice with responses to the COs CAT 2009 and ICCPR 2010 provided that, except for two $\mathrm{COs},{ }^{136}$ none 'require new work initiatives' and that many can be implemented as 'business as usual: that is, they can be successfully addressed as part of the government's existing work programme'. ${ }^{137}$ For a lot of these rather broadly formulated COs work was 'already underway'.138 Officials argued that the concerns of treaty bodies were already known and hence being addressed by the government. ${ }^{139}$

Secondly, other COs were dismissed or not acted upon, because they were 'likely to be difficult to respond to' or because 'the intervention proposed by the Committee is not preferred by New Zealand'. ${ }^{140}$ These COs are found politically unacceptable or budget-wise not feasible. Examples are the continued use of tasers by the police and the unwillingness to halt the privatisation of (some) prisons. In these cases, domestic policy considerations have taken precedence and the government has decided not to take further action in the light of 'a lateral approach [that] may be taken to respond' to the COs. ${ }^{141}$ Sometimes, the response to the COs implies that the treaty bodies made a wrong appraisal or that the $\mathrm{CO}$ 'arose because of a misunderstanding of the legal frameworks. ${ }^{142}$

A third category includes COs that have been (partly) effective and resulted in new or additional police and legislative measures. There were more New Zealand

136 The only CO that 'would require active steps if they are to be addressed in full' had to do with the withdrawal of reservations to ICCPR. The review was eventually deferred. Illingsworth (2012). The other CO was the extension of the mandate of the NZ Human Rights Commission to receive complaints of human rights violations in the context of immigration. Justice officials recommended the Minister of Justice not to revise the issue at that time. HUM-06-02-03 (2011), para. 6,14 and 16 .

137 The briefing, for example, outlined steps taken before CAT 2009 to ensure that sufficient capacity was developed for prisons which 'should go some way to addressing' CAT COs 2009. HUM-06-14-02 (2009), para. 3, 9, 21 and 71.

138 The first CRC work programme divided the COs 1997 into two types: issues in relation to which work was 'already underway' and issues that called for 'new work'. The programme aimed to minimise the amount of issues in the latter category by developing responses to the COs 'as part of existing work wherever possible'. UN Doc. CRC/C/93/Add.4 (2011), para. 20-22. Likewise, the majority of COs 2011 'are already part of existing work programmes'. A5324854 (2011), para. 5 .

The response to CAT COs 2009 stated that: 'none of the matters raised are a surprise.' HUM06-14-02 (2009), para. 5.

140 PIN-02-2007, para. 14-16.

141 Idem.

142 The briefing stated that the CAT Committee's concerns about the discretion of the police to prosecute acts of torture were 'misplaced'. Likewise, a legislative amendment to exclude the admissibility of evidence obtained by torture was not necessary because this was already guaranteed by the Evidence Act 2006. HUM-06-14-02 (2009), para. 3, 50 and 62. 
government than Dutch officials who could give examples of effective COs. This might be due to the existence of two rather high profile cases in which the COs played a role, the prohibition of corporal punishment (chapter XII, section 4.1) and the repeal of the Foreshore and Seabed Act (chapter XII, section 4.3), which were mentioned as an example 16 and 7 times respectively. The remainder of this section will discuss eight (partly) effective COs with the objective of highlighting the factors that contributed to the COs' effectiveness.

\subsection{Prohibition of corporal punishment through the repeal of section 59}

The most cited example of an effective $\mathrm{CO}$ was the prohibition of corporal punishment as recommended in the CRC COs 1997 and 2003. ${ }^{143}$ As a matter of fact, it was not a prohibition, but a repeal of section 59 of the Crimes Act 1961 which provided a defence for parents charged with assaulting their children to use reasonable force for the purpose of correction. There was a lot of opposition from civil society groups, Christian lobby groups and large parts of the population who feared that repeal would seriously undermine the authority and autonomy of parents and give children an excuse to misbehave. There was also an aversion against the idea of children having rights independent of their parents. ${ }^{144}$

Several crucial steps leading to the eventual repeal of section 59 in 2007 were directly influenced by the CRC COs 1997 and 2003. As a first step, the relevant CO 1997 was included in the CRC Work Programme and instigated a governmental investigation as to what might be done with section 59.145 Eventually the government chose to start a national public education campaign while deferring a decision on the repeal of section 59 following the evaluation of the campaign in December 2005. The second crucial step was the Private Members Bill of Sue Bradford (Green Party) which was first announced on 6 October 2003 in response to the COs 2003 which were adopted three days earlier. After her Bill was drawn by pure luck from the ballot of Member's Bill on 9 June 2005 a heated and polarising social, public and political debate followed. The Crimes (Substituted Section 59) Amendment Act was finally adopted in an amended form on 16 May 2007 by an overwhelming majority of 113-8 after a compromise was reached between Prime Minister Clark and the leader of opposition Key (National), with the support of Bradford. During this lengthy and complex political process of 23 months, the COs

143 UN Doc. CRC/C/15/Add.71 (1997), para. 29. UN Doc. CRC/C/15/Add.216 (2003), para. 29-30.

144 Children have traditionally been seen as 'appendages' of their parents. Wood et al. (2008), 55 and 57. Moore (2009), 55-56. A large part of the population sees the CRC as 'the hobbyhorse of special interest groups and of dubious origins, legitimacy and relevance'. Hassall and Davies (2003), 34.

145 In October 2000, Cabinet directed government officials to examine the reaction of other comparable countries 'have addressed the issue of compliance with CRC'. Wood et al. (2008), 39, 59-60 and 172. UN Doc. CRC/C/93/Add.4 (2001), para. 80-81 and 112. UN Doc. CRC/C/ SR.897 (2003), para. 37. 
of the CRC Committee were referred to only once during a parliamentary debate by a Labour MP. ${ }^{146}$ The children's rights or the CRC did not play a major role in parliamentary debates. This illustrates that some proponents deliberately eschewed to frame the matter in terms of children's rights and chose to base their argument on positive outcomes for parents and society. The reasons for this related to the misconceptions about and antipathy towards the notion of children's rights. ${ }^{147}$

The COs were, nonetheless, considered an essential or sometimes even decisive factor by many interviewees. Government officials acknowledged that the COs prompted government work. Likewise, Bradford explicitly stated that she was 'stirred into political action by the recommendations that the UN Committee on the Rights of the Child made on two occasions' ${ }^{148}$ The CRC and the COs were also considered useful instruments for advocates to hang their arguments on and gave them a strong position to discuss and advocate for the matter with ministers. CRC and the COs were also an (international) endorsement and support for domestic NGOs who (already) advocated for the matter. ${ }^{149}$ It gave them an additional level of legitimacy and as a justification for change. Wood, one of the founders of End Physical Punishment of Children (EPOCH), held that: 'I am sure we were influenced by the knowledge that the UN Committee opposed corporal punishment of children and was likely to make a recommendation to New Zealand that section 59 of the Crimes Act be repealed.' 150 EPOCH's launch as an official organisation in early 1997 even coincided with the CRC COs 1997 which were adopted following the constructive dialogue on 20 and 21 January 1997.151

The COs of the CRC Committee were not sufficient in themselves to realise the legislative change. A comprehensive and detailed study of 2008 about the issue concluded that the eventual repeal was due to a 'rich combination of influences that helped to bring about the eventual change'.152 The 'strongly and determined political leadership of Bradford' was also essential for the legislative change. ${ }^{153}$ While the advocacy of the Children's Commissioner and NGOs like (EPOCH), ACYA, UNICEF and Save the Children was also crucial. This lobby already started

146

Chadwick (Labour) (27 July 2005) 627 NZPD 22086. Note that the COs were mentioned three times before 2005 by Bradford (Green Party) and twice by Stewart (NZ First).

Supra n. 144.

At the same time she acknowledged that other factors 'added impetus' to her action, including research findings, the high levels of domestic violence and the lobby work of advocates. Wood et al. (2008), 176 and 204.

The Children's Commissioner and ACYA made use of rights-based arguments in their lobby. UNICEF sent GC 8 of the CRC Committee to all politicians. Wood et al. (2008), 46, 55-57 and $64-65$.

Email to author from Beth Wood of 20 July 2012.

EPOCH-Newsletter No. 1 (October 1997) explicitly referred to the COs and made a link between the launch in its opening paragraph. The EPOCH committee had been meeting in 1996 to establish it. Moore also concluded that the COs 1997 gave an impetus and inspired domestic advocates. Moore (2009), 51.

Wood et al. (2008), 33, 167 and 201.

Wood et al. (2008), 167 and 187-188. 
before the COs 1997 and continued until 2007. ${ }^{154}$ There were regular exchanges between Bradford and child advocates, some of which acted as advisors to her. ${ }^{155}$

\subsection{Avoiding age mixing in prison}

Another example of an effective $\mathrm{CO}$ were the measures taken in relation to the withdrawal of the reservation to Article 37 (c) to avoid mixing minors with adult prisoners in prisons and to ensure sufficient youth facilities. ${ }^{156}$ Minister of Youth Affairs Harré wrote a paper on 'Options for removing Aotearoa NZ's reservation to the United Nations Convention on the Rights of the Child on age-mixing in prisons' in response to a request from Cabinet to further examine the issue. ${ }^{157}$ This issue was included in the first CRC Work Programme of 2001 as a matter of 'high priority'. ${ }^{158}$ As a result of the COs 1997, Cabinet agreed 'in principle' in 2001 to remove the reservation and requested the development of a test of best interests based on Article 3 CRC and the construction of specialist youth units. ${ }^{159}$ In 2005 , the Department of Corrections lowered the age threshold from 20 to 18 in the Corrections Regulations in order to avoid mixing 18 years old and adult prisoners together. ${ }^{160}$ In 2008, the Department also developed a checklist for female youth offenders under $18 .{ }^{161}$ Note that the reservation has not been withdrawn yet and there are still some (practical) problems with respect to age mixing in police custody, especially in rural areas, as well as female youth offenders for whom no female youth units exist. ${ }^{162}$ The government noted that these shortcomings will not be addressed in the short-to-medium term, because of the 'excessive cost of full compliance'. 163

The COs were a contributory cause of several of the above-mentioned initiatives and measures together with many other domestic factors. Several government

154 Wood et al. (2008), 112-116 and appendix B.

155 The advisors were Coleman (Barnardos) and Wood (EPOCH NZ). Another example was the media conference of Bradford with Pillay (Labour MP) and representatives from Every Child Counts, Plunket, Barnardos and EPOCH NZ. Wood et al. (2008), 199-120.

156 UN Doc. CRC/C/15/Add.71 (1997), para. 21. CRC/C/15/Add.216 (2003), para. 49 and 50. CRC/C/ NZL/CO/3-4 (2011), para. 49 and 50. Progress in relation to these COs was also noted in the NZ Human Rights Commission (2010), 171 and 242.

157 Goldingay (2009), 112.

158 UN Doc. CRC/C/93/Add.4 (2001), para. 24.

159 UN Doc. CRC/C/RESP/38 (2003), 114-115.

160 UN Doc. CRC/C/NZL/3-4 (2008), para. 40-41.

161 Goldingay (2009), 178-9.

162 A female youth unit is 'unviable' given the low number of female youth prisoners. CRC/C/ NZL/3-4 (2008), para. 40. Officials from the Ministry of Justice noted that further work is required in relation to Article 37 (c) $\mathrm{CRC}$ with respect to police transportation and court cells, but it stated that the latter might not always be possible in small, remote courthouses. HUM-0614-02 (2009), para. 45.

163 Ministry of Youth Development, '2008 reporting (summary document)': <www.docstoc.com/ docs/106107249/2008-summary-cabinet-paper>, accessed 31 July 2013, 6. 
officials acknowledged that the COs were a stimulus to look at the reservations, but some also noted that this is part of the on-going work. Some interviewees pointed to the advocacy role of NGOs and youth advocates as an important factor for the COs' effectiveness. ${ }^{164}$ Several of these domestic stakeholders relied on the COs. Several interviewees also pointed to the salience of the issue as an important facilitating factor, especially after the high profile incident of the murder of a 17-year-old remand prisoner by an adult in the back of a prison van. ${ }^{165}$

\subsection{The repeal of the Foreshore and Seabed Act 2004}

In 2005, the CERD reviewed the Foreshore and Seabed Act 2004 under its early warning procedure (for a discussion of the case see chapter XII, section 3.1). As said before, the CERD determined that the Act contained 'discriminatory aspects' against the indigenous Maori population. The Committee reiterated its concerns in its COs 2007 and also suggested legislative amendment 'where necessary'. ${ }^{166}$ A review of the Foreshore and Seabed Act was only started in the beginning of 2009 after a change of government from Labour to National. This review included the establishment of an independent panel of experts and consultations with the public. The Act was eventually repealed and replaced by the Marine and Coastal Area (Takutai Moana) Act 2011. ${ }^{167}$

The long timespan between the criticism of CERD and the eventual replacement of the Act was the result of the fierce governmental resistance to the Act being repealed (chapter XII, section 3.1). The government - and large parts of the population - defended the Act out of fears that property of large parts of the coastline would be transferred to Maori, resulting in limited public access to beaches. CERD's decision and the COs were, thus, not sufficient to cause a legislative change. Rather, they played a role as a contributory cause alongside many other domestic and international factors. There was already domestic opposition to the Act prior to and irrespective of the CERD decision and other international criticism. Interviewees noted the hugely politicised nature of the debate in 2004 and 2005. There was a huge amount of pressure on the government to change the Act with protest marches of approximately 50,000 people (see the photo of similar protests in 2011 in the top right corner of the cover of this book).

The CERD decision and the COs were one element in the political discussions and an additional argument used by several domestic stakeholders in favour of the repeal. Maori organisations saw the 2005 decision as recognition of their plight and

164 There was considerable domestic advocacy on the part of the judiciary, youth advocates, NGOs, the police and the Children's Commissioner. The Children's Commissioner, for example, presented the report 'Young people in police cells' already in 1997. Barrington (2004), 56. NZ Human Rights Commission (2010), 371.

166 UN Doc. CERD/C/NZL/CO/17 (2007), para. 19.

167 UN Doc. CERD/C/NZL/20 (2012), para. 40-43. 
were content that they had an alternative international avenue where they were listened to. ${ }^{168}$ Maori organisations and the Maori Party consequently used the 2005 decision and the COs 2007 as support and legitimation for their position. The Maori Party mentioned them on numerous occasions during parliamentary debates (see chapter XII, section 3.2). Several interviewees noted that these international pronouncements galvanised or added fuel to the flames and, hence, further increased politicisation of the matter, as the quotes in earlier sections also showed. ${ }^{169}$

Most interviewees attributed the eventual repeal to the role of the Maori Party and the change of government in 2009. The Maori Party was established following the dissatisfaction with and opposition to the Foreshore and Seabed Act 2004. The new National-led government needed the parliamentary support of the Maori Party and made so-called confidence and supply agreements with them. ${ }^{170}$ The review and possible repeal of the Act were important prerequisites for the Maori Party's support. ${ }^{171}$ The preamble of the new 2011 Act explicitly referred to 'the criticism [...] voiced against the discriminatory effect' by the CERD. ${ }^{172}$

\subsection{Education for unlawfully present children}

The CRC Committee has also constantly recommended the withdrawal of New Zealand's general reservation to the CRC and to provide children who are unlawfully in New Zealand access to health, education, welfare services and housing. ${ }^{173}$ Since 2000, the government has been examining whether the reservation to the CRC could be removed after it identified potential difficulties. ${ }^{174}$ The withdrawal of this reservation was given 'high priority' in the first CRC Work

168 See for example the letter of Turia and Sharples of the Maori Party sent to the CERD in May 2007: 'We acknowledge and sincerely thank the Committee members for their March 2005 finding [...] This provided critical support to the position of the Waitangi Tribunal, the New Zealand Human Rights Commission, and whānau, hapū and iwi Māori throughout Aotearoa.: <www2.ohchr.org/english/bodies/cerd/docs/ngos/maoriparty.doc>, accessed 31 July 2013.

169 A 2006 report of the UN Special Rapporteur for indigenous issues about the Act met similar resistance. The report was described by the government as 'disappointing, unbalanced and narrow'. The Rapporteur was said to be 'out of touch' with and 'failed to grasp' the situation in New Zealand. Cullen further held that: 'it's hardly surprising that Mr Stavenhagen has come to selective conclusions when he only spent about eight working days consulting in the country all up.' Michael Cullen, 'Response to UN Special Rapporteur report', 4 April 2006: <www.scoop. co.nz/stories/PA0604/S00062.htm>, accessed 31 July 2013.

170 UN Doc. CCPR/C/SR.2696 (2010), para. 72.

171 'Confidence and Supply Agreement between us and the National Party', November 2008: $<$ www.maoriparty.org/index.php?pag=cms\&id $=153 \& p=$ national-party-and-the-m $\% \mathrm{C} 4 \% 81$ oriparty-agreement.html>, accessed 31 July 2013.

172 Para. 2 of the preamble also referred to a report of the New Zealand Waitangi Tribunal and the UN Special Rapporteur for indigenous issues.

173 UN Doc. CRC/C/15/Add.71 (1997), para. 8 and 21. UN Doc. CRC/C/15/Add.216 (2003), para. 6 and 7. UN Doc. CRC/C/ NZL/CO/3-4 (2011), para. 8 and 9.

174 UN Doc. CRC/C/93/Add.4 (2001), para. $24 \mathrm{i}$. 
Programme as well. ${ }^{175}$ Cabinet asked several Ministries, including Youth Affairs, Labour and Heath to report back to Cabinet about the options. In 2005 and 2006, Cabinet agreed to the changes in education regulations and the decision to make the Immigration Act 1987 compliant with the CRC with respect to access to education. ${ }^{176}$ The amended Immigration Act 2009 removed the offence provisions against education providers who enrol these unlawfully present children in compulsory education. Prior to this legislative change, an interim measure to extend free education to these children was already introduced in 2007. ${ }^{177}$ Note that the COs have not been fully effective yet, because the current government is, however, not willing to completely withdraw the reservation since it does not want to remove the restrictions on access to social assistance and social housing given the considerable financial consequences. ${ }^{178}$

Interviewees - also those who did not give this as an example of an effective $\mathrm{CO}$ - noted the strong correlation between the policy and legislative change and the COs. This view is confirmed by the answer of the Minister of Immigration Coleman to a question for written answer in which he held that the 2007 interim measure was put in place in recognition of New Zealand's obligations under the CRC. ${ }^{179}$ One official argued that the COs 1997 put the issue on the agenda, since it brought to light that some children had no access to education. Another held that the government would not have paid attention to this without the COs. COs, thus, strengthened the discussion and they were helpful in arguing that it was an issue that needed to be addressed. The rather slow progress was the result of the considerable financial implications and because it relates to the effectiveness of immigration controls. ${ }^{180}$ One facilitating factor for the effectiveness of the COs is also the specificity of the COs. The implication of the COs are specific, clear and straightforward which also makes it easy for domestic actors to hold government to account.

\subsection{Withdrawal of the reservation to CEDAW: women in armed forces}

The government withdrew its last reservation to Article 11 (a) CEDAW concerning women in combat in May 2007. This had been recommended by the CEDAW Committee since 1994. ${ }^{181}$ Note that the restrictions on the employment of women in combat roles were already lifted by the Chief of the Defence Forces in January

\footnotetext{
175 UN Doc. CRC/C/93/Add.4 (2001), para. 24.

176 CAB Min (05) 18/40 and CAB Min (05) 41/3.

177 UN Doc. CRC/C/NZL/3-4 (2008), para. 23-31.

178 The delegation asked the CRC Committee whether it could partially lift the reservation. UN Doc. CRC/C/SR.1588 (2011), para. 8 and 41.

179 Coleman (25 June 2009) Question for written answer 8209.

180 UN Doc. CRC/C/NZL/3-4 (2008), para. 24 and 31.

181 UN Doc CEDAW A/49/38 (1994), para. 663. UN Doc. CEDAW A/53/38 (1998), para. 261 and 264. CEDAW A/58/38 (2003), para. 428.
} 
2000. One official argued that the Ministry of Women's Affairs used the reporting process strategically in order to secure a recommendation of the CEDAW Committee that could be used as leverage back at home by the Ministry. The Ministry did so by being open about the problems and by stating rather frankly in the 1998 CEDAW state report that 'women are not yet able to be employed in combat arms trades'. ${ }^{182}$ Several government officials argued that CEDAW and the COs were used, among other sources, as a lever by the Ministry and Minister of Women's Affairs Shipley (1990-98) in meetings and discussions with the Minister of Defence and in Cabinet meetings to achieve this change. ${ }^{183}$

The actual withdrawal of the reservation in 2007 was also influenced by the reporting process under CEDAW. ${ }^{184}$ That is to say, the COs and the anticipated dialogue with the CEDAW Committee were used as a justification or leverage to accelerate the legislative process, as was also mentioned by several interviewees. The issue was initiated by the MP Pillay (Labour) who introduced a Private Member's Bill, the Human Rights (Women in Armed Forces) Amendment Bill 2006. This Bill was eventually taken over by the government and elevated to the status of a government Bill before its third reading, because the government wanted to be sure that the Bill was adopted before the dialogue with the CEDAW Committee in August 2007. ${ }^{185}$ Minister of Women's Affairs Dalziel also stated: 'The exact words from the committee, after considering New Zealand's fifth report, were: "state party is urged to expedite the steps necessary for the withdrawal of its remaining reservation to the Convention...". So this legislation is us doing precisely what we were asked to do - to expedite the steps remaining to enable us to ensure that we can withdraw this remaining reservation to the Convention.' ${ }^{186}$ The COs were also mentioned by different MPs on four occasions. ${ }^{187}$

182 This official argued that CEDAW was a necessary condition, without which no policy change would probably have taken place. UN Doc. CEDAW/C/NZL/3-4 (1998), under Article 11. Efforts to address the issue were already undertaken before the COs 1998, as the CEDAW Committee acknowledged as well. UN Doc. A/53/38/Rev.1 (1998), para. 261.

183 Other factors were the 1998 report of the NZ Human Rights Commission which included a Gender Integration Audit of the New Zealand Defence Force and the multiple incidences of harassment of women in 1997. UN Doc. CEDAW/C/NZL/5 (2002), 82.

184 The withdrawal did not require any practical changes anymore, because the Defence Force had already formally rescinded its policy seven years earlier. Nonetheless, it was felt necessary to adopt an Act in order to officially remove the reservations. Foreign Affairs, Defence and Trade Committee, 'International treaty examination of Removal of Reservation to Convention on the Elimination of All Forms of Discrimination against Women (17 May 2007), para. 8.

185 Dalziel (3 May 2007) 638 NZPD 8922.

186 Dalziel (3 May 2007) 638 NZPD 8922.

187 Soper (Labour) in (29 March 2007) 638 NZPD 8516. Pillay (Lavour) and Mapp (National) in (27 March 2007) 638 NZPD 8385. Pillay, Dalziel and Chauvel (Labour) in (6 September 2006) 633 NZPD 5249. 


\subsection{The independence of the Police Conduct Authority}

In its COs 2009, the CAT Committee expressed concern about the impartiality of the Independent Police Conduct Authority with respect to an investigation into alleged acts of torture and ill-treatment by members of the police, because of the inclusion of current and former police officers. ${ }^{188}$ It recommended that the Authority be staffed with independent experts only. There was initial reluctance among government officials to address this $\mathrm{CO}$ because legislative changes had recently been made to insure the Authority's independence already. ${ }^{189}$ The COs were, nonetheless, acted upon and led to a big overhaul of staff. One factor that contributed to the willingness to take measures was that the $\mathrm{CO}$ coincided with existing concerns about the Authority's independence. ${ }^{190}$ Another important factor was that the Chair of the Police Conduct Authority, Justice Goddard, was deeply concerned about the $\mathrm{CO}$ and its effect on how the Authority would be perceived. This might be because of her interest in and knowledge about the international human rights framework and its importance, which is illustrated or caused by her election to the Subcommittee on the prevention of torture in October 2010. Another factor contributing to compliance with this $\mathrm{CO}$ of the CAT Committee was that the Police Conduct Authority was designated as one of the national preventive mechanisms under OPCAT.

\subsection{The strengthening of the Children's Commissioner}

The CRC Committee recommended in 1997 to strengthen the Office of the Children's Commissioner. ${ }^{191}$ As a result of the COs 1997, the government introduced the Commissioner for Children Bill in September 2001 which aimed to reinforce the provisions dealing with the Commissioner and include them in a separate statute. The Bill also appended to the text of the CRC. Increased funds were also assigned to the Commissioner in the 2002 budget. ${ }^{192}$ During the legislative discussion of the Bill, MPs addressed the $\mathrm{CRC}$ at length, almost unanimously in a positive light. ${ }^{193}$ Interviewees noted that the $\mathrm{CO}$ played a role in the adoption of the Bill by supporting earlier calls of proponents to strengthen the status and independence of the Commissioner. Both ACYA and the Children's

188 UN Doc. CAT/C/NZL/CO/5 (2009), para. 12.

189 The Ministry of Justice initially held that the COs did not need to be addressed. HUM-06-1402 (2009), para. 62. Amendments were made to the Independent Police Conduct Authority Act 1988 in 2007. NZ Human Rights Commission (2010), 356.

190 The homepage of the Police Conduct Authority provides that 'We are not part of the police' and it has at least five references to 'independent'. <www.ipca.govt.nz/>, accessed 31 July 2013. UN Doc. CRC/C/15/Add.71 (1997), para. 24.

192 Hollingsworth (2004), 602-603 and 620.

193 (18 November 2003) 613 NZPD 10113 (Third Reading), (11 November 2003) 613 NZPD 9891 (in Committee), (6 November 2003) 613 NZPD 9777 and 9817 (Second Reading). 
Commissioners Hassall and O'Reilly, for example, advocated for this with a reference to the CO 1997. ${ }^{194}$ The CO supported such pleas and made it easier for them to be accepted. Six interviewees agreed that the $\mathrm{CO}$ played a role in the adoption of the Act.

\subsection{The incorporation of the prohibition of non-refoulement}

The Immigration Act 2009 codified New Zealand's non-refoulement obligations under Articles 6 and 7 ICCPR and Article 3 CAT as recommended in the ICCPR COs 2002 and CAT COs $2004 .{ }^{195}$ Government officials made clear that the inclusion of the prohibition of non-refoulement resulted from COs and the will to address and avoid overseas criticism. The importance of codifying CAT and ICCPR and prohibiting non-refoulement was explicitly mentioned by the Minister of Immigration and some MPs in parliament at several occasions. ${ }^{196}$ Parliament also recommended a number of amendments aiming to align the wording in the Bill more closely with the texts of the two treaties. ${ }^{197}$ These recommendations were (partly) the result of submissions of civil society actors to the Bill. Several of these submissions referred to the criticism of the CAT Committee and stressed that a 'more appropriate approach' to CAT and ICCPR was needed. ${ }^{198}$ Inclusion of the prohibition was, however, only accepted reluctantly, especially by the Department of Labour. The criteria for asylum protection and the burden of proof were initially formulated rather strict. They were eased as a result of the submissions and pressure from the Ministry of Justice and the Ministry of Foreign Affairs, who were in favour of more lenient criteria and used international obligations and the COs to support their arguments. ${ }^{199}$ One important factor for the effectiveness of the COs especially those of CAT 2004 - was their salience and timing which coincided with the review of the Immigration Act 1987 in 2005. Another contributing factor was a

194 There were also private members' Bills in 1997 and 1998 that aimed to give the CRC 'a proper place in New Zealand law'. Wright's (Alliance) Parliamentary Commissioner for Children Bill 1998 mentioned the COs 1997. Barrington (2004), 38, 76-77 and 105-108. Hollingsworth (2004), 602.

195 UN Doc. CCPR/CO/75/NZL (2002), para. 11. UN Doc. CAT/C/CR/32/4 (2004), para. 5 and 6.

196 Minister of Immigration Cunliffe held that this 'reflects best-practice standards internationally'. (16 August 2007) 641 NZPD 11231. Coleman (5 March 2009) 652 NZPD 1708; (22 September 2009) 657 NZPD 6757. The following MPs mentioned CAT and ICCPR: Robertson (Labour) (3 March 2009) 652 NZPD 1605. Cunliffe (Labour) (22 September 2009) 657 NZPD 6752.

197 Wilkinson (3 March 2009) 652 NZPD 1592. Immigration Bill 2007 (2008 No312-2) (7 May 2009) Bills Digest No 1684.

198 See the submissions of the Auckland Refugee Council and the Human Rights Foundation Aotearoa in Yarwood (2008), 463.

199 The requirement was abolished that a claimant needs to demonstrate that torture or inhuman and degrading treatment is not generally faced by others in the country. Cunliffe (Labour) (22 September 2009) 657 NZPD 6752. 
high profile judgment of the Supreme Court, in which the prohibition of nonrefoulement under CAT and ICCPR also played a prominent role. ${ }^{200}$

\subsection{Conclusion}

Table 12.3 shows that there have been 20 (partly) effective COs in New Zealand. The majority of effective COs have been from the CRC Committee (11). It is noteworthy that there were also several COs of the CAT Committee that have been effective (4).

Table 12.3. Quantitative overview of the number of COs that have been effective in New Zealand

\begin{tabular}{|c|c|c|c|c|c|c|}
\hline CRC & CEDAW & ICERD & CAT & ICCPR & ICESCR & Total \\
\hline 11 & 3 & 2 & 4 & 0 & 0 & 20 \\
\hline
\end{tabular}

The previous section showed that the COs have not been sufficient to generate policy or legislative measures on their own. COs need to be complemented with other domestic and international factors and developments. COs have, thus, primarily been a contributory cause for policy or legislative measures among many other factors. This is also illustrated by the placement of the majority of (partly) effective COs in the column in the middle of table 12.4. One important role that the COs have played, as the previous subsections illustrated, is assisting one side in the debate by supporting or strengthening policy arguments. As was argued before with respect to the repeal of the Foreshore and Seabed Act 2004, there was, for instance, already domestic opposition prior to the 2005 early warning decision of CERD, but the decision and the COs 2007 became a factor in and galvanised the domestic debate. Several COs have been a more decisive factor and were sometimes essential to generate policy or legislative change, as in the case of the prohibition of corporal punishment (see column to the right in table 12.4). The government has also used the COs on some occasions to justify an intended policy or legislative measure, such as the introduction of paid parental leave (see column to the left in table 12.4). ${ }^{201}$

The Supreme Court ruled that the applicant could not be deported if there is danger of him being tortured in his home country. Attorney-General v Zaoui [2005] NZSC 38, [2006] 1 NZLR 289 (SC). Geiringer (2006), 306-307 and 315. Yarwood (2008), 464.

201 For a further discussion of this issue, see Krommendijk (2013b), 13-14. 
Table 12.4. Overview of (partly) effective COs in New Zealand

\begin{tabular}{|c|c|c|c|}
\hline & $\begin{array}{l}\text { COs used as support } \\
\text { by the government for } \\
\text { already intended } \\
\text { initiatives }\end{array}$ & $\begin{array}{l}\text { COs as contributory } \\
\text { cause among many other } \\
\text { factors }\end{array}$ & $\begin{array}{l}\text { COs as an essential or } \\
\text { decisive factor }\end{array}$ \\
\hline $\begin{array}{l}\text { Agenda } \\
\text { setting } \\
\text { function }\end{array}$ & & $\begin{aligned} & \text { - Child poverty/Green } \\
& \text { Paper (CRC) } \\
& \text { - Overrepresentation of } \\
& \text { Maori in prison (CERD) } \\
& \text { - Double bunking (CAT) }\end{aligned}$ & \\
\hline $\begin{array}{l}\text { Studies or } \\
\text { evaluations }\end{array}$ & & $\begin{array}{l}\text { - Data budget allocation } \\
\text { (CRC) }\end{array}$ & \\
\hline $\begin{array}{l}\text { Policy } \\
\text { measures or } \\
\text { initiatives }\end{array}$ & $\begin{array}{l}\text { - Youth Suicide } \\
\text { Prevention Strategy } \\
\text { (CRC) }\end{array}$ & $\begin{aligned}- & \text { Age mixing in prison } \\
& \text { (CRC) } \\
- & \text { Human rights training } \\
& \text { Corrections Department } \\
& \text { (CAT) } \\
- & \text { Strengthening } \\
& \text { employment position of } \\
& \text { children (CRC) }\end{aligned}$ & $\begin{aligned}- & \text { Public education } \\
& \text { campaign on corporal } \\
& \text { punishment (CRC) } \\
\text { - } & \text { Independent Police } \\
& \text { Conduct Authority } \\
& \text { (CAT) } \\
\text { - } & \text { Measures to address } \\
& \text { inconsistencies in age } \\
& \text { limits (CRC) } \\
- & \text { Translation CEDAW in } \\
& \text { Maori (CEDAW) }\end{aligned}$ \\
\hline $\begin{array}{l}\text { Legislative } \\
\text { changes }\end{array}$ & $\begin{array}{l}\text { - Introduction of paid } \\
\text { parental leave (CEDAW) }\end{array}$ & $\begin{aligned} \text { - Withdrawal reservation } \\
\text { CEDAW concerning } \\
\text { women in armed forces } \\
\text { (CEDAW) } \\
\text { - Strengthening Children's } \\
\text { Commissioner (CRC) } \\
\text { - Incorporation of the } \\
\text { prohibition of non- } \\
\text { refoulement (CAT) } \\
- \text { Repeal Foreshore and } \\
\text { Seabed Act 2004 } \\
\text { (CERD) } \\
- \text { Young Persons and their } \\
\text { Families Bill (No 6) } \\
\text { (CRC) }\end{aligned}$ & $\begin{aligned} &- \text { The prohibition of } \\
& \text { corporal punishment } \\
& \text { through the repeal of } \\
& \text { section } 59 \text { (CRC) } \\
& \text { - Education for unlawfully } \\
& \text { present children (CRC) }\end{aligned}$ \\
\hline
\end{tabular}

For a further explanation of the table, see table 11.3 in chapter XI, section 3. 


\section{EXPLAINING THE (IN)EFFECTIVENESS OF COS}

\subsection{Factors facilitating the effectiveness of COs}

The greater effectiveness of COs of the CRC Committee is not surprising in the light of the earlier mentioned CRC Work Programme which primarily outlined measures to be taken on the basis of the COs. In addition, there has also been more lobbying on the basis of the CRC and the COs of the CRC Committee than for the other treaties. NGOs and the Children's Commissioner have deliberately used the $\mathrm{CRC}$ and the COs as awareness, information and lobby tools and to inform their advocacy. As was addressed before, officials from the Ministry of Youth Affairs also had more interest in and commitment towards the CRC and the COs. They were dedicated to work on the issues and CRC and COs were used strategically to advance the children's agenda and to secure political support via the CRC Work Program.

There are several specific factors that have contributed to the effectiveness of the COs of the CAT Committee. Firstly, as was argued before, one important reason for the heightened attention for CAT and the COs was the ratification of OPCAT on 14 March 2007 which led to the establishment of national preventive mechanisms to monitor places of detention. It could be argued that this annual monitoring with regular roundtable meetings also facilitates the follow-up to CAT COs, because there is an inbuilt and institutional knowledge of (OP)CAT with a form of continuity. Secondly, interviewees considered the COs of the CAT Committee relatively useful. Interviewees argued that there were some new issues or even surprises among the COs that were not being addressed or discussed at the national level already. In addition, it was argued that the COs were more sensible as a result of the inclusion of officials from the Department of Corrections with an operational background in delegations which led to more technical and better informed discussions with the CAT Committee. ${ }^{202}$ Hence, the COs trickled through to the Department of Corrections and a couple of things were done at the operational level. Thirdly, as the latter shows, there has been increased interest in and a strong focus on (compliance with) UN human rights treaties in the Department of Corrections. Within this Department there has been a policy group that focuses on treaties and works on research and projects. ${ }^{203}$ Several interviewees especially noted the interest and enthusiasm of the official Monk of the Department of Corrections who attended the dialogue with CAT 2009 and ICCPR 2010. Someone even referred to him as a 'human rights champion'. Monk himself expressed

202 Edwards, Office Solicitor for Public Prisons Service, and McCarthy, General Manager, Public Prisons, attended CAT 2004. Monk, Southern Regional Manager, Prison Services, attended CAT 2009, UPR 2009 and ICCPR 2010.

203 A review found that since 2004 human rights considerations and standards have been consolidated within penal institutions and penal legislation, regulation and policy have also improved. Stanley (2011), 6. 
genuine willingness to learn from overseas and also change things to improve them. ${ }^{204}$ Monk, for example, initiated training workshops on the framework of international human rights obligations for prison personnel that the Department of Corrections organised together with the NZ Human Rights Commission. ${ }^{205}$ After the dialogue he also discussed several issues with a CAT Committee member via email.

Several interviewees noted that the smallness of the country is a facilitating factor for the effectiveness of COs. Politicians are, firstly, rather accessible for members of the public, NGOs and lobby groups. In the context of the prohibition of corporal punishment, for example, advocates worked closely with the MP Bradford during the passage of the Bill. ${ }^{206}$ Secondly, the smallness also means that the effectiveness depends upon the dedication of individuals. Individual government officials, MPs or ministers can, thus, make a difference, as the example of Monk from the Department of Corrections shows as well.

Another important factor is that smaller political parties have considerable political power in New Zealand due to the proportional voting system. They are often needed to give the government a majority in parliament. This means that parties which have traditionally been favourable towards human rights and/or the rights of Maori, such as the Green Party and the Maori Party, are able to contribute to the effectiveness of COs. Examples of the latter are the earlier discussed repeal of the Foreshore and Seabed Act 2004 and the prohibition of corporal punishment. ${ }^{207}$

\subsection{Factors obstructing the effectiveness of COs}

As already mentioned in the previous section, one explanation for the ineffectiveness of COs is that they are often rather broad and unspecific and do not outline a specific course of action. In addition, another important explanation for the limited effectiveness of a lot of the COs, especially those from the HRC and CESCR, is the absence of domestic mobilisation and the invisibility of COs. ${ }^{208}$ Because parliament, NGOs and the media hardly pay attention to or lobby on the basis the COs, the government can easily get away with doing nothing. This section

Interview 8 June 2012 (via Skype).

UN Doc CCPR/C/NZL/CO/5/Add.2 (2012), para. 3-6. See also the internal Ministry of Justice briefing about CAT COs 2009 which stated that the Department of Corrections had noted that refresher human rights could be introduced. HUM-06-14-02 (2009), para. 38.

Wood et al. (2008), 169.

Under the mixed member proportional system, people can cast two votes, one for the politician in their electorate and the other for their preferred political party. In 2005, all Green Party MPs were elected on the latter basis, which means that they were consequently not accountable to their constituency in their district and, hence, less manageable to pressure. This meant that Green Party MPs could unite in their support for the repeal of section 59. Wood et al. (2008), 169.

For more specific explanations related to the limited effectiveness of the COs of the CEDAW Committee in particular, see Krommendijk (2013b), 14-17. 
will pay attention to four other factors. While the first two factors are also present in the Netherlands and to a lesser extent Finland, the last two are more typical for New Zealand.

The first factor relates to the rather critical views of government officials as to the quality and functioning of the treaty bodies. The criticism was directed at all treaty bodies across the board, although some committees or sessions were considered better than others. ${ }^{209}$ As said before, it is not the purpose of this research to examine whether these critical and sometimes dismissive views are justified. The main objective is to illustrate that New Zealand officials are generally not persuaded to act upon the COs and that there is hardly a compliance pull coming from the COs. In addition, these views also show a defensive self-righteousness on the part of officials rather than an open-minded attitude and a willingness to learn (see below).

Several aspects were mentioned that especially undermine the credibility and authority of the treaty bodies and also explain why often little notice is taken of COs. Firstly, the factual mistakes and inaccuracies in some of the COs undermine their credibility. The CAT COs 1998, for example, recommended the completion of an investigation which had already been completed. The results were even annexed to the 1997 state report. The Committee expressed regret for this mistake. ${ }^{210}$ At other times, the treaty bodies have been more reluctant or did not give any possibility for the correction of such factual inaccuracies. ${ }^{211}$ Secondly, another critical aspect is the (over) reliance on NGO input without giving due consideration to the alternative viewpoint of the government. Both government officials and NGO representatives noted the great influence of NGOs on the Committee's questions and COs. NGO representatives were obviously content with this. Government officials were, however, rather critical about the treaty bodies reliance on NGO information without verification. A lot of questions and COs came from NGOs which were said to have used incorrect or outdated information. The internal briefing of the Ministry of Women's Affairs about the CEDAW COs 2007 hence stated that 'some criticism [...] is unbalanced. In particular, some of the criticism gives undue weight to the input of non-governmental organisations without any

209 The sessions/committees that were considered better or above average were ICCPR 2002 and ICCPR 2010, CRC 2003, CAT 2004, and 2009. Government officials were more critical about CERD 2005, CEDAW 2003 and 2007 and especially ICESCR 2003 and 2012 and CERD 2002. This variance has not resulted in significant differences as to the impact or effectiveness of the COs adopted during the respective sessions. The COs of the $\mathrm{HRC}$, for example, have had a limited impact and have largely remained ineffective, even though the two sessions with the HRC were considered relatively good. By contrast, the early warning decision of CERD 2005 and the subsequent COs 2007 have had a considerable impact and were eventually effective, even though officials were critical about the (quality of the) sessions. disabilities in relation to the provision of accommodation is not explicitly prohibited, although this is provided for in the HRA 1993 and there is also case law about this. UN Doc. E/C.12/NZL/ $\mathrm{CO} / 3$ (2012), para. 13. 
supporting evidence.'212 Thirdly, interviewees noted the plain misunderstanding of the domestic context visible in the questions of treaty bodies and their COs. Although government officials acknowledged that the amount of reading is considerable, they expressed their disappointment in the inadequate preparation on the part of the treaty bodies. Almost all government officials lamented the (complete) lack of understanding of the Committee, with some individual exceptions about the structure and social make-up of New Zealand's society and its democratic process. Don MacKay, the former Deputy Secretary of the Ministry of Foreign Affairs and Permanent Representative to the UN in Geneva, who was part of the delegation in 2003 (CEDAW) and head of the delegation in 2007 (CERD) and 2009 (CAT), argued that treaty bodies do not have the background or expertise to deal with 'huge policy issues' with 'huge significance for states'. ${ }^{213}$ Treaty bodies were said to inadequately grasp subtle but essential details. The Ministry of Women's Affairs briefing held that: 'it is disappointing that some of the recommendations do not fully reflect New Zealand's domestic situation'. ${ }^{214}$ Several officials, for example, mentioned that some treaty body members did not seem to understand indigenous Maori issues and were under the impression that Maori lived in reserves. ${ }^{215}$

Although the number of 'extreme' questions and odd COs might be limited, interviewees held that such stupid questions and COs put the delegation off and negatively affect their willingness to act upon the COs. Some officials even argued that if only one member said something outlandish, this would call into question the credibility of the whole Committee. Some interviewees expressed a genuine concern that such COs generate ignorance and undermine the other COs that were better targeted. They held that even if the COs include a couple of reasonable recommendations, they can and will easily be dismissed altogether. This is because politicians, the media, the public perception and some government officials focus on these to discredit the rest. The quotes in chapter XII, sections 3.1 and 2 show that politicians have indeed been rather eager to dismiss the process.

A second factor contributing to the ineffectiveness of the COs is complacency in assuming that there is an ideal human rights situation in New Zealand. Related to this is the idea that the UN human rights treaties and the treaty bodies are primarily seen as relevant for others, which is similar to the attitude of many Dutch - and to a lesser extent Finnish - officials. The internal debriefing to the Minister for Social Development about the dialogue with the CRC Committee in 2011, for example, mentioned that: 'The Chair of the Committee later told me that our examination was [as though] they look to New Zealand as a world leader and they wanted to

\footnotetext{
212 PIN-02-2007, appendix B.

213 MacKay (1999), 16.

214 PIN-02-2007, appendix B.

215 See, for example, the reference of Sadi to 'the refusal of the Maori community to integrate or assimilate' and of Ceausu to 'communities could become integrated'. UN Doc. E/C.12/2003/ SR.11 (2003), para. 36, 40 and 42.
} 
really test us and learn from our experience'. ${ }^{216}$ There is a strong perception among government officials and ministers that New Zealand is already in compliance with the UN human rights treaties. This is based on the practice that New Zealand, just like the Netherlands or Finland, only becomes a party to international treaties when existing domestic legislation, policy and practice are in accordance with the respective treaty. ${ }^{217}$ This means that legislation and policies are 'reviewed at length' to be sure that they meet the obligations under the respective treaty prior to the decision to accede to it. ${ }^{218}$ Several interviewees also referred to the self-image of government ministers and officials that in New Zealand the right thing is being done. ${ }^{219}$ There is an understanding that what human rights require is already the way of life in New Zealand. The logic follows that if there is a good policy reason to do something, it is inevitably consistent with human rights. The former AttorneyGeneral and Prime Minister, Sir Geoffrey Palmer, observed that: 'New Zealand has always prided itself on respecting fundamental human rights [...] the rhetorical political tendency was to say that New Zealand always honoured fundamental human rights without looking to see whether the claim was valid. Too often it was not. Administrative convenience, a tendency to trust the state and the use of its powers, and a homogenous political culture with a unicameral legislature made New Zealand in historical terms rather self-satisfied and uncritical about rights. ${ }^{220}$ This view has led to a 'complacency in a seemingly ideal situation', as the CEDAW Committee cautioned against. ${ }^{221}$

A third factor is the reluctance to accept external interference and criticism. Several interviewees mentioned that New Zealanders do not like to be criticised, especially from overseas. ${ }^{222}$ This discourse was (said to be) particularly voiced by politicians and ministers (chapter XII, section 3.1) and less by government officials during interviews. Deputy Prime Minister Cullen, for example, held that the Special Rapporteur on the rights of indigenous peoples' 'raft of recommendations is an attempt to tell us how to manage our political system. This may be fine in countries without a proud democratic tradition, but not in New Zealand where we prefer to debate and find solutions to these issues ourselves.' 223 Borrows (National) referred to New Zealand's 'autonomy and sovereignty as a nation' as a justification for not

A5296830 (2011), para. 12. It was also noted that: 'It seems that the Committee expects developed countries like ours to implement UNCROC to a higher level than developing countries'. A5324854 (2011), para. 12.

UN Doc. CAT/C/SR.876 (2009), para. 5 and 6. UN Doc. CEDAW/C/NZL/6 (2006), para. 18.

UN Doc. E/C.12/1993/SR.24 (1993), para. 30 and 38.

Charters argued that New Zealanders have 'an exaggerated, and possibly misguided, sense of their own benevolence that impairs their ability to critically assess their ability to protect rights'. Charters (2006), 652.

Geoffrey Palmer, 'Foreword' in A. Butler and P. Butler (2005), para. 39.

Ministry of Women's Affairs, 'Panui', September 2003, 3.

Wood et al. (2008), 57.

Michael Cullen, 'Response to UN Special Rapporteur report', 4 April 2006: <www.scoop.co.nz/ stories/PA0604/S00062.htm>, accessed 31 July 2013. 
acting in accordance with CRC. ${ }^{224}$ Brownlee (National) stated that 'New Zealanders don't need to be told by the UN what it means to be a Kiwi. Fair-minded Kiwis will reject these statements outright, because they know them to be untrue. ${ }^{225}$ There is considerable resentment towards bodies composed of countries with a not so good human rights record. Hassall and Davies referred to deeply held fears of losing sovereignty and autonomy and a reluctance to grant the UN too much power, because the public sees it as 'an agency of doubtful politics, ignorance of local issues and lack of accountability'. ${ }^{226}$ Several interviewees noted that framing the fact that something needs to be done because the UN or a treaty body is telling the state to do so is not very effective or helpful in realising a policy change. One example is the debate on the prohibition of corporal punishment during which actors primarily relied on arguments other than the CRC or the COs of the CRC Committee (chapter XII, section 4.1).

A fourth factor relates to the limited legal, political and societal status of human rights. UN human rights treaties are not incorporated into the New Zealand legal order. They consequently play a limited political and societal role. Related to this is the limited understanding of human rights among the wider public. ${ }^{227}$ Moreover, as several interviewees and scholars noted, the language of rights does not work in New Zealand. ${ }^{228}$ The American scholar Hunter observed that in contrast to the US, there is less litigation in New Zealand and that fairness is emphasised over legality. ${ }^{229}$ Not only is there a limited awareness and knowledge about human rights - something which is also mentioned in relation to the Netherlands and Finland - but there is also a rather negative attitude towards (human) rights. There is an idea that an appeal to rights is 'a last resort of people pursuing an unworthy agenda'. ${ }^{230}$ The domestic Bill of Rights is perceived by the population as a 'drunk drivers' charter' which 'does not offer something to all New Zealanders' or a criminals or rogues charter. ${ }^{231}$ Likewise, the rights approach to children's issues is not widely accepted in New Zealand yet, as is shown by the huge controversy over the prohibition of corporal punishment. Another example is the announcement of

224 Borrows (14 July 2011) 674 NZPD 20146. Collins (National) was against the government 'ticking of the boxes to make sure that we have a UN Convention all ticked off, so we can all be happy'. Collins (4 March 2008) 645 NZPD 14584. Mark (NZ First) was equally critical and lamented that 'we get the convention thrown at us as if it is a holy grail that we must all bend down and bow to'. He also stated that New Zealand has the right to pass laws fitting New Zealand's situation. Mark (4 March 2008) 645 NZPD 14592.

Gerry Brownlee, 'UN assumptions biased presumptions', 25 November 2005: <www.scoop. co.nz/stories/PA0511/S00387.htm >, accessed 31 July 2013.

226 Hassall and Davies (2003), 34-35.

227 Education in schools on human rights is limited. In addition, Butler and Butler held that 'Bill of Rights do not rate here'. A. Butler and P. Butler (2005), para. 2 and 3. Charters (2006), 652. (2009), 45.

230 Wood et al. (2008), 55.

231 A. Butler (2002), 72. A. Butler and P. Butler (2005), para. 35.9.2. 
aggrieved red-zone residents in earthquake hit Christchurch to take their case to the 'the UN'. The great majority of the reactions to this was dismissive and the residents were labelled by some as selfish, arrogant or 'spoilt children stamping their feet' and contrasted with 'people starving, wars, killing' or 'concentration camps' in other countries worse off. ${ }^{232}$ The language of (human) rights is, thus, less accepted than in the Netherlands and Finland, where human rights are used by a wide range of actors and have become an integral part of the domestic political decisionmaking process.

\section{Conclusion}

This chapter showed that the impact of the process of reporting is far from perfect. Nonetheless, the process of reporting is now more on the (political) agenda than it was ten years ago. That is to say, the organisation of the process of reporting has improved since the Ministry of Justice took over the responsibility for the compilation of reports. In addition, both the NZ Human Rights Commission and NGOs are more involved by way of compiling alternative reports and attending the treaty body sessions. The (domestic) lobby of NGOs is still rather minimal, except for the CRC. One major actor that is also rather absent is parliament.

It was mentioned in the introduction that one objective of this chapter about New Zealand was to examine whether UN human rights treaties and COs have had more of an impact and have been more effective in a country that is not a member of a stronger regional human rights mechanism as the Netherlands and Finland. This does not seem to be the case, except maybe for the COs of the CAT Committee. The number of (partly) effective COs is roughly similar or even slightly higher in the Netherlands and Finland. The COs are also not referred to more often by MPs during parliamentary debates or in written questions. In addition, UN human rights treaties in general have had significantly less of an impact on the legislative process, parliamentary debates and legal practice in New Zealand. This difference between New Zealand and the two European countries can primarily be explained by the absence of a truly effective external human rights check for New Zealand in line with the ECHR and ECtHR. The latter has not only contributed to a lower impact and effectiveness of COs but also to a lower popularity and salience of (the concept of) human rights in general. ${ }^{233}$ As will be argued in the next chapter, the Finnish experience illustrates that it was exactly the rather late ratification of the ECHR in 1990 that was a turning point and led to a growing profile and culture of human rights.

232

So posted comments to 'Red-zone residents threaten UN action', 10 June $2012:<$ co.nz/the-press/news/christchurch-earthquake-2011/7074536/Red-zone-residents-threaten-UNaction>, accessed 26 July 2012.

For a further discussion of this point, see Krommendijk (2012a), 613-614. 


\section{Chapter XIII \\ FinLAND}

'Finns like to think that they are a sort of model-student in an imaginary global human rights class of nations'. [Husa in 2011] ${ }^{1}$

This chapter assesses the impact and effectiveness of the COs of the six main UN human rights treaty bodies in Finland. ${ }^{2}$ A Nordic country was chosen because it was considered a most likely case for the effectiveness of COs, because the Nordic countries are traditionally regarded as taking international processes and norms rather seriously (chapter III, section 1.3). Some even pointed to a 'distinct Nordic exceptionalism' in the implementation of EU law. ${ }^{3}$ This chapter will examine whether the effectiveness of COs in Finland is also considerable, as the good implementation record of European law suggests.

This chapter is based upon a document analysis of primary sources, such as state reports and NGO parallel reports, as well as academic literature (see chapter III, section 2 for a description of the methodology). In addition, 50 interviews were held in Helsinki with Finnish domestic stakeholders who were (in)directly involved in the reporting process, in November 2012 and April/May 2013. This includes Finnish officials from different ministries ${ }^{4}$ and NGO representatives ${ }^{5}$ as well as representatives from ombudsman institutions and the Human Rights Centre, academics, MPs and judges (see appendix 1).

\section{BACKground: The FinNiSh LEgAL AND POLITICAL SYSTEM}

Finland is a Nordic country in the Northern part of Europe. It borders Sweden, Norway and Russia. It has a population of around 5.4 million of which roughly $90 \%$ is Finnish speaking and 5\% Swedish speaking. In addition, there is also a very small - constitutionally recognised - indigenous Sami community of around 7,000 people in Lapland, the northern part of the country. ${ }^{6}$ Finland was a largely autonomous Grand Duchy within the Russian empire until 1917. Before that, it was part of Sweden until 1809, which has had a considerable influence on its legal

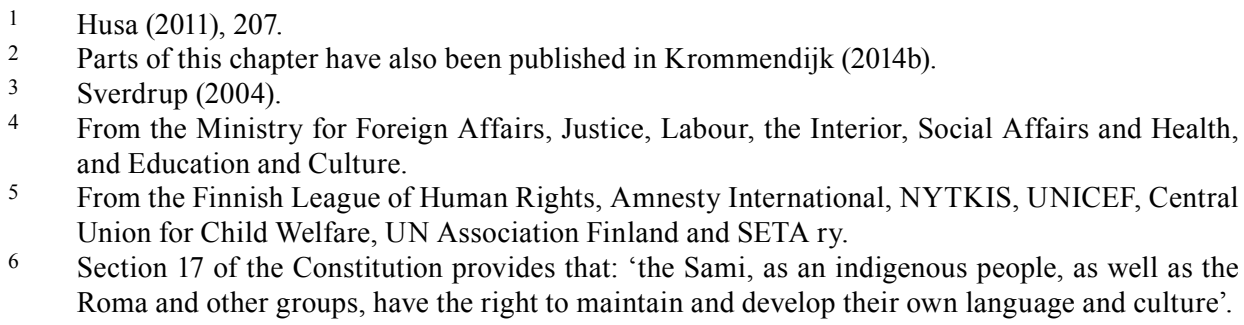

6 Section 17 of the Constitution provides that: 'the Sami, as an indigenous people, as well as the Roma and other groups, have the right to maintain and develop their own language and culture'. 
system. ${ }^{7}$ Finland is a parliamentary democratic republic with a president as the head of state and a unicameral parliament with 200 seats. It has a multiparty system with rather broad and stable coalition governments of sometimes up to six political parties. $^{8}$

While Finland ratified the UN human rights treaties relatively early, it only acceded to the $\mathrm{CoE}$ in 1989. ${ }^{9}$ The ECHR and its protocols were ratified on 10 May 1990. This relatively late accession to the CoE and the ECHR was the result of Finland's policy of 'active neutrality' during the Cold War and the need to maintain relations with both the East and West. The CoE and the ECHR were not joined because they were perceived as a 'Western European' human rights system. ${ }^{10}$ Finland has also started to play a more active role on the international stage with respect to human rights since the end of the Cold War. ${ }^{11}$ There is a strong desire to set a positive example at the international level. ${ }^{12}$ Husa noted that the level of internationalism is relatively high in comparison to the other Nordic countries. ${ }^{13}$ Finns have a self-image as a country that promotes human rights. ${ }^{14}$

Finland is formally a dualist country, just like New Zealand. The difference with New Zealand is that all UN human rights treaties have been incorporated into the Finnish domestic legal order and they, hence, could in principle be directly applied by courts. Because of this, the Finnish situation has been characterised as being 'de

$7 \quad$ Heyns and Viljoen (2002), 265.

8 Lipponen I (1995-1999) consisted of the Social Democratic Party, the liberal conservative National Coalition Party, the liberal Swedish People's Party and the centrist liberal Green League. The same coalition continued in Lipponen II (1999-2003) with the Left Alliance. The Jäätteenmäki government was only 69 days in office in 2003. Vanhanen I (2003-2007) was a government of the Centre Party (formerly the Agrarian League) with the Social Democratic Party and the Swedish People's Party. Vanhanen II (2007-2010) and Kiviniemi (2010-2011) were centre-right/green coalition governments of the Centre Party, the National Coalition Party, the Green League and the Swedish People's Party. Katainen I (since 2011) consists of the National Coalition Party and the Social Democratic Party as well as the Left Alliance, the Green League, the Swedish People's Party and the Christian Democrats.

9 ICERD (signed on 6 October 1966 and ratified on 14 July 1970), ICESCR (signed on 11 October 1967 and ratified on 19 August 1975), ICCPR (signed on 11 October 1967 and ratified on 19 August 1975), CEDAW (signed on 17 July 1980 and ratified on 4 September 1986), CAT (signed on 4 February 1985 and ratified on 30 August 1989), and CRC (signed on 26 January 1990 and ratified on 20 June 1991).

10 Rosas (1988), 426. Rosas (2001), 292 and 298. Heyns and Viljoen (2002), 273-274.

11 Heyns and Viljoen (2002), 264. Several scholars noted that Finland's foreign and domestic human rights policy was influenced until the end of 1980s by its relationship with the Soviet Union and marked by a reluctance to criticise individual countries. Since the end of the 1980s, Finland has associated itself more with Western Europe. Halme (2007). Rosas (1988), 429-431 and 434.

12 Heyns and Viljoen (2001), 491.

13 Husa (2010), 10.

14 Forrest (2006), 234. 
facto monist' or 'mitigated dualist'. ${ }^{15}$ An extensive bill of rights catalogue was included in the Constitution in 1995 in order to make it consistent with international human rights treaties and to incorporate the ECHR. ${ }^{16}$ Social rights were also included in the Constitution. ${ }^{17}$ Section 22 of the Constitution even contains an obligation for the public authorities to 'guarantee the observance of basic rights and liberties and human rights'. This explicit reference to human rights is interpreted as giving semi-constitutional status to human rights treaties. ${ }^{18}$

There has traditionally been a belief in the idea of a majoritarian democracy and the supremacy or sovereignty of parliament. Finland has been referred to as 'the northern tower of the democratic bastion of constitutionalist legislative supremacy. ${ }^{19}$ Courts have until recently not occupied a prominent place in the protection of human rights. ${ }^{20}$ Human rights are primarily protected in a political or nonjuristocratic way. ${ }^{21}$ Hence, the 'key supervisor' of human rights used to be and still is the parliamentary Constitutional Law Committee, which has a duty under section 74 of the Constitution to 'issue statements on the constitutionality of legislative proposals [...] as well as on their relation to international human rights treaties. ${ }^{22}$ Although the Committee is composed of politicians, it has been characterised as a legal expert body free of political interests and party political pressures that adopts a quasi-judicial approach. ${ }^{23}$

15 Scheinin (2003), 243. Scheinin (1990), 26-27. While ICERD and ICESCR were incorporated with a government decree or statutory order, for the more recent human rights treaties an Act of parliament was used. Incorporation is nothing more than a 'blank legislative act' which simply refers to the treaty and pronounces it to be part of Finnish laws. Rosas (1988), 428. Ojanen (2009), 197.

16 The Fundamental Rights Drafting Commission (1989-1992) started its work by compiling a comparative chart of all obligations in the human rights treaties ratified by Finland. One of the aims of the reform was to enhance the domestic protection of human rights to a level higher than the minimal level required by the ECHR so as to diminish the need for individuals to go to Strasbourg. Hallberg (2000), 585. Rosas (2001), 290. Heyns and Viljoen (2001), 525. See also Lavapuro et al. (2011), 516. Husa (2010), 1. Ojanen (2009), 198.

17 The obligations of ESC were a major background reason for their inclusion. Hallberg (2000), 584. The rights to free basic education and social assistance and care are even formulated as individual subjective rights that are justiciable and can be invoked before courts. Sections 13(1) and 19(1) respectively. Others are framed as a duty on the public authority. Scheinin (2003), 242. Rosas (2001), 311. Husa (2010), 11

Ojanen (2012), 106.

Cameron (2009).

21 Rights have traditionally been seen as essentially moral and political issues which imply the allocation of public resources, which should generally be for the legislature to decide. Cameron (2009).

22 Tuori (2012), 14-15. Formin (2010), 93.

23 The Constitutional Law Committee relies on precedents, doctrine and judgments of the various supreme courts. It always consults constitutional experts, especially public law professors, whose input is frequently decisive. It has been noted that the group of experts in a small country like Finland is rather circumscribed, although it has grown in the past 20 years. Lavapuro et al. (2011), 510-511. According to Husa, the Committee is even 'very close to a quasi- 
Since the end of the 1980s, however, there has been a process of transformation towards a model of rights-based judicial review whereby rights are increasingly seen as justiciable. ${ }^{24}$ This development was primarily a result of the Europeanisation of Finnish law following Finland's ratification and domestic incorporation of ECHR and accession to the EU in $1995 .^{25}$ In addition, the constitutional reforms of 1995 explicitly aimed to increase the direct applicability of constitutional rights in courts, while the reforms in 1999 leading to the present Constitution, which entered into force in 2000, introduced a system of decentralised constitutional review. The latter means that courts have the competence not to apply national legislation that manifestly conflicts with the constitution. ${ }^{26}$ Courts have tried to avoid open conflicts by way of constitution-friendly interpretation, just as in the Netherlands and New Zealand. ${ }^{27}$ This approach is based on the presumption that parliament would not have wanted to deviate from international commitments. ${ }^{28}$

Another important state institution that deals with human rights is the Parliamentary Ombudsman. The Ombudsman has an express constitutional task to monitor 'the implementation of basic rights and liberties and human rights' in the performance of its duties. ${ }^{29}$ In addition, Finland has had an Ombudsman for Children since 2005, while a Human Rights Centre opened its doors on 2 January 2012.

This short overview shows that the Finnish Constitution and legal order is rather open to international human rights. ${ }^{30}$ It is, thus, different from (several of) the other Nordic countries where (UN) human rights treaties are not always incorporated and, hence, enjoy a more limited legal and political status. ${ }^{31}$

constitutional court'. Husa (2000), 375. See also Tallroth (2012), 33-34, 36-38 and 106. Tuori (2012), 11-12. Husa (2011), 198. Ojanen (2009), 196.

24 number of complaints to the Ombudsman and the Chancellor of Justice. Paunio (2010), 12. Tallroth also observed that the expression of 'going to Strasbourg' has become widely accepted. Tallroth (2012), 94-95 and 104. to be the final straw' in the development of ex post judicial review. Ojanen (2009), 204. Husa (2000), 368 . Section 106 provides that: 'If, in a matter being tried by a court of law, the application of an Act would be in evident conflict with the Constitution, the court of law shall give primacy to the provision in the Constitution'. Courts have only used section 106 five times, which means the ex ante constitutional review by the Constitutional Law Committee still remains the primary mechanism for legislative review. In only one judgment did the Supreme Administrative Court rule that there was a manifest conflict. Lavapuro et al. (2011), 524. Ojanen (2012), 108. principle of cautiousness'. Husa (2000), 374 and 380. Sections 108 and 109 of the Constitution. The Ombudsman is one of the two 'supreme guardians of legality' together with the Chancellor of Justice. Tallroth (2012), 8, 50-55 and 58.

30 See also Husa (2011), 172.

'The Nordic human rights paradox', 11 April 2012: <www.jus.uio.no/smr/english/research/ projects/nordic-paradox $>$, accessed 24 June 2013. Infra n. 257-259. 


\section{THE BROADER INFLUENCE OF THE REPORTING PROCESS}

The first sub question to the first research question on the broader influence of the process of state reporting examines whether reporting has been used as an opportunity for human rights review and dialogue in Finland. In order to answer this question an overview will be provided of the (bureaucratic) organisation of the reporting process (section 2.1). This is followed by a discussion of the views of Finnish government officials towards the value of reporting (section 2.2). The second sub question about the extent to which reporting has led to an increased understanding or awareness about the respective rights and treaties will be addressed in section 2.3.

\subsection{The organisation of the process of state reporting}

The Ministry for Foreign Affairs is responsible for the compilation and writing of all Finland's periodic state reports on the basis of input provided by the other ministries. The Ministry for Foreign Affairs keeps track of the reporting deadlines with a schedule which is updated regularly. This schedule hung on the notice board of several interviewed government officials. This Ministry plays a rather dominant and central role in the process of reporting in comparison to New Zealand and the Netherlands. ${ }^{32}$

The reporting process was reorganised within the Ministry for Foreign Affairs in the mid-1990s. State reports submitted between 1991 and 1997 had significant delays between 10 and 43 months, because of organisational problems. Reporting was largely done in an ad hoc way by only a few people who happened to have time. ${ }^{33}$ The reorganisation was influenced by Minister for Foreign Affairs Tarja Halonen (SDP) (1995-2000) who had a particular interest in human rights. ${ }^{34}$ The importance of human rights at the domestic level and in foreign policy increased partly as a result of her efforts, but also because of the earlier mentioned fundamental rights reform of the Constitution and the ratification of the ECHR. Since the mid-1990s, reporting has been undertaken by a dedicated team within the Legal Department following a more structured and professional process. ${ }^{35}$ Reporting has also been given a greater importance. This was also noted by

32 See, for example, UN Doc. CERD/C/FIN/19 (2007), para. 255.

33 ICESCR 1995 (10 months), CAT 1995 (11.5 months), ICCPR 1995 (12 months), CEDAW 1993 and 1997 (both 16 months), CRC 1994 (17 months), ICERD 1997 (27 months) and ICERD 1995 (43 months). Note that the report of ICCPR 1995 was rather short and had only 24 pages. Heyns and Viljoen (2002), 286.

34 During her term, the role of human rights in foreign policy was strengthened through the establishment of a Unit for Human Rights and Humanitarian Affairs in 1996 (currently the Unit for Human Rights Policy). Lempinen (2008a), 132.

35 Since the beginning of the 2000s, the task of reporting has been entrusted with the Unit for Human Rights Courts and Conventions within the Legal Service. 
Dahlgren from the NGO Finnish League for Human Rights in 2001 who held that reporting was initially approached as a mere formality, but that, since the end of the 1990 s, a lot of work had been put into reporting. She also held that the government increased the transparency and visibility of the process. ${ }^{36}$ Almost all interviewees characterised the process since then as professional, efficient, open, and transparent. At the same it was noted that the organisation of the reporting process within most of the other ministries has been less structured and more ad hoc, with little continuity in the involvement of officials. The latter has somehow changed in recent years with the establishment of an interdepartmental network (see below).

Compliance with the reporting requirements has significantly improved since 1998 as a result of the organisational changes. All reports since then have been submitted with only relatively short delays of less than 4 months, with the exception of ICESCR and ICCPR: CAT on average with a delay of less than one month, ICERD (1.5 months), CRC (3 months), CEDAW (3.5 months), ICESCR (5.5 months) and ICCPR (10.5 months). Finland has the best reporting record of the three countries in this research. It also ranked first in the 2001 Heyns and Viljoen study on 20 countries. ${ }^{37}$ It is noteworthy that the delays have increased once again since $2011 .{ }^{38}$ This might be attributed to the lack of personnel to compile reports in the Ministry for Foreign Affairs. ${ }^{39}$ The fact that the (common) core document - which outlines a country's general political structure and its legal framework for the protection of human rights - has not been updated since February 1997 is also reflective of the latter. ${ }^{40}$

As in New Zealand, Finland also has a practice - which is even more developed - of consulting interested stakeholders during the compilation of the state report. Since the mid-1990s, NGOs have been requested to comment on the draft state report during a public hearing. ${ }^{41}$ Since the beginning the 2000 s, NGOs have also been given the opportunity to provide information to the Ministry for Foreign Affairs even at an earlier stage. The observations provided by NGOs and other actors are included in state reports as far as possible and as appropriate. ${ }^{42}$ As a result, Finnish state reports have been rather honest and frank as to the existence of problems and shortcomings in the implementation of the treaties. This has also been noted by most of the interviewed NGO representatives. ${ }^{43}$ The 'cooperative

\footnotetext{
$36 \quad$ Heyns and Viljoen (2002), 295.

37 Heyns and Viljoen (2002), 280.

38 ICCPR 2011 (21 months), ICESCR 2011 (11 months) and CEDAW 2012 (6.5 months).

39 This was noted by several interviewees. The Unit is also responsible for the negotiation and ratification of international human rights treaties as well as handling complaints before the ECtHR and treaty bodies.

40 UN Doc. HRI/CORE/1/Add.59/Rev.2 (1998).

41 UN Doc. CCPR/C/SR.1659 (1998), para. 18.

42 UN Doc. CCPR/C/FIN/6 (2011), para. 3. Formin (2004), 138-139. The 2008 CRC state report, for example, included the opinions of the Children and Parliamentary Ombudsmen and NGOs in a more structural way.

43 See also Nousiainen and Pentikäinen (2013), 579.
} 
drafting' of state reports with NGOs in two stages has now become an established practice. ${ }^{44}$ According to the government, this practice is rather unique when compared to other states where NGOs usually only have the possibility of commenting on the final report, or not at all (as in the Netherlands). ${ }^{45}$

Contrary to the Netherlands and New Zealand, ministers or secretaries of state have rarely attended the dialogue as the head of the delegation. This only happened for CEDAW in 1987 and 1995 when the Minister for Equality led the government delegation. ${ }^{46}$ The most recent delegations have been chaired by the Head of the Legal Division, Kosonen. He has been involved in at least 12 cycles since the mid$1990 \mathrm{~s} .{ }^{47}$ The latter also illustrates that there has been a relatively great continuity of government officials involved in the process of state reporting. ${ }^{48}$ There have been at least 11 other officials who attended the dialogue with more than three treaty bodies. Some have even been involved since the mid-1990s. The Ministry for Foreign Affairs has also taken the initiative to involve MPs from the Constitutional Law Committee in the reporting process with a view to increasing their awareness about the process. Hence, several MPs have been part of the government delegation to several treaty body sessions since $2005 .{ }^{49}$

Another difference with the Netherlands is that the state reports are consistently available in Finnish. ${ }^{50}$ The COs have also been systematically translated into Finnish and Swedish since the mid-1990s. ${ }^{51}$ According to Niemi, Finland has the best record in terms of translation of the six industrialised Western countries in her study.52 All the documents in the context of the process of state reporting have also been put on the website of Ministry for Foreign Affairs since 2000.

The process of follow-up is the least developed part of the Finnish reporting cycle, just as in the Netherlands and New Zealand. The Ministry for Foreign Affairs has sent the COs to the responsible ministries for them to determine whether any follow-up action is needed. It has consequently been left to the individual ministries to decide whether to take action or not. The Ministry for Foreign Affairs has not monitored whether the responsible ministries have actually implemented the

44 The term 'cooperative drafting' was used in CERD's COs 1996. UN Doc. A/51/18 (1996), para. 172.

45 Formin (2004), 139-140.

46 Respectively Halonen and Enestam.

47 CERD 1996, 1999, 2000, 2003, 2009 (Head of Delegation (HoD)) and 2012 (HoD), ICESCR 2007 (HoD), CRC 2005 (HoD) and 2011, CAT 2005 and 2011, CEDAW 2008 (HoD).

48 Finland has a relatively low turnover of staff. Semb (2012), 123.

49 Formin (2010), 93. Taipale (Social Democratic Party) attended CAT 2005, Thors (Swedish People's Party) took part in CRC 2005, Karvo (National Coalition Party) in ICESCR 2007, Nauclér (SPP) in CEDAW 2008 and Koskinen (SDP) in CERD 2012. CERD 2009 was not attended. CRC 2011 and CAT 2011 were not attended, because government negotiations took place in the same period following the elections in April 2011.

50 Reports are firstly written in Finnish and only subsequently translated into English.

51 Heyns and Viljoen (2002), 286.

52 The comparative study included Sweden, the Czech Republic, Australia, Spain and Canada. Niemi (2003), 25. 
COs. ${ }^{53}$ Until 2012, there has not been any form of inter-ministerial coordination or monitoring of the implementation of COs or human rights treaties. Nor have there been inter-ministerial follow-up meetings to discuss the COs. ${ }^{54} \mathrm{It}$ is therefore not surprising that the Ministry for Foreign Affairs held in 2004 that COs 'are too often left in abeyance and are not taken up until for the purpose of preparing the following report'. ${ }^{55}$ The Constitutional Law Committee likewise considered in 2004 and 2010 that follow-up to COs is 'an essential challenge'. ${ }^{56}$ Several interviewees also held that the follow-up phase has been the weakest link in the reporting process and has so far not been systematic. It was noted that after the dialogue with the treaty bodies it has often been silent for five years until the next report.

The Ministry for Foreign Affairs has performed a somewhat greater role in relation to follow-up to the COs of the CRC Committee. ${ }^{57}$ Since the COs 2005, the Ministry and the NGO Central Union for Child Welfare have organised annual seminars during which the implementation of CRC and the COs have also been discussed. These seminars focused on different themes that were (in)directly raised in the COs. The COs were primarily used to introduce the issue. The seminars aimed to keep the COs on the agenda and raise awareness about them and the process of reporting in order to strengthen the implementation of the CRC and the COs. ${ }^{58}$ These follow-up seminars which were jointly organised by the Ministry and an NGO is reflective of the fact that the reporting process under the CRC has contributed to enhanced contacts between government officials, MPs, NGOs and ombudsman institutions, as was noted by several interviewees as well. It has also stimulated cooperation and exchange between NGOs, the Ombudsman for Children and the Parliamentary Ombudsman.

Several initiatives have been taken more recently to enhance cooperation and coordination and strengthen follow-up to COs. In 2012, an interdepartmental network of contact persons for fundamental and human rights was established to, among others, assess which measures are appropriate to take in relation to the COs

53 The Ministry for Foreign Affairs has no mandate to give instructions to the other ministries. Since 2000, it has at times tried more 'intensified monitoring' by sending reminders and requests for written information to the ministries about the implementation of the COs. UN Doc. CERD/C/409/Add.2 (2001), para. 299. Interviewees noted that this was not very successful.

$54 \quad$ Niemi (2003), 35.

55 'The follow-up to the implementation of recommendations based exclusively on reporting is not adequately effective'. Formin (2004), 140.

56 It stressed that the COs' implementation must be monitored 'continuously, actively and comprehensively'. Ministry of Justice Finland (2012), 20-21.

57 The Ministry for Foreign Affairs also organised one seminar on the implementation of the CEDAW COs 2008 with respect to violence against women in May 2010. During the seminar, the negotiations on the draft $\mathrm{CoE}$ Convention on preventing and combating violence against women and domestic violence were also discussed. UN Doc. CEDAW/C/FIN/7 (2012), para. 235.

58 UN Doc. A/HRC/WG.6/1/FIN/1 (2008), para. 87. In February 2008, a seminar was, for example, organised about violence against children. UN Doc. CRC/C/FIN/4 (2008), para. 106. 
and monitor progress in their implementation. ${ }^{59}$ Officials expressed their hope that the network could provide a more coherent and systematic approach to the implementation of COs. Several ministries, including the Justice and the Interior, started to restructure their internal organisation in 2011 by creating a focal point for human rights who would also be the contact person for the network. It is too early to judge whether the network had indeed contributed to a more structural follow-up. Some officials already indicated that the network had at least contributed to an enhanced awareness of the reporting process. The 2012 national human rights action plan also proposed the development of a monitoring mechanism for the implementation of the COs of the CRC Committee. ${ }^{60}$

\subsection{Attitude of government officials towards the process of state reporting}

The attitude of Finnish government officials towards the process of state reporting has been markedly more positive than in the Netherlands and New Zealand, both in terms of the importance that officials attach to reporting as well as their views about the quality of the treaty bodies and COs (for the latter, see chapter XIII, section 5.1). The 23 government officials who were interviewed were generally motivated and interested in the (outcome of the) process and the COs. They did not question the necessity or relevance of reporting or the existence of treaty bodies, as some officials in the other two countries. Even though almost all officials noted the labour and time intensity of the process, ${ }^{61}$ the burden of reporting seems not to have affected the officials' willingness to report, at least of those interviewed. ${ }^{62}$ Most of the NGO representatives also noted that the Finnish government has seen the reporting process as valuable and has taken it rather seriously. An illustration hereof is that reporting has not (solely) been undertaken by interns or junior officials.

Reporting was seen less as a defence than in New Zealand and especially the Netherlands. Several officials held that reporting can actually be a vehicle or tool for improving the domestic human rights situation by raising attention and awareness about (new) challenges and issues at the domestic level. ${ }^{63}$ They realised

59 As a legal basis for this action plan, the government referred to, among others, the COs of the six treaty bodies to increase human rights awareness. Ministry of Justice Finland (2012), 22 and 26.

60 The responsible Ministry for this is the Ministry of Social Affairs and Health. Ministry of Justice Finland (2012), 28.

61 Replying to LOIs 'amounts to a new report and unreasonably increases the workload'. Formin (2012), 2 .

62 Only a small minority of the officials were critical about the actual results in comparison with the time spent on reporting. Several officials acknowledged that a substantial group of officials who have not been on the government delegation only do the minimum and provide short answers. These officials are not interested in the process as such and primarily see it as a burden.

63 See also Ministry of Justice Finland (2012), 15. The initial CRC report acknowledged that reporting is 'a remarkable tool for placing issues relating to children and young people on the agenda in all sectors of administration' and that it increases the awareness of CRC. Reporting 
that the process can also be useful for them, because it provides an opportunity for self-reflection and to have a dialogue with NGOs and hear their comments. Several officials also acknowledged that external pressure and support in the form of COs can be used vis-à-vis other ministries or politicians and are sometimes helpful or necessary to change a policy or legislation or to increase the availability of resources for a certain issue. The more positive attitude might have been affected by the earlier mentioned continuity of government officials involved in the process. ${ }^{64}$

Another reason for the fact that there are fewer negative or sceptical officials from other government departments than in the Netherlands and New Zealand is the dedication of (former) officials from the Ministry for Foreign Affairs which are responsible for the coordination of the entire process. These officials in particular portrayed the exercise of reporting as important and useful. They referred to the process of reporting as 'a spiral continuum' or a circle and something which serves as 'national sources of information on human rights'. ${ }^{65}$ One official even stated that it is their duty to defend and promote the treaty body system. ${ }^{66}$ It is not unreasonable to assume that the enthusiasm of these officials might have positively affected the attitude and willingness of officials from other ministries. It is obviously also in the interest of the Ministry to portray reporting as important as possible in order to get good cooperation and input from other ministries. Another contributory factor for the positive and progressive spirit is the fact that the Ministry for Foreign Affairs is not responsible for the implementation of COs and does not have to bear the financial consequences. Several interviewees, however, noted a gap between the commitment of the Ministry for Foreign Affairs and the other ministries as well as the discrepancy between rhetoric and the actual - more limited - implementation of the COs.

\subsection{Increased understanding or awareness?}

The previous two subsections showed that the reporting process in Finland is used more as an opportunity for dialogue and review than in the two other countries.

was seen to 'support work' to improve the situation of children. UN Doc. RC/C/8/Add.22 (1994), 4.

64 This continuity has also made it easier and less time consuming for officials to report, because they are familiar with the system and know what is expected. They furthermore know where to find the required information and how to present it.

65 For the quotes, see, respectively, UN Doc. A/HRC/WG.6/1/FIN/1 (2008), para. 87 and Formin (2004), 138.

66 The 2004 Ministry for Foreign Affairs report provided that the government had deliberately chosen to show a good example by reporting on time and cooperating with treaty bodies in order to counter the global trend of non or late submission of periodic reports to treaty bodies. It is also recognised that the international human rights policy is closely connected to the domestic human rights protection and that consistency between them is needed for Finland's credibility at the international level to address human rights issues. Formin (2004), 8, 10 and 135. 
Several positive features were identified, including the involvement of domestic stakeholders in the preparation of the state reports, the central and enthusiastic role of the Ministry for Foreign Affairs and the more positive attitude of Finnish officials towards the value and usefulness of reporting.

Several interviewees pointed to the broader influence of the reporting process. It was said to have educated government officials and contributed to a better knowledge about international standards. This has especially been the case for the $\mathrm{CRC}$, which has an increased impact and has been a driving force for legislation (for a further discussion, see also section XIII.3). ${ }^{67}$

\section{DOMESTIC IMPACT AND DOMESTIC MOBILISATION}

As was sketched in the introduction to this chapter, human rights awareness was limited in Finland and lower than the other Nordic countries until the ratification of ECHR. ${ }^{68}$ Far into the 1980 s, the Finnish internal human rights situation was an inappropriate issue to discuss. ${ }^{69}$ Human rights treaties played an insignificant role in the legislative process, in the government bureaucracy and in parliamentary proceedings.$^{70}$ In 1986, Tornüdd questioned whether the UN human rights system has had any considerable, direct and distinguishable impact on Finland. He argued that the ICCPR and ICESCR simply reflect the values that were already protected. ${ }^{71}$ It was primarily the late ratification of the ECHR in 1990 that was a 'turning point' ${ }^{72}$ and a 'rupture in the Finnish basic-rights culture'. ${ }^{73}$ Another important factor which contributed to the change in human rights culture as well was the four years 'action research' by Scheinin which started in autumn 1987. Together with human rights lawyers and organisations, he initiated domestic court proceedings and cases before the HRC and ECtHR, to challenge Finnish legislation in order to stimulate the development of case law on the applicability of human rights treaties in Finland. ${ }^{74}$

The role of human rights treaties has increased tremendously since the 1990s. Until the end of the 1980s, even superficial references to constitutional or human

67 Several interviewees attributed this to the role of NGOs and especially the Ombudsman for Children. Infra n. 124-126. Koulu and Hetemäki (2010), 5-8 and 17.

68 Rosas (1988), 427.

69 The first PhD on 'Finland and the international norms of human rights' was only published in 1986. Törnudd (1986).

70 An illustration of this is that the government simply forgot to recognise the individual complaints procedure under ICERD. Heyns and Viljoen (2002), 269. Rosas (2001), 297.

71 Tornüdd (1986), 28, 37 and 278. The HRC asked why many legislative amendments were made prior to the accession to ECHR, whereas little had happened prior to ratification of ICCPR. The government replied that Finnish lawmakers were unaware of legislative changes required by the ICCPR. UN Doc. CCPR/C/SR.1660 (1998), para. 5.

72 Rosas (2001), 310-311.

73 Tuori (2012), 9.

74 Scheinin (1991), 360. Infra n. 117. 
rights in court judgments were exceptional. ${ }^{75}$ The idea was that lawyers who had to fall back on human rights had a rather weak case. ${ }^{76}$ There is even an idea that lawyers who do not use human rights in their argumentation fail to live up the requirements for a professional lawyer. ${ }^{77}$ Scheinin pointed to the emergence of a 'human rights culture' with 'rapid changes' in the press, NGOs and legislator. ${ }^{78}$ Lavapuro et al. observed that human rights consciousness among all the major domestic actors has increased tremendously over the last 20 years. ${ }^{79}$ HalmeTuomisaari also argued that the human rights discourse has moved from the periphery to the centre and has become a popularised discourse which is used by a wide range of actors. She noted that human rights have become an integral part of the domestic political decision-making process since the 1990s and that they constitute a new set of universal norms used by policy makers to socialise the population. ${ }^{80}$ This section examines whether this transformation has also extended to the COs of the UN human rights treaty bodies and whether they have been given attention by domestic actors.

\subsection{Governmental attention}

Niemi found that the use of treaty body output in Finland is 'unique' or a 'best practice' compared to the five other Western countries in her study. This is because the findings of treaty bodies, including the COs, have been used in government Bills. ${ }^{81}$ Heyns and Viljoen also noted that the ICCPR and the COs and Views of the HRC have been the reason for amending legislation. ${ }^{82}$ A 2004 report of the International Law Association outlined some legislative proposals which were drafted in response to the COs. ${ }^{83}$ The report also noted more generally that Finland offers an example of 'frequent' or 'fairly extensive' reference to human rights treaties in the development

75 It was only in 1988, prior to the ratification of the ECHR, that the Supreme Administrative Court started to refer to human rights treaties. The Supreme Court followed suit in 1990. Before that, human rights treaties were never mentioned in court judgments, except for one reference in a minority opinion to article 26 ICCPR. KHO 1979 I 4. Rosas (2001), 291. Lavapuro et al. (2011), 520.

76 Pölönen (2010), 54. While the number of judgments of the Supreme Court in which human rights treaties were cited was 39 in the 1990s, this more than doubled to 88 in the period of 2000-2009. Lavapuro et al. (2011), 520. The Supreme Administrative Court has been even more eager to use human rights treaties. Scheinin (1991), 358. Koulu and Hetemäki (2010), 10.

Pölönen (2010), 54. Supra n. 24.

Scheinin (1990), 36.

Lavapuro et al. (2011), 520 .

Halme (2008), 29-30. Halme-Tuomisaari (2010), 257.

Niemi (2003), 31.

Heyns and Viljoen (2002), 290-291 and 294.

The critique of the HRC during the discussion of the state report in 1990 concerning the restrictions to travel abroad was referred to in the 1997 Bill amending the Passport Act, while the ICCPR COs 1998 were mentioned in a 2001 Bill establishing separate facilities for immigration detention. International Law Association (2004), para. 161-162. Heyns and Viljoen (2002), 287. 
and examination of legislative proposals. ${ }^{84}$ Bills usually include a section outlining the constitutional and human rights dimensions in which international recommendations and judgments are reflected upon, whereby most attention is paid to the ECtHR and the ECJ. The UN human rights treaties and the treaty body output are given considerably less attention. Out of the six UN treaties, most attention has been paid to the ICCPR and, more recently, the CRC. ${ }^{85}$ Several interviewees also stated that they try to use the COs in their work and that COs are used in government Bills, papers and speeches. They, furthermore, mentioned that working groups which are established to amend or draft a new law or to establish an action plan, usually collect all the relevant recommendations and COs that deal with the respective issue. ${ }^{86}$

The COs have also played a rather extensive role in the reports of the Ministry for Foreign Affairs, who has informed parliament about the government's (foreign) policy on human rights every couple of years since 1999. ${ }^{87}$ Since 2004, these reports have also addressed the domestic situation of human rights, including some of the COs. The COs are seen as providing a 'good starting point' to address problems in the protection of human rights in Finland and as 'criteria for the selection of the national aspects' in the report. ${ }^{88}$ The 2009 report even included a separate section about the recommendations and conclusions issued by international monitoring bodies, while it also referred to the treaty bodies and COs in relation to various thematic issues. ${ }^{89}$

The COs also played a part in the formulation of the 2012 human rights action plan. ${ }^{90}$ The working group appointed by the Ministry of Justice in September 2011 was asked to take into account, among others, the 'recommendations and decisions issued by the international human rights organs'. ${ }^{11}$ The Ministry for Foreign

84 International Law Association (2004), para. 158. Heyns and Viljoen also pointed to the 'ample evidence' of the impact of human rights treaties on legislation. Heyns and Viljoen (2001), 502. See, more recently, Tuori (2012), 31.

85 The UN human rights treaties, and especially ICCPR, played a role in the constitutional fundamental rights revisions of 1995, albeit smaller than the ECHR. The explanatory part of the Bill discussed a lot of the constitutional provisions in the light of ICCPR and ECHR. UN Doc. CCPR/C/FIN/2003/5 (2003), para. 3. Heyns and Viljoen (2002), 273 and 294.

86 The instructions for legislation (Helo), for example, provide that: 'If the Bill is significant in view of fundamental rights, care should be taken also to avoid controversy with the international human rights obligations binding on Finland. If necessary, the praxis of international human rights bodies, such as the European Court of Human Rights, should be discussed.' Ministry of Justice Publication 2006:3, 26.

87 References to the COs in the 2004 report were the result of a request of the Foreign Affairs Committee in 2000. Formin (2004). For the 2009 report, parliament requested an even more 'comprehensive assessment' of the implementation of human rights in Finland. Formin (2010), $81-86$.

88 Formin (2004), 8 and 10.

89 Formin (2010), 81-86.

90 The government initially did not intend to write a plan, because this 'would have required considerable work and involved the allocation of resources'. Formin (2010), 82. Parliament, nonetheless, requested the government to do so (brief No. 3/2010).

91 'Preparation of a national human rights action plan', September 2011: <213214137012.edelkey. net/text/en/Etusivu/Valmisteilla/Kehittamishankkeita/1302674002425>, accessed 31 July 2013. 
Affairs drafted a long list which included all the recommendations available, including the COs. Hence, the plan listed the COs as one of the 'essential sources' which provide information on problems with the implementation of human rights..$^{92}$ The COs of the CAT, CRC and CEDAW Committee in particular were listed among various sources as the legal basis for intended policy or legislative projects (see table 13.1 in section 4). Several government officials held that COs were used as part of the justification for concentrating on or prioritising a certain issue.

The COs of the CRC Committee received increased governmental attention during the years 2007-2011. The Ombudsman for Children noted the government's decision to commit itself to the implementation of the COs 2005 in this period. ${ }^{93}$ This was especially the result of the Policy Programme for the well-being of children, youth and families (2007-2011), which had as an objective to overcome a fragmented approach to children's rights and to strengthen the implementation of the CRC. ${ }^{94}$ The CRC served as 'a guiding document' and was explicitly referred to a couple of times. ${ }^{95}$ Interviewees held that the COs were a factor in the background of the Policy Programme, but they were not the primary driver. ${ }^{96}$ The Programme contributed to the effectiveness of some COs (see also section 4). It led to several improvements in line with the COs, such as improved data collection and dissemination of the CRC. ${ }^{97}$

\subsection{Parliamentary scrutiny}

The state reports or COs are not tabled or discussed in parliament. ${ }^{98}$ There is no structural attention for and guaranteed awareness about the COs or the implementation of UN human rights treaties, as several interviewees also noted.

92 Other sources include, among others, the observations of the Constitutional Law Committee, the Parliamentary Ombudsman, UPR recommendations and judgments of the ECtHR. Ministry of Justice Finland (2012), 19.

93 UN Doc. CRC/C/FIN/4 (2008), para. 51.

94 UN Doc. CRC/C/FIN/4 (2008), para. 38-42.

95 UN Doc. CRC/C/FIN/4 (2008), para. 53. CRC/C/FIN/Q/4/Add.1 (2011), para. 5 and 8. Niemi (2003), 36-37.

96 The 2008 state report, for example, provided that 'the objective of the Policy Programme [...] reflect the development needs emphasised in the general observations of the UN Committee on the Rights of the Child'. UN Doc. CRC/C/FIN/4 (2008), para. 39.

97 NGOs also considered that the government and the Ombudsman for Children have increased dissemination of the CRC 'in compliance with the' COs. UN Doc. CRC/C/FIN/4 (2008), para. 97-98 and 102. Koulu and Hetemäki (2010), 14-15. The government, for example, developed a national communications strategy and commissioned a study about people's awareness of the CRC in 2008 and 2010. CRC/C/SR.1629 (2011), para. 42. The Child Welfare Act 2007 and a new financing system alleviated the concerns of the CRC Committee as to the inconsistencies among social welfare and health service delivery by municipalities. The COs of the CRC Committee were considered one element that had contributed to this Act. Cardol (2010), 93 and 99.

One exception is the 1991 state report under CEDAW which was discussed during a public hearing in parliament with the Ministers for Equality, Justice and the Environment. UN Doc. CEDAW/C/FIN/2 (1993), 3-4. 
The Constitutional Law Committee has, however, referred to the output of the HRC on several occasions. ${ }^{99}$ The 2004 report of the International Law Association even noted that there are 'a significant number of cases' in which this Committee used the output of treaty bodies, but these were almost all confined to the Views of the HRC and not so much the COs. ${ }^{100}$

Some interviewees noted that the frequent reliance on the HRC around the 2000s was the result of Scheinin, who was a member of the HRC from 1997-2004. He was regularly consulted by the Constitutional Law Committee in this period. ${ }^{101}$ Some interviewees, however, noted that after Scheinin went abroad, other experts have not really filled this vacuum and have hardly referred to the COs or even the Views. Interviewees and academics noted that members of the Constitutional Law Committee and constitutional law experts have primarily relied on the ECHR and the judgments of the ECtHR and more recently the ECJ. As a result, the case law of the ECtHR is routinely referred to by the Committee. ${ }^{102}$ Another reason for the heightened attention to the ECHR is that the Finnish judge of the ECtHR has given the Committee an update about new case law and its implications on a regular basis. ${ }^{103}$

It is not unthinkable that the COs have had some impact on the Constitutional Law Committee in recent years, because MPs from the Committee have attended some of the dialogues with treaty bodies since 2005. ${ }^{104}$ Nauclér (SPP), who attended CEDAW 2008, stated that she would report back to parliament on the outcome of the dialogue and 'would be attentive to follow-up'. ${ }^{105}$ Nauclér indeed mentioned the CEDAW and the COs several times, as was also noted by one government official as well. ${ }^{106}$ Other parliamentary committees have also mentioned the COs on some

99 Heyns and Viljoen (2002), 294. Niemi (2003), 31. legislation on minimum wages. Opinion 4/2002. The other 12 opinions referred to the HRC, its Views (7), GCs (2) and COs for other countries (3). International Law Association (2004), para. 160.

101 See also Niemi (2003), 31-32.

102 Tuori (2012), 8.

103 Tallroth (2012), 28-29.

104 Petri Helander, Counsel to the Constitutional Law Committee, performed a search on 13 May 2013 in the database with the opinions of the Committee with the word 'komitea' (Committee) in the period after 2003. He found two opinions in which the COs for Finland were explicitly mentioned. The COs 2005 of the CRC Committee were cited in Opinion 58/2006 concerning the right of the child to express his or her considerations to the court. Opinion 20/2005 referred to the HRC COs 2004 concerning prisoners on remand and to the CAT COs 2005 concerning prison conditions and the acceleration of prison renovation. Note that Opinion 4/2004 and 31/2002 referred to the COs for Slovakia, Austria and Trinidad and Tobago.

106 Nauclér especially referred to CEDAW and the COs with respect to violence against women. See for example the speech to Finland's UN Women on 22 April 2013 (in Finnish): <www.naucler. ax/category/speeches-and-material/>, accessed 31 July 2013. In April 2011 she also organised a discussion meeting about CEDAW and the process of reporting, which was also attended by the 
occasions. ${ }^{107}$ Especially the debates about the human rights reports of the Ministry for Foreign Affairs were said to be used as an opportunity to refer or discuss certain COs. ${ }^{108}$ Several interviewees also noted that some COs have been highlighted as an extra argument during debates about issues that were already in the media and discussed, such as the issue of Sami land rights and the ratification of ILO Convention 169 (chapter XIII, section 4.2) and violence against women. There were, however, quite a number of interviewees who were hardly aware of concrete instances in which parliament relied on or asked a (written) question about the COs. They argued that reference to COs remains limited to only a couple of MPs who are human rights minded and are aware of the UN human rights treaty bodies and their COs.

\subsection{Courts and legal practice}

The role of COs in legal practice and in judgments of Finnish courts is marginal. The author is only aware of one reference to the COs in a court case. The Supreme Administrative Court explicitly referred to CERD's COs 2009 in its judgment concerning the definition of Sami. ${ }^{109}$ Likewise, Niemi found in 2003 that the use of treaty body findings by courts had been 'very limited'. She referred to only one judgment of the Supreme Court in which the Views of the HRC were relied upon. ${ }^{110}$

By contrast, the case law of the ECtHR is rather systematically and routinely referred to by courts and has increasingly played a central and high profile role, especially in judgments of the two highest judicial authorities, the Supreme Court and Supreme Administrative Court. ${ }^{11}$ The ICCPR has been mentioned to a lesser extent. $^{112}$ The role of the CRC has recently increased, although not as much as might be expected on the basis of its role in the legislative process. ${ }^{113}$ By contrast, ICERD, CAT and CEDAW have been given very little attention to by courts, if at

Finnish member of the CEDAW Committee, Niklas Bruun. <www.naucler.ax/2011/04/>, accessed 31 July 2013 (in Finnish).

A report of the Committee on Social Affairs and Health referred to the COs of the CRC Committee with respect to the lack of coordination among authorities. Report 23/2002. International Law Association (2004), para. 160.

The government also held that the reports have resulted in more attention to human rights in parliamentary debates. UN Doc. CCPR/C/SR.2226 (2004), para. 2.

109 In these COs, the CERD noted that the definition was 'too restrictive', see UN Doc. CERD/C/ FIN/CO/19 (2009), para. 13. It its judgment of 26 September 2011 (KHO:2011:81), the Court adopted a wider definition than the Sami Parliament in line with the COs by also considering the self-identification of individuals. UN Doc. CERD/C/FIN/CO/20-22 (2012), para. 12.

$110 \quad$ Niemi (2003), 50.

111 Lavapuro et al. (2011), 520. Husa (2010), 21. Ojanen (2009), 198.

112 In the period 1990-1997, there were 108 judgments of higher courts in which human rights were mentioned. In almost all of these cases, the ECHR was referred to. The ICCPR was mentioned 32 times. Rosas (2001), 303. Heyns and Viljoen (2002), 277-278.

Koulu and Hetemäki (2010), 8-11. 
all. The low number of judgments in which ICESCR played a role (four) was characterised by the government as 'numerical scarcity'.114 The government attributed the limited role of UN human rights treaties to the preference of courts to rely on corresponding domestic law provisions or case law of the ECtHR as well as the limited human rights training of judges up to the 1990s. ${ }^{115}$ Lavapuro et al. also pointed to the 'minimalist approach to human rights' whereby Finnish courts easily satisfy themselves with the minimum standard of protection under the ECHR. ${ }^{116}$

The focus on Strasbourg and the limited familiarity with the UN human rights treaty regime in legal practice is illustrated by the limited number of individual complaints lodged with the treaty bodies. Only 27 communications were considered by the HRC. It is especially noteworthy that there have only been three cases since $2000 .{ }^{117}$ By contrast, the number of communications for the Netherlands has been significantly higher. There have been, for example, 23 Dutch cases under ICCPR since 2000. ${ }^{118}$ Several explanations for the limited use of the individual communications procedure can be given. Firstly, there is a preference for bringing a case before the ECtHR, because this can result in a binding judgment. ${ }^{119}$ This is also quicker and more cost-effective, since the case can be brought before the ECtHR in Finnish or Swedish. Secondly, the system of legal aid for the ECtHR does not apply to individual communications under UN human rights treaties. Thirdly, there is a lack of knowledge about the procedure before the UN treaty bodies. Fourthly, whereas members of the NGO Finnish League for Human Rights helped applicants with their communications to the HRC in the 1990s, they have ceased doing this since the 2000s (chapter XIII, section 3.5). As will be described below, several of the communications in the 1990s dealt with Sami land rights under the 'unique provisions' of articles 25 and 27 ICCPR (chapter XIII, section 4.2)..$^{120}$

114 This marginal role is remarkable given the rather extensive case law in the field of economic, social and cultural rights which shows that courts have approached (dimensions of domestic social rights as justiciable and have provided judicial remedies for them. In quite a lot of cases, courts have annulled decisions of municipal authorities not to provide social assistance. Scheinin (2003), 245-249. UN Doc. E/C.12/FIN/5 (2006), para. 12.

115 UN Doc. CEDAW/C/SR.841 (2008), para. 31. UN Doc. E/C.12/FIN/5 (2006), para. 13. Another explanation for the limited role of ICESCR and CERD is that these treaties were incorporated through a government decree only, which is hierarchically subordinate to acts of parliament. Scheinin (1996), 260 and 275.

116 Lavapuro et al. (2011), 523.

117 The last was on 1 April 2005. The majority of the communications (14 of 27) were submitted in the period of 1988-1992. <sim.law.uu.nl/sim/Dochome.nsf>, last modified on 19 April 2012. Supra $\mathrm{n} .74$.

118 For the Netherlands, the number of communications for ICCPR in April 2012 was 70, while the Netherlands ratified the Optional Protocol more than two years later than Finland on 11 December 1978 (Finland 11 December 1976).

119 Heyns and Viljoen (2002), 289.

120 Heyns and Viljoen (2001), 515-516. 
Chapter XIII

\subsection{Ombudsmen and Human Rights Centre}

In Finland, there are three thematic Ombudsmen in addition to the Parliamentary Ombudsman. There is an Ombudsman for Gender Equality, Children and Minorities. ${ }^{121}$ The Ombudsmen's involvement in the reporting process and their use of COs at the domestic level has been rather ad hoc and issue based, except for the Children's Ombudsman.

The Ombudsman for Children has been rather extensively involved in the reporting process under the $\mathrm{CRC}$ since its establishment in 2005. Ombudsman Aula (2005-present), for instance, submitted a rather extensive alternative report in 2011 to the CRC Committee. She also attended the CRC Committee's pre-session working group meeting with NGOs and the dialogue with the government, both in 2011. ${ }^{122}$ The Ombudsman has also been particularly active in terms of (monitoring) follow-up to the COs. She kept an eye on the government's commitment to implement the COs 2005 in the years 2007-2011. ${ }^{123}$ After the COs 2011, she made information material about the process of reporting for young people. In 2013, the Ombudsman organised a follow-up workshop together with NGOs to take stock of the implementation of the COs 2011. It is not surprising that the Ombudsman's involvement is rather considerable. The Ombudsman has the explicit duty to promote the implementation of the $\mathrm{CRC}$ and disseminate information and increase awareness about it. ${ }^{124}$ Aula has used the $\mathrm{CRC}$ as a normative foundation or 'guiding document' for its work. ${ }^{125}$ She has also consistently commented on Bills with children and young persons from a CRC perspective. In this way, she has clearly enhanced the role of the CRC. ${ }^{126}$

The Ombudsman for Gender Equality, which was established in 1987, has been involved in the reporting process under CEDAW for a rather long time. Remarkably, the Ombudsman has not submitted any parallel reports to the CEDAW Committee. Rather, the (deputy) Ombudsman has been part of the government delegation during the dialogue. However, this does not mean that the Ombudsman has merely defended the government's policy. The Ombudsman has been rather open and honest about Finland's challenges. ${ }^{127}$ The Ombudsman has occasionally used the COs as well, especially those related to violence against women, in discussions with

121 The three thematic Ombudsmen are independent but administratively situated in the Ministry of Social Affairs and Health (the former two) or the Ministry of Interior (Minorities).

122 Office of the Ombudsman for Children, 'Report to the UN Committee on the Rights of the Child' 2011:1 (Jyväskylä, 2011).

123 UN Doc. CRC/C/FIN/4 (2008), para. 51.

124 Ojanen (2008), 11-12 and 22.

125 UN Doc. CRC/C/FIN/4 (2008), para. 51.

126 Koulu and Hetemäki (2010), 13.

127 See particularly the honest statements in 2001 that legislation needed to be developed with respect to fixed term contracts and that inviting eminent academics to take up professorships without advertising was 'clearly discriminatory'. UN Doc. CEDAW/C/SR.495 (2001), para. 14. UN Doc. CEDAW/C/SR.494 (2001), para. 34. 
government and in statements before parliament about Bills as supporting arguments to strengthen its advocacy (see also chapter XIII, section 4.6).

The Ombudsman for Minorities, earlier the Ombudsman for Aliens (1991-2002), has also been involved in the reporting process, albeit in a more limited and unsystematic way than the other two thematic Ombudsmen. It has not submitted any reports or information to the treaty bodies directly. Sometimes information has been provided to the Ministry for Foreign Affairs during the compilation of the state report on a rather ad hoc basis. The Ombudsman has occasionally used the COs or UN human rights treaties in its domestic work, especially in relation to the Sami land rights issue and the ratification of ILO Convention 169 (see also chapter XIII, section 4.2). ${ }^{128}$

The involvement of the Parliamentary Ombudsman is comparable to the Ombudsman for Minorities. Its involvement in relation to CRC has, however, been more systematic given the special statutory responsibility with respect to children's rights and its ability to deal with individual complaints from children. Hence, it has been involved in the drafting of all the state reports under CRC. ${ }^{129}$ In 2011, the deputy Ombudsman also attended the pre-session working group meeting with the CRC Committee. The Ombudsman has sometimes referred to the COs of the treaty bodies in its decisions, especially those of the CRC Committee. ${ }^{130}$ The reliance on these international sources is illustrative of the pioneering role of the Ombudsman in the use of human rights treaties already in the 1980s. ${ }^{131}$

On 2 January 2012, the Human Rights Centre opened its doors. Its formal tasks include the dissemination of information, education, training and research on human rights as well as the monitoring of the implementation of human rights treaties. ${ }^{132}$ To date, its involvement in the reporting process has been limited. The Centre, for example, did not submit an alternative report to the HRC in $2013 .{ }^{133}$ It is

128 The human rights perspective has become more important in the work of the Ombudsman, especially since 2009. 'Annual report of the Ombudsman for Minorities 2009', 2010: <www. vahemmistovaltuutettu.fi/download/31681_VV_Vuosikertomus_englanti.pdf>, accessed 31 July $2013,4$.

129 Kurki-Suonio (2010), 339.

130 Koulu and Hetemäki (2010), 12. The contributions to a jubilee book marking the $90^{\text {th }}$ anniversary of the Ombudsman, written by the (Deputy) Ombudsman and her staff, show a great awareness of the (existence of) treaty bodies and their pronouncements on the Finnish situation. Pirjola noted that the Ombudsman regularly follows the COs. Pirjola (2010), 135. Pölönen (2010), 54.

131 Several authors referred to the 'pioneering role' and commitment to human rights of Heinonen, Ombudsman from 1986 to 1989. Since 1995, the Ombudsman has increasingly and 'vigorously' relied and reflected on constitutional rights, as well as human rights treaties. Tallroth (2012), 59-60. Interviewees noted that several Ombudsmen, including Lauri Lehtimaja (1995-2001) and Riitta-Leena Paunio (2002-2009, deputy Ombudsman between 1996-2001), were interested in human rights.

132 UN Doc. CRC/C/SR.1628 (2011), para. 18 and 43.

133 Neither did it attend the dialogue with the HRC in 2012. It only gave more detailed information on its own organisational structure and operation to the HRC. 
unclear whether the Centre will start monitoring the follow-up to COs. ${ }^{134}$ In this context, it should be noted that the Centre probably lacks the financial resources and staff to be structurally involved in the reporting process and conduct such a follow-up assessment. It only consists of three people without secretarial support. In addition, other issues, such as human rights education and awareness, are considered more of a priority.

\subsection{NGOs}

The involvement of NGOs in the process of reporting has decreased since the turn of the millennium, except for the CRC and CEDAW. While NGOs made 'systematic efforts' to use the reporting process in the 1990s, ${ }^{135}$ hardly any alternative reports have been submitted since then. This is rather surprising in the light of the increased popularity and importance of human rights, the growth of the membership of human rights NGOs and the rising human rights advocacy by NGOs. ${ }^{136}$

The major explanation for the limited involvement of NGOs in the reporting process is that the Finnish League for Human Rights who had been writing alternative reports since 1989 for almost all the treaties, except CEDAW, ceased doing this in $2000 .{ }^{137}$ Representatives from the League held that they decided not to write alternative reports anymore, because of a lack of resources, expertise and organisational difficulties. Another reason was the feeling that the process had only limited influence at the national level and that hardly anything happened with the COs. ${ }^{138}$ Other NGOs who had cooperated with the League, or contributed to the alternative reports by submitting information, did not take over the coordinating role of the League. ${ }^{139}$ As a consequence, there have been no parallel reports from domestic NGOs for CERD 2003 and 2009, CAT 2005 and 2011, ICCPR 2004 and ICESCR 2007.140 This shows that there has not been much interest or awareness

134 The Centre is planning to create a portal through which the COs are more easily accessible, but this portal will not be built until 2014-2015. Email from Leena Leikas of 25 September 2013. Scheinin (2000), 242. Heyns and Viljoen (2002), 266.

136 The membership of Amnesty International, for example, more than tripled between 2003 and 2007 from 10,000 to over 30,000. Halme-Tuomisaari (2010), 280-281. Lavapuro et al. (2011), 519.

137 The League was especially focused on racial discrimination, ICERD and ICCPR. It wrote its first report for ICCPR in 1989 and submitted its last report to the CESCR in 2000. Other reports were written for ICCPR 1998, ICERD 1996 and 1999, CAT 1996 and 2000, CRC 1996 and ICESCR 1996. Heyns and Viljoen (2002), 284-285. It was also felt that results could be achieved more easily at the domestic level by submitting statements in relation to government Bills and through preventive work, (human rights) education and training on the ground. The Association for Foreigners cooperated with CERD 1996 and 1999 and Amnesty International with ICCPR 1998. Heyns and Viljoen (2002), 284-285.

140 During CERD 2012 there was a submission of the Saami Council, an umbrella organisation of Sami organisations in Russia, Finland, Sweden and Norway. 
about especially ICESCR or CAT and ICERD. ${ }^{141}$ Another illustration of the limited involvement of NGOs in international human rights processes is the cancellation of the national briefing of NGOs during UPR 2012, because no Finnish NGOs were present. Amnesty International, nonetheless, decided in 2011 to become more active in submitting alternative information. ${ }^{142}$ Several other NGOs have followed suit and submitted parallel reports to the HRC in 2013. ${ }^{143}$

The first alternative report for CEDAW was only prepared in December 2000 on behalf of NYTKIS (the Coalition of Finnish Women's Associations) on the initiative of two individuals. ${ }^{144}$ NYTKIS' alternative reports since then have, however, been limited in the number of pages and have not paid attention to (the implementation of) previous COs, except for the COs 2001 related to violence against women. ${ }^{145}$ Several authors noted that NYTKIS and other women's NGOs have not used CEDAW as an essential component of their work or promoted or raised awareness about CEDAW. ${ }^{146}$ This also reflects the views expressed by interviewees that the knowledge and expertise about CEDAW, the process and the COs has been limited, even among women's NGOs. Lobbying on the basis of CEDAW COs has also been limited, except for violence against women. ${ }^{147}$ Representatives from women's rights NGOs argued that COs were more seen as an inspiring tool inside NGOs, rather than a lobbying tool.

The COs of the other treaties have hardly been followed-up and used by NGOs in a systematic way either. Several interviewees noted that the Finnish League for Human Rights - when it was still active with alternative reporting in the 1990s hardly lobbied on the basis of COs, because of limited resources and the fact that the League was largely volunteer based. Since then, the advocacy on the basis of COs

141 No public hearings were organised for ICCPR 1998 and ICESCR 1996 and 2000. NGOs in the field of racial discrimination have hardly been aware of and paid almost no attention to ICERD. Heyns and Viljoen (2002), 274 and 283-284. The interest of NGOs in presenting their views with respect to the 1999 report under CAT was minor. UN Doc. CAT/C/44/Add.6 (1999), para. 6.

142 This was during the reporting process under CAT 2011 when the CAT Committee asked Amnesty to submit some information informally. It has subsequently submitted information to the UPR in 2012 and the HRC and CERD in 2013.

143 In addition to Amnesty International, information was submitted by the Saami Council, NYTKIS, the Finnish Disability Forum, SETA ry (LGBTI rights), the Union of Conscientious Objectors, and the Union of Freethinkers. Likewise, several NGO representatives attended the dialogue, including Nuorgam and Århus (Saami Council) Aija Salo (SETA ry).

144 These were Sinikka Mustakallio, equality consultant, and Merja Pentikäinen, professor in international law.

145 The 2000 report had 26 pages, while the 2008 report had 27 pages.

146 Zwingel (2005), 308-309. Nousiainen and Pentikäinen also stated that NGOs increasingly rely on the Beijing Document, because this is seen as more useful and concrete. Nousiainen and Pentikäinen (2013), 579-580.

147 See, for example, the press release of Nytkis of 29 September 2010 (in Finnish): <www.nytkis. org/doc/TIEDOTE290910_Naisiin_kohdistuvan_vakivallan_vahentamisen_ohjelman_rahoitus. doc>, accessed 31 July 2013. See also the references of Pakkanen (Feminist Association Unit) to the COs of the CEDAW Committee with respect to shelters in 'Government planning measures for better gender equality', Helsingin Sanomat, 22 October 2010. 
has been rather ad hoc and issue based and not so much focused on the implementation of the treaty per se. Examples of COs that were used and that were given during interviews include the land rights of Sami and the ratification of ILO Convention 169 (chapter XIII, section 4.2), the rights of Roma and racial discrimination. Amnesty International has, nonetheless, started to use the COs as an important additional argument to forward its domestic advocacy in relation to particular issues, such as violence against women and the criminalisation of torture (chapter XIII, section 4.3). ${ }^{148}$ The photo at the bottom of the cover of this book portrays an Amnesty International campaign against violence against women in Finland.

The issue of limited resources and expertise of NGOs is an important explanation for the limited lobbying and use of the reporting process by NGOs. That being said, the limited NGO activity is remarkable in the light of the more extensive involvement and advocacy activities of NGOs in New Zealand and the Netherlands where NGOs face similar problems. The most important reason for the limited lobby in Finland is that several NGOs considered it sufficient to present their views directly to the Ministry for Foreign Affairs during the compilation of the state report. ${ }^{149}$ Some NGO representatives noted that they do not have major disagreements with (most of) the ministries and especially the Ministry for Foreign Affairs. Some even referred to their relationship with the latter Ministry as a joined effort, also given the relatively positive attitude of officials from this Ministry towards the value of reporting (chapter XIII, section 2.2). One interviewee even noted that NGOs are lapdogs of the government rather than watchdogs. Harjunen observed that NGOs are frequently included or part of the policy-making process to such an extent that it is often not easy to distinguish between them and the government. There are, hence, hardly any NGO texts or reports other than the official policy documents. 150 This has been referred to as 'a government civil society and a civil society government'. ${ }^{151}$ The close relationship between NGOs and the government was attributed to the fact that a large part of the financing of many NGOs comes (in)directly from the state. In addition, it might also be the result of the Finnish tendency to trust the authorities and to achieve consensus beforehand. ${ }^{152}$ Moreover, another factor is the small size of the country which

148 Amnesty has already been relatively active with respect to violence against women since 2004 . It contributed to the $2008 \mathrm{NGO}$ report to the CEDAW Committee and has used the COs. More recently, it also used several COs of CAT 2005 and 2011 and CRC 2011 in relation to the criminalisation of torture, the detention of asylum children, the access to a lawyer for minor offences and the exclusion of evidence obtained through torture. See, for example, the letter with respect to the detention of asylum children of 21 June 2012 (SM072:00/2011) (in Finnish): $<$ www.amnesty.fi/kannanotot/lausunto-sisaministeriolle-lasten-sailoon-otosta/files/sailoonotto. pdf/attachment_download/attachedFile>, accessed 31 July 2013.

Harjunen (2007).

Pesonen and Riihinen (2002), 284.

One illustration is the high level of trust in the police in comparison with other countries. Kääriäinen (2008), 156-157. 
means that everyone in the human rights field knows each other and that (childhood) friendships between NGO representatives and government officials are not uncommon. Another - more cultural - explanation is that - as Rosas also observed - that Finnish NGOs are not as active in criticising or putting forward proposals as NGOs in other Nordic countries. ${ }^{153}$ Several interviewees also had the feeling that Finnish NGOs are not as active as NGOs in other Nordic countries or the Netherlands, where NGOs are more vocal and pushier. By contrast, Finnish NGOs were characterised as generally more pragmatic, less confrontational, less aggressive, and more willing to cooperate.

Several NGOs representatives criticised the too close relationship, because it might make it more difficult for NGOs to be critical towards the government and really push for (real) change if things do not advance. It is difficult to say whether the limited lobby and advocacy is a factor that hampers the effectiveness of COs. It could be argued as well that the cooperative relationship and the incorporation of concerns of NGOs actually contribute to the effectiveness of COs.

The CRC is without doubt the treaty in relation to which the greatest activity of NGOs exists at the moment. The Finnish government also noted the important and strong role of NGOs in influencing the drafting of legislation, disseminating and raising awareness about the CRC and stimulating the debate about it. ${ }^{154}$ Since Finland's initial report in 1995, alternative reports have been coordinated by the Central Union for Child Welfare. This is an umbrella organisation for child welfare with currently 94 NGOs, such as UNICEF and Save the Children, and 36 municipalities as member organisations. Both the Central Union and UNICEF, whose work is clearly underpinned by the $\mathrm{CRC}$, also have a strong and relatively well resourced organisation with permanent staff. The quality of the alternative reports for CRC has been relatively high in comparison with the NGO reports for the other treaty bodies and has improved, especially since the 2005 NGO report. ${ }^{155}$ While hardly any NGOs have been to Geneva or New York to address the treaty bodies, children's rights NGOs have consistently been present during the presession working group and the dialogue with the government. In 2011, for example, there were at least five different NGOs present. ${ }^{156}$

The Central Union and the other (children's rights) NGOs like UNICEF have also been rather active in using COs in their advocacy, especially since the COs of $2005 .{ }^{157}$ COs are seen as giving a strategy and a good tool to lobby the government to have an impact on legislation, projects and funding. NGOs see it as their duty to

\footnotetext{
153 Rosas (2001), 298.

154 UN Doc. CRC/C/FIN/4 (2008), para. 22 and 28.

155 The report of 1995 was 6 pages, the 2001 report 14 pages and the 2005 and 2008 reports 33 and 38 pages.

156 There were two representatives from the Central Union, as well as representatives from UNICEF, Save the Children, The Federation of Mother and Child Homes and Shelters and one youth organisation.

157 A brochure of the Union mentioned that it monitors the COs. Central Union for Child Welfare, Finland and its children. Challenges and responses (Kirjapaino Oma, Jyväskyla, 2008), 9.
} 
repeat the message in the COs. The Central Union, for example, took the initiative to organise a seminar to develop strategies on the implementation of the COs 2005 in February 2006, which was also attended by the 2005 country rapporteur for Finland. The CRC Committee appreciated this activity and considered it to be a model for other countries. ${ }^{158}$ After this, the Central Union started to organise yearly follow-up seminars on one or two COs in specific together with the Ministry for Foreign Affairs. ${ }^{159}$ The Central Union and other NGOs have tried to involve and lobby parliament as well. The Central Union, for instance, sent the CRC and COs 2011 to the newly elected parliament in 2011. There was also a seminar in the fall 2011 during which the COs 2011 were discussed in terms of priorities for parliament. MPs and government officials were present, in addition to NGOs and the Ombudsman for Children. The latter is also illustrative of the rather good relations between NGOs, the government, Ombudsman for Children, and the Parliamentary Ombudsman. They meet regularly and also cooperate in the context of follow-up. It was acknowledged by interviewees that all actors have the same goal and realised that it is fruitful to cooperate.

\subsection{Media coverage}

Heyns and Viljoen and interviewees noted in 2002 that there was some, albeit rather limited, media coverage of the COs. When the COs and the process were covered in the media, it was usually in a rather short and descriptive way. ${ }^{160}$ The latter was also noted by interviewees, who argued that it is often difficult to get the media interested in the reporting process. This is despite the fact that the media is increasingly publishing about human rights and (violations of) human rights treaties in Finland. Especially judgments of the ECtHR are reported on. ${ }^{161}$ At the end of the 1990 s, there was a practice of organising press conferences with a view to informing the media, officials, NGOs and other interested parties and to encourage the media to write about the dialogue and the COs. ${ }^{162}$ Officials explained that this practice was abandoned, because of the limited interest of the media. At the

158 CRC member Krappmann participated in the seminar. See the letter of the Chair of the Committee Doek to Kuikka of 12 October 2006: <asiakas.poutapilvi.fi/ltk/palve/uploads/726 ORG_>, accessed 31 July 2013. The Central Union also invited country rapporteur Herczog to speak to NGOs and children in May 2011.

159 Supra n. 58.

160 The attention was primarily attributed to the press conference organised by the Ministry for Foreign Affairs and/or the Finnish League for Human Rights. There was quite a lot of media attention for the CERD COs 1996 as well as ICCPR and CRC. Heyns and Viljoen (2002), 288. Nousiainen and Pentikäinen (2013), 576.

161 The ECtHR has also been treated as more authoritative by the media. UN Doc. CERD/C/FIN/19 (2007), para. 253-254. Heyns and Viljoen (2002), 274.

162 See, for example, CRC/C/70/ADD.3 (1998), para. 30-31. UN Doc. CERD/C/363/Add.2 (2000), para. 97. 
moment, the Ministry for Foreign Affairs only issues a press release on its website and circulates the translated COs to domestic stakeholders.

The Heyns and Viljoen study noted that the HRC and ICCPR received more media attention in the period of 1997-2000, also as a result of the membership of Scheinin. ${ }^{163}$ In recent years, the comments of the HRC with respect to the Sami land rights issue and the reindeer herding dispute (chapter XIII, section 4.2) has received considerable attention as well. ${ }^{164}$ There has also been relatively more media coverage of the reporting process under the CRC. A couple of newspapers wrote about the 1998 state report under CRC and observed that the interest in the rights of the child was growing. ${ }^{165}$ Some interviewees also noted that there was also some coverage of the visit of the country rapporteur of the CRC Committee to Finland in May 2011.

\section{Assessing the efFectiveness of COS}

This assessment of the effectiveness of COs in Finland in this section is primarily based on the response of the government to the COs in state reports and other UN documents, the human rights reports of the Ministry for Foreign Affairs of 2004 and 2009 and NGO reports. This document analysis was complemented with the examples of effective COs given by interviewees (see table 13.1). For a further discussion of the methodology, see chapter III, section 2.3 and chapter XII, section 4.

As in the Netherlands and New Zealand, the great majority of - often broad and unspecific - COs has been ineffective because they simply coincided with existing or intended policy or legislative measures without having had any (causal) effect on them. In addition, several COs have been rejected or have remained completely unaddressed, but their number is more limited in Finland than in the Netherlands or New Zealand. ${ }^{166}$ As reasons for the ineffectiveness of such COs, government officials mentioned financial restraints, conflicting (political) priorities and interests, problems and attitudes that are difficult to change in practice and the unrealistic nature of the COs. Especially COs that would imply additional resources, such as additional shelters for victims of violence against women, are not likely to be (fully) effective.

163 Several dozens of newspaper articles were devoted to the cases Vuolanne and Torres. Heyns and Viljoen (2002), 274 and 280.

164 See, for example, 'UN Human Rights Committee criticises Finland over Sami issue', 8 November 2004, Helsingin Sanomat International Edition.

165 UN Doc. CRC/C/FIN/4 (2008), para. 28 and 30-31.

166 Ineffective COs include, among others, the accelerated asylum procedures, the explicit mentioning of race and ethnic origin as ground of discrimination in section 5 of the Constitution, the definition of Sami, the gathering of statistical data on ethnic background, the ratification of the International Convention on Migrant Workers, the withdrawal of the reservations to ICCPR, the provision of more resources to ombudsman institutions and the introduction of a minimum wage. 
Chapter XIII

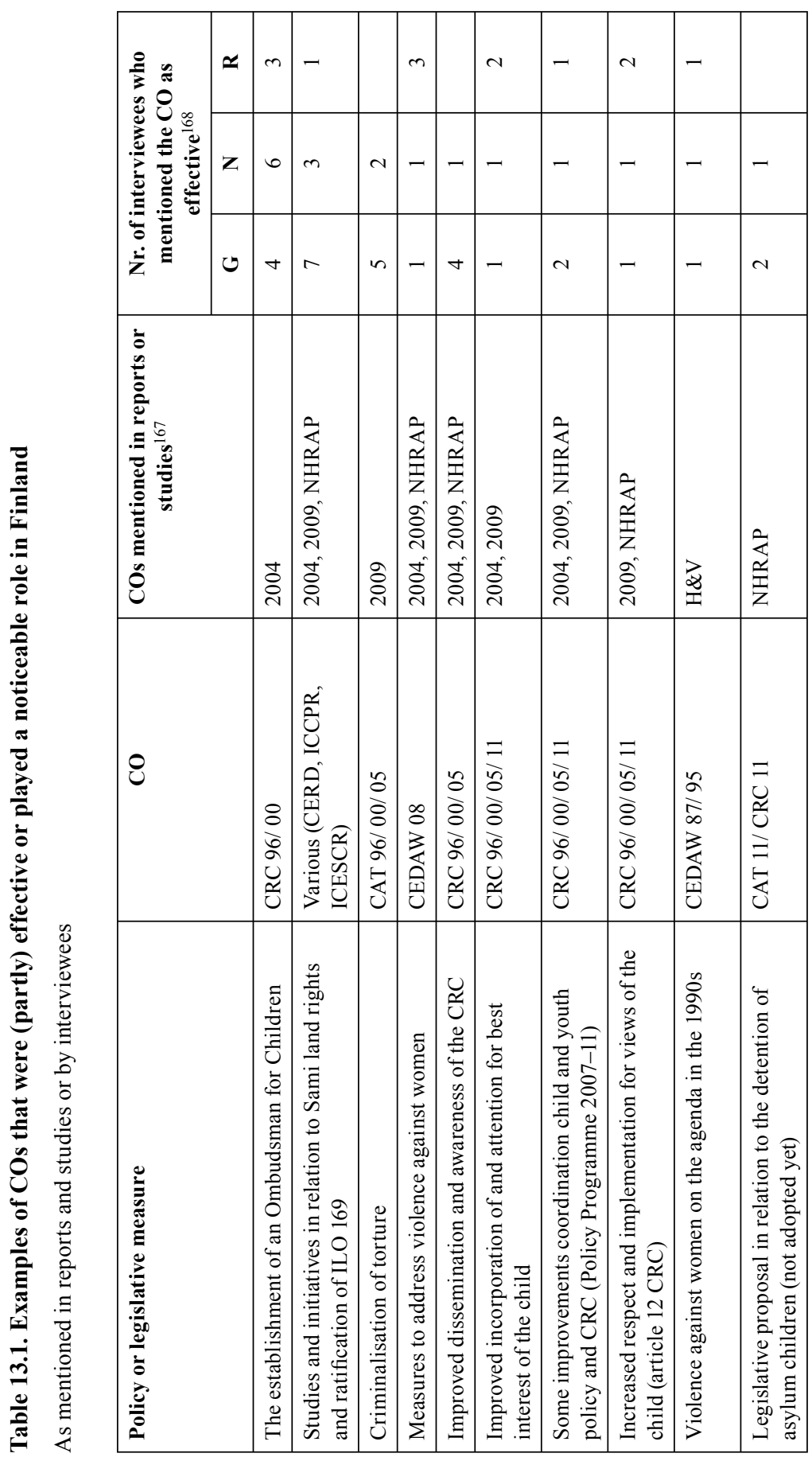

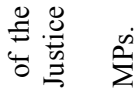

苛范

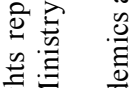

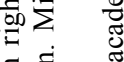

ีㅡㄹ कै

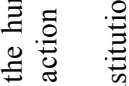

을

离

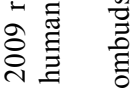

플

实急

ํํㄱㄹㅠ

료

ญี 응

亭 立

焉

约

空艺

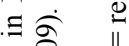

융

:

䒿

च ट्य

范 卷

음ㅇํㅇำ

ह

施

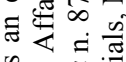

ป

उृ. $\frac{000}{0}$ ज

产寄泀

$\|$ 苛要

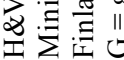

$\stackrel{\circ}{\circ}$ 
Finland

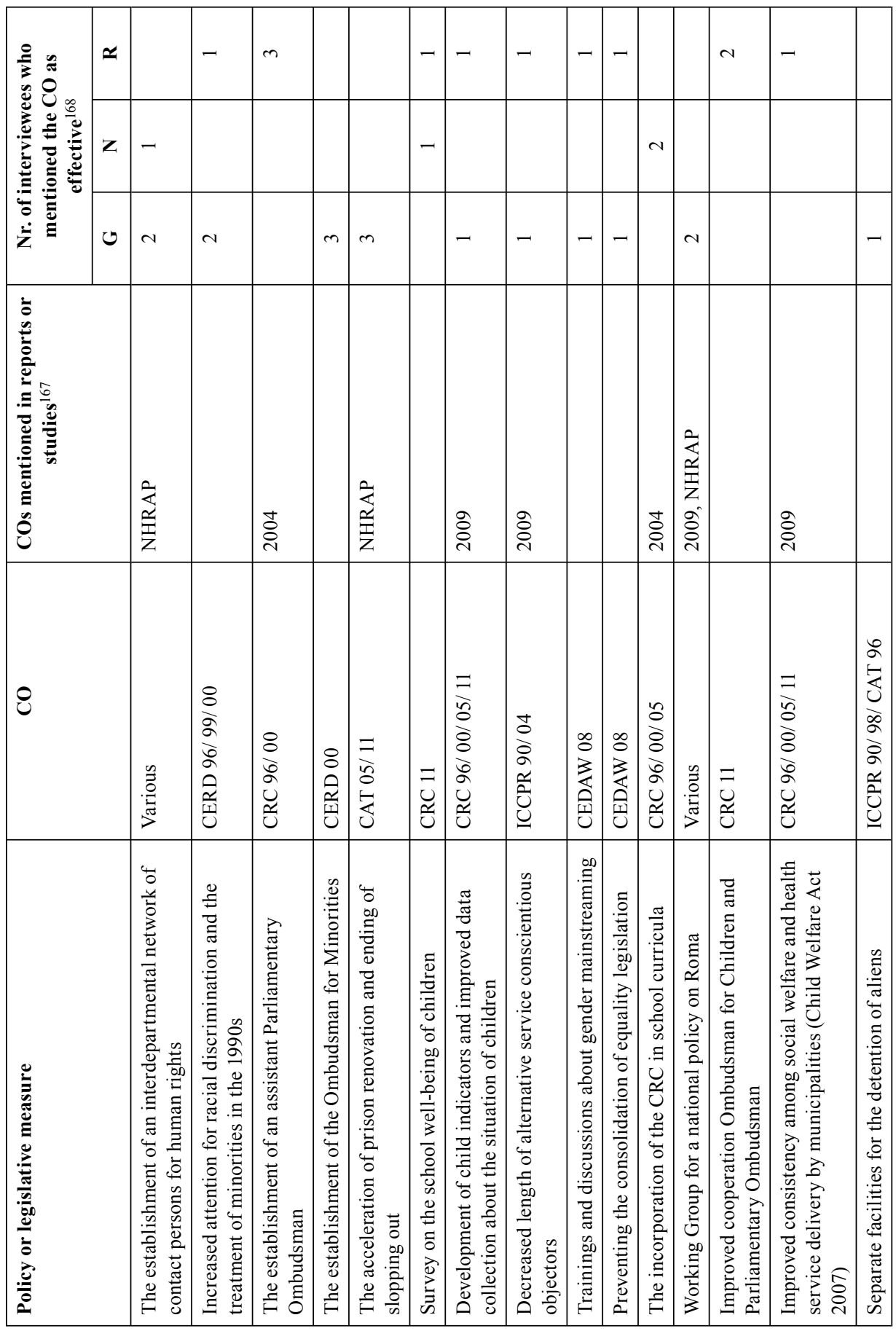


Chapter XIII

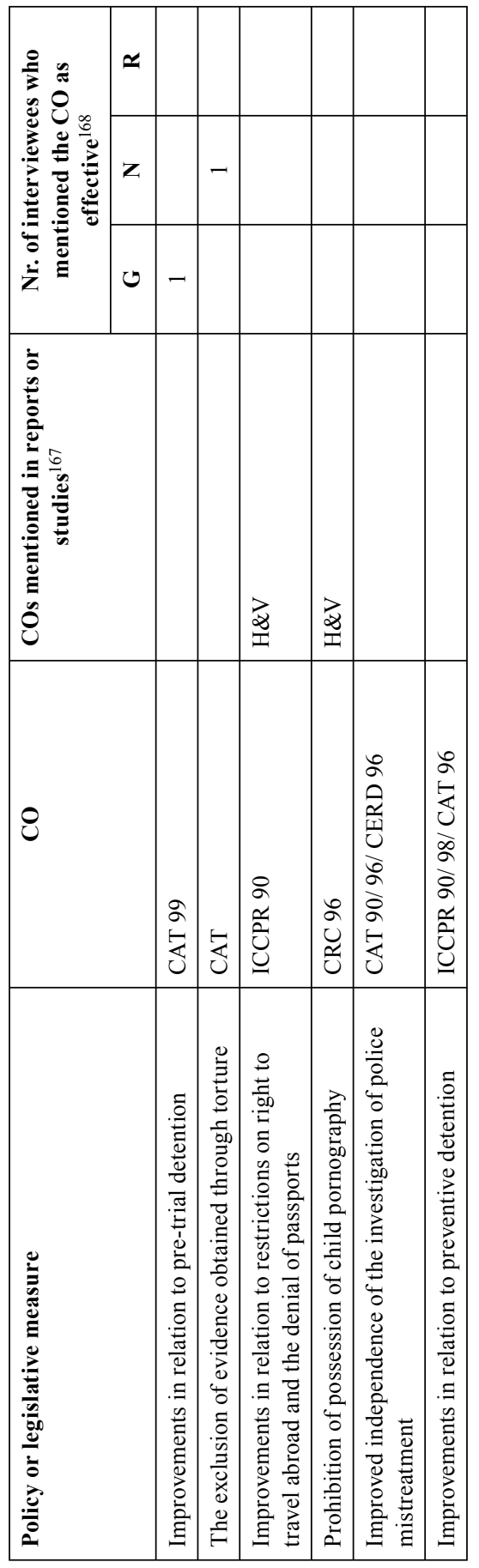


Most of the interviewees acknowledged that there have been COs that were a reason for change. They could mention some examples of effective COs as well. Table 13.1 shows that most of the examples given relate to issues that have also been addressed in the human rights reports of the Ministry for Foreign Affairs or the 2012 human rights action plan in connection with the COs. The remainder of this section will discuss eight (partly) effective COs as an illustration with the objective of distilling important factors for the effectiveness of COs.

\subsection{The establishment of an assistant Parliamentary Ombudsman and an Ombudsman for Children}

The CRC Committee recommended the establishment of an Ombudsman for Children in 1996 and 2000. ${ }^{169}$ In 1997, parliament adopted a government Bill proposing the establishment of an assistant Parliamentary Ombudsman on child issues with a special task of overseeing the implementation of children's rights. ${ }^{170}$ The discussions on establishing a separate Ombudsman, nonetheless, continued, because the assistant Parliamentary Ombudsman was only considered an intermediate solution by children's rights advocates. ${ }^{171}$ The government expressed the view in 2000 that it was 'unlikely, in the current political atmosphere, that a separate Ombudsman for Children would be created', especially because there was no budget for it. ${ }^{172}$ Nonetheless, the new Vanhanen I government 'arrived at a significant milestone in 2003' by including the establishment of a separate Ombudsman as one of the objectives in its government programme of 24 June 2003. ${ }^{173}$ The subsequent Act on the Ombudsman for Children (1221/2004) mentioned the CRC by name in the Ombudsman's job description. ${ }^{174}$ The Ombudsman took office on 1 September 2005 with a rather minimal staff, as noted by one government official. ${ }^{175}$

According to Niemi, the establishment of the assistant Parliamentary Ombudsman was 'possibly as a response' to the COs $1996 .{ }^{176}$ This conclusion would, however, obscure the fact that there had already been a discussion in Finland about it since the 1980s. It had especially been on the political agenda since 1995 ,

\footnotetext{
169 UN Doc. CRC A/51/41 (1996), para. 1027.

170 Bill HE 129/1997. UN Doc. CRC/C/70/Add.3 (1998), para. 9-10. Kurki-Suonio (2010), 328.

171 The Constitutional Law Committee considered that the establishment of the deputy Parliamentary Ombudsman did not resolve the issue. PeVM 5/1997 as referred to in UN Doc. CRC/C/129/Add.5 (2003), para. 32-33. Kurki-Suonio (2010), 328.

172 UN Doc. CRC/C/SR.643 (2000), para. 43.

173 UN Doc. CRC/C/129/Add.5 (2003), para. 37.

174 The reason that the CRC was explicitly included was that the Bill and the job description of the Ombudsman were discussed during meetings of the National Committee on the Rights of the Child which was set up in the spring of 2003 to prepare 'A Finland fit for children'. Several representatives of NGOs were also a member of the Committee. Koulu and Hetemäki (2010), 13.

175 The Ombudsman is supported by three senior officers and two secretaries (one part-time).

176 Niemi (2003), 36.
} 
prior to the COs $1996 .{ }^{177}$ The COs, thus, primarily coincided with the will and needs at the national level. Several interviewees reasoned that there would probably also have been an assistant Parliamentary Ombudsman and a separate Ombudsman for Children without the COs, while a smaller group of interviewees was of the view that the Ombudsman for Children would not have been established without the COs. Be that as it may, the COs undeniably played a strong role by increasing the pressure and by helping proponents in national discussions with an extra argument. In that way, the COs gave a final or extra push and, hence, sped up the process. One important factor was the role of NGOs who kept the issue on the agenda. Another important reason for the eventual establishment was the fact that Finland's neighbouring countries Norway and Sweden already had an Ombudsman for Children since 1981 and 1993 respectively.

\subsection{Sami land rights and the ratification of ILO Convention 169}

Several UN human rights treaty bodies as well as other international and European (human rights) monitoring organisations have expressed their concerns as to the situation of the indigenous Sami people and their land rights. ${ }^{178}$ Since the 1990 s, there have been conflicts in the Sami homeland in Northern Finland about the use of land between Sami reindeer herders, on the one hand, and forestry and mining companies and the State Forest Administration (Metsahällitus), on the other hand. The Sami reindeer herders claim that the latter activities destroy the pastoral areas necessary for their herding and, hence, threaten their traditional way of life. Various treaty bodies have recommended that Finland resolve this issue and ratify ILO Convention 169 concerning indigenous and tribal peoples in independent countries. The COs have not been effective in securing a policy or legislative change with respect to the issue. Neither has the ILO Convention 169 been ratified. The major reason for this is that Finnish legislation is not considered to be in compliance with the Convention, especially in relation to the issue of Sami land rights. ${ }^{179}$

177 A 1995 government report on children's policy mentioned that it is necessary to have one. Parliament had also required the government to establish one. CRC/C/SR.284 (1996), para. 14. Government report 2/1995 vp. UN Doc. CRC/C/70/Add.3 (1998), para. 9. Niemi (2003), 36. Kurki-Suonio (2010), 328.

178 The CERD was the first to address the matter in the COs of 1996, while the HRC addressed the issue in its Views in 1994 and in its COs 1998 and 2004. UN Doc. CERD A/51/18 (1996), para. 177 and 189. UN Doc. CERD A/54/18 (1999), para. 76 and 80. UN Doc. CERD A/55/18 (2000), para. 214. CERD UN Doc. A/58/18 (2003), para. 405. UN Doc. CERD/C/FIN/CO/19 (2009), para. 14. UN Doc. CERD/C/FIN/CO/20-22 (2012), para. 13. UN Doc. CCPR A/53/40 (1998), para. 261. UN Doc. CCPR/CO/82/FIN (2004), para. 17. UN Doc. CESCR E/2001/22 (2001), para. 451. UN Doc. E/C.12/FIN/CO/5 (2007), para. 11 and 20. Other international organisations include the ILO, ECRI, FCNM, the Committee of Ministers and the European Commissioner for Human Rights.

UN Doc. CERD/C/320/Add.2 (1998), para. 18. 
There are several factors that have precluded the resolution of the difficult and controversial issue in relation to which conflicting views exist. Firstly, the lack of a comprehensive government policy for Sami affairs and the absence of a single authority responsible for Sami issues have also hampered the resolution of the matter. There have been notable differences between several ministries in their position towards the fulfilment of the rights of the Sami. The Ministry of Agriculture and Forestry (initially) had difficulties to accept that Sami are an indigenous people and also saw no reason to ratify ILO Convention 169, despite the constitutional recognition of the Sami. ${ }^{180}$ The Ministry has, together with the Ministry of Trade and Industry, frequently prioritised logging and mining over the protection of the Sami's traditional way of life out of a fear that this protection will harm the important Finnish forestry industry. ${ }^{181}$ The forestry industry has also been a powerful lobbyist against legislation recognising Sami land rights. The Ministry for Foreign Affairs, the Ministry of Education and the Ministry of Justice have adopted a more favourable approach and have at times pressed for additional measures. ${ }^{182}$ Secondly, another factor hampering the resolution of the matter is the lack of clarity as to the implications of ratification of ILO Convention 169 because of the ambiguity regarding the definition of the notions of people and selfdetermination. ${ }^{183}$ This has resulted in a fear that self-determination of Sami is detrimental for the sovereignty of the Finnish state and would open up possibilities for secession. ${ }^{184}$ Thirdly, extending rights to Samis has also been perceived as detrimental to the rest of the Finnish population. This also explains why there have been protests by non-Sami against the extension of land rights and the ratification of ILO Convention 169. ${ }^{185}$ Fourthly, and more generally, the notion of collective minority rights and group-specific rights has not been accepted easily in Finland, because of the dominant idea of individual rights and a universalist discourse on formal equality that would not allow for special treatment. ${ }^{186}$

Despite their ineffectiveness, the COs and other international criticism were, nonetheless, one factor which have contributed to the numerous reports and legislative attempts to settle the question of Sami land rights. ${ }^{187}$ Over the years, numerous reports and studies and attempts to prepare legislation have been undertaken by several

\footnotetext{
180 Semb (2012), 141-142. Lempinen (2008c), 17.

181 Semb (2012), 147.

182 Semb (2012), 147.

183 Forrest (2006), 237. Semb (2012), 145.

184 Koivurova pointed to the fear of a 'territorial approach' to self-determination as used in the decolonisation process. Hence, the government 'is careful not to make any promises that would undermine its sovereignty, or be seen as giving unfair privilege to the demands of a small minority over the rights and interests of the population as a whole. In this situation, no action is preferable to taking a wrong step, and so the continuing deadlock should not be surprising.' Koivurova (2006/7), 110 and 132.

185 Joona (2005). UN Doc. CERD/C/SR.1141 (1996), para. 25.

186 Tuulentie (2003), 288 and 293.

187 Joona (2005), 312-314 and 319.
} 
committees and working groups, but without success. ${ }^{188}$ As was mentioned before, the COs have also had a considerable impact and have been an important factor in the debate (chapter XIII, sections 3.2-5). The COs have been highlighted in parliamentary discussions as an argument and other domestic actors, such as the Ombudsman for Minorities, the Finnish League for Human Rights and MPs from the Sami Parliament have also used the COs. ${ }^{189}$ Another example is the 26-page compilation made by the Ministry for Foreign Affairs of all international recommendations, including the COs, with respect to the Sami issue for the latest working group on the matter. In this way, the COs have kept the issue almost constantly on the agenda and have also increased the pressure to proceed with the matter.

This sketch also illustrates that the COs and international human rights standards and mechanisms have been used more generally as a tool to strengthen the weight of arguments of proponents in order to increase the political pressure. ${ }^{190}$ Article 27 ICCPR has been one of the most important international standards for 'human rights based litigation and advocacy' at the national and international level. ${ }^{191}$ Sami reindeer herders have also sought redress before the HRC via the individual communication procedure in the 1990s. In the two landmark cases of Länsman, the HRC considered reindeer herding a significant part of the Sami culture. The HRC, however, did not conclude that article 27 ICCPR was violated. ${ }^{192}$ Not only have the COs and the Views formed an important part of the arguments of reindeer herders and environmental NGOs, they have also impacted on the recognition and understanding of Sami as indigenous people with special rights.

\subsection{The criminalisation of torture}

The CAT Committee has consistently recommended that Finland include a separate punishable offence for torture in its penal code since the consideration of

188 These initiatives were primarily led by the Sami Parliament and/or the Ministry of Justice. For a summary, see, for example, UN Doc. CCPR/C/FIN/6 (2011), para. 50-54. Semb (2012), 140-145. The parliamentary Commerce Committee explicitly held, for example, that the requirements in the Mining Bill must be interpreted in a constitution-friendly way and that the practice of the HRC with respect to article 27 ICCPR must be taken into account. UN Doc. CERD/C/FIN/20 22 (2011), para. 14. Sellheim (2010), 80.

191 The Constitutional Law Committee also paid attention to article 27 ICCPR in its opinions. Scheinin (2001), 275-276. Article 27 ICCPR was also referred to by the Supreme Court and Supreme Administrative Court in mining and forestry cases. Scheinin (2001), 258-259. Lavapuro et al. (2011), 519. The travaux préparatoires to section 17(3) of the Constitution made clear that the positive obligation in relation to minority rights to culture and language must be seen in the light of the jurisprudence of the HRC. Scheinin (2004), 9.

192 The HRC, however, held that it might amount to a breach if mining activities were to be 'approved on a large scale and significantly expanded' in the future. Ilmari Länsman et al. v. Finland, 26 October 1994, Communication No. 511/1992, U.N. Doc. CCPR/C/52/D/511/1992 (1994). para. 9.8. Jouni E. Länsman et al. v. Finland, 30 October 1996, Communication No. 671/1995, U.N. Doc. CCPR/C/58/D/671/1995 (1996).para. 10.7. 
its initial report in 1991. This was repeated in the COs of 1996, 2000 and 2005. 193 The matter has also been recommended by the ECPT during its four country visits since 1992. Until 2005, the government was of the view that the absence of a specific provision was not a problem, because the penal code already fully covered and punished actions that would constitute torture under article 1 CAT. ${ }^{194}$ The government furthermore argued that several other penal provisions could be relied on. ${ }^{195}$ During the dialogue of 2005, the delegation, nonetheless, promised the CAT Committee that it would carefully consider the matter (again). ${ }^{196}$ The Ministry of Justice established a working group to study the issue in 2007. On 1 January 2010, new penal provisions entered into force with a definition of torture based on CAT. ${ }^{197}$ The government delegation held during the subsequent dialogue with the CAT Committee in 2011: 'There was a wide national debate on this issue, including the inter-ministerial working group, scholars and civil society. Finally, your Committee's desire led to respective changes in the Criminal Code'. 198

Four government officials saw the legislative change as a direct result of the COs arguing that the COs were the main reason behind the amendment. ${ }^{199}$ Among the factors that facilitated the effectiveness of the COs, interviewees mentioned the Ministry for Foreign Affairs and Amnesty International, who had both been pressing for criminalisation also on the basis of the COs. ${ }^{200}$ They were later joined in their efforts by the Minister of Justice Brax (Green League) and a justice official who had attended several dialogues with the CAT Committee. Another factor was that the issue was considered largely of 'symbolic value' and primarily considered necessary to give an international signal that would reinforce the absolute prohibition of torture in all circumstances. ${ }^{201}$ It was, thus, a relative non-issue and a formal matter that did not encompass a real change requiring considerable (additional) resources, as was also noted by one interviewee.

193 UN Doc. CAT A/46/46 (1991), para. 189 and 207. UN Doc. CAT A/51/44 (1996), para. 128 and 132. UN Doc. CAT A/55/40 (2000), para. 54 and 55 (a). UN Doc. CAT/C/CR/34/FIN (2005), para. 4 and 5 (a). UN Doc. CAT/C/SR.650 (2005), para. 3. UN Doc. CAT/C/67/Add.1 (2002), 93-94. The Finnish practice was to stick to general provisions where possible in order to decrease the number of provisions and, hence, interpretation problems. UN Doc. CAT/C/44/Add.6 (1998), para. 45. UN Doc. CAT/C/CR/34/FIN (2008), para. 3. UN Doc. CAT/C/SR.650 (2005), para. 4.

197 Act No 990/2009. UN Doc. CAT/C/FIN/5-6 (2010), para. 11-13. Formin (2010), 123.

198 'Opening statement by the delegation of Finland', 18 May 2011: <www2.ohchr.org/english/ bodies/cat/docs/statements/Statement_Finland_CAT46.pdf >, accessed 31 July 2013, 1.

199 One official emphasised the impact of ECPT over CAT.

200 Amnesty, for example, organised a seminar about it together with the Parliament's Legal Affairs Committee on 15 February 2007. This was just before the elections on 18 March. The seminar was also attended by Brax, who was then Chair of the Legal Affairs Committee. She spoke out in favour of criminalisation.

201 UN Doc. CAT/C/CR/34/FIN (2008), para. 1. UN Doc. CAT/C/SR.650 (2005), para. 4. 


\subsection{Violence against women in the 1990s}

During the discussion of Finland's initial report with the CEDAW Committee in 1987, the delegation was questioned about the prevalence of violence against women. Three interviewees noted the effectiveness of the questions and comments of the Committee. They argued that the issue was put on the agenda and that a subcommittee within the Council for Equality was established in May 1990 to study the matter as a direct consequence of the dialogue. Zwingel quoted one member of the government delegation: 'The Finnish minister was asked about violence against women, she couldn't answer, even though we had this one day time to prepare our answers. We contacted authorities here in Finland and asked the Ministry of Justice and other persons ... if they had concrete data or information on this issue, but we couldn't get anything out. Then the minister responded that she was very sorry but she couldn't provide any information and she promised to do it in the next report. And then the Council for Equality [...] organised a special working party to investigate this issue. They invited different authorities, from the Ministry of Interior, the police, the Ministry of Justice, social workers, doctors, and started to [...] investigate what should be done. ${ }^{202}$

Nousiainen and Pentikäinen also held that the remarks of the CEDAW Committee started the discussion about the prevalence of the phenomenon and initiated the first studies. ${ }^{203}$ The subcommittee started to collect facts and data, conducted studies and came up with proposals to address the matter. ${ }^{204}$ Several other scholars also noted more generally that the international human and women's rights discourse initiated the debate on violence against women and trafficking in women and prostitution in the 1990s as a gender issue. Prior to that it was not on the political agenda and treated as a taboo subject. When it was discussed this was primarily done in a gender-neutral way in terms of domestic violence. ${ }^{205}$ The CEDAW Committee might have put the issue on the agenda, but other factors were consequently more decisive in influencing legislative and policy measures. ${ }^{206}$ It was, for instance, noted that especially the Beijing conference in 1995 made violence against women a 'high profile issue and have accelerated social and legal reforms'. ${ }^{207}$

202 Zwingel (2005), 305.

203 Nousiainen and Pentikäinen (2013), 582-584.

204 Harjunen (2007), 47. Zwingel (2005), 289-290.

205 Zwingel (2005), 289-290. Harjunen (2007), 45-47.

206 The first legislative measure was the criminalisation of rape within marriage in 1994. This was followed by several other laws such as restraining orders and legal aid for victims. UN Doc. CEDAW/C/FIN/2 (1993), 13.

207 It was especially the Beijing Platform for Action that had an important effect and led to the equality plan 'The programme for the prevention of prostitution and violence against women 1998-2002, as well as a study on violence. The government held that 'especially the Beijing conference and its follow-up had helped to raise public awareness of the problem in Finland'. 


\subsection{The establishment of the Ombudsman for Minorities}

The CERD recommended in its COs 2000 to provide the Ombudsman for Minorities, which was being established at that time, with the necessary human and financial resources. ${ }^{208}$ This $\mathrm{CO}$ did not so much prompt the actual establishment of the Ombudsman. ${ }^{209}$ Rather, the $\mathrm{CO}$ was used by government officials as an endorsement of its intended political choice. That is to say, the government delegation used the dialogue in August 2000 with CERD to secure a recommendation that could be used as an additional argument in discussions with, for example, the Ministry of Finance to ensure that the Office would have sufficient resources. Laakkonen, a Ministerial Advisor from the Ministry of Labour stated before the CERD: 'The government would reach a final decision the following week about establishing the post of that Ombudsman, and the statements made by members of the Committee would provide arguments in favour of establishment ${ }^{\prime}{ }^{210}$ This CO, thus, came at the right moment.

\subsection{Consolidation of equality legislation}

At the time of the constructive dialogue between the Finnish government and the CEDAW Committee in July 2008, the reform of non-discrimination legislation was discussed. One option proposed in an interim report of February 2008 was a consolidation of the Equality Act 1986 and the Non-Discrimination Act 2004, with a view to targeting multiple and intersectional discrimination better. ${ }^{211}$ The issue of consolidation was debated heatedly and fervently lobbied against by women's rights NGOs, the Council for Equality and the Ombudsman for Gender Equality. ${ }^{212}$ NGOs and the Ombudsman for Gender Equality expressed their fears about the merger in their submissions to the CEDAW Committee. ${ }^{213}$ As a consequence of their submission, the CEDAW Committee expressed its concern that this 'might

UN Doc. CEDAW/C/SR.494 (2001), para. 7. Harjunen (2007), 45-47. UN Doc. CEDAW A/56/38 (Part I) (2001), para. 285.

208 UN Doc. CERD A/55/18 (2000), para. 220. Note that the Ombudsman for Minorities replaced the Ombudsman for Aliens in 2002. The mandate was extended to cover ethnic minorities and ethnic discrimination. This was earlier welcomed by the CERD. UN Doc. CERD A/54/18 (1999), para. 72.

209 The reason for its establishment was primarily to fulfil EU requirements under the $2000 \mathrm{EU}$ Race Directive. Harjunen (2007), 15.

210 UN Doc. CERD/C/SR.1404 (2000), para. 21.

211 The issue was examined by a Committee on Non-Discrimination, established by the Ministry of Justice.

212 The parliamentary Employment and Equality Committee was against consolidation as well. UN Doc. CEDAW/C/SR.841 (2008), para. 25.

213 Coalition of Finnish Women's Associations, 'Submission to the CEDAW Committee', June 2008: <www2.ohchr.org/english/bodies/cedaw/docs/ngos/CFWA.pdf>, accessed 31 July 2013, $3-5$. 
lead to a loss of visibility of the issue of discrimination against women, including its cross-cutting nature and consequently to a lower level of protection for women'. ${ }^{214}$ Two interviewees mentioned the decision to maintain the two separate acts as an example of effectiveness out of their own motion. Four other interviewees concurred with this when they were asked about it and noted that the COs played an important role in the decision. ${ }^{215}$ The interviewees noted that the domestic actors opposing a consolidation used the COs and based their arguments partly on them. One government official argued that the proponents for consolidation were initially in a majority, but that the COs were an important factor in helping to tilt the debate in favour of the opponents. This example illustrates that COs can be effective in stopping a certain development or intended legislative change, especially when there is a right momentum.

\subsection{The reduction of the length of the alternative service for conscientious objectors}

During the dialogue in 1990, members of the HRC held that the length of the alternative service should be proportionate to the length of military service. At that time, military service was 180,270 or 362 days, while the alternative service was 480 days. Members of the HRC also expressed their concern about freedom of religion and expression given the difference in treatment between Jehovah's Witnesses and other conscientious objectors. ${ }^{216}$ Some of these critical aspects were repeated by the HRC in 1998 and 2004. ${ }^{217}$

The alternative service was shortened with 85 days to 395 days in 1991 after the five-year trial period of the 1985 Act which had lengthened the alternative service to 16 months. There were other legislative proposals by the Ministry of Labour to further shorten the duration to 263 days in 1998 and 2000 in order to make the practice consistent with the principle of equality in the Constitution and human rights treaties. These were, however, rejected by parliament. ${ }^{218}$ The system of civilian service was again reviewed in 2004 and eventually led to the adoption of the Non-Military Service Act 1446/2007 that reduced the length of the alternative service from 395 to 362 days, which equals the longest military service. ${ }^{219}$

\footnotetext{
214 UN Doc. CEDAW/C/FIN/CO/6 (2008), para. 9.

215 UN Doc. CEDAW/C/FIN/7 (2012), para. 8.

216 UN Doc. CCPR A/46/40 (1990), para. 115 and 139. Note that there had been no changes, as of May 2013, as to the exempted status of Jehovah's Witnesses. This has been justified by reference to the ECtHR and the HRC who ruled in several cases that their exemption was not a violation of international human rights obligations. UN Doc. CCPR/C/SR.2227 (2004), para. 25. In its COs 1998, the HRC only reiterated its concern that Jehovah's Witnesses are treated preferentially. UN Doc. CCPR A/53/40 (1998), para. 271. Only in 2004, did the HRC criticise both aspects. UN Doc. CCPR/CO/82/FIN (2004), para. 14.

218 Lempinen (2008b), 7. UN Doc. CCPR/C/SR.2227 (2004), para. 24.

219 UN Doc. CCPR/C/FIN/6 (2011), para. 29 and 34. Lempinen (2008b), 7-8.
} 
Lempinen concluded that 'a modest legislative adjustment took indeed place, but it was anything but rapid'. 220

One crucial obstructing factor for the initial ineffectiveness of the COs in the 1990 s and early 2000s was the opposition in parliament to change. ${ }^{221}$ Another factor complicating the effectiveness of COs was that it was unclear whether the practice was truly incompatible with Finland's international treaty obligations. The ECtHR, for example, considered the different treatment of both services proportional. $^{222}$ In addition, there were also inconsistencies between the various COs and the Views of the HRC. In 1988, the HRC concluded in Järvinen that the 'extended length of alternative service is neither unreasonable nor punitive'. ${ }^{223}$ The difference in length was, however, critically commented upon by the HRC in 1990, while the HRC remained silent on it in its COs 1998. Only in 2004, was there a clear pronouncement by the $\mathrm{HRC}$ in the form of a $\mathrm{CO}$ which recommended that Finland 'end the discrimination inherent in the duration of alternative civilian service' which it considered 'punitively long. ${ }^{224}$

The COs and similar international criticism were a contributory factor among many national factors. ${ }^{225}$ The critical remarks of the HRC were, for example, mentioned as one reason for the 1991 legislative amendment. ${ }^{226}$ The Minister of Labour, Cronberg (Green League), also made clear that the 2007 amendment was 'a question of human rights' and noted that 'Finland has been blacklisted by international human rights organisations. The new law is a step in the right direction. Non-military service should not be punitive'.227 Other domestic explanations include the considerable discussion about the issue, also in the context of the ratification of the ECHR. ${ }^{228}$ In addition, the issue was also subject to human rights-based litigation and lobby by NGOs and lawyers. ${ }^{229}$ Interviewees considered

220

Lempinen (2008b), 10.

Parliament rejected a government Bill to reduce the length of alternative civilian service in 2000, although the Employment and Equality Committee was in favour of it. In 2007, the Defence Committee was still against it, but parliament as a whole adopted the Bill. Lempinen (2008b), 4 and 7-8.

Tomi Autio v. Finland, 6 December 1991, Application No. 17086/90. Lempinen (2008b), 4 and 8. Järvinen v. Finland, 25 July 1990, Communication no. 295/1988, UN Doc. CCPR/ C/39/D/295/1988. Lempinen (2008b), 8.

UN Doc. CCPR/CO/82/FIN (2004), para. 14.

'The wide international attention' was, for example, noted in the 2004 report of the Ministry for Foreign Affairs. Formin (2004), 15. The concerns and COs of the HRC were complemented by similar recommendations from, among others, the ECSR in 2004 and the European Commissioner for Human Rights in 2001.

Scheinin (1996), 273. International Law Association (2004), para. 161. Järvinen v. Finland was also mentioned in support for the proposal to reduce the length.

'Government bill: New Non-Military Service Act reduces service period to 362 days', 18 October 2007: <www.mol.fi/mol/en/01 ministry/06 press/01 2006/2007-10-19-01/index. jsp >, accessed 31 July 2013. See also 'Length of non-military service to be reduced from 13 to 12 months’, Helsingin Sanomat International Edition, 19 October 2007.

Halme (2008), 44.

Lavapuro et al. (2011), 519. 
these domestic pressures by NGOs, such as Amnesty International, as important factors keeping the issue on the agenda. Another facilitating factor was the role of the Ministry for Foreign Affairs who acted as a promoter of the issue. Already in 1998, it advised the government to reconsider the length of the alternative service because of Finland's international human rights obligations. ${ }^{230}$

\subsection{The CRC in school curricula}

The CRC Committee has also over and over again recommended incorporating the rights of the child in school curricula. ${ }^{231}$ In August 2010, the National Board of Education issued a special regulation to incorporate the CRC, UDHR and ECHR in the national core curricula as 'underlying values of basic education' for grades 1-9 and the upper secondary level. ${ }^{232}$ Two NGO representatives noted that the COs were one reason for this policy change. One important facilitating factor in the effectiveness of these COs is the considerable NGO lobby on the issue. The issue has been repeated by children's rights NGOs for years, who have used the COs in their lobby in relation to the government and National Board ${ }^{233}$ UNICEF also cooperated with the National Board of Education with a forum about education based on the CRC in 2007-2008. ${ }^{234}$

\subsection{Conclusion}

There have in total been 30 (partly) effective COs in Finland (table 13.2). Although the COs of the CRC Committee have been most effective (11 COs), several COs of the other treaty bodies have been (partly) effective as well. ${ }^{235}$

Table 13.2. Quantitative overview of the number of COs that have been effective in Finland

\begin{tabular}{|c|c|c|c|c|c|c|}
\hline CRC & CEDAW & ICERD & CAT & ICCPR & ICESCR & Total \\
\hline 11 & 4 & 4 & 4 & 3 & 0 & $30^{236}$ \\
\hline
\end{tabular}

230

Written statement prepared by the Legal Department of 22 October 1998. Lempinen (2008b), 4. UN Doc. CRC A/51/41 (1996), para. 1032. UN Doc. CRC CRC/C/100 (2000), para. 46. UN Doc. CRC/C/15/Add.272 (2005), para. 16.

'NGO report', October 2010: <www.crin.org/docs/Finland CCWU NGO Report.pdf $>$, accessed 31 July 2013, 8. Before that, teaching on rights of the child was included in the tuition of human rights 'which are taught mainstreamed'. UN Doc. CRC/C.11/WP.6 (1996), para. 32. Toivanen (2007), 38.

Koulu and Hetemäki (2010), 15.

Formin (2010), 98.

Supra n. 97.

For Finland, there have been four effective COs which were recommended by two or more treaty bodies. These are not put in the table, which explains why the number of effective COs for Finland adds up to 26 instead of 30 . 
Most interviewees argued that COs are often merely one factor or reason in a broader national discussion or political process contributing to policy or legislative measures. This is illustrated by the placement of the majority of (partly) effective COs in the middle column of table 13.3 outlining COs as contributory cause among many other factors. ${ }^{237}$ It was noted that there are hardly, if any, measures which were solely taken because of the COs. Often a combination of factors is needed in order for COs to be effective. Interviewees noted that recommendations from different (international) actors (UN, $\mathrm{CoE}$ and $\mathrm{EU}$ ) are frequently mutually reinforcing. Especially the effectiveness of several COs in the 1990s, such as the separate detention facilities for aliens and improvement in relation to pre-trial and preventive detention, were also linked to the ratification of the ECHR. Likewise, the acceleration of prison renovation to end the use of buckets as toilets was (primarily) attributed to the ECPT as well. ${ }^{238}$ Interviewees held that it is often impossible to single out which factor was eventually decisive. In several instances, the COs played a more decisive or essential role, such as the establishment of the Ombudsman for Children and the criminalisation of torture (column to the right). COs have sometimes been used by the government to support - an already intended - policy or legislative measure, such as in the case of the Ombudsman for Minorities (column to the left).

Interviewees noted that an important prerequisite for the effectiveness of COs is national momentum or discussion. COs should coincide with discussions and initiatives going on at the national level. If they do, COs can support or give extra strength to a certain direction and can, hence, speed up the issue. NGO pressure and lobbying was considered an important precondition for follow-up as well, because it has reminded the government of the COs and has kept the COs on the agenda. Interviewees noted that for COs to be effective, it is essential that the issue is included in the government programme, because this determines whether the issue is prioritised and whether there are sufficient resources.

The effectiveness of the process of state reporting has been greater in Finland than in the Netherlands and - especially - New Zealand. Firstly, as said, fewer COs have been rejected or remained completely unaddressed. ${ }^{239}$ Secondly, whereas several officials in the Netherlands and New Zealand see COs as mere views and opinions or an aspirational wish list that can easily be disregarded, there is an idea among Finnish officials that strong counterarguments and careful reasoning are needed to proceed in a manner other than in compliance with the CO. Thirdly, there are slightly more (partly) effective COs in Finland (30) than in the Netherlands (24) and New Zealand (20). The greater effectiveness, however, does not mean that COs are immediately implemented, as the examples above also illustrate. It is not uncommon that there was a considerable time period between the COs and

237 See especially, sections 4.2 (Sami land rights), 4.5 (Ombudsman for Minorities) and 4.7 (Conscientious objectors).

238 The media attention for this issue focused on the ECPT. "Anti-torture committee criticises Finnish prison conditions again', Helsingin Sanomat, 21 January 2009. See also Formin (2010), 82.

239 Supra n. 166. 
follow-up measures, such as with the establishment of the Ombudsman for Children. ${ }^{240}$ Likewise, Lempinen observed inconsistencies and contradictions in the Finnish international and domestic human rights policy with respect to, for example, conscientious objection to military service and the rights of the indigenous Sami. ${ }^{241}$ As was outlined above, progress with respect to these two areas, but also other issues such as violence against women and asylum, has indeed been imperfect and slow. Moreover, as several interviewees observed, the law in the book is different from the law in action. In other words, legislative or policy changes on the basis of the COs might not result in the desired changes or improvements in practice.

Table 13.3. Overview of (partly) effective COs in Finland

\begin{tabular}{|c|c|c|c|}
\hline & $\begin{array}{l}\text { COs used as support by } \\
\text { the government for } \\
\text { already intended } \\
\text { initiatives }\end{array}$ & $\begin{array}{l}\text { COs as contributory } \\
\text { cause among many other } \\
\text { factors }\end{array}$ & $\begin{array}{l}\text { COs as an essential or } \\
\text { decisive factor }\end{array}$ \\
\hline $\begin{array}{l}\text { Agenda } \\
\text { setting } \\
\text { function }\end{array}$ & & $\begin{array}{l}\text { - Racial discrimination in } \\
\text { the 1990s (CERD) }\end{array}$ & $\begin{array}{l}\text { - Violence against women } \\
\text { in the 1990s (CEDAW) }\end{array}$ \\
\hline $\begin{array}{l}\text { Studies or } \\
\text { evaluations }\end{array}$ & $\begin{array}{l}\text { - Roma working group } \\
\text { (CERD) }\end{array}$ & $\begin{array}{l}\text { - ILO } 169 \text { and Sami land } \\
\text { rights (various) }\end{array}$ & $\begin{array}{l}\text { - Survey school well- } \\
\text { being children (CRC) }\end{array}$ \\
\hline $\begin{array}{l}\text { Policy } \\
\text { measures or } \\
\text { initiatives }\end{array}$ & & $\begin{aligned} &- \text { Accelerating prison } \\
& \text { renovation (CAT) } \\
&- \text { Gender mainstreaming } \\
& \text { (CEDAW) } \\
&- \text { Coordination child and } \\
& \text { youth policy (CRC) } \\
&- \text { Best interest of the child } \\
& \text { (CRC) } \\
&- \text { Consistency } \\
& \text { municipalities (CRC) } \\
&- \text { Dissemination CRC } \\
&- \text { Child indicators (CRC) } \\
&- \text { CRC in school curricula } \\
& \text { (CRC) } \\
&- \text { Violence against women } \\
& \text { in the 2000s (CEDAW) } \\
&- \text { Interdepartmental } \\
& \text { human rights network } \\
& \text { (various) }\end{aligned}$ & $\begin{aligned}- & \text { Consolidation of } \\
& \text { equality legislation } \\
& \text { (CEDAW) } \\
- & \text { Cooperation } \\
& \text { Ombudsmen (CRC) }\end{aligned}$ \\
\hline
\end{tabular}

See also Heyns and Viljoen (2002), 286.

He argued that while Finland tries to contribute to international human rights structures, by for example taking the initiative to create a European Commissioner for Human Rights, COs and recommendations of other monitoring bodies are sometimes 'ignored'. Lempinen wrote separate reports in a series entitled 'The Activity, Progressiveness and Consistency of the Human Rights Policy of Finland'. Lempinen (2008a-c). 


\begin{tabular}{|c|c|c|c|}
\hline $\begin{array}{l}\text { Legislative } \\
\text { changes }\end{array}$ & $\begin{array}{l}- \text { Ombudsman for } \\
\text { Minorities (CERD) }\end{array}$ & $\begin{aligned} \text { - } & \text { Prohibition of child } \\
& \text { pornography (CRC) } \\
- & \text { Views of the child (CRC) } \\
\text { - } & \text { Conscientious objectors } \\
& \text { (ICCPR) } \\
\text { - } & \text { Detention of aliens } \\
& \text { (ICCPR) } \\
- & \text { Restrictions on right to } \\
& \text { travel abroad (ICCPR) } \\
- & \text { Pre-trial detention } \\
& \text { (CAT) } \\
- & \text { Independent } \\
& \text { investigation of police } \\
& \text { mistreatment (CAT and } \\
& \text { CERD) } \\
- & \text { Detention of asylum } \\
& \text { children (CAT and CRC) } \\
- & \text { Exclusion of evidence } \\
& \text { obtained through torture } \\
& \text { (CAT) }\end{aligned}$ & $\begin{array}{l}\text { - } \text { Criminalisation of } \\
\text { torture (CAT) } \\
\text { - Assistant Parliamentary } \\
\text { Ombudsman (CRC) } \\
\text { - Ombudsman for } \\
\text { Children (CRC) }\end{array}$ \\
\hline
\end{tabular}

For a further explanation of the table, see table 11.3 in chapter IX, section 3.

\section{EXPLAining THE (IN)EFFECTIVENESS OF COS}

\subsection{Factors facilitating the effectiveness of $\mathrm{COs}$}

Finland stands out from the two other countries in terms of the effectiveness of COs, but also because of the more positive views of government officials towards the importance of reporting (chapter XIII, section 2.2). There are several explanations for this.

First, Finnish government officials were less negative and sceptical about the quality and functioning of the UN human rights treaty bodies than Dutch and New Zealand government officials. In New Zealand, and especially in the Netherlands, reporting is primarily seen as a burden and approached in terms of defending the report and the domestic human rights situation. Officials in these countries were especially critical about the knowledge of treaty body expert members about their countries and, hence, the quality and specificity of recommendations. Finnish officials were less dismissive and did not question the need of reporting or the COs. The public contestation of the authority of treaty bodies as in New Zealand was absent. Neither has there been an atmosphere in which the limited knowledge of treaty bodies about the domestic situation is constantly emphasised over and over again as in the Netherlands. 
This does not mean, however, that the deficiencies in the functioning of the treaty bodies were not acknowledged or ignored. ${ }^{242}$ Several officials mentioned the same critical issues as in the Netherlands and New Zealand, such as the 'many misunderstandings and some mistakes' in the $\mathrm{COs},{ }^{243}$ or the inclusion of issues in COs that were not addressed during the dialogue or in LOI. ${ }^{244}$ Almost all interviewees also noted that COs are rather unclear and 'should be targeted more specifically', because otherwise they are not very useful and have hardly any impact. $^{245}$ There have hardly been any COs which were considered to be so persuasive or urgent that they automatically led to follow-up measures. Other issues mentioned were the long period between the submission and the consideration of the state reports, the duplication between treaty bodies or the fact that treaty bodies easily go beyond the scope of the treaty. ${ }^{246}$ The majority of interviewed officials were, however, better able to put these deficiencies into perspective by pointing to the difficult context of the treaty bodies, such as the limited resources and time as well as the politicised elections for new expert members. ${ }^{247}$ In addition, several officials attributed some critical issues not only to the treaty bodies, but also to an apparent deficient explanation by the Finnish delegation during the dialogue. They argued that the government should explain and describe things more carefully the next time. By contrast, officials in New Zealand and the Netherlands tended to focus on the odd and mistaken questions and recommendations and the bad preparation of some expert members to discredit the whole Committee and the value of process. In other words, while Dutch and New Zealand officials see the

242 The HRC and CAT Committee were generally mentioned as the most professional and best treaty bodies with the most detailed and focused questions and structured dialogue. The CESCR and CERD were mentioned as the weakest treaty bodies.

In addition, 'answers given in the hearing where not sufficiently taken into account'. This was stated in a five-page commentary, which addressed misunderstandings and mistakes in seven COs 2011 of the CRC Committee. Reijo Väärälä and Tarja Kahiluoto, 'Comments on the CRC Conclusions', Ministry of Social Affairs and Health, 20 June 2011, 471694 v. 1. Document provided during the interview.

244 The head of delegation noted, for example, with astonishment that one recommendation was not addressed in any area of concern beforehand. UN Doc. CAT/C/SR/402 (1999), para. 3. The Ministry for Foreign Affairs was critical about this, because the state party should have had an opportunity to express its views, since this is a 'basic criteria for equal and fair proceedings'. Formin (2012), 3.

The COs should also 'prioritise key issues in a realistic manner' by including three to five recommendations that 'require immediate measures'. The Views are sometimes 'too general or imprecise' and lacking 'detailed reasoning'. Formin (2012), 2 and 4.

The human rights report of 2004 noted the 'slowness and inefficiency' of the reporting system and the 'long intervals' of a year or two years between the submission and consideration of the report as a result of which the information is out of date. Formin (2004), 136 and 138. The government, for example, argued that violence against women does not fall within the scope of CAT, unless committed by public officials. UN Doc. CAT/C/FIN/5-6 (2010), para. 165.

There was a minority of Finnish officials who argued that the deficiencies negatively affect the authority and credibility of the treaty bodies. 
functioning of the treaty bodies as a glass which is half empty, their Finnish counterparts see it as half full.

Second, another reason for the difference between Finland and the two other countries is the relatively professional way in which the process of reporting has been organised (chapter XIII, section 2.1). The latter can be attributed to the central role of the Legal Department of Ministry for Foreign Affairs in the process. The continuity of officials in this Department is relatively great. Officials from this Department see themselves as defenders of the treaty body system and have sometimes promoted the COs and pressed for change on this basis (chapter XIII, section 2.2). Officials from several other ministries also tended to be rather positive about the process, including officials from the Ministry of Justice and, more recently, the Ministry of the Interior. The Ministry of Justice, for example, submitted a written statement to the Constitutional Law Committee in which it argued that COs 'ought to have a guiding role when developing national legislation'. ${ }^{248}$

Third, Finland has - at least until recently - a very good record in the implementation of international and European norms. Several studies from the beginning of the 2000s showed that Finland was among the best performing EU countries in the transposition of EU law into national legislation. ${ }^{249}$ Another recent study also found that Finland ranked first among European countries in conforming to the ESC. ${ }^{250}$ The compliance culture has been attributed to the legalistic culture in which the rule of law and the law as such have a strong position and strict adherence to laws is the preferred option. ${ }^{251}$ This is also visible in the attitude of civil servants, who do what they are being told to do as 'loyal bureaucrats'. ${ }^{252}$ Some interviewees noted that another (cultural) explanation in this context might be that Finns generally do not tend to be sceptical towards the authorities. ${ }^{253}$ Finns see themselves as more law-abiding than other citizens. ${ }^{254}$ Others referred to a 'distinct Nordic exceptionalism' or a 'promised land of legalism'. ${ }^{255}$ Some interviewees, however, noted that there has been a more critical approach and opposition to international

248 Quoted in Lempinen (2008a), 134.

249 Sverdrup (2004). Finland and the other Nordic EU countries were said to belong to the so-called 'world of law observance' where EU Directives are implemented on time and correct, because of a culture of good compliance in which infringing EU law is seen as an unacceptable state of affairs. Falkner et al. (2005).

250 The author made a barometer in 2009 in which the number of paragraphs on which countries received a positive conclusion from the ECSR were recorded. Finland scored 62 out of a total of 98 paragraphs, while the Netherlands had 48 positive conclusions. Mikkola (2010), 69 .

251 This legalism goes back to the times when Finland was a Grand Duchy within the Russian empire and defended its autonomy by arguing that its constitutional guarantees are binding and should be guaranteed by the Russian authorities. Ojanen (2012), 98. Holli et al. (2006), 185.

253 Supra n. 152.

254 Husa et al. (2007), 13. Cardol noted that Finnish people are more law-abiding than Dutch. Cardol (2010), 99.

255 Lehtimaja (1999), 97. 
organisations and norms in more recent years, partly as a result of the rising popularity of the populist and nationalist True Finns party, which became the third largest party after the 2011 elections. ${ }^{256}$

Fourth, the compliance culture also reflects the tendency to accept external (human rights) criticism relatively easily. It was argued by several interviewees that Finland has a rather sensitive ear to international critique and that the impact of international human rights mechanisms has traditionally been big in Finland. They noted that there have been few human rights reforms without international pressure. Husa noted in 2010 that there is no noticeable vigorous resistance towards the jurisprudence of the ECtHR and that there had hardly been any debate as to whether the powers of the ECtHR are too far-reaching as is the case of Denmark and Norway or the Netherlands. ${ }^{257}$ He likewise argued that Finland seems more removed from the 'sovereignty of people rooted constitutionalism' than Sweden. ${ }^{258}$ Several interviewees also argued that the discourse has - at least until recently been different than in Denmark where there is more distrust towards foreign interference. $^{259}$ In contrast to New Zealand, MPs generally talk about human rights treaties, treaty bodies and the COs with considerable respect, as several interviewees also noted.

Fifth, Finland's relative late accession to the ECHR and EU might also explain the effectiveness of and positive views towards the reporting process and the sensitive ear to international criticism. One official argued that many of the current generation of government officials in decision-making positions still remember the time before the 1990s in which human rights hardly played a role. Officials, thus, have a lot of faith in international human rights, especially because the domestic system of human rights protection was largely the result of international influences which made such dramatic changes to the legal culture and policies and legislation. In addition, there is a desire to strengthen and continuously affirm Finland's connection with the Western world by conforming to international and European human rights standards after having remained neutral during the Cold War. ${ }^{260}$

256 One interviewee pointed to populist speeches in which human rights are discredited as relevant only for criminals and immigrants. Another held that human rights are increasingly seen as limiting the decision-making capacity of the legislature. This reflects the traditional reluctance towards rights based judicial review. Supra n. 19-21.

Husa also noted that the Finnish system has been more receptive towards the ECHR and ECtHR than those two countries, as well as Sweden. Husa (2010), 10, 14 and 21. Judgments of the ECtHR and Views of the HRC have generally been complied with and remedial action has been taken by the government. Rosas (2001), 309-310. Heyns and Viljoen (2001), 516. See also Halme (2007), 280-281. Zwingel (2005), 285-286, 310 and 315.

The Danish scholar Wind noted that 'controversial and dynamic legal interpretations of vague European treaties and legislation by foreign judges are bound to fan the flames of the debate'. Wind (2010), 1060. 
Sixth, related to the previous point is that the Finnish population values human rights more positively than the people in New Zealand. ${ }^{261}$ Politicians, journalists and columnists all talk about human rights in a favourable way and human rights experts are treated as 'doing something good' by 'always being on the side of the weak ones' ${ }^{262}$ Several interviewees, nonetheless, noted that the population and some political parties have become more critical about human rights in recent years. $^{263}$

Seventh, another important factor which was mentioned by several interviewees was the presidency of Halonen (2000-2012), who was the former Minister for Foreign Affairs (1995-2000). In Finland, the President still has competence in Finland's foreign policy in relation to the UN. ${ }^{264}$ As mentioned before, Halonen is generally regarded as a fervent supporter of human and women's rights who was active in this field during her term both as Minister and President. ${ }^{265}$ Several interviewees noted that her interest had a wider impact on the government programme and the realisation of human rights. Another element that contributed to the latter is also the fact that the Green League has been in almost all governments since 1995, except for the Vanhanen I (2003-2007). The Greens are generally considered to be rather human rights minded. As we have seen, individual ministers from the Green League have often been important drivers for the effectiveness of $\mathrm{COs}$, as in the case of criminalisation of torture and the reduction of the length of the alternative for military service.

\subsection{Factors obstructing the effectiveness of $\mathrm{COs}$}

As in the Netherlands and New Zealand, there are also factors that have hindered the effectiveness of COs. Firstly, as in the other two countries there is the idea among officials and politicians that Finland is a human rights leader and already fulfilling the international standards. This belief is based on the careful ratification process of international treaties. The 1999 state report under CAT, for example, provided that there were no significant problems with respect to the implementation of CAT. ${ }^{266}$ Likewise, when Finland signed the CRC, it was believed that the Finnish legislation already protected the rights of the child 'to a very considerable extent'. This was coupled with the view that the CRC is primarily relevant for the developing world. ${ }^{267}$ Husa held that 'Finns like to think that they are a sort of model-student in an imaginary global human rights class of nations'. ${ }^{268}$ Finland's

\footnotetext{
261 Halme-Tuomisaari (2010), 79.

262 Halme (2008), 4 and 9. See also The editors (2012), 120.

263 Supra n. 256. The editors (2012), 120.

264 Section 93 of the Constitution. Ojanen (2012), 105-106.

265 Supra n. 34. Halme (2008), 47.

266 UN Doc. CAT/C/44/Add.6 (1999), para. 4.

267 Koulu and Hetemäki (2010), 4.

268 Husa (2011), 207.
} 
good performance and position as role model for other countries has been acknowledged by scholars and treaty bodies alike. ${ }^{269}$ The Chair of the HRC, for example, already held in 1998 that the high level of human rights protection in Finland surpassed that required by human rights treaties. ${ }^{270}$ This has led to a certain level of complacency among Finnish politicians and officials. Toivanen, for example, pointed to the attitude within the state administration that certain issues, such as the drafting of a national action plan on human rights education, are not considered matters of urgency, because of the idea that Finland is already 'above the world average in human rights'. ${ }^{271}$ One government official acknowledged, during the dialogue with CESCR in 1992, the tendency among officials to think that there are no problems with respect to human rights, because the idea is that legislation is already consistent with human rights treaties. ${ }^{272}$

Secondly, there has been a focus on the ECHR regime, somehow to the detriment of the UN human rights treaty regime. Several interviewees pointed to a minimalist approach to human rights and noted that there is a tendency not to think and go beyond the requirements of the European regime. Especially courts, the Constitutional Law Committee and constitutional law experts consulted by the latter Committee have tended to focus on the ECHR and the binding judgments of the ECtHR, while paying considerably less attention to the legally non-binding COs. ${ }^{273}$ This almost exclusive focus has, however, been less prevalent among Finnish government officials than their Dutch counterparts. ${ }^{274}$ As was mentioned before, reports, national action plans and Bills often cite a diverse range of UN human rights treaties and COs. ${ }^{275}$

\section{Conclusion}

The impact of the reporting process in Finland gives a rather mixed picture. The government and, to a lesser extent, parliament have been rather active in referring to the COs in the context of Bills, action plans, working groups and reports. By

Törnudd (1986), 287-288. Halme (2007), 280. UN Doc. CERD/C/SR.1600 (2003), para. 32. UN Doc. CCPR/C/SR.1660 (1998), para. 64.

This is coupled with the idea that human rights (education) is especially there for people in less developed countries. Toivanen (2007), 39-40.

UN Doc CESCR E/1992/23 (1992), para. 196. Scheinin held that the initial report under ICCPR was written with the idea that Finnish legislation was already fully compliant with ICCPR, even though hardly any amendments were made to legislation at the time of ratification. Scheinin (1990), 26 and 30-31. Supra n. 71.

273 Supra n. 102-103.

274 Finnish government officials also contrasted the non-binding recommendations and the deficient functioning of the UN human rights treaty bodies less with the binding judgments of the ECtHR than their Dutch counterparts.

Rosas noted 'a distinctive Finnish feature' that it is not unusual that several human rights instruments are invoked during the legislative process or before courts. Rosas (2001), 297 and 300 .
} 
contrast, NGOs have hardly submitted any separate alternative reports to the treaty bodies since 2000 besides their submission of information to the Ministry for Foreign Affairs for the compilation of the state report. The use of COs in the NGO advocacy has also been fairly limited. Likewise, the ombudsman institutions have also been involved in the reporting process and used the COs in a limited and ad hoc way. The major exception to this is the CRC. The Central Union for Child Welfare, UNICEF and the Ombudsman for Children have been active in the process by submitting parallel reports, monitoring the implementation of COs and lobbying on the basis of COs, especially since the COs of 2005.

The latter has also translated into a greater effectiveness of the COs of the CRC Committee, although several COs of other treaty bodies have also been effective. Moreover, the reporting process has been more effective in Finland than the Netherlands and New Zealand. This chapter gave several explanations for this, including the more positive attitudes of government officials towards the value of the reporting process and the treaty bodies, the professional organisation of the process, the compliance culture and the tendency to accept (external) human rights criticism. 


\section{Part D}

\section{Conclusion}




\section{Chapter XIV Conclusion: Main Findings and Reflections}

This final chapter presents the major findings and answers to the research questions discussed in the first chapter of this book. It will compare and contrast the findings as to the broader influence, impact and effectiveness of the reporting process and the COs in the Netherlands, New Zealand and Finland (sections 1-3). In this context a reflection will also be given on the extent to which the COs have had more impact and have been more effective in New Zealand because it is not a member of a (strong) regional human rights system and only part of the UN human rights machinery (chapter III, section 1.3). The eventual aim of the comparison is to identify the most important factors that affect the (in)effectiveness of the COs (section 4). The chapter ends with some reflections (section 5) and policy recommendations for the treaty bodies and domestic stakeholders (section 6).

Before turning to a discussion of the empirical results, a brief recapitulation of the theoretical and methodological approach used in this research will be provided. As discussed in chapter II, this research has been grounded on two causal compliance mechanisms identified in IR literature (see chapter II, section 4 in particular). The first mechanism incorporated in this research rests on the argument that government officials need to be persuaded and feel bound to comply with the legally non-binding COs in order for the COs to be effective. Such a compliance pull is contingent on the legitimacy, usefulness, persuasiveness and legal quality of the COs, as well as the authority of the treaty body in the eyes of government officials and members of government. 175 interviews were therefore held in the three countries in order to establish the attitudes and perceptions of officials towards the process of state reporting, the committees and the COs. The second mechanism included in this research builds on liberal and constructivist theories about domestic and transnational human rights mobilisation and advocacy. It reflects the idea that the activities of domestic actors are particularly crucial for the effectiveness of COs given the absence of (strong) international enforcement mechanisms. This theoretical starting point called for an analysis of the extent to which domestic actors, such as NGOs and MPs, have been involved in the reporting process and have used the COs in their domestic work. This was done through a document analysis of a wide variety of documents, including parliamentary papers, court judgments, newspaper articles and NGO websites, as well as interviews with a wide range of domestic actors (chapter III, section 2). This chapter will give a reflection on the applicability of these two underlying theoretical models. 


\section{The BROADER INFLUENCE OF THE REPORTING PROCESS}

The first research question relates to the broader, and often more subtle, impact or influence of the reporting process, beyond individual COs. Two sub questions were examined specifically. Firstly, it was examined whether reporting has been used domestically as an opportunity for human rights review and dialogue. As was mentioned in chapter I, reporting should ideally be 'part of a continuing process designed to promote and enhance respect for human rights rather than an isolated event absorbing precious resources [...]. The process should be treated as an opportunity, rather than a chore or formality'.

The way in which the reporting exercise has been undertaken in the three countries primarily reflects the latter approach. In all three countries, albeit to a lesser extent in Finland, reporting has mostly been another item to cross off the 'to do' list which includes many other items that compete for attention. ${ }^{2}$ Especially in the Netherlands and New Zealand, reporting is largely seen as a burden and approached in terms of defending the report and the domestic human rights situation. These findings coincide with the observations discussed in chapter I, section 2 that reporting is approached without much engagement as a mere formality and bureaucratic exercise. Reporting is often done separate from day-today activities and is not perceived as an element in policy making. One important explanation for this is the reporting and evaluation fatigue on the part of the states stemming from overlapping reporting requirements under the several UN human rights treaties and other international and regional (human rights) systems. Reporting has hardly been used as an opportunity to have a dialogue with domestic actors about the domestic human rights situation, except for the CRC (chapter XIV, section 4.3.2). There has also not been a reflection or analysis on what has purposively been done to implement the treaty during the compilation of the state report. There has only been some reflection or discussion following the dialogue and the COs, whereby the need to act upon certain COs is examined in the light of existing policies and legislation. A structural follow-up mechanism has, however, been absent, except for the COs of the CRC Committee in New Zealand. These bureaucratic and organisational aspects have diminished the domestic impact (and effectiveness) of COs (chapter XIV, section 4.3.2).

The reporting process under the CRC has come closest to the idea of reporting as a continuous process that is used as an opportunity for human rights review and dialogue. ${ }^{3}$ The process has, for example, led to an improved interaction and dialogue between the government and NGOs and Children's Ombudsmen. In the Netherlands there have been half-yearly meetings and in Finland yearly seminars

Alston (1997b), 20.

Woll (2000), 73 and 76. Heyns and Viljoen (2001), 508 and 519-520.

This reflects Lansdown's observation as to the UK, where reporting was used as a tool to have a dialogue about and promote children's rights. Lansdown (2000), 121-122. See also Karp (2000), 37. Byrnes (2000), 311. 
organised by the Ministry for Foreign Affairs and NGOs on the basis of the COs. The most systematic and structural practice existed in New Zealand until 2008 in the form of a CRC Advisory Group consisting of government officials, NGOs and human rights institutions.

The second sub question asks whether the reporting process has led to a better understanding of the treaties and rights concerned. The previous chapters have shown that reporting has contributed to an increased awareness about (international) human rights obligations among those directly involved in the process, although this increased awareness should not be exaggerated. ${ }^{4}$ It is undeniable that government officials who (directly) participated in the process and were part of the government delegation to New York or Geneva increased their understanding and knowledge about the UN human rights treaties. Their involvement has prompted some officials to reflect on certain issues and has reminded them of the human rights implications of policies. The (preparation for) the dialogue in particular has also stimulated interaction and exchange between government officials from different ministries. The reporting process under the CRC in particular has contributed more generally to an increased acceptance and prominence of the notion of children's rights and the idea of children as subjects of rights. That is to say, there has been a shift in thinking from children's wellbeing to viewing them as having rights. For the Netherlands, this broader influence was visible in the growing number of references to the CRC by the government, parliament and courts, which could be partly attributed to the reporting process under the CRC (see figure 10.4 and chapter $\mathrm{X}$, section 1.6).

The process of reporting has also supported and informed the work of some NGOs and national human rights and ombudsman institutions and provided them with networking cooperation and exchange between them and the government. ${ }^{5}$ The latter especially happened for the CRC where the process helped NGOs to build coalitions and strengthen the children's rights movement. ${ }^{6}$

\section{THE DOMESTIC IMPACT OF THE REPORTING PROCESS AND THE COS}

The second research question addressed in the previous chapter is: How and in what way have domestic actors referred to, used and discussed the reporting process and the COs at the domestic level? The previous section on the broader influence, already noted that the reporting process under the CRC stands out. It should not come as a surprise that the COs of the CRC Committee have had the largest impact

4 Several scholars also noted that reporting can raise awareness and contribute to and stimulate a discourse of human rights norms. Byrnes (2000), 302-305. Connors (2000), 7. Steiner (2000), 50 .

5 For a similar conclusion as to the work and recommendations of UN Special Rapporteurs, see Piccone (2011), 212. Woll (2000), 72, 73 and 76. Lansdown (2000), 120-121.

$6 \quad$ Woll (2000), 72, 73 and 76. Leckie (2000), 134. 
of all the six UN human rights treaties in the three countries, especially in terms of NGO advocacy and parliamentary scrutiny. By contrast, the impact of the COs of the other five treaty bodies has been fairly limited, except for some of the COs of the CEDAW Committee in the Netherlands. A simplified overview of the findings is provided in table 14.1 .

\section{Table 14.1. The impact of COs in the Netherlands, New Zealand and Finland compared}

The darker the shading, the more attention paid to the COs by the respective domestic actor in comparison with the other two countries. In case there are notable differences between the (COs of the) six treaty bodies within a country, this is also mentioned in the table. For example, regarding 'government attention to COs', the table should be read as following: more attention has been paid to the COs by the Dutch and Finnish government, than the New Zealand government. Secondly, in the Netherlands, the COs of the CRC Committee have been referred to considerably more often by the government than the COs of the other treaty bodies. For New Zealand and Finland, there are no COs of a particular treaty body that have received (significantly) more government attention than the other treaty bodies. The shadings are relative indicators used to highlight the main differences between the three countries. A further qualitative elaboration on the impact of the COs in the three countries is provided in the previous chapters. ${ }^{7}$

\begin{tabular}{|l|l|l|l|}
\cline { 2 - 4 } \multicolumn{1}{l|}{} & The Netherlands & New Zealand & Finland \\
\hline $\begin{array}{l}\text { Government attention } \\
\text { to COs }\end{array}$ & CRC & & \\
\hline $\begin{array}{l}\text { Parliamentary } \\
\text { attention to COs }\end{array}$ & $\mathrm{CRC} / \mathrm{CEDAW}$ & $\mathrm{CERD}$ & \\
\hline COs in legal practice & $\mathrm{CEDAW}$ & & $\mathrm{CRC/CEDAW}$ \\
\hline $\begin{array}{l}\text { Ombudsmen and } \\
\text { human rights } \\
\text { institutions }\end{array}$ & $\mathrm{CRC}$ & $\mathrm{CRC} / \mathrm{CERD}$ & $\mathrm{CRC}$ \\
\hline $\begin{array}{l}\text { NGO lobby on COs } \\
\text { Media coverage }\end{array}$ & $\mathrm{CRC/CEDAW}$ & $\mathrm{CRC}$ & $\mathrm{ICCPR} / \mathrm{CRC}$ \\
\hline
\end{tabular}

There are notable differences as to the extent to which several domestic actors in the three countries have used the reporting process and the COs. There have, first of all, been differences in the use of COs by the government. The Dutch and Finnish government have paid considerably more attention to the process and the COs than the New Zealand government. The Dutch government has recently started to give its reaction to the COs of most of the treaty bodies in a letter to parliament. In addition, it has also referred to some of the COs of the CRC and CEDAW Committees in other policy notes and bills. Although the Finnish government has

7 For a schematic - quantitative - overview of the impact of the COs in the Netherlands, see table 11.1. 
not informed parliament about the several COs individually or its reaction, it has referred to the COs of various treaty bodies in policy documents, bills, human rights reports and action plans. By contrast, the New Zealand government has only sporadically paid attention to the COs and sometimes even in a dismissive way.

A similar picture can be drawn for the three parliaments. The New Zealand parliament has hardly been active in relation to the process and the follow-up to the $\mathrm{COs}$, except for the recommendations of CERD in relation to the highly controversial Foreshore and Seabed Act 2004. By contrast, Dutch MPs have also been fairly active in using or referring to the COs of the CRC Committee and - to a lesser extent - the CEDAW Committee. In addition, some of the COs of the CRC and CEDAW Committee have also been tabled in the Dutch parliament for discussion. Finnish MPs have been directly involved in the process by being part of the government delegation for the dialogue with several treaty bodies.

The COs have been absent in legal practice in the three countries. Litigation by NGOs and individuals on the basis of COs has been non-existent, except for the Dutch SGP case. One important explanation for the fact that courts rarely refer to COs is the limited knowledge among lawyers and judges about the UN human rights treaties and the reporting mechanism. ${ }^{8}$ Another reason is the legally nonbinding status of the COs and the fact that COs usually only provide a short legal motivation.

There is also considerable difference in the level of activity of NGOs both in terms of writing alternative reports and using COs in their lobby. While the NGO activity has grown in New Zealand since the early 2000s, NGOs have become less active in submitting alternative reports in Finland in the same period. Children's rights NGOs in particular have used the COs of the CRC Committee quite frequently in their advocacy in all the three countries. The same holds true for Dutch women's rights NGOs who have been relatively active in using the COs of the CEDAW Committee in their political lobby and litigation. With respect to the human rights and ombudsman institutions, the relatively big role of the Children's Commissioner and Ombudsman in New Zealand and Finland stands out, especially in terms of lobbying and advocacy on the basis of COs of the CRC Committee.

Media coverage of the process and the COs has by and large remained limited as well, except for some politically controversial issues, such as the Sami issue in Finland and the Foreshore and Seabed Act saga in New Zealand. The reporting process under the CRC has received relatively the most attention.

In sum, the COs have had the least impact in New Zealand. In addition, the reporting process under the $\mathrm{CRC}$ has had the highest impact of the six treaties in all three countries in terms of attention paid by domestic actors. Reporting under the $\mathrm{CRC}$ has also led to an improved interaction and dialogue between domestic actors and has also contributed to a better understanding of children's rights. The next

8

See also De Vos (2013), 77. 
section will examine whether the COs of the CRC Committee have also been more effective than the other treaty bodies.

\section{EfFectiveness of the COS}

The third research question about effectiveness is: To what extent have policy, legislative or any other measures been taken at the domestic level as a result of the COs? The previous chapters showed that most of the COs have remained ineffective in terms of leading to or influencing actual policies and legislation. This is, first of all, because COs are generally and vaguely formulated without prescribing any specific course of action. Many policy and legislative measures that have been taken subsequent to and in line with the COs are not influenced by the COs. Such general COs have simply coincided with measures which had already been in place or foreseen. A second set of COs has been rejected or disagreed with by the three governments. ${ }^{9}$ Governments have justified noncompliance by pointing to, among others, budgetary constraints, different views as to the desirability of policy action or other conflicting interests or human rights obligations.

There has been a relatively limited number of COs that have been effective in the sense of having (partly) led to or contributed to follow-up measures. 74 (partly) effective COs were identified for the three countries. In order to put this into perspective, it should be noted that there has been a total of around 1,000 COs for the three countries of all six treaty bodies since 1995 (chapter I, section 4). This effectiveness has taken the form of policy or legislative measures, but also studies and evaluations, the creation of new institutions such as a Children's Ombudsman or the initiation of a debate by putting an issue higher on the (political) agenda (see tables 11.2, 12.3 and 13.2 for an overview of (partly) effective COs).

Many of the COs that have eventually become effective were initially disregarded by the government. ${ }^{10}$ The previous chapters showed that some COs eventually became effective when they were taken up and lobbied on by domestic actors. This often requires a long political process of years to convince the government of the necessity of a change on the basis of COs, especially for COs with considerable financial consequences. This means that domestic actors need to (be willing and able to) pay attention to and constantly come back to the issue over a long period of time. ${ }^{11}$ At the same time, when domestic actors do not use the

9 Rejecting COs is actually not uncommon for governments to do. This conclusion mirrors Alter (2013), 20. Cohen (1996).

10 For similar observations, see Byrnes (2000), 295-296 and 306-307. Lansdown (2000), 123. Schmidt (2000), 236. Clapham (2000), 178.

11 For a similar conclusion as to the work of UN Special Rapporteurs, see Piccone (2011), 217. 
COs in their work and pressure the government to act upon them, the government can easily get away with ignoring the COs.

It should be emphasised that the COs have rarely been a necessary or sufficient cause for these follow-up measures. That is to say, there has not - or hardly - been any policy or legislative measure that would not have come about without the COs. Nor have the COs alone been sufficient to cause a follow-up response. There are almost no measures which were solely taken because of the COs. ${ }^{12}$ Multiple factors have in nearly all instances been necessary. This means that COs had to coincide with domestic political considerations and resonate with the activities, interests and claims of domestic actors. Often a right momentum in the form of on-going discussions at the national level has also been necessary. Most COs have only been one factor or element contributing to policy or legislative measures. The effect of some COs has, thus, primarily been an intensifying or catalyst effect, whereby COs have supported, strengthened or legitimised the arguments of domestic actors. ${ }^{13}$ COs have in this way supported or given extra strength to a certain direction and have pushed or accelerated a certain political process. ${ }^{14}$ This also mirrors Simmons' finding that international human rights norms can influence legislative and policy priorities. ${ }^{15}$

The weight of COs as a factor contributing to follow-up measures has varied. In the previous chapters, a distinction was made between three categories of (partly) effective COs, which indicate the weight or the importance of the role that the COs played in the follow-up measures. Firstly, the strongest role for COs is when they have been an essential or even decisive factor in certain follow-up measures. Sub $\mathrm{b}$ in table 14.2 shows that only a minority of the COs of the total number of COs fall in this category (21 out of the total number of 74 (partly) effective COs in the three countries). Secondly, the majority of COs has just been one of many (inter)national factors that have contributed to a policy or legislative change (45 out of the 74). ${ }^{16}$ Thirdly, COs have also been used by the government to justify or give support to - already intended - policy initiatives, especially when these were still controversial or in the developmental phase $(7 \mathrm{COs}$ were identified). ${ }^{17}$

12 Perhaps life imprisonment for minors would not have been abolished in the Netherlands had the COs of the CRC Committee not recommended this. Likewise, CEDAW would possibly not have been translated into Maori without the COs of the CEDAW Committee.

13 This corresponds to what Alston termed as a 'catalyst to action'. Alston (2000), 509. Piccone (2011), 210.

14 Lansdown (2000), 116. Kälin (2012), 40. Clapham (2000), 181. Connors (2000), 7. Leckie (2000). Byrnes (2000), 302-305 and 311-312. Steiner (2000), 50.

15 Simmons (2009), 128.

16 This figure was obtained by adding up the COs listed in the middle columns of the tables 11.2, 12.3 and 13.2 .

17 This figure was obtained by adding up the COs listed in the left column of the tables 11.2, 12.3 and 13.2. 
Table 14.2. Quantitative overview of the number of COs that have been effective in the Netherlands, New Zealand and Finland

\begin{tabular}{|c|c|c|c|c|c|c|c|}
\hline & CRC & CEDAW & ICERD & CAT & ICCPR & ICESCR & Total \\
\hline \multicolumn{8}{|c|}{ a. Number of effective COs } \\
\hline NL & 11 & 7 & 4 & 1 & 1 & & 24 \\
\hline $\mathrm{NZ}$ & 11 & 3 & 2 & 4 & & & 20 \\
\hline FIN & 11 & 4 & 4 & 4 & 3 & & $30^{18}$ \\
\hline Total & 33 & 14 & 10 & 9 & 4 & & $\mathbf{7 4}^{19}$ \\
\hline
\end{tabular}

b. COs as essential or sometimes even decisive factor

\begin{tabular}{l|c|c|c|c|c|c|c|} 
NL & 6 & 2 & & & & 8 \\
NZ & 4 & 1 & & 1 & & & 6 \\
FIN & 5 & 1 & & 1 & & & $\mathbf{2 1}$ \\
\hline
\end{tabular}

c. COs that have been a factor in a legislative change

\begin{tabular}{l|c|c|c|c|c|c|c|} 
NL & 5 & 1 & & 1 & & & 7 \\
NZ & 4 & 2 & 1 & 1 & & & 8 \\
FIN & 4 & & 2 & 3 & 3 & & 12 \\
Total & $\mathbf{1 3}$ & $\mathbf{3}$ & $\mathbf{3}$ & $\mathbf{5}$ & $\mathbf{3}$ & & $\mathbf{2 7}$ \\
\hline
\end{tabular}

Table 14.2 shows the exceptional position of the COs of the CRC Committee. These COs have undeniably been the most effective in all three countries, with 33 out of the total number of 74 (partly) effective COs. Sub b in the table also shows that the majority of COs that have been an essential factor were from the CRC Committee (15 out the $21 \mathrm{COs).} \mathrm{In} \mathrm{addition,} \mathrm{most} \mathrm{of} \mathrm{the} \mathrm{legislative} \mathrm{changes} \mathrm{that} \mathrm{have} \mathrm{been} \mathrm{taken}$ (partly) as a result of the COs were related to the COs of the CRC Committee as well (13 out of $27 \mathrm{COs,}$ see sub c in table 14.2). The COs of the CRC Committee have, for example, contributed to the prohibition of corporal punishment and public education campaigns against child abuse in the Netherlands and New Zealand. In Finland and the Netherlands, the COs were also one stimulating factor for initiatives in relation to human rights education and children's rights in school curricula. Likewise, a Children's Ombudsman has been created or strengthened in all three countries (partly) as a result of the COs of the CRC Committee. The COs of the CEDAW Committee have been the second most effective, as table 14.2 illustrates as well. Both in Finland and the Netherlands, the COs have, for instance, played a role in relation to the policy on violence against women among many other factors. By

18 For Finland, there have been four effective COs which were recommended by two or more treaty bodies. These are not put in the table, which explains why the number of effective COs for Finland (under a.) adds up to 26 instead of 30. Idem. 
contrast, the COs of the HRC and especially those of the CESCR have by and large remained ineffective.

The effectiveness of COs has been highest in Finland. As table 14.2 illustrates, there have been slightly more (partly) effective COs in Finland (30) than in the Netherlands (24) and New Zealand (20). There are other supporting arguments for the conclusion that the effectiveness of COs in Finland has been highest in Finland in addition to this small quantitative difference in the number of effective COs. Firstly, the previous chapters showed that a smaller number of COs have been explicitly rejected in Finland than in the other two countries. Secondly, there is an idea among Finnish officials that strong counterarguments and careful reasoning are needed to proceed other than in conformity with the CO, whereas several Dutch and New Zealand officials by and large treat COs as mere opinions that can easily be dismissed.

It is noteworthy that the COs have had the lowest impact and have been least effective in New Zealand. This is surprising in the light of the expectation that the COs would have a higher impact and be more effective in a country which is not a member of a (strong) regional human rights system but is only part of the UN human rights machinery (chapter III, section 1.3). The opposite might actually be true. The absence of a truly effective external human rights check for New Zealand in line with the ECHR and ECtHR has actually been one factor contributing to a lower impact and effectiveness of COs, because of a lower salience and more limited role of human rights in general. The research findings thus suggest that the presence of several human rights systems simultaneously increases the visibility and overall attention for human rights. This is also illustrated by the Finnish experience where the ratification of the ECHR in 1990 actually led to a growing profile and culture of human rights in general, not necessarily at the expense of the UN human rights treaties and the reporting process. Rather, reporting has been taken more seriously and given more priority since then. Whether the concurrent membership of different human rights regimes also leads to a higher effectiveness of the COs is still open for discussion and warrants further research. For the Netherlands it was concluded that the almost exclusive focus on the ECHR has negatively affected the effectiveness of $\mathrm{COs}$, since there is an assumption in government circles that the Netherlands is in compliance with the UN human rights treaties when the ECHR and the judgments of the ECtHR are observed. This view has been less pervasive in Finland. It is, however, unclear to what extent these less prevalent views have affected the effectiveness of COs in Finland and thus what weight should be attached to this factor, also in the light of all the other domestic factors that play a role (chapter XIV, section 4.3).

In conclusion, two findings stand out: the higher effectiveness of the COs of the $\mathrm{CRC}$ Committee and the higher effectiveness of the COs in Finland. The next section will examine which factors explain these differences among the six treaty bodies and the three countries. 


\section{FaCtors CONTRIBUting to the (IN)EFFECTIVEnESS OF COS}

The sub question to the third research question deals with the factors that contribute to the (in)effectiveness of COs. This section will firstly discuss the factors related to the treaty body system. Secondly, the subject matter and specificity of COs will be touched upon. Thirdly, the domestic factors which affect the effectiveness of COs will be discussed.

\subsection{Factors contributing to ineffectiveness of $\mathrm{COs}$}

The ineffectiveness of the majority of COs is not surprising given the weak capacities and procedures of the treaty bodies. This includes the legally nonbinding character of the $\mathrm{COs}$ and the fact that the treaty bodies lack true enforcement powers in the form of, for example, sanctions. In addition, the treaty bodies and the Secretariat of the OHCHR have only limited resources at their disposal. ${ }^{20}$ Expert members work on an unremunerated and part-time basis. In addition, follow-up to COs has been monitored insufficiently and primarily in an ad-hoc way. The ineffectiveness of the COs also stems from the deficient functioning of the treaty bodies in practice as discussed before (chapter I, section 2.2). The most important aspect is the limited expertise and knowledge of treaty body expert members about the legal and political system of the particular country. This has resulted in vague and uninformed COs of a poor quality. ${ }^{21}$ Most of these factors contributing to the ineffectiveness of COs reflect the explanations offered by neo(realist) IR theories and rationalist international incentives models as to the unimportance of and non-compliance with international law (chapter II, section $1.1)$.

As a result of the deficient functioning of the UN human rights treaty body system, the normative compliance mechanism incorporated in this research based on legitimacy, persuasion and the idea of a compliance pull hardly operates in practice. That is to say, one of the biggest obstacles for the effectiveness of COs is the absence of a compliance pull coming from the treaty bodies and their COs. Government officials in all three countries, to a lesser extent in Finland, were rather negative about the usefulness, legitimacy and persuasiveness of the $\mathrm{COs}$ and the treaty bodies. They pointed to the poor preparation of some members. Officials also lamented the one-sided approach of treaty bodies and the fact that they easily accept information and criticism of NGOs without any factual check. Government officials had the feeling that some of the COs were already completed before the actual dialogue, which in their view also hampered the authority of treaty bodies. The lack of independence of experts and the political nature of the reporting process and the dialogue were mentioned as well.

\footnotetext{
20 For a similar conclusion as to the work of UN Special Rapporteurs, see Piccone (2011), 224.

21 For a similar conclusion as to the work of UN Special Rapporteurs, see Piccone (2011), 216.
} 
Other critical aspects that were mentioned include the factual mistakes and inaccuracies in COs, the plain misunderstanding of the domestic context and a prejudiced and unwarrantedly critical approach. Note that such deficiencies in the functioning of the treaty bodies have made it easier for states to use this as a pretext for noncompliance and to ignore or dismiss the COs. ${ }^{22}$ As is argued below, the dismissive views of the Dutch and New Zealand officials also reflect a defensive self-righteousness rather than an open-minded attitude and a willingness to learn.

The structural shortcomings in the reporting process also become clear when examining the fulfilment of scope conditions for persuasion formulated in the IR literature. Checkel developed several conditions under which circumstances actors are more likely to be persuaded to change their views (chapter II, section 2.2). The first condition, which holds that persuasion can occur when the persuader is seen as authoritative, is not fulfilled, given the negative and critical views of government officials as to the quality and legitimacy of the treaty bodies. The other conditions are also not met. Firstly, the issues discussed with the treaty bodies hardly ever deal with new issues. Most of the time, the critical issues are already known by governments, also because they have already been discussed in parliament and with NGOs or other domestic actors. Governments have frequently already made a decision after - at least ideally - considering all conflicting view points and interests. Governments thus repeat their replies in a mantra-like way without any new reflection. Secondly, the latter also suggests that governments and government officials have also considerable prior, ingrained beliefs based on domestic preferences and political interests. Especially the Dutch and New Zealand government have regarded state reporting as defending their policies instead of an opportunity to learn and exchange ideas. There is a reluctance to 'wash one's dirty linen in public' because this could backfire and result in (more) critical COs. Thirdly, the treaty bodies, as potential persuaders, hardly rely on deliberative argumentation. COs are usually fairly short and lack a legal and evidential basis, concrete policy suggestions or references to best practices in other countries that can inspire governments. Fourthly, there is no high degree of interaction, because of the limited frequency and length of the dialogue. Governments are only confronted with a treaty body once every four to six years and sometimes even less frequently. This means that COs can easily be put into a big pile of paper, only to be taken out years later. In addition, the government only meets with the treaty body for a period of a maximum of nine hours, usually spread over two days. This means that the dialogue is frequently a rushed exercise in which the delegation is bombarded with questions that can only be answered briefly.

Government officials were not more positive about the quality of the CRC Committee and their COs. This illustrates that the higher effectiveness of the

22 See also Mutua (1998), 213. Mechlem (2009), 908. 
COs of the CRC Committee cannot be explained by the presence of a compliance pull in relation to the CRC Committee. This implies that the (higher) effectiveness should primarily be attributed to domestic factors (see the following chapter XIV, section 4.3). Support for this line of reasoning can also be derived from the position of the HRC. Government officials in all three countries were less negative about the HRC. They noted that the HRC is the most authoritative, most professional and most serious committee. Officials generally mentioned the sessions and dialogues as among the best given the detailed and focused questions and structured dialogue. These relatively positive views have, nonetheless, not resulted in a higher impact or effectiveness of the COs of the HRC.

The only exception to the finding that legitimacy and persuasion based explanations can hardly account for the effectiveness COs is the position of the CAT Committee in New Zealand and - to a lesser extent - Finland. ${ }^{23}$ Government officials in New Zealand considered the COs of the CAT Committee, especially those of 2009, relatively useful. They argued that there were some new issues or even surprises among the COs that were not already being addressed or discussed at the national level. It was stated that the dialogue and the resulting COs were better informed and more sensible. One official from the New Zealand Corrections Departments, for example, expressed a genuine willingness to learn from overseas and also change things to improve them. He noted that he was inspired by the dialogue with the CAT Committee in 2009 and persuaded to act upon the COs.

\subsection{The subject matter and specificity of $\mathrm{COs}$}

One factor favouring the effectiveness of COs is their specificity. Almost all COs that have been effective were specific recommendations outlining a concrete course of action, such as the establishment of a Children's Ombudsman or the prohibition of corporal punishment. With such COs it is clear what is expected from the government. The concretely formulated COs have also been the ones used most by other domestic actors in their domestic advocacy (chapter XI, section 2.1). It should, however, be acknowledged that not all specific COs have been effective. There is a paradoxical situation that concrete COs also have a bigger chance of being disregarded by governments, because they are more likely to be in conflict with the policies and legislation in place. ${ }^{24}$ It is therefore not surprising that the initial response of the government is to reject such concrete COs. The position of the

23 Finnish government officials mentioned the CAT Committee and the HRC as the most professional and best treaty bodies with the most detailed and focused questions and structured dialogue. Note that Dutch officials hardly mentioned the (dialogue with or the COs of the) CAT Committee. They were not more critical - or more positive - about the CAT Committee (section IX.3.2).

24 Some scholars also noted that when COs are detailed and contain technical or legal considerations, there is a greater risk that they overlook important aspects or do not accurately 
government can, however, change over time, primarily as a result of domestic pressure (chapter XIV, section 3).

Another important factor for the effectiveness of COs is the salience of the subject matter. This finding is in line with earlier studies which highlight salience as an important factor for compliance (chapter II, section 1.2). The importance of salience is clearly illustrated by the exceptional position of the COs of the CRC Committee in terms of their (impact and) effectiveness (chapter X, section 3.1 and chapter XI, section 2.1). That is to say, the (higher) effectiveness of the COs of the CRC Committee can be explained by the topical interest and increasing popularity of the issue and language of children's rights. It is widely acknowledged that children are in a vulnerable position. Children's rights meet a clear response in the wider society. Children's rights and the CRC have by definition a large constituency: children. This means that there are a large number of active specific interest groups and NGOs working in the field of children and children's rights. Politicians are usually more interested and committed to children's rights than the rights of other groups, such as prisoners or migrants. The subject matter of children('s rights) explains the greater domestic mobilisation in relation to the COs of the CRC Committee, which reflect similar findings of Simmons (chapter XIV, section 1.1.2) ${ }^{25}$ By contrast, other treaties, such as ICESCR, ICERD and CEDAW are sometimes perceived as obsolete and outdated or the character of rights is contested, as in the case of ICESCR. ${ }^{26}$ Treaties such as ICESCR and ICCPR also have only one small group of interested people.

\subsection{Domestic factors contributing to the effectiveness of $\mathrm{COs}$}

Given the weaknesses in the system, the general ineffectiveness of many of the COs should not come as a surprise. What is surprising is that there have been COs that have been effective and played a role in policy and legislative changes. These follow-up measures should primarily be attributed to domestic (f)actors though. These (f)actors at the national level also account for the variances among countries and between the six treaties. Table 14.3 illustrates that there are more favourable factors which affect the effectiveness of COs present in Finland than the two other countries. Likewise, table 14.3 shows that the higher effectiveness of the COs of the CRC Committee is primarily to be attributed to domestic factors as well. The remainder of this section will discuss and explain the factors included in this table.

portray the situation in the state. Such COs offer the state an opportunity to dismiss the COs. Tistounet (2000), 393. Gaer (2011), 112.

25 Simmons (2009), 357-358.

26 Heyns and Viljoen (2001), 521. 
Table 14.3. A comparison across countries of the factors affecting the effectiveness of COs

The darker the shading, the more that factor, which enhances the effectiveness of COs, is present in a particular country. The table also mentions the treaties/ treaty bodies for which this particularly holds true between, if there are notable differences between the (COs of the) six treaty bodies. For an example of how this table should be read, see the explanation with respect to table 14.1.

\begin{tabular}{|c|c|c|c|}
\hline & The Netherlands & New Zealand & Finland \\
\hline \multicolumn{4}{|l|}{ 1. Domestic mobilisation } \\
\hline $\begin{array}{l}\text { Government attention } \\
\text { to COs }\end{array}$ & $\mathrm{CRC}$ & & \\
\hline $\begin{array}{l}\text { Parliamentary attention } \\
\text { to COs }\end{array}$ & $\mathrm{CRC} / \mathrm{CEDAW}$ & CERD & \\
\hline COs in legal practice & CEDAW & & \\
\hline $\begin{array}{l}\text { Ombudsmen and human } \\
\text { rights institutions }\end{array}$ & $\mathrm{CRC}$ & CRC/ CERD & $\mathrm{CRC} / \mathrm{CEDAW}$ \\
\hline NGO lobby on COs & CRC/ CEDAW & $\mathrm{CRC}$ & CRC \\
\hline Media coverage & CRC/ CEDAW & $\mathrm{CERD} / \mathrm{CRC}$ & ICCPR/ CRC \\
\hline \multicolumn{4}{|c|}{ 2. Structure: the organisation of the reporting process and follow-up to COs } \\
\hline $\begin{array}{l}\text { Ownership of and } \\
\text { professionalism of the } \\
\text { reporting }\end{array}$ & $\begin{array}{l}\text { Directorate/ Ministry of } \\
\text { Youth Affairs [CRC] }\end{array}$ & $\begin{array}{l}\text { Directorate/ Ministry of } \\
\text { Youth Affairs [CRC] }\end{array}$ & $\begin{array}{l}\text { Ministry for Foreign } \\
\text { Affairs }\end{array}$ \\
\hline Follow-up mechanism & & $\begin{array}{l}\text { Only CRC [CRC Work } \\
\text { Programme until 2008] }\end{array}$ & \\
\hline $\begin{array}{l}\text { Reporting embedded in } \\
\text { national process }\end{array}$ & $\begin{array}{l}\text { Only CRC (2000s) and } \\
\text { CEDAW (1990s) }\end{array}$ & Only CRC (until 2008) & \\
\hline \multicolumn{4}{|c|}{ 3. Commitment: views and outlook of decision makers } \\
\hline $\begin{array}{l}\text { International outlook } \\
\text { government }\end{array}$ & $\begin{array}{l}\text { Varying: Kok I \& II and } \\
\text { Balkenende IV more } \\
\text { than others }\end{array}$ & $\begin{array}{l}\text { Varying: Labour more } \\
\text { than National }\end{array}$ & $\begin{array}{l}\text { Relatively stable over } \\
\text { time }\end{array}$ \\
\hline $\begin{array}{l}\text { Commitment to } \\
\text { reporting }\end{array}$ & $\mathrm{CRC}$ & $\mathrm{CRC}$ & \\
\hline \multicolumn{4}{|l|}{$\begin{array}{l}\text { Idea that not already in } \\
\text { compliance }\end{array}$} \\
\hline \multicolumn{4}{|l|}{$\begin{array}{l}\text { A felt need to } \\
\text { implement COs }\end{array}$} \\
\hline $\begin{array}{l}\text { Positive views about } \\
\text { quality treaty bodies }\end{array}$ & & & \\
\hline
\end{tabular}




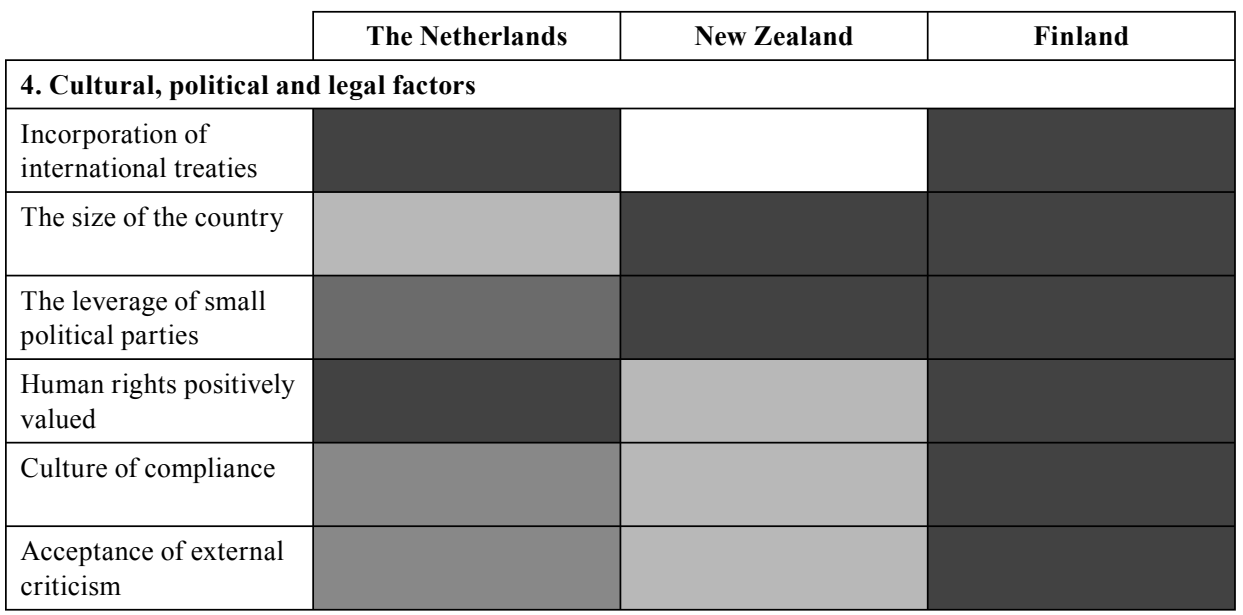

\subsubsection{Domestic mobilisation}

As was mentioned already in chapter XIV, section 3, the most important group of factors crucial for COs to be effective relates to the level of (political) mobilisation by domestic actors. Previous chapters showed that one crucial actor is parliament, which can either urge the government to act upon COs or it can take direct (legislative) action itself. ${ }^{27}$ Other important actors for the effectiveness of COs are NGOs and Ombudsman and human rights institutions who can press the government and parliament to address a matter. ${ }^{28}$ Media coverage can act as a catalyst and strengthen the mobilisation of domestic actors. ${ }^{29}$ The dominance of domestic mobilisation as the primary mechanism for the effectiveness of COs is well illustrated by the greater effectiveness of the COs of the CRC Committee. The strongest and most active NGOs with respect to reporting in all three countries were children's rights NGOs. There have been large coalitions of NGOs having an interest in and focusing on the reporting process. They have deliberately used reporting and COs to inform their advocacy and to support their arguments or legitimise their work. In addition, MPs have also been relatively active with respect to the CRC and COs of the CRC Committee. Domestic mobilisation has been considerably smaller for the other UN human rights treaties, as chapter XIV, section 2 also concluded.

27 De Vos (2013), 55-73.

28 Connors labelled the NGO involvement as the 'most critical dependency' for the success of state reporting. Connors (2000), 15. Clapham argued that without a follow-up dialogue between NGOs and the government about the COs, they 'are more than likely to remain a dead letter'. Clapham (2000), 182. Lansdown (2000), 121.

29 For a similar conclusion as to the work of UN Special Rapporteurs, see Piccone (2011), 212 and 217. 
The previous section already referred to the salience of children's rights as an explanation for the relatively high mobilisation in relation to the CRC. Another explanation for the considerable involvement and lobby of children's rights NGOs in the context of the reporting process under the CRC is that the CRC Committee has traditionally strong links with NGOs, given the latter involvement in the negotiations of the CRC. ${ }^{30}$ In addition, there has been a Geneva-based NGO group for the $\mathrm{CRC}$ which has provided information and training about the process of reporting and linked domestic NGOs with the CRC Committee. ${ }^{31}$ Another reason for the limited impact and mobilisation in relation to the other treaties is the dominance and almost exclusive focus on the regional equivalent in the European human rights regime as well as EU legislation and monitoring mechanisms, such as ECRI for ICERD, the ECPT for CAT, the ECHR for ICCPR, the ESC and ILO Conventions for ICESCR (chapter XI, section 2.1). There has also been an implicit assumption among government officials that when there are no judgments of the ECtHR determining a violation, one is automatically in compliance with the ECHR and UN human rights treaties as well. This assumption has particularly been strong among Dutch officials and to a lesser extent in Finland.

The prominence of the mobilisation of domestic and transnational actors as the primary mechanism for the effectiveness of COs is, firstly, consistent with liberal IR theories on domestic politics (chapter II, section 1.2). A recently published book by Hafner-Burton reaches a similar conclusion as to the importance for international laws and procedures 'to creep into domestic affairs [and] be taken up by local advocates'. ${ }^{32}$ The intensifying or supportive effect of COs discussed in chapter $\mathrm{XIV}$, section 3 dovetails with rationalist models which treat domestic actors as strategic utility maximisers who use $\mathrm{COs}$ as a tool to increase the pressure on governments. COs are political opportunity structures which strengthen domestic actors' power vis-à-vis opponents by granting them additional resources. ${ }^{33} \mathrm{COs}$ can in this way provide a 'leverage effect' or act as a 'selective amplifier' by legitimating and pushing through reforms. ${ }^{34}$ COs can thus act, in the words of Simmons and Dai, as a valuable tool or focal point which supports domestic mobilisation. ${ }^{35}$ The results can, secondly, also be viewed in normative terms with domestic actors as norm entrepreneurs who start a process of socialisation and persuasion of other actors (chapter II, section 3). The most important normative theoretical model that can be applied to the effectiveness of COs is Keck and Sikkink's 'boomerang effect'. COs have been most effective when NGOs highlight an issue in their alternative reports to the committees that they are already lobbying for domestically, in order to obtain a useful and 'authoritative' recommendation that will give extra

Bayefsky (2001), 46.

This is the liaison office of the NGO-Group for the CRC financed by UNICEF.

Hafner-Burton (2013), 11.

Börzel and Risse (2000). Schimmelfennig and Sedelmeier (2004), 672. Hafner-Burton (2013),64.

Zeitlin (2009), 231-232. Vanhercke (2009), 13.

Simmons (2009), 135. Dai (2013), 96. 
strength and legitimacy to their claims. Domestic compliance constituencies and NGOs, thus, seek international support and link up with transnational networks to put pressure on their states from above and below. ${ }^{36}$ This is a two way process. The COs not only legitimise the demands and work of domestic stakeholders, but these stakeholders are also essential in supporting the COs by translating them to the national level. These domestic stakeholders hence act as crucial intermediates between the national and international level, as was also noted by Hafner-Burton. ${ }^{37}$

\subsubsection{Structure: the organisation of the reporting process and follow-up to COs}

The effectiveness of the COs is also determined by the organisation of the reporting process at the national level and the structures and procedures put in place. ${ }^{38}$ The reporting process and the consequent $\mathrm{COs}$ have been more effective when the reporting was entrusted to a ministry which has 'ownership' over the process and treaty. This was the case with reporting under the CRC by the Ministry of Youth Affairs (until 2008) in New Zealand and the Directorate Youth Policy and the Ministry of Youth and Families (2007-2010) in the Netherlands. Dutch Minister of Youth and Families Rouvoet, for example, referred to the CRC as 'his' Convention and called himself the 'owner' of the Convention. As a result, government officials from the Directorate Youth Policy, responsible for the coordination, attached more importance to reporting (chapter XIV, section 4.3.3). In Finland, reporting under the six treaties has been undertaken by a dedicated team within the Legal Department of the Ministry of Foreign Affairs following a structured, transparent and professional process. (Timely) reporting has also been given greater importance. The Ministry has been the central actor in the process and there has been a relatively great continuity in the government officials involved in the process.

Secondly, the (in)effectiveness of COs is also affected by the presence - or as is frequently the case, the absence - of a mechanism which coordinates and monitors follow-up to COs. Both in the Netherlands and Finland, there has not been any other form of inter-ministerial coordination monitoring mechanism for the implementation of COs. ${ }^{39}$ It is therefore not surprising that the Finnish Ministry of Foreign Affairs held in 2004 that COs 'are too often left in abeyance and are not taken up until for the purpose of preparing the following report'. ${ }^{40}$ Only in New Zealand were there regular CRC Work Programmes with concrete targets for policy

Risse and Sikkink (1999), 4.

Hafner-Burton (2013), 5.

For similar conclusions, see Niemi (2003). De Vos (2013), 15 and 25-28.

The ministries, who are responsible for the implementation of follow-up measures, are merely asked for a (substantive) reaction to COs for the purpose of informing parliament or the respective treaty body. The Dutch and Finnish Ministry of Foreign Affairs do not consider themselves well placed to monitor whether and how the other ministries implement the COs that almost always deal with domestic issues.

40

Formin (2004), 140. 
and legislative action on the basis of the COs from 2000 until 2008. The Programmes were deliberately tabled for discussion during government meetings to obtain the approval of other ministers and ministries. This was considered essential because most of the issue areas covered in the COs and the Work Programme were the responsibility of other departments. The CRC Work Programmes were one of the most important factors for the effectiveness of COs of the CRC Committee in New Zealand.

A related third factor favouring the effectiveness of the reporting process and the COs is when reporting is embedded in a national process of dialogue and interaction with NGOs and human rights or ombudsman institutions. This has, for example, happened in New Zealand, where the CRC Work Programme was complemented by a CRC Advisory Group which consisted of government officials, NGOs and human rights institutions and which has met at least twice a year. Both in the Netherlands and Finland, there has also been a continuous and interactive dialogue between the government, NGOs and the Children's Ombudsman with respect to the CRC in the 2000s. As will be outlined below, the government officials involved in these national processes were also more positive about the importance and usefulness of reporting.

\subsubsection{Commitment: views and outlook of decision makers}

Another group of factors that affect the (in)effectiveness of the COs are the commitment and views of decision makers, both government officials and members of government, about human rights and the reporting process. ${ }^{41}$ One obvious prerequisite for the commitment of decision makers is that they actually have the knowledge and experience about the process and international human rights obligations. By and large, officials from the Ministry of Justice and the Ministry of Foreign Affairs were best informed in all three countries.

Firstly, the government's international outlook and receptiveness towards international law is important for the effectiveness of COs. Generally speaking, governments consisting of left-leaning political parties, such as Labour or the Greens, tend to be more receptive to human rights treaties or the COs. Finnish government members from the Green League, which have been in almost every government in Finland since 1995, have been an important driver for the effectiveness of COs. Examples include the criminalisation of torture and the shortening of the length of the alternative for military service for conscientious objectors (chapter XIII, sections 4.3 and 6).

Secondly, another contributory factor for the effectiveness of COs is the commitment and enthusiasm towards the reporting process of individual decision makers. ${ }^{42}$ The effectiveness of several COs was clearly the result of the endeavours

\footnotetext{
$41 \quad$ See also De Vos (2013), 16.

42 For a similar conclusion as to the work of UN Special Rapporteurs, see Piccone (2011), 216-217.
} 
of individuals, such as the abolition of life imprisonment for minors and the prohibition of corporal punishment in the Netherlands. There have also been differences between several government departments within the three countries. Government officials and several Ministers of the New Zealand Ministry of Youth Affairs and the Dutch Directorate Youth Policy and the Ministry of Youth and Families (2007-2010) have, for example, been relatively positive about the value of reporting. They have used the process and COs strategically in order to realise their own agenda. Many officials and some Ministers from the Ministry of Youth Affairs had a personal interest in CRC and some were keen children's rights advocates themselves. Especially in New Zealand, officials acknowledged that the CRC was useful to help advance domestic issues, also because the CRC was consistent with what the Ministry of Youth Affairs was advocating for. Officials from the Finnish Ministry of Foreign Affairs have also been relatively dedicated to the process and have at times pressed other government departments to act upon COs. They referred to the process of reporting as 'a spiral continuum' or a circle and something which serves as 'national sources of information on human rights'. ${ }^{43}$ One official even held that it is their duty to defend and promote the treaty body system.

Thirdly, a view which has diminished the effectiveness of reporting and the COs is the idea existing among most of the decision makers and politicians in the three countries that the UN human rights treaties are already complied with. Officials and politicians in all three countries see their country as a human rights leader and role model for other countries, which has led to a certain level of complacency and a tendency to think that there are no human rights problems. The logic runs that their countries only become party to international treaties when existing domestic legislation, policy and practice are in accordance with the respective treaty. There is a feeling that the UN human rights treaties and the treaty bodies are primarily relevant for other less developed and democratic countries. This view has reduced the reporting process almost to a symbolic and formalistic exercise as was noted in chapter XIV, section 1. This view was present in all three countries, but it was present to a lesser degree in Finland.

Fourthly, the (in)effectiveness of COs has also been affected by decision makers' views as to the need to implement COs. In the Netherlands and New Zealand COs are seen as an aspirational wish list or mere opinions that can easily be disregarded as opposed to authoritative and compelling statements. There were more Finnish officials who had the latter view and argued that strong counterarguments and careful reasoning are needed to deviate from the COs.

Fifthly, as was already mentioned in chapter XIV, section 4.1, the largest hurdle for the effectiveness of COs are the negative and dismissive views of government officials as to the functioning of the UN human rights treaty bodies, especially in the Netherlands and New Zealand.

43 For the quotes, see, respectively, UN Doc. A/HRC/WG.6/1/FIN/1 (2008), para. 87 and Formin (2004), 138. 


\subsubsection{Cultural, political and legal factors}

One important factor influencing the effectiveness of COs is the legal culture and the legal and political status of the UN human rights (treaties). When international human rights treaties are automatically part of the legal order (as in the Dutch monistic order) or legally incorporated (as in the Finnish dualist system), this offers more scope for domestic actors to rely on them. The same can be said for constitutional provisions permitting or even obliging domestic authorities like courts and the parliament to examine the compatibility of legislation with (UN) human rights treaties, as in the Netherlands (Articles 93 and 94) and Finland (sections 22, 74 and 108-109). In this light it is not surprising that the COs have had a lower impact and have been less effective in New Zealand, where the UN human rights treaties are not incorporated in the legal order and have a much lower legal and political status.

Closely related to the legal status is, secondly, the extent to which human rights resonate with politicians and the wider public. In the Netherlands and Finland, human rights are generally positively valued and used by a wide range of actors and have become an integral part of the domestic political decision-making process. Politicians, the population and the media have until recently talked about human rights primarily in a favourable way. Such views and the political and societal status of human rights have also contributed to the effectiveness of COs. By contrast, several interviewees and scholars noted that the language of rights does not work in New Zealand, where an appeal to human rights is seen as 'a last resort of people pursuing an unworthy agenda', ${ }^{44}$ Likewise, relying on $\mathrm{COs}$ or international standards is sometimes intentionally avoided by domestic actors, because it can be counterproductive.

Thirdly, in Finland in particular there is a legalistic culture in which compliance with international standards is the norm and external or international criticism is largely accepted. This compliance culture was attributed to the legalistic culture in which the rule of law has a strong position and strict adherence to laws is the preferred option. This culture might also explain the less dismissive views of Finnish officials about the COs and, hence, the higher effectiveness of COs. By contrast, New Zealanders find it more difficult to deal with criticism, especially from overseas. The best example is the hostile reaction of the New Zealand government to the criticism of CERD about the discriminatory elements in the Foreshore and Seabed Act 2004 against the indigenous Maori population. The Prime Minister, for example, held that CERD is 'on the outer edges of the UN system'.

Fourthly, another factor that has contributed to the effectiveness of COs is the proportional electoral system in the three countries. Such a system has empowered small political parties. Small parties can therefore initiate or prompt action on the

Wood et al. (2008), 55. 
basis of COs. The latter was the case with the earlier discussed bill prohibiting corporal punishment in New Zealand, which was proposed by an MP from the small Green Party (Bradford). Another example is the repeal of the Foreshore and Seabed Act 2004 in New Zealand, which was partly the result of the efforts of the Maori Party that also used the recommendations of CERD as support for its position.

Fifthly, related to this is the small size of the country. Especially in New Zealand and Finland, government officials, members of government and MPs are quite accessible for the concerns and lobby activities of NGOs and Ombudsmen and human rights institutions. This accessibility has sometimes contributed to the effectiveness of COs. This is well illustrated by the bill prohibiting corporal punishment in New Zealand proposed by Bradford. Bradford closely cooperated with children's rights advocates to achieve the adoption of her bill.

\section{REFLECTIONS AND DISCUSSION}

What do these findings tell us about the reporting process and the UN human rights treaty body system? In order to answer this question it is necessary to know to what extent the findings are valid for and can be generalised for other countries as well. It is not unreasonable to assume that the situation in countries similar to the ones included in this research, unitary industrialised Western liberal democracies without a constitutional court, will not be fundamentally different. A different matter is whether the findings can also be extended to Western democracies with a federal system like Germany, Canada and the United States. Is the effectiveness of COs indeed lower in these countries because implementation of international norms and recommendations is more complex in a federal system? An even more difficult question is whether the findings also hold true for even more 'contrasting' or different states, which include non-democratic, non-western and non-industrialised countries. It is beyond the scope of this research to provide answers to these questions. Further research is necessary to answer this question for these dissimilar countries.

Such future research should especially focus on countries in transition from a dictatorial or autocratic regime to a more democratic system. This is because some scholars recently found that human rights treaties have had the biggest effect in such transitioning countries (chapter III, section 1.1). ${ }^{45}$ It would be interesting to know whether such findings also hold true for international human rights monitoring bodies and their judgments or recommendations. Two conflicting hypotheses or expectations can be formulated in relation to the impact and effectiveness of the COs in transitioning countries on the basis of the empirical results of this research and other (theoretical) literature. On the one hand, one could argue that COs have (potentially) more effect in these transitioning countries, since

45 Simmons (2009), 149-153. Moravscik (2000), 220 and 229. 
these countries have simply more issues to make progress on. It might also be easier for treaty bodies to pronounce on more flagrant and 'clear violations' of human rights in transitioning countries, such as extrajudicial killings, torture and arbitrary arrest. ${ }^{46}$ By contrast, it can be argued that there is frequently less room for improvement in established liberal democracies with a higher (domestic) standard of human rights protection and numerous (independent) domestic human rights monitoring mechanisms. It might consequently be more difficult for treaty bodies to come up with COs that add something and really matter in those countries. This is because - as some government officials argued as well - COs often deal with relatively minor or technical issues in relation to which one can reasonably and more easily have different opinions.

On the other hand, it could be argued that the greater potential for COs is not very likely to be fulfilled in practice in transitioning countries. As was mentioned before, most (transitioning) countries have submitted considerably fewer reports and have appeared on a less frequent basis before the treaty bodies (chapter III, section 1.1). ${ }^{47}$ This might not only reflect a lower commitment to the usefulness or value of reporting, but above all reflects a more limited bureaucratic and financial capacity to satisfy the burdensome reporting requirements. The fulfilment of many of the factors favouring the effectiveness of COs (as outlined in table 14.3) actually depends to a large extent upon the availability of sufficient resources and bureaucratic capacity. Examples include the creation of a follow-up mechanism for COs, embedding the reporting process in a domestic consultative and dialogue process and the creation of knowledge of officials about treaties and the reporting process. The availability of resources also determines the involvement and mobilisation of (other) domestic actors. Producing alternative NGO reports, attending the session in Geneva or New York and especially monitoring follow-up and conducting a political lobby on the basis of COs is not a cost-free exercise, but it requires considerable investments over a long period of time. It is unclear whether transitioning countries have the capacity and resources to deal with the resource intensity of the entire reporting process and the demands it places on government bureaucracies. Further in-depth and systematic research is needed to examine which expectation or hypothesis is (more) dominant.

The findings also beg for reflection on the title of this book as to whether the reporting process is paper-pushing or policy prompting. In other words, does the reporting process and COs lead to a change in state behaviour in the form of policy or legislative measures? Or does the reporting process result in nothing more than paper being circulated without any effect? The findings call for a nuanced answer. On the one hand, calling the reporting process policy prompting might be an exaggeration in the light of the findings that there have hardly been any measures that would not have come about without COs and which were only taken because of the COs. On the other hand, the process has not been merely paper-pushing. There

$46 \quad$ Kalin (2012), 51.

47 LeBlanc, Huibregtse, Meister (2010). 
have been several COs which have been a contributory - and sometimes even a decisive - factor contributing to legislative and policy change.

The findings might disappoint some, especially those who are intimately connected with and have a strong belief in the UN human rights treaty body system. Others, especially legal positivists or (neo) realist IR theoreticians, might however be surprised that given the non-binding nature of $\mathrm{COs}$ and the weaknesses in the system, there have been COs that played a role at all. How these findings are interpreted clearly depends upon one's prior expectations. The same findings can thus be interpreted differently. While looking at the same glass, which represents the UN human rights treaty body system, the former group of people might see the glass as half empty. The latter group of people, without any expectations, might actually regard the glass as half full.

These differences in expectations and perspectives also imply divergent views on the broader implications of these findings for the reporting process under UN human rights treaties. For some, the limited effectiveness of COs, whereby they primarily act as devices of support and legitimisation for domestic actors, might actually be the maximum achievable for treaty bodies. Such a role dovetails with propositions of liberal IR theories which argue that international norms must always work their influence through the filter of domestic structure and domestic norms, ${ }^{48}$ Likewise, such a function conforms to the envisaged role of treaty bodies as 'essentially catalytic and secondary' and is consistent with the principle of subsidiarity of human rights review and monitoring at the international level. ${ }^{49}$ For others there is still unrealised potential for the treaty bodies.

\section{Policy ReCOMmendations}

Concluding this final chapter, several critical issues in the current functioning of the treaty bodies that need to be addressed most urgently will be highlighted. In addition, this section will suggest some measures that governments and other domestic stakeholders could take in order to strengthen the impact and effectiveness of the reporting process and the resulting COs. It should be acknowledged from the outset that this research has focused purely on the effectiveness of the reporting process under UN human rights treaties. Policy recommendations would thus solely flow from a perspective of how to enhance the effectiveness of COs without actually considering whether such an attempt, assuming that it is feasible, is cost-effective or desirable in the light of other interests and objectives. For example, one recommendation that flows logically from the findings is that states take the reporting obligation more seriously and also create domestic mechanisms for follow-up. This obviously requires an investment on the part of the state. Whether states indeed act upon such a recommendation is essentially a political decision and also requires an assessment as

\footnotetext{
$48 \quad$ Finnemore and Sikkink (1998), 893.

49 Alston (1993), para. 95.
} 
to whether such investments are also the most (cost-)effective in improving the protection of human rights. Would the pay-off, for example, not be higher when resources are directed to the formulation of a national human rights action plan?

\subsection{Suggestions for the treaty bodies: less is more $\mathrm{e}^{50}$}

There are obviously some matters that can and also should be improved by the treaty bodies without any institutional or procedural 'change', but they simply require (some members of) the treaty bodies to have better self-discipline, to be better prepared and to examine NGO information as critically as information provided by states. There are also some other more difficult issues which require changing the current modalities of the current reporting system without requiring an amendment of the treaties. The aim of this section is to point out in what direction improvements should be sought. As such, this section will discuss three suggestions. There are other valuable recommendations that have been constantly repeated by almost all stakeholders involved in the treaty body strengthening discussion and which have also been included in the 2014 General Assembly's Resolution on the strengthening of the treaty body system (chapter I, section 1.2). This includes, among others, recommendations to draft more specific and focused COs and to strengthen the independence and expertise of treaty body members. ${ }^{51}$ These useful recommendations will not be examined in-depth in this section. Note that the three proposals can be taken into consideration by the treaty bodies in conjunction with the GA Resolution, since there is considerable overlap.

Before turning to some concrete proposals, several issues should be addressed. Firstly, any proposal for change requires a 'diagnosis' of the main difficulty. The core problem of the current reporting system is the negative views and attitudes of government officials as to the legitimacy of treaty bodies as well as the value of reporting. The two most important -and interrelated - explanations for this are: the limited quality of the dialogue, treaty bodies and their COs as well as the evaluation fatigue among government officials. The latter is the result of the duplication of reporting requirements in different international contexts and the constant need to update information and produce new documents for the treaty bodies within one

50 These proposals are largely based on a set of recommendations for the treaty body strengthening process that were sent earlier to the OHCHR by the author on the basis of the suggestions of the panellists and participants of the seminar 'The Universal Periodic Review Process and the Treaty Bodies: Constructive Cooperation or Deepening Divisions?', 25 November 2011, Maastricht, the Netherlands. <www2.ohchr.org/english/bodies/HRTD/docs/ ReportMaastrichtSeminar.doc $>$, accessed 28 October 2013.

51 The treaty bodies themselves adopted 'Guidelines on the independence and impartiality of members of the human rights treaty bodies' ("the Addis Ababa guidelines" of June 2012). UN Doc. A/68/L.37 (2014), para. 6, 10, 36. See, for example, Pillay (2012), 60-62 and 74-79. 
reporting cycle (state report, LOI, oral information and additional written information). The three proposals outlined below aim to address these problems. ${ }^{52}$

Secondly, the three proposals are based on the idea that the external problems that the treaty bodies are confronted with (such as the insufficient meeting time, the limited financial resources and expertise) are unlikely to improve in a significant way. ${ }^{53}$ Acknowledging such limitations entails that treaty bodies should no longer conduct a comprehensive assessment of the implementation of the entire treaty and all problematic areas. The current six or nine hours are simply not enough to discuss the entire human rights situation in a country. Doing so results in a dialogue which is superficial, irrelevant and not constructive and which only results in poorly informed COs (see primarily sections 1.2 and 4.5). Treaty bodies should thus be more strategic in how they utilise their scarce resources, as Hafner-Burton also suggested. ${ }^{54}$ Maybe the word limit for each treaty body document 'decided' by the 2014 GA Resolution is a good starting point for treaty bodies to prioritise. ${ }^{55}$

Thirdly, the three proposals are primarily aimed at the review of countries such as those included in this research - with a relatively high domestic standard of human rights and which do report and appear before treaty bodies on a regular basis; at least once every year before one of the six treaty bodies (and in some periods even three times a year). The suggestions are even more relevant for countries which are also subject to monitoring and review at the regional (human rights) level. Treaty bodies should reduce the burden for "cooperating" states, rather than demanding ever more from them. At the moment, the system is by and large focused on countries which need them least. For such countries, treaty bodies should perform a more subsidiary and secondary role.

In light of the previous three preliminary issues, the following three proposals are made which could improve the quality and usefulness of the reporting process and reduce the burden of reporting and evaluation fatigue. The proposals could possibly have a positive impact on the domestic impact and effectiveness of the process and the COs. Nonetheless, it remains to be seen whether this will be the case in practice as well, especially in the light of the conclusion of this research that the domestic effectiveness of COs could primarily be attributed to domestic (f)actors.

- A treaty body (cycle) should merely concentrate on a limited number of the most urgent and critical issues or articles of the treaty. Treaty bodies should ideally focus on the five most serious problems instead of the entire treaty and

52 The proliferation of treaties and procedures was one of the four critical issues noted by HafnerBurton, who suggested streamlining of reporting and the lowering of the burden for states. Hafner-Burton (2013), 119-121.

53 Note that the GA Resolution increased the allocation of meeting time for treaty bodies. It, however, seems that this increase is mainly to 'prevent the recurrence of backlogs'. UN Doc. A/68/L.37 (2014), para. 26(c).

54 Hafner-Burton (2013), 121.

55 UN Doc. A/68/L.37 (2014), para. 15. 
all the developments which have taken place in previous years. This would require states to increase the quality and detail of input in their reports to the treaty bodies. The latter would enable treaty body members to have more detailed, specific and technical knowledge about these issues. It also allows for a (more) structured and in-depth dialogue instead of the current superficial dialogue of an enormous amount of issues. In addition, it would facilitate the adoption of more focused and SMARTly formulated COs which better reflect the realities on the ground. The follow-up to such COs could also be better monitored by domestic actors and by the treaty bodies.

- All treaty bodies should (uniformly) apply the List of Issues Prior to Reporting (LOIPR). ${ }^{56}$ Currently only the $\mathrm{HRC}$ and CAT Committee do so. The encouraging practice of adopting a LOIPR is another way for having more focused reporting. Since the government's answers to the LOIPR replace the necessity of writing a separate periodic state report prior to the LOI, this practice could in theory diminish the reporting burden on the part of the state. This, however, depends upon how treaty bodies deal with the LOIPR. When the LOIPR is applied, it should indeed lead to a real reduction instead of requiring them to write more or less the same as they would have done in the absence of a LOIPR. This means that the questions on the part of the treaty bodies should be limited and specifically formulated as far as possible, which would require restraint from treaty bodies. This corresponds with the GA Resolution's reference to 'a limit on the number of questions'. ${ }^{57}$ The following general questions should, for example, as far as possible be avoided: 'What recent efforts have been made to strengthen the mechanisms available to provide effective remedies against discrimination and to promote substantive equality?'58 'Please provide information on significant political and administrative measures taken since the previous report to promote and protect human rights under the Covenant since the previous report'. ${ }^{59}$

- Treaty bodies should avoid unnecessary duplication and therefore should - in principle - not focus on issues which other treaty bodies have sufficiently dealt with before or which will be considered in the near future. This means that there should be a better division of labour among the treaty bodies. In practical terms, this, for example, means that the HRC should in theory leave the consideration of the issue of gender equality or the position of ethnic minorities to the CEDAW Committee and CERD, at least with respect to states that have ratified these two treaties and also report (regularly) to the committees.

56 This reflects and supports the proposal of the High Commissioner for a simplified reporting procedure which was also included in the GA Resolution. Pillay (2012), 47-50. UN Doc. A/68/L.37 (2014), para. 1-2.

57 UN Doc. A/68/L.37 (2014), para. 1.

58 UN Doc. CCPR/C/AUS/Q/6 (2012), para. 9.

59 UN Doc. CCPR/C/DNK/Q/6 (2011), para.2. 


\subsection{Suggestions for domestic stakeholders: COs as practical props}

The overall conclusion of this book is that the impact and effectiveness of COs is primarily affected by domestic (f)actors. This means that domestic stakeholders ultimately determine how effective the international reporting system is. What follows are some proposals for domestic stakeholders which they can implement when they want to strengthen the domestic impact and effectiveness of reporting and the resulting COs. Many suggestions follow logically from the section outlining the domestic factors favouring the effectiveness (chapter XIV, section 4.3).

\section{The government}

The government is obviously the primary actor who 'decides' whether reporting and the COs have an impact and are effective. Several of the identified factors that favour the effectiveness of COs are difficult to change through concrete measures. The 'easiest' steps that can be taken relate to the institutional structure and the organisation of reporting (see table 14.3 under 2), and include the following:

- The most straightforward measure includes the establishment of a follow-up mechanism with concrete targets and deadlines for policy and legislative action on the basis of the COs.

- This could be supplemented with an interdepartmental governmental working group on human rights to strengthen awareness about and facilitate coordination of the reporting process, stimulate discussion and enhance follow-up to the COs. Such a working group should include highly placed officials that are able to make actual decisions.

- Reporting should also have a clearer domestic purpose and should feed into domestic processes of human rights review and policy formulation. Reporting could, for example, be linked more closely to the development of a national human rights action plan or to the writing of national reviews or reports on the implementation or realisation of human rights (treaties). As far as the latter is concerned, one could think of yearly thematic reports on a different human rights issue, the choice of which might be linked to the international agenda of reporting. These domestic reports should also be embedded in a national process of reporting or dialogue which include regular interaction with and close consultation of NGOs, human rights or ombudsman institutions and parliament. When the domestic value and pay-off is more pertinent, this could also result in a more positive spirit to reporting among officials. Furthermore, such domestic cyclical reviews and reports could possibly also result in a decrease in the administrative burden for states since they could use such domestic reports more easily to fulfil their international reporting requirements. 


\section{$N G O s$, civil society actors and human rights and ombudsman institutions}

The second group of domestic stakeholders who are well placed to influence the effectiveness of COs include those who are directly involved in the reporting process by way of submitting alternative reports and/or attending sessions in Geneva or New York. This includes NGOs and other civil society actors, such as lawyers or academics, and human rights and ombudsman institutions.

- Parallel reports should, first of all, not only be written for the respective treaty body but also for the relevant actors in the country concerned, preferably in the national language(s). This report should not only be a message to Geneva, but above all it should be a message to the (political) capital and directed at national politicians and decision makers as well as the media. Although the writing of such parallel reports is in itself valuable, some actors should better realise that their work does not stop with the inclusion of their concerns in the COs.

- Domestic stakeholders should invest in and develop a clear follow-up strategy based on influencing domestic media to report on the COs, lobbying parliament as well as using the COs in litigation, where possible. Merely writing a parallel report and lobbying the treaty bodies is not enough in itself to realise domestic change. Rather, the most essential work only starts after the COs have been published. This book has shown that such a domestic advocacy strategy on the basis of COs can be effective over time even though it is often a long term endeavour.

\section{Parliament}

Another actor which is often only marginally involved in the reporting process is parliament.

- Parliament should hold a debate on a structural basis on the domestic human rights situation and the implementation of human rights treaties and findings and judgments of monitoring mechanisms, including the COs. This debate should be clearly embedded in a domestic process of human rights review as described above. The debate should ideally be with all members of government but at the very least with the ministers who are responsible for policy areas that are closely related to human rights.

- Parliament should be closely informed about the reporting process. However, in order not to overload parliament with piles of documents, the government could send a (two-) yearly overview of all the international recommendations received in that period with its reaction. This overview could also be part of the national reporting exercise or human rights action plan as described above. 
- Another suggestion that would heighten the awareness of MPs about international human rights and the reporting process is including an MP in the government delegation for the constructive dialogue, as happens in Finland.

In sum, this books' conclusions and recommendations reflect the thesis that it is essentially up to domestic stakeholders to decide whether the reporting process and the COs largely remain a "paper-pushing" exercise or whether they are used as "policy prompting" devices. Domestic actors should in any case realise that COs constitute "practical props" which can give extra strength or legitimacy to their arguments and demands when they are advocating for policy or legislative change. 


\section{NeDERLANDSE SAMENVATTING [Summary IN Dutch]}

Mensenrechten zijn overal. De term wordt te pas en te onpas gebruikt door politici, in krantenartikelen, in campagnes van Amnesty International of in televisieseries zoals het Deense Borgen. Een belangrijke illustratie hiervan - en tegelijkertijd een reden voor de aanwezigheid van mensenrechten - zijn de verscheidene mensenrechtenverdragen en - verklaringen die de afgelopen decennia zijn aangenomen op internationaal en Europees niveau. De naleving van mensenrechten wordt op verschillende niveaus door steeds meer instanties en organisaties in de gaten gehouden: internationaal (de Verenigde Naties, Amnesty International of Unicef), regionaal (het Europees of Inter-Amerikaans Hof voor de Rechten van de Mens) en nationaal (het College voor de Rechten van de Mens, de Nederlandse rechter of het parlement).

Heeft deze "monitoring" van de naleving van mensenrechten ook zin? In hoeverre leidt kritiek van eerder genoemde instanties tot aanpassing van beleid of wetgeving? Wordt op nationaal niveau geluisterd naar kritiek "van buiten"? Het zijn deze vragen die centraal stonden in dit promotieonderzoek. Meer in het bijzonder is gekeken naar de effectiviteit van de kritiek en aanbevelingen van VN-mensenrechtencomités in de context van een rapportageproces en de mate waarin beleids- of wetgevingsmaatregelen zijn genomen in Nederland, NieuwZeeland en Finland. Er is tot op heden niet of nauwelijks onderzoek gedaan naar de impact en effectiviteit van dit proces, terwijl dit rapportageproces als een van de belangrijkste mechanismen wordt gezien om de naleving van mensenrechten wereldwijd in de gaten te houden. In dit hiaat tracht dit promotieonderzoek te voorzien.

\section{DE VERDRAGEN EN HET RAPPORTAGEPROCES}

Voor het onderzoek is gekeken naar de volgende zes oudste mensenrechtenverdragen en - comités:

- het Verdrag en Comité inzake de Uitbanning van Raciale Discriminatie,

- het Verdrag inzake Burgerlijke en Politieke Rechten (vaak afgekort als BUPO) gemonitord door het VN-Mensenrechtencomité,

- het Verdrag en Comité inzake Economische, Sociale en Culturele Rechten (ESOCUL of IVESCR),

- het Verdrag en Comité inzake de Uitbanning van Discriminatie van Vrouwen (Vrouwenverdrag),

- het Verdrag en Comité inzake de Uitbanning van Foltering, en

- het Verdrag en Comité inzake de Rechten van het Kind (IVRK). 
Op grond van VN-mensenrechtenverdragen zijn landen die deze verdragen hebben ondertekend, verplicht iedere 4 of 5 jaar zelf een rapport op te stellen waarin zij de stand van zaken wat betreft de implementatie van de mensenrechten in dat verdrag uiteenzetten. Tegelijkertijd krijgen niet-gouvernementele organisaties (NGOs) of mensenrechteninstituten de kans hun visie te geven aan de comités. Deze rapportages zijn vaak minder rooskleurig en een stuk kritischer dan het rapport van de regering. Alle ingediende rapporten worden vervolgens door het comité met de regering besproken tijdens een zitting in Genève of New York. Het comité stelt op grond van alle informatie die haar is toegekomen kritische vragen aan de regeringsdelegatie. $\mathrm{Na}$ de bespreking neemt het comité een rapport (de Concluderende Observaties) aan, waarin zij aangeeft waar de betreffende staat tekortschiet en zijn beleid of wetgeving dient te veranderen. De aanbevelingen in het rapport zijn juridisch gezien niet bindend, wat betekent dat landen niet verplicht zijn gevolg te geven aan deze aanbevelingen en er ook voor het comité geen mogelijkheid bestaat sancties op te leggen.

\section{A. De onderzoeksopzet}

\section{De landenkeuze}

Bewust is er voor dit onderzoek gekozen voor landen waarvan men (mag) verwacht(en) dat zij externe mensenrechtenkritiek serieus nemen. Gekozen is voor economisch ontwikkelde en liberale democratieën in de westerse wereld. Deze landen hebben de financiële en personele middelen om te voldoen aan de zeer arbeidsintensieve rapportageverplichting en daarnaast de internationale aanbevelingen uit te voeren. De keuze voor westerse liberale democratieën vindt ook steun in de literatuur op het gebied van Internationale Betrekkingen (IB) en Internationaal Recht (IR) ten aanzien van de nakoming of implementatie van internationaal (mensen)recht(en). Zo is de heersende - maar zeker niet algemeen aanvaarde gedachte - dat internationale verdragen meer effect hebben in landen met een parlementair stelsel, een vrije pers, onafhankelijke rechters en waar NGO's de mogelijkheid hebben zich kritisch uit te spreken.

Voor de keuze binnen de grote groep westerse liberale democratieën zijn bewust landen gekozen die met Nederland vergelijkbaar zijn. Dat wil zeggen, geen federale staten en/of landen met een sterk grondwettelijk hof, zoals de Verenigde Staten of Duitsland. Er is ook opzettelijk besloten om een niet-Europees land (NieuwZeeland) op te nemen met als doel te kijken in hoeverre VN-mensenrechtenverdragen en de aanbevelingen meer effect hebben in een land dat geen lid is van een regionale mensenrechtenorganisatie. Lopende het onderzoek naar Nederland kwam naar voren dat er in Nederland veel aandacht uitgaat naar het Europese Verdrag inzake de Rechten van de Mens (EVRM) met het relatief sterke Europees Hof voor de Rechten van de Mens in Straatsburg (EHRM). Dit gaat vaak ten koste van de VN-evenknieën. In Nederland heerst namelijk de idee dat zolang voldaan wordt aan 
de Europese afspraken, er nauwelijks problemen zijn met de naleving van de $\mathrm{VN}$-verdragen. Finland is gekozen omdat de Noordse landen algemeen gezien worden als trouwe nalevers van internationaal recht. Daar kwam bij dat over Finland relatief veel Engelse literatuur beschikbaar is.

\section{Twee theorieën \& methodologie}

Voor het ontwikkelen van een methodologie voor de vaststelling van de effectiviteit van aanbevelingen is allereerst nagegaan wat voor verklaringen er worden gegeven in bovengenoemde IB- en IR-literatuur. Uitgangspunt daarbij was het idee dat de aanbevelingen juridisch niet bindend zijn en er geen sancties volgen bij nietopvolging. Dit maakt dat het effect van de aanbevelingen in hoge mate afhangt van de volgende twee aspecten:

1. Kwaliteit en gezag. Een eerste aspect is de kwaliteit en het gezag van de aanbevelingen en de mensenrechtencomités in de ogen van diegenen die ermee worden geconfronteerd; bewindspersonen en ambtenaren. Ook al zijn landen niet verplicht gevolg te geven aan de aanbeveling, zij zouden op basis van de goede argumenten van de comités overtuigd kunnen worden van de noodzaak beleid of wetgeving te veranderen. Deze overtuiging hangt ook af van het gezag van de comités. Op grond van deze theoretische insteek is er voor gekozen om interviews te houden met ambtenaren in Nederland, Nieuw-Zeeland en Finland, om zo achter hun opvattingen ten aanzien van de aanbevelingen, de comités en het rapportageproces te komen.

2. Binnenlandse mobilisatie. Een tweede factor voor de effectiviteit van aanbevelingen is de mate waarin nationale actoren, zoals het parlement, rechters, de media, NGO's en mensenrechteninstituten, de regering onder druk zetten de aanbevelingen op te volgen. Voor het vaststellen van de mate van binnenlandse mobilisatie is - voor Nederland - uitgebreid onderzocht in hoeverre er in parlementaire documenten, rechterlijke uitspraken, krantenartikelen en informatie en documenten van NGO's wordt verwezen naar de aanbevelingen en verdragen. Voor Nieuw-Zeeland en Finland is dit onderzoek beperkter van aard geweest en bovenal gebaseerd op secundaire literatuur en interviews met eerder genoemde nationale actoren. In totaal zijn er voor dit onderzoek 175 personen geïnterviewd.

\section{B. De belangrijkste bevindingen}

\section{Vaak genegeerd, maar soms effect}

De belangrijkste conclusie van dit onderzoek is dat de grote meerderheid van de aanbevelingen niet effectief zijn gebleken en niet hebben geleid tot nieuwe of aanvullende beleids- of wetgevingsmaatregelen. Vaak beklemtoonden de regeringen dat zij reeds voldeden aan de aanbevelingen en er genoeg gedaan werd aan de 
problemen die door de verschillende comités werden aangekaart. In sommige gevallen werden aanbevelingen bewust ter zijde gelegd en verworpen. Desalniettemin hebben verscheidene aanbevelingen in sommige gevallen wel effect gehad. Zo is er in Nederland en Finland een Kinderombudsman in het leven geroepen, mede naar aanleiding van de aanbevelingen van het Kinderrechtencomité. De aanbevelingen van hetzelfde comité hebben er in Nieuw-Zeeland en in Nederland voor gezorgd dat de "corrigerende tik" is verboden. Voor Nederland kan men daarnaast nog denken aan de afschaffing van de mogelijkheid minderjarigen een levenslange gevangenisstraf op te leggen, de verminderde inzet van detentie van uitgeprocedeerde kinderen of het vermijden van het samen plaatsen van strafrechtelijk veroordeelde jongeren met jongeren met gedragsproblemen in penitentiaire instellingen. Een ander voorbeeld zijn de aanbevelingen van het Vrouwenrechtencomité ten aanzien van de SGP en de onmogelijkheid voor vrouwen zich verkiesbaar te stellen. Na een lang politiek en juridisch proces is de SGP uiteindelijk overstag gegaan en heeft zij haar reglementen zo aangepast dat dit wel mogelijk is. De eerste SGP-vrouw, Lilian Janse, is in maart 2014 gekozen in de gemeenteraad van Vlissingen.

\section{Een van de vele factoren \& versterking van argumenten}

Deze en andere beleids- en wetgevingsmaatregelen zijn niet allemaal één-op-één het gevolg geweest van de aanbevelingen. In bijna alle gevallen waren de aanbevelingen slechts één van de vele factoren die hebben geleid tot dergelijke aanpassingen. Essentieel was dat de aanbevelingen werden opgepikt door binnenlandse actoren en werden gebruikt in hun lobby richting regering en/of parlement. Hierbij is zeker geen sprake van eenrichtingsverkeer. Integendeel. In veel gevallen waren het juist de binnenlandse actoren zelf die bepaalde zaken aan de kaak hebben gesteld bij de comités met als doel een aanbeveling te krijgen die als steun zou dienen voor hun binnenlandse werk. Dit wordt in de literatuur het "boemerangeffect" genoemd. Dit maakt gelijk de belangrijkste functie van aanbevelingen duidelijk, zij dienen primair als versterking of rechtvaardiging van de argumenten van binnenlandse actoren. Op die wijze kunnen zij bepaalde debatten in het voordeel van deze actoren beslechten en zo de aanname van beleidsof wetgevingsaanpassingen versnellen of vergemakkelijken. Er zijn bijna geen gevallen geweest waarbij de aanbevelingen "automatisch" navolging hebben gekregen zonder dat een dergelijke lobby of mobilisatie heeft plaatsgevonden.

\section{De aanbevelingen van het VN-Kinderrechtencomité hebben het meeste effect}

Een aantal bevindingen verdient nog nadere beschouwing. Allereerst waren er grote verschillen tussen de comités en de effectiviteit van hun aanbevelingen. In alle drie de landen waren het de aanbevelingen van het VN-Kinderrechtencomité die de meeste navolging hebben gekregen. Maar liefst 33 van de 74 effectieve 
aanbevelingen kwamen van dit Comité. De aanbevelingen van twee andere comités, het Mensenrechtencomité (BUPO) en het ESOCUL-comité, hebben daarentegen niet of nauwelijks effect gehad, met respectievelijk 4 en 0 effectieve aanbevelingen. Hoe kan deze positieve uitschieter van het Kinderrechtencomité verklaard worden? Voor het beantwoorden van deze vraag is het zinvol terug te grijpen naar de twee eerder besproken theorieën.

1. Meer kwaliteit en gezag? Een eerste verklaring zou kunnen zijn dat ambtenaren positiever waren over de kwaliteit en het gezag van het Kinderrechtencomité en haar aanbevelingen en daardoor eerder geneigd waren maatregelen te nemen naar aanleiding van de aanbevelingen. Deze vlieger gaat niet op. Ambtenaren waren zeker niet positiever over de kwaliteit van de aanbevelingen van het Kinderrechtencomité. Zij toonden zich in de interviews zelfs negatiever over het Kinderrechtencomité dan over de andere comités. Verscheidene ambtenaren waren kritisch over de activistische of juist zeer negatieve toon van het comité. De aanbevelingen van het Kinderrechtencomité, maar ook de andere comités, werden gekenschetst als algemeen geformuleerde aanbevelingen, met weinig uitleg en een onduidelijke juridische grondslag is. Deze theoretische verklaring vindt dus weinig steun in de empirische bevindingen. Interessant is om hierbij te vermelden dat het Mensenrechtencomité (BUPO), dat door veel ambtenaren als het meest gezaghebbend wordt gezien, juist relatief slecht scoort in termen van effectiviteit van aanbevelingen (namelijk slechts 4 effectieve aanbevelingen).

2. Meer binnenlandse mobilisatie? De tweede verklaring voor de positieve uitzondering van het Kinderrechtencomité zou kunnen zijn dat de aanbevelingen van dit comité meer gebruikt zijn door binnenlandse actoren in hun lobby richting de regering en/of het parlement, dan de aanbevelingen van de andere comités. Het is deze verklaring waar de bevindingen inderdaad steun voor aandragen. In alle drie de landen was de "binnenlandse mobilisatie" inderdaad het grootst voor de aanbevelingen van het Kinderrechtencomité. Het rapportageproces in het kader van het IVRK kent de sterkste en meest georganiseerde NGO's. In alle drie de landen hebben kinderrechten-NGO's zich georganiseerd in een coalitie die zich sterk richt op het rapportageproces en de aanbevelingen. De aanbevelingen worden door hen gezien als een essentieel element in hun binnenlandse lobby. Een andere belangrijke actor in NieuwZeeland, Finland en recent Nederland die niet onvermeld mag blijven, is de Kinderombudsman. Net als de NGO's ziet deze Ombudsman het IVRK en de aanbevelingen als een belangrijke basis voor haar werk. Parlementariërs in de drie onderzochte landen zijn ook zeer gevoelig voor en soms ook zelf zeer actief geweest met het bespreken van aanbevelingen. In Nederland was de oprichting van een Kinderombudsman het rechtstreekse gevolg van het initiatief van het Tweede Kamerlid Arib (PvdA), terwijl het verbod op de corrigerende tik in Nieuw-Zeeland het resultaat was van een initiatiefwetsvoorstel van Bradford (de 
Groenen). De mate van mobilisatie met betrekking tot de andere verdragen is een stuk lager, met uitzondering van het VN-Vrouwenverdrag en - Comité. Dit laatste is ook terug te zien in de effectiviteit van de aanbevelingen van het Vrouwenrechtencomité. Veertien beleids- en wetgevingsmaatregelen zijn in de drie landen genomen (mede) als gevolg van de CO's van het Vrouwenrechtencomité.

\section{De aanbevelingen hebben het meeste effect in Finland...}

Er zijn ook opmerkelijke verschillen tussen de drie landen. Finland springt er in positieve zin uit. Niet alleen hebben de aanbevelingen de meeste navolging gekregen in Finland, ook waren er minder aanbevelingen die uitdrukkelijk zijn verworpen door de Finse regering. Een belangrijke verklaring voor de positieve uitschieter van Finland is gelegen in de houding van Finse ambtenaren, die over het algemeen positiever waren over het belang van rapporteren en de kwaliteit en het gezag van de mensenrechtencomités. Nederlandse en Nieuw-Zeelandse ambtenaren waren hierover veel negatiever en kritischer. Daarnaast bestaat in Finland ook meer een cultuur van getrouwe naleving van internationaal recht en is men in Finland meer bereid internationale kritiek ter harte te nemen. In Nederland en NieuwZeeland wordt er juist vaak verongelijkt en geprikkeld gereageerd op dergelijke kritiek. Dit komt ook omdat er veel meer een zelfgenoegzame houding is dat er nog maar weinig binnenlands te verbeteren is qua mensenrechten.

\section{... en het minste effect in Nieuw-Zeeland}

In Nieuw-Zeeland zijn de aanbevelingen het minst effectief geweest. Hoe kan dit worden verklaard? Voor Nieuw-Zeeland geldt dat men veel minder vertrouwd is met een sterke doorwerking van internationaal recht in de binnenlandse rechtsorde en politiek, zoals dat wel geldt voor Nederland en Finland. Beide landen zijn de afgelopen decennia, binnen de EVRM, maar bovenal in de EU-context, gewend geraakt aan het idee dat internationaal en Europees recht rechtstreeks kan werken en nationaal recht opzij kan zetten. In Nieuw-Zeeland is men niet alleen minder gericht op de buitenwereld, maar is men ook sneller geneigd kritiek naast zich neer te leggen.

\section{Papieren tijger of beleidsinitiërend?}

In de ondertitel van dit boek wordt de vraag gesteld of het rapportageproces een papieren tijger (paper tiger) is of beleidsinitiërend (policy prompting). De bevindingen van dit onderzoek laten zien dat het van allebei een beetje is. Het proces en de resulterende aanbevelingen zijn meer gebleken dan louter een papieren werkelijkheid en hebben soms wel degelijk bijgedragen aan beleids- of wetgevingsaanpassingen. De conclusie dat het proces en de resulterende 
aanbevelingen beleidsinitiërend zijn geweest, lijkt eveneens een overdrijving van de rol van het proces en de aanbevelingen. Zoals eerder is geopperd, waren de aanbevelingen vaak slechts één van de vele factoren die hebben bijgedragen aan aanpassingen. Daarnaast hebben de aanbevelingen ook bijna nooit automatisch tot maatregelen geleid. De waarheid ligt dus ergens in het midden. Dit onderzoek laat zien dat de belangrijkste rol van aanbevelingen is: het versterken en rechtvaardigen van de argumenten en positie van binnenlandse actoren die ijveren voor bepaalde maatregelen of wijzigingen van beleid of wetgeving. De aanbevelingen kunnen dus fungeren als bruikbare steunpilaar (practical prop). 


\section{APPENDiX 1 LIST OF PERSONS INTERVIEWED BY THE AUTHOR}

This appendix provides a list of people who have been formally interviewed by the author. The author has talked or had (email or telephone) contact with many more people on a more informal basis over the course of the years. Some of them are mentioned in the acknowledgments and in Chapter III, section 1.1. In total, 175 people were interviewed in the period January 2010 - October 2013: 63 in the Netherlands, 62 in New Zealand and 50 in Finland. For a further description of the methodology with respect to the interviews, see Chapter III, section 2.6.

\section{The NetherlandS}

Aalders, Regina, senior adviser of the Department of International Affairs, Ministry of Health, Welfare and Sport (since 2006), attended CRC 2009 and CEDAW 2010, interview: 29 June 2010 (by telephone).

Alkemade, Anne-Mieke, adviser of the Department of International Affairs, Ministry of Health, Welfare and Sport (1999-12), involved in reporting CEDAW 2010, interview: 29 June 2010 (by telephone).

BeEts, Lauris, Director of the Department of International Affairs, Ministry of Social Affairs and Employment (2002-13), head of delegation ICESCR 2010, interview: 28 June 2011, The Hague, the Netherlands.

Bijleveld, Leontien, member of the Vereniging voor Vrouw en Recht Clara Wichmann and Dutch CEDAW Network (since 2006), writer alternative report and attended CEDAW 2010, interview: 28 January 2010, Geneva, Switzerland.

Bleeker, Edith, senior policy adviser of the Immigration Policy Department, Ministry of Justice (since 1990) attended CEDAW 2007 and 2010 and ICESCR 2010, interview: 4 June 2010, The Hague, the Netherlands.

BöHRE, VINCENT, member NJCM (since 2007), coordinated alternative report ICCPR 2009, interview: 16 May 2011, Amsterdam, the Netherlands.

Böcker, Roeland, senior legal adviser of the International Law Division, Ministry of Foreign Affairs (since 1987), attended CAT 2000 and ICCPR 2001, interview: 14 June 2011, The Hague, the Netherlands.

De Boer, Margreet, researcher and Director of the Clara Wichmann Instituut (2000-04) and member Dutch CEDAW Network (since 2001), writer alternative report and attended CEDAW 2007 interview: 17 March 2010, Amsterdam, the Netherlands.

De Groot, Anita, policy officer of the Directorate Emancipation, Ministry of Education, Culture and Science (since 2008), coordinated report and attended CEDAW 2010, interview: 2 June 2010, The Hague, the Netherlands. 
De Jong, Ian, Ambassador Permanent Representative of the Permanent Mission in Geneva (2002-06), attended CERD 2004, CRC 2004, interview: 27 June 2011, The Hague, the Netherlands.

De Leeuw, Petra, senior policy officer of the Directorate Emancipation, Ministry of Social Affairs and Employment (2006-08), coordinated report and attended CEDAW 2007, interview: 2 June 2010, The Hague, the Netherlands.

DE VRIES, JAN, member of NJCM (2005-10), contributed to alternative reports ICESCR 2006 and 2010 and CEDAW 2007 and 2010, interview: 12 April 2011, Utrecht, the Netherlands.

De Wildt, Jeroen, (senior) policy officer of the Directorate Emancipation, Ministry of Social Affairs and Employment (1979-98) and Secretary of the Emancipation Review Committee (2004-07), attended CEDAW 1994, interview: 1 June 2010, The Hague.

Den Otter, Joost, member of the Johannes Wier Foundation (since 1992), contributed to alternative reports since 2000, including CAT, ICESCR, CRC, ICCPR and CEDAW, interview: 20 May 2011 (by telephone).

Dijksterhuis, Robert, Head of the Gender Division of the Human Rights, Gender, Good Governance and Humanitarian Aid Department, Ministry of Foreign Affairs (200711), attended CEDAW 2010, interview: 1 June 2010, The Hague, the Netherlands.

DoEK, JAAP, Emeritus Professor of family and juvenile law at the VU University Amsterdam (since 2004), founder of the Dutch section of Defence for Children and member (1999-07) and Chair (2001-07) of the CRC Committee, interview: 16 May 2011, Lisse, the Netherlands.

Dopheide, Tessa, legal adviser human rights of the Legislation Department, Ministry of Justice (2006-10), attended CEDAW 2007, CRC 2009 and ICCPR 2009, interview: 20 June 2011, Brussels, Belgium.

Dreessen, Joyce, legal adviser human rights of the Legislation Department, Ministry of Justice (2006-12), attended CERD 2010 and CEDAW 2010, interview: 3 June 2010, The Hague, the Netherlands.

Driece, Roland, attaché of the Ministry of Health, Welfare and Sport at the Permanent Mission of the Kingdom of the Netherlands Geneva (since 2009), attended CERD 2010 and ICESCR 2010, interview: 17 June 2011 (by telephone).

Ellerman, Annelies, senior policy officer of the Human Rights Division, Ministry of Foreign Affairs (2008-10), attended CRC 2009, ICCPR 2009 and CERD 2010, interview: 21 May 2011 (by telephone).

FERrIER, JoAn, Director of E-quality (1998-12), interview: 3 June 2010, The Hague, the Netherlands

FREDRIKS, Gody, senior policy adviser Integration Directorate, Ministry of Housing, Spatial Planning and the Environment/ Ministry of the Interior (since 1997), involved in reporting CERD 2010, interview: 30 June 2011, The Hague, the Netherlands.

Goris, Annemieke, adviser of the Department of International Affairs, Ministry of Health, Welfare and Sport (1993-98), attended ICESCR 1998, CERD 1998, interview: 27 June 2011, Leiden, the Netherlands. 
Hesselmans, Marlies, member of NJCM (since 2009), coordinated alternative report ICESCR 2010, interview: 19 May 2011 (by telephone).

Hilhorst, Laura, policy adviser of the Ministry for Youth and Families (2008-09), attended CRC 2009, interview: 28 June 2011, The Hague, the Netherlands.

Hoekstra, Bernadette, policy officer of the Dutch Refugee Council (2007-11), contributed to alternative report ICCPR 2009, interview: 17 June 2011, The Hague, the Netherlands.

HoltmaAt, Rikki, Professor of international non-discrimination law Leiden University (since 2003), writer alternative report and attended CEDAW 2001, interview: 17 March 2010, Leiden, the Netherlands.

Houtzager, Dirk, legal policy adviser of LBR/Art. 1 (2000-10), contributed to alternative reports CERD 2000, 2004 and 2010, attended CERD 2000 and 2004, interview: 19 April 2011, Utrecht, the Netherlands.

KAANDORP, MAJORIE, project manager of Defence for Children International (1996-08) and UNICEF (since 2008), contributed to alternative reports and attended CRC 1999, 2004 and 2009, interview: 28 April 2011 (by telephone).

Klos, Gerbrig, senior policy officer of the Dutch section Amnesty International (since 2008), interview: 16 May 2011, Amsterdam, the Netherlands.

Koelman, Suzanne, legal adviser of the Constitutional and Legal Affairs Department, Ministry of Interior and Kingdom Relations (since 2000), attended ICESCR 2006, interview: 27 June 2011, The Hague, the Netherlands.

Kroes, Marianne, senior legal officer of the Dutch Council of the Chronically ill and the Disabled (CG-Raad) (2003-13), interview: 21 March 2011 (via email).

KuiJer, MARTin, senior legal adviser human rights of the Legislation Department, Ministry of Justice (since 2003), attended CERD 2004, ICESCR 2006, CAT 2007 and ICESCR 2010, interview: 14 June 2011, The Hague, the Netherlands.

LEE, WING, policy officer of the Integration Directorate, Ministry of Housing, Spatial Planning and the Environment (since 2008), attended CERD 2010, interview: 30 June 2011, The Hague, the Netherlands.

Licher, Frederic, Director of Directorate Emancipation, Ministry of Social Affairs and Employment/ Ministry of Education, Culture and Science (2003-11), attended CEDAW 2007 and 2010, interview: 2 June 2010, The Hague, the Netherlands.

Ling Ket On, LuCiA, legal adviser of the Legislation Department, Ministry of Justice (199910), attended CRC 1999, CERD 2000 and CEDAW 2001, interview 6 June 2011 (via email).

LouriJssen, MARIA, member of NJCM (2005-10) and legal adviser of Justitia et Pax (200810), involved in reporting ICCPR 2009, CRC 2009, CERD 2010 and CEDAW 2010, interview: 29 March 2010, The Hague, the Netherlands

MANS, LINDA, freelance researcher (since 2008), writer alternative report and attended CEDAW 2010, interview: 28 January 2010, Geneva, Switzerland.

Meumese, Stan, Director of Defence for Children (1992-07), involved in reporting and attended CRC 1999, 2004 and 2009, interview: 18 April 2011, Leiden, the Netherlands. 
Appendix 1

Morrée, RobBert, senior policy adviser of the Directorate for International Affairs, Ministry of Social Affairs and Employment (2005-11), attended ICESCR 2006, ICCPR 2009, CRC 2009, ICESCR 2010 and CEDAW 2010, interview: 1 June 2010 and 30 June 2011, The Hague, the Netherlands.

Oosterwisk, Cato, policy adviser of the Dutch Ombudsman for Children (since 2013), interview: 15 October 2013 (by telephone).

Pennings, Evelien, (senior) policy officer of the Law Enforcement Department, Ministry of Justice (since 2006), attended ICCPR 2009 and CEDAW 2010, interview: 3 June 2010, The Hague, the Netherlands.

Potman, Peter, Deputy Head of the Social Affairs Division, United Nations Department, Ministry of Foreign Affairs (1997-00), head of delegation ICESCR 1998 and CERD 2000, interview: 30 June 2011, The Hague, the Netherlands.

Ramaer, Pieter, Head of the Political and Security Affairs Division, Ministry of Foreign Affairs (2001-05) and counsellor of the Permanent Mission of the Netherlands to the United Nations in Geneva (2007), head of delegation ICCPR 2001 and attended CERD 2004 and CAT 2007, interview: 6 June 2011 (by telephone).

Rensman, Liesbeth, legal adviser of the Legislation Department, Ministry of Justice (199905), attended CRC 1999 and 2004, interview: 14 June 2011, The Hague, the Netherlands.

SCHIFERLI, Joyce M., legal policy adviser of LBR/Art. 1 (2007-12), contributed to alternative report and attended CERD 2010, interview: 9 May 2011 (by telephone).

Snelders, Petra, senior policy adviser domestic and sexual violence, Movisie (since 2004), interview: 5 April 2011 (via email).

StaAl, Claudia, senior policy adviser of the Directorate for International Affairs, Ministry of Social Affairs and Employment (1996-06), attended ICESCR 1998, CRC 1999, ICCPR 2001 and CERD 2000 and 2004, interview: 1 July 2011 (via Skype).

Stappers, Beata, advocacy officer of Defence for Children (since 2003), coordinated alternative report CRC 2009 and 2012, interview: 18 April 2011, Leiden, the Netherlands.

Struyker-Boudier, JACOB, human rights coordinator (1998-02) and legal adviser (since 2002) of the Legislation Department, Ministry of Justice, attended CRC 1999 and CAT 2000, interview: 15 June 2011, The Hague.

TALSMA, LARA, member of NJCM (2003-09), coordinated alternative report CAT 2007, interview: 18 May 2011 (by telephone).

VAN DER BURG, JAN, (international) youth policy adviser of the Ministry for Youth and Families/ Ministry of Health, Welfare and Sport (since 2000), coordinated report and attended CRC 2004 and 2009, interview: 27 June 2011, The Hague, the Netherlands.

VAN DER TOL, WENDY, senior policy adviser of the Netherlands Equal Treatment Commission / Institute for Human Rights (since 2008), attended CEDAW 2010, interview: 15 April 2013, Utrecht, the Netherlands.

Van Dooren, Machteld Inge, member of NJCM (since 1989), contributed to alternative reports CERD 2000, 2004 and 2010, CRC 2004 and ICESCR 2006, interview: 26 April 2011 (by telephone). 
Van Houmelingen, Flora, Directorate for the Coordination of Emancipation Policy, Ministry of Social Affairs and Employment, attended CEDAW 2001, interview: 15 June 2010 (by telephone).

Van Muijden, Sanne, policy adviser of the Ministry for Youth and Families/ Ministry of Health, Welfare and Sport (2003-11), attended CRC 2004 and 2009, interview: 28 June 2011, Utrecht, the Netherlands.

VAN Os, CARLA, legal adviser of Defence for Children (since 2005), coordinated alternative report CRC 2007, interview: 18 April 2011, Leiden, the Netherlands.

VAn RoozendaAl, BJöRn, International Advocacy Officer of COC Netherlands (2004-12), attended CEDAW 2010, interview: 18 and 22 March 2011 (via email).

Van SAsse Ysselt, Paul, coordinating legal adviser of the Constitutional and Legal Affairs Department, Ministry of Interior and Kingdom Relations (since 2003), attended ICCPR 2009, interview: 30 June 2011, The Hague.

Van Weele, Esther, legal policy offer of the Netherlands Institute for Human Rights (since 2011), coordinates alternative reports, interview 1 October 2013, Utrecht, the Netherlands.

Verhagen, Cindy, policy officer of the Directorate Labour Market and Personnel Policy, Ministry of Education, Culture and Science (2002-12), attended CEDAW 2007, interview: 2 June 2010, The Hague.

Versluis, Adriann, policy adviser of the Human Rights Division, Ministry of Foreign Affairs (2008-11), attended ICESCR 2010, interview: 16 June 2011, The Hague.

Verstappen, Joyce, legal adviser of the Constitutional and Legal Affairs Department, Ministry of Interior and Kingdom Relations (since 2008), attended ICCPR 2009, CEDAW 2010, CERD 2010 and ICESCR 2010, interview: 4 June 2010, The Hague.

\section{New Zealand}

Anderson, Beryl, member of the National Council of Women of New Zealand (since 1998), attended CEDAW 2007 and 2012, interview: 20 June 2012, Wellington, New Zealand.

Angus, John, social policy manager of the Ministry of Social Development (1987-06) and Children's Commissioner (2009-2011), attended CRC 1997, interview: 7 June 2012, Wellington, New Zealand.

Bedggood, Margaret, Professor of law at the University of Waikato (since 1994), Chief Commissioner of the Human Rights Commission (1989-94) and founder and member of the Human Rights Foundation (since 2001), involved in reporting CAT 2004 and 2009, CERD 2007, ICCPR 2010 and ICESCR 2012, interview: 27 June 2012 (by telephone).

Beresford, StuARt, principal adviser/policy manager of the Bill of Rights/ Human Rights Team, Ministry of Justice (2003-12), attended CAT 2009 and ICCPR 2010, interview: 8 June 2012, Wellington, New Zealand.

Bell, Sylvia, principal legal policy analyst of the Human Rights Commission (since 1990), attended ICCPR 2010, interview: 5 July 2012, Auckland New Zealand. 
Appendix 1

Benkert, Nicole, policy analyst of the Ministry of Women's Affairs (since 2008), involved in reporting CEDAW 2012, interview: 18 June 2012, Wellington, New Zealand.

Bennett, Kitty, National President of the Maori Women's Welfare League (2002-05), involved in reporting and attended CEDAW 2003, interview: 13 June 2012, Wellington, New Zealand.

Blaiklock, Alison, member of ACA (1995-02) / Chair of ACYA (2002-10), lead editor/ coordinator of ACYA's alternative report CRC 1997, 2003 and 2011 and attended CRC 1997 and CAT 2004, interview: 3 July 2012, Auckland, New Zealand.

BREen, Claire, senior lecturer at the University of Waikato, involved in ACYA's alternative report CAT 2004 and CERD 2007, interview: 24 July 2012 (via Skype).

BRYDON, AMANDA, advocacy and government relations manager of Amnesty International (since 2011), interview: 4 July 2012, Auckland, New Zealand.

Butler, Andrew, lecturer at the Victoria University Wellington (1991-99), Crown Counsel at the Crown Law Office (2000-05) and lawyer (since 2005), involved in reporting ICCPR 2010, interview: 21 June 2012, Wellington, New Zealand.

Butler, Petra, Associate Professor at Victoria University Wellington (since 2000) wrote the reports and attended the dialogue of ICCPR 2002 and ICESCR 2003 as an independent adviser to the government, interview: 13 June 2012, Wellington, New Zealand.

Carter, Anne, Chief Executive of the Ministry of Youth Affairs (1999-03), interview: 19 June 2012, Wellington, New Zealand.

Castro Whare, Tracey, trustee of the Aotearoa Indigenous Rights Trust (since 2000), involved in reporting CERD 2007, ICCPR 2010, ISESCR 2012 and attended ICCPR 2010, interview: 29 May 2012 (via Skype).

CAughley, Tim, international legal adviser, Ministry of Foreign Affairs and Trade (1997-01) and Ambassador and Permanent Representative of New Zealand to the United Nations in Geneva (2002-06), head of delegation ICCPR 2002, CERD 2002, ICESCR 2003 and CAT 2004 and attended CRC 2003, interview: 14 May 2012 (by telephone).

Charters, Claire, senior lecturer at the Victoria University Wellington (2002-10), involved in the early-warning procedure of CERD 2005 and wrote CERD 2007 alternative report for the Aotearoa Indigenous Rights Trust, interview: 27 July 2012 (via telephone).

Cheshire, Finnian, policy officer of the UN and Human Rights and Commonwealth Division, Ministry of Foreign Affairs and Trade (since 2011), coordinates state reports, interview: 11 June 2012, Wellington, New Zealand.

Crooke, David, senior adviser of the Bill of Rights/ Human Rights Team, Ministry of Justice (since 2006), coordinated ICCPR 2010 and involved in ICESCR 2012 and CERD 2012, interview: 8 June 2012, Wellington, New Zealand.

De Bres, Joris, Race Relations Commissioner of the Human Rights Commission (2002-12), attended CERD 2007, interview: 13 June 2012, Wellington, New Zealand.

Dempster, Jillian, First Secretary at the Permanent Mission of New Zealand in Geneva (2002-05), attended CERD 2002, ICESCR 2003, CRC 2003, CAT 2004, interview: 1 June 2012 (via Skype). 
Dyson, Ruth, MP Labour Party (since 1993), Minister with different portfolios (1999-08), including Minister of Women's Affairs (2002-05), head of delegation CEDAW 2003, interview: 14 June 2012, Wellington, New Zealand.

Ellis, Tony, barrister of the High Court, involved in reporting CAT 2009, ICCPR 2010, interview: 6 June 2012, Wellington, New Zealand.

ElSE, ANNE, member of the National council of Women of New Zealand (since 2006), editor of alternative reports CEDAW 2007 and 2012, interview: 20 June 2012, Wellington, New Zealand.

Geddis, Andrew, lecturer/ Associate Professor of law at the University of Otago (since 2000), interview: 13 June 2012 (by telephone).

Geels, Deborah, counsellor of the New Zealand Permanent Mission in Geneva (1998-02), attended CAT 1998 and ICCPR 2002, interview: 28 June 2012, Wellington, New Zealand.

Glazebrook, Susan, judge of the Court of Appeal of New Zealand (since 2002), interview: 15 June 2012, Wellington, New Zealand.

Gleisner, Shenagh, Chief Executive of the Ministry of Women's Affairs (2004-10) and independent consultant (since 2010), attended CEDAW 2007 and involved in reporting CRC 2011, interview: 26 June 2012, Wellington, New Zealand.

GobBi, Mark, parliamentary counsel (since 1999), interview: 14 June 2012, Wellington, New Zealand.

HANCOCK, JoHN, member of ACYA (since 2003), principal legal adviser of the Office of the Children's Commissioner (since 2011), lead editor/coordinator of ACYA's alternative report and attended CRC 2003 and 2011, interview: 3 July 2012, Auckland New Zealand.

Harré, Leila, Minister of Women's Affairs and Youth Affairs (1999-02), interview: 5 July 2012, Auckland, New Zealand.

Hinton, Wendy, New Zealand Deputy Permanent Representative to the UN (2007-11) and Deputy Director of the Human Rights Division, Ministry of Foreign Affairs and Trade (2011-13), attended CAT 2009 and CRC 2011, interview: 11 June 2012, Wellington, New Zealand.

Hughes, Edwina, coordinator of the Peace Movement Aotearoa (since late 1990s), involved in reporting CERD 2007, ICCPR 2009, CRC 2011, ICESCR 2012, interview: 21 June 2012, Wellington, New Zealand.

Hyndman, Christine, principal analyst/ manager of immigration policy of the Department of Labour (since 1998), attended CAT 2009, interview: 18 June 2012, Wellington, New Zealand.

JAmison, Andrea, policy adviser of the Children's Commissioner (1993-95 and since 2011) and Ministry of Youth Affairs (1995-01), involved in reporting CRC 1997, 2003 and 2011, interview: 26 June 2012, Wellington, New Zealand.

Judge, Ross, general manager of strategic social policy, Ministry of Social Development (2000-09), attended ICESCR 2003, interview: 6 June 2012, Wellington, New Zealand. 
Appendix 1

Keith, Benjamin, Crown Counsel of the Crown Law Office (since 2001), attended ICCPR 2010, CRC 2011 and ICESCR 2012, interview: 12 June 2012, Wellington, New Zealand.

King, Alice, legal adviser of the Legal Division, Ministry of Foreign Affairs and Trade (since 2009), interview: 11 June 2012, Wellington, New Zealand.

KIro, Cindy, Children's Commissioner (2003-08), interview: 5 July 2012, Auckland New Zealand.

LAMBourn, Barbara, advocacy manager of UNICEF (since 2008), involved in reporting CRC 2011, interview: 21 June 2012, Wellington, New Zealand.

Lawrence, Judy, Chief Executive of the Ministry of Women's Affairs (1995-03), attended CEDAW 1998 and involved in reporting CEDAW 2003, interview: 19 June 2012, Wellington, New Zealand.

Locke, Keith, MP Green Party (1999-11), interview: 3 July 2012, Auckland New Zealand.

LuDBROOK, ROBERT, youth Advocate (since 1989), interview: 12 June 2012, Wellington, New Zealand.

LyNCH, Nessa, lecturer at the Victoria University Wellington (since 2008), contributed to ACYA alternative report CRC 2011, interview: 28 June 2012, Wellington, New Zealand.

Mackwell, Sue, Deputy Chief Executive of the Ministry of Social Development (since 2008), attended CRC 2011, interview: 22 June 2012, Wellington, New Zealand.

McGregor, Judy, Equal Employment Opportunities Commissioner of the Human Rights Commission (since 2003), attended ICCPR 2010 and CEDAW 2012, interview: 5 July 2012, Auckland New Zealand.

McIver, Tim, Deputy Director of the UN and Human Rights and Commonwealth Division, Ministry of Foreign Affairs and Trade (since 2012), interview: 7 June 2012, Wellington, New Zealand.

McLean, Janet, senior lecturer/ Professor of Law at the University of Auckland/Dundee (since 1991) and member of the ministerial inquiry into human rights protection in New Zealand (2000), interview: 4 July 2012, Auckland, New Zealand.

Monk, PAUL, southern regional manager of the prison services, Department of Corrections (1996-11), attended CAT 2009 and ICCPR 2010, interview: 8 June 2012 (via Skype).

Moran, Deb, acting policy manager (1998) and policy director (since 2011), Ministry of Women's Affairs, attended CEDAW 1998 and 2012, interview: 18 June 2012, Wellington, New Zealand.

Morris-Travers, Deborah, Associate Minister of Women's Affairs (1997-98), Minister of Youth Affairs (1996-98) and advocacy adviser of Plunket, Barnardos, Every Child Counts and Save the Children (since 2004), attended CEDAW 1998, interview: 20 June 2012, Wellington, New Zealand.

Nuatia, Jessica, policy analyst of the Human Rights Commission (since 2005), involved in reporting CAT 2007 and 2012, interview: 5 July 2012, Auckland.

Palmer, Matthew S.R., Deputy Secretary for Justice, Ministry of Justice (1995-00) \& Deputy Solicitor-General (public law) of the Crown Law Office (since 2008), interview: 22 June 2012, Wellington, New Zealand. 
Ruri, Mereana, policy adviser of the Ministry of Youth Affairs (1998-04) and Children's Commissioner (2004-10), involved in reporting CRC 2003 and 2011, interview: 26 June 2012, Wellington, New Zealand.

Schaer, Bettina, policy officer and manager of the Department of Labour (1999-04), attended CEDAW 2003, interview: 15 June 2012, Wellington, New Zealand.

Shuttleworth, Peter, children's rights advocate associated with ACYA, involved in reporting in CAT 2004 and 2009, ICCPR 2010, ICCPR 2010 and CRC 2010, interview: 12 April 2012 (via email).

Singham, Mervin, Chief Director of the Office of Ethnic Affairs (since 2006), attended the dialogue of CERD 2007, interview: 19 June 2012, Wellington, New Zealand.

Staal, Claudia, senior adviser of the Bill of Rights/ Human Rights Team, Ministry of Justice (2006-11) interview: 1 July 2011 (by telephone).

Te Kani, Jacqui, National President (1992-02) and general manager (since 2002) of the Maori Women's Welfare League, involved in reporting and attended CEDAW 2003, 2007 and 2012, interview: 12 June 2012, Wellington, New Zealand.

Todd-Lambie, Anne, member of the National Council of Women of New Zealand, attended CEDAW 2003 and 2007, interview: 12 June 2012 (by telephone).

Tuony, Pat, chief adviser on child and youth health, Ministry of Health (since 1997), CRC 2011, interview 18 June 2012, Wellington, New Zealand.

Wilson, Margaret, Minister of the Crown (1999-05), speaker of parliament (2005-08) and Professor of law and public policy at the University of Waikato (since 2009), attended CERD 1995, interview: 2 July 2012, Hamilton, New Zealand.

Wood, Beth, spokesperson of End Physical Punishment of Children New Zealand (199708) and advocacy manager of UNICEF (2002-08), interview: 14 June 2012, Wellington, New Zealand.

\section{Finland}

Aarnio, Eero J., counsellor of legislation of the Ministry of Justice (1987-07), head of delegation CERD 1996, 2000, CERD 2003 and attended CERD 1999, interview: 17 April 2013 (via email).

Arrhenius, VivecA, ministerial adviser of the Ministry Social Affairs and Health (since 1993), attended CEDAW 2008 and CERD 2012, interview: 6 November 2012, Helsinki, Finland.

Aula, Maria Kaisa, MP Centre Party (1991-03), Chair of the Central Union for Child Welfare (2004-05), Ombudsman for Children (since 2005), attended CRC 2012, interview: 15 November 2012, Helsinki, Finland.

Auvinen, TAnja, Secretary General of NYTKIS (2004-11), interview: 12 November 2012, Helsinki, Finland.

Biaudet, Eva, MP Swedish People's Party (1991-06), Minister of Health and Social Affairs (1999-00, 2002-03) and Ombudsman for Minorities (since 2010), interview: 2 May 2013, Helsinki, Finland. 
Appendix 1

BRUUn, NiKLAS, member CEDAW Committee (since 2009) and Professor of private law at Helsinki University (since 2006), interview: 22 April 2013, Helsinki, Finland.

Cortés Télllez, Mikko, (senior) planning officer of the Ministry of Education and Culture (since 1995), attended CERD 1996, 1999, 2000, 2003 and 2009, ICESCR 2000, ICCPR 2004 and CRC 2011, interview: 16 November 2012, Helsinki, Finland.

Hagelstam, Petra, counsellor of the Legal Department, Ministry for Foreign Affairs (199799), attended CAT 1999 and CERD 1999, interview: 18 October 2012 (via Skype).

Hallberg, Pekka, President of the Supreme Administrative Court of Finland (1993-12), head of delegation ICCPR 1998 and 2004, interview: 24 April 2013, Helsinki, Finland.

Halme-Tuomisaari, Miia, researcher and lecturer at the Erik Castrén Institute of International Law and Human Rights, University of Helsinki (2002-12), interview: 6 November 2012, Helsinki, Finland.

Hannikainen, Lauri, Vice Chair/ member Finnish League for Human Rights (1979-99), member of the European Commission against Racism and Intolerance (since 2000) and Professor (Emeritus) of international law at the University of Turku/ Helsinki (since 2003), interview: 7 November 2012, Helsinki, Finland.

Heilio, Pia-LiIsa, senior legal officer of the Ministry of Social Affairs and Health (1993-03 and since 2008) and consultant, Save the Children (2003-06), CRC 1996 and 2000, interview: 26 April 2013, Helsinki, Finland.

Heinonen, Hanna, Programme Director of the Central Union for Child Welfare (since 2010), attended CRC 2011, interview: 8 November 2012, Helsinki, Finland.

Hetemaki, Inka, Programme Director of UNICEF (since 2000), attended CRC 2005 and 2011, interview: 13 November 2012, Helsinki, Finland.

Hurmalainen, Eeva, communications officer of the UN Association of Finland (since 2010), interview: 22 April 2013, Helsinki, Finland.

Johansson, Frank, Director of Amnesty International (since 1996), interview: 24 April 2013, Helsinki, Finland.

Kahiluoto, TARJA, ministerial adviser of the Ministry of Social Affairs and Health (since 1995), attended CRC 2011, interview: 12 November 2012, Helsinki, Finland.

Ketokoski, Anja-Riitta, Ministry for Foreign Affairs (1966-2011), including Director of the Department for Legal Affairs, attended CEDAW 1995, interview: 7 November 2012, Helsinki, Finland.

Koskinen, Johaness, MP Social Democratic Party, Minister of Justice (1999-05) and member (since 1991)/ Chair (since 2011) of the Constitutional Law Committee, attended CERD 2012, interview: 15 November 2012, Helsinki, Finland.

Kosonen, ARto, legal counsellor of the Legal Department (since 1992) and Head of Unit for Human Rights Courts and Conventions (since 2002), Ministry for Foreign Affairs, attended CERD 1996, 1999, 2000 and 2003 and head of delegation CERD 2009 and 2012, CRC 2005 and 2011, CAT 2005 and 2011, ICESCR 2007 and CEDAW 2008, interview: 16 November 2012, Helsinki, Finland.

Kouros, Kristina, Secretary General of the Finnish League for Human Rights (2000-11), expert of the Human Rights Centre (since 2011), interview: 14 November 2012, Helsinki, Finland. 
Kuikka, MaArit, coordinator for international affairs of the Central Union for Child Welfare (2002-11), attended CRC 2005 and 2011, interview: 3 May 2013, Helsinki, Finland.

Kurki-SuOnio, Kirsti, senior legal adviser of the Office of the Parliamentary Ombudsman (since 2000), attended NGO hearing CRC 2011, interview: 14 November 2012, Helsinki, Finland.

LaAjapuro, Nina, Policy Director of Amnesty International (2000-07 and since 2013), interview: 3 May 2013, Helsinki, Finland.

LaAkKonen, Risto, ministerial adviser of the Ministry of Labour (1995-04), attended CERD 1999, 2000 and 2003, interview: 26 April 2013, Helsinki, Finland.

Laukko, Helena, Executive Director of the UN Association of Finland (since 2003), interview: 22 April 2013, Helsinki, Finland.

Lehmus, Kaarle, inspector general of the Police Department, Ministry of the Interior (since 1992), attended CAT 1996, 2000 and 2005, interview: 12 November 2012, Helsinki, Finland.

Lempinen, Miko, researcher at the Institute for Human Rights at the Åbo Akademi University (1998-08), Secretary General Finnish League for Human Rights (200506) and senior officer of the Office of the Equality Ombudsman (since 2008), interview: 13 November 2012, Helsinki, Finland.

Leikas, Leena, legal officer of the Ministry for Foreign Affairs (2003-07) and expert of the Human Rights Centre (since 2011), attended CRC 2005 and involved in reporting CERD, interview: 23 April 2013, Helsinki, Finland.

LundBerg, Erik, Head of the Unit for Human Rights Policy, Ministry for Foreign Affairs (since 2011), interview: 5 November 2012, Helsinki, Finland.

Makinen, PirkKo, member CEDAW Committee (1993-96) and Ombudsman for Equality (1995-02 and since 2007), attended CEDAW 2001, interview: 12 November 2012, Helsinki, Finland.

Makkonen, Timo, member Finnish League for Human Rights (1990s) and senior officer of the Ministry of the Interior/ Justice (since 2006), attended CERD 2009, interview: 8 November 2012, Helsinki, Finland.

Martikainen, Ritta, ministerial adviser of the Gender Equality Unit, Ministry of Social Affairs and Health (since 2006), attended CEDAW 2008, interview: 5 November 2012, Helsinki, Finland.

Mehtonen, Susanna, legal adviser of Amnesty International (since 2008), involved in reporting CAT 2011 and ICCPR 2013, interview: 24 April 2013, Helsinki, Finland.

Mohell, Ulla, counsellor of legislation of the Ministry of Justice (since 2001), attended CAT 2005 and 2011, interview via email on 24 and 25 April 2013.

Mustakallio, SinikKa, equality consultant of the Secretary Preparatory Committee for the CEDAW state report 1993, attended CEDAW 1995 and wrote alternative report CEDAW 2001, interview: 8 November 2012, Helsinki, Finland.

Nauclér, Elisabeth, MP Swedish People's Party and member of the Constitutional Law Committee (since 2007), attended CEDAW 2008, interview: 23 April 2013, Helsinki, Finland. 
Appendix 1

OINONEN, KRISTA, senior officer of the Department for Legal Affairs/ Unit for Human Rights Courts and Conventions (1999-04 and since 2011)/ Permanent Mission Geneva (2008-11), Ministry for Foreign Affairs, and officer OHCHR Secretariat (2004-07), attended ICESCR 2000, CRC 2000 and CRC 2011, interview: 13 November 2012, Helsinki, Finland.

OJanen, Tuomas, (Assistant) Professor of constitutional/ European Law at the University of Helsinki/ Turku (since 1991) and member (since 2003) and (Vice)Chair (since 2006) of the Board of the Finnish League for Human Rights, interview: 23 April and 3 May 2013, Helsinki, Finland.

Panu, Artemjeff, senior adviser of the Ministry of the Interior (since 2008), involved in reporting CERD 2012, interview: 6 November 2012, Helsinki, Finland.

Pelkonen, MarjaAna, senior adviser of the Ministry of Social Affairs and Health (since 2002), attended CEDAW 2008 and CRC 2011, interview: 12 November 2012, Helsinki, Finland.

Pietarinen, PÄIVI, legal officer of the Legal Department, Ministry for Foreign Affairs (1993-00) and Secretary General of the Supreme Administrative Court (since 2009), attended CRC 1996, CERD 1996, ICESCR 1996 and ICCPR 1998, interview: 14 November 2012, Helsinki, Finland.

Pietarinen, PäIVI, senior adviser of the Ministry of the Interior (since 2010), attended CAT 2011 and CERD 2012, interview: 24 April 2013, Helsinki, Finland.

PölÖnen, PASI, legal adviser of the Office of the Parliamentary Ombudsman (since 2004), interview: 14 November 2012, Helsinki, Finland.

Romanov, Pärvi, (Deputy) Ombudsman for Equality (1994-07) and Secretary General of the Office of the Parliamentary Ombudsman (since 2010), attended CEDAW 1995 and 2001, interview: 8 November 2012, Helsinki, Finland.

SALO, AIJAN, Secretary General of SETA ry (since 2005), involved in reporting ICESCR and CEDAW, interview: 13 November 2012, Helsinki, Finland.

Scheinin, Martin, (Associate) Professor of constitutional (and international law) at the University of Helsinki (1993-98) / Åbo Akademi University (1998-08) and member of the HRC (1997-04) / Professor of international law and human rights (since 2008), interview: 27 September 2011, Maastricht, the Netherlands.

Sintonen, HARRI, senior officer of the Legal Affairs Department, Ministry of Social Affairs and Health (1991-01) and Committee Counsel of the parliamentary Social Affairs and Health Committee (since 2003), attended CAT 1996 and 1999, interview: 23 April 2013, Helsinki, Finland.

SuUrpäÄ, Johanna, Head of the Unit for Human Rights Policy, Ministry for Foreign Affairs (1995-07), Ombudsman for Minorities (2007-10), Director of the Unit for Democracy, Language Affairs and Fundamental Rights, Ministry of Justice (since 2010), attended CRC 2011, interview: 7 November 2012, Helsinki, Finland.

Viljanen, Veli-PekKa, legislative counsellor of the Ministry of Justice (1992-98) and (Acting) Professor of constitutional law at the University of Turku (since 1998), attended ICCPR 1998, interview: 26 April 2013 (via telephone). 


\section{ApPENDix 2 \\ DATABASES AND SEARCH TERMS USED}

For the search of Dutch parliamentary papers, the database <parlando.sdu.nl $>$ was used. This database, which contained the parliamentary papers until 6/4/2010, is currently out of operation. For the parliamentary papers since then, use was made of <zoek. officielebekendmakingen.nl/zoeken/parlementaire_documenten/ $>$ (referred to as 'OB search'). For the newspaper articles, the Lexis Nexis database on <academic.lexisnexis.nl/> was used. This database contains articles published in five major Dutch newspapers (Algemeen Dagblad, De Volkskrant, Het Parool, NRC Handelsblad and Trouw). Judgments of Dutch courts were searched through <uitspraken.rechtspraak.nl/>. This database was created in December 1999 and contains a selection of judgments since then. $<$ Google.nl $>$ was used to search websites of Dutch NGOs for documents in which the COs are mentioned.

\section{CHAPTER 5. ICERD}

\section{Parliamentary papers}

Parlando search on 29/06/2010 for the period 1/9/1995 - 5/4/2010

- rassendiscriminatie AND verdrag (267); IVURD (1); ICERD (7); IVRD (7); IVUR (11); rassenverdrag (4); antiracismeverdrag (4); CERD (79)

OB search on 08/09/2011 for the period 6/4/2010 - 31/08/2011:

- rassendiscriminatie AND verdrag (7); IVURD (0); ICERD (1); IVRD (0); IVUR (1); rassenverdrag (0); antiracismeverdrag (0); CERD (12)

OB search on 13/09/2011 for the period 1/9/1995 - 31/8/2011:

- "Committee on the Elimination of Racial Discrimination" (23); "Convention on the Elimination of All Forms of Racial Discrimination" (50)

\section{Newspaper articles}

Lexis Nexis search on 08/09/2011 for the period 1/9/1995 - 31/8/2011:

- rassendiscriminatie AND verdrag (69); IVURD (0); ICERD (0); IVRD (0); Rassenverdrag (1); Antiracismeverdrag (4); CERD (16); rassendiscriminatie AND comite (44); "Committee on the Elimination of Racial Discrimination" (0); "Convention on the Elimination of All Forms of Racial Discrimination" (0)

\section{Court judgments}

Rechtspraak.nl search on 08/09/2011 for judgments until 31/8/2011:

- IVURD (0); ICERD (0); IVRD (0); Antiracismeverdrag (0); Rassenverdrag (0); "verdrag ter uitbanning van alle vormen van discriminatie" (0); VURD (0); IVUR (1); "internationaal verdrag inzake de uitbanning van alle vormen van rassendiscriminatie" 
Appendix 2

(14); CERD (6); rassendiscriminatie AND verdrag (16); "Committee on the Elimination of Racial Discrimination" (0); "Convention on the Elimination of All Forms of Racial Discrimination" (5); “CO/17-18” (0); “64/CO/7” (0); “Add.104” (0)

\section{NGO documents}

Google search on 22/01/2010 of www.njcm.nl [Dutch section of the International Commission of Jurists]; www.artl.nl [Before the Landelijk Bureau Rassendiscriminatie]; www.acvz.org [Advisory Committee on Migration Affairs]; www.commissie-meijers.nl [Standing Committee of Experts on International Immigration, Refugee and Criminal Law]; www.forum.nl [Institute for Multicultural Affairs]; www.vluchtelingenwerk.nl [Dutch Council for Refugees]; www.onderwijsraad.nl [Educational Council]; www. amnesty.nl:

- CERD; IVUR; ras AND Comité; rassendiscriminatie; "CO/17-18”; "64/CO/7"; "Add.104"

\section{Chapter 6. ICCPR}

\section{Parliamentary papers}

Parlando search on 7/9/2010 for the period 1/9/1995 - 5/4/2010:

- "internationaal verdrag inzake burgerrechten en politieke rechten" (376); verdrag AND "burgerrechten en politieke rechten" NOT "internationaal verdrag inzake burgerrechten en politieke rechten" (173); BUPO NOT "internationaal verdrag inzake burgerrechten en politieke rechten" (90); IVBPR NOT "internationaal verdrag inzake burgerrechten en politieke rechten” NOT BUPO (83); Mensenrechtencomité NOT “internationaal verdrag inzake burgerrechten en politieke rechten" NOT BUPO NOT IVBPR (13); "Comité voor de Rechten van de Mens" (0); comité AND "Rechten van de Mens" (0); "International Covenant" AND "Civil and Political Rights" NOT ICCPR (34); ICCPR (39); "Human Rights Committee” NOT ICCPR (34)

OB Search on 13/09/2011 for the period 6/4/2010 - 31/08/2011:

- "internationaal verdrag inzake burgerrechten en politieke rechten" (39); "burgerrechten en politieke rechten" (48); BUPO (9); IVBPR (37); Mensenrechtencomité (11); “Comité voor de Rechten van de Mens" (0); comité AND "Rechten van de Mens" (0); "International Covenant" AND "Civil and Political Rights" (19); ICCPR (6); "Human Rights Committee" (9)

\section{Newspaper articles}

Lexis Nexis search on 30/9/2010 for the period 1/9/1995 - 31/8/2011:

- "Internationaal Verdrag inzake burgerrechten en politieke rechten" (28); Verdrag AND "burgerrechten en politieke rechten" (65); BUPO (35); IVBPR (9); Mensenrechtencomité (50); "Comite voor de rechten van de mens" (39); "international covenant" AND "civil 
Databases and search terms used

and political rights" (2); ICCPR (2); "human rights committee" (2); mensenrechtencomite NOT mensenrechtencomité (39)

\section{Court judgments}

Rechtspraak.nl search on 20/09/2011 for judgments until 31/8/2011:

- "Internationaal verdrag inzake burgerrechten en politieke rechten" AND comite (54); Mensenrechtencomite (14); "human rights committee" (28); verdrag AND "burgerrechten en politieke rechten" AND comite (56): BUPO AND comite (4); IVBPR AND comite (58); "CCPR/C/NLD/CO/4" (0); "CCPR/CO/72/NET" (0); "Internationaal verdrag inzake burgerrechten en politieke rechten" NOT IVBPR (439); IVBPR NOT "Internationaal verdrag inzake burgerrechten en politieke rechten" (840)

\section{NGO documents}

Google search on 4/10/2010 of www.njcm.nl; www.art1.nl; www.vrouwenrecht.nl [Dutch CEDAW Network and Vereniging voor Vrouw en Recht Clara Wichmann]; www. vluchtelingenwerk.nl; www.unicef.nl; www.defenceforchildren.nl; www.acvz.org; www. commissie-meijers.nl/; www.amnesty.nl:

- Mensenrechtencomité; "human rights committee"; "comité voor de rechten van de mens"; "internationaal verdrag inzake burgerrechten en politieke rechten" AND comité OR committee; verdrag "burgerrechten en politieke rechten" AND comité OR committee; BUPO AND comité OR committee; IVBPR AND comité OR committee; "NLD/CO/4"; "72/NET"

\section{CHAPTER 7. ICESCR}

\section{Parliamentary papers}

Parlando search on 25/10/2010 for the period 1/9/1995 - 5/4/2010:

- "verdrag inzake economische sociale en culturele rechten" (206); ESOCUL (35); IVESCR NOT "verdrag inzake economische sociale en culturele rechten" (25); IVESC NOT "verdrag inzake economische sociale en culturele rechten" (10); ICESCR (25); ESCR NOT "verdrag inzake economische sociale en culturele rechten" NOT IVESCR NOT IVESC (10); ESC-verdrag NOT "verdrag inzake economische sociale en culturele rechten" NOT IVESCR NOT IVESC NOT ESCR (8); ICESC NOT "verdrag inzake economische sociale en culturele rechten” NOT IVESCR NOT IVESC NOT ESCR (1)

OB Search on 13/09/2011 for the period 6/4/2010 - 31/08/2011:

- "verdrag inzake economische sociale en culturele rechten" (21); ESOCUL (1); IVESCR (11); IVESC (0); ICESCR (3); ESCR (2); ESC-verdrag (2); ICESC (0)

OB Search on 13/09/2011 for the period 1/9/1995 - 31/08/2011:

- "Covenant on Economic, Social and Cultural Rights" (60); "Committee on Economic, Social and Cultural Rights" (13) 
Appendix 2

\section{Newspaper articles}

Lexis Nexis search on 13/09/2011 for the period 1/9/1995 - 31/8/2011:

- "verdrag inzake economische, sociale en culturele rechten" (22); ESOCUL (3); IVESCR NOT "verdrag inzake economische sociale en culturele rechten" (2); verdrag AND economische AND sociale AND culturele rechten NOT "verdrag inzake economische sociale en culturele rechten” NOT IVESCR NOT ESOCUL (34); ESCR NOT "verdrag inzake economische sociale en culturele rechten" NOT IVESCR (1); ICESC NOT "verdrag inzake economische sociale en culturele rechten" NOT IVESCR (0); ESCVerdrag NOT "verdrag inzake economische sociale en culturele rechten" NOT IVESCR (0); ICESCR NOT "verdrag inzake economische sociale en culturele rechten" NOT IVESCR (0); IVESC NOT "verdrag inzake economische sociale en culturele rechten" NOT IVESCR (0); "Covenant on Economic, Social and Cultural Rights" (0); "Committee on Economic, Social and Cultural Rights" (0)

\section{Court judgments}

Rechtspraak.nl search on 20/09/2011 for judgments until 31/8/2011

- IVESCR (73); ivesc NOT ivescr (12); "verdrag inzake economische sociale en culturele rechten” NOT IVESCR NOT ivesc (46); ICESCR NOT IVESCR (2); ECOSUL (0); ESOCUL (0); ESC-verdrag (0); ICESC (0); ESCR (1); "Covenant on Economic, Social and Cultural Rights" (1); "Committee on Economic, Social and Cultural Rights" (4); "NDL/CO/4-5" (0); "NLD/CO/3” (0); "1/Add.25” (0)

\section{NGO documents}

Google search on 15/09/2011 of www.njcm.nl; www.johannes-wier.nl [Johannes Wier Foundation]; www.cmo.nl/pmre/ [Platform Mensenrechteneducatie]; www.fnv.nl [trade unions confederation]; www.cnv.nl [National Federation of Christian Trade Unions]; www. vrouwenrecht.nl; www.vluchtelingenwerk.nl; www.defenceforchildren.nl; www.acvz.org; www.commissie-meijers.nl; www.amnesty.nl:

- "verdrag inzake economische sociale en culturele rechten"; ESOCUL NOT "verdrag inzake economische sociale en culturele rechten"; IVESCR NOT ESOCUL NOT "verdrag inzake economische sociale en culturele rechten"; IVESC NOT ESOCUL NOT "verdrag inzake economische sociale en culturele rechten"; ESCR NOT ESOCUL NOT "verdrag inzake economische sociale en culturele rechten"; ESC-verdrag NOT IVESCR NOT ESOCUL NOT "verdrag inzake economische sociale en culturele rechten"; ICESCR NOT ESOCUL NOT "verdrag inzake economische sociale en culturele rechten"; ICESC NOT ESOCUL NOT "verdrag inzake economische sociale en culturele rechten"; "NDL/CO/4-5"; "NLD/CO/3"; 1/Add.25"

\section{Chapter 8. CEDAW}

\section{Parliamentary papers}

Parlando search on 9-2-2010 for the period 1/9/1995 - 3/2/2010:

- Vrouwenverdrag (386) 
Parlando search on 18/11/2010 for the period 1/9/1995-5/4/2010:

- Verdrag AND "Uitbanning van Alle Vormen van Discriminatie van Vrouwen" NOT CEDAW NOT Vrouwenverdrag (53); CEDAW NOT vrouwenverdrag (114); Vrouwenrechtenverdrag NOT CEDAW NOT vrouwenverdrag (1)

OB search on 13/09/2011 for the period 4/2/2010 - 31/8/2011:

- Vrouwenverdrag (27)

OB search on 13/09/2011 for the period 6/4/2010 - 31/8/2011:

- "Uitbanning van Alle Vormen van Discriminatie van Vrouwen" (8); CEDAW (26); Vrouwenrechtenverdrag (0)

OB search on 13/09/2011 for the period 1/9/1995 - 31/8/2011:

- "Committee on the Elimination of Discrimination against Women" (60); "Convention on the Elimination of all Forms of Discrimination against Women" (84)

\section{Newspaper articles}

Lexis Nexis search on 11/10/2011 for the period 1/9/1995 - 31/8/2011:

- Vrouwenverdrag (168); Verdrag AND Vrouwen AND discriminatie NOT Vrouwenverdrag (142); CEDAW NOT vrouwenverdrag (8); Vrouwenrechtenverdrag (0); "Committee on the Elimination of Discrimination against Women" (1); "Convention on the Elimination of all Forms of Discrimination against Women" (1)

\section{Court judgments}

Rechtspraak.nl search on 11/10/2011 for judgments until 31/8/2011:

- Vrouwenverdrag (19); CEDAW (10); "Verdrag inzake de Uitbanning van alle Vormen van Discriminatie van Vrouwen" (21); Vrouwenrechtenverdrag (2); "Committee on the Elimination of Discrimination against Women" (4); "Convention on the Elimination of all Forms of Discrimination against Women" (4)

\section{NGO documents}

Google search on 22/01/2010 of www.vrouwenrecht nl; www.iiav.nl [International Information Centre and Archives for the Women's Movement]; www.e-quality.nl [Dutch information centre for gender, family and diversity issues]; www.njcm.nl:

- Comité Vrouwenverdrag; A/56/38; CEDAW/C/NLD/CO/4; CEDAW/C/NLD/CO/5

\section{Chapter 9. CAT}

\section{Parliamentary papers}

Parlando search on 22/12/2010 for the period 1/9/1995-5/4/2010

- "verdrag tegen foltering" (198); folteringverdrag NOT "verdrag tegen foltering" (22); folterverdrag NOT "verdrag tegen foltering" NOT folteringverdrag (56); "comite tegen 
Appendix 2

foltering" NOT “verdrag tegen foltering" NOT folteringverdrag NOT folterverdrag (41); folteringcomite NOT "verdrag tegen foltering" NOT folteringverdrag NOT folterverdrag (1); foltercomite NOT "verdrag tegen foltering" NOT folteringverdrag NOT folterverdrag (4); "verdrag tegen marteling" (31); martelingverdrag (0); martelverdrag (1); "comite tegen marteling" (5); martelcomite (0); martelingcomite (0); "Convention against torture" NOT "verdrag tegen foltering" NOT folteringverdrag NOT folterverdrag (58); "Committee Against Torture" NOT "verdrag tegen foltering" NOT folteringverdrag NOT folterverdrag NOT "Convention against torture" (14)

OB search on 12/09/2011 for the period 6/4/2010 - 31/08/2011:

- "verdrag tegen foltering" (27); folteringverdrag (4); folterverdrag (1); "comite tegen foltering" (4); folteringcomite (0); foltercomite (1); "verdrag tegen marteling" (5); martelingverdrag (0); martelverdrag (1); “comite tegen marteling” (5); martelcomite (0); martelingcomite (0); "Convention against torture" (12); "Committee Against Torture" (3)

\section{Newspaper articles}

Lexis Nexis search on 12/09/2011 for the period 1/9/1995 - 31/8/2011

- "verdrag tegen foltering" (36); folteringverdrag NOT "verdrag tegen foltering" (10); folterverdrag NOT "verdrag tegen foltering" NOT folteringverdrag (80); "comite tegen foltering" NOT "verdrag tegen foltering" NOT folteringverdrag NOT folterverdrag (15); "verdrag tegen marteling" NOT "comite tegen foltering" NOT "verdrag tegen foltering" NOT folterverdrag (37); martelingverdrag NOT "comite tegen foltering" NOT "verdrag tegen foltering" NOT folterverdrag (0); martelverdrag NOT "comite tegen foltering" NOT "verdrag tegen foltering" NOT folterverdrag (6); "comite tegen marteling" NOT "comite tegen foltering" NOT "verdrag tegen foltering" NOT folterverdrag (23); NB: "commissie tegen marteling" NOT "comite tegen foltering" NOT "verdrag tegen foltering" NOT folterverdrag (25); "commissie tegen foltering" NOT "comite tegen foltering" NOT "verdrag tegen foltering" NOT folterverdrag (3); "Convention against torture" NOT "comite tegen foltering" NOT "verdrag tegen foltering" NOT folterverdrag (1); "Committee Against Torture" NOT "comite tegen foltering" NOT "verdrag tegen foltering" NOT folterverdrag (4)

\section{Court judgments}

Rechtspraak.nl search on 12/09/2011 for judgments until 31/8/2011:

- "verdrag tegen foltering" (95); folteringverdrag (26); folterverdrag (23); “comite tegen foltering" (3); "verdrag tegen marteling" (0); martelingverdrag (0); martelverdrag (0); "comite tegen marteling" (1); "Convention against torture" (12); "Committee Against Torture" (14); "NET/CO/4" (0)

\section{NGO documents}

Google search on 12/09/2011 of www.amnesty.nl; www.defenceforchildren.nl; www.njcm. nl; www.johannes-wier.nl; www.pharos.nl [National Knowledge and Advisory Centre on 
Migrants, Refugees and Health Care Issues]; www.acvz.org; www.commissie-meijers.nl; www.vluchtelingenwerk.nl

- "verdrag tegen foltering"; folteringverdrag; folterverdrag; "comite tegen foltering"; folteringcomite; foltercomite; "verdrag tegen marteling"; martelingverdrag; martelverdrag; "comite tegen marteling"; martelcomite; martelingcomite; "Committee Against Torture"; "NET/CO/4"

\section{Chapter 10. CRC}

\section{Parliamentary papers}

Parlando search on 21/12/2010 for the period 1/9/1995- 5/4/2010

- Kinderrechtenverdrag (110); "verdrag inzake de rechten van het kind" (763); IVRK NOT Kinderrechtenverdrag NOT "verdrag inzake de rechten van het kind” (58); VRK NOT Kinderrechtenverdrag NOT "verdrag inzake de rechten van het kind (5); "verdrag voor de rechten van het kind" NOT Kinderrechtenverdrag NOT "verdrag inzake de rechten van het kind" NOT IVRK NOT VRK (162); "Convention on the rights of the child" NOT Kinderrechtenverdrag NOT "verdrag inzake de rechten van het kind NOT "verdrag voor de rechten van het kind" NOT IVRK (72); "Committee on the rights of the child" NOT "Convention on the rights of the child" NOT Kinderrechtenverdrag NOT "verdrag inzake de rechten van het kind NOT "verdrag voor de rechten van het kind” NOT IVRK (6); "rechten van het kind” AND comité NOT Kinderrechtenverdrag NOT "verdrag inzake de rechten van het kind NOT "verdrag voor de rechten van het kind” NOT IVRK (119); kinderrechten AND comité NOT Kinderrechtenverdrag NOT "verdrag inzake de rechten van het kind NOT "verdrag voor de rechten van het kind" NOT IVRK (42)

OB search on 26/09/2011 for the period 6/4/2010 - 31/8/2011:

- Kinderrechtenverdrag (50); "verdrag inzake de rechten van het kind" (101); IVRK (53); VRK (3); "verdrag voor de rechten van het kind" (31); "Convention on the rights of the child" (12); "Committee on the rights of the child" (1); "rechten van het kind" AND comité (50); kinderrechten AND comité (27)

\section{Newspaper articles}

Lexis Nexis search on 28/09/2011 for the period 1/9/1995 - 31/8/2011:

- Kinderrechtenverdrag AND comite (13); "Verdrag Inzake de Rechten van het Kind" AND Comite NOT Kinderrechtenverdrag (9); "verdrag voor de rechten van het kind" AND comite NOT "Verdrag Inzake de Rechten van het Kind" NOT kinderrechtenverdrag (15); kinderrechtencomite (23); kinderrechten AND comite NOT Kinderrechtencomite (33); "rechten van het kind" AND comite NOT Kinderrechtencomite (70); Kinderrechtenverdrag AND commissie (13); "Verdrag Inzake de Rechten van het Kind" AND commissie NOT Kinderrechtenverdrag (5); "verdrag voor de rechten van het kind" AND commissie NOT "Verdrag Inzake de 
Appendix 2

Rechten van het Kind" NOT Kinderrechtenverdrag (17); kinderrechten AND commissie (27); "rechten van het kind" AND commissie AND VN (34)

\section{Court judgments}

Rechtspraak.nl search on 28/09/2011 for judgments until 31/8/2011:

- IVRK comite (19); VRK comite (0); kinderrechten comite (0); kinderrechtenverdrag comite (2); "rechten van het kind" comite NOT IVRK (5); "convention on the rights of the child (6); "committee on the rights of the child" (2); "children's rights committee" (0); CRC (12); NLD/CO/3 (0); C/15/Add.227 (1); C/15/Add.114 (0); IVRK (590); VRK NOT IVRK (10); kinderrechtenverdrag NOT VRK NOT IVRK (7); “verdrag inzake de rechten van het kind" NOT kinderrechtenverdrag NOT VRK NOT IVRK (236); "verdrag voor de rechten van het kind" NOT "verdrag inzake de rechten van het kind" NOT kinderrechtenverdrag NOT VRK NOT IVRK (29)

\section{NGO documents}

Google search on 22/12/2010 of www.defenceforchildren.nl; www.kinderrechten.nl; www. unicef.nl; www.njcm.nl; www.acvz.org; www.commissie-meijers.nl; www. vluchtelingenwerk.nl; www.amnesty.nl:

- IVRK comite; VRK comite; Kinderrechten comite; Kinderrechtenverdrag comite; "rechten van het kind" comite; "convention on the rights of the child"; "committee on the rights of the child"; "children's rights committee"; CRC

\section{Chapter 12. New Zealand}

\section{Parliamentary papers}

On 14 June 2012, an advanced search was conducted on Hansard, which contains the transcript of debates in the House of Representatives as well as written and oral questions since 1 January 2000:

- "Committee on economic, social and cultural rights" (4 results); "Covenant on economic, social and cultural rights" (6), "committee against torture" (51); "convention against torture" (107); "Committee on the Elimination of All Forms of Discrimination against Women" (3); "Convention on the Elimination of All Forms of Discrimination against Women" (67); "Committee on the Elimination of Racial Discrimination" (82); "Convention on the Elimination of All Forms of Racial Discrimination" (28); "committee on the rights of the child" (21), "Convention on the rights of the child" (273); "human rights committee" (69) and "international covenant on civil and political rights" (121).

\section{Newspaper articles}

A search was performed of NZ newspapers with Newztext on <www.knowledge-basket. co.nz/search/search_form.php?id=39>. This digital archive contains the major daily 
metropolitan and provincial newspapers, including The Dominion Post and the NZ Herald. The search was performed for the period from 1 September 1995 until 7 June 2012:

- "Committee on Economic, Social and Cultural Rights" (9); "Covenant on Economic, Social and Cultural Rights" (23); "Committee on the Elimination of All Forms of Discrimination against Women" (2); "Convention on the Elimination of All Forms of Discrimination against Women" (46); "Committee on the Elimination of All Forms of Racial Discrimination" (0); "Convention on the Elimination of All Forms of Racial Discrimination" (25); "committee against torture" (43); "Convention Against Torture" (53); "committee on the rights of the child" (66); "convention on the rights of the child" (373); "Human rights committee" (273); "International covenant on civil and political rights" (106). 


\section{ApPENDix 3 \\ InTERview Checklist}

The following checklist was used during interviews. The questions were not necessarily asked in the indicated order. Usually several issues raised under the questions in B-F were already brought up by the interviewees in the context of the rather broad and open introductory questions under A. In addition to these more general questions, interviewees were also asked about specific policy or legislative measures and their (causal) relation to the COs (see chapter III, section 2.3).

\section{A. InTRODUCTORY QUESTIONS}

- Can you shortly describe your background and past and current function(s) (since when)?

- Can you describe your involvement in the reporting process?

- How did you experience your involvement in the reporting process?

\section{B. Organisation OF THE REPORTING PROCESS AT THE NATIONAL LEVEL}

- How do you regard the value/ usefulness of reporting? / How is the reporting process approached by the government?

- How is the reporting process organised by the government at the national level?

- How is the relationship/ interaction between NGOs and the government in the context of the reporting process?

\section{The InVOLVEMENT OF DOMESTIC ACTORS}

- How do you qualify the role of the following actors in relation to the reporting process and their use of the COs in their domestic work (especially in the follow-up phase)?

- parliament

- national courts

- NGOs

- the media

- Ombudsmen and human rights institutions

\section{THE (WIDER) ROLE OF HUMAN RIGHTS}

- What role do (UN) human rights (treaties) play in policymaking and legislative process?

- How do you characterise the knowledge of the (UN) human rights (treaties) among domestic actors? (e.g. government officials, members of parliament etc.) 


\section{E. The UN hUMAN RIGHTS TREATY BODIES}

- How did you experience the constructive dialogues you attended?

- What do you think of the UN human rights treaty bodies? (e.g. in terms of professionalism, knowledge about the national context etc.)

- What do you think of the COs? (e.g. in terms of their quality, persuasiveness, usefulness for the national context etc.)

- Are there (notable) differences among the various treaty bodies with respect to the latter issues? Or differences with other international supervisory organs (e.g. ILO, UN, CoE, EU)?

\section{F. THE DOMESTIC IMPACT AND EFFECTIVENESS OF THE REPORTING PROCESS AND THE COS}

- How do you qualify the impact or influence of the reporting process at the national level?

- Which role have COs played during the policy making and legislative process?

- Do you have concrete examples of COs that have been (partly) effective and have, for example, led to new or additional policy and/or legislative measures?

- What were the main reasons for the policy or legislative change? What was the role of the COs in the particular policy or legislative change (also in the light of other (inter) national factors)?

- What factors and reasons determined that the COs were (partly) effective? 


\section{BibliograPhy}

Acar, Feride (2007), 'Thoughts on the Committee's past, hopes for its future', in Cees Flinterman and Beate Schöpp-Schilling (eds.), The circle of empowerment: twentyfive years of the UN Committee on the Elimination of Discrimination Against Women (New York: The Feminist Press), 340-45.

Adviesraad voor International Vraagstukken (2008), 'Universaliteit van de Rechten van de Mens, principes, praktijken en perspectieven' (The Hague).

Alkema, Evert A. (2011), 'Netherlands', in Dinah Shelton (ed.), International Law and Domestic Legal Systems. Incorporation, Transformation, and Persuasion (Oxford University Press: Oxford), 407-28.

Allan, James, Huscroft, Grant, and Lynch, Nessa (2007), 'The citation of overseas authority in rights litigation in New Zealand: How much bark? How much bite?', Otago Law Review, 11 (3), 433-67.

Alston, Philip (1989), 'Initial report on enhancing the long-term effectiveness of the United Nations human rights treaty system', UN Doc. A/44/668.

— (1993), 'Interim report on updated study', UN Doc. E/CN.4/1997/74.

- (1997a), 'Final report on enhancing the long-term effectiveness of the United Nations human rights treaty system', UN Doc. E/CN.4/1997/74.

- (1997b), 'The purposes of reporting', Manual on human rights reporting under six major international human rights instruments (Geneva: United Nations).

— (2000), 'Beyond 'them' and 'us': putting treaty body reform into perspective', in Philip Alston and James Crawford (eds.), The Future of UN Human Rights Treaty Monitoring (Cambridge: Cambridge University Press), 501-25.

Alston, Philip and Crawford, James (eds.) (2000), The Future of UN Human Rights Treaty Monitoring (Cambridge: Cambridge University Press).

Alter, Karen J. (2003), 'Do international courts enhance compliance with international law', Review of Asian and Pacific Studies, 25, 51-78.

- (2012), 'Tipping the balance: international courts and the construction of international and domestic politics', Cambridge yearbook of European legal studies, 13, 1-21.

- (2013), 'The new terrain of international law: courts, politics, and rights', Northwestern University Roberta Buffett Center for International and Comparative Studies Working Paper No. 13-001

Alvarez, José E. (1991), 'Book review essay. The quest for legitimacy: an examination of The power of legitimacy among nations by Thomas M. Franck', International Law and Politics 24, 199-267.

Baehr, Peter, Castermans-Holleman Monique, and Grünfeld, Fred (2002), Human rights in the foreign policy of the Netherlands (Antwerp: Intersentia).

Baehr, Peter R. (2000), 'Trials and errors: The Netherlands and human rights', in David P. Forsythe (ed.), Human rights and comparative foreign policy (Tokyo/ New York/ Paris: United Nations University Press), 49-86. 
Baluarte, David C. and Vos, Christian M. De (2010), 'From Judgment to Justice. Implementing International and Regional Human Rights Decisions' (New York: Open Society Foundations).

Bank, Ronald (2000), 'Country oriented procedures under the Convention Against Torture', in Philip Alston and James Crawford (eds.), The Future of UN Human Rights Treaty Monitoring (Cambridge: Cambridge University Press), 145-74.

Banton, Michael (2000), 'Decision-taking in the Committee on the Elimination of Racial Discrimination', in Philip Alston and James Crawford (eds.), The Future of UN Human Rights Treaty Monitoring (Cambridge: Cambridge University Press), 55-78.

Barkhuysen, T., Emmerik, M.L. van, and Voermans, W.J.M. (2009), 'De Nederlandse Grondwet geëvalueerd: anker- of verdwijpunt?' (Deventer).

Barrington, John (2004), A Voice for children. The Office of the Commissioner for Children in New Zealand 1984-2003 (Wellington: Dunmore Press).

Bassiouni, M. Cherif (2011), 'A critical introduction assessment of the UN human rights mechanisms', in M.C. Bassiouni and W. A. Schabas (eds.), New Challenges for the UN human rights machinery (Antwerpen: Interesentia), 1-11.

Bassiouni, M.C. and Schabas, W. A. (2011), New Challenges for the UN human rights machinery (Antwerpen: Interesentia).

Bayefksy, Anne F. (1996), 'Report on the UN human rights treaties: facing the implementation crisis', International Law Association.

Bayefsky, Anne F. (2000a), 'Discussion', in Anne F. Bayefsky (ed.), The UN Human Rights System in the 21 ${ }^{\text {st }}$ Century (The Hague: Kluwer), 315-30.

- (ed.), (2000b), The UN Human Rights System in the 21 st Century (The Hague: Kluwer).

- (ed.), (2001), The UN Human Rights Treaty System. Universality at the Crossroads.

Beach, Derek (2005), 'Why governments comply: an integrative model that bridges the gap between instrumental and normative models of compliance', Journal of European Public Policy, 12 (1), 113-42.

Besselink, L.F.M. and Wessel, R.A. (2009), De invloed van ontwikkelingen in de international rechtsorde op de doorwerking naar Nederlands constitutioneel recht. Een 'neo-monistische' benadering (Alphen aan de Rijn: Kluwer).

Boer, Margreet de (2007), 'Zorgen over de status van het VN-Vrouwenverdrag in de Nederlandse rechtsorde', NJCM-Bulletin, 32 (8), 1218-26.

- (2008), 'Onwil of spraakverwarring? Of wat er moeilijk is aan het implementeren van het VN-Vrouwenverdrag', Tijdschrift voor genderstudies, 11 (4), 47-53.

Boerefijn, Ineke (1999), The reporting procedure under the Covenant on Civil and Political Rights (Antwerp: Intersentia).

Boerefijn, Ineke, Gans, Alex van, and Oostland, Rolanda (2003), 'De rol van nietgouvernmentele organisaties in de toezichtprocedures op basis van VN-mensenrechtenverdragen', in Cees Flinterman and Willem van Genugten (eds.), Niet-statelijke actoren en de rechten van de mens; gevestigde waarden, nieuwe wegen (Den Haag: Boom Juridische Uitgevers), 121-33.

Bogdandy, Armin von (2008), 'Pluralism, direct effect and the ultimate say: On the relationship between international and domestic constitutional law ', International journal of constitutional law 6(3\&4), 397-413. 
Böhre, Victor (2010), 'Happy landings? Het biometrisch paspoort als zwarte doos', (Den Haag: Wetenschappelijke Raad voor het Regeringsbeleid).

Börzel, Tanja A. and Risse, Thomas (2000), 'When Europe hits home: Europeanization and domestic change', European Integration online Papers, 4 (15), 1-13.

- (2012), 'From Europeanisation to diffusion: introduction', West European Politics, 35 (1), $1-19$.

Boven, Theo van (2005), 'De Nederlandse rapportage aan het Verdragscomité tegen Rassendiscriminatie', NJCM-Bulletin, 30 (1), 111-18.

Brenninkmeijer, Alex (2010), 'Verdwijnende mensenrechten in Nederland', NTM/NJCMBulletin, 35 (3), 277-85.

Brink, Marjolein van den (2001), 'VN-Vrouwenverdrag: de eerste tandjes komen door. Kroniek 1999-2001', NJCM-Bulletin, 26 (8), 1069-79.

- (2013), 'The CEDAW after all these years: firmly rooted in Dutch clay?', in Anne Hellum and Henriette Sinding Aasen (eds.), Women's Human Rights. CEDAW in International, Regional and National Law (Cambridge: Cambridge University Press), 482-510.

Brink, Marjolein van den and Jacobs, Myriam (1994), 'The wonderful way they are dealing with women in the Netherlands", 19 (6), 742-50.

Broeksteeg, J.L.W., et al. (2005), 'Zicht op wetgevingskwaliteit. Een onderzoek naar de wetgevingsadvisering van de Raad van State ' (Den Haag).

Bron, Jeroen and Thijs, Annette (2011), 'Leaving it to the schools: citizenship, diversity and human rights education in the Netherlands', Educational Research, 53 (2), 123-36.

Bruning, Mariëlle R. (2004), 'Tweede rapportage VN-Verdrag voor de Rechten van het Kind door Nederland: nieuwe rond, nieuwe kansen', NJCM-Bulletin, 29 (7), 1066-74.

Bruning, Mariëlle R. (2010), 'The CRC 20 years: achievements and remaining challenges in the Netherlands', Newsletter School of Human Rights Research, 14 (1), 4-5.

Brunnée, Jutta and Toope, Stephen J. (2013), 'Constructivism and international law', in Jeffrey Dunoff and Mark Pollack (eds.), Synthesizing insights from International Law and International Relations (Cambridge: Cambridge University Press), 119-45.

Brysk, Alison (2009), Global good Samaritans: human rights as foreign policy (Oxford: Oxford University Press).

Bustelo, Mara A. (2000), 'The Committee on the Elimination of Discrimination Against Women at the crossroads', in Philip Alston and James Crawford (eds.), The Future of UN Human Rights Treaty Monitoring (Cambridge: Cambridge University Press), 79-111.

Butler, Andrew (2002), 'Judicial review, Human rights and democracy', in Grant Huscroft and Paul Rishworth (eds.), Litigating rights. Perspectives from domestic and international law (Oxford and Oregon: Hart Publishing), 47-72.

Butler, Andrew and Butler, Petra (1999), 'The judicial use of international human rights law in New Zealand', Victoria University of Wellington Law Review, 15 (1), 173-91.

- (2005), The New Zealand Bill of Rights Act: A Commentary (Wellington: LexisNexis NZ).

Butler, Petra (2006), ' 15 years of the NZ Bill of Rights: time to celebrate, time to reflect, time to work harder?', Victoria University Human Rights Research, 1-31.

- (2011), 'It takes two to tango. Have they learned their steps?', SSRN, 1-52. 
Byrnes, Andrew (2000), 'Uses and abuses of the treaty reporting procedure: Hong Kong between two systems', in Philip Alston and James Crawford (eds.), The Future of UN Human Rights Treaty Monitoring (Cambridge: Cambridge University Press), 287-315.

Çali, Başak and Koch, Anne (2010), 'Bringing the elites back in: the ideational mechanism for compliance with the judgments of the European Court of Human Rights'.

Çali, Başak, Koch, Anne, and Bruch, Nicola (2011), 'The legitimacy of the European Court of Human Rights: the view from the ground'.

Cameron, Iain (2009), 'The influence of European human rights law on national law', in Erkki J. Hollo (ed.), National law and Europeanisation (Helsinki: Suomalainen Lakimiesyhdistys), 63-84.

Cardol, G. (2010), 'De nieuwe jeugdzorg- en jeugdbeschermingswet in Finland', Tijdschrift voor familie- en jeudgrecht, 40 (4), 93-99.

Charlesworth, Hilary, et al. (2006), No country is an island. Australia and international law (Sydney: UNSW Press).

Charters, Claire (2006), 'Responding to Waldron's defence of legislatures: Why New Zealand's parliament does not protect rights in hard cases', New Zealand Law Review, 621-63.

Charters, Claire and Erueti, Andrew (2005), 'Report from the inside: the CERD Committee's review of the Foreshore and Seabed Act 2004', Victoria University of Wellington Law Review, 36, 257-88.

Chayes, Abram and Chayes, Antonia Handler (1993), 'On compliance', International Organization, 47 (2), 175-205.

Checkel, Jeffrey T. (1999), 'Social construction and integration', Journal of European Public Policy, 6 (4), 545-60.

- (2001), 'Why comply? Social learning and European identity change', International Organization, 55 (3), 553-88.

- (2003), "Going native" in Europe? Theorizing social interaction in European institutions', Comparative Political Studies, 36 (1/2), 209-31.

- (2005), 'International institutions and socialization in Europe: introduction and framework', International Organization, 59, 801-26.

Claes, Monica and Witte, Bruno de (1998), 'Report on the Netherlands', in Anne-Marie Slaughter, Alec Stone Sweet, and J.H.H. Weiler (eds.), The European Court and national courts - Doctrine and jurisprudence. Legal change in its social context (Oxford: Hart Publishing), 171-94.

Claes, Monica and Schyff, Gerhard van der (2008), 'Towards judicial constitutional review in the Netherlands?', in Gerhard van der Schyff (ed.), Constitutionalism in the Netherlands and South Africa. A comparative study (Nijmegen: Wolf Legal Publishers), 123-42.

Claes, Monica and Leenknecht, Gert Jan (2011), 'The Netherlands. A case of constitutional leapfrog. Fundamental rights protection under the Constitution, the ECHR and the EU Charter in the Netherlands', in Patricia Popelier, Catherine van de Heyning, and Piet van $\mathrm{Nuffel}$ (eds.), Human rights protection in the European legal order: the interaction between the European and the national courts (Cambridge: Intersentia), 287-307. 
Claes, Monica and Gerards, Janneke (2012), 'Protection of fundamental rights post-Lisbon. The Netherlands', FIDE 2012.

Clapham, Andrew (2000a), 'Defining the role of Non-Governmental Organizations with regard to the UN human rights treaty bodies', in Anne F. Bayefsky (ed.), The UN Human Rights System in the $21^{\text {st }}$ Century (The Hague: Kluwer), 183-94.

- (2000b), 'UN human rights reporting procedures: an NGO perspective', in Philip Alston and James Crawford (eds.), The Future of UN Human Rights Treaty Monitoring (Cambridge: Cambridge University Press), 175-98.

Clark, Helen (2008), 'Foreword', New Zealand Handbook on international human rights (Wellington: Printlink), 5-6.

Clark, Ian (2005), Legitimacy in International Society (Oxford: Oxford University Press).

Cohen, Stanley (1996), 'Government responses to human rights reports: claims, denials, and counterclaims', Human Rights Quarterly, 18 (3), 517-43.

Cohn, Cindy (2001), 'The early harvest: domestic legal changes related to the Human Rights Committee and the Covenant on Civil and Political Rights', Human Rights Quarterly, 13 (3), 295-321.

Connors, Jane (2000), 'An analysis and evaluation of the system of state reporting', in Anne F. Bayefsky (ed.), The UN Human Rights System in the 21st Century (The Hague: Kluwer), 3-21.

Coomans, Fons (1998), 'Nederland voor het VN-Comité inzake Economische, Sociale en Culturele Rechten', NJCM-Bulletin, 23 (7), 939-46.

- (2004), 'De 'witte' en 'zwarte' scholen discussie: waar zijn de mensenrechten?', NJCMBulletin, 29 (3), 300-03.

- (2007), 'Een 'rosy picture'? Nederlandse IVESCR-rapportage beoordeeld door VN-Comité', NJCM-Bulletin, 32 (5), 745-53.

Cooper, Peter, et al. (2000), 'Re-evaluation of the human rights protections in New Zealand' (Wellington: Ministry of Justice).

Craven, M.C.R. (1993), 'The domestic application of the International Covenant on Economic, Social and Cultural Rights', Netherlands International Law Review, 367-404.

Crawford, James (2000), 'The UN human rights treaty system: a system in crisis?', in Philip Alston and James Crawford (eds.), The Future of UN Human Rights Treaty Monitoring (Cambridge: Cambridge University Press), 1-13.

Cremers-Hartman, Eva (2007), 'Zwangere zelfstandige moet beter verzekerd', Sociaal Recht, 52 (7/8), 233-41.

Dai, Xinyuan (2005), 'Why comply? The domestic constituency mechanism', International Organization, 59, 363-98.

- (2013), "The "compliance gap" and the efficacy of international human rights institutions', in Thomas Risse, Stephen C. Ropp, and Kathryn Sikkink (eds.), The persistent power of human rights. From commitment to compliance (Cambridge: Cambridge University Press), 85-102.

Dam, Dominique van (2009), Who's right(s)? International monitoring of compliance with human rights of migrants in the Netherlands 2000-2008 (Nijmegen: Wolf Legal Publishers). 
Dijk, Pieter van (1988), 'Domestic status of human rights treaties and the attitude of the judiciary. The Dutch case', in Manfred Nowak, Dorothea Steurer, and Hannes Tretter (eds.), Progress in the spirit of Human Rights (Kehl/ Strasbourg/ Arlington: N.P. Engel Verlag), 631-49.

Dimitrijevic, Vojin (2001), 'State reports', in Gudmundur Alfredsson, et al. (eds.), International human rights monitoring mechanisms. Essays in honour of Jakob Th. Möller (The Hague: Kluwer), 185-200.

Doek, Jaap E. (2004), 'Rechten van kinderen: some concluding observations and recommendations', Valedictory speech given on 8 September 2004 at VU University Amsterdam, <www.jaapedoek.nl/publications/keynotes/keynote_328.doc>, accessed 26 March 2014.

Dooren, Machteld Inge van (2007), 'Using the racial discrimination Convention during the legislative process' (Oegstgeest).

Downs, George W., Rocke, David M., and Barsoom, Peter N. (1996), 'Is the good news about compliance good news about cooperation?', International Organization, 50 (3), $379-406$.

Dunworth, Treasa (2005), 'Lost in translation: customary international law in domestic law', in Hilary Charlesworth, et al. (eds.), The fluid state. International law and national legal systems (Sydney: The Federation Press), 136-55.

Dür, Andreas (2008), 'Measuring interest group influence in the EU: a note on methodology', European Union Politics, 9 (4), 559-96.

Dutch Ministry of Justice (2009), 'Handleiding rapportages aan VN verdragcomités', unpublished manual.

Emmerik, Michiel van (2005), 'Toepassing van het Kinderrechtenverdrag in de Nederlandse rechtspraak', NJCM-Bulletin, 30 (6), 700-16.

- (2008), 'Verplichtingen voor de wetgever na Straatsburgse uitspraken op grond van het EVRM', in R. de Lange (ed.), Wetgever en grondrechten (Nijmegen: Wolf Legal Publishers), 129-60.

Erdos, David (2007), 'Aversive constitutionalism in the Westminster world: The genesis of the New Zealand Bill of Rights Act (1990)', I-CON, 5 (2), 343-69.

Evatt, Elizabeth (2000), 'The future of the human rights treaty system: forging recommendations', in Anne F. Bayefsky (ed.), The UN Human Rights System in the $21^{\text {st }}$ Century (The Hague: Kluwer), 287-97.

Falkner, Gerda, et al. (2005), Complying with Europe. EU harmonisation and soft law in the member states (Cambridge: Cambridge University Press).

Felice, William F. (2002), 'The UN Committee on the Elimination of All Forms of Racial Discrimination: race, and economic and social human rights', Human Rights Quarterly, 24 (1), 205-36.

Finnemore, Martha and Sikkink, Kathryn (1998), 'International norm dynamics and political change', International Organization, 52 (4), 887-917.

Fleuren, Joseph (2010), 'The application of public international law by Dutch courts', Netherlands International Law Review, 57, 245-66.

Flinterman, Cees (2011), 'Eight years in CEDAW', Netherlands Quarterly of Human Rights, 29 (1), 8-12. 
Formin (2004), Government report to parliament on the human rights policy of Finland 2004 (Helsinki: Edita Prima Oy).

- (2010), Government report to parliament on the human rights policy of Finland 2009 (Helsinki: Edita Prima).

- (2012), 'Submission to the UN Treaty Body Strenghtening Process by Finland', <www2. ohchr.org/english/bodies/HRTD/docs/FinlandSubmission03022012.pdf >, accessed 26 March 2014.

Forrest, Scott (2006), 'Indigenous selfdetermination in Finland: a case study in normative change', Polar Record, 42 (3), 229-38.

Franck, Thomas M. (1988), 'Why a quest for legitimacy', Davis Law Review, 21 (3), 535-47. - (1990), The power of legitimacy and institutions (New York: Oxford University Press).

Gaer, Felice D. (2011), 'Implementing treaty body recommendations: establishing better follow-up procedures', in M.C. Bassiouni and W. A. Schabas (eds.), New Challenges for the UN human rights machinery (Antwerpen: Interesentia), 107-21.

Geddis, Andrew (2009), 'The Comparative Irrelevance of the NZBORA to Legislative Practice ', New Zealand Universities Law Review, 23, 465-88.

- (2011), 'Prisoner voting and rights deliberation: How New Zealand's parliament failed', New Zealand Law Review, 443-74.

Geddis, Andrew and Fenton, Bridget (2008), “Which is to be master?" Rights-friendly statutory interpretation in New Zealand and the United Kingdom ', Arizona Journal of International \& Comparative Law, 25 (3), 733-78.

Geiringer, Claudia (2006), 'International law through the lens of Zaoui: Where is New Zealand at?', Public Law Review, 17, 300-21.

- (2008), 'The principle of legality and the Bill of Rights Act: A critical examination of $R v$ Hansen', New Zealand Journal of Public and International Law, 6 (1), 59-93.

- (2009), 'On a road to nowhere: implied declarations of inconsistency and the New Zealand Bill of Rights Act', Victoria University of Wellington Law Review, 40, 61348.

Geiringer, Claudia and Palmer, Matthew S.R. (2007), 'Human rights and social policy in New Zealand', Social policy Journal of New Zealand, 30 (1), 12-41.

Gerards, Janneke (2012), 'Kroniek van de grondrechten', Nederlands Juristenblad, 87 (35), 2443-53.

Gibson, James L. and Caldeira, Gregory A. (1995), 'The legitimacy of transnational legal institutions: compliance, support, and the European Court of Justice', American Journal of Political Science, 39 (2), 459-89.

Goertz, Gary and Levy, Jack S. (2007), 'Causal explanation, necessary conditions, and case studies', in Gary Goertz and Jack S. Levy (eds.), Explaining war and peace: case studies and necessary condition counterfactuals (New York: Routledge), 9-45.

Goff, Phill (2004), 'International institutions and governance: a New Zealand perspective', New Zealand Yearbook of International Law, 1 (1), 1-7.

Goldingay, Sophie Jennifer Elizabeth (2009), 'Separation or mixing: issues for young women prisoners in Aotearoa New Zealand prisons’ (University of Canterbury). 
Goodman, Ryan and Jinks, Derek (2008), 'Incomplete internalization and compliance with human rights law: a rejoinder to Roda Mushkat', The European Journal of International Law, 20 (2), 443-46.

Gourevitch, Peter (1978), 'The second image reversed: the international sources of domestic politics', International Organization, 32 (4), 881-912.

Graaf, J.H. De (2012), 'Eindbeschouwing', in J.H. de Graaf, et al. (eds.), De toepassing van het Internationaal Verdrag inzake de Rechten van het Kind in de Nederlandse Rechtspraak (Nijmegen: Ars Aequi Libri), 275-86.

Gras, Jutta (2001), Monitoring the Convention on the Rights of the Child (Helsinki: Helsinki University Press).

Greatrex, Helen Patricia (2010), 'Complementarity: Towards robust human-rights governance in the New Zealand state sector' (Victoria University of Wellington).

Grugel, Jean and Peruzzotti, Enrique (2012), 'The domestic politics of international human rights law: implementing the Conventuion on the Rights of the Child in Ecuador, Chile, and Argentina', Human Rights Quarterly, 34 (1), 178-98.

Gurowitz, Amy (1999), 'Mobilizing international norms. Domestic actors, immigrants, and the Japanese state', World Politics, 51 (3), 413-45.

Guzman, Andrew T. (2008), How international law works (New York: Oxford University Press).

Hafner-Burton, Emilie M. (2008), 'Sticks and stones: naming and shaming the human rights enforcement problem', International Organization, 62, 689-716.

Hafner-Burton, Emilie M. and Tsutsui, Kiyoteru (2005), 'Human rights in a globalizing world: the paradox of empty promises', American Journal of Sociology, 110 (5), 1373411.

Hakimi, Monica (2009), 'Secondary human rights law', Yale Journal of International Law, 34 (2), 596-604

Hakki, M. M. (2002), 'The silver anniversary of the UN Human Rights Committee: anything to celebrate?', The International Journal of Human Rights, 6 (3), 85-102.

Hallberg, Pekka (2000), 'Fundamental rights in the practice of the Supreme Administrative Court of Finland and the provisions of the Finnish Constitution', in Paul Mahoney, et al. (eds.), Protecting human rights: the European perspective. Studies in memory of Rolv Ryssdal (Köln/ Berlin/ Bonn/ München: Carl Heymanns Verlag KG), 577-86.

Halme-Tuomisaari, Miia (2010a), “Absolute and Undefine': exploring the popularity of human rights in Finland', Rediscriptions, 15 (1), 71-99.

- (2010b), Human Rights in Action: Learning Expert Knowledge (Boston: Martinus Nijhoff Publishers).

Halme, Miia (2007), 'From the Periphery to the Centre: Emergence of the Human Rights Phenomenon in Finland', Finnish Yearbook of International Law, 257-81.

- (2008), Human rights in action (University of Helsinki: Research Series in Anthropology).

Harjunen, Hannele (2007), 'Issue Histories Finland: Series of Timelines of Policy Debates', QUING Project (Vienna: Institute for Human Sciences (IWM)). 
Harrington, Joanna (2007), 'The democratic challenge of incorporation: International human rights treaties and national constitutions', Victoria University of Wellington Law Review, 38, 217-325.

Hassall, Ian and Davies, Emma (2003), 'The Use and Misuse of the UN Convention', ChildreNZ Issues, 7 (1), 34-36.

Hathaway, Oona A. (2002), 'Do human rights treaties make a difference?', The Yale Law Journal, 111, 1935-2042.

Hawkins, Darren and Jacoby, Wade (2010), 'Partial compliance: A comparison of the European and Inter-American American Courts for Human Rights', Journal of International Law and International Relations, 6 (1), 35-85.

Heidenreich, Martin and Zeitlin, Jonathan (2009), 'Introduction', in Martin Heidenreich and Jonathan Zeitlin (eds.), Changing European employment welfare regimes: The influence of the Open Method of Coordination on national reforms (London: Routledge), 1-9.

Helfer, Laurence R. and Slaughter, Anne-Marie (1997), 'Toward a theory of effective supranational adjudication', Yale Law Journal, 107 (2), 273-391.

Hellum, Anne and Aasen, Henriette Sinding (2013), Women's Human Rights. CEDAW in International, Regional and National Law (Cambridge: Cambridge University Press).

Heringa, Aart Willem (1988), 'Het internationale verdrag inzake burgerlijke en politieke rechten en de Nederlandse rechtsorde', in P. van Dijk (ed.), Het internationale verdrag inzake burgerlijke en politieke rechten en zijn betekenis voor Nederland (Nijmegen: Ars Aequi Libri), 103-25.

Heyns, Christof and Viljoen, Frans (2001), 'The impact of the United Nations human rights treaties on the domestic level', Human Rights Quarterly, 23, 483-535.

Heyns, Christof H. and Viljoen, Frans (2002), The impact of the United Nations human rights treaties on the domestic level (The Hague: Kluwer Law International).

Hirschl, Ran (2011), 'The Nordic counternararrative: Democracy, human development, and judicial review', I-CON, 9 (2), 449-69.

Holli, Anne Maria, Luhtakallio, Eeva, and Raevaara, Eeva (2006), 'Quota trouble. Talking about gender quotas in Finnish local politics', International Feminist Journal of Politics, 8 (2), 169-93.

Hollingsworth, Kathryn (2004), 'Speaking Loudly and Carrying A Small Stick? The New Zealand Commissioner for Children', Otago Law Review, 10 (4), 599-622.

Holtmaat, Rikki and Tobler, Christa (2005), 'CEDAW and the European Union's policy in the field of combating gender discrimination', Maastricht Journal of European and Comparative Law, 12 (4), 399-425.

Hoof, Fried van (1998), 'De praktische betekenis van economische, sociale en culturele rechten in Nederland?', in M.K.C. Arambulo, A.P.M. Coomans, and B.C.A. Toebes (eds.), De betekenis van economische, sociale en culturele rechten in de Nederlandse rechtsorde: vrijblijvend of verplichtend? (Leiden: Stichting NJCM-Boekerij), 7-20.

Hopkins, John (2011), 'New Zealand', in Dinah Shelton (ed.), International Law and Domestic Legal Systems. Incorporation, Transformation, and Persuasion (Oxford: Oxford University Press), 429-47. 
Houtzager, Dirk (2010), 'Vreemdelingen- en asielbeleid vanuit mensenrechtelijk perspectief. Wat zeggen international toezichthouders over het Nederlandse beleid?', Journaal Vreemdelingenrecht, 3, 211-23.

Hunter, Kerry L. (2009), 'American Constitutionalism an Impediment to the Pursuit of Fairness? Lessons from New Zealand political culture', Policy Quarterly, 5 (3), 44-49.

Hurd, Ian (1999), 'Legitimacy and Authority in International Politics', International Organization, 53 (2), 379-408.

Husa, Jaakko (2000), 'Guarding the constitutionality of laws in the Nordic countries: a comparative perspective', The American journal of comparative law, 48, 345-82.

- (2010), 'Nordic constitutionalism and European human rights. Mixing oil and water?', Scandinavian Studies in Law, 55, 101-24.

- (2011), The Constitution of Finland. A contextual analysis (Oxford and Portland, Oregon: Hart Publishing).

Husa, Jaakko, Nuotio, Kimmo, and Pihlajamäki, Heikki (2007), 'Nordic Law - Between Tradition and Dynamism', in Jaakko Husa, Kimmo Nuotio, and Heikki Pihlajamäki (eds.), Nordic Law - Between Tradition and Dynamism (Antwerp-Oxford: Intersentia), $1-39$.

Illingsworth, Fiona (2012), 'Reply of 22 May 2012 to Mr. Shuttleworth's Official Information Act request concerning the government response to concluding observations '.

International Law Association (2002), 'Interim report on the impact of the work of the United Nations human rights treaty bodies on national courts and tribunals' (New Delhi: Committee on international human rights law and practice).

- (2004), 'Final report on the impact of findings of the United Nations human rights treaty bodies (Berlin: Committee on international human rights law and practice).

Jacobsson, Kerstin and Vifell, Åsa (2007), 'Deliberative transnationalism? Analysing the role of Committee interaction in soft co-ordination', in I. Linsenmann, C.O. Meyer, and W.T. Wessels (eds.), Economic government of the EU: A balance sheet of new modes of policy coordination (Houndmilss: Palgrave Macmillan), 163-86.

Janse, Ronald and Tigchelaar, Jet (2010), 'Het vrouwenrechtencomité: niet bekend en niet geacht.', in N. Doornbos, N. Huls, and W. van Rossum (eds.), Rechtspraak van buiten (Deventer: Kluwer), 309-17.

Johnstone, Rachael Lorna (2007), 'Cynical savings or reasonable reform? Reflections on a single unified UN human rights treaty body', Human Rights Law Review, 7 (1), 173200.

Jong, M.A.D.W. de and Kummeling, H.R.B.M. (2009), 'De teloorgang van de tweede kamer als medewetgever', in P.P.T. Bovend'Eert, et al. (eds.), De staat van wetgeving. Opstellen aangeboden aan Prof.mr. C.A.J.M. Kortmann (Deventer: Kluwer), 67-97.

Joona, Tanja (2005), 'The political recognition and ratification of ILO Convention No. 169 in Finland, with some comparison to Sweden and Norway', Nordisk Tidsskrift for Menneskerettigheter, 23 (3), 305-20.

Kaandorp, Majorie (2004), 'Het bondgenootschap tussen Niet-Gouvernementele Organisaties en het VN-Verdrag inzake de Rechten van het Kind', in DCI (ed.), Nederland rapporteert over kinderrechten, 33-36. 
Kääriäinen, Juha (2008), 'Why do Finns trust the police?', Journal of Scandinavian Studies in Criminology and Crime Prevention, 9 (2), 141-59.

Kälin, Walter (2012), 'Examination of state reports', in Helen Keller and Geir Ulfstein (eds.), UN human rights treaty bodies. Law and legitimacy (Cambridge: Cambridge University Press), 16-72.

Karp, Judith (2000), 'Reporting and the Committee on the Rights of the Child', in Anne F. Bayefsky (ed.), The UN Human Rights System in the 21st Century (The Hague: Kluwer), 35-44.

Keck, Margaret E. and Sikkink, Kathryn (1999), 'Transnational advocacy networks in international and regional politics', UNESCO, 89-101.

Keith, Linda Camp (1999), 'The United Nations International Covenant on Civil and Political Rights: Does it make a difference in human rights behavior?', Journal of Peace Research, 36 (1), 95-118.

Keller, Helen and Sweet, Alec Stone (2008), A Europe of Rights. The Impact of the ECHR on National Legal Systems (Oxford: Oxford University Press).

Keller, Helen and Ulfstein, Geir (2012a), 'Conclusions', in Helen Keller and Geir Ulfstein (eds.), UN human rights treaty bodies. Law and legitimacy (Cambridge: Cambridge University Press), 414-25.

Keller, Helen and Grover, Leena (2012), 'General Comments of the Human Rights Committee and their legitimacy', in Helen Keller and Geir Ulfstein (eds.), UN human rights treaty bodies. Law and legitimacy (Cambridge: Cambridge University Pres ), 116-94.

Keller, Helen and Ulfstein, Geir (2012b), UN human rights treaty bodies. Law and legitimacy (Cambridge: Cambridge University Press).

Kelley, Judith (2004), 'International actors on the domestic scene: membership conditionality and socialization by international institutions', International Organization, 58, 425-57.

Kelly, James B. (2011), 'Judicial and political review as limited insurance: the functioning of the New Zealand Bill of Rights Act in 'hard' cases', Commonwealth and Comparative Politics, 49 (3), 295-317.

Kennedy, James (2006), 'Nederland als het meest progressieve land ter wereld' in Wim van Noort en Rob Wiche (eds.), Nederland als voorbeeldige natie (Hilversum: Uitgeverij Verloren), 105-118.

Keohane, Robert O. (1997), 'International Relations and International Law: two optics', Harvard International Law Journal, 38 (2), 487-502.

Kinderrechtencollectief (2003), 'Growing up in the Low Countries. Children's rights in the Netherlands. The second report of the Dutch NGO Coalition for Children's Rights on the implementation of the Convention on the Rights of the Child in the Netherlands.', $<$ www.crin.org/docs/resources/treaties/crc.35/Netherlands_coalition_ngo_report. pdf>, accessed 26 March 2014.

- (2008), 'Children's rights in the Netherlands. The third report of the Dutch NGO Coalition for Children's Rights on the implementation of the Convention on the Rights 
Bibliography

of the Child', <www.crin.org/docs/Netherlands_KRC_NGO_Report.pdf $>$, accessed 26 March 2014.

- (2012), 'Kinderrechten in Nederland 2008-2012. De vierde ngo-rapportage van het

Kinderrechtencollectief aan het VN-Kinderrechtencomité ', <www. defenceforchildren.nl/images/68/1760.pdf>, accessed 26 March 2014.

Koh, Harold Hongju (1997), 'Why do nations obey international law?', The Yale Law Journal, 106, 2599-659.

- (1998-1999), 'The 1998 Frankel lecture: bringing international law home', Houstan Law Review, 35, 623-81.

- (2005), 'Internalization through socialization', Duke Law Journal, 54, 975-82.

Koivurova, Timo (2006/7), 'The Draft for a Nordic Saami Convention', European Yearbook of Minority Issues, 6, 103-36.

Koops, Bert-Jan (2011), 'The evolution of privacy law and policy in the Netherlands', Journal of Comparative analysis: research and practice, 13 (2), 165-79.

Koulu, Sanna and Hetemäki, Inka (2010), '20 years of CRC in Finland', unpublished work.

Krommendijk, Jasper (2011a), 'Non-Compliance with Concluding Observations of the HRC in the Netherlands: The ECHR and the ECtHR as one Explanation', Maastricht Faculty of Law Working Paper (2011-8).

- (2011b), 'The effectiveness of non-judicial mechanisms for the implementation of human rights', Human Rights \& International Legal Discourse, 5 (2), 264-93.

- (2012a), 'Can Mr. Zaoui freely cross the foreshore and seabed? The effectiveness of UN human rights monitoring mechanisms in New Zealand', Victoria University of Wellington Law Review, 43 (4), 579-616.

- (2012b), 'The impact and effectiveness of state reporting under the Women's Convention. The case of the Netherlands', in Ingrid Westendorp (ed.), The Women's Convention Turned 30: Achievements, Setbacks, and Prospects (Antwerp: Intersentia), 487-512.

- (2012c), 'The (Non) Implementation of Recommendations of the Committee on the Elimination of Racial Discrimination in the Netherlands Explained', Perspectives on European Politics and Society, 13 (4), 462-79.

- (2013a), 'De beperkte effectiviteit van de aanbevelingen van het VN-Mensenrechtencomité in Nederland nader bekeken en verklaard', NTM/NJCMBulletin, 38 (2), 212-28.

- (2013b), 'Just 'a little UN Committee' or important policy driver? The impact and effectiveness of the CEDAW Committee in New Zealand.', Tijdschrift voor Genderstudies, 16 (1), 8-22.

- (2014a), 'The Domestic Politics of International Children's Law: the Growing Role of the UN Convention and Committee on the Rights of the Child in the Netherlands', in Karin Arts and Jeff Handmaker (eds.), Pursuing Global Justice: Reflections on International Law (Cambridge Cambridge University Press).

- (2014b), 'Finnish exceptionalism at play? The effectiveness of the recommendations of UN human rights treaty bodies in Finland', Nordic Journal of Human Rights, 32 (1), $18-43$. 
Kuijer, Martin (2009), 'De betekenis van het Europees Verdrag voor de Rechten van de Mens voor de nationale wetgever', in H.R. Schouten (ed.), Wetgever en constitutie (Nijmegen: Wolf Legal Publishers), 43-86.

- (2013), 'The impact of the case law of the European Court of Human Rights on the political debate in the Netherlands concerning the court', in Marjolein van Roosmalen, et al. (eds.), Fundamental rights and principles. Liber amicorum Pieter van Dijk (Antwerp: Intersentia), 99-114.

Kurki-Suonio, Kirsti (2010), 'The Parliamentary Ombudsman as an overseer of the rights of the child', Parliamentary Ombudsman 90 years (Sastamala: Vammalan Kirjapaino Oy), 326-40.

Landman, Todd (2009), 'Social science methods and human rights', in Fons Coomans, Fred Grunfeld, and Menno T. Kamminga (eds.), Methods of human rights research (Antwerp: Intersentia), 19-44.

Langford, Malcolm (2010), 'Refraction? The Constitutional-Regional Variable and the Domestic Effects of International Human Rights Treaties', Colloquium on the Domestic Consequences of Internaitonal Human Rights Treaty Ratification, 15-16 October 2010 (New York University).

Lansdown, Gerison (2000), 'The reporting process under the Convention on the Rights of the Child', in Philip Alston and James Crawford (eds.), The Future of UN Human Rights Treaty Monitoring (Cambridge: Cambridge University Press), 113-28.

Lavapuro, Juha, Ojanen, Tuomas, and Scheinin, Martin (2011), 'Rights-based constitutionalism in Finland and the development of pluralist constitutional review', I-CON, 9 (2), 505-31.

Lawson, Rick A. (1999), 'De internationale rechter en de Nederlandse rechtsorde' (Preadvies Handelingen Nederlandse Juristen-Vereniging).

Leary, Virginia A. (1992), 'Lessons from the experience of the International Labour Organisation', in Philip Alston (ed.), The United Nations and human rights. A critical appraisal (Oxford: Clarendon Press), 580-619.

Leblanc, Lawrence, Huibregtse, Ada, and Meister, Timothy (2010), 'Compliance with the reporting requirements of human tights conventions', International Journal of Human Rights, 14 (5), 789-807.

Leckie, Scott (2000), 'The Committee on Economic, Social and Cultural Rights: catalyst for change in a system needing reform', in Philip Alston and James Crawford (eds.), The Future of UN Human Rights Treaty Monitoring (Cambridge: Cambridge University Press), 129-44.

Lempinen, Miko (2008a), 'The activity, progressiveness and consistency of the human rights policy of Finland', unpublished manuscript on file with the author.

- (2008b), 'The Activity, Progressiveness and Consistency of the Human Rights Policy of Finland: Conscientious Objection to Military Service', Research reports (Åbo Akademi University, Institute for Human Rights).

- (2008c), 'The Activity, Progressiveness and Consistency of the Human Rights Policy of Finland: The Rights of Indigenous Peoples', Research reports (Åbo Akademi University, Institute for Human Rights). 
Liefaard, Ton (2013), 'De waarde van de rapportageverplichting van Nederland aan het VN-Kinderrechtencomité', NTM/NJCM-Bulletin, 38 (4), 469-481.

Loof, Jan Peter (2008), 'Het parlement, de mensenrechten en de zorgvuldigheid in het wetgevingsproces', in R. de Lange (ed.), Wetgever en grondrechten (Nijmegen: Wolf Legal Publishers), 85-127.

Low, Jo En (2008), 'Engaging with the United Nations Treaty Bodies: A fruitful dialogue?', University of New South Wales Faculty of Law Research Series 36.

MacKay, Don (1999), 'The UN Covenants and the Human Rights Committee', Victoria University of Wellington Law Review, 29 (1), 11-18.

Mahoney, James and Goertz, Gary (2006), 'A tale of two cultures: constrasting quantitative and qualitative research', Political Analysis, 14, 227-49.

March, James G. and Olsen, Johan P. (1998), 'The institutional dynamics of international political orders', International Organization, 52 (4), 943-69.

Marchand, Marianne H. (2003), 'Emancipatie op een zijspoor?; tweede nationale rapportage inzake de implementatie van het VN-Vrouwenverdrag' (Amsterdam: Belle van Zuylen Instituut).

Martin, Lisa L. (2013), 'Against compliance', in Jeffrey Dunoff and Mark Pollack (eds.), Synthesizing insights from International Law and International Relations (Cambridge: Cambridge University Press), 591-610.

Mastenbroek, Ellen (2009), 'Procedural legitimacy and EU compliance', Politicologenetmaal, 18-19 May 2009.

Mastenbroek, Ellen and Kaeding, Michael (2006), 'Europeanization beyond the goodness of fit: domestic politics in the forefront', Comparative European Politics, 4, 331-54.

Mavrommatis, Andreas (2001), 'The first ten years of the Human Rights Committee ', in Gudmundur Alfredsson, et al. (eds.), International human rights monitoring mechanisms. Essays in honour of Jakob Th. Möller (The Hague: Kluwer), 147-52.

McPhedran, Marilou, et al. (2000), 'The first CEDAW impact study' (New York: New York University and the International Women's Right Project Centre for Feminist Research).

Mechlem, Kirsten (2009), 'Treaty Bodies and the interpretation of human rights', Vanderbilt Journal of Transnational Law, 905-47.

Mens, College voor de Rechten van (2013), 'Mensenrechten in Nederland 2012. Jaarlijkse rapportage van het College voor de Rechten van de Mens'.

Meron, Theodor (1985), 'The meaning and reach of the International Convention on the Elimination of all forms of Racial Discrimination', The American Journal of International Law, 79 (2), 283-318.

Meuwese, Stan (2003), 'Working towards the full implementation of the Convention on the Rights of the Child in The Netherlands: 14 priorities', <www.allianceforchildhood.eu/ files/20031008presentationdfcgeneve.pdf $>$, accessed 26 March 2014.

- (2004), 'Tussen Genève en Den Haag', in Defence for Children (ed.), Nederland rapporteert over kinderrechten, 11-14.

Mikkola, Matti (2010), Social human rights of Europe (Porvoo: Bookwell Ltd). 
Ministry of Justice Finland (2012), 'National Action plan on fundamental and human rights 2012-2013'.

Mitchell, Ronald B. (1994), 'Regime design matters: intentional oil pollution and treaty compliance', International Organization, 48 (3), 425-58.

Moore, Dan (2009), 'Reconciling normative dissonance in Canada and New Zealand: comparing the judicial and political paths to children's rights implementation', Fifth annual conference on student publishing in law, 10 March 2009 (Toronto, Canada).

Moravcsik, Andrew (1995), 'Explaining international human rights regimes: liberal theory and Western Europe', European Journal of International Relations, 1 (2), 157-89.

Morijn, John (2011), 'Reforming United Nations human rights treaty monitoring reform', Netherlands International Law Review, 58, 295-334.

Mutua, Makau wa (1998), 'Looking past the Human Rights Committee: An argument for de-marginalizing enforcement', Buffalo Human Rights Law Review, 4, 211-60.

Netwerk VN-Vrouwenverdrag (2008), 'Monitor Uitvoering van de Concluding Comments CEDAW', <www.vrouwenverdrag.nl/_documenten/vvnl/nieuws/2008/monitoreindversie-def3.pdf $>$, accessed 26 March 2014.

Neumayer, Eric (2005), 'Do international human rights treaties improve respect for human rights?', Journal of Conflict Resolution, 49 (6), 925-53.

Niemi, Heli (2003), 'National Implementation of Findings by United Nations Human Rights Treaty Bodies: A Comparative Study', Research reports Åbo Akademi University 20.

Niemi, Heli and Scheinin, Martin (2002), 'Reform of the United Nations human rights treaty body system seen from the developing country perspective' (Institute for Human Rights Åbo Akademi University).

NJCM (2008), 'Commentary on the Fourth Periodic Report of the Netherlands on the International ICCPR on Civil and Political Rights (ICCPR)', <www2.ohchr.org/ english/bodies/hrc/docs/ngos/NJCMNetherlands94.pdf>, accessed 26 March 2014.

- (2009a), 'Addendum to the Commentary on the $4^{\text {th }}$ periodic report of the Netherlands on the International ICCPR on Civil and Political Rights', <www2.ohchr.org/english/ bodies/hrc/docs/ngos/NJCMS_Netherlands_HRC96.pdf>, accessed 26 March 2014.

- (2009b), 'Joint parallel report to the combined fourth and fifth periodic report of the Netherlands on the International Covenant on Economic, Social and Cultural Rights', $<$ www2.ohchr.org/english/bodies/cescr/docs/ngos/JointParallelReport_ Netherlands43.pdf>, accessed 26 March 2014.

- (2013), 'Commentary on the sixth periodic report submitted by the Kingdom of the Netherlands on the implementation of the UN Convention Against Torture and Other Cruel, Inhuman or Degrading Treatment or Punishment (CAT/C/NLD/Q/6)', <www2. ohchr.org/english/bodies/cat/docs/ngos/NJCM_Netherlands_CAt50.pdf >, accessed 26 March 2014.

NJCM and JWS (2006), 'Contribution of the Dutch section of the International Commission of Jurists (NJCM) and the Johannes Wier Stichting (JWS) to Committee on Economic, Social and Cultural Rights', <www2.ohchr.org/english/bodies/cescr/docs/info-ngos/ NJCM-JWS.pdf>, accessed 26 March 2014. 
Bibliography

Nollkaemper, André (2009), 'Netherlands', in David Sloss (ed.), The role of domestic courts in treaty enforcement: a comparative study (Cambridge: Cambridge University Press), 326-69.

Nollkaemper, André and Alebeek, Rosanne van (2012), 'The legal status of decisions by human rights treaty bodies in national law', in Helen Keller and Geir Ulfstein (eds.), UN human rights treaty bodies. Law and legitimacy (Cambridge: Cambridge University Press), 356-413.

Nousiainen, Kevät and Pentikäinen, Merja (2013), 'Rise and fall of CEDAW in Finland: time to reclaim its impetus', in Anne Hellum and Henriette Sinding Aasen (eds.), Women's Human Rights. CEDAW in International, Regional and National Law (Cambridge Cambridge University Press), 557-87.

NZ Human Rights Commission (2004), 'Human rights in New Zealand today ', <www.hrc. co.nz/report/>, accessed 26 March 2014.

- (2010), 'Human Rights in New Zealand 2010: Ngā Tika Tangata O Aotearoa'.

O'Flaherty, Michael (2006), 'The Concluding Observations of United Nations human rights treaty bodies', Human Rights Law Review, 6 (1), 27-52.

- (2010), 'The Dublin Statement on the process of strenghtening of the United Nations human rights treaty body system', Netherlands Quarterly of Human Rights, 28 (1), 116-27.

O'Flaherty, Michael and Tsai, P. (2011), 'Periodic reporting: the backbone of the UN treaty body review procedures', in M.C. Bassiouni and W. A. Schabas (eds.), New Challenges for the UN human rights machinery (Antwerpen: Interesentia), 37-56.

Ojanen, Tuomas (2009), 'From constitutional periphery toward the center - transformations of judicial review in Finland', Nordisk Tidsskrift for Menneskerettigheter, 27 (2), 194 207.

- (2012), 'The Europeanization of Finnish law. Observations on the transformations of the Finnish scene of constitutionalism', in Kimmo Nuotio, Sakari Melander, and Merita Huomo-Kettunen (eds.), Introduction to Finnish law and legal culture (Helsinki: Forum Iuris), 97-110.

Oomen, Barbara (2011), 'Small places: the home-coming of human rights in the Netherlands', Inaugural lecture on 2 December 2011, Middelburg.

- (2013a), 'The rights for others: the contested homecoming of human rights in the Netherlands', Netherlands Quarterly of Human Rights, 31 (1), 41-73.

- (2013b), 'Waving with treaties? The politics of implementing human rights education in the Netherlands', Journal of human rights practice, 5 (2), 291-317.

Outshoorn, J.V. (2007), 'Instituties voor emancipatiebeleid: Nederland in een internationale context' (Den Haag: Visitatiecommissie Emancipatiebeleid.

Palmer, Matthew S.R. (2006), 'What is New Zealand's Constitution and Who Interprets It? Constitutional Realism and the Importance of Public Office-holders', Public Law Review, 17, 133-62.

- (2007), 'New Zealand Constitutional Culture', New Zealand Universities Law Review, $22,565-97$. 
Palmer, Sir Geoffrey (1998), 'Human rights and the New Zealand's government treaty obligations', Victoria University of Wellington Law Review, 29, 57-74.

Paunio, Riitta-Leena (2010), 'Objectives and challenges - 90 years of the Ombudsman's oversight of legality ', Parliamentary Ombudsman 90 years (Sastamala: Vammalan Kirjapaino Oy), 7-17.

Pesonen, Pertti and Riihinen, Olavi (2002), Dynamic Finland. The political system and the welfare state (Tampere: Tammer-Paino Oy).

Peter, Chris Maina (2011), 'Accessign justice by all means: Individual Communication before UN treaty bodies - A case study of CERD', in M.C. Bassiouni and W. A. Schabas (eds.), New Challenges for the UN human rights machinery (Antwerpen: Interesentia), 123-35.

Peters, J.A. (2009), 'Geen groen maar rijp voorstel. De angst voor constitutionele toetsing (Het wetsontwerp-Halsema)', in P.P.T. Bovend'Eert, et al. (eds.), De staat van wetgeving. Opstellen aangeboden aan Prof.mr. C.A.J.M. Kortmann (Deventer: Kluwer), 99-127.

Piccone, Ted (2011), 'The contribution of the UN's special procedures to national level implementation of human rights norms', The International Journal of Human Rights, 15 (2), 206-31.

Pillay, Navanethem (2012), 'Strengthening the United Nations human rights treaty body system. A report by the United Nations High Commissioner for Human Rights'.

Pirjola, Jari (2010), 'UN's national preventive mechanism for the prevention of torture ', Parliamentary Ombudsman 90 years (Sastamala: Vammalan Kirjapaino Oy), 125-37.

Pölönen, Pasi (2010), 'Monitoring fundamental and human rights as the Parliamentary Ombudsman's duty', Parliamentary Ombudsman 90 years (Sastamala: Vammalan Kirjapaino Oy), 51-63.

Pulles, Gerrit Jan (2011), 'Onduidelijkheid over de rechtstreekse werking van kernbepalingen van het VN-kinderechtenverdrag', Nederlands Juristenblad, 86 (4), 231-34.

Putnam, Robert D. (1988), 'Diplomacy and domestic politics: the logic of two-level games', International Organization, 42 (3), 427-60.

Race Relations Commissioner (2008), 'Tūi Tūi Tuituiā: Race Relations in 2007'.

— (2009), 'Tūi Tūi Tuituiā: Race Relations in 2008'.

- (2011), 'Tūi Tūi Tuituiā: Race Relations in 2010 '.

Raustiala, Kal (2000), 'Compliance and effectiveness in international regulatory cooperation', Case Western Reserve Journal of International Law, 32, 387-440.

Raustiala, Kal and Slaughter, Anne-Marie (2002), 'International law, international relations and compliance', in Walter Carlsnaes, Thomas Risse, and Beth Simmons (eds.), Handbook of international relations (London: Sage Publications), 538-58.

Redactioneel (1998a), 'De verkiezingsprogramma's als graadmeter voor toekomstig mensenrechtenbeleid', NJCM-Bulletin, 23 (3), 259-61.

- (1998b), 'Het struisvogelei', NJCM-Bulletin, 23 (4), 419-21.

- (2002), 'Structurele parlementaire aandacht nodig voor kritiek toezichthoudende mensenrechtencomité's', NJCM-Bulletin, 27 (1), 3-5. 
- (2011), 'Mensenrechten in discussie: linkse hobby, recht liberaal gedachtengoed, of van ons allemaal?', NTM/NJCM-Bulletin, 36 (4), 429-32.

- (2012), 'Hebben ze het wel goed gezien? Hoe om te gaan met oordelen van internationale mensenrechtencomités', NTM/NJCM-Bulletin, 37 (4), 387-89.

Reiding, Hilde (2007), The Netherlands and the development of international human rights instruments (Antwerp: Intersentia).

- (2012), 'The Netherlands gradually changing views on international economic and social rights protection', Human Rights Quarterly, 34, 113-40.

Risse, Thomas and Ropp, Stephen C. (1999), 'International human rights norms and domestic change: conclusions', in Thomas Risse, Stephen C. Ropp, and Kathryn Sikkink (eds.), The power of human rights: international norms and domestic change (Cambridge: Cambridge University Press), 234-78.

Risse, Thomas and Sikkink, Kathryn (1999), 'The socialization of international human rights norms into domestic practices: introduction', in Thomas Risse, Stephen C. Ropp, and Kathryn Sikkink (eds.), The power of human rights: international norms and domestic change (Cambridge: Cambridge University Press), 1-38.

Risse, Thomas and Ropp, Stephen C. (2013), 'Introduction and overview', in Thomas Risse, Stephen C. Ropp, and Kathryn Sikkink (eds.), The persistent power of human rights. From commitment to compliance (Cambridge: Cambridge University Press), 85-102.

Römkens, Renée G. (2008), 'Met recht 'n zorg? Overdenkingen bij wet- en regelgeving over geweld in privésfeer', Speech held on 12 December 2008 at the Tilburg University, $<$ http://arno.uvt.nl/show.cgi?fid=113963>, accessed 26 March 2014.

Rosas, Allan (1988), 'The Nordic Countries and the International Protection of Human Rights', Nordic Journal of International Law, 57, 424-41.

- (2001), 'Finland', in Robert Blackburn and Jörg Polakiewicz (eds.), Fundamental Rights in Europe. The European Convention on Human Rights and its Member States, 1950 2000 (Oxford: Oxford University Press), 289-312.

Rouvoet, André (2009a), 'Bouwen aan kinderrechten', Speech during the conference "Bouwen aan kinderrechten" on 19 February 2009, The Hague, <www.rijksoverheid. nl/documenten-en-publicaties/toespraken/2009/02/19/bouwen-aan-kinderrechten. html>, accessed 26 March 2014.

- (2009b), 'Kinderrechtentop in Leiden', Speech during the children's rights summit on 20 November 2009, The Hague, <www.rijksoverheid.nl/documenten-en-publicaties/ toespraken/2009/11/20/kinderrechtentop-in-leiden.html>, accessed 26 March 2014.

Ruitenberg, G.C.A.M. (2003), Het Internationaal Kinderrechtenverdrag in de Nederlandse rechtspraak (Amsterdam: SWP).

Saurugger, Sabine and Radaelli, Claudio M. (2008), 'The Europeanization of public policies: introduction', Journal of Comparative Policy Analysis, 10 (3), 213-19.

Scheinin, Martin (1990), 'The Status of Human Rights Conventions in Finnish Domestic Law', in Allan Rosas (ed.), International Human Right) Norms in Domestic Law: Finnish and Polish Perspectives. (Helsinki: Finnish Lawyers Publishing Company), 25-43.

— (1991), Ihmisoikeudet suomen oikeudessa (Jyväskylä: Gummerus Kirjapaino Oy). 
- (1996), 'Incorporation and implementation of human rights in Finland', in Martin Scheinin (ed.), International human rights norms in the Nordic and Baltic countries (Dordrecht: Martinus Nijhoff Publishers), 257-94.

- (2000), 'Domestic implementation of international human rights treaties: Nordic and Baltic experiences', in Philip Alston and James Crawford (eds.), The Future of UN Human Rights Treaty Monitoring (Cambridge: Cambridge University Press), 229-43.

- (2001), 'Protection of Economic, Social and Cultural Rights in Finland. A rights-based variant of the welfare state?', in Martin Scheinin (ed.), The Welfare State and Constitutionalism in the Nordic Countries (Copenhagen: Nordic Council of Ministers), 245-85.

— (2003), 'Protection of the right to housing in Finland', in Scott Leckie (ed.), National perspectives on housing rights (The Hague/ London/ New York: Martinus Nijhoff Publishers), 241-52.

Schimmelfennig, Frank (2005), 'Strategic calculation and international socialization: membership incentives, party constellations, and sustained compliance in Central and Eastern Europe', International Organization, 59, 827-60.

Schimmelfennig, Frank and Sedelmeier, Ulrich (2004), 'Governance by conditionality: EU rule transfer to the candidate countries of Central and Eastern Europe', Journal of European Public Policy, 11 (4), 669-87.

Schmidt, Markus (2000b), 'Servicing and financing human rights supervisory bodies', in Philip Alston and James Crawford (eds.), The Future of UN Human Rights Treaty Monitoring (Cambridge: Cambridge University Press), 481-98.

Schmidt, Markus G. (2000a), 'Follow-up mechanisms before UN human rights treaty bodies and the UN mechanisms beyond', in Anne F. Bayefsky (ed.), The UN Human Rights System in the $21^{\text {st }}$ Century (The Hague Kluwer), 233-49.

- (2001), 'Follow-up procedures to individual complaints and periodic state reporting mechanisms', in Gudmundur Alfredsson, et al. (eds.), International human rights monitoring mechanisms. Essays in honour of Jakob Th. Möller (The Hague: Kluwer), 201-15.

Schmidt, Markus G., Bayefsky, Anne F., and Rodley, Nigel (1997), 'Does the United Nations human rights program make a difference?', Proceedings of the Annual Meeting (American Society of International Law), 91, 461-75.

Schöpp-Schilling, Hanna Beate (2007), 'Treaty body reform: the case of the Committee on the Elimination of Discrimination Against Women', Human Rights Law Review, 7 (1), 201-24.

Schrijver, Nico (2011), 'Paving the way towards... one worldwide human rights treaty!', Netherlands Quarterly of Human Rights, 29 (3), 257-60.

Sellheim, Nikolas (2010), 'The tradition and the state. Sámi reindeer husbandry and the forestry challenge in Norhern Finland', Lögfrceðingur 4(1), 75-87.

Semb, Anne Julie (2012), 'Why (not) commit? Norway, Sweden and Finland and the ILO Convention 169', Nordic Journal of Human Rights, 30 (2), 122-47.

Simmons, Beth (2009), Mobilizing for human rights. International law in domestic politics (Cambridge: Cambridge University Press). 
Smith, Anne B., Taylor, Nicola J., and Tapp, Pauline (2003), 'Rethinking children's involvement in decision-making after parental separation', Childhood, 10 (2), 201-16.

Smits-Baauw, Gerianne and Os, Carla van (2007), 'Geen Kind in de Cel. "Het voelt niet recht', Tijdschrift voor de Rechten van het Kind, 17 (4), 2-5.

Spendzharova, Aneta and Versluis, Esther (2013), 'Issue salience in the European policy process: what impact on transposition?', Journal of European Public Policy, 20 (10), 1499-1516.

Stanley, Elizabeth (2011), 'Human rights and prisons. A review to the Human Rights Commission' (Auckland: NZ Human Rights Commission).

Statement, Dublin (2009), 'The Dublin statement on the process of strengthening of the United Nations human rights treaty body system'.

Stein, Jana von (2013), 'The engines of compliance', in Jeffrey Dunoff and Mark Pollack (eds.), Synthesizing insights from International Law and International Relations (Cambridge: Cambridge University Press), 477-501.

Steiner, Henry J. (2000), 'Individual claims in a world of massive violations: what role for the Human Rights Committee', in Philip Alston and James Crawford (eds.), The Future of UN Human Rights Treaty Monitoring (Cambridge: Cambridge University Press), 15-53.

Sverdrup, Ulf (2004), 'Compliance and conflict management in the European Union: Nordic exceptionalism', Scandinavian Political Studies, 27 (1), $23-43$.

Swart, Bert (1999), 'The European Convention as an invigorator of domestic law in the Netherlands', Journal of Law and Society, 26 (1), 38-53.

Tallberg, Jonas (2002), 'Paths to compliance: enforcement, management, and the European Union', International Organization, 56 (3), 609-43.

Tallroth, Paulina (2012), Who Safeguards Our Rights? The Finnish Institutions and the Discussion About a Constitutional Court (Helsinki: Unigrafia).

The Economist Intelligence Unit (2013), 'Democracy index 2012. Democracy at a standstill'. Theytaz-Bergman, Laura (2009), 'What happened? A study on the impact of the Convention on the Rights of the Child in five countries: Estonia, Nepal, Peru, Uganda and Yemen' (Stockholm: Save the Children).

Thornberry, Patrick (2005), 'Confronting racial discrimination: a ICERD perspective', Human Rights Law Review, 5 (2), 239-69.

Tistounet, Eric (2000), 'The problem of overlapping among different treaty bodies', in Philip Alston and James Crawford (eds.), The Future of UN Human Rights Treaty Monitoring (Cambridge: Cambridge University Press), 383-401.

Toivanen, Reetta (2007), 'Education on Human Rights - a Method for Inducing Global Critical Thinking', in Taina Kaivola and Monica Melén-Paaso (eds.), Education for Global Responsibility - Finnish Perspectives (Publications of the Ministry of Education 2007; Helsinki: Helsinki University Press), 34-44.

Tomuschat, Christian (2008), Human rights. Between idealism and realism (Oxford: Oxford University Press).

Törnudd, Klaus (1986), Finland and the international norms of human rights (Dordrecht: Martinus Nijhoff Publishers). 
Trimble, Philip R. (1990), 'International law, world order, and critical legal studies', Stanford Law Review, 42 (3), 811-45.

Tuori, Kaarlo (2012), 'Landesbericht Finnland', unpublished work.

Tuulentie, Seija (2003), 'For and against the rights of the Sami people: the argumentation of the Finnish majority in the debate on the Sami rights', in Svein Jentoft, Henry Minde, and Ragnar Nilsen (eds.), Indigenous peoples: resource management and global rights (Delft: Eburon), 275-95.

Tyagi, Yogesh (2011), The UN Human Rights Committee (Cambridge: Cambridge University Press).

Uvin, Peter (2004), Human Rights and Development (Bloomfield: Kumarian Press).

Uzman, Jerfi, Barkhuysen, Tom, and Emmerik, Michiel L. van (2010), 'The Dutch Supreme Court: A reluctant positive legislator?', Electronic Journal of Comparative Law, 14 (3), 1-35.

Vandenhole, Wouter (2004). The procedures before the UN human rights treaty bodies. Divergence or convergence? (Antwerp/ Oxford: Intersentia)

Vanhercke, Bart (2009), 'Against the odds. The Open Method of Coordination as a selective amplifier for reforming Belgian pension politics', European Integration online Papers 13.

Versluis, Esther (2003), Enforcement matters. Enforcement and compliance of European Directives in four member states (Delft: Eburon).

Visitatiecommissie Emancipatie (2007a), 'Coördinatie van emancipatiebeleid en gender mainstreaming bij de rijksoverheid' (Den Haag).

- (2007b), 'Een beetje beter is niet goed genoeg. Emancipatiebeleid en gender mainstreaming bij de rijksoverheid. Eindrapportage visitaties 2005-2006' (Den Haag).

- (2007c), 'Emancipatiebeleid en gender mainstreaming bij het Ministerie van Justitie. Eindrapportage visitatie 2005-2006' (Den Haag).

Vos, Christian M. De (2013), 'From Rights to Remedies. Structures and Strategies for Implementing International Human Rights Decisions' (Open Society Justice Initiative)

Vries, T.L de. (2007), 'De tanden van het internationale recht: het individuele klachtrecht', in T. Hoogenboom, et al. (eds.), In vele kwaliteiten. Liber amicorum ter gelegenheid van het afscheid van mr. H. van Leeuwen van de Centrale Raad van Beroep (Utrecht: Centrale Raad van Beroep), 81-87.

Waldron, Jeremy (2005), 'Compared to what? Judicial activism and New Zealand's Parliament', New Zealand Law Journal, 441-45.

Waters, Melissa A. (2007), 'Creeping monism: the judicial trend toward interpretive incorporation of human rights treaties', Columbia law review, 107, 628-705.

Wet, Erika de (2008), 'The reception process in the Netherlands and Belgium', in Helen Keller and Alec Stone Sweet (eds.), A Europe of rights: The impact of the ECHR on national legal systems (Oxford: Oxford University Press), 229-310.

Wit, Joke de (2013), Artikel 94 Grondwet toegepast: een onderzoek naar de betekenis, de bedoeling en de toepassing van de woorden 'vinden geen toepassing' in Artikel 94 van de Grondwet (Den Haag: Boom Uitgevers). 
Witte, Rob (2010), Al een eeuwenlang een gastvrij volk, racistisch geweld en overheidsreacties in Nederland (1950-2009) (Amsterdam: Aksant).

Witte, Rob and Scheepmaker, Marit (2012), 'De bestrijding van etnische discrminatie: van speerpunt tot non-issue?', Justitielle Verkenningen, 38 (6), 107-26.

Woll, Lisa (2000), 'Reporting to the UN Committee on the Rights of the Child: A catalyst for domestic debate and policy change', The International Journal of Children's Rights, 8, 71-81.

Woltjer, A.J.T. (2002), Wetgever, rechter en het primaat van de gelijkheid: over primaten in het recht (Den Haag).

Wood, Beth, et al. (2008), Unreasonable Force. New Zealand's journey towards banning the physical punishment of children (Wellington: Save the Children).

Yarwood, Lisa (2008), 'Immunity of refugees from prosecution', New Zealand Law Journal, 461-63.

Young, Oran R. (1979), Compliance and public authority. A theory with international applications (Baltimore: Johns Hopkins University Press).

Young, Oran R. and Levy, Marc A. (1999), 'The effectiveness of international environmental regimes', in Oran R. Young (ed.), The effectiveness of international environmental regimes: causal connections and behavioural mechanisms (Cambridge: MIT Press), $1-32$.

Ysselt, Paul van Sasse van (2003), 'Wetgeving en toezicht betreffende de strafrechtelijke aanpak van discriminatie op grond van ras', NJCM-Bulletin, 28 (4), 411-27.

Zeitlin, Jonathan (2009), 'The open method of coordination and reform of national social and employment policies: influences, mechanisms, effects', in Martin Heidenreich and Jonathan Zeitlin (eds.), Changing European employment welfare regimes: The influence of the Open Method of Coordination on national reforms (London: Routledge), 214-45.

Zohlnhöfer, Reimut and Ostheim, Tobias (2005), 'Paving the way for employment? The impact of the Luxembourg process on German labour market policies', Journal of European Integration, 27 (2), 147-67.

Zwaak, Leo (2001), 'The Netherlands', in R. Blackburn and J. Polakiewicz (eds.), Fundamental rights in Europe (Oxford: Oxford University Press), 595-624.

Zwingel, Susanne 'How do international women's rights norms become effective in domestic contexts? An analysis of the Convention on the Elimination of all Forms of Discrimination against Women (CEDAW)', <www2.potsdam.edu/zwinges/ cv-englisch.pdf>, accessed 26 March 2014. 


\section{INDEX}

\section{A}

abortion 92, 139, 250

accelerated asylum procedure 123, 199, 204, 215,237

access to a lawyer 134, 199, 205-206

Action for Children and Youth in Aotearoa Incorporated (ACYA) 294-295, 300, 306

action plan, human rights $28,74,82,100$, $215,242,259,261,325,329,342,345$, 362, 390, 393-394

Administrative Measures for National Security, Bill on 127, 135

Advisory Committee on Migration Affairs (ACVZ) 205-206

age mixing in prison 297, 301

Albayrak, Nebahat 190, 206, 210

Aliens Act 200, 205, 210, 251

Alston, Philip 1, 5-6, 9, 10, 14-15, 50, 158

Alter, Karen J. 37-38, 372

Amnesty International 45, 104, 149, 202, 205, 207, 239, 243, 293, 337-338, 349, 354

anonymous witnesses 123,132

Antilles, Netherlands 53, 140, 200, 208

Antillean Reference Index (Verwijsindex Antillianen) 103, 108, 117

Arib, Khadijah 219, 234-235

Art. 1 103-104, 204, 349

Article 26 ICCPR 124, 156

Article 27 ICCPR 348

Article 93 of the Dutch Constitution 72, 78

Article 94 of the Dutch Constitution 72, 78, 146

Aruba 53, 140, 200, 208

asylum policy $92,99,120,127,184,190,195$, 238-239, 264, 269

audit, national human rights 25

\section{B}

backlog 14, 91, 251

Balkenende government I-III 71, 75, 237-238

Balkenende IV government 71, 75, 109, 168, 177, 205, 214, 216, 220, 238, 248, 269, 380

Bayefsky, Anne F. 10, 15, 17, 19

Beijing Platform for Action 166, 350

Bill of Rights/ Human Rights Team 274, 276277, 284, 315, 319

Black schools 102, 112-113

boomerang effect $45-46,48,65,382$

Boxtel, Roger van 115-116

Boven, Theo van 95, 108, 117

Bradford, Sue 287, 299-301, 311, 387

breastfeeding 92, 215, 234, 245, 250, 264

broader influence

definition 25

operationalisation $57-58,68$

findings $368-369$

Finland 321-327

Netherlands 82-90, 131, 227-229, 253-255

New Zealand 276-283

Broeks 124, 127

Bussemaker, Jet 170, 261

C

causal relationship 20,22, 26, 61-64, 183, $187,232,240$

CDA $71,75,82,154,238$

Central Appeals Tribunal 124, 128, 146, 172, 221, 223

Central Union for Child Welfare (CUCW) 324, 339, 363

Charter of Fundamental Rights of the European Union (CFR) 107, 145

Checkel, Jeffrey T. 43-44, 46, 377

child abuse 123, 134, 218, 226, 230, 234, 374 
Index

Children's Commissioner (NZ) 271, 282-283, 291, 293, 295, 300, 302, 306, 310, 371

Children's Ombudsman (FIN) 320, 324, 330, $334,340,342,343,345,346,355,363$

Children's Ombudsman (NL) 82, 213, 215, $218-219,225,227,233-235,246,252$, 257, 259-260, 268, 374, 378, 384

ChristenUnie (CU) 71, 75, 126, 130, 179, 219, 238-239

civic integration 99,108

Clara Wichmann 171-174, 188

Clark, Helen 273, 275, 285, 299

coalition agreement $77,109,126,133,187$, $205,232,237,262$

COC Netherlands 175

coercion 34-36, 44

Committee Against Torture 4-5, 18, 20, 392

Finland 337, 348-349, 358, 378

Netherlands 144, 199-212, 258

New Zealand 288, 290, 298, 306-308, 310-311, 316, 378

Committee on Economic Social and Cultural

Rights (CESCR) 4-7, 25, 375

Finland 331, 336, 358, 362

Netherlands $52,56,90,92,94,97,143$ $163,190,203,258-260$

New Zealand 275, 281, 289-290, $292-$ 293, 311-312

Committee on the Elimination of all Forms of

Racial Discrimination (CERD) 4, 5, 15, $20,51,342$

Finland 332, 336-337, 340, 346, 351, 356,358

Netherlands $\quad 56,88,90-92,94-96$, 99-121，128，137, 179, 197, 202, 258-260, 264, 266-267, 269

New Zealand 273, 276-278, 285-287, 291-292, 294, 302-303, 312, 370$371,380,386-387$

Committee on the Elimination of Discrimination Against Women 4, 5, 14, 19-20, 23, 370, 374

Finland 330, 334, 337-338, 350-351
Netherlands 56, 85, 90, 92-95, 97, 105, 118, 131, 165-198, 203, 214, 218, $255,259-261,263,266-266,269$, 371

New Zealand 273, 285, 294, 304-305, 314,373

Committee on the Rights of the Child 4-5, 19-20, 23, 369-371, 374-375, 377-379, 381-382

Finland 324-325, 330-332, 334-335, 340-341, 345, 354, 358, 363

Netherlands $90,92,95,105,148,159$, 211, 213-252, 255, 257, 259-261, $263,267,269,371,373$

New Zealand 279, 283, 290, 293-296, 300, 303-304, 306, 308, 310, 313, $315,368,384$

compartmentalisation 218,259

compliance pull $47,65,68,90,98,117,195$, $198,249,252,267,312,367,376,378$

Concluding Observation

Drafting proces $4-5,15,17,117,159$ 160

Legal status 7-9, 138, 156, 219, 265266,362

Treaty basis 5

conscientious objectors $337,343,352,384$

Constitution 3, 72, 73, 78-79, 81-82, 103, 124, 149, 274, 319-321, 341, 348, 352

Constitutional Law Committee (FIN) 319$320,323,324,331,345,348,359,362$

constitutional review $78,81,320$

Constructivism $42-44,46,65,367$

contraception 178,182

contributory cause $65,198,207,264-265$, 301-302, 308-309, 355-356

Core Document 83, 93, 277, 322

core obligations, minimum 149, 152, 155, 212

Council of State (NL) 74, 77, 103, 126, 147, $171,186,194,211,216,222,250$

country rapporteur 4, 5, 117-118, 159-161, 249, 261, 340, 341

CRC Advisory Group (NZ) 295, 369, 384 


\section{Index}

CRC Monitoring Group (NZ) 280, 293

CRC Work Programme (NZ) 296, 298-299, 301, 310, 380, 384

criminalisation of torture $338,342,348,355$, 361,384

curricula $150,218,242,343,354,374$

D

D66 71, 75, 102, 115-116, 127, 135, 200, 205, $207,211,213,234$

Dai, Xinyuan 40, 382

deductive 34

Defence for Children International (DCI) 28, $146,219,223,224-228,235,238-239$, $243,251,258$

delay $14,75,83,101-102,104-105,120,126$, 128, 144, 169, 198, 200, 208-209, 246, 277,322

denial 128,344

Department of Corrections (NZ) 301, 310311

detention of children 238-239

Dijksma, Sharon 84, 165, 196

direct effect $54,73,103,124,143-147,149$, $151-152,156,160,172,178,180,194$, 221-222, 274

Directorate Emancipation (NL) 83, 85, 98, 193-194, 265

Directorate Youth Policy (NL) 83, 86, 98, 246-249, 265, 269, 383, 385,

dissemination (of the CRC) 215, 233, 236$237,246,277,330,335,342$

DNA testing 221

domestic workers 148

Donner, Piet Hein 186, 216, 235, 240, 241

drugs policy 92,250

dualism 54, 284

Dublin Statement 10-11, 13

Durban 115

Dutch CEDAW Network 148, 172, 175, 257, 268

Dutch Refugee Council 202, 205, 207, 239
E

Early Warning 285, 302, 308, 312

Education Council (NL) 112-113, 150

effectiveness definition 26-27

operationalisation 60-65

Emancipation Review Committee 168, 193

Equal Treatment Commission 82, 100, 113, 157, 187, 259

EU Directive 55, 116, 195, 210, 216, 359

European Commission against Racism and Intolerance (ECRI) 75, 99, 100, 104, 106, 108, 111, 113-117, 258, 382

European Commissioner for Human Rights 104, 218, 242, 356

European Committee for the Prevention of Torture and Inhuman or Degrading Treatment or Punishment (ECPT) 206, 209-210, 212, 258, 349, 355, 382

European Committee of Social Rights (ECSR) 226, 240-241, 258, 353, 359

European Convention on Human Rights (ECHR) 23, 54, 375, 382

Finland 318-321, 327-329, 331, 354-355, 360,362

Netherlands $\quad 73-75,78,80-81,85,98$, 103-104, 108, 116-117, 125-126, $129,132,136-139,142,145,147$, 158,375

New Zealand 209-211, 216-217, 251, 255, 258, 267, 273, 290-291, 316

European Court of Human Rights (ECtHR) $23,36,43,54,375,382$

Finland 327, 329, 330-332, 340, 353, 360,362

Netherlands $75,80-82,86,104,109$, $116-117,127,132,134,136-138$, 142, 158, 181, 185-186, 195, 200, 202, 205-206, 209, 210-212, 239, $255,258,266-267,362,375$

New Zealand 273, 290, 291, 316

European Court of Justice (ECJ) 54, 117, $128,137-138,181,195,266,329,331$ 
Index

European Social Charter (ESC) 145, 158, $162,258,319,382$

European Union (EU) 116, 120, 382

Finland 55, 74, 87, 94, 98, 104, 117, 125, $132,138-139,147,162,181,195$, 197, 216, 258, 267

The Netherlands $54,317,320,351,355$, $359,360,362$

europeanisation $33,38-39,320$

euthanasia $80,92,123,125-127,130-131$, 133, 139, 141, 231, 250-251, 259, 262

evaluation fatigue $13,86-87,98,368,390-$ 391

F

family reunification, income requirement for $116,182-183,216$

fingerprints, storage of $130,134-135,142$, 264

Finnish League for Human Rights 322, 333, 336-337, 340, 348

First Chamber 71

Flinterman, Cees 51, 151, 197

follow-up procedure 19-20, 125, 141

Foreshore and Seabed Act 2004 296, 297, 302, 303, 308, 311, 371, 386, 387

Fortuyn, Pim 115, 120

Framework Convention for the Protection of National Minorities (FCNM) 100, 346

Franck, Thomas 43

free education 151,304

Frisian 94, 118

G

General Comment (GC) [General Recommendation] 7, 22, 167, 206, 240241, 300, 331

of the Committee on Economic, Social and Cultural Rights 5-6, 145, 149, 152,155

Geus, Aart Jan de 157, 167, 181, 188

Gogh, Theo van 115,120

Green League 349, 353, 361, 384

Green Party 275, 287-289, 290, 299, 311, 387
GroenLinks (GL) 75, 101, 144, 149, 183, 186, 200, 203, 207, 228, 239

Groenman Committee 86, 165, 171

H

Hafner-Burton, Emilie 51, 56, 382, 383, 391

Halonen, Tarja 321, 361

Harmonisatiewet 147, 151

Helfer, Laurence R. 37-38, 50, 54

Heyns, Christof 19, 22, 51, 55-56, 64, 322, 328, 340-342

Hirsch Ballin, Ernst 83, 186

hobbyhorse 94, 140, 251, 267, 299

Human Rights Centre (FIN) 317, 320, 334335

Human Rights Committee (HRC) 3-5, 7, 15, $18,20-23,375,378,392$

Finland $327-328,331-333,335,337,341$, $346-348,352-353,358,360,362$

Netherlands 52, 90, 92, 104, 123-142, 190, 201, 258-260, 267

New Zealand 278, 280, 284-285, 288291, 293, 311-312

human rights education $145,213,215,234$, 242-243, 264, 336, 362, 374

Human Rights Watch 45, 201, 205, 239

Husa, Jaakko 56, 317, 318, 360-361

I

ILO Convention $169332,335,338,346-347$

impact

definition 25-26

operationalisation $\quad 58-60$

International Labour Organisation (ILO) 3, 87, 94, 98, 100,147, 157, 159, 162, 188, $197,258,332,335,338,342,346-347$, 356,382

individual complaints procedure [individual communications] 1,21, 138, 156, 333, 335

inductive 34

inspanningsverplichting $72,155,180$

instructions for legislation $74,125,329$ 


\section{Index}

Inter-American Court of Human Rights

(IACHR) 36, 55

International Court of Justice (ICJ) 7, 275

International Law Association (ILA) 7-8, 23, 258

International Labour Organisation (ILO) 3, $87,94,98,100,147,157,159,162,188$, $197,258,332,335,338,342,346-347$, 356,382

Interstedelijk Studenten Overleg (ISO) 146, 149

Istanbul Protocol 199, 202, 206-207

$\mathbf{J}$

Johannes Wier Stichting (JWS) 148, 201

justiciability $146,156,319,333$

K

Kok ('purple') governments 71, 75, 115, 267

Koppelingswet 152

$\mathbf{L}$

Landelijk Bureau Racismebestrijding (LBR) $100,103-105,111,113-114$

langstudeerdermaatregel 146

Law on Names $165,167,169,171,176,179$, 181, 184-186, 198, 264

legalistic culture 359,386

Legislative Department 83,86

legitimacy $9,34,42-44,47,55,65,117,157$, $158,300,367,376-378,383,390,395$

leverage $39,40,45,282,295,305,381-382$

Liberalism 37

life imprisonment 214-215, 234, 243-244, $252,269,385$

List Of Issues (LOI) 4, 14, 59, 61, 89, 97, 120, $127,139,141,143,167-177,179,198,210$, 225-226, 230, 251, 391, 392

List Of Issues Prior to Reporting (LOIPR) 4, $19,199,211,392$

Locke, Keith 288-289

logic of appropriateness 34, 38, 41-42, 50

logic of consequences $34-35$

\section{M}

Maori Party 285-289, 303, 311, 387

managerial model $34,42-43,50$

maternity benefits $157,165,172,175,184$, 187-188, 198, 264

medical reports (in the asylum procedure) 199, 201-203, 206-207, 210, 212, 269

Medical Research (Human Subjects) Act 123, 125-126, 130-132, 138-139, 141, 260

minimalist interpretation $75,155,333,362$

Ministry for Foreign Affairs (FIN) 317, 321$323,324,326-327,329,332,335,338$, $340-342,345,347-349,354,359,363$, 369,380

Ministry for Youth and Families (NL) 214, 216, 220, 236, 237, 248, 269

Ministry of Education, Culture and Science (NL) 83, 167, 194

Ministry of Foreign Affairs (NL) 71, 83-85, $87,157,209,263,276-278,281,307,383-$ 385

Ministry of Justice (NL) 83, 86, 180, 189, 209, 234, 237, 241, 249, 265, 276-278, 292, 298, 316, 329, 342, 347, 349-350, 359,384

Ministry of Social Affairs and Employment (NL) 83, 193

Ministry of Social Development (NZ) 278, 283, 293

Ministry of the Interior (NL) 242, 259, 261, 359

Ministry of Women's Affairs (NZ) 276, 278, 285, 296, 305, 312-313

Ministry of Youth Affairs (NZ) 276, 278, 281-283, 295, 310, 380, 383, 385

mobilisation $6,26,34,37,40-41,46-47$, $50-51,55,58,60-61,66,99,114,124$, $136,142-143,154,163,165,175,185$, 192, 198, 200, 203, 213, 245, 258, 267, 273, 284, 311, 327, 367, 379, 380-382, 388

monism 54, 284

most likely case $50,52,317$

most similar (design) 53 
Index

$\mathbf{N}$

necessary cause 65

Nederlands Juristen Comité voor de Mensenrechten (NJCM) 28, 103-105, 114, 126, 128-129, 146-149, 175, 201-202, 209, 258

Nederlandse VolksUnie (NVU) 120

Netherlands Institute for Human Rights 25, $28,82,259$

New Zealand Bill Of Rights Act 1990 (NZBORA) 273-274, 288

New Zealand Human Rights Commission 278, 282, 284, 288, 291-293, 295, 298, $303,311,316$

non-refoulement, prohibition of 129, 210, 211, 297, 307

O

O'Flaherty, Michael 7-8, 10

Objectives of reporting 5-6, 25

Office of the United Nations High Commissioner for Human Rights (OHCHR) 10, 13, 16, 21-22, 37, 67, 83, $97,127,213,376,390$

Ombudsman for Children See Children's Ombudsman (FIN)

Ombudsman for Gender Equality (FIN) 334, 351

Ombudsman for Minorities (FIN) 335, 343, $348,351,355$

Oomen, Barbara 76, 79-80, 88, 145, 254

Optional Protocol to ICESCR 145-146, 156157

Optional Protocol to CAT (OPCAT) 208-209, 288, 292, 306, 310

$\mathbf{P}$

Parliamentary Assembly (CoE) 239-241

Parliamentary Ombudsman (FIN) 320, 324, 334-335, 340, 343, 345-346

Parliamentary supremacy/ sovereignty 275, 319

part-time work $165,178,180-181$

Pechtold, Alexander 127, 135, 186 persuasion $34,42-44,46-47,50,65-66,68$, $117,376-378,382$

Pharos 202, 207

Photo (book cover) 185, 332, 338

Pillay, Navanethem 10, 20, 160, 305

Plasterk, Ronald 185, 242

Police Conduct Authority 297, 306

Power, Simon 273, 278, 280-281, 288

pre-trial detention $123,132,344$

preventive mechanism (OPCAT) 291-292, 306,310

proportional voting system $71,275,311$

prostitution 92,161, 169, 173-174, 179, 191, 350

PvdA 71, 75, 87, 101-102, 127, 145, 165, 168, $170,200,205,218-220,225,234-235$, 238,261

PVV 71, 75, 82, 214

\section{$\mathbf{R}$}

Race Relations Commissioner (NZ) 291-292

Realism 35, 376, 389

reciprocity $35-36$

reputation $35-36,90,280-281$

Risse, Thomas 38-39, 45-46, 50, 382-383

Rosenthal, Uri 253

Ross-van Dorp, Clémence 84, 171, 216, 218, 233

roundtable (follow-up) meeting 102, 104, 111, 113, 147, 243, 258, 260, 293, 310

Rouvoet, André 213-214, 218, 220, 224-225, 231, 233, 235, 237, 247-248, 251-252, 269,283

Rutte I government $71,75,82,109,113,177$, 185,238

Rutte II government 71,181

Rutte, Mark 81-82

S

Saami Council 336-337

salience $39-40,66,106,112-113,115,121$, $186,207,212,227,247,252,257,266$, $302,307,316,375,379,382$

same-sex marriage 161,250 


\section{Index}

Sami land rights $332-333,335,341-342,346-$ 347, 355-356

Scheinin, Martin 8, 50-52, 54, 56, 67, 73, 319, $327-328,331,341,348,362$

Scheltema Commission 205

Second Chamber 71, 76, 81, 114

section 59, repeal of 297, 299-300, 309, 311

segregration 99, 102, 104-105, 110-113, 121, 198, 269

self-righteousness $90,312,377$

SGP $126,130,165,167,169,171-172,175-$ $176,184-185,192,197-198,255,264$, 268,371

Sikkink, Kathryn 48, 382

Simmons, Beth 25, 36, 39-41, 46, 51, 373, 379, 382

Simplified reporting 11,392

socialisation 44-46, 382

Socialistische Partij (SP) 75, 102, 201, 218, 225

special measures $108,120,178,180$

spiral model $45-46,48$

Staaij, Kees van der 126, 192

Studie- en Informatiecentum Mensenrechten (SIM) 104, 114, 129, 147

Supreme Court 54

Finland 328, 332, 348

Netherlands $77-79,124,137,144,147$, 151, 169, 171-172, 184-185, 221

New Zealand 274, 290, 308

Sufficient cause 65,373

Suyver Committee 135, 136

\section{T}

Timmermans, Frans 102, 127, 145, 253

trafficking $91,94,123,140,152,159-160$, $178,180,182,190,195,211,258,350$

transgenders 175

transnational human rights advocacy 44-45, $48,382-383$

treaty conform interpretation $78,102,222$, 320

Treaty of Waitangi 274

triangulation 56,64
True Finns 360,

tuition fees, rise in 143-146, 149, 151

\section{$\mathbf{U}$}

UNHCR 201, 205, 238-239

UNICEF 219, 223-226, 228, 238, 243, 249, 293-295, 300, 339, 354, 363

unified standing treaty body 10-11,

Universal Declaration of Human Rights (UDHR) 79, 125, 354

Universal Periodic Review (UPR) 1, 174, 238, 280, 337

Unlawfully present children $297,303-304$

V

Verdonk, Rita 99, 226, 237-238, 248

Verhagen, Maxime 52, 85, 157, 189, 200

Vereniging Vrouw en Recht 28, 173-174

Vienna Convention on the Law of Treaties (VCLT) 7-8, 109

Views (in Individual Communications) 7, 21-23, 51

Finland $328,331-332,348,353,358$, 360

Netherlands $124,127-128,145,137-138$, $145,206,248$

New Zealand 284, 286, 290-291

Viljoen, Frans 19, 22, 25, 51, 55-56, 64, 322, 328-329, 340- 342

Violence against women $14,143,153,165-$ $167,189,195,211,258,332,334,338$, $341-342,350,356,358,374$

VVD $71,75,81-82,126,129,232,237-238$

\section{W}

water, right to 157

Wet SAMEN 101-102

Wilders, Geert 103

withdrawal of reservation 127, 226, 231-232, 277, 298, 301, 303-305, 341

$\mathbf{Z}$

Zwaan- de Vries 124, 127 


\section{Curriculum vitae}

Jasper Krommendijk (Wijchen, 1985) holds an LLM degree (cum laude) in International Law and the Law of International Organisations from the University of Groningen, the Netherlands. He previously completed bachelor degrees in International Relations (cum laude) and International and European Law (cum laude) at the same university. During his studies, Jasper worked as a research assistant on international investment law and did an internship at the Dutch Ministry of Economic Affairs, working on issues relating to the implementation of the EU Services Directive. Afterwards he worked at the Ministry of Justice in the field of EU criminal law and on the development of an additional 'rule of law' evaluation mechanism to strengthen mutual trust between EU member states.

Jasper started as a PhD researcher at the Maastricht Centre for Human Rights in November 2009. For the purpose of his research, Jasper was a visiting researcher at the Victoria University of Wellington, New Zealand and the Erik Castrén Institute of International Law and Human Rights, Helsinki, Finland. He was also a research fellow at the MultiRights Summer Institute 2013 at the Norwegian Centre for Human Rights in Oslo, Norway. During his appointment, he taught various courses at the Faculty of Law, University College and the China-EU School of Law in the fields of international and European law, human rights law and International Relations. In addition to his research and teaching, Jasper was also a member in the Board of the Maastricht Centre for Human Rights, the Chair of the PhD Council and, as such, active in the Board and Graduate Programme Committee of the School of Human Rights Research. In addition, Jasper was a member of the Dutch National Human Rights Institute's sounding group for the annual report about the human rights situation in the Netherlands (Klankbordgroep Jaarlijkse Rapportage).

In July 2014, Jasper began as an Assistant Professor of European Law at Radboud University Nijmegen, where he conducts research on (the domestic impact of) the evolving EU human rights architecture, including the Charter of Fundamental Rights of the European Union and judgments of the Court of Justice of the European Union in the field of human rights. 


\section{School of Human Rights ReSEARCh SERIES}

The School of Human Rights Research is a joint effort by human rights researchers in the Netherlands. Its central research theme is the nature and meaning of international standards in the field of human rights, their application and promotion in the national legal order, their interplay with national standards, and the international supervision of such application. The School of Human Rights Research Series only includes English titles that contribute to a better understanding of the different aspects of human rights.

Editorial Board of the Series:

Prof. dr. J.E. Goldschmidt (Utrecht University), Prof. dr. D.A. Hellema (Utrecht University), Prof. dr. W.J.M. van Genugten (Tilburg University), Prof. dr. M.T. Kamminga (Maastricht University), Prof. dr. P.A.M. Mevis (Erasmus University Rotterdam), Dr. J.-P. Loof (Leiden University) and Dr. O.M. Ribbelink (Asser Institute).

For previous volumes in the series, please visit http://shr.intersentia.com.

Published titles within the Series:

54. Jeroen Blomsma, Mens rea and defences in European Criminal Law ISBN 978-1-78068-104-7

55. Masha Fedorova, The Principle of Equality of Arms in International Criminal Proceedings

ISBN 978-1-78068-111-5

56. Martine Boersma, Corruption: A Violation of Human Rights and a Crime Under International Law?

ISBN 978-1-78068-105-4

57. Hendrik J. Lubbe, Successive and Additional Measures to the TRC Amnesty Scheme in South Africa ISBN 978-1-78068-116-0

58. Hana van Ooijen, Religious Symbols in Public Functions: Unveiling State Neutrality. A Comparative Analysis of Dutch, English and French Justifications for Limiting the Freedom of Public Officials to Display Religious Symbols ISBN 978-1-78068-119-1

59. Sarah Haverkort-Speekenbrink, European Non-Discrimination Law. A Comparison of EU Law and the ECHR in the Field of Non-Discrimination and Freedom of Religion in Public Employment with an Emphasis on the Islamic Headscarf Issue ISBN 978-1-78068-126-9

60. Johannes Keiler, Actus Reus and Participation in European Criminal Law ISBN 978-1-78068-135-1

61. Simone F. van den Driest, Remedial Secession. A Right to External Self-Determination as a Remedy to Serious Injustices?

ISBN 978-1-78068-153-5

62. Ramona Biholar, Transforming Discriminatory Sex Roles and Gender Stereotyping: The implementation of Article 5(a) CEDAW for the realisation of women's right to be free from gender-based violence in Jamaica

ISBN 978-1-78068-167-2 
